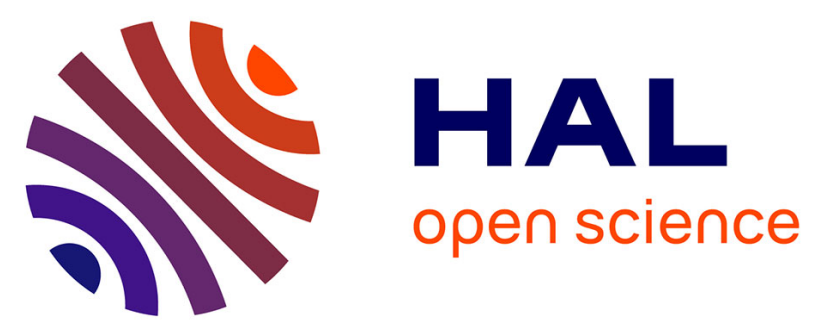

\title{
The anatomy and phylogenetic affinities ofCynthiacetus peruvianus, a largeDorudon-like basilosaurid (Cetacea, Mammalia) from the late Eocene of Peru
}

\author{
Manuel Martínez-Cáceres, Olivier Lambert, Christian De Muizon
}

\section{To cite this version:}

Manuel Martínez-Cáceres, Olivier Lambert, Christian De Muizon. The anatomy and phylogenetic affinities ofCynthiacetus peruvianus, a largeDorudon-like basilosaurid (Cetacea, Mammalia) from the late Eocene of Peru. Geodiversitas, 2017, 39 (1), pp.7 - 163. 10.5252/g2017n1a1 . hal-03424280

\author{
HAL Id: hal-03424280 \\ https://hal.science/hal-03424280
}

Submitted on 10 Nov 2021

HAL is a multi-disciplinary open access archive for the deposit and dissemination of scientific research documents, whether they are published or not. The documents may come from teaching and research institutions in France or abroad, or from public or private research centers.
L'archive ouverte pluridisciplinaire HAL, est destinée au dépôt et à la diffusion de documents scientifiques de niveau recherche, publiés ou non, émanant des établissements d'enseignement et de recherche français ou étrangers, des laboratoires publics ou privés. 


\section{9 \\ geodiv

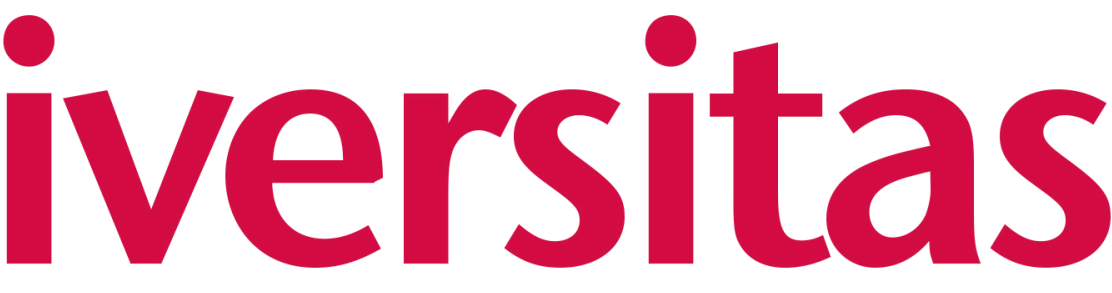 \\ $2017 \cdot 39(1)$}

The anatomy and phylogenetic affinities of Cynthiacetus peruvianus, a large Dorudon-like basilosaurid (Cetacea, Mammalia)
from the late Eocene of Peru
Martínez-Cáceres M., Lambert 0. \& Muizon C. de basilosaurid (Cetacea, Mammalia)
from the late Eocene of Peru
Martínez-Cáceres M., Lambert 0. \& Muizon C. de basilosaurid (Cetacea, Mammalia)
from the late Eocene of Peru
Martínez-Cáceres M., Lambert 0. \& Muizon C.ide

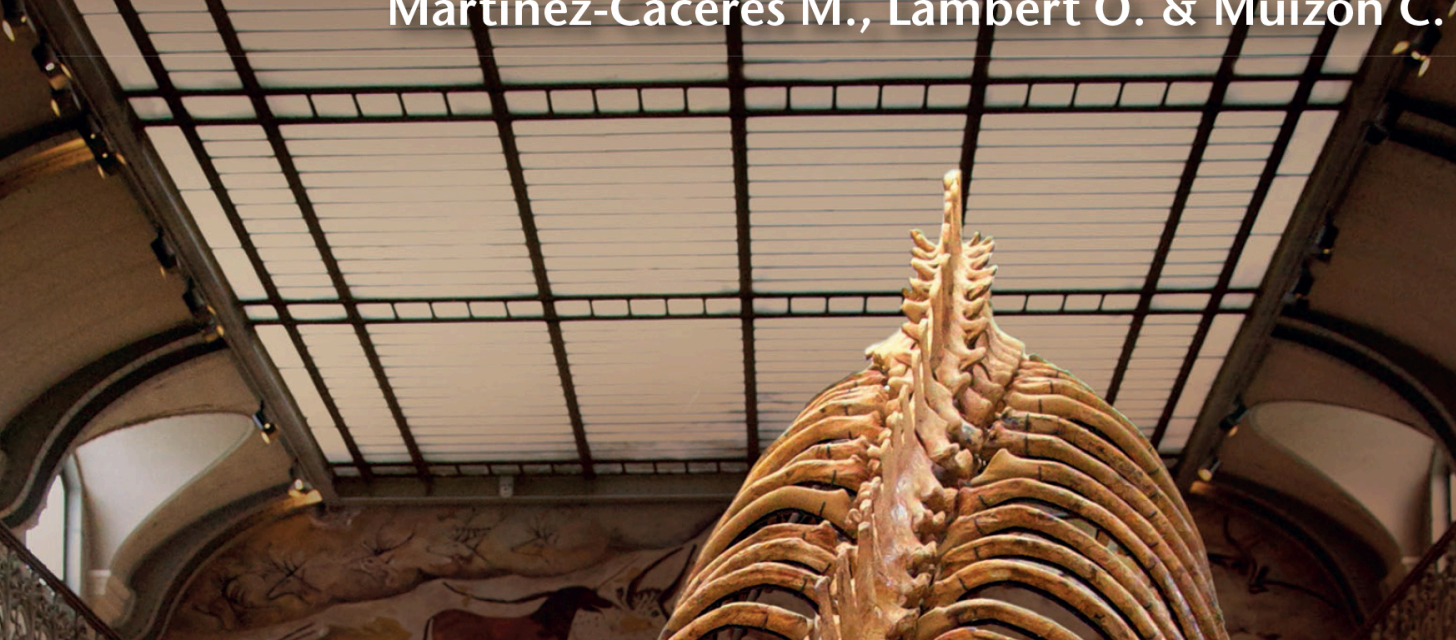
(lus

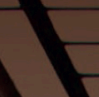




\title{
The anatomy and phylogenetic affinities of Cynthiacetus peruvianus, a large Dorudon-like basilosaurid (Cetacea, Mammalia) from the late Eocene of Peru
}

\author{
Manuel MARTÍNEZ-CÁCERES \\ CR2P UMR 7207 (CNRS, MNHN, UPMC, Sorbonne Universités), \\ Muséum national d'Histoire naturelle, Département Origines et Évolution, \\ case postale 38, 57 rue Cuvier, F-75231 Paris cedex 05 (France)
}

Olivier LAMBERT

D.O. Terre et Histoire de la Vie, Institut royal des Sciences naturelles de Belgique, 29 rue Vautier, B-1000 Brussels (Belgium) olivier.lambert@naturalsciences.be

Christian de MUIZON CR2P UMR 7207 (CNRS, MNHN, UPMC, Sorbonne Universités), Muséum national d'Histoire naturelle, Département Origines et Évolution, case postale 38, 57 rue Cuvier, F-75231 Paris cedex 05 (France) muizon@mnhn.fr (corresponding author)

Published on 31st March 2017 urn:Isid:zoobank.org:pub:40D6C996-226D-49BF-8BF2-E07050BE9035

Martínez-Cáceres M., Lambert O. \& Muizon C. de 2017. - The anatomy and phylogenetic affinities of Cynthiacetus peruvianus, a large Dorudon-like basilosaurid (Cetacea, Mammalia) from the late Eocene of Peru. Geodiversitas 39 (1): 7-163. https://doi.org/10.5252/g2017n1a1

\begin{abstract}
Cynthiacetus peruvianus Martínez-Cáceres \& Muizon, 2011 is a Dorudon-like basilosaurid (Cetacea, Basilosauridae), being one of the largest members of the family. The holotype of this species is a sub-complete skeleton, which comes from the late Eocene (Priabonian) of the Otuma Formation on the southern coast of Peru. A thorough description of this specimen is presented here. Cynthiacetus peruvianus differs from the other species of the genus (C. maxwelli) in having fewer accessory cusps on the distal and mesial edges of $\mathrm{p} 3$ and p4. Its skull shows the general pattern of the basilosaurid skull, which is relatively monotonous across the whole family, but it is much larger than those of Dorudon and Zygorhiza, and slightly smaller and distinctly more slender than that of Basilosaurus. The most characteristic features of $C$. peruvianus stand on the postcranial skeleton: it presents large vertebrarterial foramina on the cervical vertebrae; it lacks a ventral expansion of the transverse processes of C3-C5; it presents the greatest number of thoracic vertebrae (20) observed in cetaceans; and its first thoracics have an almost vertical neural spine. The second part of the monograph is devoted to evolutionary trends and phylogenetic relationships of Archaeocetes with a special focus on Basilosauridae. Some of the major trends considered concern, the rostrum morphology, the asymmetry of the rostrum, the supraorbital region, the neurocranium, the pelvic girdle and hind limb, and the chevrons. A parsimony analysis confirms the monophyly of the Basilosauridae, which are supported by four unambiguous synapomorphies: the presence of well-defined embrasure pits between the upper incisors, a narrow palate anterior to P4, a cleft on the mesial edge of the lower molars, and more than 13 thoracic vertebrae. In contrast with previous hypotheses, in which Saghacetus was the sister taxon of the Pelagiceti, the results of our analysis reveal this taxon as the most basal basilosaurid. In all the analyses performed Cynthiacetus forms a clade with Dorudon and Basilosaurus, being almost constantly the sister taxon of Basilosaurus.
\end{abstract}

KEY WORDS

Basilosauridae,

Late Eocene,

Peru, anatomy, phylogeny. 


\author{
MOTS CLÉS \\ Basilosauridae, \\ Éocène supérieur, \\ Pérou, \\ anatomie, \\ phylogénie.
}

\begin{abstract}
RÉSUMÉ
Anatomie et affinités phylogénétiques de Cynthiacetus peruvianus, un grand basilosauridé ressemblant à Dorudon (Cetacea, Mammalia) de l'Éocène supérieur du Pérou.

Cynthiacetus peruvianus Martínez-Cáceres \& Muizon, 2011 est un basilosauridé (Cetacea, Basilosauridae) présentant de grandes ressemblances avec le genre Dorudon et l'un des plus grands membres de la famille. L'holotype de cette espèce est un squelette sub-complet qui provient des couches de la Formation Otuma, d'âge Éocène supérieur (Priabonien), sur la côte sud du Pérou. Une description exhaustive de ce spécimen est présentée dans ce travail. Cynthiacetus peruvianus diffère de l'autre espèce du genre (C. maxwelli) par le nombre plus faible de cuspides accessoires sur les bords mésial et distal des p3-p4. Son crâne présente le patron général de celui des basilosauridés, lequel est relativement uniforme dans toute la famille, mais il est plus grand que ceux de Dorudon et Zygorhiza, légèrement plus petit et nettement plus gracile que celui de Basilosaurus. Les principales caractéristiques de C. peruvianus résident dans son squelette post-crânien: présence de grands foramens artériels vertébraux sur les vertèbres cervicales; absence d'expansion ventrale du processus transverse des C3-C5; présence du plus grand nombre de vertèbres thoraciques observé chez tous les cétacés; et appophyses neurales de ses premières vertèbres thoraciques presque verticales. La deuxième partie de ce travail est conscrée aux tendances évolutives et aux relations phylogénétiques des archaeocètes en général et des basilosauridés en particulier. Les principales tendances évoquées concernent: la morphologie du rostre, l'asymétrie du rostre, la région supraorbitaire, le neurocrâne, la ceinture pectorale et le membre postérieur et les chevrons. Une analyse de parcimonie confirme la monophylie des basilosauridés qui est soutenue par quatre synapomorphies non-ambigües: la présence de fosses interdentaires bien développées entre les incisives supérieures, un palais étroit entre et en avant des P4, une échancrure sur le bord mésial des molaires inférieures et plus de 13 vertèbres thoraciques. Contrairement à des hypothèses antérieures qui plaçaient Saghacetus en goupe-frère des Pelagiceti, notre analyse interprète ce taxon comme le plus basal des basilosauridés. Dans toutes les analyses réalisées, Cynthiacetus forme un clade avec Dorudon et Basilosaurus, et est presque constament le taxon-frère de Basilosaurus.
\end{abstract}

\section{INTRODUCTION}

It is commonly admitted that modern cetaceans (Neoceti) evolved from basilosaurid archaeocetes (Barnes \& Mitchell 1978; Uhen 1998, 2004, 2008a, b, c; Fordyce \& Muizon 2001; Gingerich 2010; Marx et al. 2016). Basilosaurids are considered so far as the closest relatives of modern cetaceans, the Neoceti, and both groups form together a clade named Pelagiceti (Uhen 2008a). However, the monophyly of the Basilosauridae remains uncertain. Luo \& Gingerich (1999), Fitzgerald (2010), Martínez-Cáceres \& Muizon (2011), and Gol'din \& Zvonok (2013) regard the Basilosauridae as monophyletic and sister taxon to the Neoceti. In contrast, Uhen \& Gingerich $(2001)$ and Uhen $(2004,2005)$ suggest a paraphyletic basilosaurid group.

The Basilosauridae is the first described archaeocete family (Cope 1868). It includes 13 genera (nine of which are monospecific) and 18 species (excluding the two described species of Pontogeneus, regarded here as incertae sedis - see below). Unfortunately, many basilosaurids species are based on fragmentary or poorly preserved specimens and reasonably complete skulls and skeletons are not common. Moreover, virtually complete basilosaurid skulls are known only in five genera and many diagnostic features have been observed on the postcranial skeleton (Kellogg 1936; Gingerich \& Uhen 1996; Uhen 1998; Gingerich 2007, 2010; Martínez-Cáceres \& Muizon 2011). Kellogg (1936) pointed out some important inter-specific differences within the Basilosauridae. However, various basilosaurid species recognized by the latter author have been synonymized since then and most of the currently accepted species have been described in the last two decades (Gingerich \& Uhen 1996; Gingerich et al. 1997; Uhen \& Gingerich 2001; Uhen 2005; Gingerich 2007; Martínez-Cáceres \& Muizon 2011; Uhen et al. 2011; Gol'din \& Zvonok 2013). In fact, several differences observed by Kellogg (1936) are the result of intra-specific variations and are related to the ontogenetic stage of the individuals. Except for Dorudon atrox (Uhen 2004), no basilosaurid taxon has been thoroughly described since Kellogg's monograph.

Basilosaurids are commonly divided into two sub-families: Basilosaurinae and Dorudontinae (Barnes \& Mitchell 1978). The former is probably monophyletic and characterized by a strong lengthening of the posterior thoracic, lumbar and anterior caudal vertebrae (Barnes \& Mitchell 1978). In contrast, "dorudontines" are probably paraphyletic (Uhen \& Gingerich 2001; Uhen 2004, 2005; Martínez-Cáceres \& Muizon 2011) and diagnosed by the plesiomorphic absence of the vertebral lengthening observed in basilosaurines.

We present here a detailed description of the holotype of Cynthiacetus peruvianus, a large Dorudon-like basilosaurid ("dorudontine") from the late Eocene of Peru (Martínez-Cáceres \& Muizon 2011). The specimen was discovered by one of us (CM) in 1977 and prepared at the Muséum national d'Histoire naturelle in Paris in 2006-2008. Cynthiacetus peruvianus is the first sub-complete archaeocete skeleton described from South America (Martínez-Cáceres \& Muizon 2011, but see also Uhen et al. 2011 for more fragmentary basilosaurid remains from the 
TABLE 1. - List of taxa, specimens and references used for comparison with MNHN.F.PRU10, holotype of Cynthiacetus peruvianus.

\begin{tabular}{|c|c|c|}
\hline Taxon & Specimen & Reference \\
\hline \multicolumn{3}{|l|}{ Protocetidae } \\
\hline Artiocetus clavis & (UM) GSP 3458 holotype & Gingerich et al. (2001a) \\
\hline Carolinacetus gingerichi & ChM PV5401 holotype, & Geisler et al. (2005) \\
\hline Eocetus wardii & USNM 310633 & Uhen (1999) \\
\hline Georgiacetus votglensis & GSM 350 holotype, & Hulbert (1998); Hulbert et al. (1998) \\
\hline Maiacetus innus & $\begin{array}{l}\text { (UM) GSP } 3551 \text { (cast) holotype, } \\
\text { (UM) GSP } 3475 a\end{array}$ & Gingerich et al. (2009) \\
\hline Rodhocetus kasrani & - & Gingerich et al. (1994) \\
\hline \multicolumn{3}{|l|}{ Basilosauridae } \\
\hline Basilosaurus cetoides & USNM 4674, USNM 4675 & Lucas (1900); Kellogg (1936) \\
\hline Basilosaurus isis & (UM) WH-74, UM 93231 & $\begin{array}{l}\text { Kellogg (1936); Gingerich et al. (1990); } \\
\text { Fahlke et al. (2011) }\end{array}$ \\
\hline Chrysocetus healyorum & SCSM87.195 (cast) holotype & Uhen \& Gingerich (2001) \\
\hline Cynthiacetus maxwelli & MMNS VP 445 holotype & Uhen (2005) \\
\hline Dorudon atrox & $\begin{array}{l}\text { Uhen (2004) and specimens cited within, } \\
\text { including UM101222 and UM93220 }\end{array}$ & - \\
\hline Saghacetus osiris & UM 997550, UM 'pink whale', MNHN.F.LBE695 & Dames (1894); Kellogg (1936) \\
\hline Zygorhiza kochii & $\begin{array}{l}\text { OU } 221000 \text { (cast), USNM 11962, USNM 16638, } \\
\text { USNM 16639, MMNS VP } 130\end{array}$ & $\begin{array}{l}\text { Kellogg (1936); Köhler \& Fordyce (1997); } \\
\text { Uhen (1999) }\end{array}$ \\
\hline \multicolumn{3}{|l|}{ Odontoceti } \\
\hline Agorophius spp. & ChM PV4256, ChM PV5852 & Fordyce (1981) \\
\hline Simocetus rayi & USNM 256517 holotype & Fordyce (2002) \\
\hline Xenorophus sloani & USNM 11049 & Kellogg (1923a) \\
\hline Echovenator sandersi & GSM 1098 & Churchill et al. (2016) \\
\hline \multicolumn{3}{|l|}{ Mysticeti } \\
\hline Chonecetus goedertorum & LACM 131146 (cast) holotype & Barnes et al. (1994) \\
\hline Janjucetus hunderi & NMV P216929 (cast) holotype & Fitzgerald (2006) \\
\hline Mammalodon colliveri & - & Fitzgerald (2010) \\
\hline Undescribed toothed mysticete & ChM PV5720 & - \\
\hline
\end{tabular}

Eocene of Peru), and also one of the few basilosaurids from the Southern Hemisphere (Borsuk-Bialynicka 1988; Köhler \& Fordyce 1997; Fitzgerald 2004; Buono et al. 2016). A detailed comparison with other derived archaeocetes and early neocetes is presented here in order to establish a data matrix, which will thereafter be used in a phylogenetic analysis. Because the holotype of $C$. peruvianus is remarkably complete and because of its late stratigraphical position, its anatomical description presented here is likely to contribute to the understanding of the emergence of modern cetaceans.

\section{MATERIAL AND METHODS}

\section{ANATOMY}

The anatomical nomenclature used in this description follows Kellogg (1936), Fraser \& Purves (1960), Kasuya (1973), Oelschläger (1986a, b), Gingerich et al. (1990), Evans \& de Lahunta (2013), Uhen (1996, 2004), Geisler \& Luo (1998), Luo (1998), Luo \& Gingerich (1999), Fordyce (2002), Geisler et al. (2005) and Mead \& Fordyce (2009). Most measurements follow those provided by Uhen (2004) for Dorudon atrox. For the sake of convenience, we refer to the "Protocetidae" and "Dorudontinae" despite the fact that these taxa are paraphyletic (Uhen \& Gingerich 2001; Geisler \& Sanders 2003; Uhen 2004; Thewissen \& Bajpai 2009; Martínez-Cáceres \& Muizon 2011). Specimens and references employed for comparison are indicated in Table 1.
The skull of MNHN.F.PRU10 has also been studied using computed tomography scanning (CT-scan). The scan (electric tension $=120 \mathrm{mV}$, intensity $141 / 210 \mathrm{~mA}$, thickness of the slice $=0.6 \mathrm{~mm}$ ) was realized at the Société d'Imagerie médicale de Bois Bernard, France. The 1840 slices of the skull are used in the reconstruction and study of the inner structures.

\section{PHYLOGENY}

A parsimony analysis has been carried out with a matrix of 32 taxa and 101 characters. Characters were selected from or based on previous phylogenies (Muizon 1991, 1994; Fordyce 1994, 2002; Luo \& Gingerich 1999; Uhen 1998; Uhen \& Gingerich 2001; Geisler \& Sanders 2003; Geisler et al. 2005, 2011; Deméré et al. 2008; Fitzgerald 2010; Marx 2010). The matrix also includes 20 new characters and was constructed using Mesquite 2.7 (Maddison \& Maddison 2010). The decision to order a character was taken independently for each case. When a multistate character results from the discretization of a numerical value (e.g. character 1: relative skull length), we decided to order this character. In contrast, when the multistate character refers directly to a qualitative character (e.g. character 21: bones participating in dorsolateral margin of the infraorbital foramen), we decided to keep the character as unordered. The parsimony analysis was carried out using Paup 4.a150 (Swofford 1993, 2002). All character-states are equally weighted and, when coded as 'non-applicable', they are processed as 'missing state' by the program. The heuristic analysis consists of 1000 random stepwise-addition replicates, using the 
tree-bisection-reconnection swapping algorithm (TBR, 'traditional search' option) and keeping 10 trees per replicate. The list of taxons considered in the phylogenetic analysis is given in Appendix 1; the character list is given in Appendix 2; the data matrix is presented in Appendix 3 and the nexus file of the matrix is available as supplementary data at the following address:

Furthermore, the list of generic and specific taxa cited in the text with authorship and date of publication is given on Appendix 4.

\section{INSTITUTIONAL ABBREVIATIONS}

CGM Cairo Geological Museum, Cairo, Egypt;

ChM The Charleston Museum, Charleston, South Carolina United States;

GSM Georgia Southern University Museum, Stateboro, Georgia, United States;

H-GSP Howard University, Geological Survey of Pakistan, Pakistan;

IITR Indian Institute of Technology at Roorkee, Uttarakhand, India;

LACM Natural History Museum of Los Angeles County, Los Angeles, California, United States;

MCZ Museum of Comparative Zoology, Harvard University, Massachusetts, United States;

MfNB Museum für Naturkunde Berlin, Berlin, Germany;

MMNS Mississippi Museum of Natural Science, Jackson, Mississippi, United States;

MNHN Muséum national d'Histoire naturelle, Paris, France;

MUSM Museo de Historia Natural, Universidad Nacional Mayor de San Marcos, Lima, Peru;

NMV Museum Victoria, Palaeontology Collection, Melbourne, Australia;

OU Geology Museum, University of Otago, Dunedin, New Zealand;

UM Museum of Paleontology, University of Michigan, Ann Arbor, Michigan, United States;

SCSM South Carolina State Museum, Columbia, South Carolina, United States;

USNM United States National Museum of Natural History, Smithsonian Institution, Washington DC, United States.

\section{GEOLOGICAL SETTING}

The holotype of Cynthiacetus peruvianus (MNHN.F.PRU10) comes from the surroundings of the city of Paracas, near the Paracas Bay, in the Pisco Basin, southern coast of Peru. In this region, the deposition of thick marine Cenozoic strata resulted from major transgressions of the Pacific Ocean, which occurred from the middle Eocene to the latest Pliocene (Muizon \& DeVries 1985; Marocco \& Muizon 1988; Dunbar et al. 1990; DeVries 1998). The beds from which the holotype of C. peruvianus was extracted belong to the Otuma Formation (DeVries 1998; DeVries et al. 2006) and are located at about 2.5 kilometers from the type section locality of the Otuma Formation (Fig. 1).

Initially, DeVries (1998) regarded the Otuma Formation as Oligocene in age. It was said to overlay layers of the older $\mathrm{Pa}-$ racas Formation and underlay layers of the younger Chilcatay Formation (sensu Dunbar et al. 1990; Fig. 2). However, recent reassessment of the age of the Otuma Formation based on microfossils and nannofossils collected from the Otuma Formation
(DeVries 2004; DeVries et al. 2006) indicate that this formation is older than previously stated and is mainly late Eocene in age, including possibly in its upper part some basal Oligocene beds. These results are supported by microfossils and $\mathrm{Ar} / \mathrm{Ar}$ isotopic dating of an ash layer just above the contact between the Paracas and Otuma formations (DeVries et al. 2006; Uhen et al. 2008, 2011). Therefore, the Otuma Formation spans from about 38 $\mathrm{Ma}$ to about $33 \mathrm{Ma}$ and should be considered as essentially Priabonian in age (DeVries et al. 2006; Fig. 2).

The Otuma Formation is mostly composed of hard yelloworange diatomaceous sandstones with abundant mollusks, especially the gastropod Turritella woodsi (DeVries 1998, 2007). In these strata, marine vertebrates are often found within sparse nodules. Thereby, the holotype skeleton of Cynthiacetus peruvianus (MNHN.F.PRU10) was found in a hard calcareous nodule and associated with two species of Turritella gastropods (T. woodsi and T. lagunillasensis - Fig. 3 - the former being much more abundant than the latter) and two suspension-feeding and burrowing bivalves (Cardita sp. and an indeterminated Veneridae). These mollusks are indicative of a shallow offshore environment (between 100 and $200 \mathrm{~m}$ ). Turritella woodsi is absent in the older Paracas Formation (sensu DeVries 2004 and DeVries et al. 2006). It is abundant in the Oligocene and the early Miocene but also occurs in the latest Eocene of southern Peru (DeVries 2007). Turritella lagunillasensis is middle to late Eocene in age (DeVries 2007). It is abundant in the middle Eocene Paracas Formation but it is scarce in the late Eocene Otuma Formation. It has never been reported from the Oligocene beds of the Pisco Basin. DeVries (2007) suggested that T. woodsi may have evolved during the late Eocene from T. lagunilasensis. Because both species are present on the site where the holotype of $C$. peruvianus has been found, it is likely that the specimen does not come from the youngest beds of the Otuma Formation. This result suggests a Priabonian age for MNHN.F.PRU10, holotype of C. peruvianus.

It is important to point out here that MNHN.F.PRU10 was found almost articulated and includes various elements often missing in archaeocete specimens (e.g. phalanges, hyoid apparatus, partial pelvis, partial femur). It is likely that the carcass was deposited in situ with no transportation. Both left forelimb and hindlimb and the last caudal vertebrae are missing and were probably removed by scavengers. An alternative interpretation is that the left limbs and fluke detached when the carcass floated near the sea surface before it deposited on the sea floor. Since the whale skeleton and all associated bivalve shells (of superficial burrowers) are articulated, we can hypothesize that the animal deposited in a calm environment and not a highly energetic tidal zone.

The holotype of Cynthiacetus peruvianus was first mentioned in Marocco \& Muizon (1988) and Fordyce \& Muizon (2001) but remained unnamed until the short description by MartínezCáceres \& Muizon (2011). However, C. peruvianus is not the only archaeocete from the Pisco Basin. Three other archaeocetes (one protocetid and two basilosaurids) have been reported from more southern localities (Uhen et al. 2008, 2011; see also a revised attribution for the protocetid in Gol'din \& Zvonok 2013). A fourth undescribed specimen (which represents probably a new genus of Protocetidae) is under preparation. 

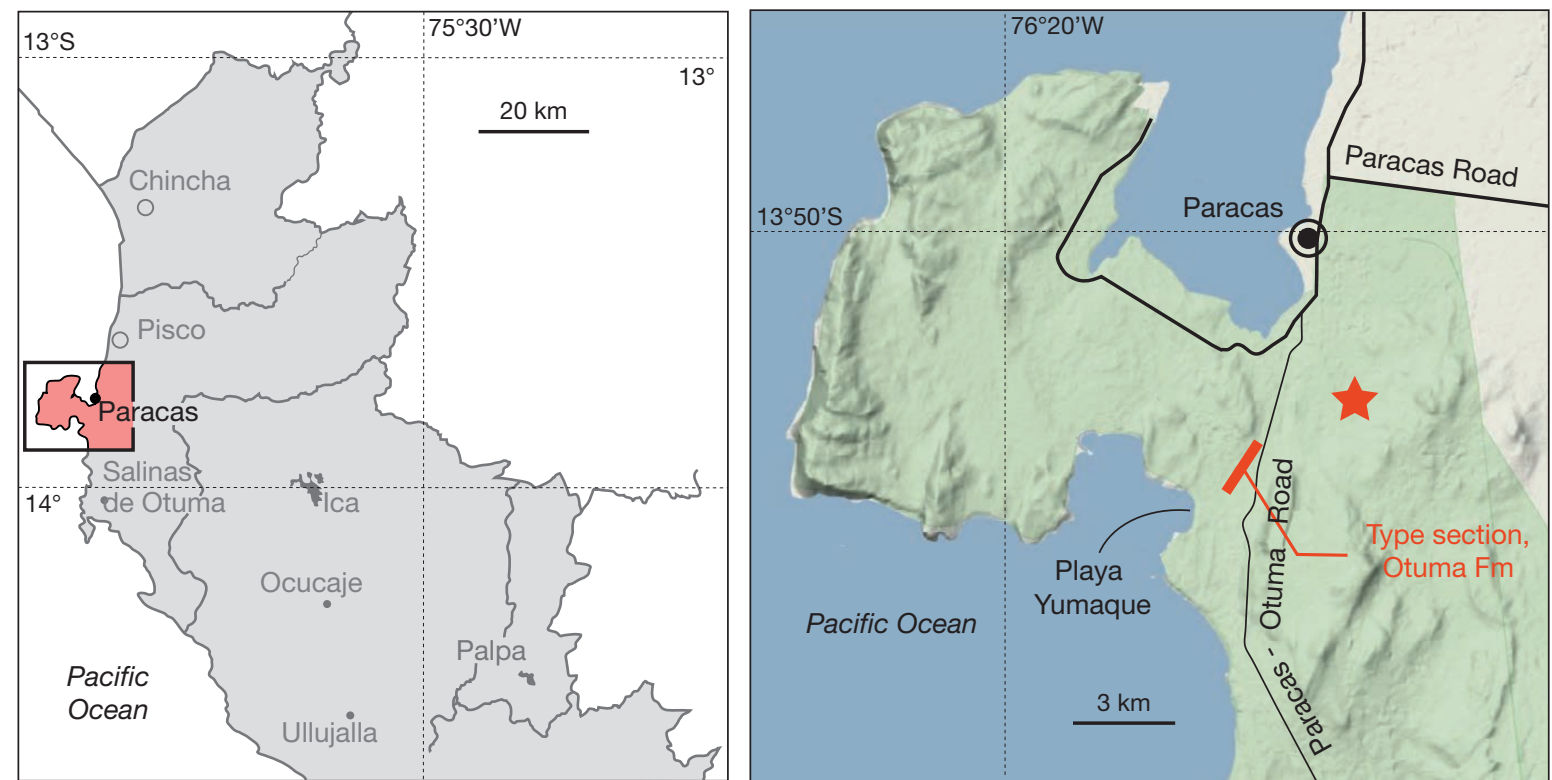

FIG. 1. - Map of the Paracas Peninsula. $\star$, locality from where the holotype of Cynthiacetus peruvianus (MNHN.F.PRU10) was extracted. The locality of the type section of the Otuma Formation is indicated by a red line.

\section{SYSTEMATIC PALAEONTOLOGY}

Order CETACEA Brisson, 1762 Clade PELAGICETI Uhen, 2008

Definition. - Pelagiceti includes the last common ancestor of both Basilosauridae and Neoceti and all its descendants.

EMENDED DIAGNOSIS. - Basilosaurids and neocetes share: 1) wide supraorbital process of the frontal, as compared with earlier archaeocetes; 2) molars and premolars labio-lingually compressed and bearing accessory denticles in both mesial and/or distal edges; 3 ) external bony nares posterior to or at the level of the diastema between P1 and P2; 4) pterygoid sinus considerably larger than in any protocetid archaeocete; 5) cervical vertebrae strongly compressed anteroposteriorly, being shorter than in any other cetaceans; 6 ) loss of the sacral region in the vertebral column (absence of the ilio-sacral synoarthrosis); 7) extreme reduction of the hindlimb (entirely absent in some recent odontocetes); 8) higher number of lumbar vertebrae than in earlier archaeocetes; and 9) posteriormost caudal vertebrae dorsoventrally compressed and rectangular in outline, forming part of the caudal fluke.

\section{Family BASILOSAURIDAE Cope, 1868}

Zeuglodontidae Bonaparte, 1849: 618.

Hydrarchidae Bonaparte, 1850: 1.

Basilosauridae Cope, 1868: 144.

Stegorhinidae Brandt, 1873: 334.

Prozeuglodontidae Moustafa, 1954: 87.

Basilosauridae Barnes \& Mitchell, 1978: 587.

Type Genus. - Basilosaurus Gibbes, 1847.
INCLUDED GENERA. - Ancalecetus Gingerich \& Uhen, 1996; Basilosaurus Gibbes, 1847; Basiloterus Gingerich Arif, Bhatti, Anwar \& Sanders, 1997; Basilotritus Gol'din \& Zvonok, 2013; Chrysocetus Uhen \& Gingerich, 2001; Cynthiacetus Uhen, 2005; Dorudon Gibbes, 1845; Masracetus Gingerich, 2007; Ocucajea Uhen, Pyenson, DeVries, Urbina \& Renne, 2011; Saghacetus Gingerich, 1992; Stromerius Gingerich, 2007; Supayacetus Uhen Pyenson, DeVries, Urbina \& Renne, 2011; Zygorhiza True, 1908

EMENDED DIAGNOSIS. - Basilosaurids are medium-to-large sized archaeocetes characterized principally by: 1) a flat palate narrowing at the level of P4; 2) absence of M3; 3) anterior edge of the orbit dorsal to the level of $\mathrm{P} 4$ or P4/M1 diastema; 4) anterior process of the periotic strongly elliptical in cross-section; 5) triangular expansion on the posterolateral corner of the pars cochlearis; and 6) well developed ventrolateral tuberosity of the periotic.

Age AND Distribution. - Earliest described specimens are from the middle to late Bartonian beds of Pakistan (Basilosaurus drazindai and Basiloterus hussaini; Gingerich et al. 1997) and from Hampshire (Basilosauridae indet.; Seeley 1876). On the other hand, latest basilosaurid specimens are the holotypes of Saghacetus osiris (Dames, 1894) (Priabonian El-Sagha Formation, Egypt; Dames 1894) and Cynthiacetus peruvianus (Priabonian Otuma Formation, Peru; Martínez-Cáceres \& Muizon 2011). Recently, several new basilosaurid specimens have been collected from the beds of the Eocene La Meseta Formation, in the Antarctic Peninsula (Buono et al. 2011, 2016). The age of one of these specimens, including a partially preserved dentary with associated teeth, has been reassessed to the middle Lutetian-early Bartonian (46-40 Ma); if the geochronological attribution is confirmed, it should be the earliest known basilosaurid (Buono et al. 2016).

\section{DISCUSSION}

When Harlan (1834) created the genus Basilosaurus based on a single vertebra, he did not designate a type species nor did he propose a binominal name for the taxon (which should invalidate Basilosaurus as a genus name). However, according to the Article 67.2.2 of the International Code 
A
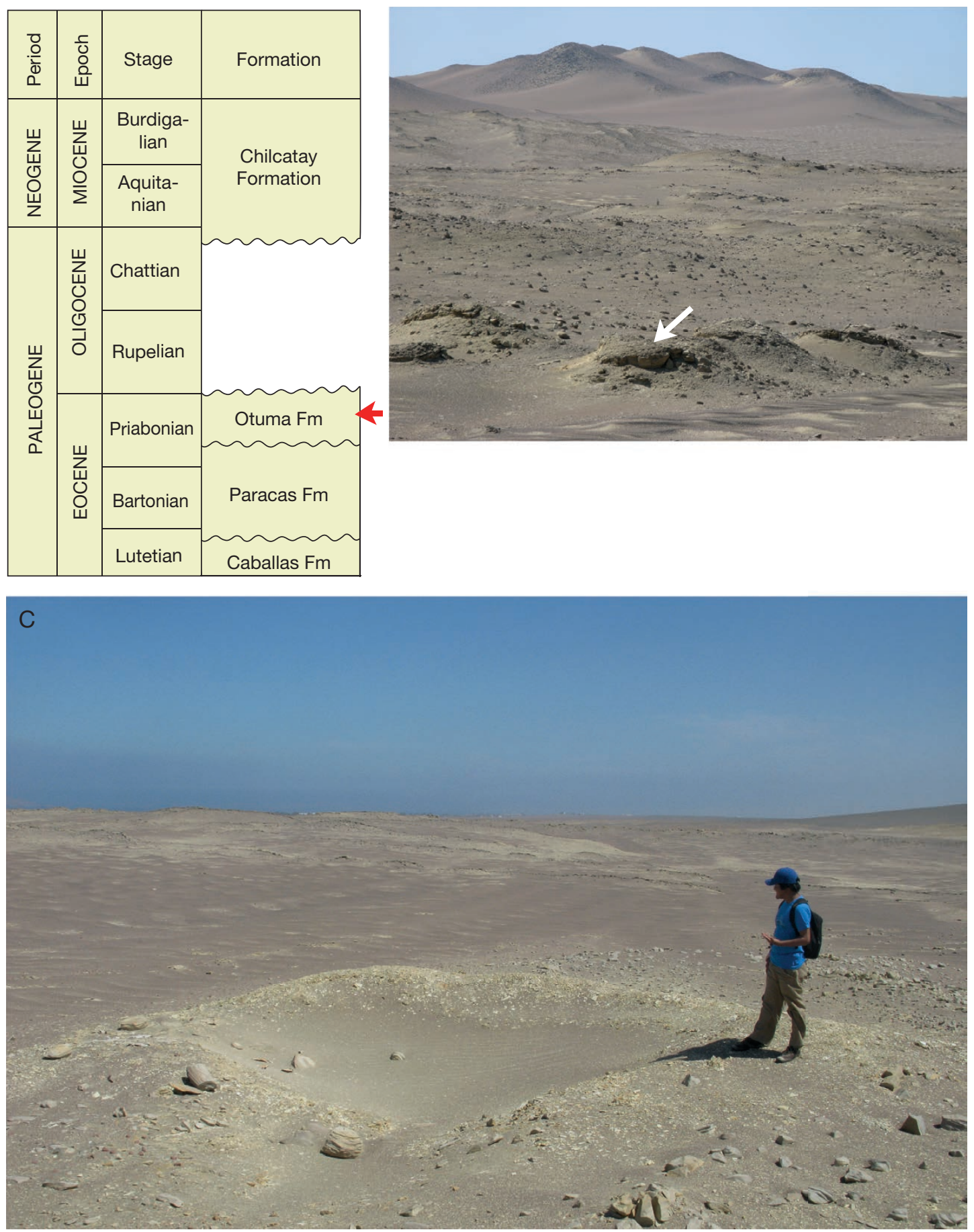

FIG. 2. - A, Stratigraphy of the Pisco Basin, after DeVries et al. (2006). The red arrow indicates the Otuma Formation; B, Otuma Formation in the area where the holotype of Cynthiacetus peruvianus (MNHN.F.PRU10) was discovered; the white arrow points a nodule; C, site in the Otuma Formation where the holotype of Cynthiacetus peruvianus was found. This photo was taken in 2010, when we returned on the site of the 1977 excavation, in order to take the exact coordinates of the locality with a GPS. Photo G. Bianucci.

of Zoological Nomenclature - ICZN (International Commission on Zoological Nomenclature 1999), Basilosaurus is considered as a valid name since it was created before 1931 . Therefore, the first species referred to the genus, $B$. cetoides (= Zeuglodon cetoides Owen, 1839) is considered as the type species. Besides, the type series of $B$. cetoides includes the specimens described by Owen (1839) and not the single vertebra described by Harlan (1834) and indicated as the holotype of $B$. cetoides by Kellogg (1936). The type series was first referred to Basilosaurus by Harlan (1835). Similarly, the name Zeuglodontidae Bonaparte, 1849 precedes that of Basilosauridae Cope, 1868 and should be retained as 

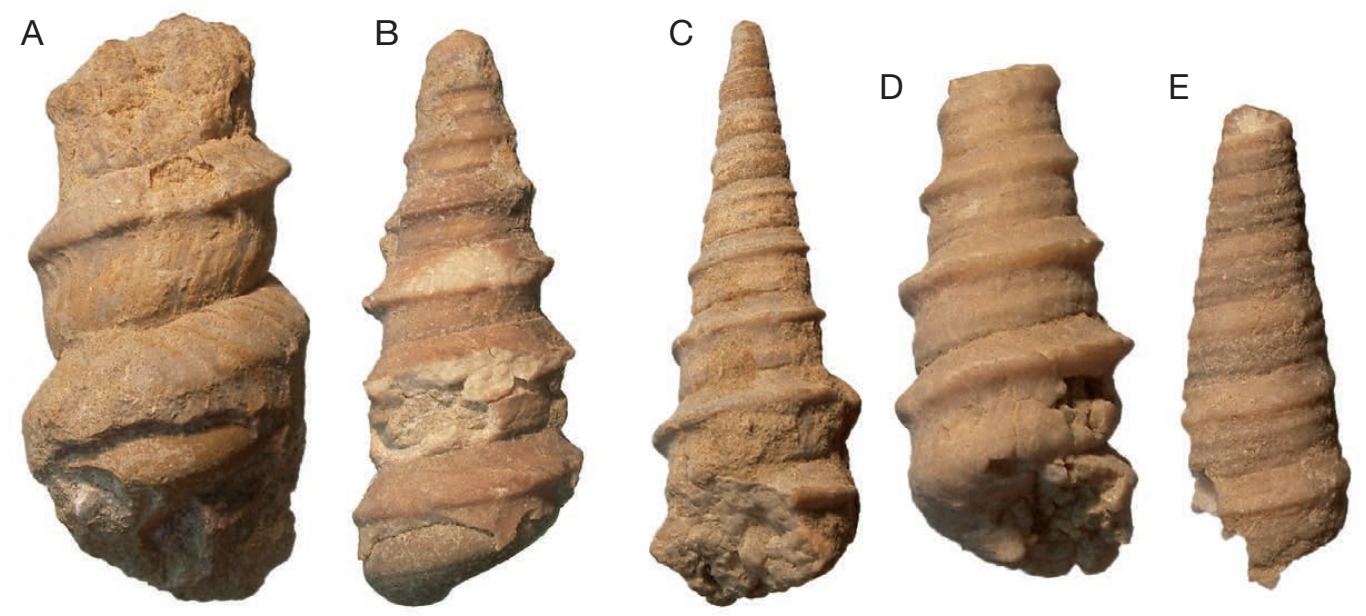

FIG. 3. - Gastropods found in association with Cynthiacetus peruvianus (holotype MNHN.F.PRU10): A-D, Turritella woodsi Lisson, 1925; A, MNHN.F.A59591; B, MNHN.F.A59592; C, MNHN.F.A59593; D, MNHN.F.A59594; E, Turritella lagunillasensis Rivera, 1957, MNHN.F.A59595. Scale bars: 20 mm.

the senior name of the family (Article 40.1 of the ICZN). However, Basilosauridae replaced Zeuglodontidae before 1961 (Cope 1868; Kellogg 1936) and is currently in prevailing usage (e.g. Barnes \& Mitchell 1978; Uhen 1998; Luo \& Gingerich 1999). According to the Article 40.2 of the ICZN, Basilosauridae should be maintained, as well as Basilosaurus, the type genus of the family.

\section{TAXA EXCLUDED FROM THE BASILOSAURIDAE}

In the present work, the New-Zealandian taxon Kekenodon onomata (Hector 1881) is not included in the Basilosauridae following Fordyce (2004). The holotype of the species includes isolated teeth with mesial and distal accessory denticles, periotic and tympanic bulla (Hector 1881). Moreover, the teeth of $K$. onomata differ from the typical basilosaurid dental morphology in being proportionally shorter mesiodistally and having a more rounded outline in labial or lingual views. The tympanic bulla of $K$. onomata is not entirely preserved but seems to be proportionally longer than in any basilosaurid and apparently has a pointed anterior edge, as observed in some toothed mysticetes (ChM PV5720; Fitzgerald 2010).

Another enigmatic taxon is Phococetus vasconum. Initially described as a basilosaurid from a single molariform tooth (Delfortrie 1873), P. vasconum has been referred to both Odontoceti (Gervais 1876; Van Beneden \& Gervais 1880) and Mysticeti (Mitchell 1989). Mitchell (1989) placed together both $K$. onomata and $P$. vasconum in the mysticete sub-family Kekenodontinae. Until the description of better-preserved material, these taxa should be regarded as Pelagiceti incertae sedis (see also Clementz et al. 2012 for a discussion of the phylogenetic affinities of Kekenodontidae)

Similarly, the Oligocene specimens referred to the Basilosauridae by Fordyce (2002) might belong to a basal neocete rather than to a basilosaurid.

\section{BASILOSAURIDAE incertae sedis}

Some taxa that have been referred to the Basilosauridae have been originally described on the basis of fragmentary holotype regarded as irrelevant to diagnose a basilosaurid. Although their names are valid, Pontogeneus priscus Leidy, 1852, P. brachyspondylus (Müller, 1849), and Masracetus markgrafi Gingerich, 2007 cannot be referred to any known species of the family nor any specimen can be reasonably referred to their holotype. They are discussed below.

Genus Pontogeneus Leidy, 1852

TYPe SPECIES. — Pontogeneus priscus Leidy, 1852.

\section{Pontogeneus priscus Leidy, 1852}

HolOtYPE. - ANSP 13668, isolated middle cervical centrum.

TYPE LOCALITY AND HORIZON. - The original description indicates that the holotype is "from the Eocene formation of Ouachita, Louisiana" (Leidy 1852: 52). Recently, Uhen (2005) pointed out the possibility that it comes from the vicinity of the Caldwell Parish, Louisiana, where the upper Eocene Jackson Group (Eargle 1959) is exposed.

\section{DisCUSSION}

Leidy (1852) created the taxon Pontogeneus priscus based on an isolated cervical vertebra (Fig. 4), figured by Kellogg (1936) and interpreted as a fifth cervical. Uhen (2005) recognized it as a more anterior cervical (C3 or C4) and considered both genus and species as nomina nuda because the original description was not diagnostic and the vertebra could belong to a small specimen of Basilosaurus (indeed, the centrum is quite similar in size to that of UM-WH74, a small Basilosaurus isis). However, it can be evaluated that the vertebarterial foramina 
TABLE 2. - Vertebral ratios of the lumbar centra of some basilosaurids. Note the high $\mathrm{L}_{\mathrm{LUM}} / \mathrm{W}_{\mathrm{LUM}}$ and $\mathrm{L}_{\mathrm{LUM}} / \mathrm{H}_{\mathrm{LUM}}$ ratios in Basilosaurus cetoides, Saghacetus osiris, and Stromerius nidensis. Symbols, *, type specimen; $\boldsymbol{\mu}$, average of all vertebrae belonging to the same species, reflects the intraspecific variation. Data come from direct measurements (Cynthiacetus maxwelli, C. peruvianus, Sa. osiris, Dorudon atrox); Slijper 1936 (Masracetus markgarfi); Kellogg 1936 (Zygorizha kochii); Uhen 2004 (D. atrox); and Gingerich 2007 (Str. nidensis).

\begin{tabular}{|c|c|c|c|c|}
\hline Taxon & Specimen & $\mathrm{L}_{\text {LUM }} / \mathbf{W}_{\text {LUM }}$ & $\mathrm{L}_{\text {LUM }} / \mathrm{H}_{\text {LUM }}$ & $\mathbf{W}_{\text {LUM }} / \mathrm{H}_{\text {LUM }}$ \\
\hline Dorudon atrox & CGM 42813 & $0.99 \pm 0.04$ & $1.02 \pm 0.04$ & $1.03 \pm 0.03$ \\
\hline Dorudon atrox & UM 97512 & $0.77 \pm 0.04$ & $0.88 \pm 0.02$ & $1.14 \pm 0.04$ \\
\hline Dorudon atrox & UM 101215 & $0.78 \pm 0.03$ & $0.90 \pm 0.04$ & $1.14 \pm 0.05$ \\
\hline Dorudon atrox $(\mu)$ & - & $0.84 \pm 0.11$ & $0.92 \pm 0.04$ & $1.11 \pm 0.06$ \\
\hline Saghacetus osiris & UM 97550 & $1.12 \pm 0.06$ & $1.26 \pm 0.06$ & $1.12 \pm 0.04$ \\
\hline Cynthiacetus maxwelli & MMNS PV445 $\left(^{*}\right)$ & $0.72 \pm 0.04$ & - & - \\
\hline Cynthiacetus peruvianus & MNHN.F.PRU10 $\left(^{*}\right)$ & $0.89 \pm 0.09$ & $0.91 \pm 0.05$ & $1.02 \pm 0.05$ \\
\hline Basilosaurus cetoides & USNM 4675 & $1.89 \pm 0.09$ & $2.08 \pm 0.13$ & $1.10 \pm 0.05$ \\
\hline Zygorhiza kochii & USNM 4678 & $0.92 \pm 0.03$ & $1.04 \pm 0.03$ & $1.12 \pm 0.05$ \\
\hline Zygorhiza kochii & USNM 4679 & $0.93 \pm 0.02$ & $1.04 \pm 0.003$ & $1.12 \pm 0.02$ \\
\hline Zygorhiza kochii & USNM 12063 & $0.86 \pm 0.03$ & $0.91 \pm 0.02$ & $1.06 \pm 0.04$ \\
\hline Zygorhiza kochii $(\mu)$ & - & $0.90 \pm 0.04$ & $1.01 \pm 0.06$ & $1.1 \pm 0.05$ \\
\hline Stromerius nidensis & UM $100140\left(^{*}\right)$ & $0.98 \pm 0.03$ & $1.23 \pm 0.08$ & $1.25 \pm 0.06$ \\
\hline Masracetus markgrafi & SMNS $11414\left(^{*}\right)$ & $0.80 \pm 0.04$ & $0.95 \pm 0.03$ & 1.20 \\
\hline
\end{tabular}

in the holotype of $P$. priscus are proportionally larger than in Basilosaurus (Fig. 4). Such a feature is diagnostic for the genus Cynthiacetus (Martínez-Cáceres \& Muizon 2011). Because of this character Pontogeneus priscus could have closer affinities with Cynthiacetus than with Basilosaurus (as proposed by Gingerich 2015). However, such a holotype (the centrum of an isolated cervical vertebra) is not regarded as diagnostic enough to characterize a basilosaurid taxon and it is suggested here that the binome Pontogeneus priscus should only refer to the cervical vertebra described by Leidy (1852). Therefore, the genus name and the species name should be regarded as a Basilosauridae or a Pelagiceti incertae sedis and restricted to the type specimen of $P$. priscus.

\section{Pontogeneus brachyspondylus (Müller, 1849)}

Hydrarchos harlani Koch, 1846: 1-20 (in part).

Zeuglodon brachyspondylus Müller, 1849: 26-28.

Zeuglodon brachyspondylum - Abel 1913: 203, 204 (unjustified emendation).

Pontogenus brachyspondylus - Kellogg 1936: 248-255.

LECTOTYPE. - A lumbar vertebra figured in Müller (1849: pl. XX) as "No. 6".

PARALECTOTYPE. - MffNB, unknown number. All the other vertebrae regarded as Zeuglodon brachyspondylus by Müller (1849) and being part of the type specimen of Hydrarchos harlani (Koch, 1846). The syntype series includes 27 vertebrae of different individuals (Kellogg 1936).

TyPE LOCALITY AND HORIZON. - Kellogg (1936) stated that the type series comes from the vicinity of Washington Old Court House, in Alabama, USA. The Upper Jackson Formation indicated in Kellogg (1936) is currently known as the Yazoo Clay Formation (upper unit of the Jackson Group) and is late Eocene in age.

\section{DISCUSSION}

Koch (1846) assembled the skeleton of several basilosaurid individuals to make a sea serpent chimera, which he named
Hydrarchos harlani (synonym of $H$. sillimani). After the discovery of the fake condition of $H$. harlani, Müller (1849) designated 27 vertebrae from Koch's chimera as the type of Zeuglodon brachyspondylus. These 27 vertebrae constitute the syntype of the species. Kellogg (1936) combined $Z$. brachyspondylus Müller and Pontogeneus priscus Leidy into Pontogeneus brachyspondylus but did not designate a lectotype for the species. In fact, the type of $P$. priscus (cf. above) cannot be regarded as the neotype of $Z$. brachyspondylus (contra Uhen 1998) because a syntype was already designated by Müller (1849). Uhen (2005) considers the combination P. brachyspondylus as nomen nudum, but Gingerich (2007) designated a lumbar vertebra of the syntype (figured in Müller 1849: 26, pl. XX, series II, "No. 6") as the lectotype of $P$. brachyspondylus. By this designation, Gingerich (2007) assumed that there were no other vertebrae of the syntype securely belonging to the same specimen as "No. 6". However, Müller (1849) pointed out that the lumbars of the syntype belonged only to two different individuals (specimens "(1)" and "(2)" in Kellogg 1936: 248). Therefore, it is probable that other vertebrae of the syntype may belong to the lectotype ("No. 6" in Müller 1849), although they cannot be identified. Furthermore, the lectotype of $P$. brachyspondylus does not present any diagnostic feature that could differentiate it from Cynthiacetus or Masracetus (see below). Therefore, Pontogeneus brachyspondylus is regarded here as a Basilosauridae incerta sedis and its use is restrained to the lectotype and paralectotype series. Most of the specimens previously referred to P. brachyspondylus have been referred to Cynthiacetus maxwelli (Uhen, 2005) or Masracetus markgrafi (cf. below and Gingerich 2007). Moreover, a third cervical referred to Zeuglodon brachyspondylus (Dames 1894) bears a very large vertebrarterial foramen, a character observed only in Cynthiacetus (Fig. 4). Currently housed in the Museum für Naturkunde in Berlin, this third cervical is associated with an axis and the specimen is regarded here as cf. Cynthiacetus sp. 

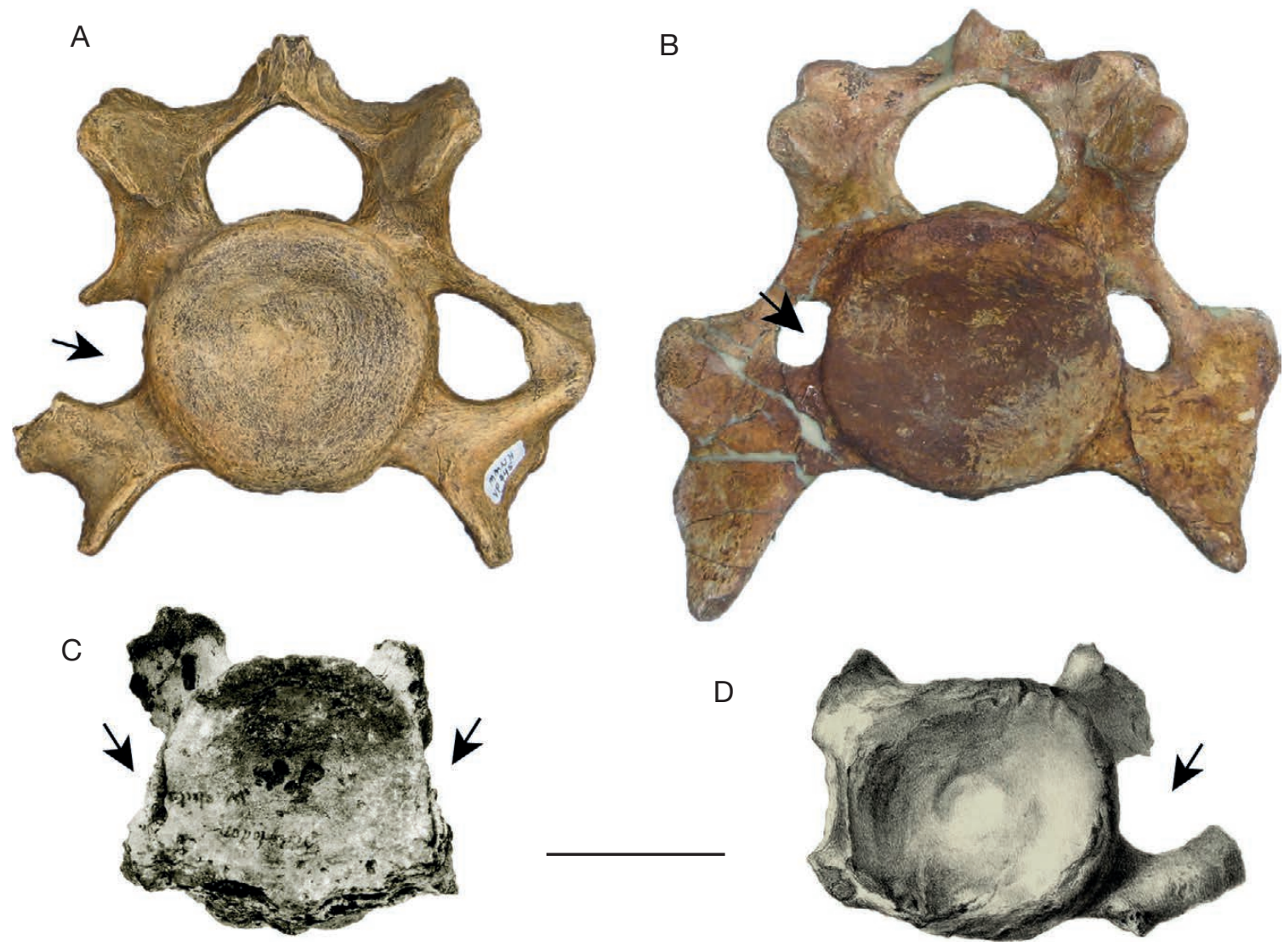

FIG. 4. - Comparison of the middle cervical vertebrae in large basilosaurids: A, MMNS VP455, third cervical vertebra of Cynthiacetus maxwelli; B, UM-WH74, third cervical vertebra of Basilosaurus isis; C, ANSP 13668, holotype of Pontogeneus priscus, probably a C3 or C4 (from Kellogg 1936); D, MffNB uncatalogued, third cervical vertebra of Cynthiacetus sp. (referred to Zeuglodon brachyspondylus by Dames [1894]). Note the large vertebrarterial foramina in C. maxwelli and $P$. priscus as compared to $B$. isis.

\section{Genus Masracetus Gingerich, 2007}

TYPE SPECIES. - Masracetus markgrafi Gingerich, 2007 by original designation.

\section{Masracetus markgrafi Gingerich, 2007}

Zeuglodon isis Stromer, 1908: 128 (in part).

Zeuglodon cf. brachyspondylus Müller, 1849: 26-28. — Stromer 1908: 136. — Kellogg 1936: 262. — Slijper 1936: 319.

Cynthiacetus maxwelli Uhen, 2005: 160 (in part).

HoLOTYPE. - SMNS 11414, vertebral column, part of specimen 'St. 8' in Stromer (1908: 129). The associated skull is catalogued as SMNS 11413.

TYPE LOCALITY AND HORIZON. - Uhen (2005) pointed out that SMNS 11414 and SMNS 11413 could come from the Gehannam Formation (Bartonian) of the Fayum Province, Egypt. However, Gingerich (2007) follows Kellogg (1936) and indicates that the holotype of $M$. markgrafi comes from the Birket Qarun Formation, in the vicinity of Dimeh, also in the Fayum Province. This formation is regarded as early Priabonian in age by Gingerich (1992).

DiAGNOSIS. - Large basilosaurid lacking the vertebral elongation observed in Basilosaurus. Masracetus is slightly larger than Cynthiacetus with a lower lumbar length-to-width ratio $\mathrm{L}_{\text {lum }} / \mathrm{W}_{\text {lum }}$ (Gingerich 2007).
DisCUSSION

The holotype of Masracetus markgrafi was initially referred to $Z$. brachyspondylus (Stromer 1908) and more recently to C. maxwelli (Uhen 2005). Gingerich (2007) pointed out that Masracetus differs from other basilosaurids in the size and proportions of its lumbar vertebrae. Based on this feature, Gingerich (2007) hypothesizes that Pontogeneus brachyspondylus could be referred to Masracetus. Because a comparison of lumbar ratios in a large sampling of basilosaurid specimens (Table 2) does not clearly distinguish Cynthiacetus from Masracetus, the differences between the two genera could very well represent intra-specific variation (when compared to the variation observed in $D$. atrox and $Z$. kochii). Until study of the most complete specimen of $M$. markgrafi (collected in 2006: Gingerich 2007) clarifies the validity of both Masracetus and M. markgrafi, we follow Gingerich (2007) and regard M. markragi as a different species from Cynthiacetus spp.

\section{Genus Cynthiacetus Uhen, 2005}

TyPE SPECIES. - Cynthiacetus maxwelli Uhen, 2005 by original designation.

INCLUdED SPECIES. - Cynthiacetus maxwelli Uhen, 2005; C. peruvianus Martínez-Cáceres \& Muizon, 2011. 
ETYMology. - Cynthia- refers to the name of the quarry in which the holotype of the type species was discovered, the Cynthia Clay Pit. -cetus derives from the Greek Kñ $\tau \circ$, meaning whale.

EMENDED DIAGNOSIS. - Large basilosaurid lacking the vertebral elongation observed in Basilosaurus; skull slightly shorter than Basilosaurus and significantly longer than most other dorudontines. Cynthiacetus differs from all other basilosaurid genera in having: 1) nasals which taper strongly anteriorly, even more than in Basilosaurus and Dorudon; 2) an atlas with a high, massive and dome-shaped neural arch; 3) significantly larger vertebrarterial foramina on the cervical vertebrae (C3-C7 series); and 4) absence or reduction of the anteroventral expansion of the parapophysis in the transverse processes of middle cervical vertebrae (C3-C5). As compared to Basilosaurus, Cynthiacetus differs principally in having a proportionally more elongated rostrum; less ornamented labial and lingual surface of premolars and molars; two large infraorbital foramina rather than one; larger neural canal in thoracic, lumbar and caudal vertebrae; proportionally shorter humerus, radius and ulna; anteriorly convex anterior border of the scapula; proportionally larger femur; and absence of vertebral elongation on thoracic, lumbar and caudal vertebrae.

Cynthiacetus is considerably larger than Saghacetus and differs mainly in having a wider occipital shield, with less pronounced transverse compression of the nuchal crests; two prominent occipital tuberosities; nasal which extends posterior to the maxilla; large anterior process of the frontal separating both posterior ends of the nasals; more inflated braincase; a proportionally shorter i1; a more densely wrinkled enamel on both lingual and labial surfaces of teeth; and shorter posterior thoracics and anterior lumbars.

Dorudon and Cynthiacetus are very similar in overall shape. Except for the size and other characters cited above, Cynthiacetus differs from Dorudon principally in having a proportionally smaller forelimb and a slightly lower occipital shield bearing two tuberosities instead of one.

As compared to Zygorhiza, Cynthiacetus has nuchal crests being posterodorsally oriented instead of being anterolaterally oriented; posterior end of the nasal being posterior to the maxilla; larger and wider anterior process of the frontal separating the posterior end of the nasals at midline; less ornamentation on the enamel; and less transversely expanded braincase.

\section{DisCUSSION}

Before 2005, the only large (c. $10 \mathrm{~m}$ long) "dorudontine" was Pontogeneus brachyspondylus (see above and Müller 1849; Kellogg 1936; Slijper 1936). Uhen (2005) and Gingerich (2007) increased to three the number of large dorudontine genera (cf. above). Recently, Gingerich (2015) proposed to synonymize Cynthiacetus maxwelli with Pontogeneus brachyspondylus. However, Pontogeneus is regarded here as a Basilosauridae incertae sedis since the type specimen of P. brachyspondylus is a single cervical vertebra that cannot be distinguished from both Cynthiacetus and Masracetus (but see discussion in Gingerich 2015 for an alternative conclusion). A more accurate diagnosis was given for Cynthiacetus by Martínez-Cáceres \& Muizon (2011) who pointed out various autapomorphies of the genus. However, this diagnosis does not differentiate Cynthiacetus from Masracetus (which was not included in the phylogenetic analysis at this time). They are regarded here as different genera but this should be confirmed by a detailed comparison with a new undescribed specimen referred to Masracetus (Gingerich 2007). If Cynthiacetus and Masracetus are synonymized, Masracetus should be considered as a junior synonym and
Cynthiacetus would become the only large dorudontine valid genus.

\section{Cynthiacetus maxwelli Uhen, 2005}

Zeuglodon cf. brachyspondylus - Müller 1849: 26-28. — Kellogg 1936: 248 (in part).

HolotyPe. - MMNS VP 445. It includes a partially preserved skull, dentaries, upper and lower dentitions, petro-tympanic complex, humerus, radius, ulna, cervical, thoracic and lumbar vertebrae.

Type locality. - Cynthia Clay Pit, Hinds County, Mississippi, USA.

Type HORIZON. - Yazoo Clay Formation, Priabonian, late Eocene.

EMENDED DIAGNOSIS. - Cynthiacetus maxwelli differs mainly from $C$. peruvianus in having one more cusp on both mesial and distal edges on $\mathrm{p} 3$ and $\mathrm{p} 4$ (5 and 6 denticles respectively in $\mathrm{p} 3$ and $\mathrm{p} 4$ ). It also possesses a longer and lower dome-shaped neural arch on the atlas and shorter and more massive humerus, radius and ulna (cf. below).

\section{Cynthiacetus peruvianus \\ Martínez-Cáceres \& Muizon, 2011}

Holotype. - MNHN.F.PRU10 (Fig. 5), an almost complete skeleton including: skull, dentaries, upper and lower dentitions, petro-tympanic complex, hyoid apparatus, sub-complete right forelimb, partial right hindlimb, cervical, thoracic, lumbar, anterior and middle caudal vertebrae, and ribs.

TyPE LOCALITY. - Surroundings of the city of Paracas, at about the level of the Km 240 of the South Panamerican Highway. The specimen was found approximately $2.5 \mathrm{~km}$ northeast to the type section of the Otuma Formation (Fig. 1). Geographical coordinates are: $13^{\circ} 52^{\prime} 54.3^{\prime \prime} \mathrm{S}, 76^{\circ} 14^{\prime} 13.4^{\prime \prime} \mathrm{W}$.

Etymology. - Peruvianus, from Peru, the country where the holotype was found.

Type horizon And Age. - Priabonian (late Eocene), Otuma Formation (DeVries et al. 2006), which spans from about $38 \mathrm{Ma}$ to about $33 \mathrm{Ma}$ (cf. Geological setting).

EMENDED Diagnosis. - Cynthiacetus peruvianus differs from C. maxwelli in having one cusp less on both mesial and distal edges on p3 and p4; anteroposteriorly shorter and higher domeshaped neural arch on the atlas; and a proximo-distally longer and anteroposteriorly more slender humerus, radius and ulna. Cynthiacetus peruvianus presents the largest number of thoracic vertebrae (20) and ribs observed in all known cetaceans. Besides, the spinal process in anterior thoracic vertebrae is more vertical than in Basilosaurus, Dorudon, Saghacetus, and Zygorhiza. However, because these two characters cannot be confirmed in C. maxwelli, they may constitute synapomorphies of the genus.

\section{DESCRIPTION OF THE HOLOTYPE OF CYNTHIACETUS PERUVIANUS}

As mentioned above, MNHN.F.PRU10 is an almost complete skeleton only missing the posterior caudal vertebrae (from Ca11) and left forelimb and hind limb. Thus, the ontogenetic 

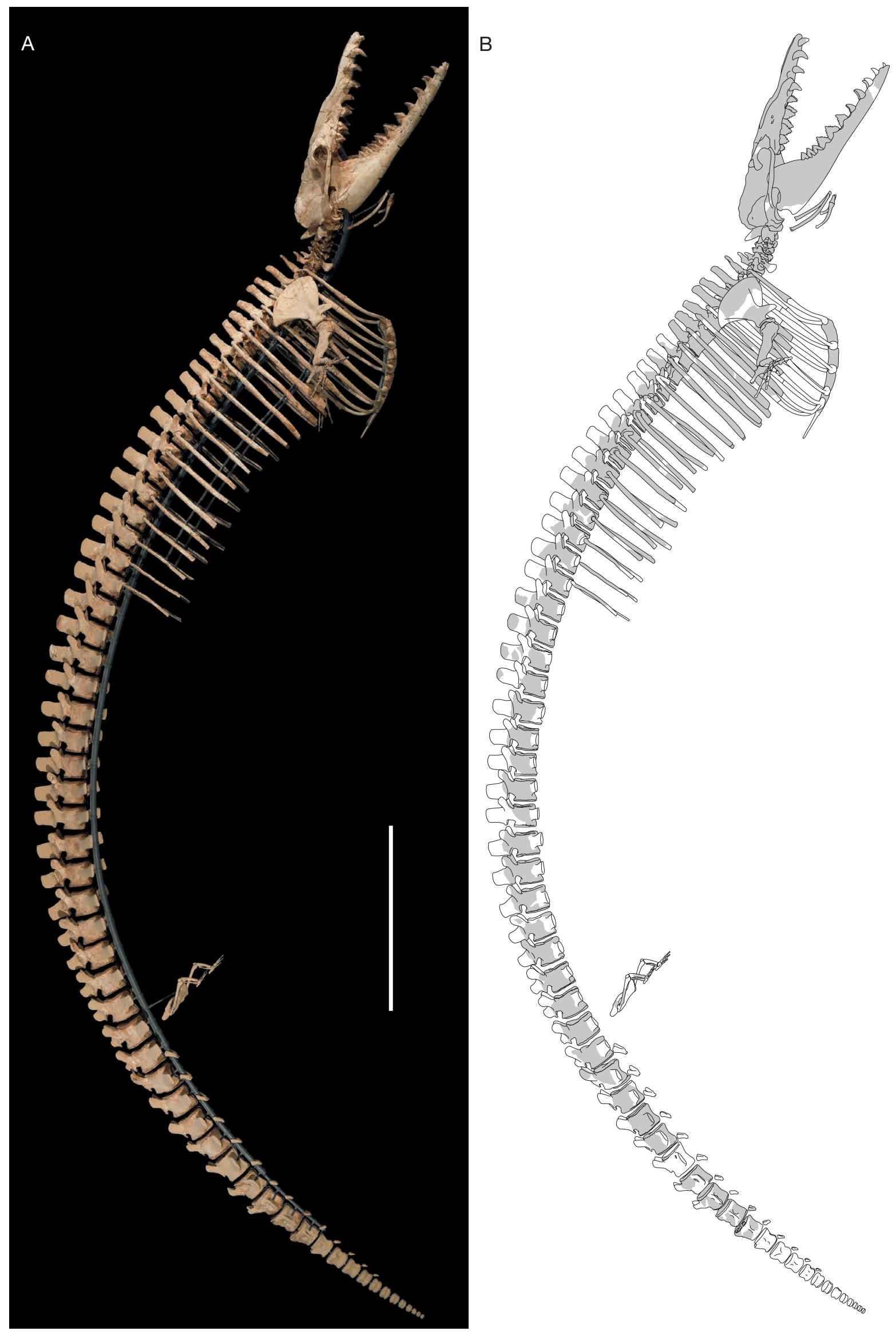

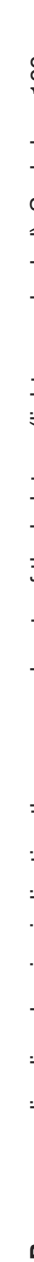$$
\text { की }
$$
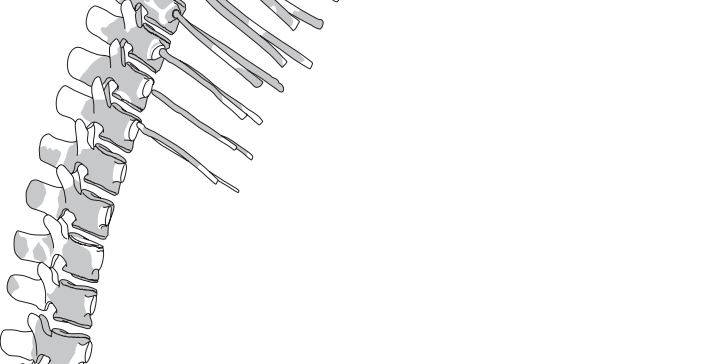

So

$x_{n=1}^{2+2}$

$x_{0=1}^{2}$

the

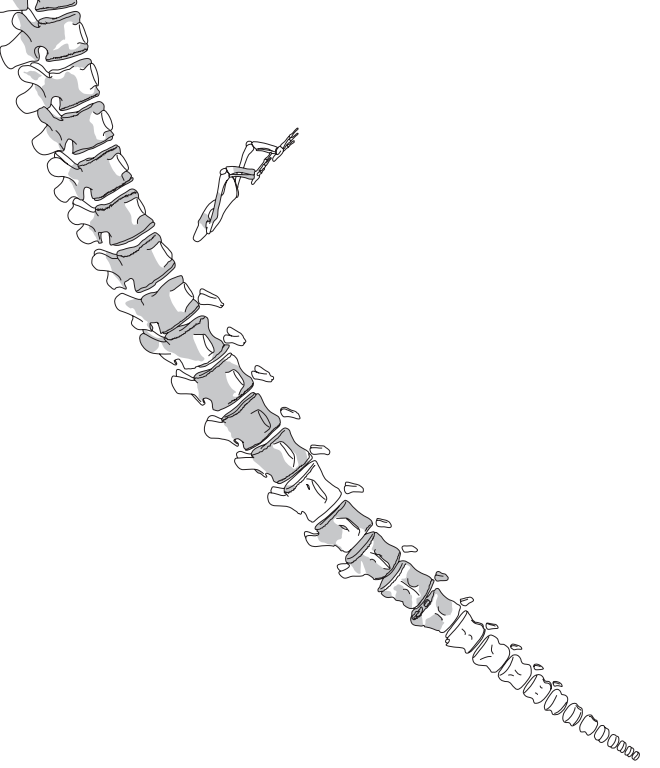


stage of the specimen can be estimated from dental eruption and the degree of fusion in cranial and vertebral sutures. MNHN.F.PRU10 has a permanent dentition without advanced wear surfaces, contrary to various adult basilosaurid specimens. Moreover, most cranial sutures remain distinguishable, except for the occipital region and median portion of the basicranium. Since the epiphyses are not entirely fused to the centra in most vertebrae or to the diaphyses in limb bones, it can be evaluated that MNHN.F.PRU10 is a young adult individual. The specimen is estimated to have been $c .9 \mathrm{~m}$. long.

\section{SKULL}

Bony skull

General morphology. In overall morphology, MNHN.F. PRU10 has a typical basilosaurid skull, with a narrow rostrum, a wide and well-developed supraorbital shield and a long and narrow intertemporal region (Figs 6, 7, 8, 9). Similar to other archaeocetes and in contrast with modern cetaceans, the mesorostral canal and occipital shield are not exposed in dorsal view. The skull of Cynthiacetus peruvianus is almost as long as that of Basilosaurus, being $40 \%$ longer than the average skull size of Dorudon atrox and 60\% longer than that of Saghacetus osiris. Main cranial measurements of MNHN.F.PRU10 are presented in Table 3.

The rostrum is the narrowest at its apex and has an elliptic cross-section. Posteriorly, it expands transversely, being roughly circular in cross-section at the level of the external bony nares. Posterior to the nares, the rostrum is wider than high and reaches its maximum width at its base, anterior to the orbit. The prenarial portion of the rostrum is bent to the left. This torsion seems to be natural in archaeocetes, since it is also observed in protocetids and other basilosaurids (Fahlke et al. 2011 and discussion here; Fahlke \& Hampe 2015). However, in MNHN.F.PRU10, it is accentuated by a taphonomic distortion of the rostrum to the left. As a consequence of this distortion, the crown of the two anterior right incisors is well exposed in dorsal view.

The external bony nares form a teardrop-shaped opening in dorsal view with the apex of the teardrop being anteriorly oriented. Because the anterior edge of the nasals is missing, the posterodorsal edge of the external bony nares is missing in the holotype of Cynthiacetus peruvianus. It was probably located at the level of the diastema between P1 and P2, as observed in other basilosaurids.

As is observed in other basilosaurids, the orbit is circular to oval-shaped in outline and proportionally smaller than in early mysticetes, as stated by Marx (2010). In lateral view, the orbit is dorsal to the level of the dental row and ventral to the level of the nasals. In contrast, the dorsal edge of the orbit in various toothed mysticetes (e.g. Aetiocetidae) is dorsal to the level of the nasals at the sagittal plane.

The temporal fossa is large and anteroposteriorly long. It is limited dorsally by a straight and elevated sagittal crest, which is higher than in most neocetes (except for some mysticetes as Eomysticetus whitmorei Sanders \& Barnes, 2002). As is observed in other basilosaurids, the temporal fossa is limited laterally by the temporal portion of the jugal and the zygo- matic process of the squamosal. There is no well-developed orbitotemporal crest.

In dorsal view, the skull (bending of the rostrum apart) is an elongated triangle and its lateral edges regularly diverge posteriorly up to the level of the anterior edge of the glenoid fossae. Posterior to this level, the occipital region of the skull rapidly narrows. A deep and large notch forms the center of the posterior edge of the skull, between the left and right parts of the lambdoid crest. In lateral view the dorsal edge of the skull gently slopes anteriorly up to the posterior extremity of the narial fossa. At the level of the narial fossa, the dorsal edge of the premaxilla is distinctly concave in lateral view; more anteriorly, above the incisors, it is slightly convex.

Premaxilla (PMx). The premaxilla forms the anterior portion of the rostrum dorsally and ventrally, as well as the anterior, lateral and part of the dorsal margins of the external bony nares. The premaxilla is one of the longest bones of the skull of Cynthiacetus peruvianus, being approximately as long as half the condylobasal length (maximum length $=585 \mathrm{~mm}$ ). Laterally, it articulates exclusively with the maxilla. Anterior to the narial fossa, the premaxillae are facing each other along the midline. In dorsal view, the posterior portion (= narial process) of the premaxilla articulates medially with the nasal. In the mesorostral region the premaxilla is partially covered by the vomer. As mentioned above, the prenarial portion of the rostrum is bent to the left. Consequently, the premaxillae are asymmetric, the right premaxilla being longer than the left.

Although the premaxillae are closely approximated in their prenarial portion, they do not contact each other dorsally. There is thus no dorsal inter-premaxillary suture but a narrow interpremaxillary space that cannot be called a mesorostral groove.

The anterior end of the premaxilla is transversely compressed, being dorsoventrally higher than transversely wide (Fig. 6). The smooth lateral surface of the anterior portion of the premaxilla is slightly convex laterally while its medial surface is roughly flat. Posterior to the level of I3, the medial surface of each premaxilla becomes medially concave and form the lateral walls, roof and floor of the anterior portion of the mesorostral canal. Most of the floor of the mesorostral canal is formed by the rostral portion of the vomer (cf. Vomer section).

Posterior to the external bony nares, the premaxilla presents a narrow, thin and elongated narial process, wedged between the nasal medially and the maxilla laterally, and which contributes to the roof of the narial cavity (Figs 6;11). The narial process of the premaxilla decreases in width posteriorly to a point dorsal to the level of the posterior edge of P3 and anterior to both the lacrimal canal and the preorbital process of the frontal. On its medial edge, the narial process contacts the anterior two thirds of the nasal bone. The naso-premaxillary (Na-PMx) sutures are straight and diverge posterolaterally. Laterally, the narial process contacts the maxilla forming the posterior portion of the external maxillo-premaxillary $(\mathrm{Mx}-$ PMx) suture.

The anterior end of the external Mx-PMx suture is just posterior to the embrasure pit for the lower canine, in the I3-C1 diastema. From this point, the Mx-PMx suture runs 
TABLE 3. - Cranial measurements (in mm) of the skull of MNHN.F.PRU10 holotype of Cynthiacetus peruvianus. (e), estimate.

\begin{tabular}{|c|c|}
\hline Measurements & $\mathrm{mm}$ \\
\hline Condylobasal length & 1170 \\
\hline Bizygomatic width & 477.8 \\
\hline Length of the rostrum, from its anterior edge to the level of the antorbital process of the maxilla & 670 \\
\hline Width of the rostrum at the level of I1 & 58 \\
\hline Width of the rostrum at the level of $\mathrm{I} 2$ & 80 \\
\hline Width of the rostrum at the level of 13 & 92.5 \\
\hline Width of the rostrum at the level of $\mathrm{C} 1$ & 113 \\
\hline Width of the rostrum at the level of $\mathrm{P} 1$ & 130 \\
\hline Width of the rostrum at the level of P2 & 170 \\
\hline Width of the rostrum at the level of P3 (base of the rostrum) & 225 \\
\hline Width of the rostrum at the level of P4 (base of the rostrum) & 264 \\
\hline Length of the alveolar portion of the skull (right side) & $710(\mathrm{e})$ \\
\hline Length of the alveolus for I1 (right side) & 42 \\
\hline Length of the diastema between I1 and I2 (right side) & 27.6 \\
\hline Length of the alveolus for 12 (right side) & 43 \\
\hline Length of the diastema between $\mathrm{I} 2$ and $\mathrm{I} 3$ (right side) & 47.5 \\
\hline Length of the alveolus for 13 (right side) & 42.5 \\
\hline Length of the diastema between $\mathrm{I} 3$ and $\mathrm{C} 1$ (right side) & 52 \\
\hline Length of the alveolus for $\mathrm{C} 1$ (right side) & 53.4 \\
\hline Length of the diastema between $\mathrm{C} 1$ and $\mathrm{P} 1$ (right side) & 34.3 \\
\hline Length of the alveolus for P1 (right side) & 39.3 \\
\hline Length of the diastema between P1 and P2 (right side) & 35.4 \\
\hline Length of the alveolus for P2 (right side) & 57.8 \\
\hline Length of the diastema between P2 and P3 (right side) & 26.9 \\
\hline Length of the alveolus for P3 (right side) & 63.3 \\
\hline Length of the alveolus for P4 (right side) & 57 \\
\hline Length of the alveolus for $\mathrm{M} 1$ (right side) & 30.21 \\
\hline Length of the alveolus for M2 (right side) & 28 \\
\hline Length of the nasal at midline & 210 \\
\hline Maximum length of the premaxilla & - \\
\hline Length of the frontal at midline & 205 \\
\hline Length of the parietal at midline & 195 \\
\hline $\begin{array}{l}\text { Length of the prenarial portion of the premaxilla, from its anterior edge to the level of P1, when the premaxilla forms } \\
\text { the lateral edge of the external bony nares }\end{array}$ & - \\
\hline $\begin{array}{l}\text { Length of the narial process of the premaxilla, from the level of the dorsal edge of the external bony nares to the } \\
\text { posterior edge of the premaxilla }\end{array}$ & - \\
\hline Width of the skull, at the level of the preorbital process of the frontal & 335 \\
\hline Width of the skull, at the level of the postorbital process of the frontal & 395 \\
\hline Width of the left supraorbital process of the frontal at its mid-length & 357 \\
\hline Length of the orbit $(\mathrm{R} / \mathrm{L})$ & $102 / 115$ \\
\hline Maximum height of the orbit & 84.5 \\
\hline Intercondylar notch breadth & 128 \\
\hline Width of the foramen magnum & 30 \\
\hline Height of the foramen magnum & 79 \\
\hline Maximum height of the supraocciptal, from the foramen magnum to the vertex & 200 \\
\hline Maximum width of the supraoccipital in dorsal view & 189.7 \\
\hline Maximum length of the jugal & 352 \\
\hline $\begin{array}{l}\text { Length of the zygomatic process of the squamosal, from the anterior edge of the supramastoid crest to the anterior } \\
\text { edge of the sulcus on the dorsal surface of the jugal }\end{array}$ & $250(e)$ \\
\hline $\begin{array}{l}\text { Maximum width of the temporal fossa in dorsal view, from the orbitotemporal crest to the zygomatic process of the } \\
\text { squamosal }\end{array}$ & $270(e)$ \\
\hline Maximum length of the glenoid fossa, from the apex of the postglenoid process to the posterior end of the jugal & $90(\mathrm{e})$ \\
\hline Width of the glenoid fossa, from its lateral border to the level of the medial edge of the postglenoid process & 74.45 \\
\hline
\end{tabular}

sinuously and posterodorsally for about $50 \mathrm{~mm}$, then it turns more posteriorly towards the vertex. At this level, the Mx-PMx suture is almost parallel to the dorsal margin of the skull (in lateral view). At the level of the narial process of the premaxilla, right and left Mx-PMx sutures are subparallel or slightly converge posteriorly. This suture ends posteriorly at about the level of the posterior edge of $\mathrm{P} 3$, where it reaches the lateral edge of the nasal at the premaxilla-maxilla-nasal triple contact, anterior to the level of the lacrimal canal.

Ventrally, the palatal surfaces of the premaxillae are flat, smooth and articulate on the midline for almost their entire length. The palatal surface widens from its anterior end to the level of the I3-C1 diastema, then it narrows progressively and forms two posterior processes that wedge between the maxillae until the level of the posterior edge of P1. Along these processes, the medial edges of the premaxillae form a low ridge at midline. This ridge extends from the level of the I3-C1 diastema to the level of the C1-P1 diastema. At this level, the medial edges of both premaxillae diverge and form the anterior end of a small vomerian window.

The ventral portion of the Mx-PMx suture runs posteromedially from the posterior end of the embrasure pit for $\mathrm{cl}$ 

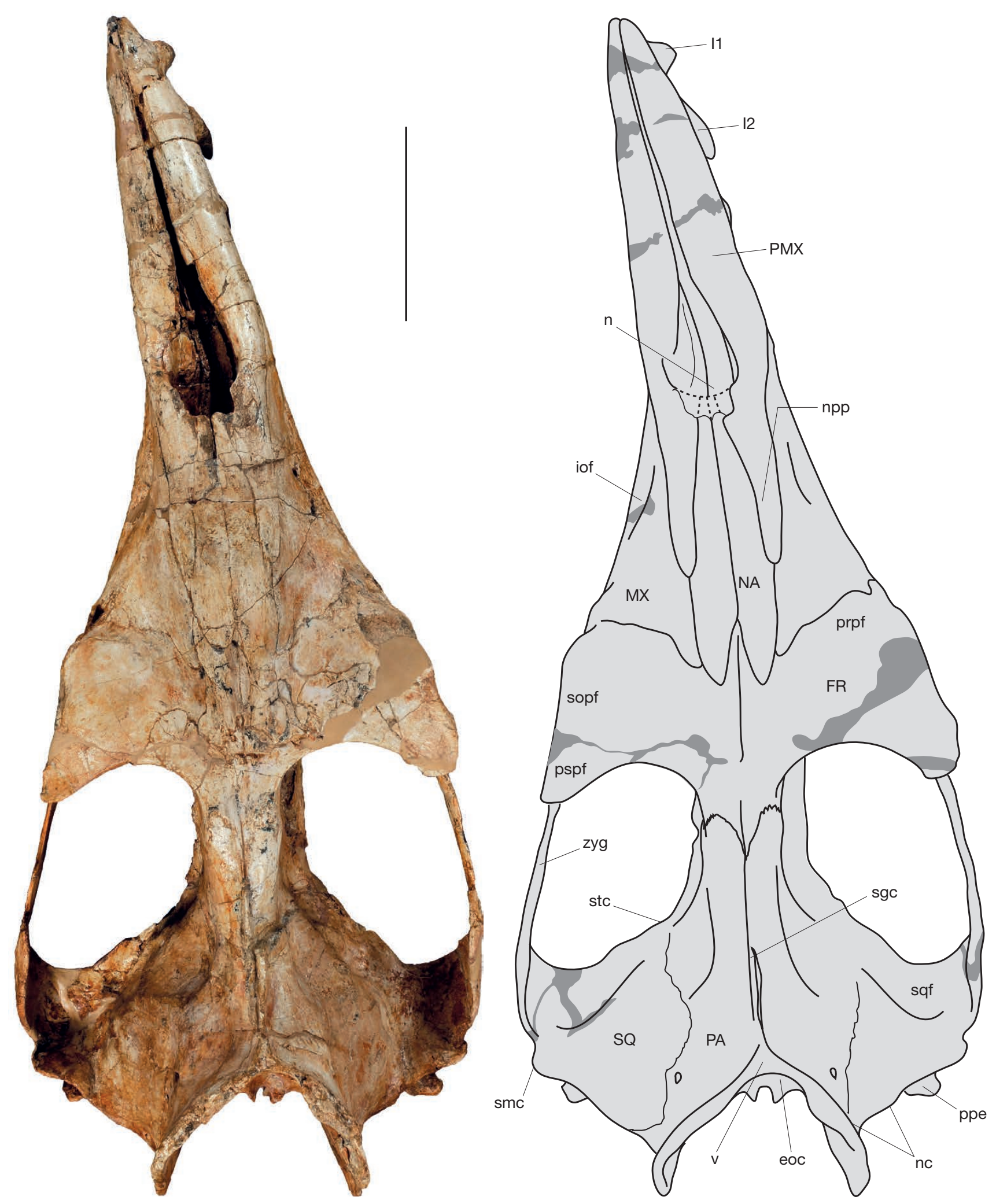

FIG. 6. - Dorsal view of the skull of MNHN.F.PRU10, holotype of Cynthiacetus peruvianus. Abbreviations: eoc, external occipital crest; FR, frontal; iof, infraorbital foramina of the maxilla; MX, maxilla; NA, nasal; nc, nuchal crest; $\mathbf{n}$, nares; $\mathbf{n p p}$, narial process of the premaxilla; PA, parietal; PMX, premaxilla; ppe, paroccipital process of the exoccipital; prpf, preorbital process of the frontal; pspf, postorbital process of the frontal; sgc, sagittal crest; smc, suprameatic crest; sopf, supraorbital process of the frontal; SQ, squamosal; sqf, squamosal fossa; stc, sub-temporal crest; v, vertex; zyg, zygomatic arc. Dark grey-shaded regions indicate the reconstructed parts of the specimen. The anterior end of the nasals has been reconstructed. Scale bar: $20 \mathrm{~cm}$. 

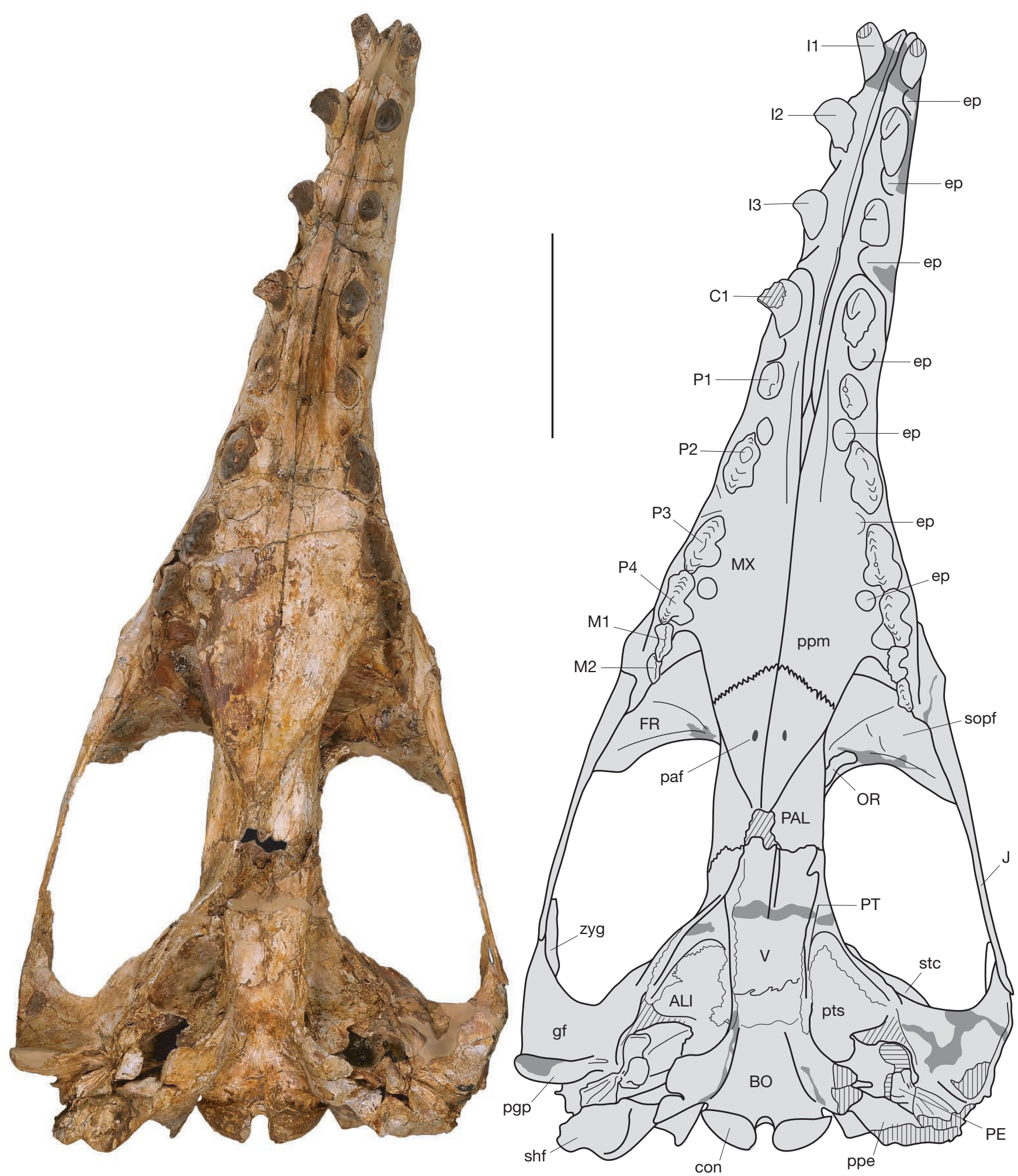

FIG. 7. - Ventral view of the skull of MNHN.F.PRU10, holotype of Cynthiacetus peruvianus. Abbreviations: ALI, alisphenoid; BO, basioccipital; con, occipital condyle; ep, embrasure pit; FR, frontal; gf, glenoid fossa; J, jugal; MX, maxilla; OR, orbitopshenoid; paf, palatine foramen; PAL, palatine; ppm, palatal process of the maxilla; PE, periotic; pgp, postglenoid process; PMX, premaxilla; ppe, paroccipital process of the exoccipital; PT, pterygoid; pts, pterygoid sinus; shf, fossa for the stylohyal contact; sopf, supraorbital process of the frontal; stc, subtemporal crest; $\mathbf{V}$, vomer; zyg, zygomatic process of the squamosal. Dark grey-shaded regions indicate the reconstructed parts of the specimen. Hatched regions indicate the break surfaces. Scale bar: $20 \mathrm{~cm}$. 

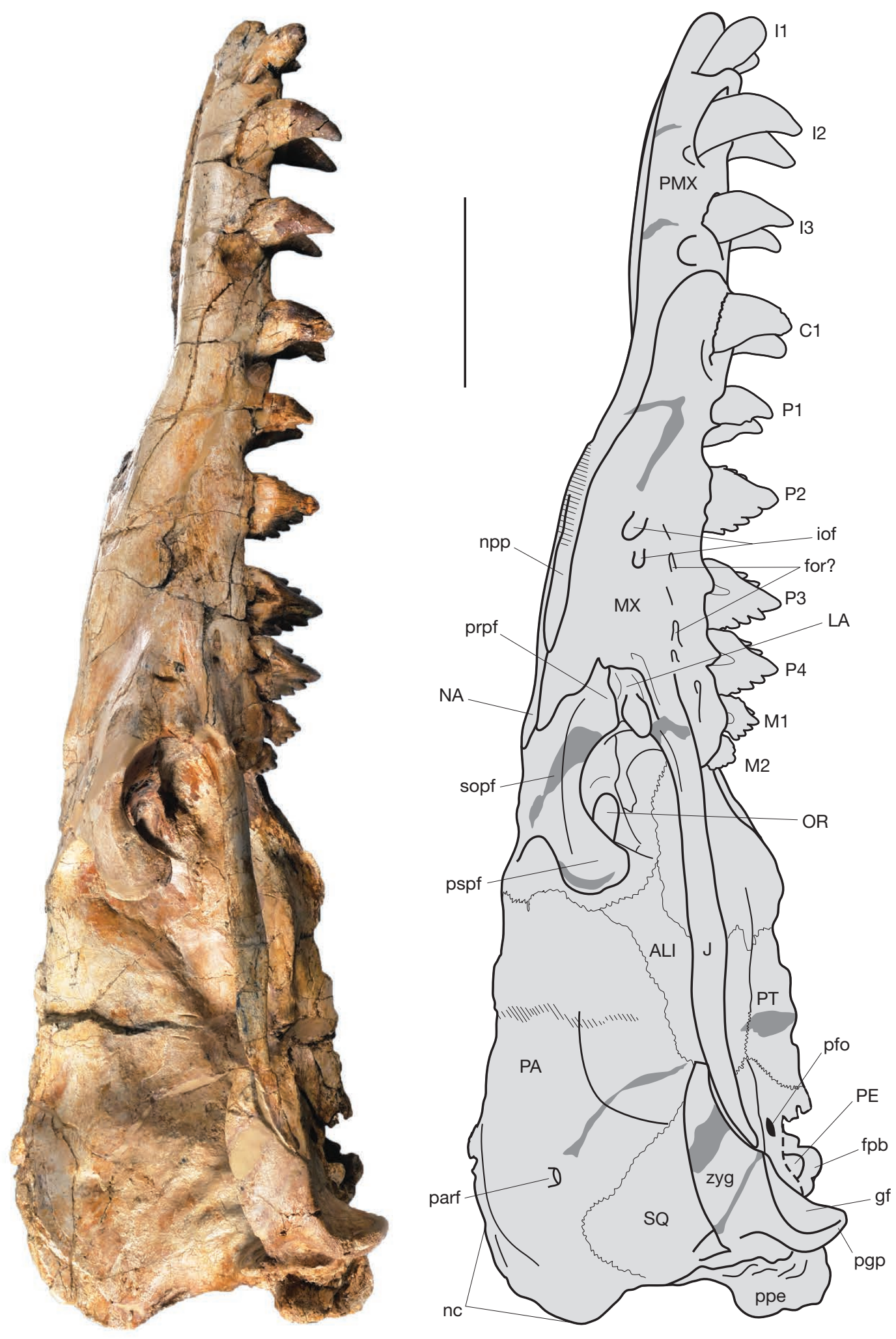

FIG. 8. - Right lateral view of the skull of MNHN.F.PRU10, holotype of Cynthiacetus peruvianus. Abbreviations: ALI, alisphenoid; for?, probable accessory foramina for the intraorbital foramina; fpb, falcate process of the basioccipital; gf, glenoid fossa; iof, infraorbital foramina; J, jugal; $\mathbf{M X}$, maxilla; $\mathbf{N A}$, nasal; nc, nuchal crest; npp, nasal process of the premaxilla; OR, orbitosphenoid; PA, parietal; parf, parietal foramen; PE, periotic; pfo, pseudovale foramen; pgp, postglenoid process; PMX, premaxilla; ppe, paroccipital process; prpf, preorbital process of the frontal; pspf, postorbital process of the frontal; PT, pterygoid; sopf, supraorbital process of the frontal; $\mathbf{S Q}$, squamosal; $\mathbf{z y g}$, zygomatic process of the squamosal. Dark grey-shaded regions indicate the reconstructed parts of the specimen. Scale bar: $20 \mathrm{~cm}$. 

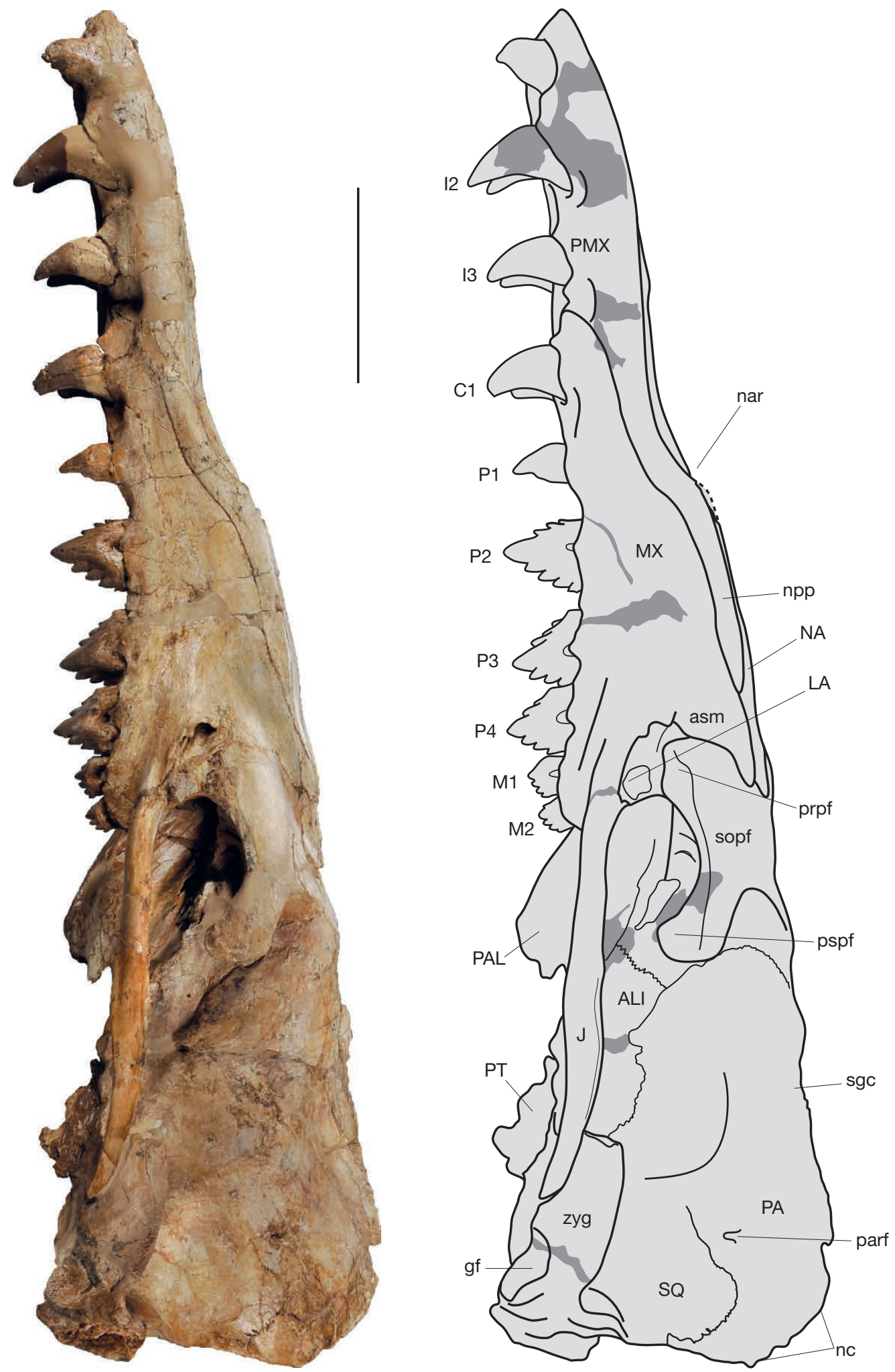

FIG. 9. - Left lateral view of the skull of MNHN.F.PRU10, holotype of Cynthiacetus peruvianus. Abbreviations: ALI, alisphenoid; asm, ascending process of the maxilla; gf, glenoid fossa; J, jugal; MX, maxilla; NA, nasal; nar, position of the external bony nares; nc, nuchal crest; npp, nasal process of the premaxilla; PA, parietal; PAL, palatine; parf, parietal foramen; PMX, premaxilla; prpf, preorbital process of the frontal; pspf, postorbital process of the frontal; PT, pterygoid; sgc, sagittal crest; sopf, supraorbital process of the frontal; SQ, squamosal; zyg, zygomatic process of the squamosal. Dark grey-shaded regions indicate the reconstructed parts of the specimen. Scale bar: $20 \mathrm{~cm}$. 
to the mid-length of the P1-P2 diastema, where it meets the lateral edge of the palatal windows for the vomer. Therefore, the Mx-PMx suture does not reach the midline in ventral view. The posterior apex of the palatal surface of the premaxilla is extremely thin.

On the lateral edge of the ventral surface of the premaxilla, the alveolar process bears three alveoli for the upper incisors. The alveoli are antero-posteriorly aligned and separated by long diastemata. As a result of the natural deformation of the rostrum, the right diastemata are longer than the left. This condition confirms that the torsion of the rostrum to the left is not only the result of taphonomical distortion, but at least partly represents the original morphology of the skull. The alveoli are roughly oriented ventrolaterally, with the alveolus for I1 more anteriorly oriented than those for I2 and I3. Moreover, both I1-I2 and I2-I3 diastemata bear embrasure pits, which receive the crown of the posterior lower incisors (i2-i3). Thereby, when the jaws are closed the lower incisors are anterior to their corresponding upper incisors.

A third embrasure pit is located posterior to $\mathrm{I} 3$ and receives the crown of the lower canine. The three embrasure pits cited above are located lateral to the dental row, open laterally and are visible in lateral and ventral view. Depth and size of the embrasure pits increase posteriorly.

Maxilla (Mx). The maxilla contributes significantly to the posterolateral wall of the rostrum. Medially, the maxilla articulates with both premaxilla and nasal. Ventrally, it mainly participates with the palatine in the posterior half of the palate. Posteriorly, the maxilla articulates principally with the frontal, but it also contacts both lacrimal and jugal. It contributes to the anterior wall of the orbit. As a consequence of the torsion of the rostrum, the left maxilla is slightly transversely wider than the right maxilla, anterior to and at the level of the external bony nares (Fig. 10B, C).

The dorsal exposure of the maxilla can be divided into an anterior rostral surface and a posterior facial surface (Figs 6; 11). While the former is somewhat laterally facing, the latter faces exclusively dorsally. The rostral surface is only partly exposed in dorsal view. Moreover, it is narrower than the facial surface, which is roughly triangular, with an anteriorly oriented apex. In lateral view, the rostral and facial surfaces of the maxilla exhibit an arrow-shaped triangular outline.

At about the level of the diastema between P2 and P3, the rostral portion of the maxilla presents the main infraorbital foramen, which is the anterior opening of the infraorbital canal (Fig. 12). This canal transmits the infraorbital nerve (branch of the maxillary nerve, part of the cranial nerve V2) from the orbit to the anterior portion of the rostrum. A smaller accessory foramen (better visible on the right side) is located at the level of $\mathrm{P} 3$ and just posteroventral to the main infraorbital foramen. On the right maxilla, four other smaller foramina are clearly visible at the antorbital portion of the maxilla (Fig. 8[for?]), posterior to the two previously described foramina. It is unclear if these foramina are homologous with the numerous infraorbital foramina observed in many Recent neocetes. Indeed, while most basilosaurids only have one or two infraorbital foramina, most Recent and fossil neocetes present numerous, relatively large infraorbital foramina at the base of the rostrum (e.g. Mammalodon colliveri, Simocetus rayi, and Waipatia maerewhenua). In Cynthiacetus peruvianus, the posteriormost of these foramina is at about the level of the posterior root of $\mathrm{P} 4$, just anterior and ventral to the level of the opening of the lacrimal canal.

In dorsal view, the maxilla contacts the premaxilla medially. The dorsal portion of the Mx-PMx suture has already been described above (cf. Premaxilla section and Figures 8, 9). The $\mathrm{Mx}-\mathrm{PMx}$ suture meets posteriorly the nasomaxillary $(\mathrm{Na}-\mathrm{Mx})$ suture, which is parallel to the midline for almost its entire length. Indeed, only the posterior $2 \mathrm{~cm}$ of the $\mathrm{Na}-\mathrm{Mx}$ suture are posteromedially oriented. Moreover, the posterior end of the maxilla is located $3 \mathrm{~cm}$ anterior to the posterior end of the nasal. The facial surface of the maxilla is smooth and bears no crest or dorsal foramen. It is slightly concave dorsolaterally and most likely received the nasofacial musculature. Besides, the facial surface of the maxilla extends posteromedially forming a narrow and short $(3 \mathrm{~cm})$ ascending process starting at about the level of the preorbital process of the frontal. The ascending process is dorsolaterally facing and can be regarded as a posteromedial and linguiform projection of the facial surface. Its posterior and lateral edges form the medial extremity of the fronto-maxillary (Fr-Mx) suture. The lateral edge of the ascending process is anterolaterally inclined, parallel to the $\mathrm{Na}-\mathrm{Ma}$ suture at the same level, and forms an angle of $25^{\circ}$ with the sagittal plane.

Lateral to the ascending process, the Fr-Mx suture turns almost perpendicular to the midline (it forms an angle of $80^{\circ}$ with the midline). The Fr-Mx suture runs towards the antorbital region and fuses with the maxillo-lacrimal (Mx-La) suture at the lateral margin of the rostrum. At this level, the maxilla forms the lateral wall of the lacrimal canal and delimits its opening anteriorly (Fig. 12). In terrestrial mammals, the lacrimal canal carries the lacrimal duct, which leads from the lacrimal sac to the inferior nasal meatus (Mead \& Fordyce 2009; Evans \& de Lahunta 2013). It is absent in Recent neocetes, but commonly occurs in archaeocetes. Ventral to the lacrimal canal, the Mx-La suture runs posteriorly and meets the jugo-maxillary (J-Mx) suture at the anteroventral corner of the orbit. Here, the maxilla forms a narrow, but conspicuous jugular process (Figs 12; 13). The jugal process of the maxilla articulates posteriorly with the orbital portion of the jugal. However, it does not contribute to the edge of the orbit. Ventrally, the jugal process contacts the posterior extension of the alveolar process of the maxilla (cf. below). In lateral view, the Ju-Mx suture is anterodorsally-posteroventrally inclined.

The ventral surface of the maxilla can be divided into palatal surface and alveolar process (Fig. 7). The flat palatal surface of the maxilla contacts anteriorly the palatal surface of the premaxilla and posteriorly the horizontal lamina of the palatine. It widens progressively posteriorly until the level of the posterior root of the last upper premolar (P4). From this level, the palatal surface gradually narrows posteriorly and turns ventrally. Posterior to $\mathrm{P} 4$, the palatal surface is separated from the alveolar process of the maxilla. No foramen can 
A

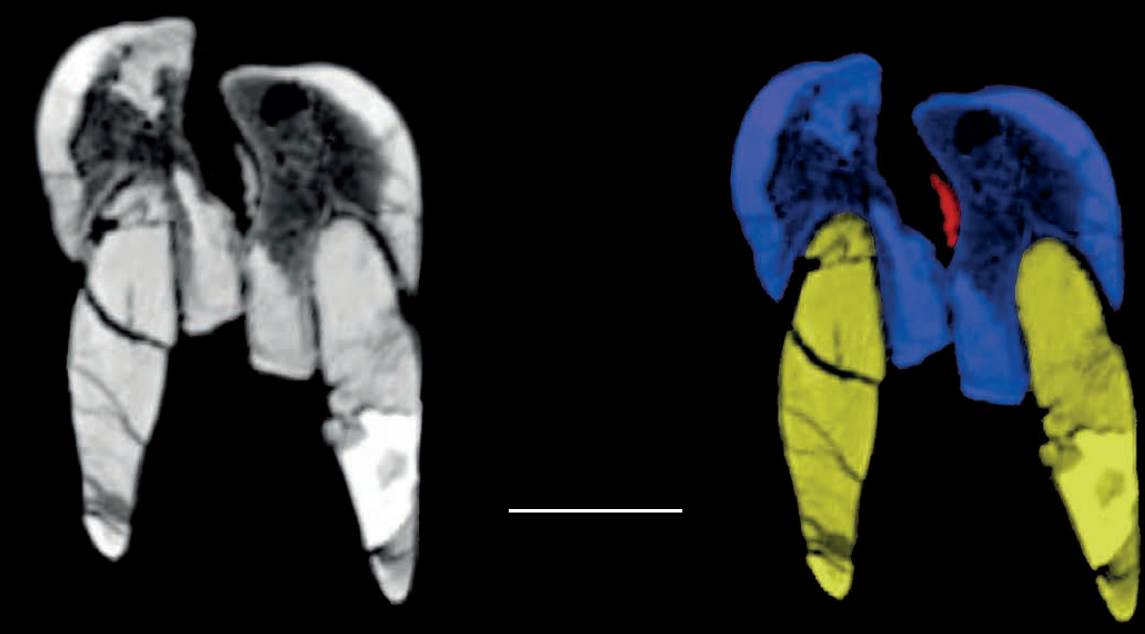

B
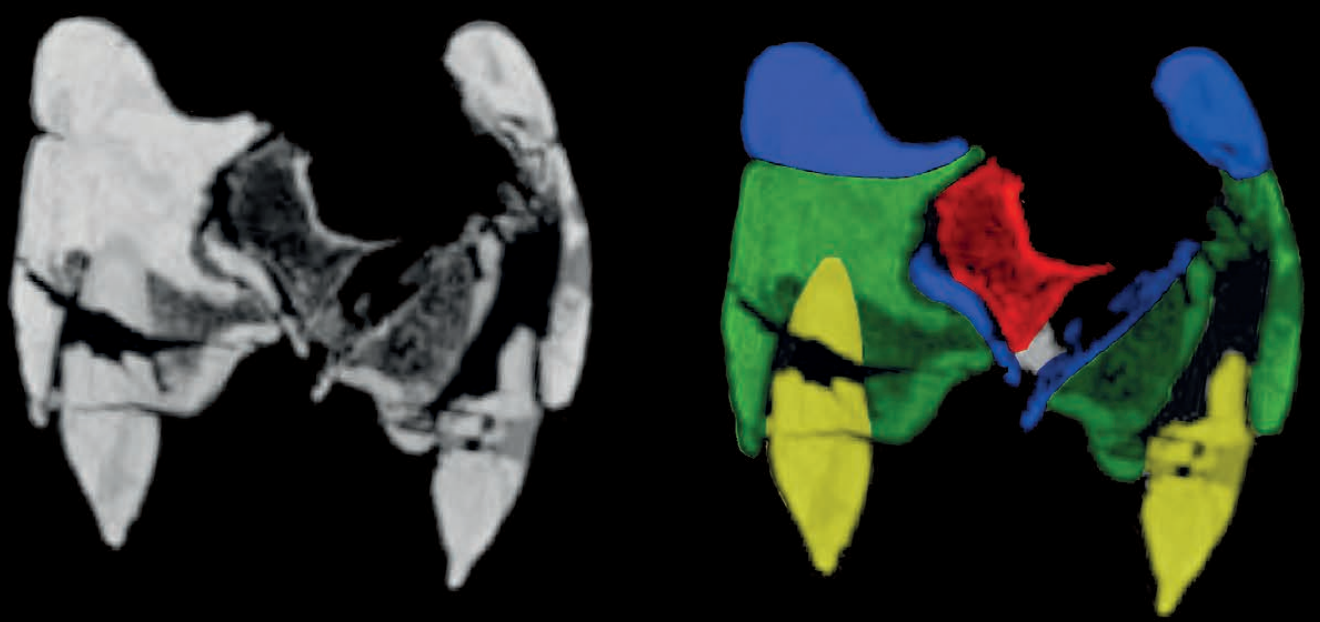

C
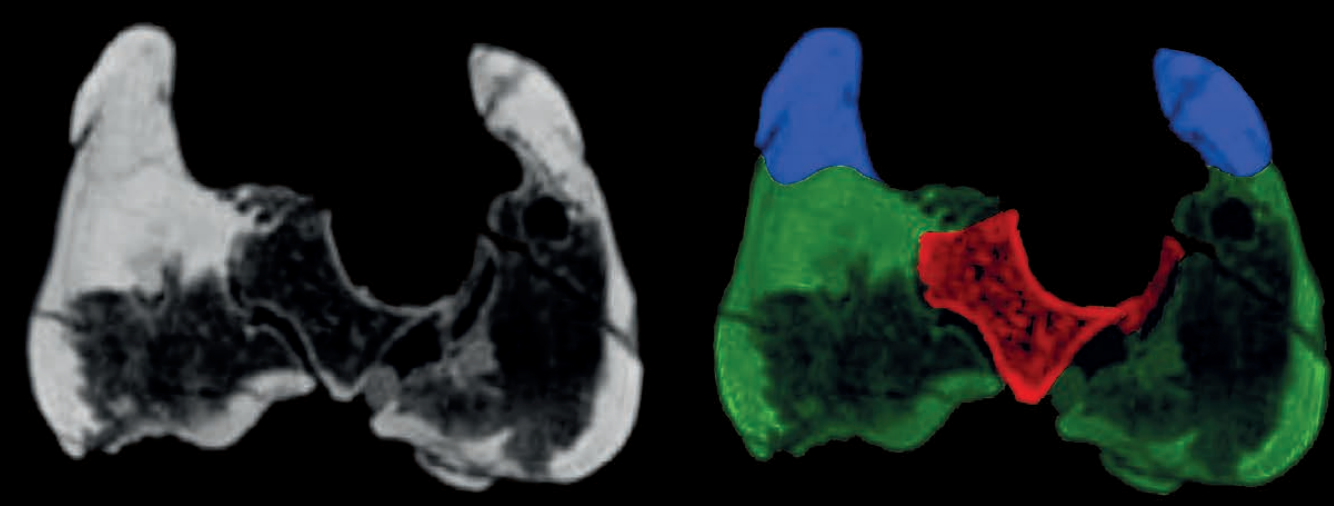

FIG. 10. - Transverse sections (from computed tomography scan) in the skull of MNHN.F.PRU10, holotype of Cynthiacetus peruvianus: A, at the level of I3; B, at the level of P1; C, at the level of the diastema between P1-P2. The different elements have been colored as follows: premaxillae in blue, maxillae in green, vomer in red and teeth in yellow. Note the difference in shape and size between right and left elements due to the rostral torsion. While the vomer is covered by the thin premaxillae in (B), it is exposed in ventral view at the level of (C). Scale bar: $4 \mathrm{~cm}$.

securely be observed on the palatal surface of the maxilla. Anteriorly, both palatal surfaces of the maxillae are separated by the premaxillae and the vomer (the ventral portion of the Mx-PMx suture has already been described, in the Premaxilla section). The Mx-PMx suture meets the midline at about the level of P2 (Fig. 7). From this point, the inter-maxillary suture runs posteriorly along the midline until the level of the P4-M1 boundary, where it meets both the inter-palatine and maxillo-palatine (Mx-Pal) sutures. Posteriorly, the $\mathrm{Mx}$ Pal suture is almost fused and barely distinguishable, while 
the inter-maxillary suture is distinct at midline. Moreover, it can be inferred that the palatal portion of the Mx-Pal suture is somewhat crenulated, curved and anteromedially oriented. As a result, right and left $\mathrm{Mx}$-Pal sutures on the palate are V-shaped and anteriorly pointing. Laterally, the $\mathrm{Mx}-\mathrm{Pal}$ suture reaches the lateral margin of the palate just posterior to the level of the second upper molar. From this level, the $\mathrm{Mx}$-Pal suture turns posterodorsally towards the posterior end of the orbital crests. In this region, the maxilla and the palatine fuse progressively and the dorsal portion of the Mx-Pal suture cannot be observed. The portion of the maxilla contacting the vertical lamina of the palatine in the orbit region contributes to the medial wall of the orbit.

The alveolar process lies on the lateral portion of the maxillary palatal surface. It bears the alveoli for seven teeth (C1-M2). On the one hand, the two anterior alveoli (for $\mathrm{C} 1$ and $\mathrm{P} 1$ ) are aligned with the incisor alveoli. On the other hand, the five posterior alveoli (for P2-M2) are aligned in a row, with the right and left rows diverging posteriorly (Fig. 7). However, as a consequence of the rostral asymmetry, the angle formed by the anterior and posterior portions of the dental row is not the same on each side, being more important on the left side (c. $\left.25^{\circ}\right)$ than on the right $\left(c .8^{\circ}\right)$. Actually, the whole right dental row appears roughly straight.

Only the anterior maxillary alveoli are separated by three diastemata (respectively located between $\mathrm{C} 1$ and P1, P1 and $\mathrm{P} 2$, and $\mathrm{P} 2$ and $\mathrm{P} 3$ ). As for the premaxilla, the anterior diastemata are longer on the right side of the skull, a condition that results from the asymmetry of the rostrum. Each diastema is excavated by a conical embrasure pit, receiving the crown of p1, p2 and p3, respectively. The embrasure pit housing p2 (in the P1-P2 diastema) is the deepest, being followed in depth by the pit for $\mathrm{p} 1$ (in the C1-P1 diastema). In contrast, the shallow embrasure pit for $\mathrm{p} 3$ is is hardly distinguishable. In a posterior direction, embrasure pits migrate progressively from the lateral side of the dental row to its medial side. Indeed, the embrasure pit for $\mathrm{p} 1$ is laterally open and lateral to the dental row, while the embrasure pits for $\mathrm{p} 2$ and $\mathrm{p} 3$ are laterally closed and medial to the dental row. The P2-P3 diastema is the shortest one (in the antero-posterior dimension). Posteriorly, the dental series (P3-M2) is continuous and has no diastema. As stated above for the incisors, when the jaws are closed, the lower teeth are anterior to their corresponding teeth in the maxilla. Furthermore, the posterior lower teeth (p4-m3) are medial to their corresponding upper teeth. Consequently, the embrasure pit for the fourth lower premolar (p4) is located medial to the anterior half of P4. At the level of the P4-M1 boundary, the palatal surface and the alveolar process are separated by a prominent notch, which receives the crown of the first lower molar $(\mathrm{m} 1)$. Therefore, this notch is regarded here as a posteriorly open embrasure pit. Posterior to the level of $\mathrm{P} 4$, the alveolar process of the maxilla projects posterolaterally, being separated from the palatal surface. The posteriormost portion of the alveolar process is probably homologous to the zygomatic process of the maxilla in terrestrial mammals (Wible 2008) and bears the alveoli for the two uppers molars.
Dorsal to the last embrasure pit (the notch receiving the crown of $\mathrm{m} 1$ ), the maxilla forms a small transverse crest, probably homologous of the infraorbital plate in modern cetaceans. Ventral to this crest, the maxilla forms the ventral margin of the maxillary foramen (Fig. 14). The latter is the posterior opening of the infraorbital canal that transmits the infraorbital nerve (branch of the maxillary nerve, cranial nerve V2) to the anterior portion of the rostrum. Posteromedial to the maxillary foramen, the maxilla fuses with the vertical lamina of the palatine and contributes to the medial wall of the orbit. At this level, the maxilla should contribute to the anterior portion of the ventral edge of the sphenopalatine foramen and the floor of nasopharyngeal duct. The former transmits the sphenopalatine artery and the caudal nasal nerve (branch of the maxillary nerve V2).

Vomer (V). The vomer is the longest bone of the skull in Cynthiacetus peruvianus (c. 70\% of the condylobasal length). It is formed by two well-defined rostral and cranial portions. Externally, it is exposed in dorsal view at the level of the external bony nares and ventrally through a small window in the palate located between the maxillae and premaxillae (Fig. 10).

The rostral portion of the vomer extends far anterior to the level of the third incisor, forming most of the floor of the mesorostral canal (Fig. 10A). In this region, the vomer overlies the medialmost portions of both maxillae and premaxillae and is somewhat crescent-shaped in cross-section. As a consequence of the asymmetry of the rostrum, the left part of the rostral portion is much thicker than the right (Fig. 10A-C). In dorsal view, the vomer is exposed at the level of the external bony nares, where it forms the floor of the narial cavity. Ventrally, the part of ventral surface of the rostral portion of the vomer is exposed through a rhomboid window at the level of P1-P2. This vomeral window is bounded anteriorly and posteriorly by the premaxillae and the maxillae, respectively. The ventral exposure of the vomer and the thin premaxillae at the level of P1 and P1-P2 diastema are observed in cross-section in Figure 10B and C.

In the narial cavity, the vomer is divided into two vomeral wings from about the level of P3. These wings are thick, crescent-shaped and extend dorsally forming the lateral walls of the narial cavity.

More posteriorly, at about the level of the M1-M2 diastema, the vomeral wings meet at midline and form the posterior portion of the roof of the narial cavity, covering the ventral surfaces of both the presphenoid and frontal. At this level, the anterior part of the cranial portion of the vomer forms a sharp ridge at midline. This median ridge serves as a septum and separates the two narial passages, extending posteriorly until the level of the internal bony nares. Posterior to the internal bony nares, the cranial portion of the vomer is extremely thin and extends on the ventral surface of the cranium. At this level, the posteriormost portion of the vomer covers almost the whole ventral surface of the basisphenoid. The posteriormost part of the cranial portion of the vomer is separated into two thin surfaces and an intravomeral suture can easily be observed in ventral view. Such a division of the vomer is also observed in Dorudon atrox, where the two surfaces are separated 

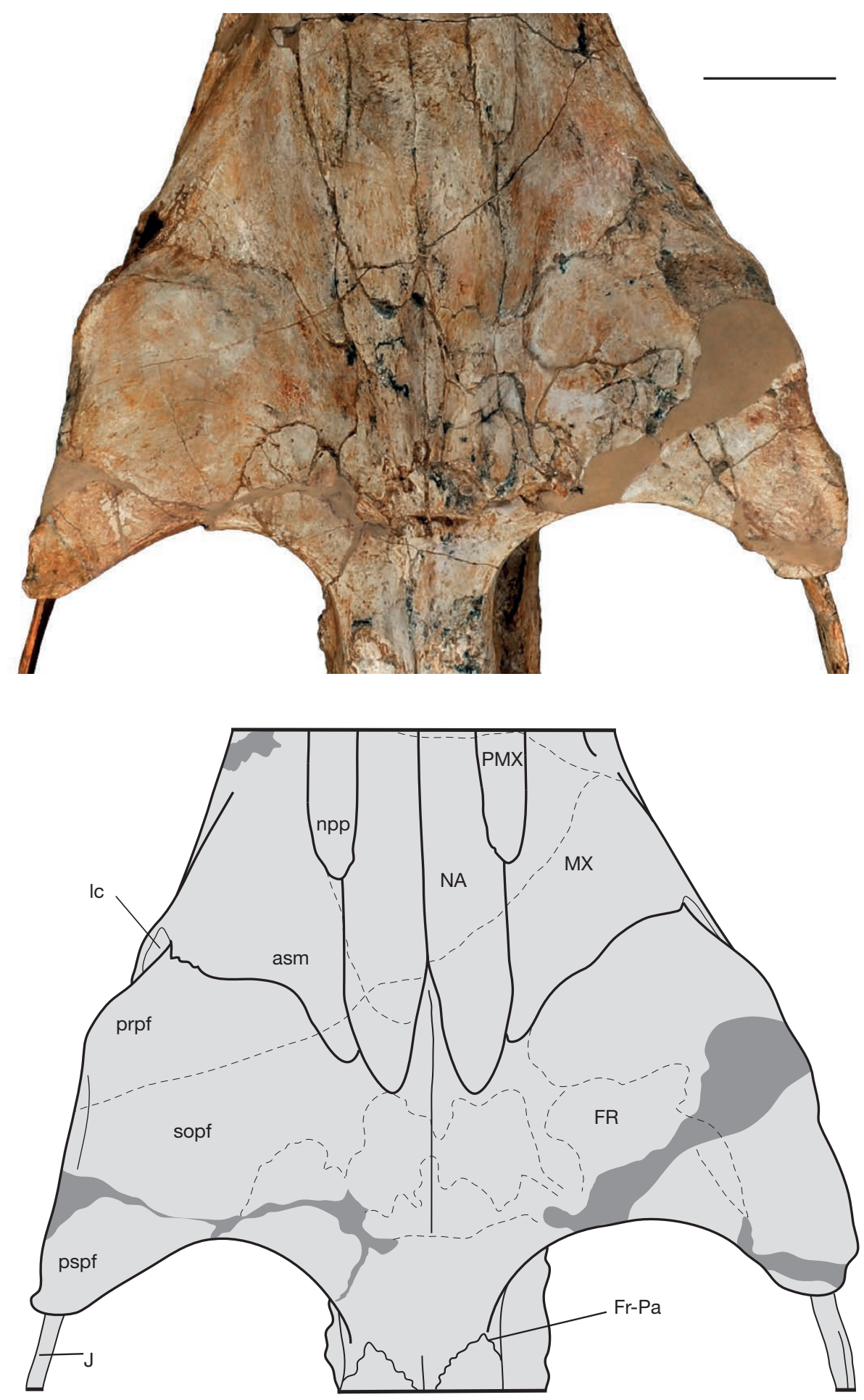

FIG. 11. - Dorsal view of the facial region of MNHN.F.PRU10, holotype of Cynthiacetus peruvianus. Abbreviations: asm, ascending process of the maxilla; FR, frontal; Fr-Pa, frontoparietal suture; J, jugal; Ic, lacrimal canal; MX, maxilla; NA, nasal; npp, narial process of the premaxilla; PMX, premaxilla; prpf, preorbital process of the frontal; pspf, postorbital process of the frontal; sopf, supraorbital process of the frontal. Dark grey-shaded regions indicate the reconstructed parts of the specimen, respectively. Dotted lines represent lines of break in the facial shield. Scale bar: $5 \mathrm{~cm}$.

by a narrow gap in a juvenile specimen (Uhen 2004). The posterior edge of the vomer is missing in MNHN.F.PRU10. However, it can be estimated that this edge was just anterior to the level of the basisphenoid-basioccipital contact. In the basicranium, the lateral edge of the vomer contacts the medial lamina of the pterygoid. 
Nasal (Na). The nasal is a thin and paired bone, which forms the median portion of the facial region and participates in the roof of the narial cavity. Laterally, the nasal articulates with the premaxilla, maxilla and frontal. Medially, both nasals meet at midline for almost their entire length and are only separated posteriorly by the anterior (or nasal) process of the frontal.

In MNHN.F.PRU10, the anterior 2-3 cm of the nasal are missing on both sides. As observed in Basilosaurus isis, Dorudon atrox, and Cynthiacetus maxwelli, the nasal is lanceolate in dorsal view, with the apex of the lance being anteriorly directed (Fig. 6). The anteriormost portion of the nasal is narrower than its posterior portion, and the anterior margin of the nasal of Cynthiacetus peruvianus (as reconstructed in Fig. 6) was probably proportionally narrower than in all other basilosaurids except $C$. maxwelli. The nasal reaches its widest point at the end of the internasal suture, located at the level of the preorbital process of the frontal. The anterior two thirds of the lateral edge of the nasal $(c .16 \mathrm{~cm})$ are slightly diverging posteriorly and form an angle of about $12^{\circ}$ with the midline. These anterior two thirds of the lateral edge contact exclusively the premaxilla (cf. Premaxilla for description of the Na-PMx suture). Posteriorly, the Na-PMx suture meets the anteroposteriorly oriented $\mathrm{Na}-\mathrm{Mx}$ suture. The latter runs for about $5 \mathrm{~cm}$ from the level of the lacrimal canal to the level of the preorbital process of the frontal, then it turns posteromedially and runs for $2 \mathrm{~cm}$ before it merges with the fronto-nasal (Fr-Na) suture (Fig. 11). Posteriorly, the Fr-Na suture continues posteriorly for approximately $3 \mathrm{~cm}$ then it turns drastically anteromedially for about $5.5 \mathrm{~cm}$ before reaching the inter-nasal suture at midline. Thus, the posteriormost portion of the nasal contacts exclusively the frontal, contrary to Saghacetus osiris and some specimens of Zygorhiza kochii (e.g. USNM 11962), where the posterior end of the nasal contacts the maxilla laterally.

Jugal (J). The jugal is a paired bone, which contributes exclusively to the zygomatic arch. As in all other basilosaurids, it is straight, long, and transversely compressed on most of its length. Anteriorly, the jugal contacts the maxilla and lacrimal. Posteriorly, it articulates with the squamosal (Figs 8; 9).

The orbital and temporal portions of the jugal occupy the anterior $40 \%$ and the posterior $60 \%$ of the jugal length, respectively. The orbital portion contributes to the ventral margin of the orbit and the temporal portion participates in the lateral wall of the temporal fossa. The jugal is somewhat rounded to oval in cross-section at its anterior end and it strongly narrows posteriorly. Thus, from about the level of the postorbital process of the frontal, the temporal region of the jugal can be regarded as a thin and vertical blade.

The anterior end of the jugal forms the ventrolateral corner of the maxillary foramen (posterior opening of the infraorbital canal); it articulates anterodorsally with the lacrimal and ventroanteriorly with the jugular process of the maxilla. The jugo-lacrimal (J-La) suture is better observed in the orbit region, where it runs transversely on the anteroventral corner of the orbit. Similarly, the J-Mx suture is better observed in lateral view at the level of the M1-M2 boundary, where it is posteroventrally inclined. The orbital portion of the jugal is wider than high and its dorsal surface is slightly concave in lateral view (Fig. 12).

At about the level of the postorbital process of the frontal, the jugal reaches its maximum height. This portion corresponds to the anterior edge of the temporal portion of the jugal. Posteriorly, it articulates dorsally with the zygomatic process of the squamosal. The jugo-squamosal (J-Sq) suture is not entirely preserved in MNHN.F.PRU10 since the anterior part of the zygomatic process is missing on both sides (with the right process appearing to be almost complete). However, a deep sulcus on the dorsal margin of the left jugal suggests that the zygomatic process of the squamosal may have extended far anteriorly, until the level of the postorbital process of the frontal. Such a deep sulcus on the dorsal margin of the jugal is also observed in other basilosaurids (e.g. Dorudon atrox UM 93220 and UM 101222; Cynthiacetus maxwelli MMNS PV 445) (see below in the squamosal section). The J-Sq suture runs posteroventrally from about the level of the postorbital process of the frontal to the level of the anterior edge of the glenoid fossa (Fig. 8). In lateral view, the temporal portion of the jugal decreases progressively in height towards its posterior end.

Lacrimal (La). The lacrimal is one of the smallest bones of the skull. It is paired and located at the posterolateral corner of the rostrum. Dorsally, the lacrimal articulates with the frontal; anteriorly and ventrally, it articulates with the maxilla; and posteroventrally, it contacts the jugal. The lacrimal also contributes to the orbit wall and to the lacrimal and infraorbital canals. The external surface of the lacrimal is mainly exposed in lateral view, but is also visible in dorsal view.

The external (lateral) exposure of the lacrimal is somewhat concave laterally, and longer than high (Fig. 13). Dorsally, the fronto-lacrimal (Fr-La) suture is almost horizontal and extends over the entire length of the preorbital process of the frontal. Similarly, the ventral edge of the external exposure of the lacrimal mostly articulates with the jugular process of the maxilla. At this level, the straight Mx-La suture occupies $80 \%$ of the ventral edge of the external exposure of the lacrimal and is slightly sloping posteroventrally. Posteriorly, it meets the J-La suture, which is somewhat posterodorsally oriented (the J-La contact has been described above).

Anteriorly, the lacrimal participates in the opening of the lacrimal canal, which is located at about mid-length of the last premolar (P4, Fig. 13). At this level, the thin maxilla forms the lateral wall of the lacrimal canal while the lacrimal forms its medial wall. Additionally, this portion of the lacrimal is medially concave. Differing from Dorudon atrox (Uhen 2004), only two channels connect the orbit to the lacrimal canal. They run anteroposteriorly on the lateral surface of the lacrimal. The dorsal channel is larger and deeper than the ventral. Moreover, the dorsal channel is almost horizontal and close to the Fr-La suture. On the other hand, the ventral channel runs parallel and close to the ventral edge of the lacrimal, then it turns anterodorsally, towards the lacrimal canal. The paths 

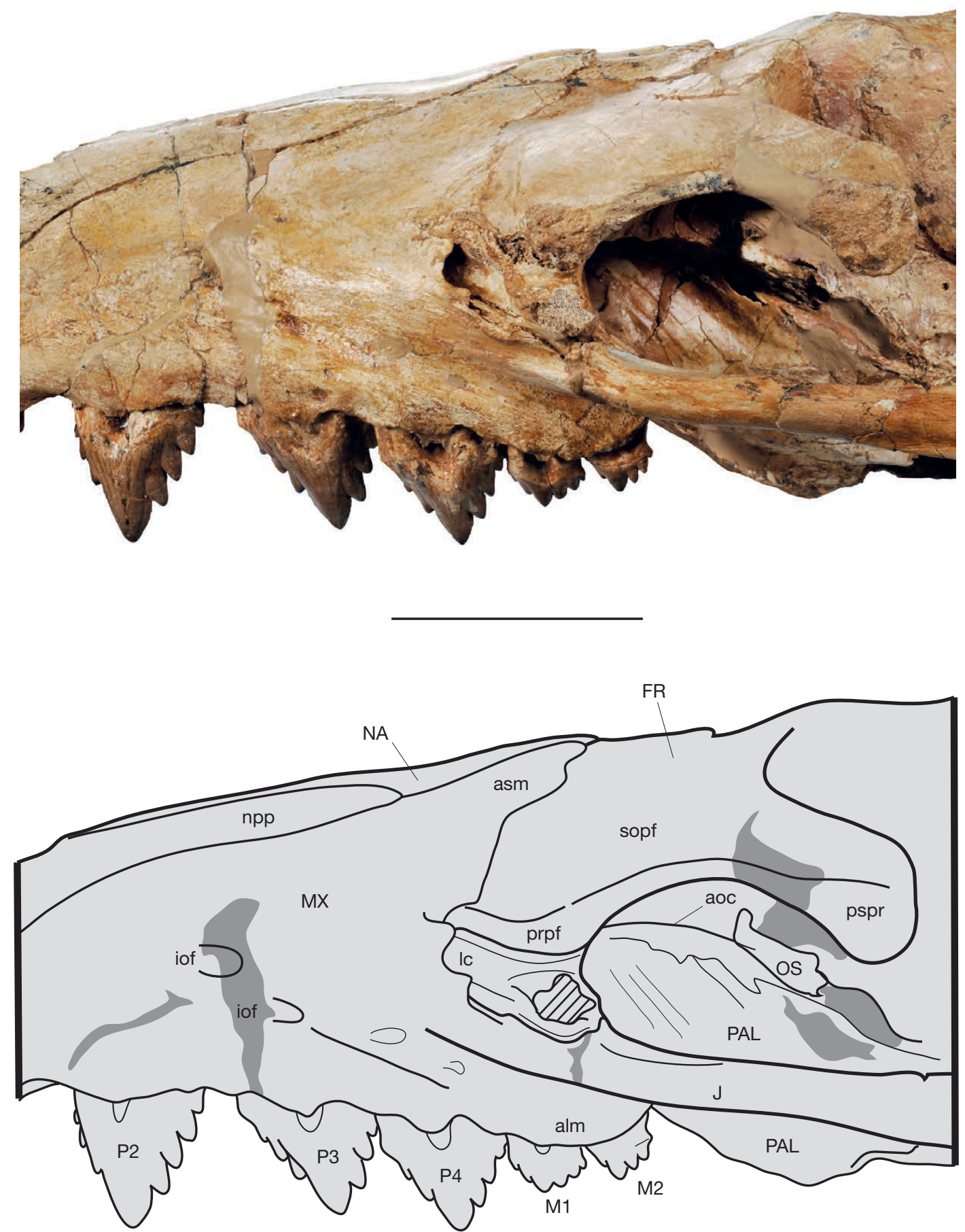

FIG. 12. - Lateral view of the left orbit region of MNHN.F.PRU10, holotype of Cynthiacetus peruvianus. Abbreviations: alm, alveolar process of the maxilla; aoc, anterior orbital crest; asm, ascending process of the maxilla; FR, frontal; iof, infraorbital foramina; J, jugal; Ic, lacrimal canal; M1, M2, upper molars; MX, maxilla; NA, nasal; npp, narial process of the premaxilla; OS, orbitosphenoid; P2-P4, second to fourth upper premolars; PAL, palatine; prpf, preorbital process of the frontal; pspf, postorbital process of the frontal; sopf, supraorbital process of the frontal. Dark grey-shaded regions indicate the reconstructed parts of the specimen. Hatched lines in the lacrimal bone indicate the broken lateral prominence.

of these channels are indicated in Figure 13. Both channels are separated by a large lateral prominence, in the posterior half of the lacrimal. This process is posterolaterally oriented and is entirely preserved only in the right lacrimal.

The posterior surface of the lacrimal is smooth, anteriorly concave, and bears numerous nutrient foramina. It participates mainly in the anterior wall of the orbit. The dorsal and ven- tral edges of the posterior surface of the lacrimal are formed by the Fr-La and Mx-La sutures, respectively, these sutures being almost parallel to each other. The medial edge of the posterior surface of the lacrimal delimits laterally the maxillary foramen. Finally, the medial surface of the lacrimal forms the posterior portion of the lateral wall of the infraorbital canal (passage for the infraorbital nerve). 
Frontal (Fr). The frontal is a paired bone. It is the main element of the supraorbital shield and forms most of the roof and medial wall of the orbit. Both frontals meet at midline and the interfrontal suture is easily distinguishable in the supraorbital region. Dorsally, the frontal articulates posteriorly with the parietal and anteriorly with the nasal and the maxilla. In the orbit, it contacts the lacrimal, maxilla, palatine and orbitosphenoid. Posteroventrally, the frontal articulates with the alisphenoid. In dorsal view, the frontals extend anteromedially, forming a triangular anterior process that separates the posterior ends of the nasals. This anterior process is anteroposteriorly longer than wide.

The frontal extends laterally forming the supraorbital process of the frontal. The latter is broad, thick and roughly trapezoidal in dorsal view, with its lateral edge being longer than its medial edge. The supraorbital process thickens at its anterolateral and posterolateral corners, forming the preorbital and postorbital processes of the frontal, respectively. The postorbital process is more massive, thicker than the preorbital process. In dorsal view, the lateral margin of the supraorbital process is straight and posterolaterally directed, forming an angle of $60^{\circ}$ with the sagittal plane (Fig. 11). In lateral view, the dorsal and ventral surfaces of the supraorbital process are dorsally convex and concave, respectively (Fig. 12). The ventral surface of the supraorbital process is much more curved than the dorsal surface and constitutes the roof of the orbit. The dorsal surface of the frontal has no foramina or sulci and is rather smooth. In contrast, the ventral surface presents numerous foramina and crests (described below). As mentioned above, the orbit is roughly circular and located dorsal to the level of the dental row. Similar to other basilosaurids and early odontocetes, the highest point in the facial region is located along the midline of the skull. In contrast, in toothed mysticetes (e.g. Aetiocetus weltoni and Mammalodon colliveri), the orbit is proportionally larger and the dorsal surface of the supraorbital process reaches a level higher than the median portion of the facial region.

The Na-Fr and the Fr-Mx sutures have been described above (maxilla and nasal sections). Both sutures form a W-shaped suture at the median portion of the skull. This "W" suture corresponds to the anterior margin of the frontal and its central apex is anteriorly oriented. From the lateral edge of this "W" suture, the Fr-Mx suture continues anterolaterally towards the posterolateral corner of the rostrum, where it ends. At this level, the preorbital process of the frontal articulates ventrally with the lacrimal, as stated above (Figs 12; 13). In dorsal view, the posterior margin of the supraorbital process of the frontal is strongly concave posteriorly. It limits anteriorly the temporal fossa and, contrary to early neocetes, it does not develop a prominent orbitotemporal crest. Posteriorly, the postorbital process of the frontal is distinctly separated from and does not articulate with the zygoma (temporal portion of the jugal or zygomatic process of the squamosal). Finally, the posterior edge of the supraorbital process is dorsoventrally thickest at its medialmost portion (maximum thickness $=52 \mathrm{~mm}$, the thickness at the mid-width point being about $22 \mathrm{~mm}$ ).
In the orbit region, the frontal forms the dorsal edge of both the maxillary and sphenopalatine foramina, at the anterior wall of the orbit. These foramina are large and sub-equally sized. As mentioned above, the maxillary foramen is the posterior opening of the infraorbital canal and transports the antorbital nerve and associated vessels from the orbit to the rostrum. Similarly, the sphenopalatine foramen conducts the nasal caudal nerve and associated vessels through the nasopharyngeal duct. The sphenopalatine foramen is more rounded than and medial to the maxillary foramen. Posteromedial to the sphenopalatine foramen, the ventral surface of the supraorbital process articulates medially with the palatine. Internally, the medial surface of the frontal should contact the presphenoid.

The fronto-palatine ( $\mathrm{Fr}-\mathrm{Pal})$ suture runs posteriorly on the dorsomedial margin of the orbit, from the sphenopalatine foramen towards the optic infundibulum (path for the optic and ophthalmic nerves and vessels, cf. below). Posterior to the optic infundibulum, this suture reaches the fronto-palato-sphenoid triple contact. From this point, the sinuous fronto-alisphenoid (Fr-Al) suture turns posterodorsally from the posterior end of the Fr-Pal suture to the level of the postorbital process of the frontal, where it meets the parietal (cf. below for the fronto-parietal and the spheno-parietal contact). At this level the frontal participates in the lateral wall of the intertemporal constriction. On the ventral surface of the supraorbital process, the optic infundibulum is separated from the maxillary and sphenopalatine foramina by a flat and triangular surface. This surface is conspicuous on the left side and obscured by matrix on the right side. The optic infundibulum lies on the ventral surface of the supraorbital process. It is anterolaterally oriented, ventrally concave and bounded by the anterior and posterior orbital crests (Fig. 14).

The orbital crests diverge anterolaterally and provide a triangular outline to the optic indunfibulum. The anterior orbital crest is ventral to and more developed than the posterior crest. It extends anterolaterally for about $10 \mathrm{~cm}$, from the anterior edge of the optic fissure towards the preorbital process of the frontal. In contrast, the posterior orbital crest extends posterolaterally from the posterior edge of the optic fissure and merges with the posterior margin of the supraorbital process on the ventral surface of the frontal. Anterolaterally, the triangular surface formed by the orbital crests bears numerous nutrient foramina. Posteromedial to them, the orbitosphenoid articulates with the frontal and covers the medial portion of the optic infundibulum. In this region, the orbitosphenoid forms most of the optic foramen, which transports the optic nerve and the ophthalmic artery (Fig. 14). Posteromedial to the optic foramen and at the posterior end of the external optic infundibulum is the sphenoidal (ou sphenorbital) fissure, which conducts the ophtalmic nerve from the braincase to the orbit region. The sphenorbital fissure is bounded ventrally by the palatine, dorsally by the frontal, medially by the orbitosphenoid and frontal, and posteriorly by the alisphenoid.

Posteriorly, the frontal articulates with the parietal in the intertemporal region, anterior to the sagittal crest. The dorsal portion of the fronto-parietal $(\mathrm{Fr}-\mathrm{Pa})$ suture is sinuous and 

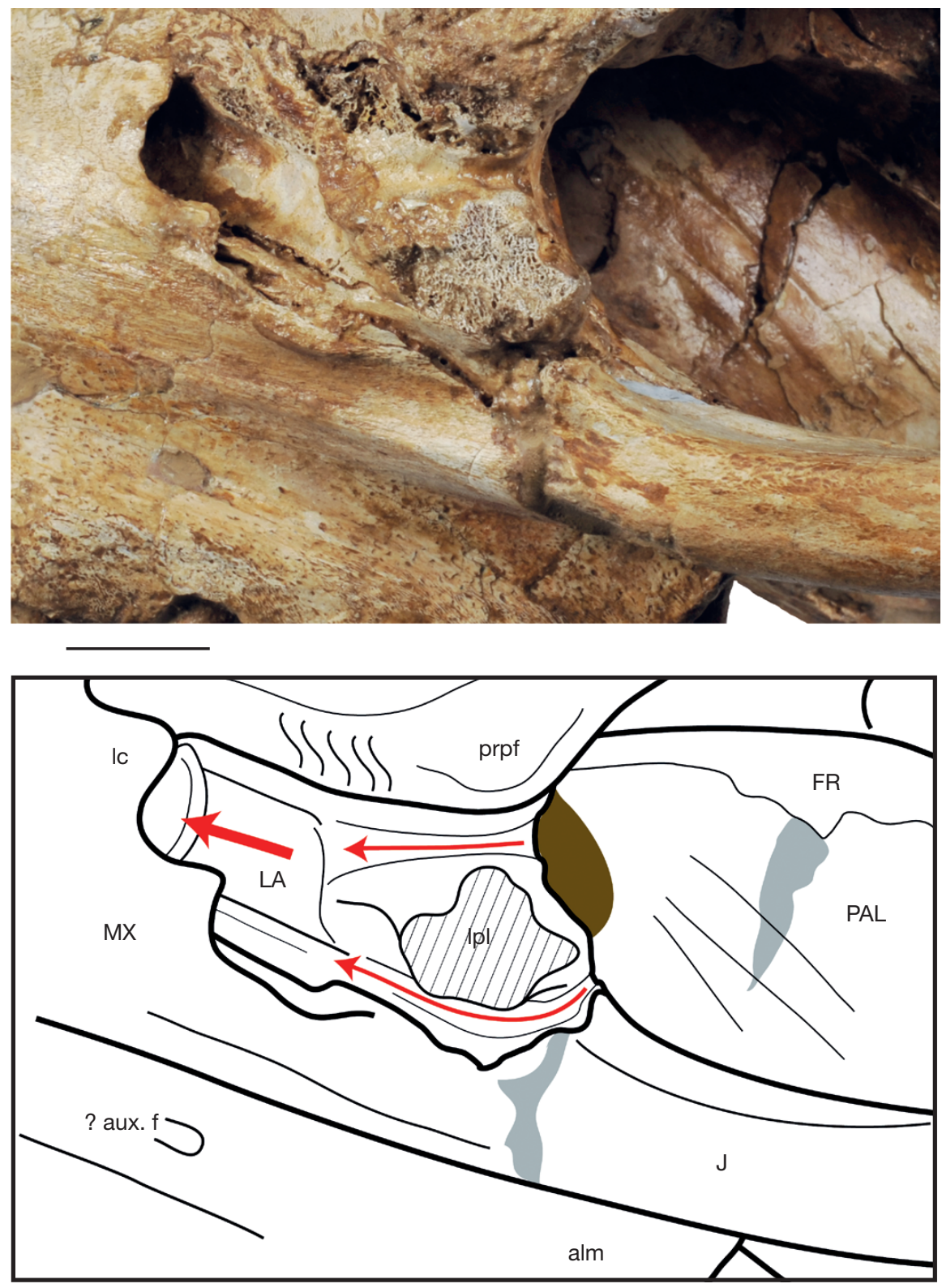

FIG. 13. - Lateral view of the left lacrimal bone in MNHN.F.PRU10, holotype of Cynthiacetus peruvianus. Abbreviations: aux.f, auxiliary foramina of the infraorbital foramina of the maxilla; alm, alveolar process of the maxilla; FR, frontal; J, jugal; LA, lacrimal; Ic, lacrimal canal; IpI, lateral prominence of the lacrimal; MX, maxilla; PAL, palatine; prpf, preorbital process of the frontal. Dark grey-shaded regions indicate the reconstructed parts of the specimen. Hatched regions and red arrows represent broken portions of the lacrimal and the path of the lacrimal canal and channels, respectively. Brown colored region represents the sediment covering the anterior wall of the orbit. Scale bar: $2 \mathrm{~cm}$.

runs anterolaterally from the midline to the lateral margin of the intertemporal constriction. In dorsal view, both Fr-Pa sutures delimit a posteriorly pointed expansion of the frontal. From the lateral margin of the intertemporal constriction, the Fr-Pa suture extends anteroventrally towards the level of the postorbital process of the frontal then it turns ventrolaterally. At this level, the parietal reaches its anteriormost edge and the Fr-Pa suture is anteriorly convex in lateral view (Figs 8 and 9). Ventral to this point, the Fr-Pa suture continues towards the anterior border of the squamosal fossa, meets the Fr-Al suture and fuses with the parieto-sphenoid suture (cf. Parietal, Alisphenoid).
Palatine (Pal). The palatine is a paired bone. It participates in the posterior portion of the hard palate (horizontal lamina of the palatine) as well as in the medial wall of the orbit (vertical lamina of the palatine). Internally, the palatine contributes to the narial passage. The palatine articulates anteriorly with the maxilla, posteriorly with the pterygoid and dorsally with the frontal and the orbitosphenoid. The thin vomer covers part of the internal surface of the palatine in the narial cavity, where the palatine forms the roof and lateral walls of the narial passages.

The ventral exposure of each palatine forms a flat and smooth surface, the horizontal lamina of the palatine. Both 
horizontal laminae articulate at midline along their entire length. In lateral view their posterior end is ventral to their anterior end, and the horizontal laminae are therefore facing anteroventrally. They can be regarded as the posterior extension of the palatal surfaces of the maxillae. On the palate, the interpalatine suture is more easily distinguishable than the $\mathrm{Mx}-\mathrm{Pal}$ suture, which is partially fused. In ventral view, the $\mathrm{Mx}-\mathrm{Pal}$ suture is sinuous and runs posterolaterally from the midline (cf. Maxilla) to the lateral edge of the hard palate, at a level posterior to the level of the last molar (M2). Besides, the lateral edge of the hard palate is straight, sharp and posteromedially oriented in ventral view (Fig. 7).

The horizontal lamina narrows posteriorly to a point posterior to the level of the postorbital process of the frontal. Thus, the palatine portion of the hard palate is triangular and posteriorly pointed in ventral view. A small palatine foramen can be observed in the center of the horizontal lamina of the palatine. From the lateral margin of the horizontal lamina, the palatine extends dorsally forming the thin vertical lamina. Most of the vertical lamina is perpendicular to the horizontal lamina and laterally convex, except for its posteroventral portion, which is concave and ventrolaterally facing. Anteriorly, the vertical lamina fuses with the maxilla to form the medial wall of the orbit. In this region, the Mx-Pal suture most likely runs dorsally towards the dorsal edge of the sphenopalatine foramen. Posteriorly, the vertical lamina of the palatine articulates with the pterygoid. At midline, it should contact the hamular process of the pterygoid, if the pterygoid was not missing in this region. The palato-pterygoid (Pal-Pt) suture is strongly sinuous and crenulated. It runs almost perpendicular to the anteroposterior axis just anterior to the level of the anterior end of sagittal crest. In this region, the palatine participates in the lateral walls and floor of the narial passage. However, it does not contribute to the internal bony nares, which are exclusively formed by the pterygoid and vomer. Dorsally, the Pal-Pt suture meets the palato-pterygo-sphenoid triple contact, at about the mid-length of the temporal fossa.

In the orbit region, the vertical lamina of the palatine articulates dorsally with the frontal and forms the lateral margin of the optic fissure. The Fr-Pal suture is strongly crenulated and extends posteriorly on the medial wall of the orbit. Posteriorly, it reaches the posteromedial end of the external optic infundibulum, where it meets the palato-alisphenoid (Pal-Al) suture. Posterodorsally, the palatine articulates with the alisphenoid. The sinuous Pal-Al suture runs slightly posterodorsally for about $10 \mathrm{~cm}$, on the lateral wall of the inter-temporal constriction. The contact of the palatine with the alisphenoid is better observed on the right side, since this region is damaged on the left side due to the detachment of the orbitosphenoid.

Pterygoid (Pt). The pterygoid is one of the most complex bones in the cetacean skull. It is paired and participates in the internal bony nares, the ventrolateral wall of the cranium and the pterygoid sinuses. The right pterygoid on the holotype of Cynthiacetus peruvianus is better preserved than the left. However, both sides are complementary and the following description is based on both pterygoids.
The anterior lamina of the pterygoid articulates anteriorly with the vertical lamina of the palatine (the Pal-Pt contact has been described above, cf. Palatine). It can be regarded as the posterior extension of the vertical lamina, being slightly dorsolaterally facing in ventral view. The anterior lamina delimits medially the posterior portion of the narial passage. Posterior to the triangular horizontal lamina of the pterygoid, both pterygoids should contact at midline, but this portion is missing in MNHN.F.PRU10. At this level, both pterygoids should form the ventral and lateral margins of the internal bony nares, as well as the hamular processes. Posterior to the level of the postorbital process of the frontal, at about the level of the anterior edge of the sagittal crest, the Pal-Pt suture meets dorsally the alisphenoid. From this point the vertical lamina splits into a lateral and a medial lamina of the pterygoid. Both laminae are extremely thin and form, respectively, the lateral and medial walls of the pterygoid sinus fossa (Figs 15; 16). The latter is an excavated and teardrop-shaped fossa, and the apex of the teardrop is anteriorly oriented. Posteriorly, the pterygoid sinus fossa is confluent with the peribullar cavity or peribullary sinus fossa. Both pterygoid and peribullary sinus fossae are ventrally open. Dorsally, the roof of the pterygoid sinus fossa is essentially formed by the alisphenoid and the squamosal.

The lateral lamina of the pterygoid articulates dorsally with the alisphenoid and the squamosal. The pterygo-alisphenoid (Pt-Al) and pterygo-squamosal (Pt-Sq) sutures are well observed on the lateral wall of cranium. These sutures are strongly sinuous and run posteroventrally towards the falciform process of the squamosal. In ventral view, the lateral lamina is anteromedially directed, with its anterior half being roughly straight and its posterior half being anterolaterally convex. The medial surface of the lateral lamina forms the lateral wall of the pterygoid sinus. Its lateral surface forms the ventralmost portion of the lateral wall of the cranium. Posteriorly, the Pt-Sq suture ends anterior to the falciform process of the squamosal and the pterygoid does not participate in the formation of the foramen pseudovale (passage for the mandibular branch of the trigeminal nerve, V3). Finally, the lateral lamina of the pterygoid is better preserved on the right side, where it presents a conspicuous taphonomic deformation.

The medial lamina of the pterygoid is also extremely thin and straight in ventral view. It extends from the posterior end of the anterior lamina to the falcate process of the basioccipital (basioccipital crest in Mead \& Fordyce 2009). The medial lamina of the pterygoid is almost parallel to the midline. Its anterior portion is almost vertical, while its posterior portion is directed slightly ventrolaterally. The lateral surface of the medial lamina forms the medial wall of the pterygoid sinus. In this region, the medial lamina contacts dorsally the alisphenoid and the basioccipital. The Pt-Al suture is strongly crenulated and runs posteriorly to the level of the basisphenoidbasioccipital contact. Here, it merges with the basioccipitalpterygoid (BO-Pt) suture, which is also strongly crenulated and posteroventrally oriented. At about the mid-length of the $\mathrm{BO}-\mathrm{Pt}$ suture is the dorsal opening of the carotid canal, which conveys the internal carotid artery (Figs 17; 18). Following 


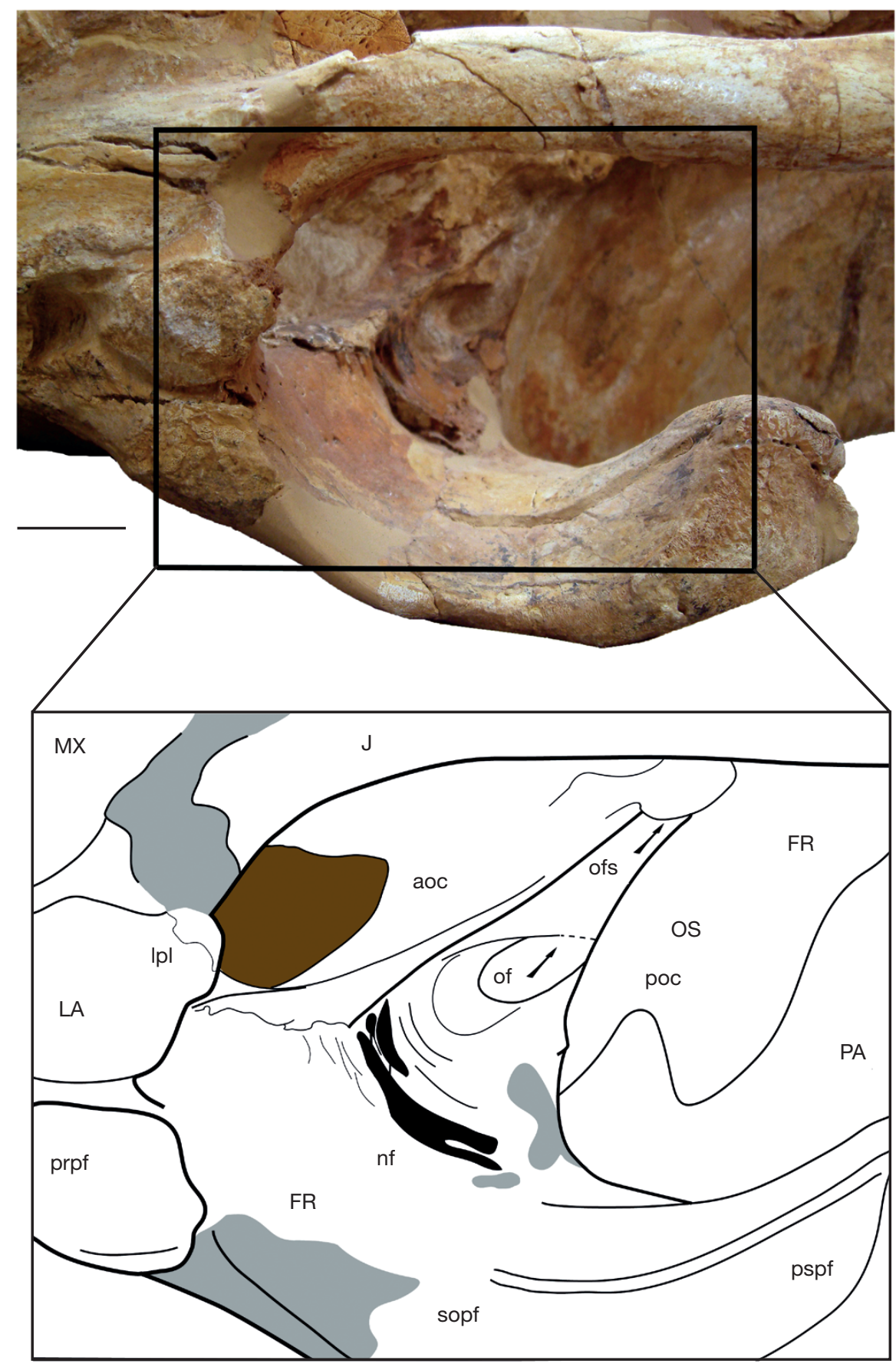

FIG. 14. - Ventrolateral view of the right orbit in MNHN.F.PRU10, holotype of Cynthiacetus peruvianus. Abbreviations: aoc, anterior orbital crest; FR, frontal; J, jugal; LA, lacrimal; Ipl, lateral prominence of the lacrimal; MX, maxilla; nf, nutrient foramina; of, optic infundibulum; ofs, optical fissure; OS, orbitosphenoid; PA, parietal; poc, posterior orbital crest; prpf, preorbital process of the frontal, pspf, postorbital process of the frontal; sopf, supraorbital crest of the frontal. Dark grey-shaded and brown colored regions indicate the reconstructed parts of the specimen and the matrix (sediment), respectively. Scale bar: $3 \mathrm{~cm}$.

Mead \& Fordyce (2009), we name this foramen the ventral carotid foramen rather than the external carotid foramen, to avoid a possible confusion with the external carotid artery. The position of the ventral carotid foramen is similar to that in Recent cetaceans. Medially, the medial lamina of the pterygoid delimits the pharyngeal passage and articulates dorsally with the vomer, basisphenoid and basioccipital (Fig. 17). At this level, the thin cranial portion of the vomer also covers the ventral surface of the basisphenoid.
Orbitosphenoid (OS). The orbitosphenoid is a paired bone. It is a small bone exposed on the medial wall of the orbit. In this region, the orbitosphenoid covers part of the frontal and participates in the medial wall of the optic infundibulum. Anterolaterally, the orbitosphenoid forms the optic foramen and part of the path for the optic nerve and the ophthalmic artery. Posteromedially, the orbitosphenoid participates in the medial wall of the sphenorbital fissure. At this level, it contacts the palatine anteroventrally and basiphenoid posteromedial- 
ly. The palato-orbitosphenoid contact cannot be detailed in MNHN.F.PRU10; while the right orbitosphenoid is partially covered by sediment in this region, the left orbitosphenoid is not in its original position and remains attached to the skull by the matrix. The path for the ophthalmic nerve probably continues posteriorly on the lateral wall of the basisphenoid. This path is laterally covered by the medial surface of the alisphenoid (cf. Alisphenoid).

Basisphenoid (BS). The basisphenoid is a single bone. It is somewhat cylindrical and located in the anterior portion of the cranium, where it contributes to the cerebral cavity. The basisphenoid most likely articulates anteriorly with the presphenoid, but this contact could not be observed. Actually, the resolution of the medical CT-scan images obtained does not allow distinguishing the presphenoid from the surrounding bones.

Most of the basisphenoid is not exposed in any external views. While its dorsal surface forms the anterior end of the floor of the braincase, most of its flat ventral surface is covered by the vomer, in the narial and pharyngeal passages. Besides, the lateral edge of its ventral surface articulates ventrally with the anterior and the medial laminae of the pterygoid. Therefore, only the posterior end of the ventral surface of the basisphenoid can be observed in ventral view (Figs 15; 16). Posteriorly, the basisphenoid fuses with the basioccipital. We can estimate that the basioccipital-basisphenoid contact is at about the level of the glenoid fossa (cf. Squamosal).

The basisphenoid is oval in cross-section anteriorly and thins drastically towards the cerebral cavity. Finally, the lateral surface of the basisphenoid probably participates in the path for the trigeminal cranial nerve (ophthalmic and maxillary nerves branches, V1 and V2, respectively) and internal carotid artery. However, these portions of the basisphenoid are covered laterally by the alisphenoid. Unfortunately, the CTscan images did not allow a safe identification of the lateral margin of the basisphenoid at this level.

Alisphenoid (Al). The alisphenoid is a paired bone. It participates in the lateral wall of the cranium and pterygoid sinus. It articulates dorsally with the frontal and parietal, ventrally with the palatine and the pterygoid, medially with the basisphenoid, and posteriorly with the squamosal. All the visible sutures formed by the alisphenoid are strongly crenulated and thus the measurements given here represent linear distances rather than the actual lengths of the sutures.

As observed in Dorudon atrox (Uhen 2004) and Zygorhiza kochii (Kellogg 1936), the alisphenoid extends dorsally from the lateral edge of the basicranium and forms a thin wing. The lateral surface of this lateral wing forms the ventral portion of the lateral wall of the cranium, while its medial surface covers the paths for the ophthalmic and maxillary nerves (branches of the trigeminal cranial nerve, V1 and V2, respectively). The lateral wing comprises the whole lateral exposure of the alisphenoid, which is strongly concave laterally and parallelogram-shaped in lateral view, with the acute angles of the parallelogram being anteriorly and posteriorly oriented. The anterior extremity of the lateral exposure of the alisphenoid is just posterior to the sphenorbital fissure. It articulates anteroventrally with the palatine and anterodorsally with the frontal. The Fr-Al suture is partly fused, but easily distinguishable on the left side. It extends posterodorsally for about $4 \mathrm{~cm}$ from the anterior edge of the alisphenoid to the fronto-parietal-alisphenoid triple contact, posterior to the level of the internal bony nares. From this point, the parietoalisphenoid ( $\mathrm{Pa}-\mathrm{Al}$ ) suture runs posteroventrally for about $17 \mathrm{~cm}$, towards the squamosal fossa (the fossa on the dorsal surface of the posterior root of the zygomatic arch). At this level, the $\mathrm{Pa}-\mathrm{Al}$ suture delimits dorsally the ventral concavity of the lateral wall of the cranium, just anterior to the lateral expansion of the braincase.

Posteriorly, the alisphenoid articulates with the squamosal, and the $\mathrm{Pa}-\mathrm{Al}$ suture meets the alisphenoid-squamosal (AlSq) suture. The crenulated Al-Sq suture is sub-parallel to the Fr-Al suture and runs anteroventrally for about $33 \mathrm{~mm}$ on the lateral wall of the cranium. Anterior to the subtemporal crest (cf. Squamosal), the Al-Sq suture meets the Pt-Al suture, which is anterodorsally oriented and subparallel to the $\mathrm{Pa}-\mathrm{Al}$ suture. The Pt-Al suture extends for about $10 \mathrm{~cm}$, forming the posterior $60 \%$ of the ventral margin of the lateral exposure of the alisphenoid. The remaining anterior $40 \%$ (about $7 \mathrm{~cm}$ ) are formed by the Pal-Al suture. Finally, the Pal-Al suture reaches anteriorly the Fr-Al suture, posterior to the orbital fissure.

From the ventral edge of the lateral wing, at the level of the pterygo-alisphenoid contact, the alisphenoid extends medially and forms a thin ventral wing. The ventral wing forms part of the roof of the pterygoid sinus fossa, which is strongly concave ventrally. Posteriorly, the ventral wing of the alisphenoid fuses with the squamosal and it is thus difficult to evaluate the participation of the squamosal in the pterygoid sinus fossa (cf. Squamosal). Medially, the alisphenoid contacts the lateral edge of the basisphenoid and the medial lamina of the pterygoid. The Pt-Al suture is sinuous and can easily be observed on the medial wall of the pterygoid sinus fossa. Since the Al-Sq suture is completely fused in the pterygoid sinus fossa, it is difficult to say if the alisphenoid contacts the basioccipital posteromedially. However, it is likely that the basioccipital only contacts the squamosal in this region.

Parietal (Pa). The parietal is a paired and long bone, which forms the dorsal portion of the cranium (Figs 6; 8). It articulates anteriorly with the frontal, anteroventrally with the alisphenoid, posteriorly with the occipital and posteroventrally with the squamosal. Dorsomedially, both parietals articulate at midline.

In lateral view, the anteriormost portion of the parietal is linguiform. At this level, the skull is elliptic in cross-section and the parietal forms the lateral walls of the long and narrow intertemporal constriction. Posterior to the intertemporal constriction, the skull expands transversely and the medial (internal) surfaces of the parietal form the roof and the dorsal portion of the lateral wall of the braincase. At midline, the parietals form a prominent and long sagittal crest. The latter 

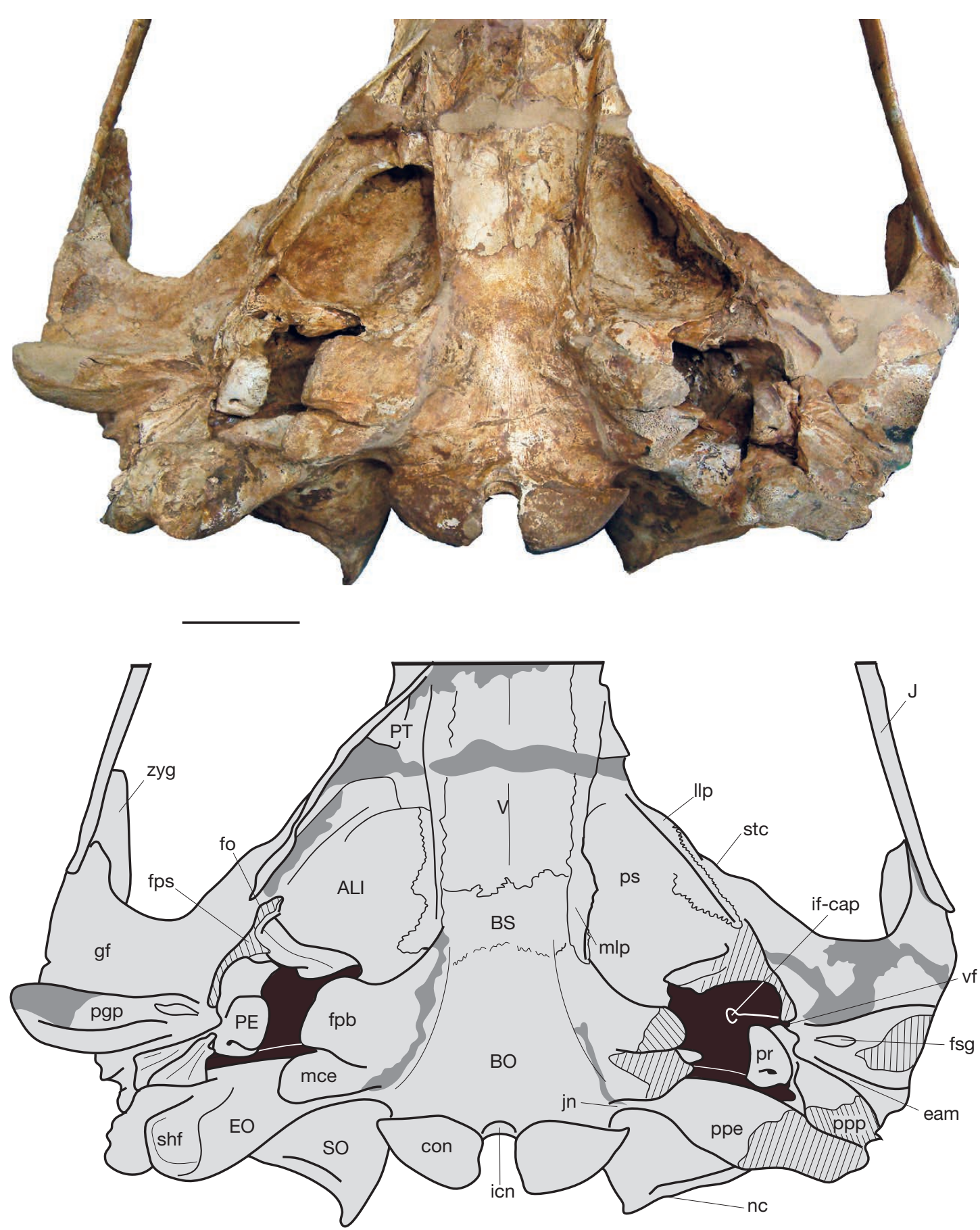

FIG. 15. - Ventral view of the basicranium of MNHN.F.PRU10, holotype of Cynthiacetus peruvianus. Abbreviations: ALI, alisphenoid; BO, basioccipital; BS, basisphenoid; con, condyles; eam, external acoustic meatus; EO, exoccipital; fo, foramen pseudovale; fpb, falcate process od the basioccipital; fps, falciform process of the squamosal; fsg, fossa for the sigmoid fossa; gf, glenoid fossa; icn, intercondylar notch; if-cap, internal foramen for the capsuloparietal emissary vein; J, jugal; jn, jugular notch; Ilp, lateral lamina of the pterygoid; mce, medial crest of the exoccipital; mlp, medial lamina of the pterygoid; nc, nuchal cresr; PE, periotic; pgp, postglenoid process of the squamosal; ppe, paroccipital process of the exoccipital, ppp, posterior process of the periotic; pr, promontorium; ps, pterygoid sinus; PT, pterygoid; shf, fossa for the stylohyal; So, supraoccipital; stc, subtemporal crest; V, vomer; vf, vascular foramen for the capsuloparietal emissary vein; zyg, zygomatic process of the squamosal. Dark grey-shaded regions indicate the reconstructed parts of the specimen and portion of the sediment. Hatched regions represent broken portions of the bone. Scale bar: $5 \mathrm{~cm}$.

occupies the posterior $80 \%$ of the interparietal suture and reaches posteriorly the vertex (highest point of the skull). There is no interparietal bone in MNHN.F.PRU10.

Lateral to the sagittal crest is the parasagittal crest, which is less developed than the probably homologous orbitotem- poral crest of modern cetaceans. The parasagittal crest can be described as a hardly defined margin on the lateral wall of the cranium. Contrary to the neocete orbitotemporal crest, the parasagittal crest does not contact anteriorly the posterior margin of the supraorbital process of the frontal. 
Posteriorly, both parietals articulate with the supraoccipital forming the nuchal crest. The nuchal crest involves the parietals, supraoccipital, squamosals and exoccipitals. As in other basilosaurids, it is much more developed than in modern cetaceans. In lateral view, the nuchal crest can be separated into two almost perpendicular portions (herein named dorsal and ventral portions, Fig. 20 [dnc, vnc]). The dorsal portion of the nuchal crest is slightly convex dorsally. At this level, the parieto-occipital ( $\mathrm{Pa}-\mathrm{SO}$ ) suture runs slightly posteroventrally for about $13 \mathrm{~cm}$, from the vertex to the posteriormost portion of the nuchal crest (Figs 8; 9). From this point the Pa-SO suture (and so the nuchal crest) turns slightly anteroventrally and runs for about $6 \mathrm{~cm}$, before meeting the squamo-parietal ( $\mathrm{Pa}-\mathrm{Sq}$ ) suture at the dorsoventral level of the ventral margin of the postorbital process of the frontal. Since the supraoccipital is not exposed in dorsal view, the nuchal crest forms the posterior margin of the skull. In dorsal view, right and left sides of the dorsal nuchal crest meet at the vertex and provide a strongly concave outline to the posterior margin of the skull in dorsal view.

Anteriorly, the parietal articulates with the frontal. As mentioned above (cf. Frontal), the Fr-Pa suture is anterolaterally oriented in dorsal view and anteriorly convex in lateral view. It provides a linguiform outline to the anterior end of the parietal. Posteroventrally, the Fr-Pa suture runs towards the squamosal fossa and merges with the $\mathrm{Pa}-\mathrm{Al}$ suture, at about the level of the postorbital process of the frontal. The $\mathrm{Pa}-\mathrm{Al}$ suture has also been described above (cf. Alisphenoid); it separates the lateral wall of the cranium into two dorsal and ventral portions, the latter being laterally concave. The crenulated $\mathrm{Pa}-\mathrm{Al}$ suture runs posteroventrally and reaches the ventral end of the parietal, at the parieto-sphenoid-squamosal triple point. From this point, the $\mathrm{Pa}-\mathrm{Sq}$ suture runs posterodorsally and sinuously on the lateral wall of the cranium $(c .28 \mathrm{~cm})$. At about the level of the mastoid process of the squamosal, the $\mathrm{Pa}-\mathrm{Sq}$ suture turns posteroventrally just before it meets the nuchal crest. Finally, the dorsal portion of the Pa-Sq suture is partially fused on the right side.

As is observed in other basilosaurids (Basilosaurus, Dorudon, and Zygorhiza), a parietal foramen lies on the lateral surface of the cranium, just anterior to the dorsalmost extremity of the $\mathrm{Pa}-\mathrm{Sq}$ suture. In protocetids, the parietal foramen is located at the $\mathrm{Pa}-\mathrm{Sq}$ suture, while it seems absent in modern cetaceans. This foramen probably transmited a temporal branch of the capsuloparietal emissary vein and accompanying artery, possibly emitted from the arteria diploëtica magna.

As a matter of fact, the parietal and the intertemporal regions are quite similar in all known basilosaurids. The main difference in this region concerns the lateral expansion of the braincase, which is more pronounced in MNHN.F.PRU10 than in Basilosaurus isis and Saghacetus osiris.

Squamosal (Sq). The squamosal is the posteroventrolateral element of the skull. It forms the lateral wall of the braincase and part of the peribullar cavity, the posterodorsal portion of the zygomatic arch, and the glenoid and squamosal fossae. The squamosal articulates anterodorsally with the parietal, anteriorly with the alisphenoid and jugal, ventrally with the pterygoid, and posteriorly with the exoccipital. Medially, the squamosal contacts both superior and anterior processes of the periotic.

In lateral view, the squamosal forms the posteroventral portion of the lateral wall of the braincase (Figs 8; 9). Anterior to the subtemporal crest (Fig. 15), the squamosal displays a small contact with the alisphenoid. This suture is crenulated and posterodorsally oriented in lateral view (cf. Alisphenoid). The $\mathrm{Al}-\mathrm{Sq}$ suture continues posterodorsally into the Pa-Sq suture, which is better observed in the right side. As indicated above (cf. Parietal), the sinuous $\mathrm{Pa}-\mathrm{Sq}$ suture runs posterodorsally towards the posterior end of the nuchal crest. Posterior to the level of the vertex, the Pa-Sq suture turns abruptly posteroventrally and runs towards the nuchal crest. The posterior margin of the squamosal contributes to the ventral portion of the nuchal crest, where it contacts the lateral portion of the occipital shield. The dorsal and ventral surfaces of the squamosal are separated by a short and prominent subtemporal crest. In dorsal and ventral views (Fig. 15), the subtemporal crest runs posterolaterally from the anterior edge of the squamosal on the anterolateral edge of the braincase to about the level of the foramen pseudovale (cf. below). At this level, the subtemporal crest extends laterally on the anterior edge of the posterior root of the zygomatic arch, towards the medial side of the zygomatic process. It passes along the anterior edge of the glenoid fossa ventrally and the squamosal fossa dorsally and defines a dorsoventrally thin and transversely wide blade of bone. The ventral surface of this blade is continuous with the glenoid fossa and is medially bordered by the falciform process of the squamosal (Fig. 16). Its dorsal surface forms the floor of the squamosal fossa, which corresponds to the posteroventral part of the temporal fossa. In dorsal view, the anterior margin of the floor of the squamosal fossa is anteriorly concave and its deepest point is anterior to the level of the vertex. The squamosal fossa is delimited medially by the lateral wall of the neurocranium, laterally by the zygomatic arch, and posteriorly by the supramastoid crest (cf. below).

Ventral to the subtemporal crest, on the ventrolateral surface of neurocranium, the squamosal forms an anteroposteriorly oriented thin crest, the pterygoid process of the squamosal which rests on the falciform process of the squamosal. The anterior end of the latter articulates anteroventrally with the lateral lamina of the pterygoid and contributes to the lateral wall of the pterygoid sinus fossa, although to a lesser extent than the alisphenoid and the pterygoid. The Pt-Sq suture is also highly crenulated and runs posteroventrally along the anterior end of the falciform process of the squamosal. At this level, the lateral surface of the pterygoid process presents a low ridge, parallel to the sub-temporal fossa. This ridge continues anteriorly on the lateral surface of the pterygoid (Fig. 19). The pterygoid process of the squamosal extends posteriorly and on the falciform process of the squamosal, which separates the peribullar and glenoid fossae (Fig. 16). The anteroventral edge of the falciform process presents a rough, long, transversely narrow and ventrally oriented surface. Such a surface contacts the processus tubarius in the anteroventral anterior 



FIG. 16. - Ventral view of the right pterygoid sinus and peribullar cavity of the skull of MNHN.F.PRU10, holotype of Cynthiacetus peruvianus. Abbreviations: ALI, alisphenoid; app, anterior process of the periotic; BO, basioccipital; EO, exoccipital; fc, cochlear window; fpb, falcate process od the basioccipital; fps, falciform process of the squamosal; fsg, fossa for the sigmoid fossa; fv, vestibular window; gf, glenoid fossa; J, jugal; Ilp, lateral lamina of the pterygoid; mce, medial crest of the exoccipital; mlp, medial lamina of the pterygoid; PE, periotic; pgp, postglenoid process of the squamosal; ppp, posterior process of the periotic; ppt, posterior process of the tympanic; ps, pterygoid sinus; PT, pterygoid; SQ, squamosal; V, vomer; V3, path for the mandibular nerve; vcf, ventral carotid foramen; zyg, zygomatic process of the squamosal. Dark grey-shaded regions indicate the reconstructed parts of the specimen and portion of the sediment. Hatched regions represent broken portions of the bone. Scale bar: $5 \mathrm{~cm}$.

region of the tympanic bulla and corresponds to the entoglenoid process (or anterior falciform process) of the squamosal (Luo \& Gingerich 1999).
Medially, the falciform process contacts the anterior process of the periotic. The medial surface of the falciform process continues dorsally and articulates with the superior process 

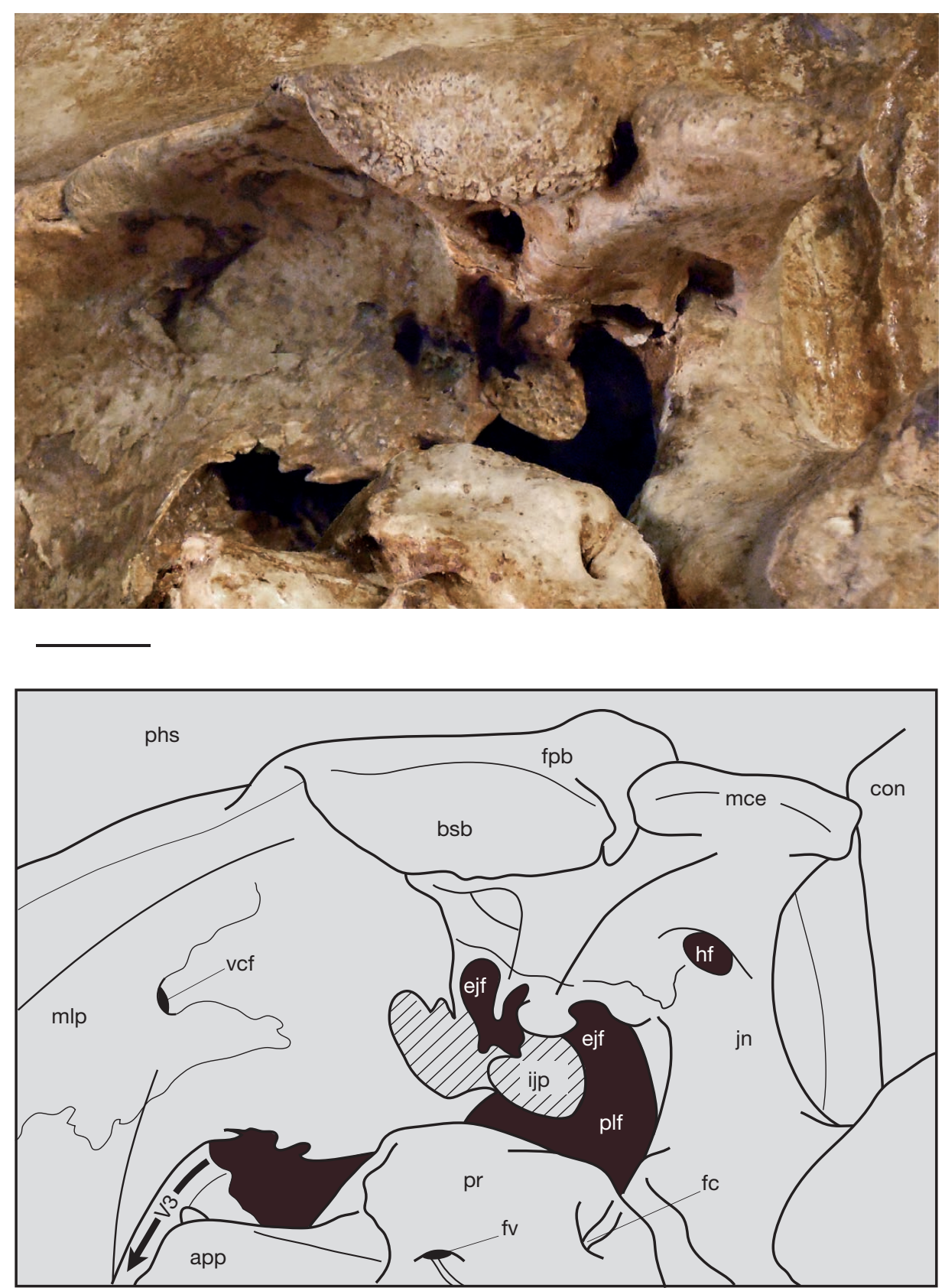

FIG. 17. - Ventromedial view of the right peribullar cavity of the skull of MNHN.F.PRU10, holotype of Cynthiacetus peruvianus. Abbreviations: app, anterior process of the periotic; bsb, basioccipital surface for the tympanic bulla; con, condyle; ejf, external jugular foramina; fc, cochlear window; fpb, falcate process od the basioccipital; fv, vestibular window; hf, hypoglossal foramen; ijp, intrajugular process; jn, jugular notch; mce, medial crest of the exoccipital; mlp, medial lamina of the pterygoid; phs, pharyngeal surface; plf, posterior lacerate foramen; pr, promontorium; vcf, ventral carotid foramen; V3, path for the mandibular nerve. Hatched regions represent broken portions of the intrajugular process. Scale bar: $1 \mathrm{~cm}$.

of the periotic. The squamo-periotic (Sq-Pe) suture can easily be observed in ventral view. The falciform process of the squamosal is transversely compressed and crescent-shaped in ventral view, being laterally convex. At about the level of the anterior bullar process, the falciform process is perforated by two foramina which are preserved on the right side of the skull (Fig. 19). The ventralmost foramen is larger and rounded, while the dorsalmost foramen is anteroposteriorly elongated. These foramina are likely homologous to the fo- ramen pseudovale, which transmits the mandibular branch of the trigeminal nerve (V3). Because it is probable that the foramen pseudovale of Basilosaurids also conveyed the ramus anastomoticus, a branch of the external carotid artery (Geisler \& Luo 1998), this ramus and the mandibular nerve may have exited the peribullar cavity through different foramina in MNHN.F.PRU10. On the left side of the skull, most of the ventral part of the falciform process is missing and the dorsal foramen pseudovale only is preserved. 

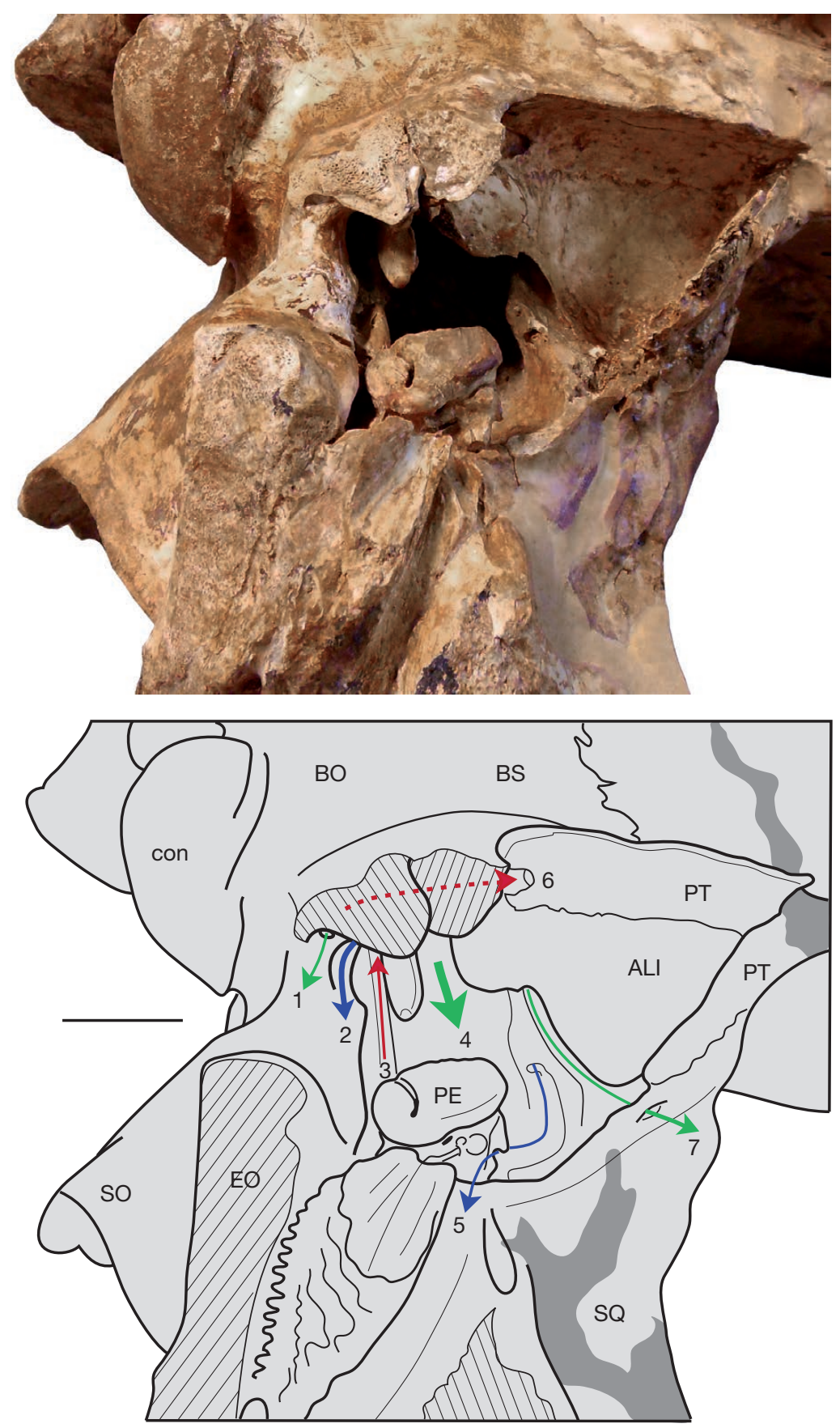

FIG. 18. - Ventral view of the left peribullar cavity of MNHN.F.PRU10, holotype of Cynthiacetus peruvianus. Abbreviations: ALI, alisphenoid; BO, basioccipital; BS, basisphenoid; con, condyle; EO, exoccipital; PE, periotic; PT, pterygoid; SO, supraoccipital; SQ, squamosal. Blue, red and green arrows indicate the path of main cranial nerves and blood vessels; 1) path of the hypoglossal nerve (XII); 2) path of the external jugular vein; 3) path of the spinal meningeal arteries; 4) path of glossopharyngeal (IX), vagus $(\mathbf{X})$ and spinal accessory (XI) nerves; 5) path of the capsuloparietal emissary vein; 6 ) path of the internal carotid foramen; 7 ) path of the mandibulary nerve (V3). Hatched regions represent broken portions of the intrajugular process. Scale bar: $3 \mathrm{~cm}$.

Medial to the falciform process and on the posterior edge of the pterygoid sinus, at the anteroposterior level of the foramen pseudovale, is the path for the mandibular nerve (V3), which exits the the cerebral cavity through the cranial hiatus. From this groove the V3 (Fig. 18 [path 7]) exits the peribullary sinus fossa via the foramen ovale. This path is distinctly observable in ventral view and separates the pterygoid sinus fossa and the peribullary sinus fossa. In the posterior portion of the pterygoid sinus fossa, the squamosal is fused anteriorly to the alisphenoid and it is difficult to evaluate if there is a squamo-basioccipital contact on the posteromedial wall of the pterygoid sinus. In modern cetaceans, the peribullary cavity includes the peribullary and the posterior sinuses, components of the auditory sinus complex. The posterior sinus fossa of MNHN.F.PRU10 is clearly smaller than in neocetes. 
Posterior to the falciform process and just anterior to the level of the ventrolateral tuberosity of the periotic (cf. Periotic), the Sq-Pe suture is pierced by a small foramen (Fig. 15). Following Geisler \& Luo (1998), we identify this foramen as being homologous to the postglenoid foramen of terrestrial mammals. This foramen transports the capsuloparietal emissary vein in modern cetaceans (e.g. Fordyce 2002; Fitzgerald 2006, 2010; Mead \& Fordyce 2009) and is common in protocetids and basilosaurids (Geisler \& Luo 1998; Luo \& Gingerich 1999; Geisler et al. 2005). In the typical terrestrial mammal skull, the postglenoid foramen is located posterior to medial to the postglenoid process, and is excavated in the squamosal (Wible 2003, 2008; Wible et al. 2004; Schaller 2007; Evans \& de Lahunta 2013). It receives the capsuloparietal emissary vein, which becomes the postglenoid vein when leaving the skull. In basilosaurids, the postglenoid foramen for the capsuloparietal emissary vein lies medial and dorsal to the glenoid fossa, within the peribullar cavity. Morever, it is formed by the squamosal and the periotic. Following the hypothesis of homology stated by previous authors (Luo \& Gingerich 1999; Geisler \& Luo 1998) we refer to this foramen as being the postglenoid foramen, even if it is anterior to the postglenoid process.

In MNHN.F.PRU10, the right postglenoid foramen is obscured by the matrix. In contrast, the left periotic is partially preserved and the sulcus transporting the capsuloparietal emissary vein can be observed on the medial (endocranial) surface of the squamosal (Fig. 18[path 5]). The sulcus for the capsuloparietal emissary vein runs dorsally from the postglenoid foramen to about the dorsal margin of the superior process of the periotic. In Dorudon atrox, Uhen (2004) mentioned that there is no canal connected to the postglenoid foramen. Actually, the canal for the capsuloparietal emissary vein should result from the fusion of the sulcus on the medial surface of the squamosal with the anteroexternal sulcus, on the lateral surface of the periotic (cf. Periotic). Dorsally, the sulcus for the capsuloparietal emissary vein ends in a small foramen on the medial surface of the squamosal (Fig. 18). At this level, the squamosal defines laterally the cranial hiatus (or posterior lacerate foramen or basicranial fossa, depending on the authors). The cranial hiatus separates the squamosal from the basioccipital in the peribullar cavity. In our description, we do not include the jugular foramen in the cranial hiatus since it can be distinguished from the hiatus (cf. Exoccipital). Finally, the cranial nerves IX, X and XI most likely exited the cerebral cavity through the cranial hiatus (Fig. 18[path 4]).

In lateral view, the wide glenoid fossa is anteroventrally concave and its anterior end is just posterior to the J-Sq suture. In ventral view, the glenoid fossa is roughly square in outline, with the anterior margin being posteriorly concave. Just posterior to the glenoid fossa, the squamosal extends ventrally and forms an anteroposteriorly compressed postglenoid process. The latter is crescent-shaped and anteriorly concave in ventral view. The left postglenoid process is missing in MNHN.F.PRU10 and the right process is broken at its ventral extremity. Medial to the postglenoid process and slightly posterolateral to the postglenoid foramen is a trans- versely elongated, oval depression. This depression probably received the sigmoid process of the tympanic.

Posterior to the postglenoid process, the squamosal forms the roof of the external acoustic meatus, which is posteriorly defined by the posterior meatal crest. The external acoustic meatus ends laterally at a teardrop-shaped depression, probably homologous to the suprameatic fossa of terrestrial mammals. Posterior to the meatal crest, the mastoid process of the squamosal articulates posteriorly with both the posterior process of the periotic and the anterior surface of the exoccipital. The lateral surface of the mastoid process is markedly rough.

Anterior and dorsal to the glenoid fossa is the zygomatic process of the squamosal. Medially, the zygomatic process forms the lateral wall of the temporal fossa. Ventrally, it articulates with the temporal portion of the jugal. In MNHN.F.PRU10, its anterior (distal) end is missing on both sides, although it appears to be almost complete on the right side as it strongly tapers at is anterior end (as preserved). However, the zygomatic process of the squamosal is preserved in some specimens of Dorudon atrox (UM93220, UM 101222) and its anterior third to half is a transversely thin and low stick of bone, which almost reaches anteriorly a point ventral to the postorbital process of the frontal (Uhen 2004: fig. 23). Based on the length of the zygomatic process in D. atrox and on the presence of a sulcus on the dorsal surface of the jugal, it can be inferred that the zygomatic process of the squamosal could have extended far anteriorly in Cynthiacetus peruvianus, ending at a point slightly posterior and ventral to the level of the postorbital process of the frontal, as observed in D. atrox. The dorsal margin of the zygomatic process is distinctly convex dorsally and extends posteriorly until the level of the postglenoid process, where it meets the supramastoid crest. In lateral view, the ventral margin of the zygomatic process is clearly concave and faces anteroventrally. The zygomatic process decreases in height towards its anterior end (as preserved). At the apex of the preserved portion of the right zygomatic process, its dorsal margin becomes slightly concave, a probable indication for the beginning of the low stick-like anterior portion of the process as observed in D. atrox (Uhen 2004: figs 23, 34). At this level, which is about the mid-length of the temporal fossa, the zygomatic process reaches its minimum dorsoventral height.

The supramastoid crest runs posteromedially from the posterior end of the dorsal edge of the zygomatic process. It is subvertical and delimits the posterior edge of the squamosal and temporal fossae. Posteriorly, it meets the ventral end of the nuchal crest, at the level of the dorsal margin of the occipital condyle. At this level, the posterior margin of the squamosal articulates with the lateral margin of the occipital shield, to form the ventral portion of the nuchal crest. The latter is less prominent than the dorsal portion of the nuchal crest.

Since the occipital shield results from the fusion of the exoccipitals, supraoccipital and basioccipital, it is difficult to say which bone of the occipital shield articulates with the squamosal. It is probable that the latter contacts exclusively the exoccipital component of the occipital shield. This assertion is based on the observation of neonate specimens of modern cetaceans (Mead \& Fordyce 2009) and of a neonate 

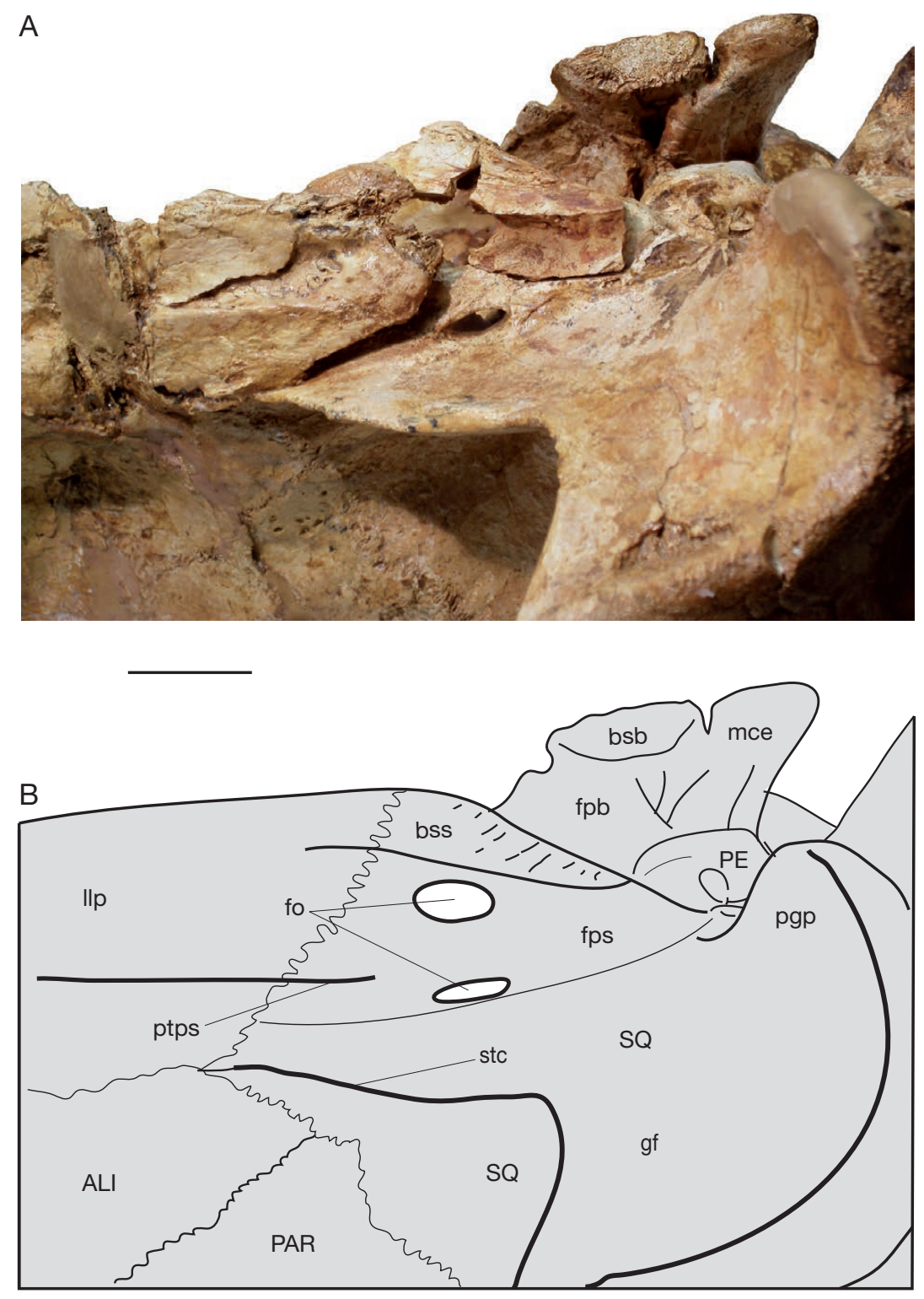

FIG. 19. - A, Subtemporal region of the skull of MNHN.F.PRU10, holotype of Cynthiacetus peruvianus; B, reconstruction of this region, based on the right side. Abbreviations: ALI, alisphenoid; bsb, bullar surface of the basioccipital; bss, bullar surface of the squamosal; fo, foramen pseudovale; fpb, falcate process of the basioccipital; fps, falciform process of the squamosal; gf, glenoid fossa; Ilp, lateral lamina of the pterygoid; mce, medial crest of the exoccipital; PAR, parietal; PE, periotic; pgp, postglenoid process; ptps, pterygoid process of the squamosal; SQ, squamosal, stc; subtemporal crest. Note the development of the pterygoid process of the squamosal and the exclusion of the pterygoid from the foramen pseudovale. Scale bar: $2.5 \mathrm{~cm}$.

specimen of Dorudon atrox (Uhen 2004). In lateral view, the squamoso-occipital (Sq-EO) suture is almost perpendicular to the longitudinal axis of the skull, being slightly oriented posterodorsally. This suture meets dorsally the Pa-SO suture, at about the level of the ventral margin of the postorbital process of the frontal.

Exoccipital (EO). The exoccipital is a paired bone. It forms the lateral portion of the posterior wall of the braincase and fuses anteroventrally with the basioccipital and dorsally with the supraoccipital, to form with the latter the occipital shield. It articulates anteriorly with the squamosal and the petro-tympanic complex, and posteriorly has a mobile synovial articulation with the atlas on the occipital condyle.
On the ventral surface of the paroccipital process of the exoccipital is a deep fossa for the contact with the stylohyal. This fossa is only preserved in the right side since the whole region is missing in the left one (Figs 15;20). A tiny bone confined by remaining sediment within the fossa is the malleus, which has been detached from the periotic and tympanic during the burial/fossilization process (Fig. 21). Unfortunately, the malleus could not be removed from the fossa for the stylohyal, because of the extreme hardness of the sediments (cf. Malleus).

Most of the exoccipital comprises the paroccipital process, which extends ventrolaterally in a plane perpendicular to the sagittal plane. The paroccipital process is roughly trapezoidal in posterior view, increasing laterally in height (Fig. 20). It articulates anteriorly with the mastoid portion of the squamosal 
and with the posterior process of the periotic. In posterior view, the paroccipital process does not extend far enough laterally to fully cover the squamosal. The dorsal and ventral margins of the paroccipital crest are straight while its lateral margin is laterally convex. On the ventral margin of the paraoccipital process is a deep fossa for the proximal end of the stylohyoid.

Ventromedial to the paroccipital process is the jugular notch, which connects the cervical region with the peribullar cavity and serves for the passage of various nerves and blood vessels (including the hypoglossal nerve and the jugular vein). The jugular notch separates the paroccipital process from the medial crest of the exoccipital (also called falcate process of the exoccipital). The latter is a thin and linguiform process on the ventral surface of the basicranium. The medial crest fuses anteriorly with the falcate process of the basioccipital and is ventrolaterally oriented in posterior view. It contributes to the separation of the peribullar cavity from the pharyngeal surface; its lateral surface participates thus in the medial wall of the peribullar cavity. The medial crest of the exoccipital and the falcate process of the basioccipital are separated by a narrow notch (Figs 16; 17).

On the medial wall of the peribullar cavity, the hypoglossal foramen lies at the base of the medial crest of the exoccipital, near its posterior end (Fig. 17). The hypoglossal foramen is the external opening of the hypoglossal canal and conducts the hypoglossal nerve (cranial nerve XII, Fig. 18[path 1]) from the cerebral cavity to the peribullar cavity. Anterodorsal to the hypoglossal foramen are the two jugular foramina (Fig. 17), conveying the internal jugular vein from the cerebral cavity to the jugular notch (Fig. 18[path 2]). The jugular foramina are separated by a broad and spine-shaped intrajugular process (its ventral extremity is only preserved on the left side). Moreover, the posteriormost foramen is not fully closed, being laterally continuous with the cranial hiatus. Since the intrajugular process is located at the level of the basioccipitalexoccipital contact, it is difficult to evaluate if it is formed by the basioccipital or the exoccipital. Similarly, the basioccipital could also participate to this jugular foramen.

The exoccipital also forms the posterior wall of the peribullar cavity. In this region, the exoccipital forms a crest, which defines anteriorly a transverse sulcus. This sulcus (Figs 18[path $3]$; 21) runs lateroventrally from the cerebral cavity to the posterior process of the periotic, passing through the cranial hiatus. It is narrower than and dorsolateral to the path for the jugular vein. This groove possibly conveyed the spinal meningeal arteries, which are probably homologous to the arterial rete mirabile in mysticetes (Geisler \& Luo 1998). Anterodorsal and parallel to the sulcus, the SQ-EO suture runs on the posterior wall of the peribullar cavity.

In a neonate specimen of Dorudon atrox, the exoccipitals form most of the dorsal edge of the foramen magnum but do not meet at midline, being separated by the supraoccipital (Uhen 2004: 60). In the same way the exoccipital do not contact on the ventral edge of the foramen magnum where they are separated by the posteromedian end of the basioccipital (Uhen 2004: 59). In MNHN.F.PRU10, the exoccipitals are fused with the basioccipital and no suture can be observed or inferred in this region. Assuming that the condition observed in the neonate Dorudon atrox is the common condition in basilosaurids, it is probable that the dorsomedial and ventromedial corners of the exoccipitals of Cynthiacetus peruvianus do not meet on the dorsal and ventral margins of the foramen magnum.

On the ventral edge of the foramen magnum, at midline, is a deep intercondylar notch formed by the exoccipital separated medially by the basioccipital. The intercondylar notch is as deep as in Dorudon, but distinctly narrower. It is also more pronounced than in modern cetaceans. Lateral to the intercondylar notch, each exoccipital bears a hardly distinguishable and shallow ventral condyloid fossa. Dorsal to the ventral condyloid fossa is the occipital condyle, which is strongly convex. The occipital condyle is higher than wide and somewhat teardrop-shaped in posterior view, with the apex of the teardrop being ventral (Fig. 20). The lateral margin of the condyle is strongly convex laterally and its medial margin is slightly concave, this condition being more pronounced ventrally. The condyles surround the foramen magnum, which is almost twice as high as wide. The foramen magnum is somewhat oval in posterior view (Fig. 20). Dorsal to each condyle is a large dorsal condyloid fossa, deeper than the ventral fossa. As observed in other basilosaurids, protocetids and neocetes, there is no condyloid foramen.

The dorsal portion of the lateral margin of the exoccipital articulates with the squamosal to form the ventral portion of the nuchal crest (Fig. 20). Ventrolaterally to the nuchal crest, the exoccipital does not participate in the supramastoid crest but develops into the paroccipital process (cf. above). In lateral view, the SQ-EO contact is subvertical. In posterior view, this suture is curved and runs ventrolaterally, being dorsolaterally concave. As stated above (cf. Parietal), it is most likely that the Sq-EO suture merges dorsally with the $\mathrm{Pa}-\mathrm{SO}$ suture and that the exoccipital does not contact the parietal. At about the level of the Pa-Sq suture, the occipital shield is transversely constricted. Since the exoccipitals and the supraoccipital are fused, it is difficult to evaluate if this constriction is in the exoccipital or the supraoccipital. Both elements most likely participate in the occipital constriction.

Supraoccipital (SO). The supraoccipital is the single dorsal element of the occipital shield. It articulates anteriorly with the parietals. Ventrolaterally, it is entirely fused with the exoccipitals. Consequently, it is impossible to characterize the supraoccipital-exoccipital contact in MNHN.F.PRU10. In a neonate Dorudon atrox, the supraoccipital forms most of the occipital shield and extends ventrally between the dorsal condyloid fossae (Uhen 2004).

The occipital shield is strongly transversely concave posteriorly (Fig. 20). Consequently, both lateral portions are almost medially facing and the posterior margin of the skull is U-shaped in dorsal view. In posterior view, the occipital shield is somewhat rectangular in outline, being higher than wide. With such an outline, the vertex is not significantly higher than the dorsolateral corners of the supraoccipital. As observed in other archaeocetes, the occipital shield is narrow- 

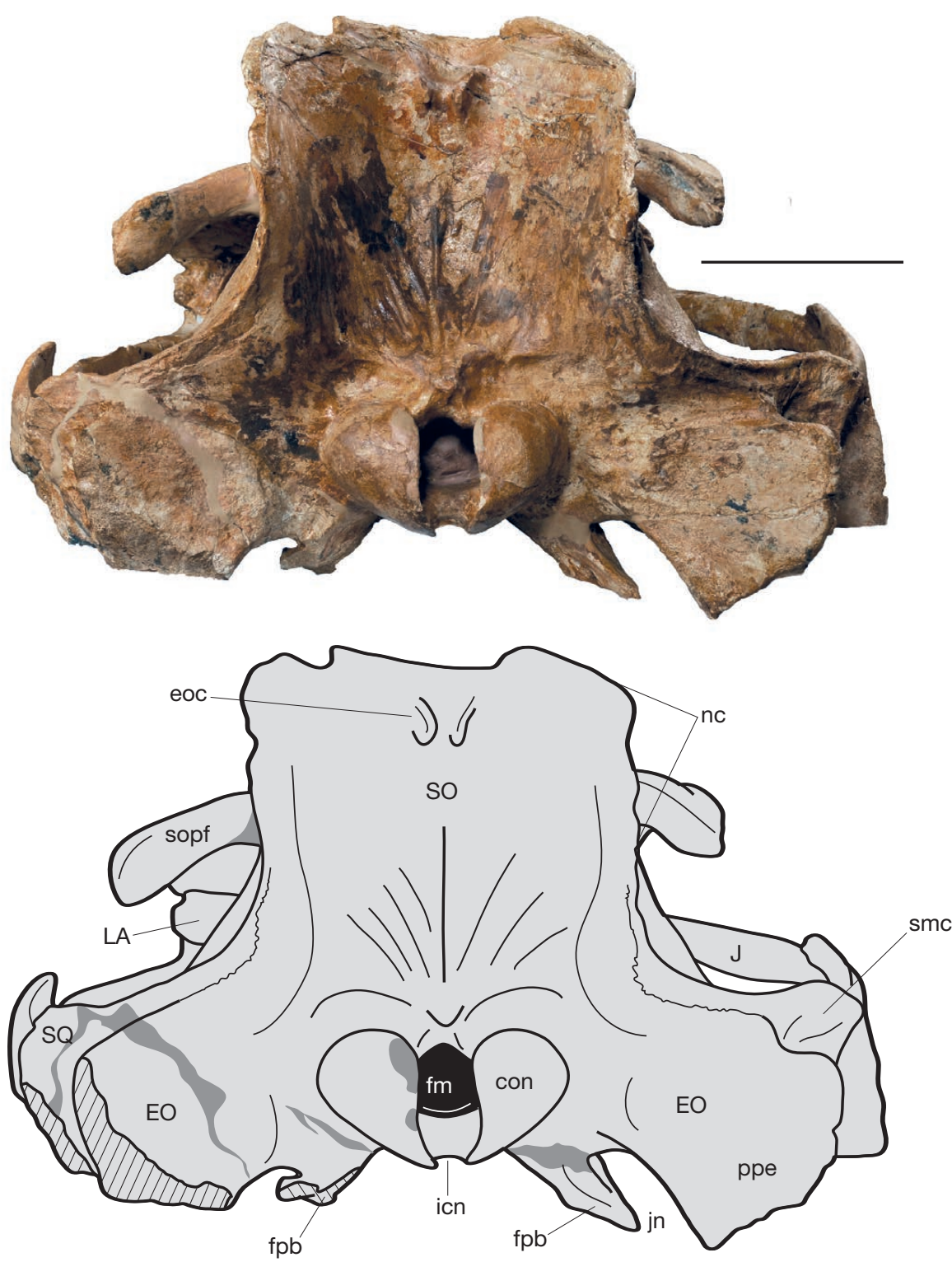

FIG. 20. - Posterior view of the skull of MNHN.F.PRU10, holotype of Cynthiacetus peruvianus. Abbreviations: con, condyle; EO, exoccipital; eoc, external occipital crest; fm, foramen magnum; fpb, falcate process of the basioocipital; icn, intercondylar notch; J, jugal; jn, jugular notch; LA, lacrimal; nc, nuchal crest; ppe, paroccipital process of the exoccipital; smc, suprameatal crest; SO, supraoccipital; sopf, supraorbital process of the frontal; SQ, squamosal. Dark greyshaded regions indicate the reconstructed parts of the specimen. Hatched regions represent broken portions of the intrajugular process. Scale bar: $10 \mathrm{~cm}$.

est at about the level of the posterior end of the Pa-Sq suture (cf. above). In Cynthiacetus peruvianus, this constriction is not as pronounced as in protocetids and in the basilosaurid Saghacetus osiris.

In the ventral region of the supraoccipital, a prominent tuberosity is located along the midline at about the level of the dorsal condyloid fossae. From this tuberosity, numerous low ridges run towards the lateral and dorsal borders of the supraoccipital. The ridges produce a pectinate pattern on the posterior surface of the supraoccipital representing the attachment surface for the nuchal musculature. Two well-developed nuchal prominences are observed dorsal to the nuchal ridges and near the vertex. Only the nuchal prominences are exposed in dorsal view, not the rest of the shield. The number of the nuchal prominences varies among basilosaurids and seems to be correlated with the size of the skull. While in Zygorhiza kochii and Dorudon atrox there is only one nuchal prominence (less developed in Zygorhiza kochii), Basilosaurus cetoides and $B$. isis present two well developed nuchal prominences. In contrast, the holotype of $C$. maxwelli displays three relatively low nuchal prominences. The presence of well-developed crests and tuberosities in the occipital shield of Cynthiacetus peruvianus denotes a powerful neck musculature, probably more developed than in smaller species (e.g. Zygorhiza kochii, Dorudon atrox and Saghacetus osiris), where these features only develop in ontogenetically older specimens.

Basioccipital (BO). The basioccipital is the posteriormost element of the basicranium floor and pharyngeal passage. It fuses anteriorly with the basisphenoid and posteriorly with 

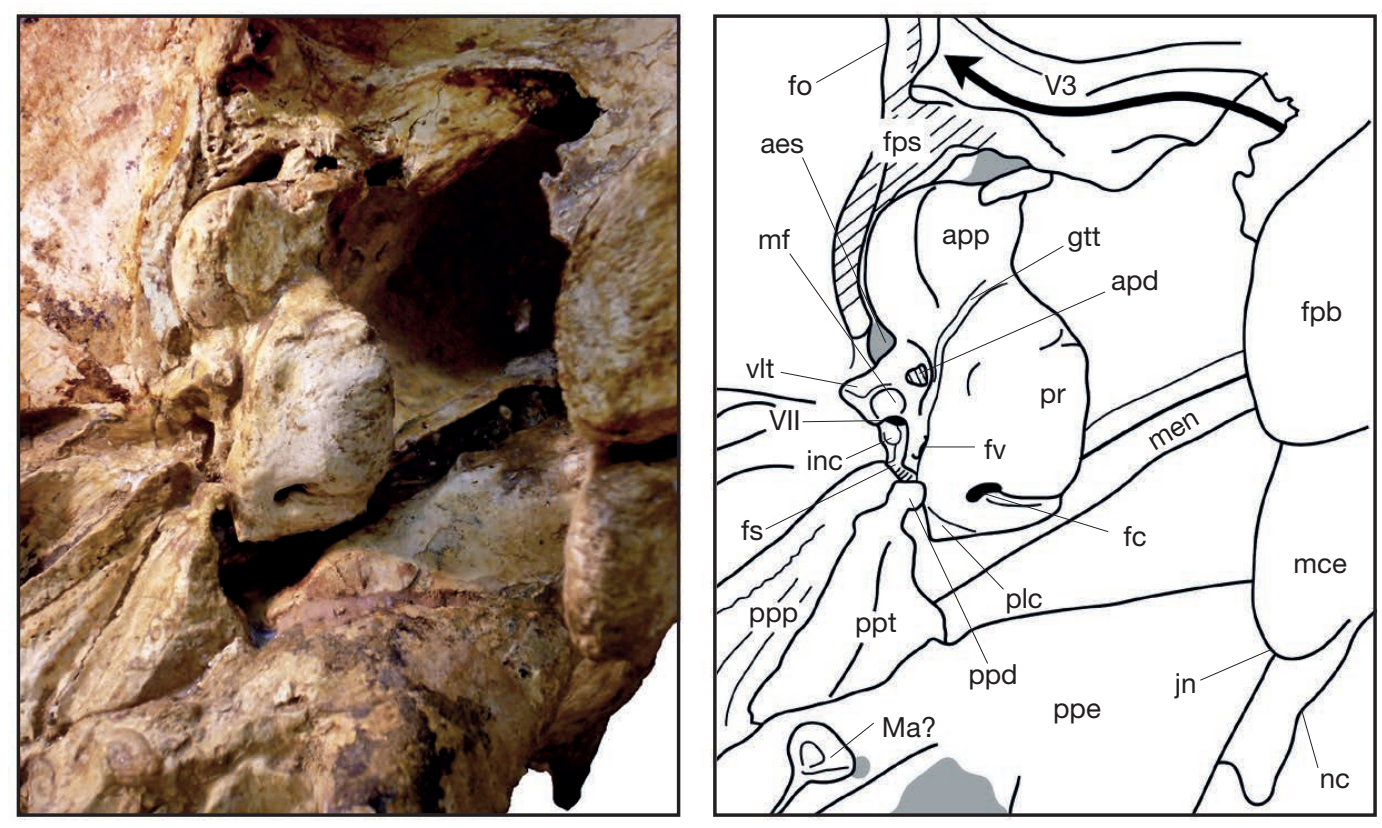

FIG. 21. - Ventral view of the right periotic of MNHN.F.PRU10, holotype of Cynthiacetus peruvianus. Abbreviations: aes, ventral edge of the anteroexternal sulcus; apd, anterior pedicle for the tympanic; app, anterior process of the periotic; fc, cochlear window; fo, foramen pseudovale; fpb, falcate process of the basioccipital; fps, falciform process of the squamosal; fs, facial sulcus; fv, vestibular window; gtt, groove for the tensor tempani; inc, incudal fossa; jn, jugular notch; Ma, malleus; mce, medial crest of the exoccipital; men, groove for the meningeal arteries; mf, mallear fossa; nc, nuchal crest; plc, posterolateral crest; ppd, posterior inner pedicle of the tympanic; ppe, paroccipital process of the exoccipital; ppp, posterior process of the periotic; ppt, posterior process of the tympanic bulla; pr, promontorium; V3, path of the mandibular nerve; VII, foramen for the facia nerve; vit, ventrolateral tuberosity. Dark grey-shaded regions and hatched regions represent the sediment and broken portions of bone, respectively. Not to scale.

the exoccipitals. The dorsal surface of the basioccipital forms the floor of the braincase. Posteriorly, it is likely that the basioccipital does not participate in the intercondyloid notch, at the ventral edge of the foramen magnum.

The ventral surface of the basioccipital is slightly concave ventrally and no foramen can be observed in this region. Anteriorly, the basioccipital contacts the basisphenoid at about the level of the pseudovale foramina. Here, the suture is completely fused and can barely be identified in ventral view. The basioccipital extends ventrolaterally in each side and forms the falcate processes of the basioccipital. The falcate process (lateral process in Kellogg 1936; basioccipital crest in Mead \& Fordyce 2009) is thin and not as massive as in the Mysticeti. It separates the pharyngeal surface from the peribullar cavity. Anteriorly, the falcate process articulates with the medial lamina of the pterygoid (the BO-Pt suture has already been described, cf. Pterygoid). At the mid-length of the BO-Pt suture is the ventral carotid foramen (the path of the ventral carotid foramen is indicated in Fig. 18). Posteriorly, most of the falcate process of the basioccipital is fused with the medial crest of the exoccipital and these structures are only separated at their distal ends. In the absence of a condyloid foramen, both the condyloid artery and condyloid vein most likely passed through the hypoglossal foramen (cf. Exoccipital).

The lateral surface of the falcate process forms the medial wall of the peribullar cavity. It also delimits both cranial hiatus and jugular foramina. The anterior jugular foramen is fully closed posterodorsally by the spine-shaped intrajugular process. In contrast, the posterior jugular foramen opens into the cranial hiatus (at the level of the posterior lacerate foramen). The glossopharyngeal, vagus and spinal accessory nerves (respectively, cranial nerves IX, X and XI) probably exit the cerebral cavity through the posterior lacerate foramen. As mentioned above (cf. Exoccipital), it is difficult to evaluate if the intrajugular process is formed by the exoccipital or by the basioccipital.

Periotic $(\mathrm{Pe})$. The periotic is the paired bone encompassing the inner ear and related structures (nerves and blood vessels). It is very dense and solidly attached to the basicranium (cf. below). In basilosaurids, the periotic is usually divided into four different parts: a body (including the pars cochlearis and pars canalicularis) and the anterior, posterior and superior processes. The right periotic of MNHN.F.PRU10 is fully preserved while the left lacks its anterior process and part of the pars cochlearis. Although it is impossible to separate the vestibular portion from the cochlear portion in ventral view, the promontorium is mostly formed by the pars cochlearis and the pars canalicularis should include only the portion lateral to the cochlear window and medial to the facial groove (cf. below).

The anterior process of the periotic (Fig. 21) can be regarded as a broad and anterior expansion of the body. Its anterior apex is blunt and directed slightly anteromedially. Most of the anterior process is oval-to-elliptic in cross-section, being dorsoventrally higher than wide. Moreover, its lateral surface is laterally convex and articulates with the squamosal at the level of the falciform process.

The pars cochlearis contains the cochlea and associated structures (nerves and blood vessels). It is somewhat rec- 

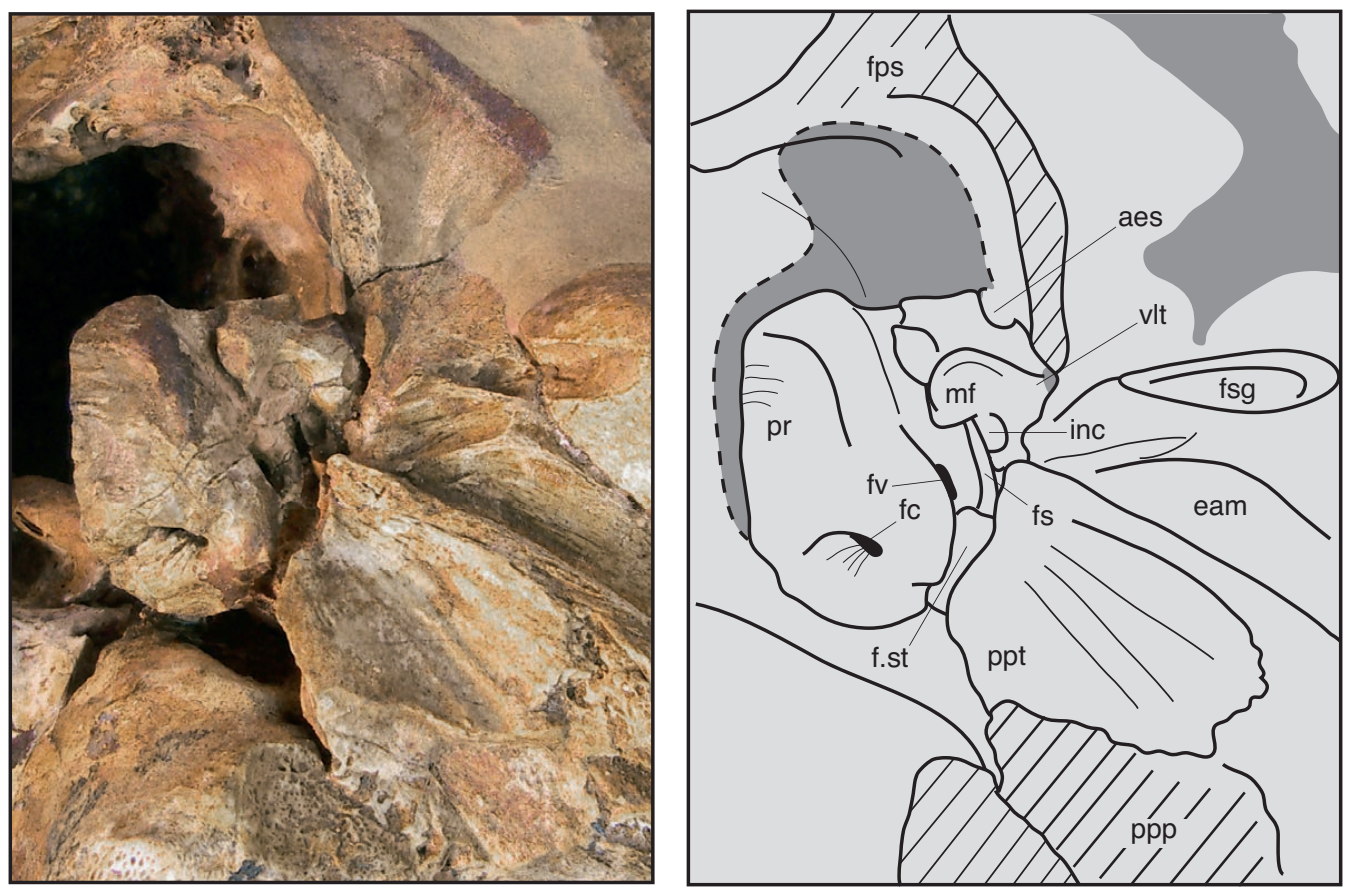

FIG. 22. - Posteroventral view of the left periotic of MNHN.F.PRU10, holotype of Cynthiacetus peruvianus. Abbreviations: aes, ventral edge of the anteroexternal sulcus; eam, external acoustic meatus; fc, cochlear window; fps, falciform process of the squamosal; fs, facial sulcus; fsg, fossa for the sigmoid process of the bulla; f.st, fossa for the stapedial muscle; fv, vestibular window; inc, incudal fossa; mf, mallear fossa; ppp, posterior process of the periotic; ppt, posterior process of the tympanic bulla; pr, promontorium; vit, ventrolateral tuberosity. Dotted line with dark grey-shaded colored region indicates the position of the missing anterior process of the periotic. Hatched regions represent broken bone. Not to scale.

tangular in ventral view, with the corners being blunt. Although its anteromedial corner is well developed at the level of the promontorium, it lacks the bump-like protuberance observed in Dorudon atrox (Uhen 2004). In this respect, the pars cochlearis of Cynthiacetus peruvianus resembles that of Basilosaurus. cetoides (e.g. USNM 6087) and Zygorhiza. kochii (e.g. USNM 10855). Laterally, the pars canalicularis (enclosing the vestibular system and associated blood vessels) is separated from the anterior process by a deep groove. This groove is slightly oriented anteromedially and ends posteriorly at the level of the fenestra vestibuli (cf. below); it probably represents the insertion of the tensor tympani muscle. Lateral to the groove for the tensor tympani is the ventrolateral tuberosity. The latter is laterally pointed and quite prominent. The anterior process and the ventrolateral tuberosity are separated by the anteroexternal sulcus of the periotic (Mead \& Fordyce 2009; "transverse vascular groove" in Luo \& Gingerich 1999; "fovea epitubaria" in Kellogg 1936). The anteroexternal sulcus runs dorsoventrally on the whole lateral surface of the body, where it forms the medial wall of the canal for the capsuloparietal emissary vein. Ventrally, it participates with the squamosal in the formation of a vascular foramen (homologous of the postglenoid foramen, cf. Squamosal).

Posterior to the tip of the ventrolateral tuberosity is the mallear fossa, which is roughly circular, posteroventrally facing and articulates with the head of the malleus. The posterior edge of the mallear fossa is located on the anteroventral edge of the foramen for the facial nerve (VII), the secondary facial foramen. This foramen (epitympanic orifice of the aqueductus Fallopii in Kellogg 1936) is the external aperture of the facial canal and opens posteriorly into a narrow, deep and long groove. The latter is bounded laterally by a small and rounded fossa (fossa incudis) and medially by the vestibular window or fenestra vestibuli. On the fenestra vestibuli articulates the footplate of the stapes (missing in MNHN.F.PRU10). The fenestra vestibuli is the lateral entrance to the osseous labyrinth. The fossa incudis is hardly distinguishable and receives the crus breve of the incus. The mallear fossa and the fossa incudis are the relicts of the epitympanic recess of terrestrial mammals. Posterior to the groove for the facial nerve is the stapedius fossa. This fossa is transversely wider than the facial groove and separates the pars cochlearis from the posterior process of the periotic. In ventral view of the right periotic, the fossa is partially covered by a portion of the posterior pedicle of the posterior process of the tympanic, but the fossa is visible on the left periotic (Fig. 22).

The posterolateral corner of the pars cochlearis forms a thin and triangular process. This process is likely homologous of the developed cochlear crest in various early odontocetes (e.g. Simocetus rayi; Albertocetus meffordorum Uhen, 2008b). Anteromedial to the cochlear crest, the cochlear window (fenestra cochleae) lies on the ventral surface of the pars cochlearis. It is roughly oval in ventral view, being transversely wider than long. From the fenestra cochleae, a sulcus extends medially towards the posteromedial corner of the pars cochlearis. In vivo, the secondary tympanic membrane attached on the fenestra cochleae (Wible et al. 2009; Wible 2010). 
A

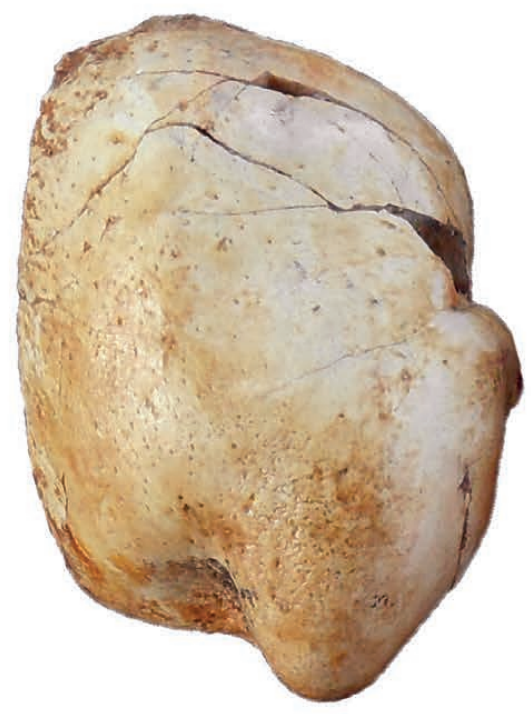

C

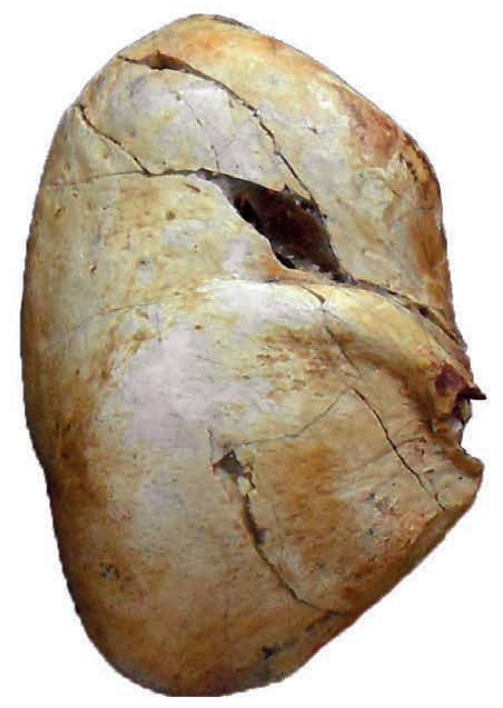

B

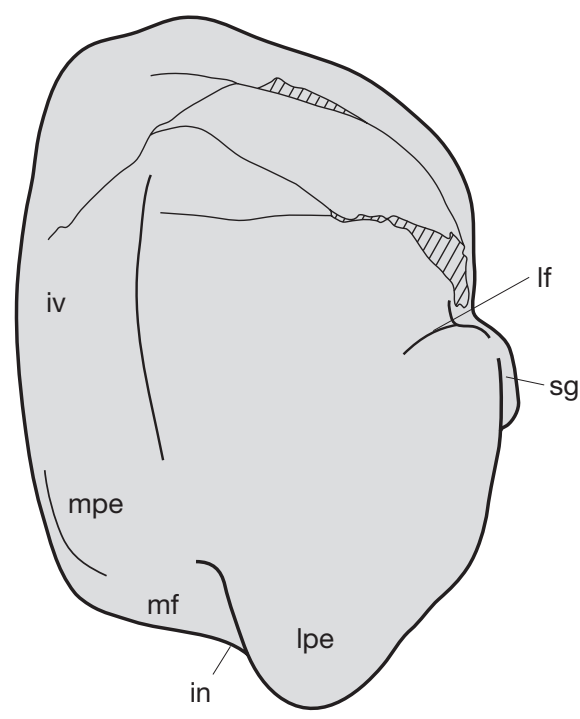

D

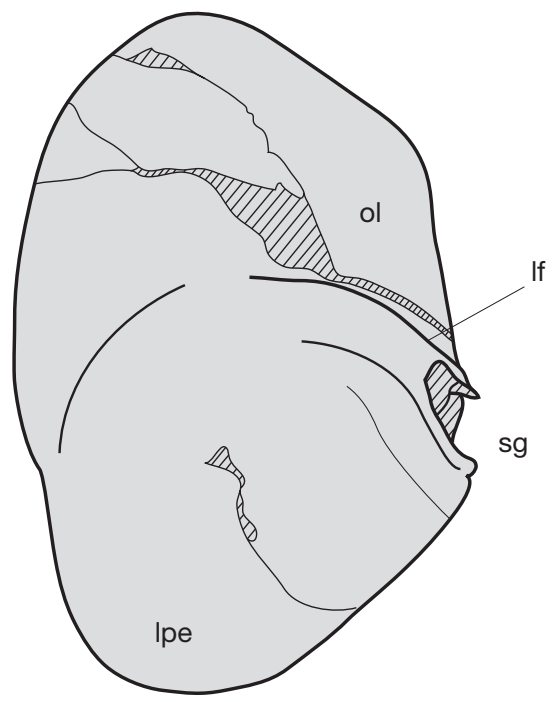

FIG. 23. - Left tympanic bulla of MNHN.F.PRU10, holotype of Cynthiacetus peruvianus: A, B, ventral view; C, D, lateral view. Abbreviations: in, interprominential notch; iv, involucrum; If, lateral furrow; Ipe, lateral posterior eminence; mf, median furrow; mpe, medial posterior eminence; ol, outer (lateral) lip; sg, sigmoid process of the bulla. Hatched regions represent broken bone. Scale bar: $2.5 \mathrm{~cm}$.

The cerebral (dorsal) surface of the periotic is not accessible for direct observation since the periotic is firmly attached to the skull. However, because the dorsal face of the periotic has been fully prepared by acid etching, it has been possible to observe it with a small dental mirror. Unlike the protocetids and the toothed mysticete Mammalodon colliveri, the internal acoustic meatus (IAM) in MNHN.F.PRU10 is within a deep fossa on the dorsal surface of the pars cochlearis. In contrast, the IAM in the protocetids is within a dorsomedially oriented and prominent tube. The IAM houses three openings: the most medial and largest one transmits the cochlear nerve (branch of the vestibulocochlear nerve, cranial nerve VIII) and the tractus spiralus foraminosus. Lateral to this opening is the foramen for the vestibular nerve (another branch of the vestibulocochlear nerve, cranial nerve VIII).
The cochlear and vestibular foramina are separated by a thin septum, which is anteroposteriorly oriented. Anterior to the vestibular nerve foramen is the internal foramen for the facial nerve or primary facial foramen (internal aperture of the aqueductus Fallopii in Kellogg 1936), which can be described as the medial opening of the facial canal. These two latter foramina (for the vestibular and facial nerves) are subequal in size and considerably smaller than the foramen for the cochlear nerve.

Posterior to the IAM are the apertures for the perilymphatic and endolymphatic aqueducts. The endolymphatic aperture (aperture of the vestibular aqueduct) lies in a deep fossa, just posterolateral to the IAM. In contrast, the perilymphatic aperture (external aperture of the cochlear canaliculus) lies at the posteromedial corner of the pars cochlearis. 
A

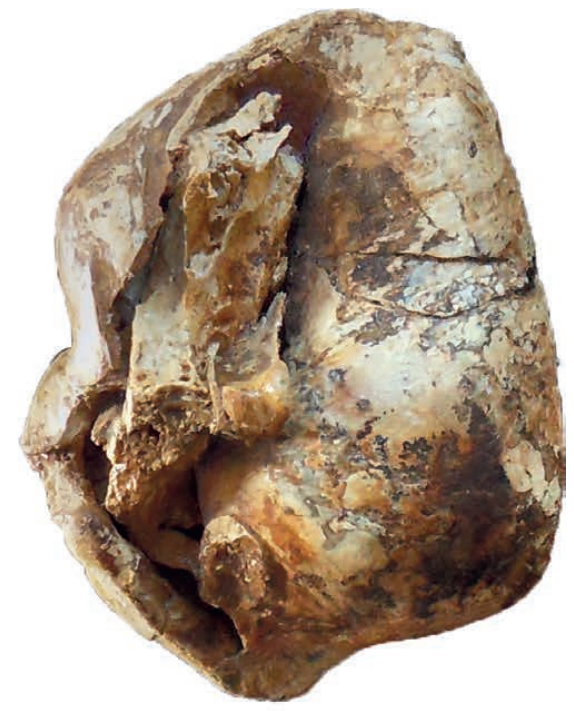

C

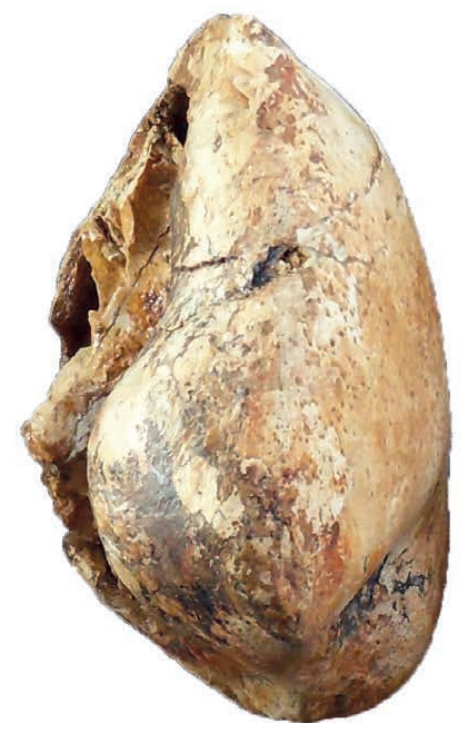

B

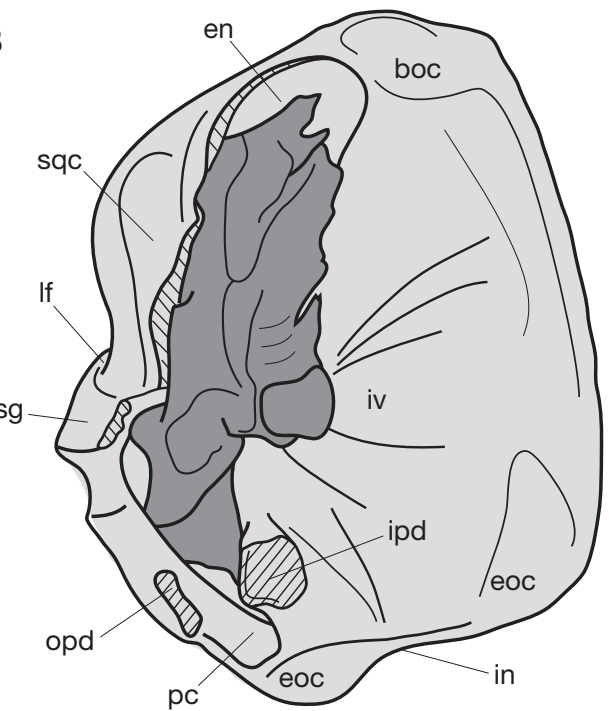

D

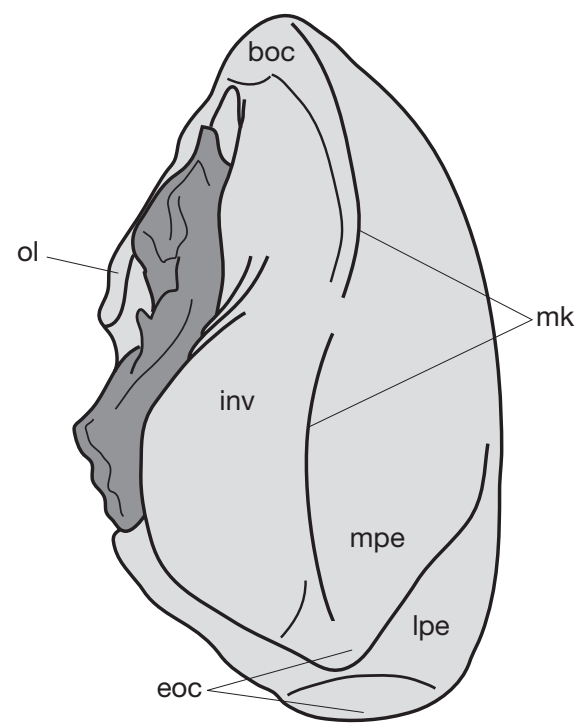

FIG. 24. - Left tympanic bulla of MNHN.F.PRU10, holotype of Cynthiacetus peruvianus: A, B, dorsal view; C, D, medial view. Abbreviations: boc, surface for the basioccipital contact; en, eustchian notch for the passage of the eustachian tube; eoc, surface for the exoccipital contact; in, interprominental notch; ipd, inner (medial) posterior pedicle; inv, involucrum; If, lateral furrow; Ipe, lateral posterior eminence; mk, medial keel; mpe, medial posterior eminence; ol, outer (lateral) lip; opd, outer (lateral) posterior pedicle; pc, posterior cleft; sg, sigmoid process of the bulla; sqc, contact for the falciform process of the squamosal. Hatched regions represent broken bone. The tympanic cavity is remplied by sediment and fragments of bone. Scale bar: $2.5 \mathrm{~cm}$.

Lateral to the IAM, the suprameatal fossa (sensu Luo \& Gingerich 1999) is a concave, wide surface connecting the IAM to the superior process of the periotic (tegmen tympani). The superior process is a transversely thin and dorsoventrally high projection of the body. Its lateral surface is laterally convex and articulates with the medial (endocranial) surface of the squamosal.

The posterior process of the periotic extends posterolaterally from the ventrolateral margin of the stapedius fossa. The posterior process of the periotic is proportionally larger than the anterior process. In Cynthiacetus peruvianus, the ventral surface of the posterior process is somewhat triangular and presents numerous longitudinal ridges. This surface articulates ventrally with the dorsal surface of the posterior process of the tympanic. Moreover, the posterior process extends dorsally in the mastoid region of the skull and is firmly wedged between the squamosal and exoccipital. Indeed, its anterior surface contacts anteriorly the posterior surface of the mastoid process of the squamosal, while its posterior surface articulates with the anterior surface of the paroccipital process of the exoccipital. The dorsal expansion of the posterior process can easily be observed in lateral view.

Unfortunately, the low resolution of the CT-scan does not allow detailed observation of the inner structures of the periotic. It is possible, however, to observe that the cochlea has two turns and that the semicircular canals are larger than in most recent cetaceans. 
TABLE 4. - Measurements (in mm) of the dentary of MNHN.F.PRU10, holotype of Cynthiacetus peruvianus. (e), estimated.

\begin{tabular}{lc}
\hline Measurements & $\mathbf{m m}$ \\
\hline $\begin{array}{l}\text { Total length, from the anterior tip of the mandible } \\
\quad \text { to the posterior edge of the condyle }\end{array}$ & 1040 \\
Length of the coronoid process & 196.3 \\
Width of the dentary at about the level & 65 \\
$\quad$ of the mandibular foramen & 145 (e) \\
Height of the mandibular foramen & 52.6 \\
Width of the mandibular condyle & 48 \\
Height of the mandibular condyle & 20.6 \\
Length of the diastema between i1 and i2 (right side) & 13 \\
Length of the diastema between i2 and i3 (right side) & 45 (e) \\
Length of the diastema between i3 and c1 (right side) & 50.6 \\
Length of the diastema between c1 and p1 (right side) & 32.3 \\
Length of the diastema between p1 and p2 (right side) & 24.9 \\
\hline
\end{tabular}

Tympanic Bulla (TB). The tympanic bulla (sensu Fraser $\&$ Purves 1960) is a paired and extremely dense bone, which has an important role in cetacean hearing. It articulates with both the basicranium and middle ear ossicles. In Recent cetaceans, the tympanic bulla is formed by the ectotympanic, without participation of the entotympanic (Ridewood 1923; Eales 1950). Following these authors, it has been proposed that the tympanic bulla in archaeocetes was entirely formed by the ectotympanic (Lancaster 1990; Luo 1998; Luo \& Gingerich 1999; Uhen 2004; Geisler et al. 2005). Both tympanics are preserved on the holotype of Cynthiacetus peruvianus but the left bulla is better preserved than the right.

In overall shape, the tympanic bulla of Cynthiacetus peruvianus vaguely resembles the shell of an egg-shaped snail (cypraeid gastropod). It is similar to the tympanic bulla of all other basilosaurids in being transversely more inflated than in early neocetes ( $89 \mathrm{~mm}$ long and $66 \mathrm{~mm}$ wide). The tympanic bulla of $C$. peruvianus differs from that of protocetids (Kellogg 1936; Gingerich et al. 1995, 2001b; Hulbert 1998; Geisler et al. 2005), in having a slightly convex medial margin (in protocetids, the medial margin of the bulla is concave).

In ventral or dorsal view, the bulla is somewhat oval to rectangular in outline, with the anterior margin of the tympanic bulla facing anterolaterally and the posterior margin being somewhat concave posteriorly (Figs 23; 24). The ventral surface of the tympanic bulla is smooth and ventrally convex. Posteriorly, the ventral surface is divided into two eminences. The lateral one (outer posterior eminence) is longer, more massive and more compressed transversely than the medial eminence (inner posterior eminence). The posterior eminences are separated by the interprominential notch, which extends anteriorly on the ventral surface of the tympanic, forming the median furrow of the bulla. In MNHN.F.PRU10, the median furrow is less pronounced, shallower than in protocetids and early neocetes. Moreover, it occupies less than $20 \%$ of the tympanic length, ending posterior to the level of the sigmoid process.

The lateral margin of the tympanic bulla is thin and forms the outer lip. It is better preserved on the left side, where it remains however incomplete. The anterior portion of the outer lip bears a dorsal surface that contacts the falciform process of the squamosal (showed in Fig. 24A, B). At about the midlength of the tympanic bulla, the outer lip bears a vertical lateral furrow. The latter is posteromedially oriented and less pronounced than the median furrow. It limits anteriorly the sigmoid process of the tympanic (broken in both bullae). An isolated sigmoid process is preserved and probably belongs to the left tympanic bulla, although the contact with the lateral margin of the bulla is missing (Fig. 23). The sigmoid process is massive, subtubular and U-shaped. It presents a dorsal surface that matches a small fossa on the squamosal, just medial to the postglenoid process (Fig. 16[fsg]). The sigmoid process supports the anterior portion of the tympanic membrane in Recent odontocetes (Mead \& Fordyce 2009). Posterior to the sigmoid process, is a notch, which corresponds to the aperture of the external acoustic meatus (EAM). Posterior to this notch, the conical process is hardly distinguishable. As observed in Dorudon atrox (Uhen 2004), the conical process should support the posterior portion of the tympanic membrane. Near its posterior end, the outer lip bears the lateral (outer) pedicle for the posterior process of the tympanic. Unfortunately, the lateral pedicle is missing in both bullae. The lateral and medial pedicles delimit the posterior cleft.

The medial portion of the tympanic body forms the dense and thick involucrum. The latter becomes more massive and expands transversely backwards, as observed in medial and dorsal views (Fig. 24). Therefore, the involucrum is somewhat triangular and dorsally convex in dorsal and medial views. The anterior and posterior portions of the involucrum are separated by a shallow transverse groove. This transverse groove is closer to the anterior margin of the bulla than to the posterior margin (Fig. 24).

The anteromedial corner of the involucrum presents a flat surface for the contact with the falcate process of the basioccipital. Lateral to this surface, the involucrum bears a low keel, running anteroposterioly along the medial margin of the bulla. This medial keel is probably homologous to the ventromedial keel of modern cetaceans. The medial keel is more accentuated posteriorly and, at the proximity of the posterior margin of the bulla, it turns posterolaterally and runs on the dorsal surface of the involucrum. At this level, the medial keel delimits anteriorly a flat posterior surface. This surface contacts the medial crest of the exoccipital. The medial keel is better developed on the right tympanic than on the left.

Anterior to the posterolateral end of the medial keel is the medial pedicle for the posterior process of the tympanic. Only the base of the medial pedicle is preserved on the left side. As mentioned above, the medial and lateral pedicles form the anterior edge of the posterior cleft, a rectangular foramen opening into the tympanic cavity (cf. below)

In dorsal view, the outer lip and the involucrum are separated by the tympanic cavity. This cavity is anteroposteriorly elongate, dorsally open and contains part of the auditory (Eustachian) tube. The auditory tube enters the tympanic cavity through the posterior cleft (pedicular foramen in Luo \& 

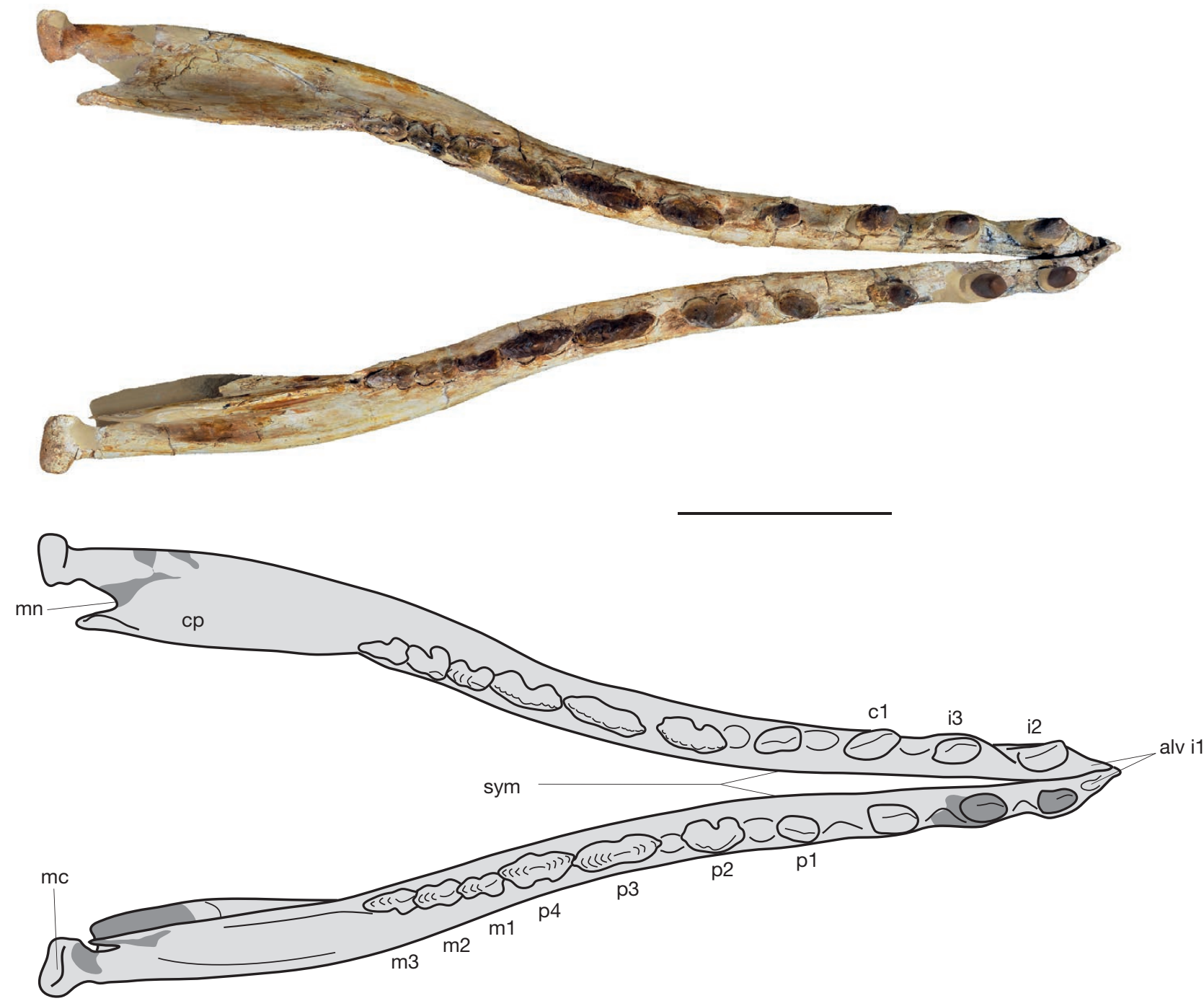

FIG. 25. - Dorsal view of the mandible of MNHN.F.PRU10, holotype of Cynthiacetus peruvianus. Abbreviations: alv i1, alveoli of i1s; cp, coronoid process; mc, mandibular condyle; mn, mandibular neck; sym, symphysis. Dark grey-shaded colored portions indicate the reconstructed parts of the specimen. Scale bar: $20 \mathrm{~cm}$.

Gingerich 1999), which is probably homologous to the elliptical foramen in recent cetaceans. It crosses longitudinally the tympanic cavity and exits through the anterior notch separating the outer lip and the involucrum (Eustachian outlet, also named Eustachian notch or anterior cleft). Like the elliptical foramen of Recent cetaceans (Fraser \& Purves 1960; Kasuya 1973), the posterior cleft may also transmit the posterior sinus (posterior pterygoid sinus in Luo 1998; sinus pneumaticus paroccipitalis in Klaauw 1931) to the paroccipital process. However, the reduced space that may correspond to the posterior sinus area in the peribullar cavity suggests that the posterior sinus was either absent or at least very small in Cynthiacetus peruvianus.

From the ventral margin of the posterior cleft, a single pedicle connects the bulla to its posterior process. This portion is broken in both tympanic bullae and the posterior process of the tympanic bulla remains firmly articulated with that of the periotic. Besides, the posterior process of the tympanic is dorsoventrally thin.
Malleus (Ma). The malleus is the largest and lateralmost element among the middle ear ossicles. It articulates with the incus, the tympanic bulla and the periotic. The malleus of the most common basilosaurids genera (Basilosaurus, Dorudon, Saghacetus, and Zygorhiza) is well documented and the morphology of the bone seems to be relatively homogeneous within the group (Pompeckj 1922; Kellogg 1936; Lancaster 1990; Uhen 2004). Usually, it includes two portions: a globular head and an elongated gonial process. The globular head articulates with the mallear fossa in the periotic, while the elongate gonial process fuses or articulates with the sigmoid process of the tympanic bulla (Pompeckj 1922; Lancaster 1990).

As cited before, the overall shape and the size of a tiny bone found within the stylohyal fossa of the exoccipital are congruent with that of the malleus. However, it is difficult to say which surface of the malleus is ventrally exposed, since hard sediment partly obscures the bone. The exposed surface of the mallear head may be excavated by a large pit (filled with sediment). If this pit serves for the insertion for the tensor tympani 

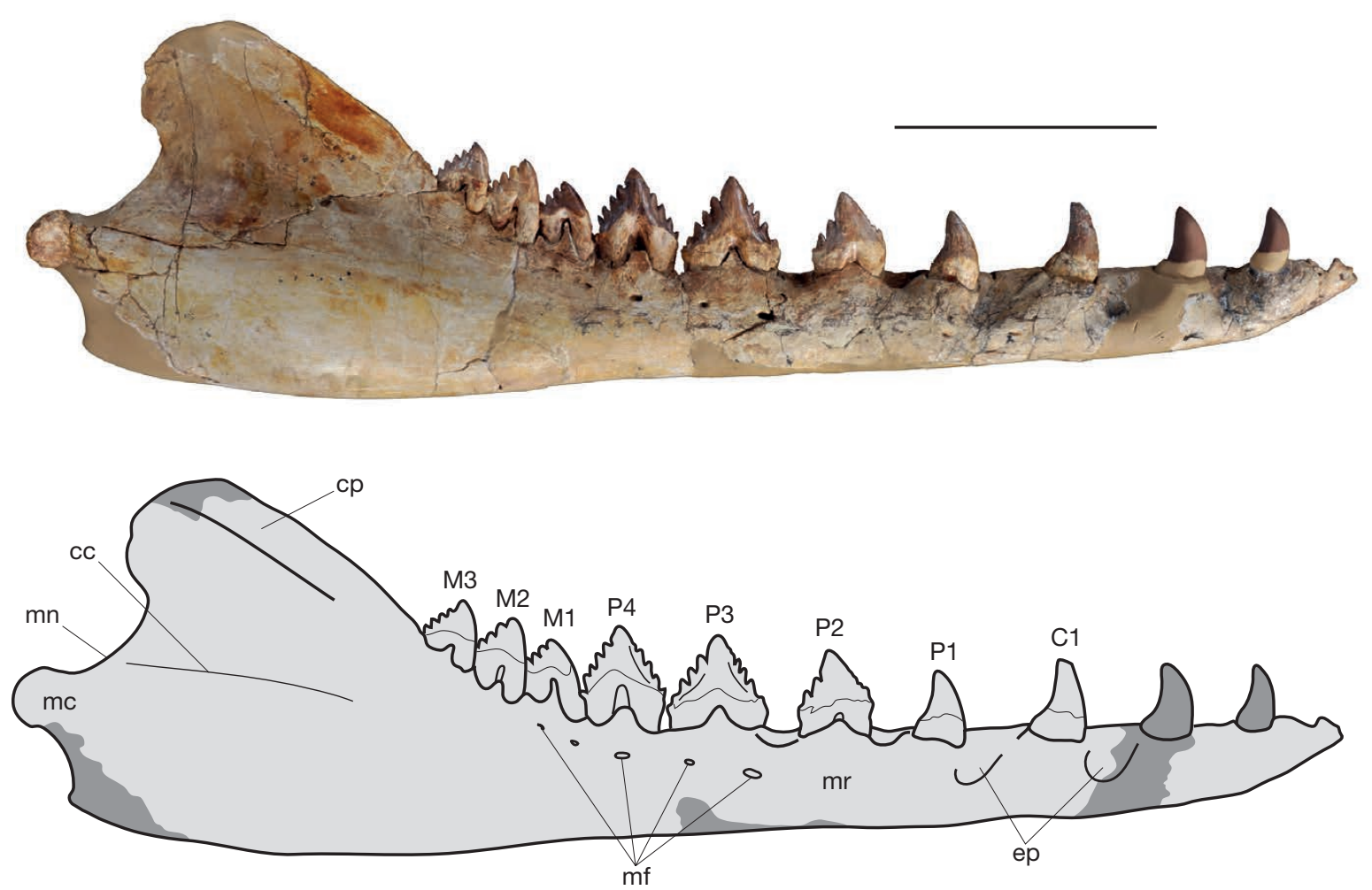

FIG. 26. - Lateral view of the right dentary of MNHN.F.PRU10, holotype of Cynthiacetus peruvianus. Abbreviations: cc, condyloid crest; cp, coronoid process; ep, embrasure pits; $\mathbf{m c}$, mandibular condyle; $\mathbf{m f}$, mental foramina; $\mathbf{m n}$, mandibular neck. Dark grey-shaded colored portions indicate the reconstructed parts of the specimen. Scale bar: $20 \mathrm{~cm}$.

muscle, thus the exposed surface is the posteromedial surface. The position and orientation of the gonial process is also in agreement with this hypothesis. The gonial process is a long and spine-like process, often broken or absent in basilosaurid specimens. In MNHN.F.PRU10, the gonial process seems to be intact; it is as long as the maximum breadth in the head.

\section{Mandible}

Both dentaries of the holotype are preserved and almost complete (Figs 25, 26, 27). The dentary can be divided into an anterior alveolar portion, which bears the teeth (horizontal ramus or corpus mandibularis), and a high and well-developed posterior portion, which bears the condylar and coronoid processes (vertical ramus or ramus mandibularis). The dentary of Cynthiacetus peruvianus is neither tubular and laterally convex as in recent mysticetes nor almost straight as in many odontocetes; as observed in other basilosaurids, it is laterally concave and transversely compressed (Fig. 25). Measurements of the dentary are presented in Table 4. The lateral concavity of the dentary is accentuated at the level of the third and fourth lower premolars (p3-p4). As in all other basilosaurids, both dentaries meet at midline anteriorly along the mandibular symphysis. The symphyseal surface is flat and extends posteriorly up to the level of the diastema between $\mathrm{p} 1$ and $\mathrm{p} 2$. The symphysis is unfused and both dentaries were hold together by a strong symphyseal ligament. This can be inferred by the long and longitudinal scars observed in the symphyseal surface (Fig. 27). The lateral surface of the dentary is strongly dorsoventrally convex, smooth and presents numerous small mental foramina (Fig. 26), from the level of p2 up to the level of $\mathrm{m} 1$. The largest mental foramen is located below the anterior root of $\mathrm{p} 3$.

The dentary of Cynthiacetus peruvianus bears alveoli for 11 teeth. The lower dental formula is the same as that observed in other basilosaurids ( 3 incisors, 1 canine, 4 premolars and 3 molars). All teeth are aligned anteroposteriorly. The five anterior alveoli (for i1-p1) are almost circular and house single-rooted teeth, except for $\mathrm{p} 1$, which is probably double-rooted. The anteriormost alveolus (corresponding to i1) is much smaller than the others and more anteriorly oriented. The alveoli for i2-c1 are slightly laterally oriented, while the alveoli for p1-m3 are roughly vertical. The posterior six alveoli (for $\mathrm{p} 2-\mathrm{m} 3$ ) are anteroposteriorly elongated and house double-rooted teeth. The seven anterior alveoli (for i1-p3) are separated by diastemata. The diastemata between $\mathrm{i} 1-\mathrm{i} 2$ and $\mathrm{i} 2-\mathrm{i} 3$ are the shortest ones and subequal in length. They are followed, in ascending order, by the diastemata between $\mathrm{p} 2$ and $\mathrm{p} 3$, between $\mathrm{p} 1$ and $\mathrm{p} 2$, and between $\mathrm{i} 3$ and $\mathrm{c} 1$. Finally, the longest diastema is that between $\mathrm{c} 1$ and $\mathrm{p} 1$ (Table 4). The four posterior alveoli (corresponding to $\mathrm{p} 3-\mathrm{m} 3$ ) are not separated by diastemata. As for the rostrum, the mandible presents a natural torsion to the left and thus the diastemata are slightly longer anteroposteriorly on the right side. However, this torsion is less marked than in the skull, since the mandible was not distorted during fossilization. As observed on the upper jaw, the diastemata present embrasure pits, except for the anterior diastema between il 

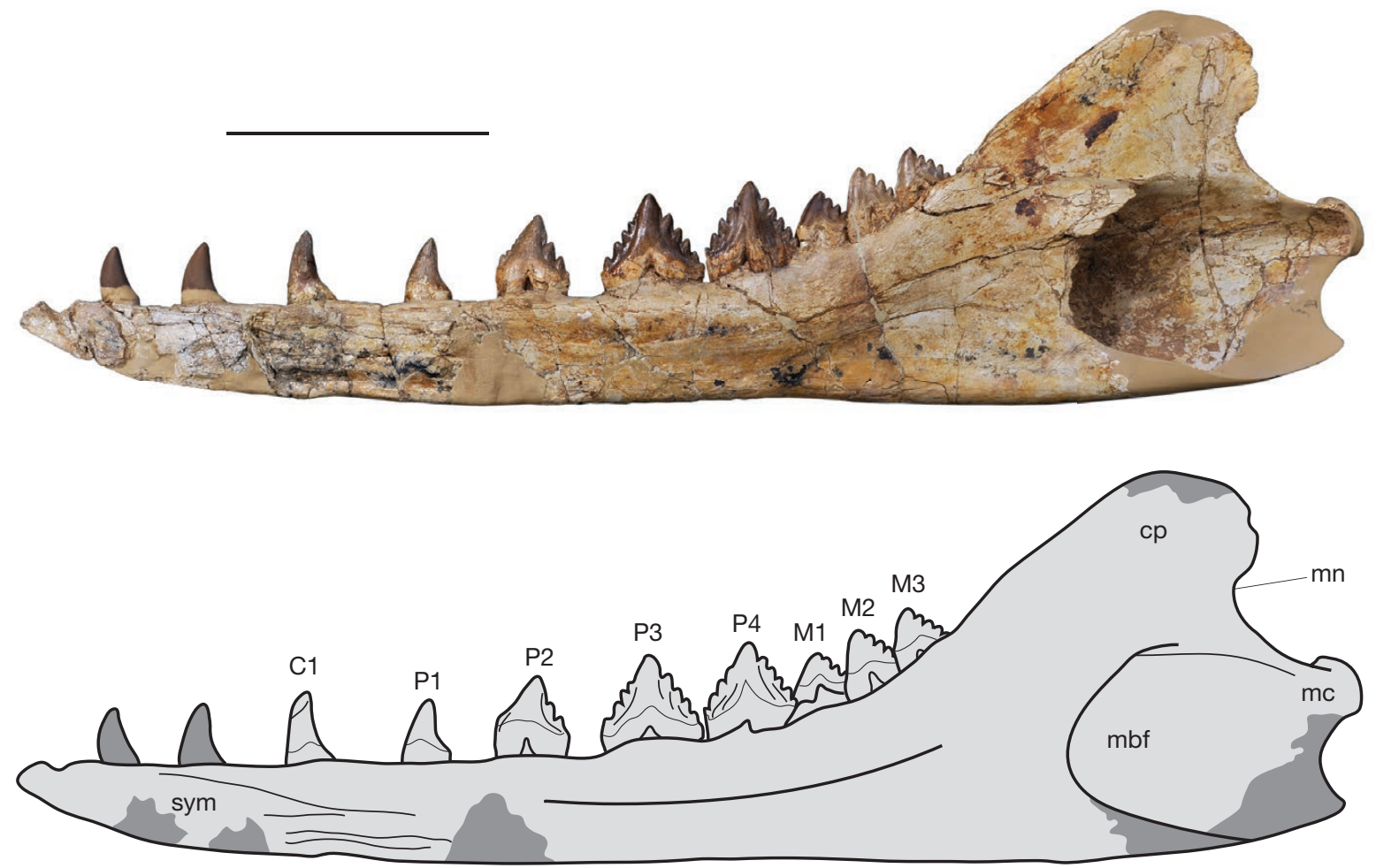

FIG. 27. - Medial view of the right dentary of MNHN.F.PRU10, holotype of Cynthiacetus peruvianus. Abbreviations: cp, coronoid process; mbf, mandibular foramen; mc, mandibular condyle; mn, mandibular neck; sym, symphysis. Dark grey-shaded colored portions indicate the reconstructed parts of the specimen.

and i2. The embrasure pits receive the crowns of upper teeth when the jaws are closed. The three anterior embrasure pits (between i2 and p1) are laterally open and lateral to the dental row, while the two posterior embrasure pits (between $\mathrm{p} 1$ and p3) are laterally closed and aligned with the dental row.

In lateral and medial views, the anterior end of the ventral margin of the dentary faces anteroventrally and forms an acute angle with the dorsal margin of the dentary. Posterior to the level of i2, both ventral and dorsal margins are subparallel. The ventral margin of the dentary is straight on most of the length of its horizontal ramus. It slightly turns dorsally posterior to the level of the anterior root of the coronoid process. The posterior end of the ventral margin of the dentary forms the angular process of the dentary, a region that is missing in both dentaries of the holotype of $C$. peruvianus.

The height of the horizontal ramus slightly increases posteriorly from its apex up to the level of the alveolus of the anterior root $\mathrm{p} 4$; then it increases more markedly,and below $\mathrm{m} 3$ it is approximately twice that below $\mathrm{p} 1$. Posterior to $\mathrm{m} 3$, the anterior sharp crest of the coronoid process raises regularly posteriorly up to its rounded apex. The anterior crest of the coronoid process is straight to slightly convex, while its posterior edge is deeply concave; this condition gives to the process a posteriorly deflected morphology, with a wide and semicircular apex. The coronoid process of Cynthiacetus peruvianus is more elevated than in any Recent cetacean. Its apex is located well above the root of $\mathrm{m} 3$, as its height makes two thirds of the height of the dentary below m3. (Fig. 27). A well-developed crest lies on the lateral surface of the coro- noid process, parallel to its anterior margin and probably corresponding to an insertion area for the M. temporalis pars superficialis. The medial surface of the process is very rough and probably received the insertion of the $M$. temporalis pars profundus. The posterior margin of the process forms the mandibular notch, which separates the apex of the process from the mandibular neck. The latter is short and bears a wider than high mandibular condyle. In posterior view, the condyle is roughly rectangular, with a strongly convex ventral edge. The condyle is posterodorsally oriented and articulates with the glenoid fossa of the squamosal.

At the level of the mandibular notch, the condyloid crest (Fig. 26) extends anteriorly on the lateral surface of the coronoid process. It is not as developed as the crest for the superficial portion of the temporal muscle (see above) and probably received the $M$. masseter pars profundus. The superficial portion of the masseter muscle ( $M$. masseter pars superficialis) most likely inserted on the angular process of the dentary, also an area of insertion of the $M$. digastricus.

Ventral to the coronoid process and on the medial surface of the dentary is a large mandibular foramen, the largest diameter of which is half the greatest height of the vertical ramus. The mandibular foramen is the posterior opening of the mandibular canal (Fig. 26), and the mandibular foramen and mandibular canal transmit the mandibular nerve (branch of the trigeminal cranial nerve, V3) and associated vessels. As in other archaeocetes (except pakicetids) and early neocetes, the large mandibular foramen of MNHN.F.PRU10 is higher than wide. 
TABLE 5. - Main dental measurements and accessory denticles in the dentition of MNHN.F.PRU10, holotype of Cynthiacetus peruvianus.

\begin{tabular}{|c|c|c|c|c|c|c|c|c|c|c|}
\hline \multirow[b]{2}{*}{ Tooth } & \multicolumn{2}{|c|}{ Length (mm) } & \multicolumn{2}{|c|}{ Width (mm) } & \multicolumn{2}{|c|}{ Height (mm) } & \multicolumn{2}{|c|}{ Mesial denticles } & \multicolumn{2}{|c|}{ Distal denticles } \\
\hline & Left & Right & Left & Right & Left & Right & Left & Right & Left & Right \\
\hline 11 & 27 & 28 & 21 & 20 & $?$ & $?$ & 0 & 0 & 0 & 0 \\
\hline 12 & - & 36 & - & 23 & - & 46 & 0 & 0 & 0 & 0 \\
\hline 13 & 31 & 34 & 23 & 24 & 44 & $42 e$ & 0 & 0 & 0 & 0 \\
\hline $\mathrm{C} 1$ & 40 & 40 & 27 & 27 & $>46$ & $?$ & 0 & 0 & 0 & 0 \\
\hline P1 & 32 & 36 & 21 & 21 & 31 & $>25$ & 2 & 2 & 0 & 0 \\
\hline $\mathrm{P} 2$ & 67 & 61 & 28 & 28 & 48 & 44 & 3 & 3 & 4 & 4 \\
\hline P3 & 70 & 67 & 33 & 31 & 47 & 45 & 3 & 3 & 3 & 3 \\
\hline P4 & 59 & 57 & 21 & 22 & 34 & 33 & 2 & 2 & 3 & 3 \\
\hline M1 & 34 & 33 & 11 & 12 & 15 & 15 & 2 & 2 & 3 & 3 \\
\hline M2 & 31 & 31 & 10 & 9.5 & 14 & 12 & 1 & 1 & 3 & 3 \\
\hline$i 1$ & - & - & - & - & - & - & - & - & - & - \\
\hline i2 & 34 & - & 22 & - & 40 & - & 0 & - & 0 & - \\
\hline i3 & $>30$ & - & 21 & - & 43 & - & 0 & - & 0 & - \\
\hline c1 & 36 & 31 & 24 & 24 & 50 & 50 & 0 & 0 & 0 & 0 \\
\hline p1 & $>37$ & 38 & 22 & 21 & 42 & 40 & 0 & 0 & 0 & 0 \\
\hline p2 & 65 & 58 & 21 & 22 & 43 & 44 & 2 & 2 & 3 & 3 \\
\hline p3 & 83 & 81 & 23 & 20 & 41 & 43 & 4 & 4 & 4 & 4 \\
\hline p4 & 73 & 71 & 22 & 21 & 38 & 41 & 4 & 4 & 5 & 5 \\
\hline $\mathrm{m} 1$ & $40 e$ & $38 e$ & 20 & 18 & 25 & 26 & 0 & 0 & 4 & 4 \\
\hline $\mathrm{m} 2$ & 41 & 42 & 21 & 20 & 31 & 32 & 0 & 0 & 4 & 4 \\
\hline $\mathrm{m} 3$ & 45 & 43 & 20.5 & 21 & 29 & 33 & 0 & 0 & 4 & 4 \\
\hline
\end{tabular}

\section{Dentition}

The holotype of Cynthiacetus peruvianus has the permanent dentition of a young adult individual; lower and upper molars have erupted, but do not present any marked wear surfaces. The dental formula is the same as that of other basilosaurids (3I-1C-4P-2M/3i-1c-4p-3m). As stated above, the anterior teeth (I1-P3 and i1-p3) are separated by diastemata. In contrast, the series $\mathrm{P} 3-\mathrm{M} 2$ and $\mathrm{p} 3-\mathrm{m} 3$ are continuous and have no diastema. All the teeth of MNHN.F.PRU10 are preserved within the alveoli except for the right i1-i3 and left first i1, which have been either lost prior to fossilization (right and left i1) or destroyed by weathering (right i2-3). Moreover, the first upper incisors and the right upper canine are broken and lack their respective apices. Similarly, the left upper second incisor lacks a portion of its crown.

The dentition of Cynthiacetus peruvianus can be separated into four different morphologies: a) conical and slightly labiolingually compressed teeth (I1-P1/i1-p1, Fig. 28A); b) large, triangular in labial view, and strongly labiolingually compressed teeth, with cutting accessory denticles on both mesial and distal edges (P2-P4/p2-p4, Fig. 28B); c) small, blunt in labial view, and labiolingually compressed teeth, with small accessory denticles on both mesial and distal edges (M1 and M2, Fig. 28C); and d) small, triangular in labial view, and labiolingually compressed teeth, with accessory denticles only on the distal edge (m1-m3, Fig. 28D). Dental measurements and the number of mesial and distal accessory denticles are presented in Table 5.

Upper dentition. The upper incisors (I1-I3), are single rooted and have a conical crown. While I1 has an almost rounded cross-section, I 2 and I 3 are slightly labiolingually compressed. The enamel of the three incisors is strongly wrinkled on both the labial and lingual surfaces. I1 is slightly smaller than the other upper incisors and probably had a relatively straight crown, as far as it can be inferred from the remaining portion of the crown. In contrast, the large I 2 and I 3 are sub-equal in size and have a distally curved crown (Fig. 29). No cingulum is observed, neither labial nor lingual, on any incisor. I1 is anteroventrally directed (procumbent), while I 2 and I3 are more ventrolaterally directed.

The upper canine (Fig. 29[C]) is the most anterior tooth of the maxilla. Its alveolus is located just posterior to the $\mathrm{Mx}-\mathrm{PMx}$ suture. $\mathrm{C}$ is single-rooted and more labiolingually compressed than the incisors. Better preserved on the left side, its crown is distally curved. As compared with the incisors, the upper canine is mesiodistally longer and higher. Its enamel is strongly wrinkled, with numerous vertical ridges on the labial and lingual sides. Besides, the tooth bears sharp mesial and distal carinae, separating the lingual and labial surfaces. The tooth bears no cingulum or accessory denticles.

The crown of $\mathrm{P} 1$ differs from that of more posterior premolars in being conical and distinctly smaller in every dimension. Moreover, its crown is slightly curved distally and has no accessory denticle on mesial and distal edges. As compared with the upper canine and the third incisor, the crown of P1 is mesiodistally shorter and dorsoventrally lower. Its distal edge is concave and bears two small humps that cannot be considered as accessory denticles. The labial and lingual surfaces of $\mathrm{P} 1$ are heavily striated but these striations are less abundant than on the upper canine. P1 has no cingulum. The base of the root of P1 is exposed outside the alveolus; it is labiolingually inflated and a sulcus can be observed on its lingual surface, as observed in other archaeocetes (e.g. Basilosaurus cetoides and Georgiacetus vogtlensis). This condition denotes the separation of the single root of earlier 


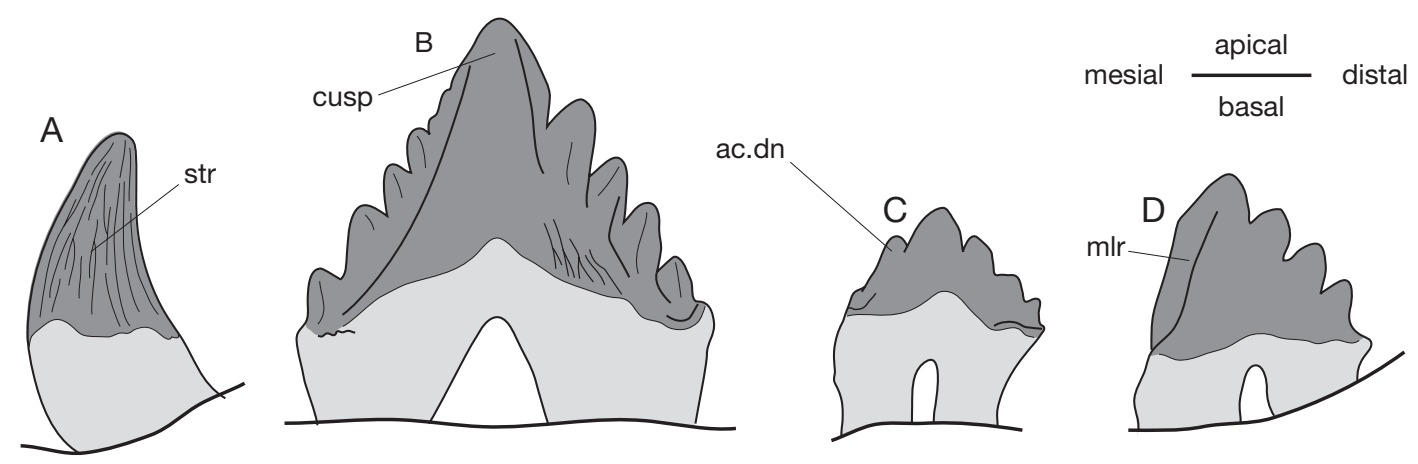

FIG. 28. - Dental morphologies observed in Cynthiacetus peruvianus and other basilosaurids: A, conical single-rooted caniniform tooth (left c1 in labial view); B, large, triangular and double-rooted premolar (right p4 in lingual view); C, small, blunt and double-rooted upper molar (right M1 in lingual ciew); and D, small, triangular and double rooted lower molar (lacking accessory denticles in the mesial margin). Abbreviations: ac.dn, accessory denticle; cusp, central cusp (homologous of the paracone in the upper teeth and of the protoconid in lower teeth); mlr, mesiolingual ridge; str, vertical striations, abundant in caniniform teeth. All drawings at same scale.

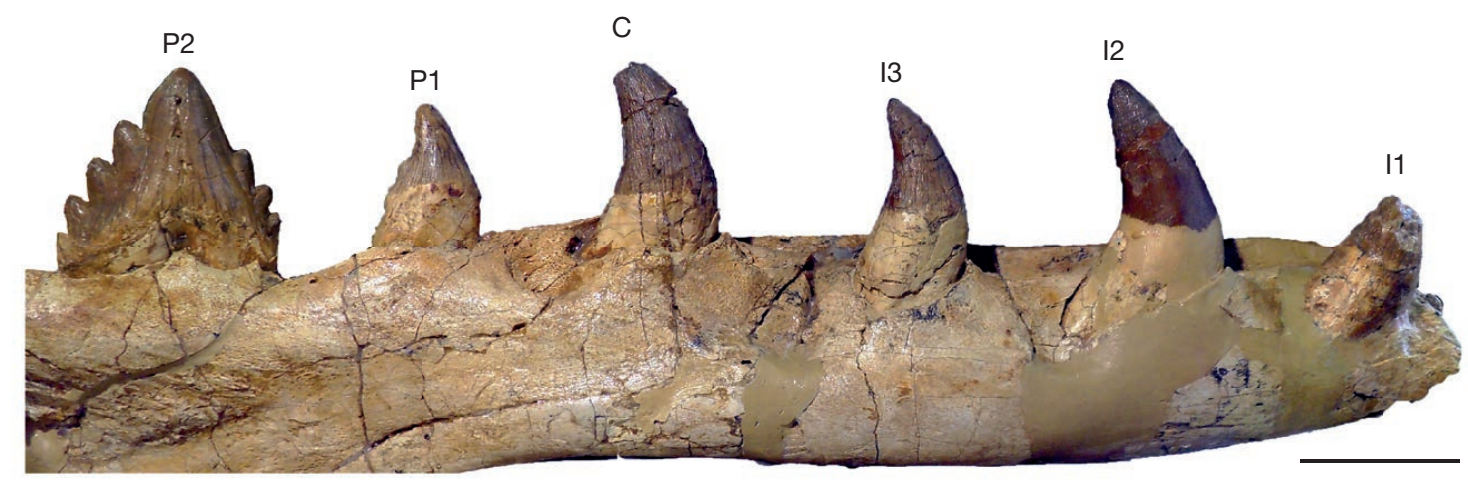

FIG. 29. - Labial view of the anterior left upper teeth (incisors and first premolars, I1-P2) of MNHN.F.PRU10, holotype of Cynthiacetus peruvianus. Scale bar: 5 cm.

archaeocetes into two coalescent roots. A similar condition is also probably present in MMNS VP 445 (holotype of Cynthiacetus maxwelli), where the outline of the alveolus for P1 suggests the presence of a sulcus on both the labial and lingual surfaces of the corresponding tooth. Uhen (2004) points out that Dorudon atrox has a single-rooted P1. However, the alveolus for P1 in UM 101222 (an adult specimen of $D$. atrox) also displays a median ridge on both its medial and lateral edges, indicating the presence of sulci on the root of the corresponding tooth.

In labial and lingual views, the posterior upper premolars (P2-P4) are triangular and have a pointed apex (Figs 29, 30). It has been hypothezised that the apex or main cusp of the premolars and molars is the paracone (Uhen 2004). These three posterior premolars are transversely compressed and have two divergent roots. P2 and P3 are sub-equal in size (P2 being only slightly longer) and are the mesiodistally longest and highest teeth in the upper dentition. P4 is smaller than $\mathrm{P} 2$ and $\mathrm{P} 3$ for all dimensions. In $\mathrm{P} 3$ and $\mathrm{P} 4$, the distal root is transversely wider than the mesial root, and the former presents a lingual inflation, which may result from the fusion of the two distal roots observed in more derived protocetids (Georgiacetus vogtlensis has P3-M3 with one mesial root and two distal roots). The enamel in P2-P4 is considerably less striated than in more anterior teeth, especially on the labial surface, where the enamel is smooth and striped (Figs 29, 30).
A hint of cingulum is present only in the distalmost region of P2-P4. This cingulum is less pronounced than in Zygorbiza kochii, resembling more the condition in Dorudon atrox.

The second, third and fourth premolars (P2-P4) have large accessory denticles on the medial and distal edges (Table 5). The accessory denticles increase in size towards the main cusp, which is located at the same mesiodistal level as the separation between the roots. The accessory denticles are larger on the distal edge than on the mesial, and the highest accessory denticle is on the distal margin. The distal margin of P2 bears small serrations between the main cusp and the highest accessory denticle.

The two upper molars (M1 and M2) are smaller in all dimensions than any upper premolar. They are subequal in size, M2 being slightly smaller than M1. In labial and lingual views, their crown is much lower than that of the premolars and forms a triangle, distinctly mesiodistally longer than high. As observed on the premolars, the upper molars are doublerooted and labiolingually compressed, with the distal root lingually inflated at its base. The lingual expansion of the distal root is probably the result of the fusion of the distolabial and distolingual roots. A reduced cingulum is present on the distal edge of the tooth, dorsal to the most basal accessory denticle. The mesial and distal edges of the molars present proportionally large accessory denticles, which increase in size from the base of the crown towards the apex. 


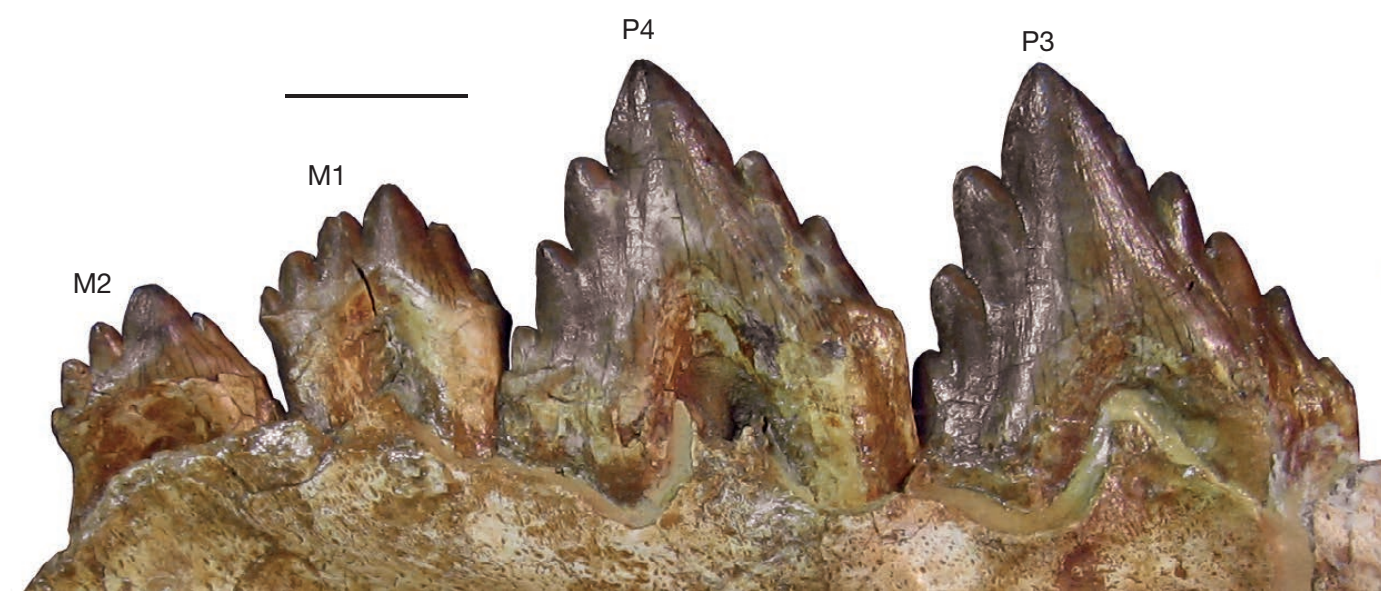

FIG. 30. - Labial view of the posterior left upper teeth (posterior premolars and upper molars, P3, P4) of MNHN.F.PRU10, holotype of Cynthiacetus peruvianus. Scale bar: $2.5 \mathrm{~cm}$.

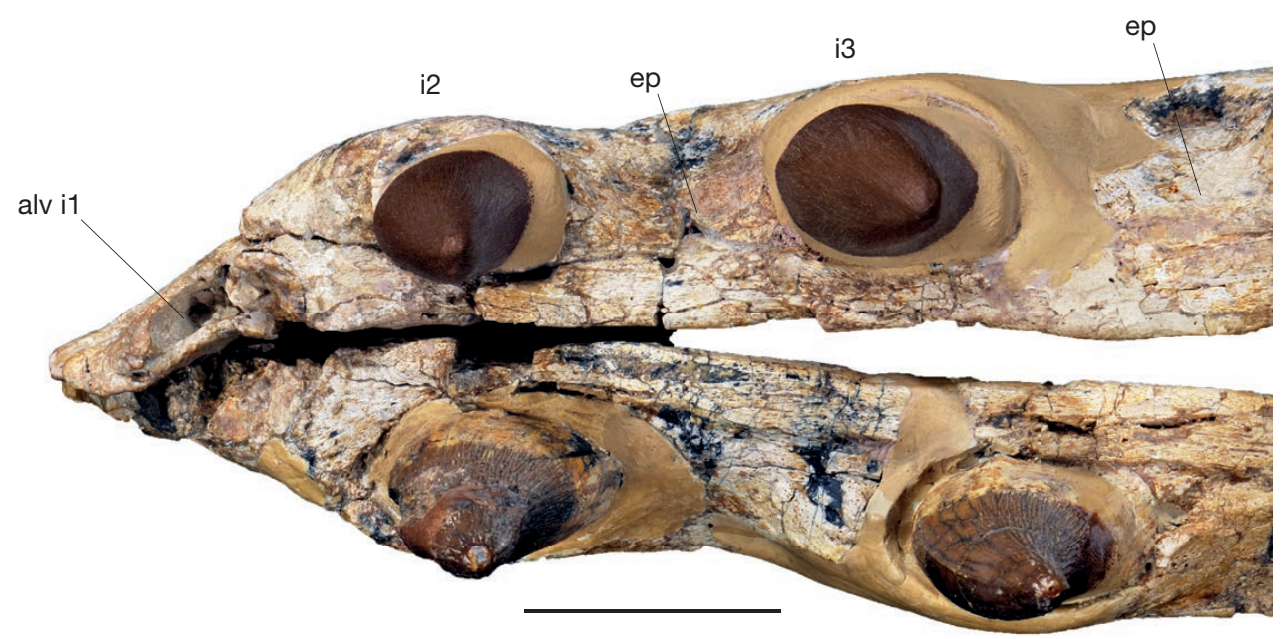

FIG. 31. - Occlusal view of the lower incisors of MNHN.F.PRU10, holotype of Cynthiacetus peruvianus. Abbreviations: alv, alveolus for i1; ep, embrasure pits. Scale bar: $3 \mathrm{~cm}$.

Lower dentition. The first lower incisor (i1) is missing in both dentaries and only its alveolus is preserved (Fig. 31). As observed in other basilosaurids, the alveolus for i1 is in close proximity with the alveolus for the second lower incisor (i2). According to the size of the alveoli, it is clear that i1 is the smallest tooth of MNHN.F.PRU10 (upper and lower dentition). As a consequence of its small size and anterior position, i1 is often missing in basilosaurid specimens. Based on the size of the alveoli, it seems that Cynthiacetus peruvianus had a slightly smaller il than Zygorhiza kochii and Dorudon atrox. A similar condition is observed on the holotype of Cynthiacetus maxwelli, in which only the alveolus of the left il is preserved.

The second and third lower incisors (i2 and i3) are subequal in size (i3 being slightly larger than i3), single-rooted, and strongly resemble the upper incisors (Figs 31; 32). Their crown is conical, slightly compressed labiolingually and distally curved. As for the upper incisors, their enamel is strongly wrinkled, with subvertical ridges on the lingual and labial surfaces. Such ridges are accentuated towards the apex of the crown. The teeth bear neither accessory denticle nor cingulum.
The lower canine (c) is single-rooted. Its crown is conical and slightly curved distally (Fig. 32). As compared to i3, the crown of the canine is higher and more labiolingually compressed. Its enamel is wrinkled and has no accessory denticle and cingulum. As a matter of fact, the crowns in the dental series i2-c1 resemble strongly to the crowns in the corresponding upper teeth (I2-C1). Nevertheless, the isolated teeth of Cynthiacetus maxwelli, allow distinguishing between upper and lower teeth. In that species the angle formed by the root and the crown is larger in the lower canine than in the upper canine, a condition that could not be observed in $C$. peruvianus, whose teeth are all in situ in their respective bones.

The first lower premolar (p1) is considerably smaller than the posterior premolars. Its crown is conical and its distal edge is slightly concave (Fig. 32). Its size and proportions are similar to $\mathrm{i} 3$. It is lower than $\mathrm{c} 1$, but similarly labiolingually compressed. Its enamel is slightly less wrinkled than in $\mathrm{cl}$ and i3. The crown has no cingulum. While no accessory denticle is observed on the mesial edge, a single accessory denticle lies on the distal edge, near the base of the crown. The root is not 

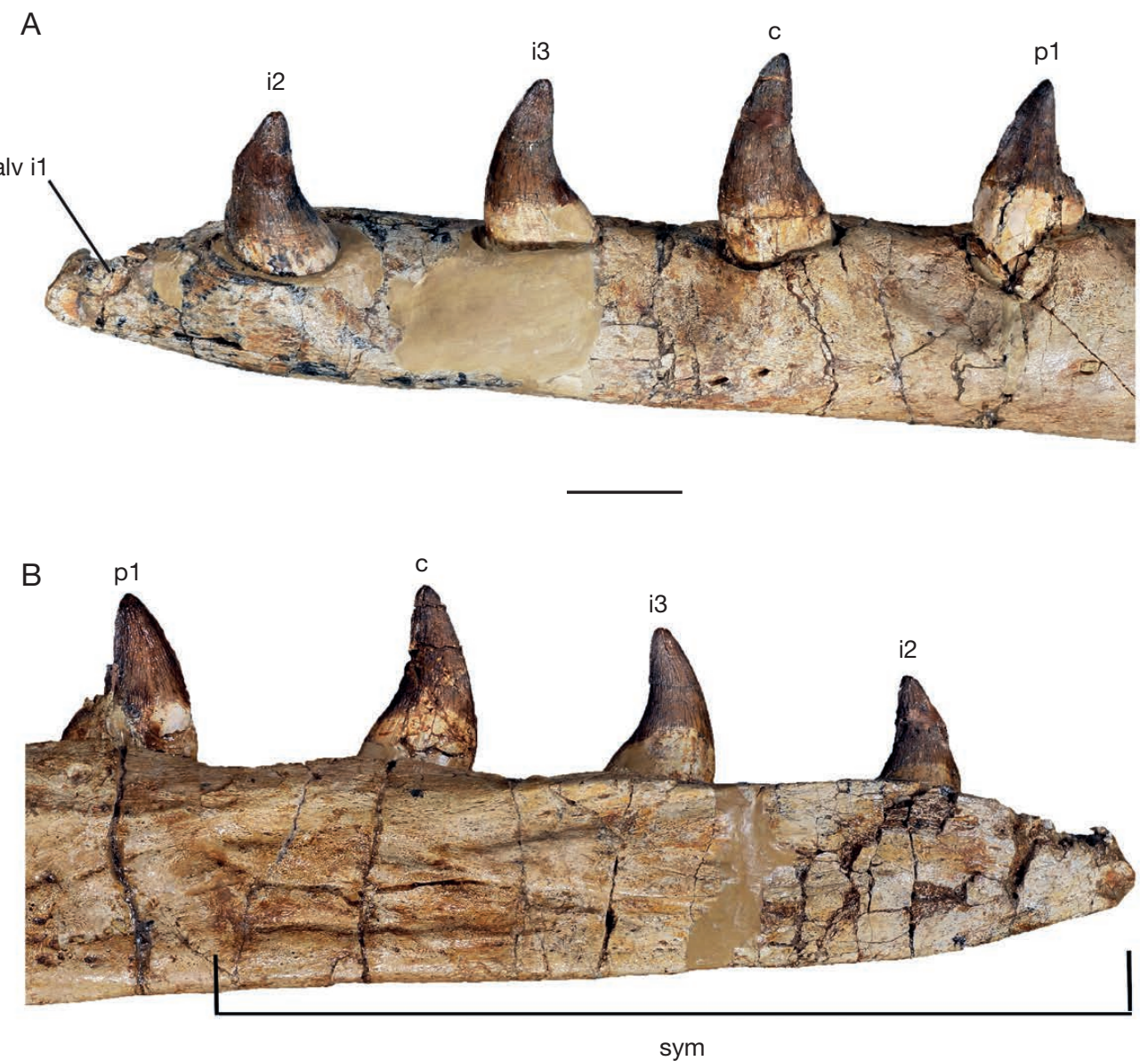

FIG. 32. - Labial (A) and lingual (B) views of the anterior lower (i2-p1) teeth in the left dentary of MNHN.F.PRU10, holotype of Cynthiacetus peruvianus. Abbreviations: alv, alveolus; sym, symphyseal surface. Scale bar: $3 \mathrm{~cm}$.

exposed but may have been double, since the crown expands mesially and distally at its base. In most basilosaurids, p1 is double-rooted and the roots can be divergent or coalescent. If $\mathrm{p} 1$ is double-rooted in MNHN.F.PRU10, then the roots should be coalescent.

As for the anterior teeth, the posterior lower premolars (p2-p4) are also somewhat similar to the posterior upper premolars (P2-P4). They are double-rooted, triangular in labial and lingual views, and strongly labiolingually compressed (Fig. 33). The crown of $\mathrm{p} 2$ is slightly curved distally, while those of $\mathrm{p} 3$ and $\mathrm{p} 4$ are straight. Both mesial and distal edges present large accessory denticles. The cingulum is only developed in the distal region, where it does not form an accessory denticle. The accessory denticles increase in size towards the apex on the distal edge and towards the base on the mesial edge. In overall shape, the accessory denticles are larger along the distal edge. The most apical accessory denticle on the distal edge is closer to the main cusp than the most apical accessory denticle on the mesial edge. Moreover, on the crown of p2-p4, two small serrations separate the most apical distal accessory denticle from the main cusp. While the enamel of $\mathrm{p} 2$ is less wrinkled than in i2-p1, the posterior premolars (p3-p4) present smooth enamel with a few subvertical large ridges. The crown of $\mathrm{p} 3$ and $\mathrm{p} 4$ in Cynthiacetus peruvianus is higher than in the holotype of $C$. maxwelli (cf. Discussion). Their distal root is not lingually expanded as in the upper premolars.

The lower molars $(\mathrm{m} 1-\mathrm{m} 3)$ are considerably smaller than the posterior premolars in all dimensions. They are similar in morphology and subequal in size, $\mathrm{m} 1$ being slightly mesiodistally shorter and lower than $\mathrm{m} 2$ and $\mathrm{m} 3$. In lateral view, their crown is an asymmetrical triangle, with the apex slightly shifted mesially. They are strongly compressed transverselly. Their enamel is smooth and not wrinkled. Four accessory denticles are observed on the distal edge of all lower molars, but none are present along the mesial edge, which is transversely wider than the distal edge. As in other basilosaurids, the mesolingual corner of the crown forms a sharp ridge. Labial to this mesolingual ridge, a notch houses the most distal accessory denticle of the preceding tooth. Therefore, the mesial notch in $\mathrm{m} 1-\mathrm{m} 3$ receives the distal accessory denticle and cingulum of $\mathrm{p} 4-\mathrm{m} 2$, respectively. At the base of the crown, the mesial notch continues into the root. In contrast to the lower premolars, the mesial root is transversely inflated and presents a labial expansion. Finally, an incipiently developed cingulum is observed in the distal region, but only for the lingual surface. This cingulum forms the base of the smallest accessory denticle on the distal edge of the crown. 

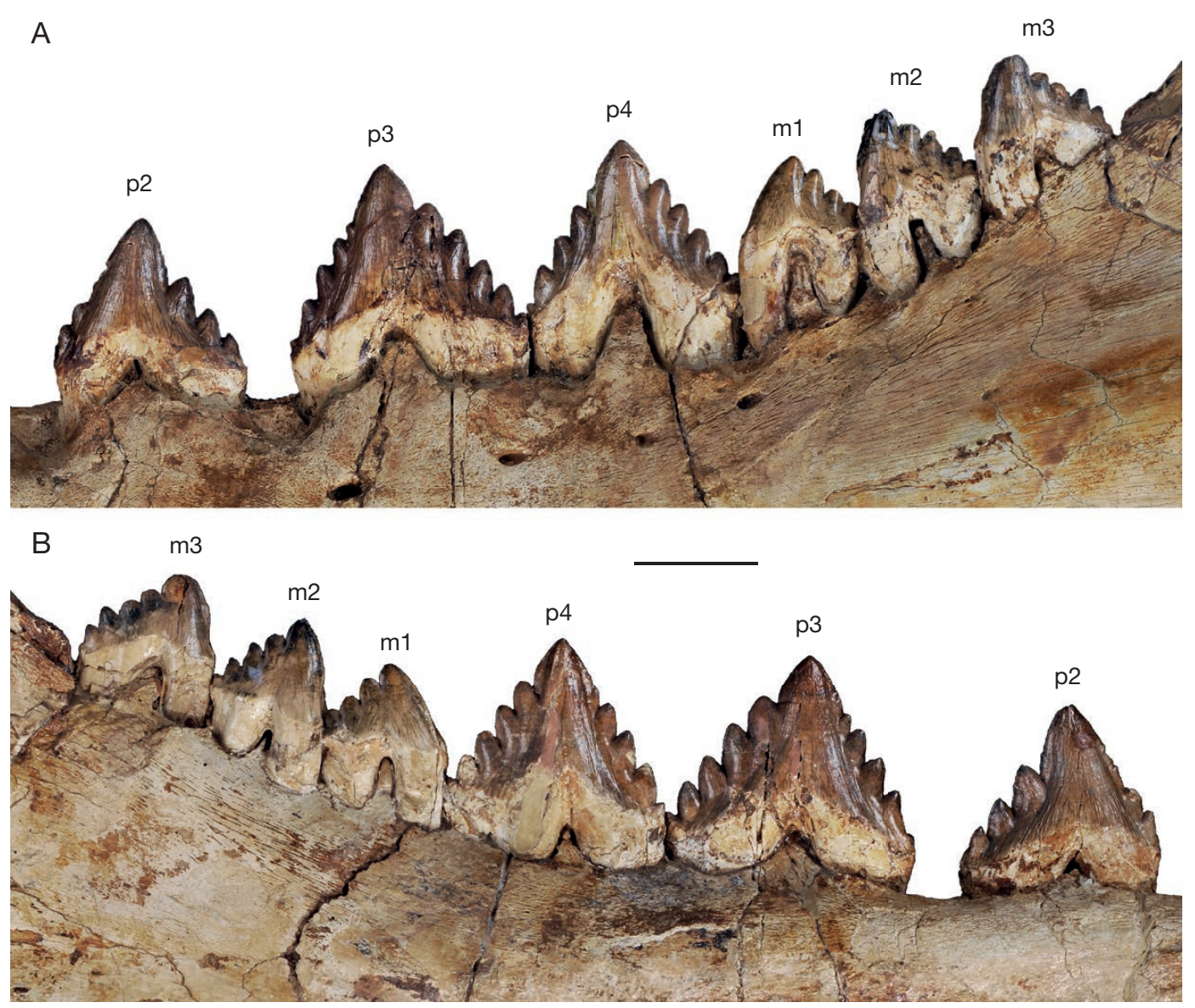

FIG. 33. - Labial (A) and lingual (B) views of the posterior lower teeth in the left dentary of MNHN.F.PRU10, holotype of Cynthiacetus peruvianus. Scale bar: 4 cm.

\section{POSTCRANIAL SKELETON}

\section{Hyoid apparatus}

The hyoid apparatus is well preserved in MNHN.F.PRU10. It includes the basihyal and two paired elements, the thyrohyals and stylohyals. The articulations and the natural position of the hyoid apparatus are shown in Figure 34. In overall view, the hyoid apparatus of Cynthiacetus peruvianus strongly resembles that of other known basilosaurids (Kellogg 1936; Uhen \& Gingerich 2001; Uhen 2004).

Stylohyal (Fig. 35). The paired stylohyal is the longest and most anterodorsal element (length $=33.5 \mathrm{~cm}$ for the right bone and $34 \mathrm{~cm}$ for the left). Proximally, it likely had a cartilaginous contact with the fossa on the ventral margin of the paroccipital process of the exoccipital. This cartilage is probably homologous to the tympanohyal. Distally, the stylohyal has a cartilaginous contact with the anterolateral corner of the basihyal.

The body of the stylohyal is a long and slender stick (19.5 and $20 \mathrm{~mm}$ wide in right and left stylohyals, respectively). Most of the body is dorsoventrally compressed. This results in an oval cross-section, which contrasts with the more rounded cross-section of the proximal and distal ends. The body of the stylohyal is smooth and lacks any crest or foramen. In dorsal or ventral view, the body is slightly convex laterally. Both the proximal and distal extremities are deeply concave and present a rough surface for the cartilaginous contact.

Basihyal (Fig. 36A, B). The single basihyal is the median element of the hyoid apparatus. It articulates anterolaterally with the stylohyal and posterolaterally with the thyrohyal. As in other basilosaurids, the basihyal is transversely wider than long (length at midline $=42 \mathrm{~mm}$, transverse width $=82 \mathrm{~mm}$ ).

Both the anterior and posterior margins are strongly concave, forming two pronounced median notches. In contrast, the lateral margins are highly convex laterally and are anteroposteriorly longer than along the midline (64 and $66 \mathrm{~mm}$ long on right and left side, respectively). Consequently, the basihyal is double-axe shaped in dorsal and ventral views. The ventral and dorsal surfaces of the basihyal are smooth.

In lateral view, the basihyal is broader in its posterior half, where its posterolateral corner contacts the proximal end of the thyrohyal. The foveae for the stylohyal are not well preserved but are considerably smaller than those for the thyrohyals. The foveae for the thyrohyals are roughly teardrop-shaped.

Thyrohyal (Fig. 36D, E). The paired thyrohyal is the distalmost bony element of the hyoid apparatus. It contacts proximally the basihyal and distally the thyroid cartilage. It is more robust than the stylohyal, being thicker and more rounded in 

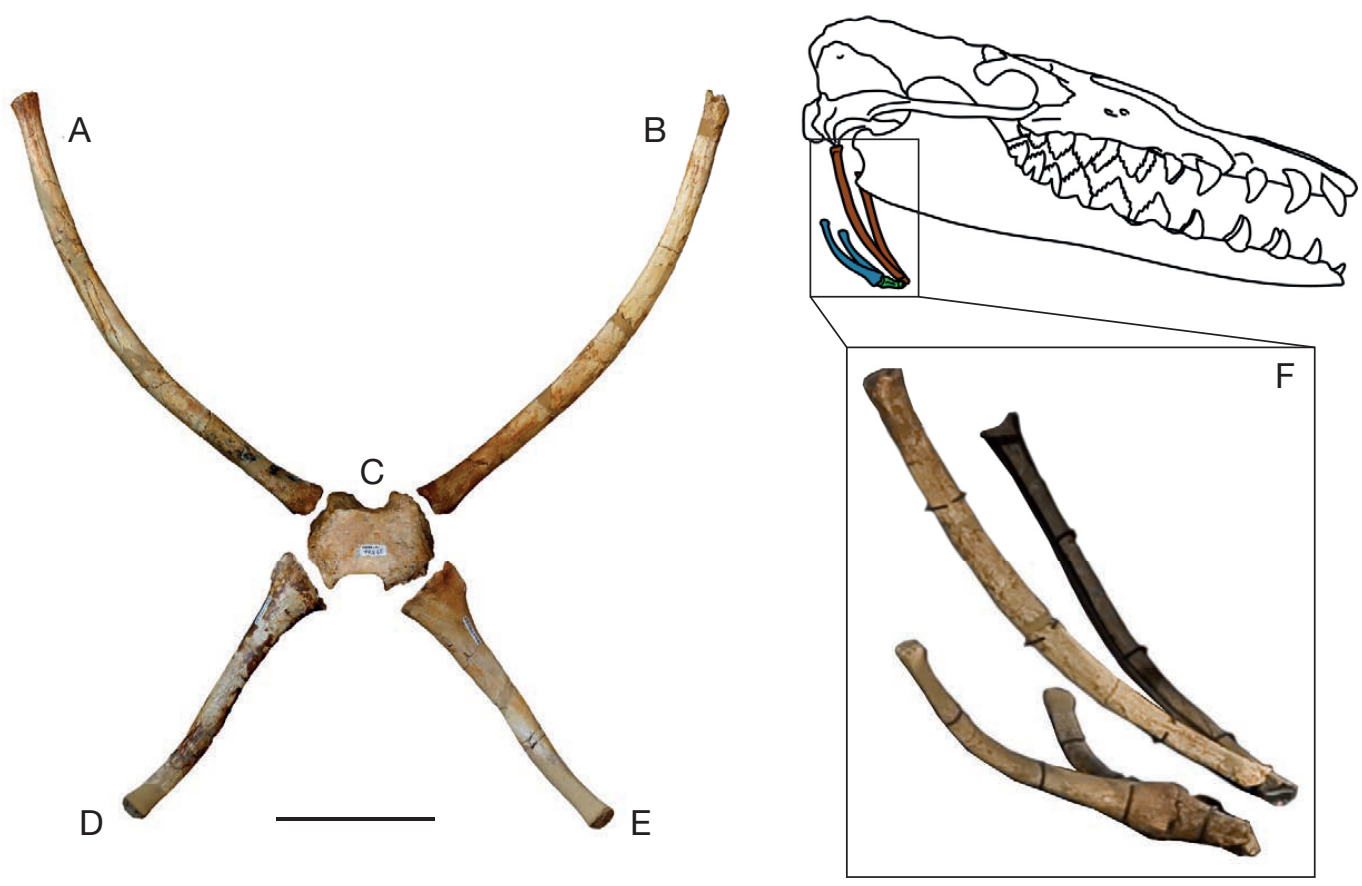

FIG. 34. - Hyoid apparatus of MNHN.F.PRU10, holotype of Cynthiacetus peruvianus in dorsal view (A-E) and natural position in slightly oblique right lateral view (F). A, left stylohyal; B, right stylohyal; C, basihyal; D, left thryrohyal; E, right thyrohyal. The missing portions have been reconstructed. Scale bar: $10 \mathrm{~cm}$.

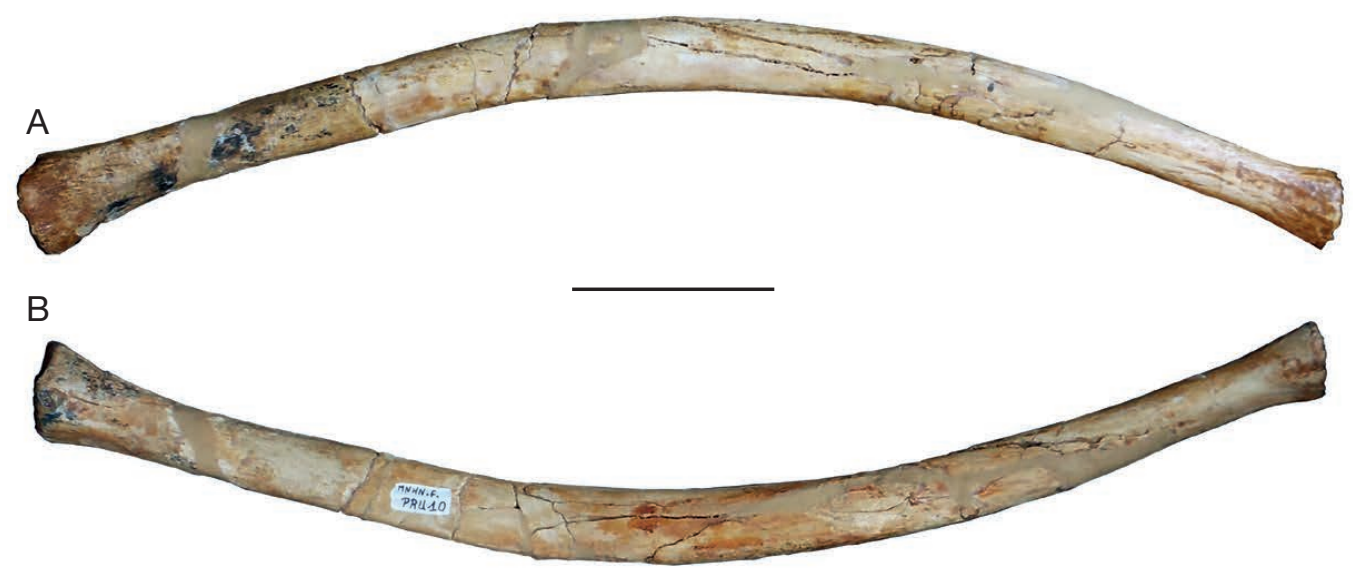

FIG. 35. - Left stylohyal of MNHN.F.PRU10, holotype of Cynthiacetus peruvianus: A, dorsal view; B, ventral view. The proximal end is on the left. Scale bar: $5 \mathrm{~cm}$.

cross-section. Unfortunately, its distal extremity is missing on each side and the actual length of the thyrohyal cannot be evaluated precisely (although it is estimated to be shorter than the stylohyal, about $20 \mathrm{~cm}$ long). The proximal end is transversely wider than dorsoventrally higher, being oval in cross-section. This end is highly expanded and not completely ossified in MNHN.F.PRU10. Therefore, it probably had a cartilaginous contact with the posterolateral corner of the basihyal. Nevertheless, this extremity most likely ossified in older specimens (cf. Basilosaurus cetoides in Fig. 36C).

Just posterior to the articular surface, the thyrohyal narrows abruptly and forms the almost cylindrical thyrohyal body. A proximodistally oriented crest lies on the anterolateral corner of this body. This crest is more pronounced than in Basilosaurus cetoides and Dorudon atrox, and could serve as attachment for $M$. hyoglossus. Except for this hyoglossial crest, the rest of the body is roughly smooth. In B. cetoides, the ventral surface of the thyrohyal presents numerous longitudinally oriented ridges. Finally, the body of the thyrohyal is strongly curved in lateral view, being ventrally concave (Fig. 34).

\section{Axial postcranial skeleton}

The axial postcranial skeleton of MNHN.F.PRU10 is well preserved. Only the posterior caudal vertebrae (from Ca11) are missing. MNHN.F.PRU10 includes 54 vertebrae (7 cervicals, 20 thoracics, 17 lumbars and 10 caudals), 20 pairs 


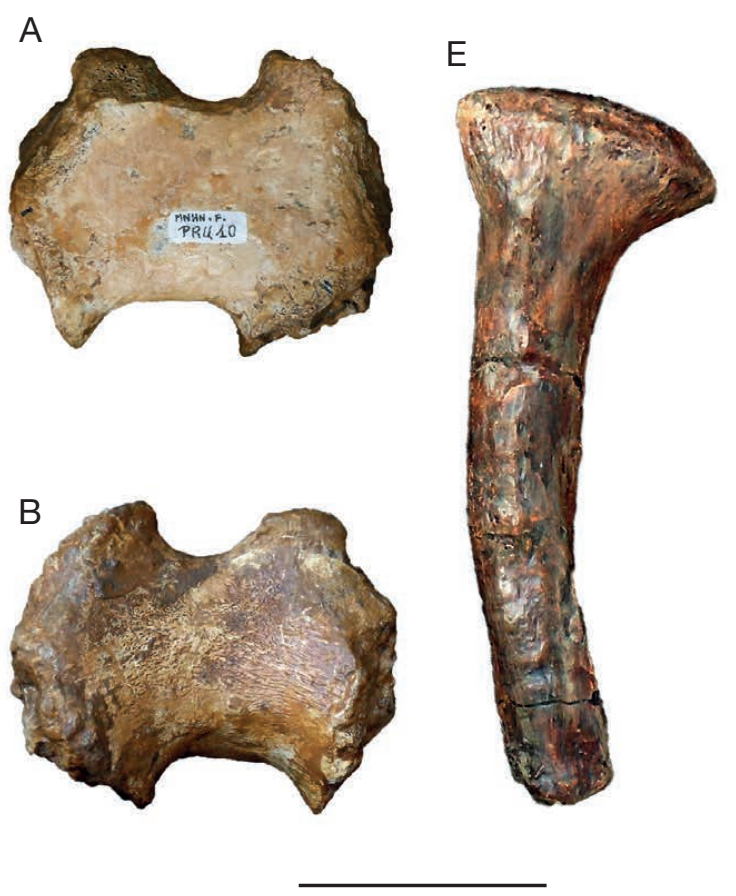

C

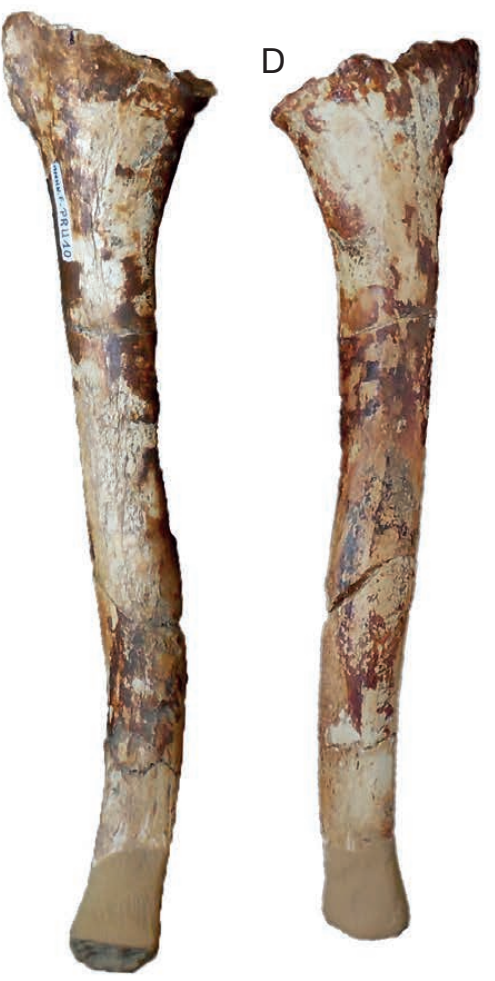

FIG. 36. - Hyoid apparatus of MNHN.F.PRU10, holotype of Cynthiacetus peruvianus (A-D), and of Basilosaurus cetoides (E): A, basihyal in dorsal view; B, basihyal in ventral view; C, left thyrohyal in dorsal view; D, left thyrohyal in ventral view; E, left thyrohyal of B. cetoides (MMNS, uncatalogued specimen, Scott County, Mississippi). The proximal ends are at the top. Scale bar: $10 \mathrm{~cm}$.

TABLE 6. - Measurements (in mm) of the cervical vertebrae of MNHN.F.PRU10, holotype of Cynthiacetus peruvianus. (e), estimated measurements. The ventral length of the vertebral body refers to the length of the axis at the level of the odontoid process and to the ventral length of the centrum in the series C3-C7.

\begin{tabular}{|c|c|c|c|c|c|c|c|}
\hline & C1 & C2 & C3 & C4 & C5 & C6 & C7 \\
\hline Maximum height, including neural spine & 158 & $220(e)$ & $125(\mathrm{e})$ & 133 & 138 & 165 & $208(e)$ \\
\hline Maximum width, at the level of transverse processes & 242 & 170 & $>170$ & 180 & 178.5 & $215(e)$ & 192 \\
\hline Width of neural canal & 66 & 50 & 52 & 39 & 56 & 57 & 61 \\
\hline Height of neural canal & 56 & 33 & 37 & 34 & 38 & 40 & 46 \\
\hline Anterior width of centrum & - & - & 72.5 & 76 & 77 & 74 & 77 \\
\hline Posterior width of centrum & - & 74 & $73(e)$ & 83 & 82 & 83 & 92 \\
\hline Anterior height of centrum & - & - & 68.5 & $71(\mathrm{e})$ & 79.5 & 81 & 78 \\
\hline Posterior height of centrum & - & 66 & 66 & 75 & 80 & 81 & 82 \\
\hline Dorsal length of centrum & - & - & 41 & $35(e)$ & 37 & 34 & 41 \\
\hline Ventral length of vertebral body & - & 80 & 37 & 30 & 33.5 & 35 & 42.5 \\
\hline Transverse breadth of transverse process (right side) & 66.5 & - & 56 & $59(e)$ & $60(e)$ & 103 & $70(\mathrm{e})$ \\
\hline Dorsoventral breadth of transverse process (right side) & 71 & - & 36 & 57.5 & $>60$ & 101 & 41.5 \\
\hline
\end{tabular}

of ribs and 5 sternebrae. Moreover, most of the vertebral centra are well preserved and virtually complete. In contrast, the neural spine and the transverse processes are frequently fragmentary or missing. In the thoracic region, the transverse processes articulate with the ribs, which are also well preserved (only the left twentieth rib is missing). Like Dorudon atrox, Cynthiacetus peruvianus presents five sternal elements.

As observed in other Pelagiceti (Basilosauridae and Neoceti), both thoracic and lumbar regions are proportionally longer than in earlier archaeocetes. Besides, Cynthiacetus peruvianus possesses the longest thorax among non-basilosaurines basilosaurids and the highest number of thoracic vertebrae among cetaceans (fossil and Recent species included).

The evolution of the size of centra along the vertebral column is showed in Figures 37 and 38. The cervical region is anteroposteriorly compressed, and thus both high/length $(\mathrm{H} / \mathrm{L})$ and width/length $(\mathrm{W} / \mathrm{L})$ ratios are higher than in the rest of the column (Fig. 38). The size of the vertebral centra increases continuously backwards, except in the caudal region, where the vertebrae become smaller. This increase in size is more pronounced in the middle thoracic vertebrae. Besides, the width and height of the centra evolve isometrically in most of the vertebral column (cf. thoracic region, lumbar region). 


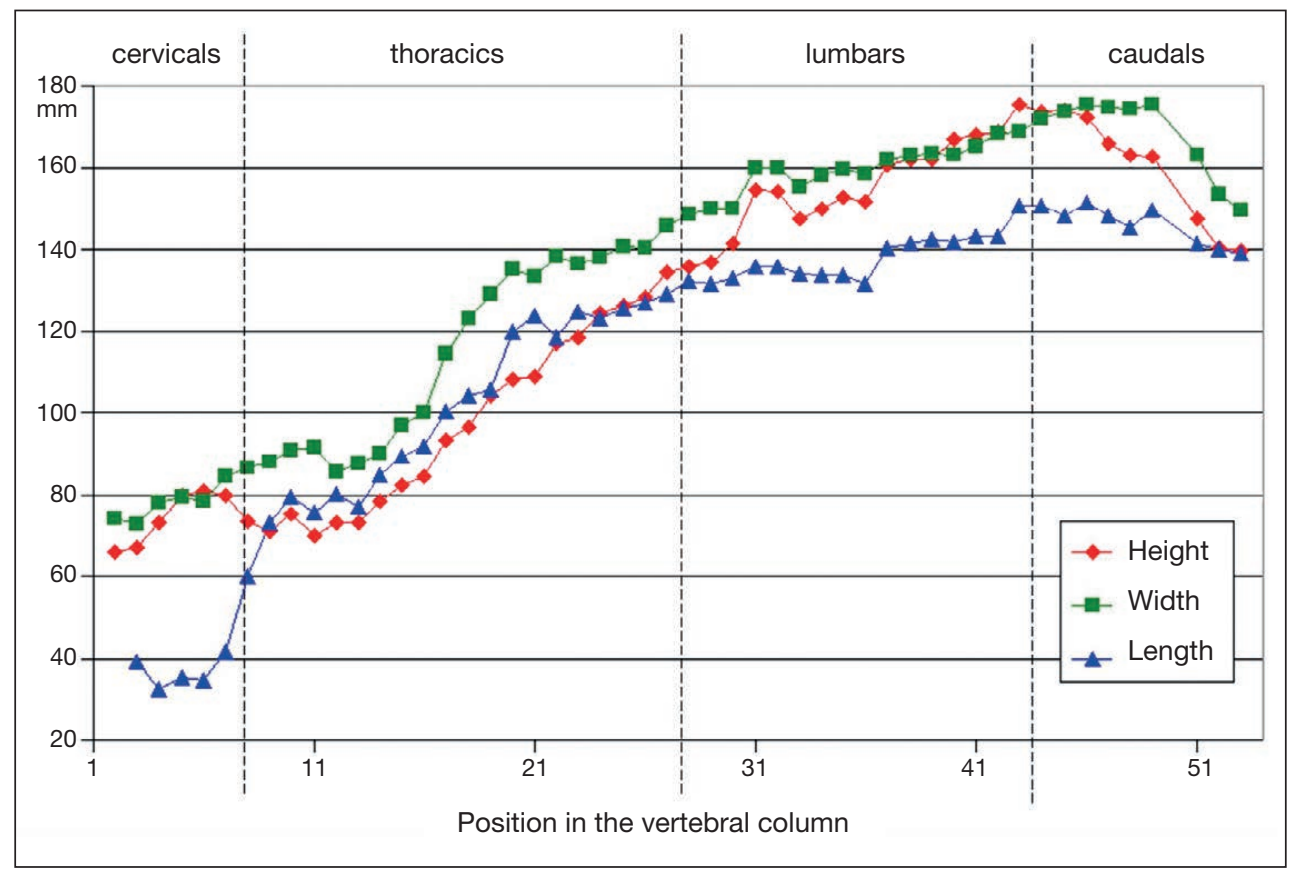

FIG. 37. - Evolution of the height $(\diamond)$, width $(\square)$, and length $(\mathbf{A})$ of the vertebral centra of MNHN.F.PRU10, holotype of Cynthiacetus peruvianus. The atlas $(C 1)$, sixth (Ca6) and tenth (Ca10) caudal vertebrae are not included in the plot.

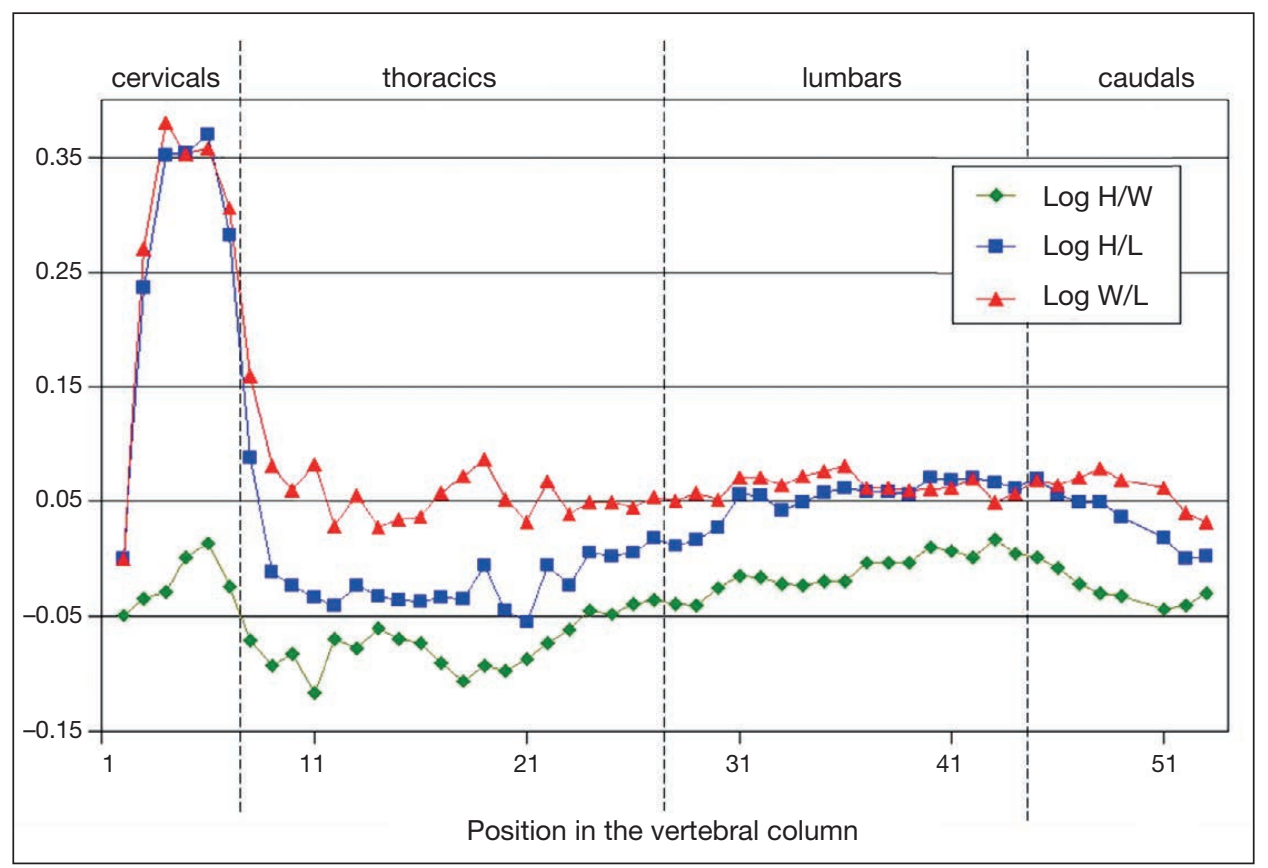

FIG. 38. - Evolution of the height/width ( $\bullet$ ), height/length (घ), and width/length $(\boldsymbol{\Delta})$ ratios of the vertebral centra of MNHN.F.PRU10, holotype of Cynthiacetus peruvianus. The atlas $(\mathrm{C} 1)$, sixth $(\mathrm{Ca} 6)$ and tenth $(\mathrm{Ca} 10)$ caudal vertebrae are not included in the plot.

Cervical region (Fig. 39). As in the vast majority of terrestrial mammals, the cervical region of Cynthiacetus peruvianus is composed of seven unfused vertebrae. Morphological features and measurements of the cervical region in MNHN.F.PRU10 are presented in Figure 40 and Table 6, respectively. These vertebrae are more compressed anteroposteriorly than in earlier archaeocetes and less compressed than in neocetes. In Recent cetaceans, the anteroposterior shortening of the cervicals is so extreme that it results in the partial or complete fusion of the vertebral bodies (exceptions are the narwhal, beluga, "river dolphins", and rorquals, in which the vertebrae are unfused but generally anteroposteriorly shortened compared to any archaeocete). Since many extinct odontocetes and mysticetes present separated cervical vertebrae (e.g. Cope 1890; Kellogg 1923b, 1965; Bouetel \& Muizon 2006; Lambert et al. 2009, 2015), it is likely that 


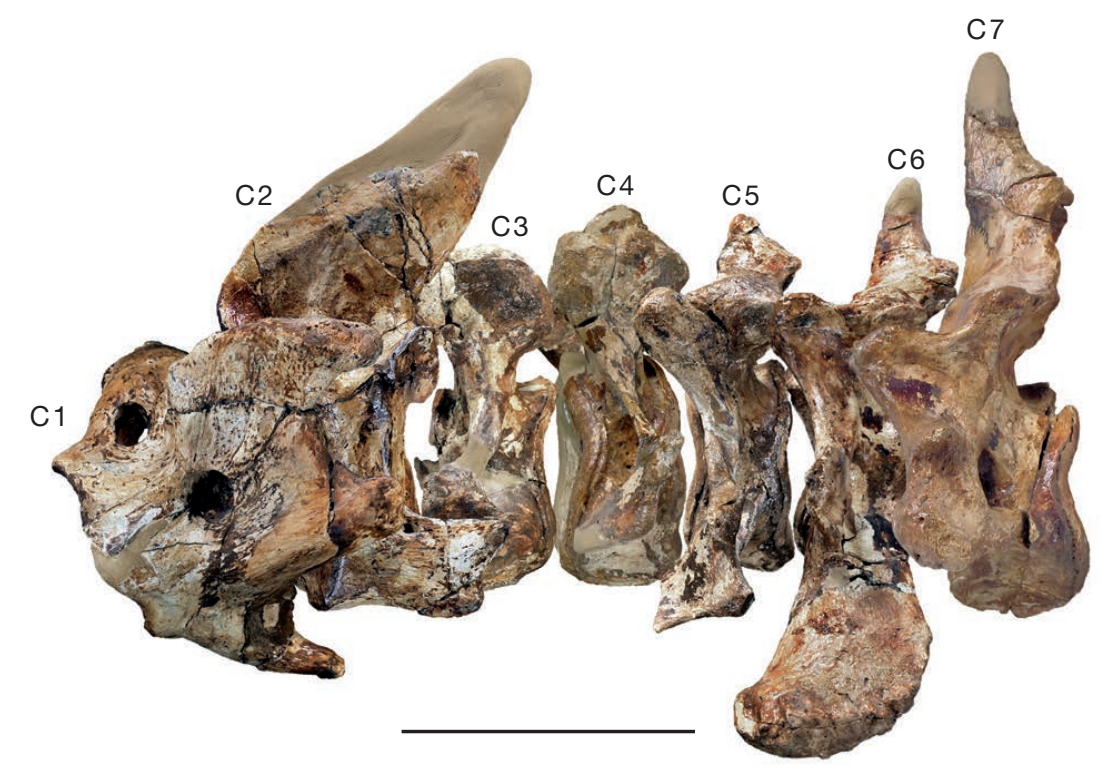

FIG. 39. - Series of the cervical vertebrae (C1-C7) of Cynthiacetus peruvianus (MNHN.F.PRU10, holotype) in left lateral view. Scale bar: $10 \mathrm{~cm}$.

the fusion of the cervical vertebrae evolved independently in various lineages of both suborders.

Atlas (C1) (Figs 40; 41). The atlas is the widest cervical vertebra and has a peculiar morphology as compared with more posterior vertebrae. The atlas does not have a centrum but is formed by two dorsal and ventral arches (Arcus dorsalis and Arcus ventralis), the former being much larger than the latter. The dorsal and ventral arches limit dorsally and ventrally the neural canal, respectively. Additionally, the ventral arch extends laterally on both sides, forming two wing-shaped transverse processes.

The ventral arch includes the anterior and posterior articular surfaces. Anteriorly, it presents two highly concave articular foveae, which articulate with the occipital condyles. They are reniform and their medial and lateral margins are laterally convex. While the ventral edges of the foveae are closely approximated, their dorsal edges are separated by a pronounced notch (supracondylar notch in Geisler et al. 2005). Medially, the articular foveae limit most of the neural canal. The latter is oval and anteriorly confluent with the foramen magnum. The dorsal portion of the neural canal is formed by the dorsal arch, which is robust, dorsally convex and proportionally higher than in other basilosaurids. A low crest runs anteroposteriorly at midline of the dorsal surface of the dorsal arch. The atlas is anteroposteriorly shortest at the level of the dorsal arch.

In dorsal and lateral views, the lateral vertebral foramen lies at the base of the dorsal arch. This foramen is located on the anterior half of the atlas and opens into the neural canal. Posteriorly, the ventral arch presents a large surface for the articulation with the axis. While the median portion of the posterior articular surface is a deep fossa, which receives the odontoid process of the axis, the lateral portions are flat, semicircular and posteriorly oriented. Ventral to the posterior articular surface the ventral arc forms a long ventral tubercle, which extends ventroposteriorly underneath the axis. When atlas and axis are articulated, the ventral tubercle does not contact the axis.

The transverse process projects posterolaterally from the lateral edge of the ventral arch. It is wing-shaped, roughly squared and perforated by a large vertebrarterial foramen, which conveyed the vertebral artery. The transverse process is a thin lamina with both ventral and dorsal margins being thick and tubular. Its lateral margin is laterally concave. Its dorsal margin is thinner than the ventral margin and presents an elevated and dorsally oriented crest. In protocetids, this crest is more developed than in C. peruvianus, making a horizontal lamina that connects the anterior articular fovea and which is perforated by a large arterial foramen. In Cynthiacetus peruvianus (and other basilosaurids), the dorsal crest of the transverse process does not contact the anterior articular fovea, and is instead separated from the latter by a large notch. This notch is the passage of the vertebral artery, which runs dorsally from the vertebrarterial foramen (in the transverse process) to the lateral vertebral foramen (in the neural arch). Finally, the dorsal and ventral portions of the transverse process in the atlas are certainly homologous with both diapophysial and parapophysial processes of more posterior cervical vertebrae (cf. below).

Axis (C2) (Figs 40; 42). The axis is the longest cervical vertebra of Cynthiacetus peruvianus. It includes a neural arch (which includes the pedicles and laminae) and a cylindrical centrum (fused with the odontoid process and bearing the anterior and posterior articular surfaces). The centrum and the neural arch limit the neural canal.

The odontoid process is fused posteriorly with the centrum of the axis; transversely wider than high, it is conical and articulates anteriorly with the posterior articular fovea of the atlas; 

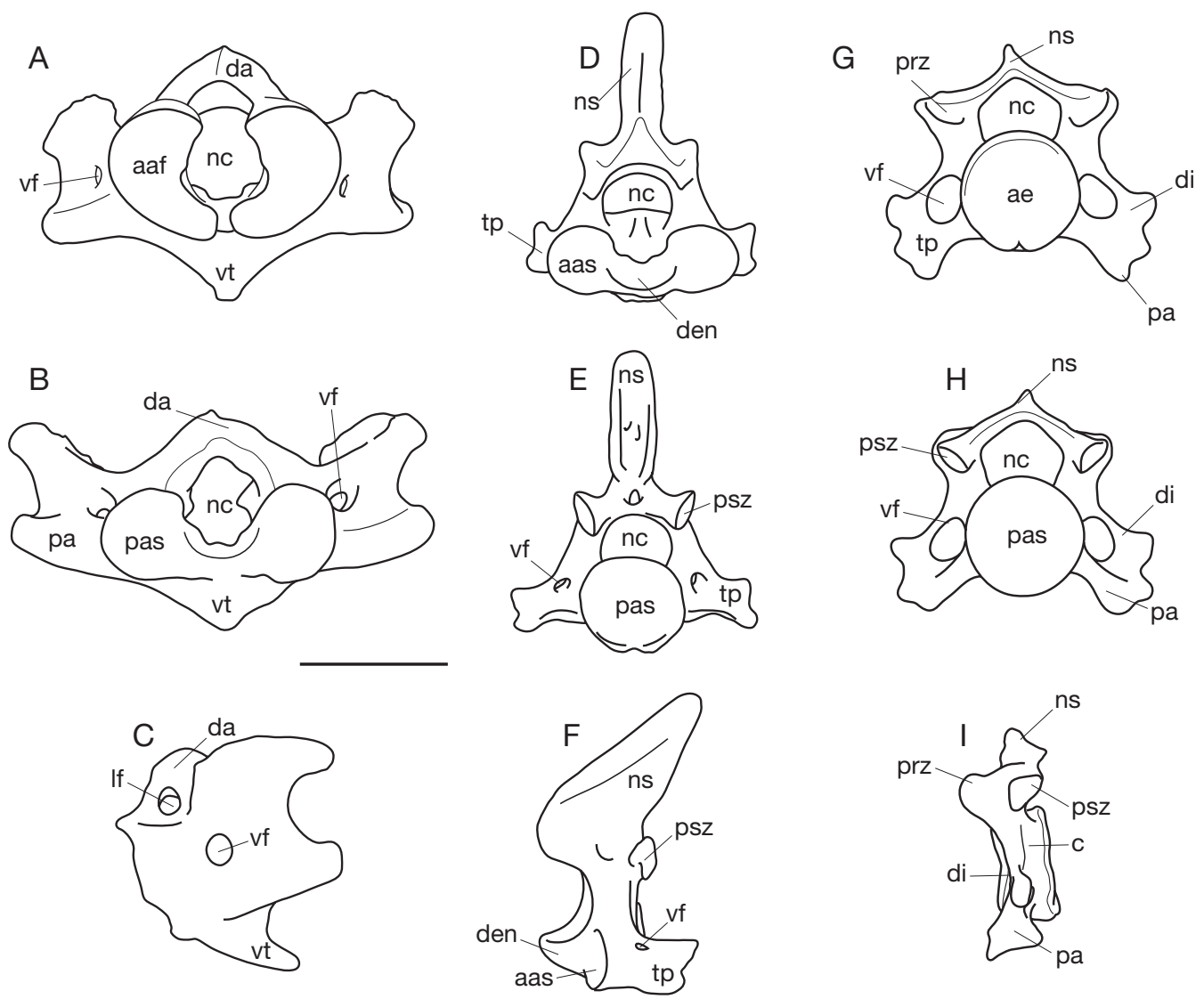

FIG. 40. - Morphology of the cervical vertebrae of Cynthiacetus peruvianus (MNHN.F.PRU10, holotype): A, atlas in anterior view; B, atlas in posterior view; C, atlas in left lateral view; D, axis in anterior view; $\mathbf{E}$, axis in posterior view; $\mathbf{F}$, axis in left lateral view; $\mathbf{G}$, fifth cervical in anterior view; $\mathbf{H}$, fifth cervical in posterior view; I, fifth cervical in left lateral view. Abbreviations: aaf, anterior articular fovea; aas, anterior articular surface; ae, anterior epiphysis; c, centrum; da, dorsal arch of the atlas; den, dentoid process; di, diapophysis; If, lateral foramen; nc, neural canal; ns, neural spine; pa, parapophysis; pas, posterior articular surface; prz, prezygapophysis; psz, postzygapophysis; tp, transverse process; vf, vertebrarterial foramen; vt, ventral tubercle of the atlas. Scale bar: $10 \mathrm{~cm}$.

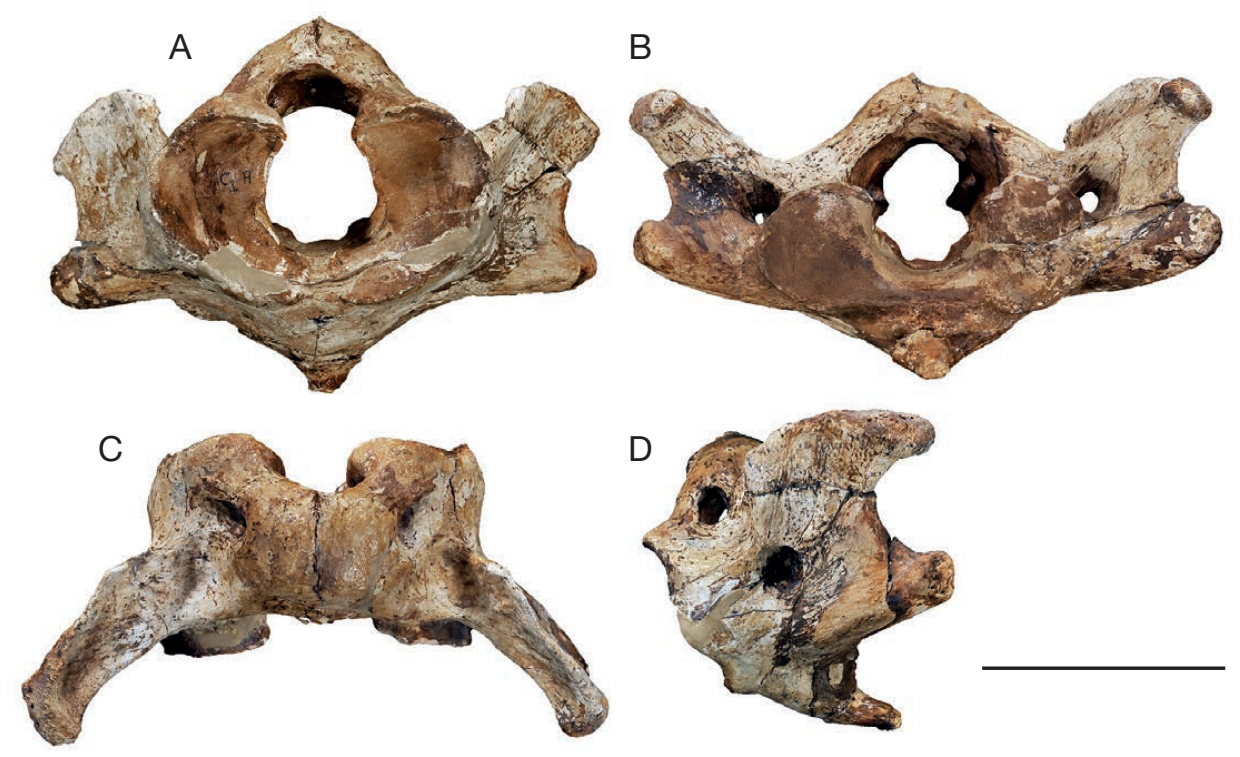

FIG. 41. - Atlas of MNHN.F.PRU10, holotype of Cynthiacetus peruvianus: A, anterior view; B, posterior view; C, dorsal view; D, left lateral view. Scale bar: $10 \mathrm{~cm}$. 


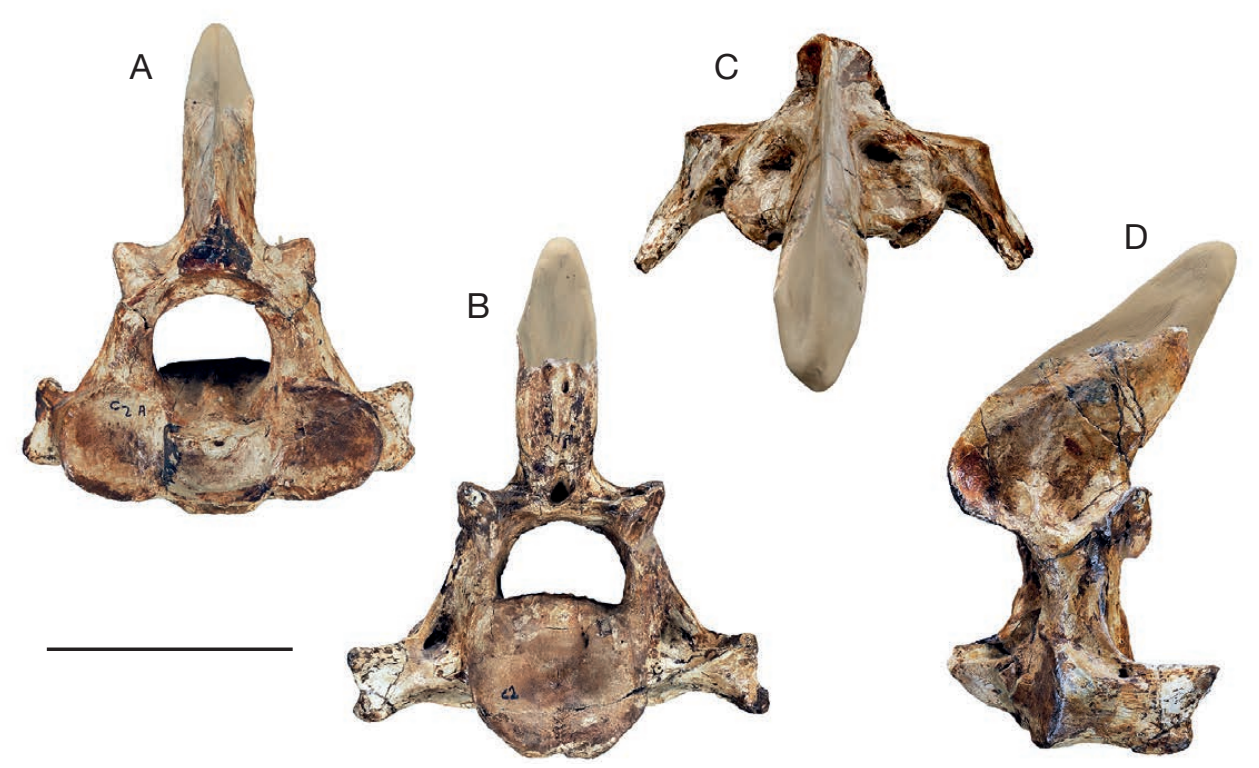

FIG. 42. - Axis of MNHN.F.PRU10, holotype of Cynthiacetus peruvianus: A, anterior view; B, posterior view; C, dorsal view; D, left lateral view. Scale bar: $10 \mathrm{~cm}$.

it is bounded laterally by the two anterior articular surfaces. The latter are almost circular, subequal in size, and articulate with the posterior articular surfaces of the atlas. Additionally, two small tuberosities lie on the ventral surface of the body, near the midline. These tuberosities are more developed in Dorudon atrox (hypapophyses in Uhen 2004).

Posteriorly, the centrum of the axis is fused with the posterior epiphysis, which is circular, slightly concave and forms the posterior articular surface of the axis (Fig. 40). The transverse processes extend from the lateral margins of the centrum and are posterolaterally oriented. They are proportionally smaller than in other cervical vertebrae. Each transverse process is roughly rectangular, being transversely wider than high. Its ventral portion (parapophysis) is well demarcated from its dorsal portion (diapophysis). The former is also more massive. Similarly to the atlas, the lateral margin of the transverse process is laterally concave.

The vertebrarterial foramen seems not to perforate the transverse process. It is located at the base of the transverse process and closer to its dorsal margin. The vertebrarterial foramen can be observed in posterior and lateral views. Its anterior opening is smaller than in all other vertebrae of the specimen and lies just posterior to the anterior articular surface. Therefore, it is likely that the vertebraterial foramen did not convey the whole vertebral artery, which probably had to cross the axis dorsal to the transverse process and lateral to the pedicle.

The dorsal arch of the axis includes the pedicles and the laminae. Each pedicle extends dorsally from the dorsolateral corner of the body, forming the lateral margin of the neural canal. Although the pedicles are robust, they are not as massive as the dorsal arch of the atlas. Dorsally, the pedicles contact the laminae.

The laminae are transversely compressed and form the roof of the neural canal. The latter is rounded and its maximum diameter is lower to that of the posterior epiphysis. The laminae contact dorsally at midline, then they extend posterodorsally, forming the neural spine. Although the apex of the spine is missing in MNHN.F.PRU10, it is clear that the axis possesses the highest and the most massive spine among the cervicals. The anteroposterior length of the spine decreases towards the apex and thus the spine had a triangular outline in lateral view (as reconstructed in Figure 40). Moreover, the spine increases in width posteriorly, having a sharp anterior margin and a broader posterior surface. Therefore, the neural spine of the axis is somewhat triangular in cross-section. Finally, a low ridge runs dorsoventrally at midline, on the posterior surface of the neural spine.

The posterior surface of the neural spine extends ventrolaterally and forms the postzygapophyses. The latter contact the prezygapophyses of the third cervical (C3). The articular surfaces of the postzygapophyses are oval and postero-ventrolaterally facing.

Third cervical (C3) (Fig. 43A-D). The third, fourth and fifth cervical vertebrae are morphologically roughly similar. Their vertebral body is cylindrical and anteroposteriorly compressed. Figure 40G-I shows the morphological features in the series C3-C5. The anterior and posterior epiphyses are circular, concave, and entirely fused with the centrum. A shallow furrow runs transversely at about the mid-height of each epiphysis.

Lateral to the vertebral body (centrum) of $\mathrm{C} 3$ are the thin transverse processes, which are posterolaterally oriented in dorsal view. The transverse process results from the fusion of both diapophyses and parapophyses, which are hardly distinguishable from each other in C3. The transverse process is roughly rectangular in anterior and posterior views. It is perforated at its base by a large vertebrarterial foramen. In C3, the vertebrarterial foramen is closer to the dorsal edge of the transverse process than to the ventral edge. Cynthiacetus differs from other basilosaurids in having proportionally larger vertebrarterial foramina and reduced anteroventral expansions in the parapophyses. As a matter of fact, the morphology of 

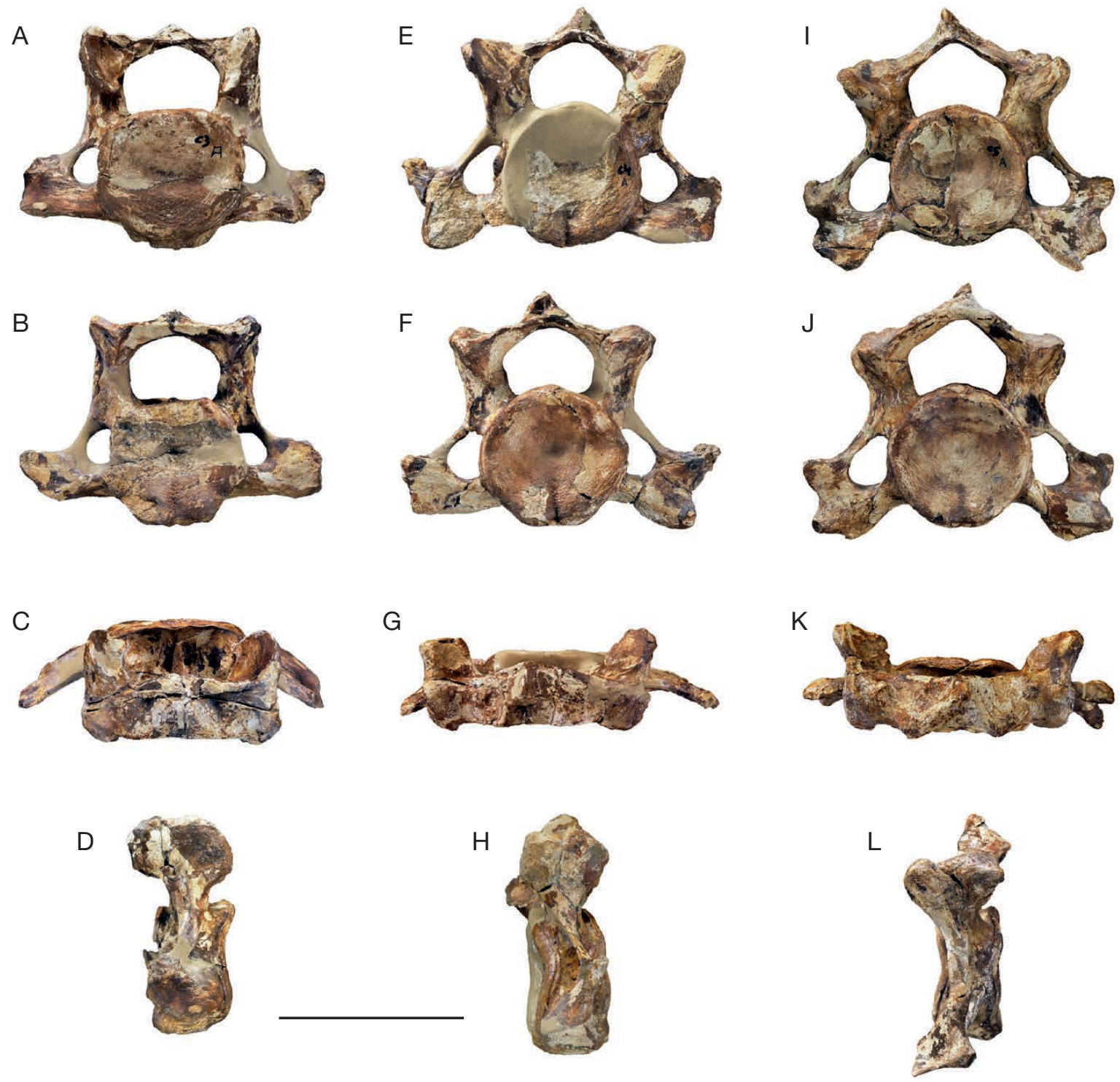

FIG. 43. - Cervical vertebrae of MNHN.F.PRU10, holotype of Cynthiacetus peruvianus: A; third cervical in anterior view; B, third cervical in posterior view; C, third cervical in dorsal view; D, third cervical in left lateral view; $\mathbf{E}$, fourth cervical in anterior view; $\mathbf{F}$, fourth cervical in posterior view; $\mathbf{G}$, fourth cervical in dorsal view; $\mathbf{H}$, fourth cervical in left lateral view; I, fifth cervical in anterior view; J, fifth cervical in posterior view; $\mathbf{K}$, fifth cervical in dorsal view; $\mathbf{L}$, fifth cervical in left lateral view. Scale bar: $10 \mathrm{~cm}$.

the diapophyses and parapophyses in MNHN.F.PRU10 are similar to that observed in a neonate specimen of Dorudon atrox (UM 94814) and these features can thus be tentatively regarded as paedomorphic in Cynthiacetus peruvianus.

The pedicles are slightly compressed anteroposteriorly, being transversely wider than long. They form the lateral walls of the neural canal, which is pentagonal to circular. The area formed by the neural canal in anterior or posterior view is smaller than that formed by the epiphysis. The difference in size between the centrum and the neural canal increases in more posterior vertebrae. Between the posterior surface of the pedicle of a vertebra and the anterior surface of the pedicle of the following vertebra is the intervertebral notch, path for the spinal nerves. Dorsally, the pedicles meet the laminae of the neural arch. As in the axis, the laminae form the dorsal arch of the neural canal. C3 does not present a true neural spine, but a sharp and low ridge. In dorsal view, the neural arch is slightly posterior to the level of the centrum (Fig. 43C). This feature is also observed in more posterior vertebrae.

Anteriorly and posteriorly, the laminae bear the prezygapophyses and postzygapophyses, respectively. The articular surface of each prezygapophysis is large and dorsomedially inclined. It received the postzygapophysis of C2. Similarly, the articular surfaces of the postzygapophyses are ventrolaterally facing and contact the prezygapophyses of $\mathrm{C} 4$.

Fourth cervical (C4) (Fig. 43E-H). As stated above, C4 and $\mathrm{C} 3$ are similar. The most important differences concern the size of homologous parts. The vertebral body (which is less completely preserved than in C3) is also anteroposteriorly cylindrical and strongly compressed anteroposteriorly. The epiphyses are concave and present a transverse furrow at mid- 


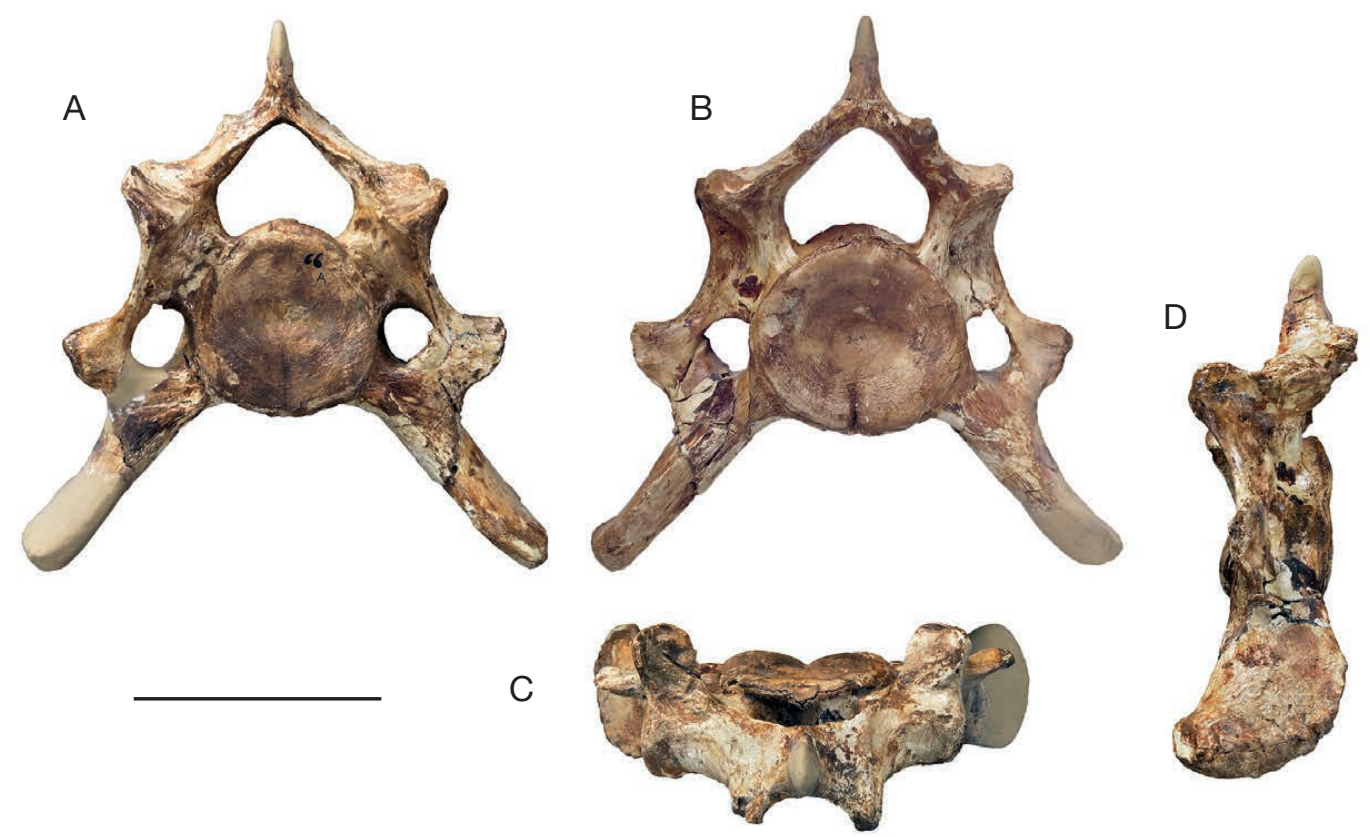

FIG. 44. - Sixth cervical vertebra of MNHN.F.PRU10, holotype of Cynthiacetus peruvianus: A, anterior view; B, posterior view; C, dorsal view; D, left lateral view. Scale bar: $10 \mathrm{~cm}$.

height. As compared with $\mathrm{C} 3$, the pentagonal neural canal is proportionally smaller in $\mathrm{C} 4$ and the pedicles are more compressed anteroposteriorly. The vertebrarterial foramina, diapophyses and parapophyses are proportionally larger and the diapophyses and parapophyses can be more easily differentiated from each other. Finally, the anteroventral projection of the parapophysis is more developed than in C3 and less developed than in other basilosaurids.

On the dorsal surface of the neural arch, the neural spine is higher than in C3, but not as developed as in the axis. The articular surfaces of the prezygapophyses and postzygapophyses differ from those of $\mathrm{C} 3$ in being proportionally larger and more horizontally facing (prezygapophyses and postzygapophyses are more dorsally and more ventrally facing, respectively).

Fifth cervical (C5) (Figs 40; 43I, J). C5 resembles strongly C4 and most of the differences pointed out between $\mathrm{C} 3$ and $\mathrm{C} 4$ can also be applied between C4 and C5. The somewhat concave epiphyses of $\mathrm{C} 5$ present a shallow transverse furrow and are entirely fused with the centrum. On its ventral surface, the centrum bears two faint tuberosities, which are less pronounced than in Dorudon atrox. The cross-section of the centrum is larger than the area occupied by the pentagonal neural canal.

The pedicles are transversely wider than in $\mathrm{C} 4$, and the neural spine is subequal in size to that of $\mathrm{C} 4$. The prezygapophyses and postzygapophyses are more dorsally and more ventrally facing than in $\mathrm{C} 4$, respectively.

On the transverse process, the parapophysis and diapophysis are better differentiated than in C3 and C4. The anteroventral elongation of the parapophysis is more pronounced than in the anterior cervicals. In fact, the development of the whole transverse process of C5 in MNHN.F.PRU10 resembles that of the third cervical of other basilosaurids (except Cynthiace- tus maxwelli and Saghacetus osiris). Finally, the vertebrarterial foramina are larger than in $\mathrm{C} 3$ and $\mathrm{C} 4$.

Sixth cervical (C6) (Fig. 44). The sixth cervical shares various features with the anterior C3-C5, but it substantially differs in having more developed transverse processes. Its centrum is also cylindrical and highly compressed anteroposteriorly. Similarly to C5, the ventral surface of the centrum bears two small tuberosities, near the midline. The epiphyses are concave and fused with the centrum. In addition to the transverse furrow observed in anterior cervicals, the epiphyses present a pronounced, but small median furrow (more pronounced than the transverse furrow), running dorsoventrally on the ventral portion of the epiphyses.

The pedicles are slightly shorter dorsoventrally and wider transversely than in C3-C5. The prezygapophyses and postzygapophyses are facing more dorsally and more ventrally, respectively. The neural spine is higher than in more anterior cervicals, except the axis; in lateral view, it is triangular and slightly curved posteriorly.

The neural canal is pentagonal and the vertebrarterial foramen is proportionally smaller than in more anterior vertebrae, including C3. As stated above, the main differences with C3-C5 concern the transverse process. The diapophysis and parapophysis are separated by a pronounced notch, ventral to the level of the vertebrarterial foramen. Dorsal to this notch, the diapophysis is slightly more developed than in C3-C5 and forms a short but massive process. In contrast, the parapophysis is almost three times longer than in C5, being larger than the diameter of the centrum; it is transversely flattened and widens anteroposteriorly toward its distal extremity. It is ventrolaterally oriented in anterior view and paddle-shaped in lateral view (Fig. 44). 


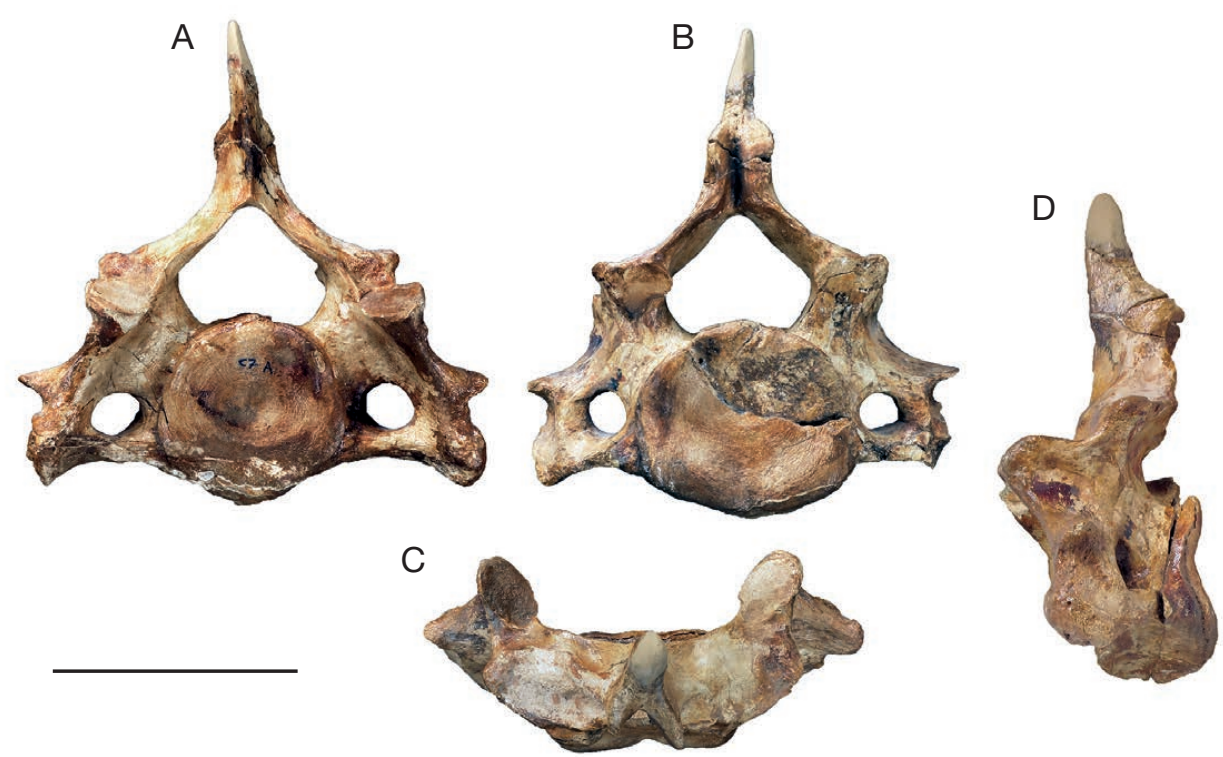

FIG. 45. - Seventh cervical vertebra of MNHN.F.PRU10, holotype of Cynthiacetus peruvianus: A, anterior view; B, posterior view; C, dorsal view; D, left lateral view. Scale bar: $10 \mathrm{~cm}$.

Seventh cervical (C7) (Fig. 45). The last cervical shares with more anterior cervicals (from C3 to C6) an anteroposteriorly compressed cylindrical centrum, concave epiphyses with a shallow transverse furrow, a pentagonal neural canal, and large vertebrarterial foramina (which are however proportionally smaller than in C3-C6). The seventh cervical has a more transversely oval centrum than more anterior vertebrae. The neural spine is also triangular in lateral view and is twice larger than that of C6, although remaining smaller than that of $\mathrm{C} 2$. The prezygapophyses and postzygapophyses are dorsally and ventrally facing, respectively.

On the other hand, the pedicles are dorsoventrally shorter and transversely broader than in more anterior vertebrae. In fact, the lateral margin of the pedicle forms part of the dorsal margin of the diapophysis. The posterior surface of the pedicle is more concave than in more anterior vertebrae, and the intervertebral notch between $\mathrm{C} 7$ and $\mathrm{T} 1$ is thus more pronounced than in C3-C6.

The transverse processes are wing-shaped and strongly anteroposteriorly compressed. Their lateral margin forms a small but conspicuous notch, just lateral to the vertebrarterial foramen. This notch separates the parapophysis from the diapophysis. The latter is larger and more massive than the former, which can be regarded as a dorsal and pointed projection of the transverse process. The fovea for the articulation with the tuberculum of the first rib (R1 tuberculum) lies at the lateral extremity of the parapophysis.

Thoracic region (Fig. 46A). The thorax of the holotype of Cynthiacetus peruvianus includes 20 thoracic vertebrae, forty ribs, and five sternebrae. Cynthiacetus peruvianus presents the highest number of thoracic vertebrae observed in both fossil and extant cetaceans. In comparison, Saghacetus osiris and Basilosaurus cetoides present only 14 thoracics (Dames 1894; Stromer 1908; Kellogg 1936); Zygorhiza kochii, 15 (Kellogg
1936); and Dorudon atrox, between 16 and 17 (Uhen 2004). Gingerich et al. (1990) indicate that Basilosaurus isis has 18 thoracic vertebrae. Nevertheless, the costal foveae of $B$. isis are inconspicuous posterior to T15. The thoracic region of the other basilosaurids is not completely preserved and the number of thoracic vertebrae remains unknown. Within the Neoceti, the average number of thoracic vertebrae is 13 to 14 (but the number of vertebrae can increase to 16 in some phocoenids). In delphinids for example, the thoracic count has a range of 8 to 14 vertebrae (Buchholtz \& Schur 2004), which is below what is observed in the Basilosauridae. Similarly, all protocetids have less than 15 thoracics. As a matter of fact, the number of thoracic vertebrae tends to increase in the Basilosauridae more than in any other cetacean family, especially in the largest species (e.g. B. isis and C. peruvianus). Although $C$. peruvianus has the highest number of vertebrae within the family, its thoracic region is shorter than that of Basilosaurus since it does not have the pronounced lengthening of the centra of the posterior thoracic vertebrae (cf. below).

As in other basilosaurids, the overall size of the thoracic centra grows gradually and posteriorly in Cynthiacetus peruvianus (Figs 46A; 47A). Their height and width increase more rapidly in middle thoracic vertebrae (from T9 to T14) than in the rest of the thorax. Such an increase in the height and width of the centra is also observed in the posterior thoracics of Basilosaurus. Moreover, as in other basilosaurids, the width and height of the thoracic centra are isometrically correlated (Figure 47B, slope of the equation $=1.142$, coefficient $\mathrm{R}^{2}=0.96$ ). As a consequence, the cross-section of the centrum of thoracic vertebrae is almost perfectly circular. It is likely that this isometric scaling results from the loss of mechanical stress related to the ground loading function of the forelimb and thorax, considering that the locomotion of the Pelagiceti is achieved by the caudal and lumbar regions. 


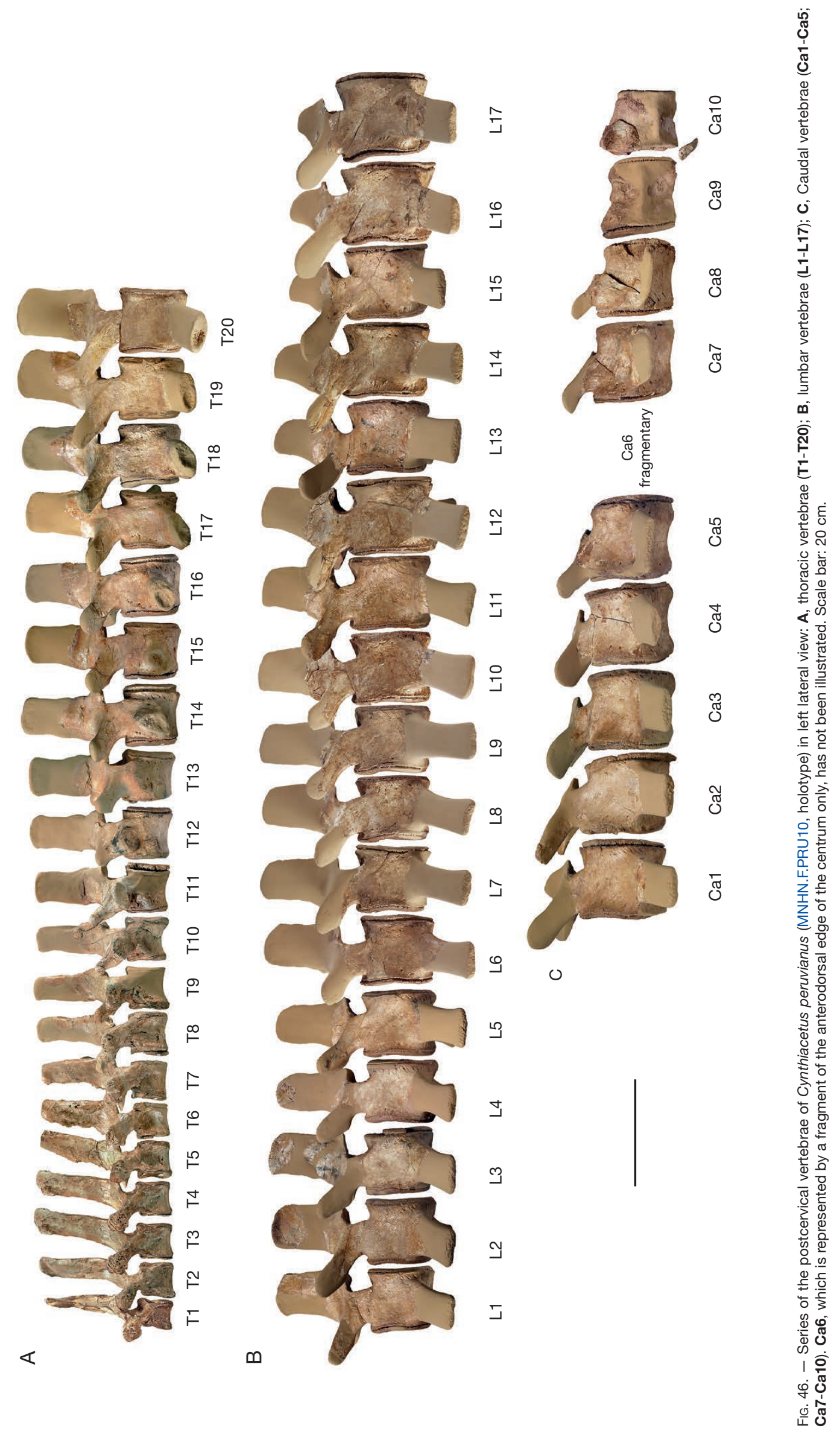



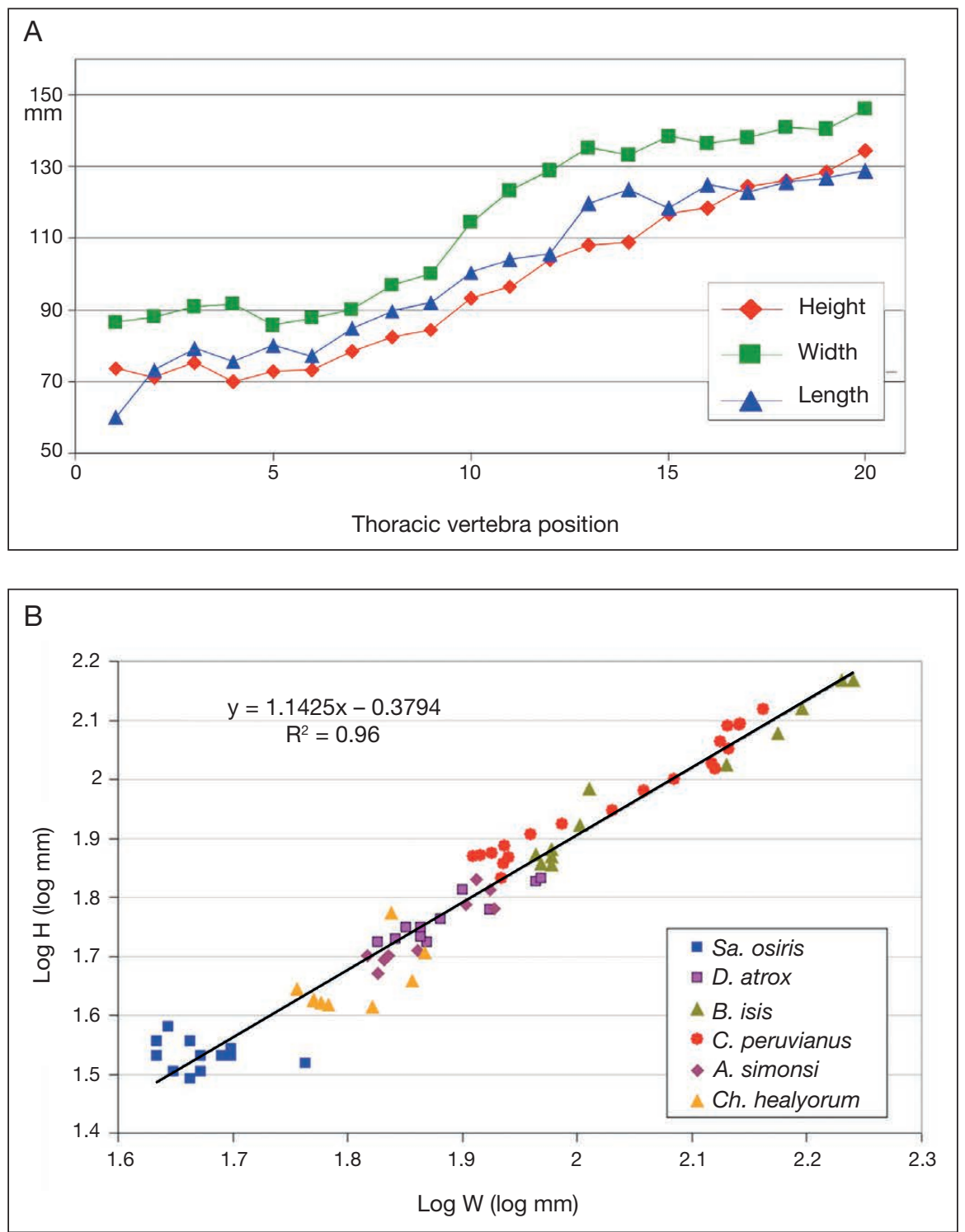

FIG. 47. - A, Evolution of height, width, and length of the centrum in the thoracic vertebrae of MNHN.F.PRU10, holotype of Cynthiacetus peruvianus; B, evolution of the centrum width in function of the centrum height in the thoracic vertebrae of the Basilosauridae. Saghacetus osiris (UM 97550), Dorudon atrox (UM 101222), Basilosaurus isis (UM97507), C. peruvianus (MNHN.F.PRU10), Ancalecetus simonsi (CGM 42290), Chrysocetus healyorum (SCSM 87.195). Only the anterior 14 thoracic vertebrae have been included for $B$. isis.

The length/width $(\mathrm{L} / \mathrm{W})$ and length/height $(\mathrm{L} / \mathrm{H})$ ratios remain roughly constant in the whole thoracic region of MNHN.F.PRU10. As stated above, Cynthiacetus peruvianus lacks the specialized elongation of the centra observed in the Basilosaurinae. In Basilosaurus isis, the height/length (H/L) ratio decreases progressively backwards, as a consequence of the anteroposterior lengthening of the centra (Fig. 48A, slope of the $B$. isis regression is of $-0.26, \mathrm{R}^{2}$ coefficient of 0.8542 ). This asymmetric relationship is absent in all the dorudontines except Saghacetus osiris (regression not figured in Fig. 48A, slope $a=$ 0.13 and $\mathrm{R}^{2}=0.88$ ). As a matter of fact, in B. isis and Sa. osi$r i s$ the anteroposterior elongation of the centra (represented by the $\mathrm{H} / \mathrm{L}$ ratio) is asymmetrically correlated to the centrum length (Fig. 48B). This means that the larger the cross-section, the more elongated the centrum is. In contrast, the $\mathrm{H} / \mathrm{L}$ ratio is not significantly correlated to the central length in other dorudontines ( $\mathrm{R}^{2}$ inferior to 0.6 ), meaning that the $\mathrm{H} / \mathrm{L}$ does not change with the increase of the overall size. Additionally, no thoracic vertebra is anteroposteriorly longer than wide (the width-to-length ratio being always superior to 1 ). In comparison, all thoracics posterior to T8 are longer than wider in $B$. isis.

Contrary to the lumbars (cf. below), the thoracics change progressively in both shape and size. We can therefore differentiate three different morphological domains (anterior, middle and posterior thoracics). The most important morphological features and main measurements of the thoracic vertebrae are presented in Figure 49 and Table 7.

First thoracic (T1) (Fig. 50A-D). The first thoracic is virtually entire in the holotype of Cynthiacetus peruvianus. It is the smallest 

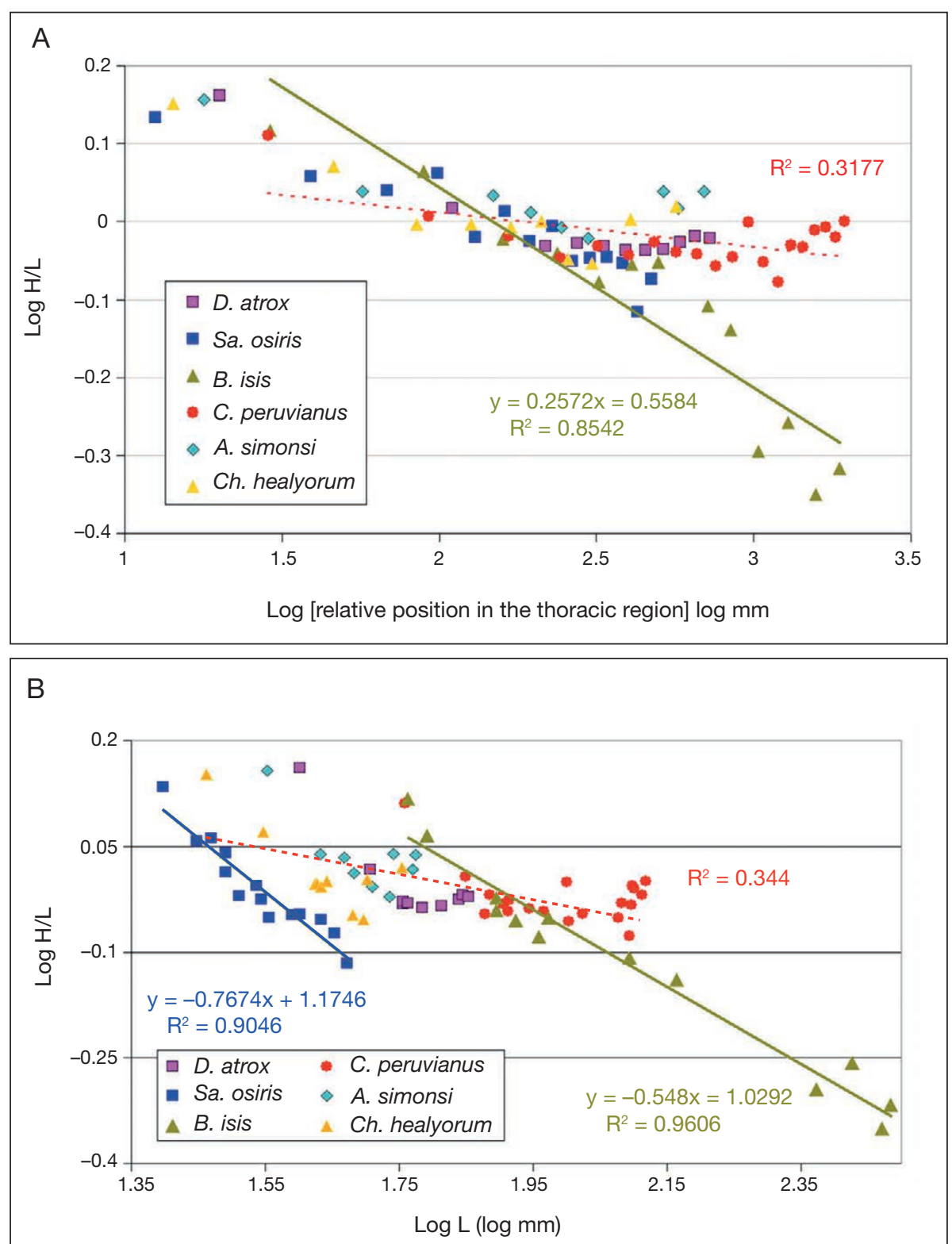

FIG. 48. - Scatter plots showing the evolution of the height-to-length ratio: $\mathbf{A}$, in function of the centra length; $\mathbf{B}$, in function of the relative position of the vertebra in the thoracic region. Saghacetus osiris (UM 97550), Dorudon atrox (UM 101222), Basilosaurus isis (UM 97507), Cynthiacetus peruvianus (MNHN.F.PRU10), Ancalecetus simonsi (CGM 42290), Chrysocetus healyorum (SCSM 87.195). Only the anterior 14 thoracics have been included for $B$. isis. The relative position of a vertebra is the distance from the anterior edge of the T1 centrum to the mid-length of the $n$ vertebra. It is calculated using the formula: $n-1 X_{n}=L o g\left[\Sigma L_{i}+\left(L_{n} / 2\right)\right] i=1$ where $L n$ is the ventral length of the centrum in the thoracic $n$.

vertebra of the thorax. Its centrum is significantly longer than that of C7. It is cylindrical with a cross-section being slightly oval transversely. The fusion of the epiphyses with the centrum is incomplete and both epiphyses remain well defined. On the dorsal half of the epiphyses is a transverse furrow running from side to side; this furrow is more pronounced on the posterior epiphysis, where it forms a notch on the lateral margin of the epiphysis. At the dorsolateral corners of the posterior surface of the centrum and lateral to the posterior epiphysis are the articular surfaces for the capitula of the second ribs (R2). These foveae are posterolaterally facing and roughly triangular in outline.

The ventral surface of the centrum is anteroposteriorly concave (feature observed in all the thoracic vertebrae); it is smooth and presents no keel or foramen. The lateral surface of the centrum forms a shallow concavity in its dorsalmost region, just ventral to the pedicle. Ventral to this concavity is a very small nutrient foramen. The dorsal surface of the centrum forms the floor of the neural canal. The outline of the latter in anterior view is pentagonal (as for the posterior cervical vertebrae). The dorsal surface of the centrum is flat and bears two large foramina, which open close to the midline into the neural canal. These foramina are surrounded by other small nutrient foramina.

The neural canal is delimited laterally by the pedicles, and dorsolaterally and dorsally by the laminae. On the medial surface of the right pedicle, is a low anteroposteriorly oriented crest. 

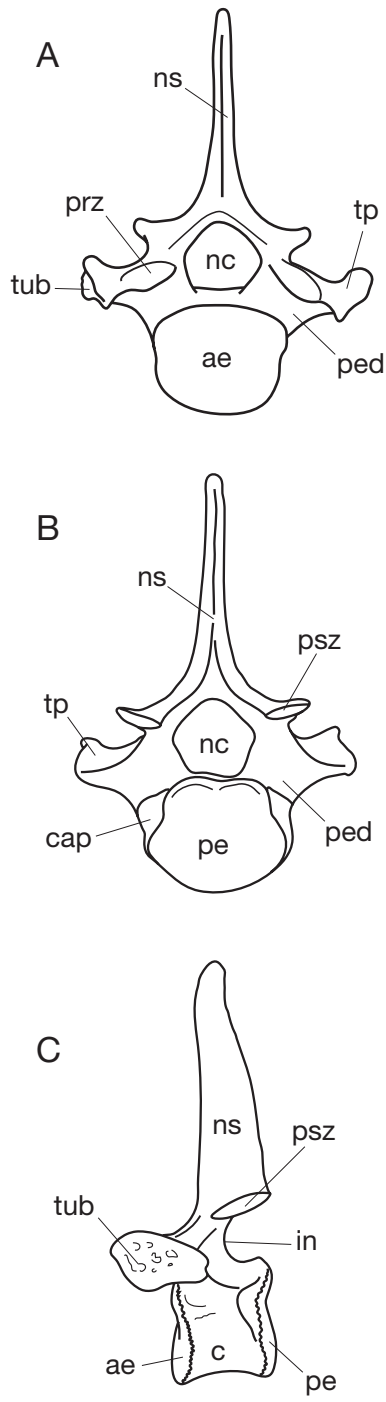

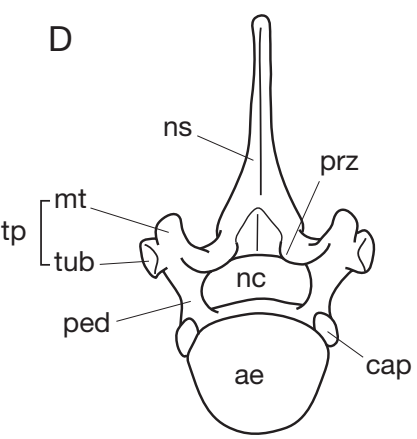

$\mathrm{E}$
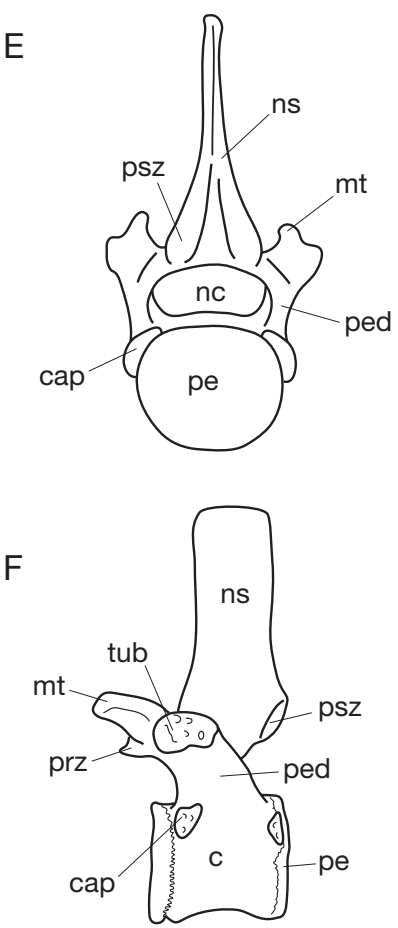

G

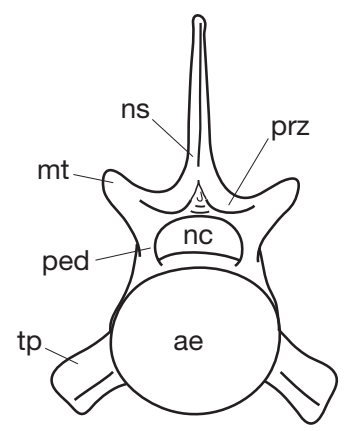

$\mathrm{H}$
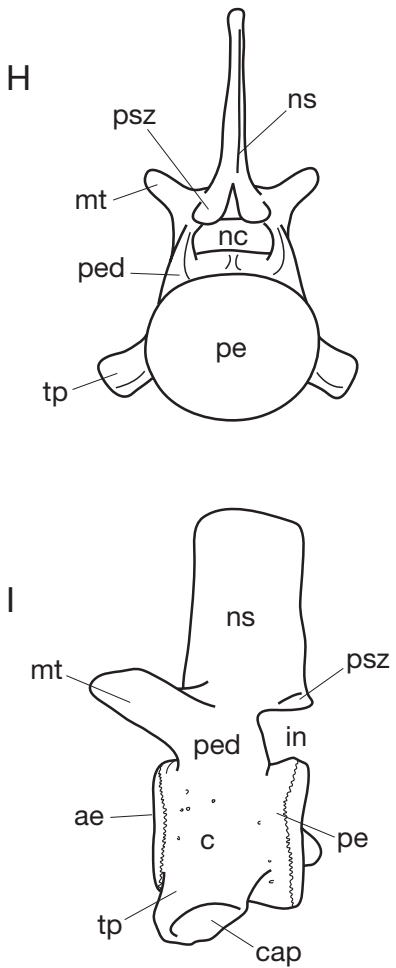

FIG. 49 . - Main morphological characters observed in the thoracic region of MNHN.F.PRU10, holotype of Cynthiacetus peruvianus: A, first thoracic in anterior view; B, first thoracic in posterior view; C, first thoracic in left lateral view; D, eighth thoracic in anterior view; E, eighth thoracic in posterior view; F, eighth thoracic in left lateral view; G, seventeenth thoracic in anterior view; H, seventeenth thoracic in posterior view; I, seventeenth thoracic in left lateral view. Abbreviations: ae, anterior epiphysis; c, centrum; cap, fovea for the capitulum of the rib; in, intervertebral notch; mt, metapophysis; nc, neural canal; ns, neural spine; pe, posterior epipophysis; ped, pedicle; prz, prezygapophysis; psz, postzygapophysis; tp, transverse process; tub, fovea for the tuberculum of the rib. Scale bars: $10 \mathrm{~cm}$.

The pedicles are wing-shaped, being highly anteroposteriorly compressed and transversely wider than high. In this respect, T1 resembles more the last cervical than the other thoracics. The pedicles are anteriorly convex. They extend laterally to form the transverse processes, which bear the foveae for the first rib (R1) tubercula. These foveae are triangular and laterally oriented. The anterior and ventral edges of each fovea are perpendicular (Fig. 50D). Medial to the foveae are the large prezygapophyses, which are dorsally facing and elliptic in shape, with the axis of the ellipse being anterolaterally oriented.

The pedicles continue dorsally into the laminae, which meet at midline to form the neural spine. Dorsal to the neural arch and at the base of the neural spine, the posterior margins of the laminae enlarge transversely forming the postzygapophyses, which are circular and face ventrally. As compared with other thoracics, the postzygapophyses are proportionally larger in T1.

The posterior surfaces of both pedicles and laminae make the posterior intervertebral notch. In this region, a small, barely defined crest runs transversely on the posterior surface of the left transverse process.

The neural spine of T1 is higher than that of C7. However, it remains the lowest spine in the thoracic region. It is almost vertical, transversely compressed and triangular-shaped in lateral view, as for C7. Its dorsal end is slightly bent posteriorly (Fig. 50D). The anteroposterior length of the neural spine decreases dorsally, while its transverse width increases posteriorly. Its narrow posterior surface forms a long median ridge, bordered by two smooth surfaces for the attachment of the epaxial muscles. At the posterior base of the neural spine 
TABLE 7. - Measurements (in mm) of the thoracic vertebrae of MNHN.F.PRU10, holotype of Cynthiacetus peruvianus. (e), estimated measurements.

\begin{tabular}{|c|c|c|c|c|c|c|c|}
\hline & T1 & T2 & T3 & T4 & T5 & T6 & T7 \\
\hline Inter-prezygapophysial width & 131.7 & 138.5 & 97.8 & 106.9 & 100 & 89 & 86.3 \\
\hline Inter-postzygapophysial width & 122.8 & 96.8 & 74.3 & $80(e)$ & 68 & 62.9 & 66.4 \\
\hline Prezygapoph.-postzygapophysial length (right side) & 91.6 & 118.4 & 111.32 & $110(\mathrm{e})$ & $115(e)$ & 117 & 125.3 \\
\hline Anterior width of the centrum & 81.2 & 86.3 & 87.1 & 86 & $84.3(\mathrm{e})$ & 82.3 & 86.4 \\
\hline Posterior width of the centrum & 92 & 89.78 & 94.77 & 97.02 & 87 & 92.6 & 94 \\
\hline Anterior height of the centrum & 73.9 & 71.8 & 73.7 & 67.8 & $74.8(\mathrm{e})$ & 74.2 & 77.1 \\
\hline Posterior height of the centrum & 73.1 & 70.3 & 76.9 & 72.1 & 71.2 & $72(\mathrm{e})$ & 80 \\
\hline Dorsal length of the centrum & 57.3 & 70.75 & 76.89 & 75.5 & 80.4 & 81.9 & 82 \\
\hline Ventral length of the centrum & 62.7 & 75.27 & 81.72 & 75.7 & 79.8 & 72.3 & 87.3 \\
\hline Width of the neural canal & 52.3 & 66.1 & 71.9 & 70 & 75 & 82 & $75(\mathrm{e})$ \\
\hline \multirow[t]{2}{*}{ Height of the neural canal } & 51.4 & 49.7 & 43.1 & 45.1 & 46.1 & 41 & 35 \\
\hline & T8 & T9 & T10 & T11 & T12 & T13 & T14 \\
\hline Inter-prezygapophysial width & 86 & 84.2 & $88(e)$ & $90(e)$ & 124.6 & 140 & 156.7 \\
\hline Inter-postzygapophysial width & 62.3 & 56 & 67.3 & $70(\mathrm{e})$ & 64.5 & 69 & 71 \\
\hline Prezygapoph.-postzygapophysial length (right side) & $113(e)$ & 109 & $110(\mathrm{e})$ & $134(\mathrm{e})$ & $122(e)$ & 134.9 & 148 \\
\hline Anterior width of the centrum & 91.2 & 97 & 107.4 & 114.3 & 121.4 & 131 & 132 \\
\hline Posterior width of the centrum & 102.5 & $103(e)$ & 121.7 & 131.8 & 136.6 & 139.2 & 134.3 \\
\hline Anterior height of the centrum & 80.5 & 84 & 88.4 & 95.7 & 99.8 & 106.4 & 104 \\
\hline Posterior height of the centrum & 84.3 & $85(e)$ & 97.8 & 97.04 & 108.6 & 109.6 & 113.9 \\
\hline Dorsal length of the centrum & $88(e)$ & 92.6 & 100.8 & 106.4 & $100(e)$ & 119.8 & 124.2 \\
\hline Ventral length of the centrum & 91 & 91.3 & 99.9 & 102 & $111(\mathrm{e})$ & - & 123.3 \\
\hline Width of the neural canal & 79.7 & 78.9 & 79.8 & 83.7 & 81.1 & 77.9 & 79.8 \\
\hline \multirow[t]{2}{*}{ Height of the neural canal } & 42.3 & 40.3 & 39 & 40 & 37.3 & 41.4 & 42 \\
\hline & T15 & T16 & T17 & T18 & T19 & T20 & \\
\hline Inter-prezygapophysial width & 151 & $144.5(\mathrm{e})$ & $154(\mathrm{e})$ & $168.7(\mathrm{e})$ & $153(e)$ & $139(e)$ & \\
\hline Inter-postzygapophysial width & 70 & 68.7 & 66.5 & 63.8 & 65.12 & $53.6(\mathrm{e})$ & \\
\hline Prezygapoph.-postzygapophysial length (right side) & 158 & $160(e)$ & 173(e) & $184.7(\mathrm{e})$ & $194(e)$ & $193(e)$ & \\
\hline Anterior width of the centrum & 135.4 & 133.2 & 135.1 & 138.4 & 138.65 & 145.2 & \\
\hline Posterior width of the centrum & 141.4 & 139.7 & 140.5 & 143 & 142.18 & 146.4 & \\
\hline Anterior height of the centrum & 112.7 & 115.8 & 123.2 & 120.7 & 124 & 131.52 & \\
\hline Posterior height of the centrum & 121.3 & 120.7 & 125.8 & 128.6 & 133 & 137.3 & \\
\hline Dorsal length of the centrum & 120.9 & 125 & 126.2 & 128.4 & 129.7 & 131.6 & \\
\hline Ventral length of the centrum & 116.1 & 124.4 & 119.5 & 122.6 & 123.8 & 126.2 & \\
\hline Width of the neural canal & 77 & 75.7 & 75 & 73 & 75.7 & 68.8 & \\
\hline Height of the neural canal & 44.5 & 43.1 & 44.2 & 47.3 & 48 & 52.5 & \\
\hline
\end{tabular}

and ventral to the posterior ridge is a triangular depression, which forms a posterior notch opening into the neural canal ventrally (Fig. 50B).

Second thoracic (T2) (Fig. 50E-H). The second thoracic in MNHN.F.PRU10 is also well preserved. It resembles more T3 than T1. Its centrum is cylindrical and rounded in cross-section. Its anterior and posterior surfaces are firmly fused with the epiphyses, but are still defined. The centrum of T2 shares with that of $\mathrm{T} 1$ and other anterior thoracics: 1) a ventral surface without large foramina or median keel; 2) an anteroposteriorly concave ventral surface; 3 ) an anterior epiphysis dorsoventrally higher than the posterior epiphysis; and 4) a dorsal surface of the centrum with two large foramina opening into the neural canal. Each dorsolateral corner of the posterior surface of the centrum of T2 bears a triangular fovea for the R3 capitulum. These posterior capitular foveae are more pronounced than the anterior capitular foveae (for the capitulum of R2). The anterior costal capitular foveae lie on the dorsolateral corners of the anterior surface of the centrum. The dorsal edge of the posterior fovea (for R3 capitulum) forms a small crest in the intervertebral notch.
The pedicles are massive, anteroposteriorly broader than wide, and proportionally higher than in T1. They form the lateral edges of the neural canal, which is oval to circular in cross-section. The neural canal is dorsoventrally higher than wide; in anterior view, it is proportionally larger than in T1. The transverse processes bear the foveae for the tubercula of $\mathrm{R} 2$, which are more dorsally located as compared with $\mathrm{T} 1$. The tubercular fovea is laterally facing and oval, being longer than high. Medial to the transverse processes, the prezygapophyses are teardrop-shaped, with the apex of the teardrop being posteromedially directed in dorsal view. Lateral to each prezygapophysis and dorsal to the capitular fovea is a small and barely defined protuberance, certainly homologous of the metapophysis. The postzygapophyses are flat, ventrally facing and oval (in contrast with the rounded postzygapophyses of T1).

The neural spine of $\mathrm{T} 2$ is quite different from that of $\mathrm{T} 1$. In lateral view, it is rectangular, with its dorsal extremity being slightly curved posteriorly. The neural spine of T2 is larger, both proportionally and in absolute size than in T1; it is transversely flattened and blade-shaped. Similarly to the cervical and first thoracic vertebrae, the neural spine widens posteriorly and gets thinner dorsally and anteriorly. 

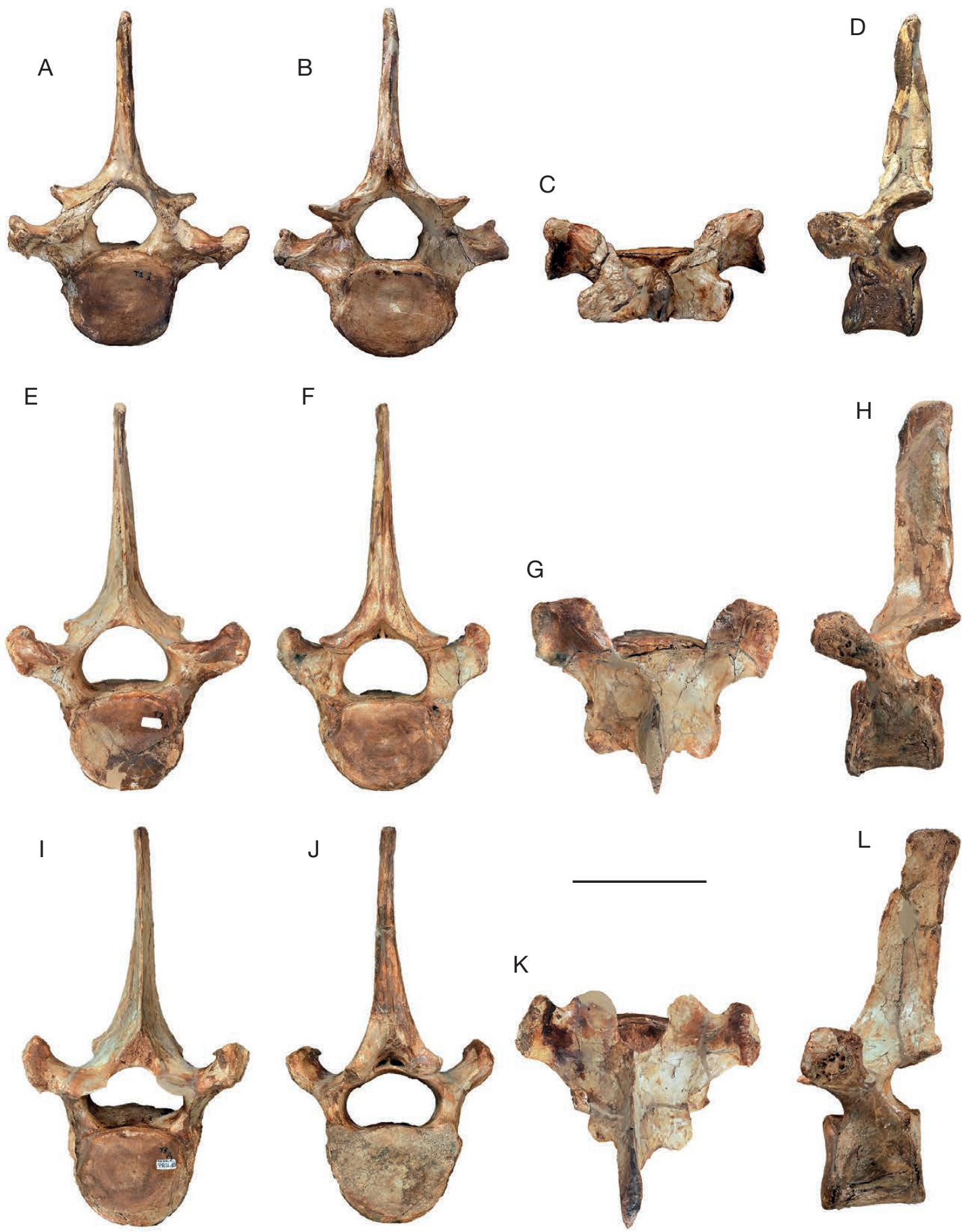

FIG. 50. - Thoracic vertebrae of MNHN.F.PRU10, holotype of Cynthiacetus peruvianus: A, first thoracic vertebra in anterior view; B, first thoracic vertebra in posterior view; C, first thoracic vertebra in dorsal view; D, first thoracic vertebra in left lateral view; $\mathbf{E}$, second thoracic in anterior view; $\mathbf{F}$, second thoracic vertebra in posterior view; G, second thoracic vertebra in dorsal view; $\mathbf{H}$, second thoracic vertebra in left lateral view; I, third thoracic vertebra in anterior view; J, third thoracic vertebra in posterior view; K, third thoracic vertebra in dorsal view; L, third thoracic vertebra in left lateral view. Scale bar: $10 \mathrm{~cm}$.

Therefore, it has a sharp anterior margin and a narrow and transversely compressed posterior surface. As for T1, there is a well-developed ridge on the posterior surface of the spine, bounded by two smooth surfaces for epaxial muscles. These structures are also present in more posterior thoracics.

At the base of the anterior margin of the neural spine, the laminae form a triangular porous depression, bounded later- ally by the prezygapophyses. Similarly, a posterior triangular notch is formed by the laminae at the base of the neural spine. This posterior notch opens ventrally into the neural canal, separates both postzygapophyses, and can be divided into two laterally aligned fossae. The anterior porous surface and the posterior triangular notch are subequal in size. On more posterior vertebrae, they are larger than in T2. 
Third thoracic (T3) (Fig. 50I-L). T3 is quite similar to T2 in both morphology and size. Some differences can however be pointed out. The anterior capitular fovea (for the capitulum of R3) is slightly more distinct than in T2, but remains smaller than the posterior fovea (for the capitulum of R4), which is large and oval. As for T2, the dorsal edge of the posterior fovea forms a conspicuous crest in the intervertebral notch. As in T1 and T2, there is no keel or foramina on the ventral surface of the centrum. Besides, two large foramina lie on the dorsal surface of the centrum and open into the neural canal.

The pedicles are transversely compressed and anteroposteriorly longer than wide. In contrast, in T1 and T2 they are wider than long. In more posterior vertebrae, the transverse compression is even more developed and the pedicles are transversely flattened. The neural canal is oval to rectangular in outline, being transversely wider than high, and having four rounded angles. Its roof (formed by the laminae) is slightly dorsally concave. The neural canal is proportionally more compressed dorsoventrally than in T2. The prezygapophyses are rounded and separated from the transverse processes by a notch, which is absent in T1 and T2 and well developed in more posterior thoracics. Moreover, the transverse distances between right and left postzygapophyses and prezygapophyses are smaller than in T2, and these distances continue to decrease backwards along the vertebral column. On the transverse process, the fovea for the $\mathrm{R} 3$ tuberculum is oval and faces ventrolaterally. This tubercular fovea presents numerous nutrient foramina. Finally, the metapophysis is slightly more pronounced than in T2, but remains inconspicuous.

The neural spine is similar in shape to that of T2, but anteroposteriorly broader and dorsoventrally higher. The spine is slightly posterodorsally inclined; the inclination is more conspicuous in the T4-T6 series. The posterior triangular notch observed at the base of the spine in $\mathrm{T} 2$, is proportionally larger in T3. Similarly, a triangular depression ventral to the anterior margin of the neural spine separates the prezygapophyses.

Fourth thoracic (T4) (Fig. 51A-D). Apart from an increase in size, only a few differences are observed between $\mathrm{T} 3$ and $\mathrm{T} 4$. The centrum of T4 is similar in shape and bears the same features than T3, except for a pronounced depression on the lateral surface of the centrum, ventral to the pedicles. This depression is observed in the T4-T7 series and provides to the centrum an hourglass outline in ventral view. In fact, the centra in T4T7 are very similar. Since both posterior epiphysis and fovea (for the capitulum of R5) are damaged in T4, it is difficult to evaluate if the posterior fovea forms the crest observed in T2 and T3. Such a crest is absent in T5 and posterior thoracics.

The neural arch resembles that of T3. However, the pedicles are even more transversely compressed and the neural canal is roughly rectangular in outline, being transversely wider than high and having rounded angles. The articular surfaces in the prezygapophyses and postzygapophyses are rounded and smaller than in T1-T3. Lateral to the prezygapophyses, the small metapophyses are not well developed and lie dorsal to the transverse processes. The latter present the foveae for the R4 tubercula, which are somewhat triangular, anteriorly pointed and laterally facing.
The neural spine is slightly higher than on T3 and presents the same morphology. In lateral view, the anterior edge and the posterior surface of the neural spine are slightly inclined posterodorsally. At the base of the spine, the anterior triangular porous depression presents two prominent protuberances. The size of the anterior triangular depression and the posterior triangular notch increases progressively in the T4-T7 series, then it decreases in more posterior thoracics (T14-T20).

Fifth thoracic (T5) (Fig. 51E-H). The centrum and neural canal of T5 are similar to those of T4. The only difference observed is the less pronounced depression on the lateral surface of the centrum of T5. Both anterior and posterior capitular foveae (for the capitula of R5 and R6, respectively) are subequal in size and larger than in T1-T3; the dorsal surface of the centrum has two large foramina; and the neural canal is transversely broader than dorsoventrally high. The prezygapophyses, postzygapohyses, transverse processes and foveae for the tubercula of $\mathrm{R} 5$ have the same morphology as in T4. The metapophysis is damaged on the right side; it was most likely as prominent as in T4.

Finally, the neural spine is posterodorsally inclined and slightly anteroposterioly longer than that in T4. The neural spine is dorsoventrally lower than in T4 and higher than in T6.

Sixth thoracic (T6) (Fig. 51I-L). The anterior and posterior epiphyses of the vertebral body are incomplete in T6, the anterior epiphysis being less complete than the posterior epiphysis. As indicated above, the morphology of T4-T7 is very similar and the descriptions of T4 and T5 match the description of T6: a cylindrical centrum, being roughly circular in cross-section; large and subequally sized anterior and posterior capitular foveae; lateral depression on the lateral surface of the centrum; no foramen or keel on the ventral surface of the centrum; pedicles being strongly compressed transversely; rectangular neural canal, with rounded angles, and being transversely wider than high; and dorsal process of the metapophysis not well-developed.

While the complete anterior epiphysis is circular, the ventral portion of the posterior epiphysis is missing. The latter has been reconstructed based on the posterior surface of the centrum; it was probably less circular than the anterior epiphysis, being roughly heart-shaped. The anterior and posterior foveae are slightly anterolaterally and posterolaterally facing, respectively. Moreover, the depression on the lateral surface of the centrum is more accentuated than in T5, and thus the hourglass-like outline in ventral view is more pronounced. As in T5 and probably T4, the anterior capitular fovea (for T6 capitulum) does not form a crest at the intervertebral notch. The centrum bears numerous nutrient foramina, which are especially visible on its right lateral and dorsal surfaces.

On the transverse process, the fovea for the sixth rib tuberculum is slightly more dorsal than in T5 and oval to elliptical in outline. The metapophysis is damaged and might have been slightly more developed than in $\mathrm{T} 5$, being slightly anterodorsally directed. Although both the prezygapophyses and the postzygapophyses decrease in size backwards along the thoracic region, their articular surfaces remain functional. As a consequence of 

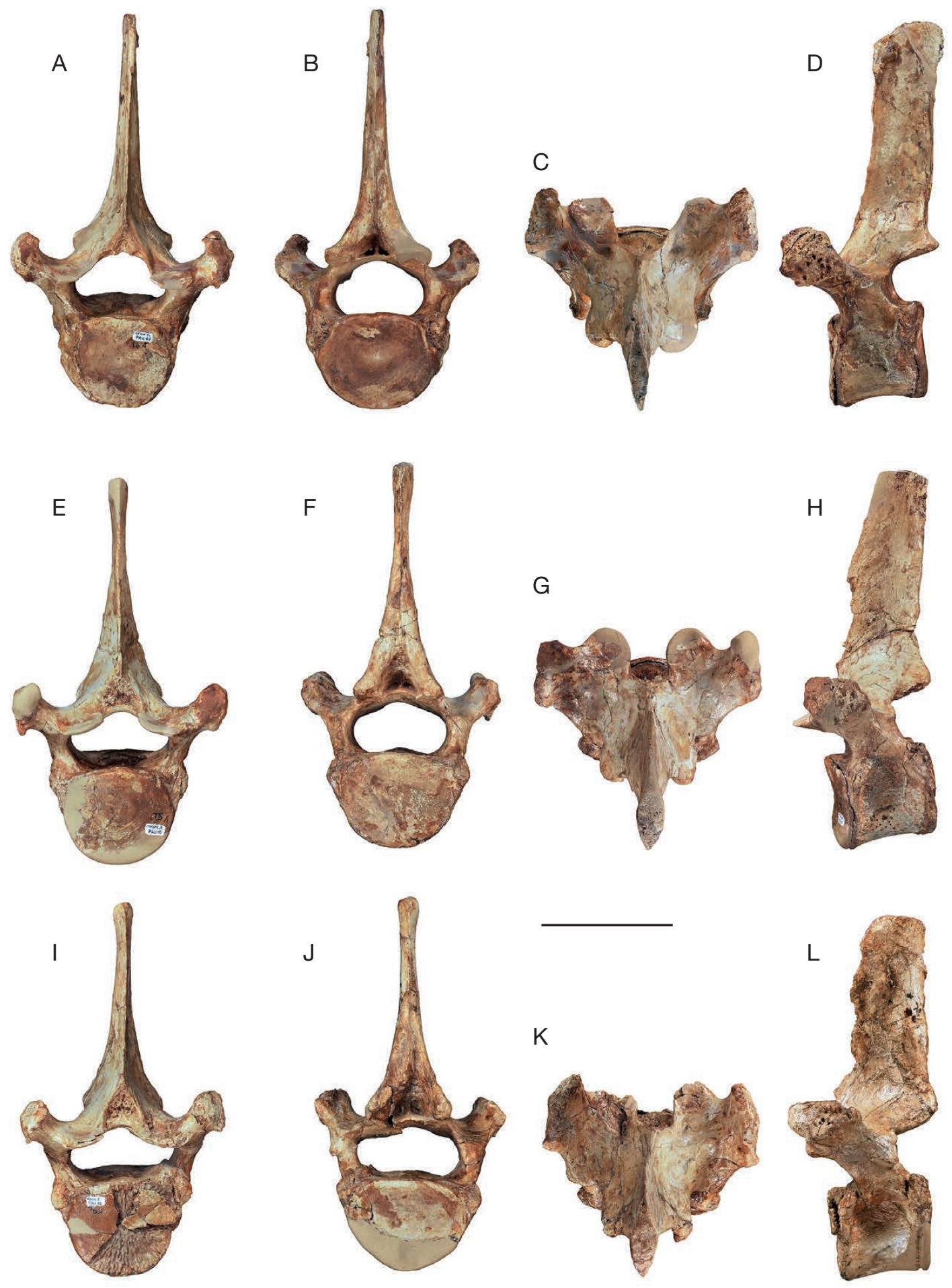

FIG. 51. - Thoracic vertebrae of MNHN.F.PRU10, holotype of Cynthiacetus peruvianus: A, fourth thoracic in anterior view; B, fourth thoracic in posterior view; $\mathbf{C}$, fourth thoracic in dorsal view; $\mathbf{D}$, fourth thoracic in left lateral view; $\mathbf{E}$, fifth thoracic in anterior view; $\mathbf{F}$, fifth thoracic in posterior view; $\mathbf{G}$, fifth thoracic in dorsal view; $\mathbf{H}$, fifth thoracic in left lateral view; I, sixth thoracic in anterior view; J, sixth thoracic in posterior view; K, sixth thoracic in dorsal view; $\mathbf{L}$, sixth thoracic in left lateral view. Scale bar: $10 \mathrm{~cm}$.

the development of the metapophysis, the neural arch of T6 is transversely broader than in more anterior thoracics (especially T3-T5; Figs 50, 51). The increase in width of the neural arch is even more pronounced in more posterior thoracics.
Finally, the neural spine resembles that of 44 and T5, being only slightly anteroposteriorly shorter and less posterodorsally inclined. Moreover, it is slightly dorsoventrally lower than the spine in $\mathrm{T} 5$. 
Seventh thoracic (T7) (Fig. 52A-D). The centrum is cylindrical and roughly circular in cross-section. Similarly to more anterior thoracics, both epiphyses are fused to the centrum but remain well defined. The depression on the lateral surface of the centrum is as pronounced as in $\mathrm{T} 6$, with an hourglass-shaped centrum in ventral view. In contrast with more anterior vertebrae, the ventral surface of the centrum presents a hardly recognizable longitudinal ridge at midline. The dorsal surface of the centrum is flat.

The foveae for the seventh and eighth rib capitula are subequal in size and roughly triangular. The anterior fovea (for R7 capitulum) is more laterally facing than in more anterior thoracics. In more posterior thoracics, this fovea migrates progressively towards the lateral surface of the centrum. The pedicles resemble those of the T3-T6 series, being strongly compressed transversely and anteroposteriorly elongated. The neural canal was distorted during the fossilization process, but it can be described as being roughly rectangular with rounded angles, as in other thoracics.

The prezygapophyses are flat, oval and dorsally facing. Lateral to them, the well-developed metapophyses extend dorsally into a robust and massive process, which is anterodorsally directed. On the transverse process, the fovea for the tuberculum of R7 is somewhat triangular and posteriorly pointing.

As compared with more anterior thoracics (T3-T6), the neural spine is vertical and not posterodorsally inclined; it is not significantly higher than the spine of T6.

Eighth thoracic (T8) (Fig. 52E-H). The morphology of T8 is slightly different from the anterior series (T4-T7), and resembles much more the more posterior series (T8-T14). From T8 to T14, the length, height, and especially the width of the centrum increase markedly and continuously. As indicated above, the length does not increase drastically as is observed in the Basilosaurinae, and the width and height evolve isometrically.

As compared to more anterior thoracics, the depression on the lateral surface of the centrum is much reduced in T8. This depression is absent in more posterior vertebrae. Therefore, the centrum is not hourglass-shaped in ventral view. Moreover, the ventral surface presents a faint median ridge, which runs anteroposteriorly. The anterior epiphysis is incomplete and seems to be transversely broader in its dorsal half. The fusion of the anterior epiphysis with the centrum is less pronounced than that of the posterior epiphysis. In more posterior vertebrae, the fusion becomes less evident, until the complete separation of the epiphyses from the centrum. Two large foramina open into the neural canal on the flat dorsal surface of the centrum. The anterior fovea (for R8 capitulum) is oval and more laterally facing than in T9. Its migration towards the anterodorsal corner of the lateral surface of the centrum is more pronounced than in T8. The posterior fovea (for R9 capitulum) is smaller than the anterior fovea.

The pedicles are slightly more elongated than in T7. The neural canal is similar to that of other thoracics (rectangular with rounded angles). The transverse process is shorter than in more anterior thoracics and the fovea for the eighth rib tuberculum is triangular and posteriorly pointing. The metapophysis is well preserved only in the right side, where it is massive and anterodorsally pointed. Medially, the notch separating the prezygapophysis from the metapophysis is hardly distinguishable. The anteroposterior distance between the anterior edge of the prezygapophysis and the posterior edge of the postzygapophysis is more important than in more anterior thoracics. This increase in length continues in more posterior vertebrae (pre- post-zygapophysial length in Table 7)

The neural spine is only partly preserved; it is impossible to evaluate its original height. It is vertical in lateral view and was probably rectangular. Both the anterior triangular depression and the posterior triangular notch at the base of the neural spine are proportionally smaller than in T7. Both structures remain subequally sized along the T8-T13 series.

Ninth thoracic (T9) (Fig. 52I-L). T9 is proportionally larger than T8. Its centrum is cylindrical and presents a barely defined median ridge on its ventral surface. Its posterolateral portion is damaged and only the right portion of the posterior epiphysis is preserved. Dorsally, the two foramina opening into the neural canal are large and close to each other. The anterior fovea (which receives the R9 capitulum) is much larger than in more anterior thoracics and it is located on the anterodorsal corner of the lateral surface of the centrum. The anterior fovea is triangular, laterally facing and just ventral to the pedicles. Its ventral edge is sharp and forms a posterodorsally inclined crest on the lateral surface of the centrum. No foramen is observed on the ventral surface. There is no posterior fovea on the posterior surface of the centrum and therefore the capitulum of R8 contacts exclusively T8. A similar feature is present in all thoracics posterior to $\mathrm{T} 8$.

The neural arch is similar to that of other thoracics (horizontal rectangle with rounded angles in outline). On the transverse process, the fovea for the $\mathrm{R} 9$ tuberculum, is triangular, concave and laterally facing. As compared with more anterior thoracics, the prezygapophyses and postzygapophyses of $\mathrm{T} 9$ are reduced, but were probably functional. This reduction persists in more posterior thoracics (cf. below). In contrast, the metapophysis extends anterodorsally, forming a prominent and transversely compressed process that is even more pronounced in more posterior thoracics. There is no conspicuous notch separating the prezygapophysis from the metapophysis.

Most of the anterodorsal portion of the neural spine is missing, but most of the posterior edge is preserved. The neural spine was probably similar in outline to those of T8 and T7, and the posterior ridge of the narrow posterior surface is less pronounced than in T8.

Tenth thoracic (T10) (Fig. 53A-D). The centrum of T10 is significantly larger than that of T9 (in height and width). It is cylindrical and has an almost circular cross-section. The epiphyses are not completely fused to the centrum and remain easily distinguishable. The lateral and ventral surfaces are smooth and do not present any ridge or depression. A single foramen is located close to the midline, on each side of the ventral surface of the centrum. Similarly, two large foramina 

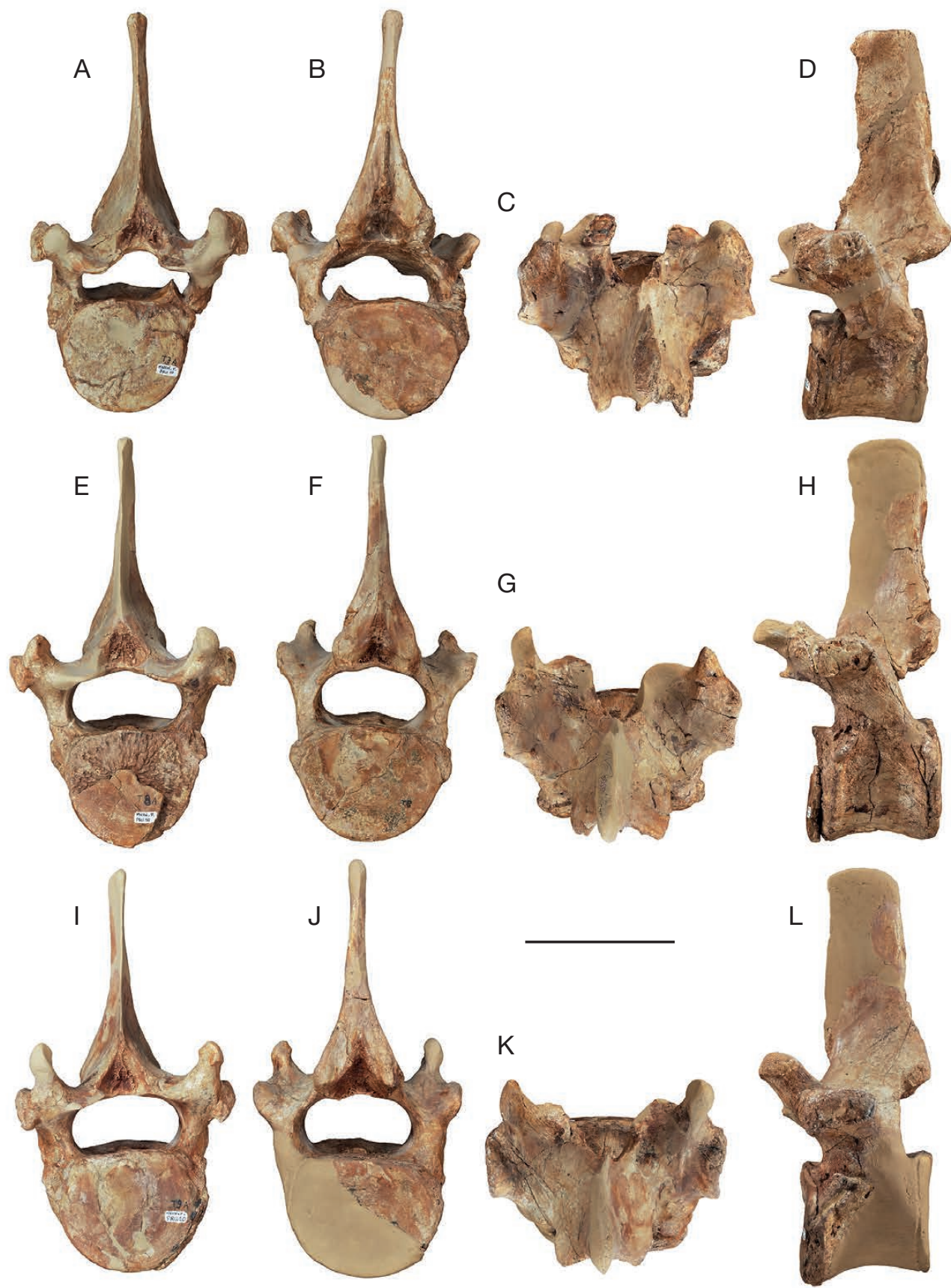

FIG. 52. - Thoracic vertebrae of MNHN.F.PRU10, holotype of Cynthiacetus peruvianus: A, seventh thoracic in anterior view; $\mathbf{B}$, seventh thoracic in posterior view; $\mathbf{C}$, seventh thoracic in dorsal view; D, seventh thoracic in left lateral view; E, eighth thoracic in anterior view; $\mathbf{F}$, eighth thoracic in posterior view; G, eighth thoracic in dorsal view; $\mathbf{H}$, eighth thoracic in left lateral view; I, ninth thoracic in anterior view; J, ninth thoracic in posterior view; $\mathbf{K}$, ninth thoracic thoracic in dorsal view; L, ninth thoracic in left lateral view. Scale bar: $10 \mathrm{~cm}$.

open into the neural canal on the dorsal surface of the centrum. The capitular fovea (for the T10 capitulum) lies on the anterodorsal corner of the lateral surface of the centrum. It is similar to that in T9, being triangular, anteriorly pointed and laterally facing.

The pedicles are strongly elongated and the transverse process does not extend as laterally as in more anterior thoracics. The fovea for the R9 tuberculum is large, and medially concave. It is oval in outline, being anteroventrally inclined in lateral view. The left metapophysis is preserved, slightly higher and more anteriorly expanded than in T9. Medial to the metapophysis, the prezygapophysis is strongly reduced and the contact with the postzygapophysis of T9 was probably either reduced or absent. Posteriorly, the postzygapophyses are oval, small and probably did not contact the prezygapophyses of T11. In fact, posterior to $\mathrm{T} 9$, there is most likely no intervertebral contact between the prezygapophyses and postzygapophyses.

The neural canal has the same outline as in anterior thoracics. The neural spine is incomplete, with only about one third preserved ventrally. It was slightly anteroposteriorly longer 
than those of T8 and T9, and we can estimate that it was also rectangular and vertical in lateral view, with a sharp anterior edge and a narrow posterior surface. The posterior notch at the base of the neural spine is smaller than in anterior thoracics and is not separated into two laterally aligned fossae.

Eleventh thoracic (T11) (Fig. 53E-H). The centrum of T11 is larger in all dimensions than that of T10. It is subcylindrical and slightly oval in cross-section, being transversely wider than dorsoventrally high. Its dorsal surface is roughly flat and the posterior epiphysis is not fused to the posterior surface of the centrum. Similarly, the fusion of the anterior epiphysis is less pronounced than in more anterior thoracics. The posterior epiphysis is poorly preserved and only a portion of the left side is present. Small nutrient foramina are observed on the ventral and lateral surfaces of the centrum. A larger foramen lies on the left side of the ventral surface, near the midline.

On the lateral surface of the centrum, the fovea for the rib capitulum is more ventrally located that in T10. This fovea is larger than in more anterior thoracics (especially T1-T8), but remains smaller than the tubercular fovea for R11. The latter is oval, located at the lateral extremity of the short transverse process and posterolaterally facing. The transverse process has migrated ventrally and is located at the level of the pedicle, level to the ventral half of the neural canal. The capitular and tubercular foveae are separated by a large notch, which runs anteroposteriorly at the dorsal margin of the lateral surface of the centrum. The transverse process is even more ventrally located in more posterior thoracics, until it fuses with the capitular fovea, making then a single costal fovea (cf. below). On the neural arch and medial to the level of the transverse process, the metapophysis is strongly developed and extends anterodorsally, as in T9 and T10. The prezygapophysis is more reduced than in T10 and can hardly be recognized as an apophysis; it is a narrow and triangular surface, being an anteromedial projection of the medial surface of the metapophysis. A large part of the postzygapophyses is missing, and it is not possible to characterize their posterior extension. At this level, the posterior intervertebral notch (formed by the postzygapohyses, pedicles and dorsal surface of the centrum) is more pronounced than in more anterior vertebrae. This intervertebral notch becomes gradually more pronounced in posterior vertebrae (from T12 to T20).

Only a basal portion of the neural spine is preserved. At this level, the spine is as long anteroposteriorly as in T9 and T10. As in T8-T10, the anterior porous surface and the posterior triangular notch are smaller than in T7.

Twelfth thoracic (T12) (Fig. 53I-L). The overall shape of T12 is similar to that of T11. Except for the larger size, a few differences can be pointed out. The centrum of T12 is markedly cylindrical and somewhat oval in cross-section, having a flat dorsal surface with two large foramina. The fusion of the epiphyses with the centrum is more accentuated in the anterior surface. A small foramen can be observed near the midline, on the left side of the ventral surface of the centrum. The number and size of the foramina on the ventral surface of the centrum increase in more posterior vertebrae. On the lateral surface of the centrum, the capitular fovea (for R12 capitulum) is somewhat squared. It is more ventrally located than in T11, being at about the level of the mid-height of the centrum. The fovea for the R12 tuberculum is teardrop-shaped, with the apex of the drop anteriorly oriented. The tubercular fovea lies on the lateral extremity of a very short transverse process, and is located at the level of the dorsal surface of the centrum. Although both capitulum and tuberculum are closely approximated on the lateral surface of the centrum, they remain separated by a narrow sulcus.

The neural canal has the same morphology as in anterior thoracics. The pedicles are as anteroposteriorly elongated as in $\mathrm{T} 11$ and the posterior intervertebral notch is less pronounced than in more anterior thoracics. As in T11, the tubercular fovea (for the R12 tuberculum) is posterolaterally facing. The neural spine, left metapophysis and both postzygapophyses are missing in T12. The right metapophysis is massive and less elevated than in T11. The prezygapophyses are even more reduced than in more anterior vertebrae and lie on the medial margin of the metapophysis. The anterior porous surface and the posterior triangular notch at the base of the neural spine are proportionally smaller than in T11.

Thirteenth thoracic (T13) (Fig. 54A-D). The centrum of T13 is cylindrical and slightly oval in cross-section, being transversely wider than high. The anterior epiphysis is damaged and only its right half is preserved. Both the anterior and posterior epiphyses are not fused to the centrum. The dorsal and ventral surfaces of the centrum present nutrient foramina (two large foramina on the flat dorsal surface and two small foramina on the convex ventral surface).

The short transverse process has entirely migrated on the lateral surface of the centrum and bears both the tubercular and capitular foveae (for R13 tuberculum and capitulum). The foveae are separated by a narrow sulcus; they are merged into a common fovea in more posterior thoracics (from T14). Both foveae are roughly triangular, the tubercular fovea being slightly larger than and dorsal to the capitular fovea. The right transverse process is damaged and the costal foveae are missing on this side.

Dorsally, the neural arch and canal are similar to those in T12. The pedicles are transversely flattened and the prezygapophyses and postzygapophyses lack any articular surface. The metapophyses are incomplete but were probably well developed and anterodorsally oriented. The neural spine lacks its dorsal portion and its original height cannot be evaluated.

Fourteenth thoracic (T14) (Fig. 54E-H). Posterior to T13, the thoracic vertebrae are similar to each other and only a few differences can be pointed out. The centrum of T14 resembles that of T13 in being cylindrical and oval in cross-section. The anterior epiphysis is not fused to the centrum, while the posterior epiphysis is entirely fused. The dorsal and ventral surfaces of the centrum present two large foramina, each one being lateral to the midline and bounded by numerous smaller nutrient foramina. 

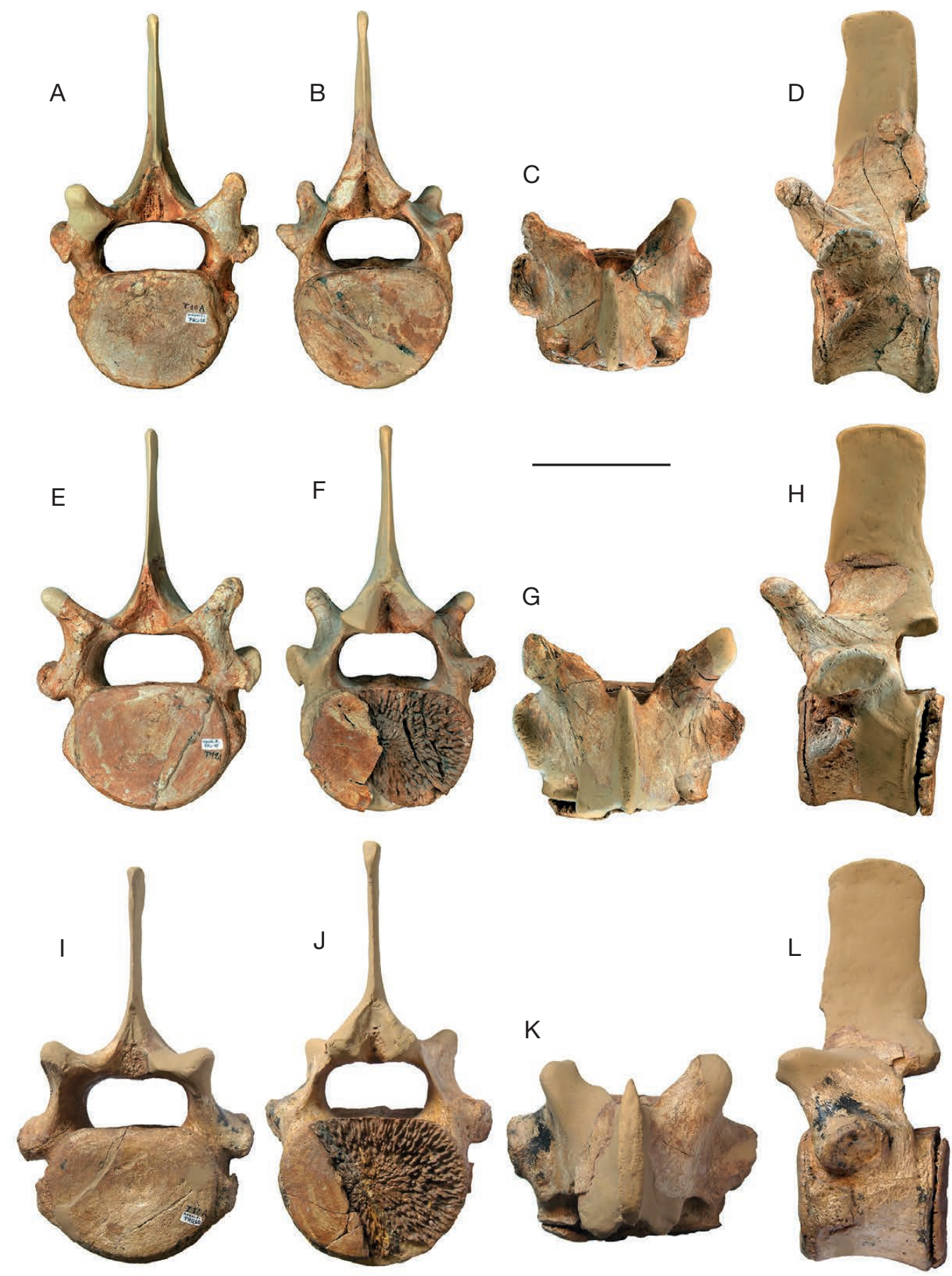

FIG. 53. - Thoracic vertebrae of MNHN.F.PRU10, holotype of Cynthiacetus peruvianus: A, tenth thoracic in anterior view; B, tenth thoracic in posterior view; $\mathbf{C}$, tenth thoracic in dorsal view; D, tenth thoracic in left lateral view; E, eleventh thoracic in anterior view; $\mathbf{F}$, eleventh thoracic in posterior view; G, eleventh thoracic in dorsal view; $\mathbf{H}$, eleventh thoracic in left lateral view; I, twelfth thoracic in anterior view; $\mathbf{J}$, twelfth thoracic in posterior view; $\mathbf{K}$, twelfth thoracic thoracic in dorsal view; L, twelfth thoracic in left lateral view. Scale bar: $10 \mathrm{~cm}$.

On the lateral surface of the centrum, the transverse process presents a single costal fovea for T14, resulting from the fusion of the capitular and tubercular foveae. This fovea occupies almost the entire lateral surface of the transverse process and is somewhat teardrop-shaped, with the apex of the drop being anteroventrally oriented. The dorsal edge of the transverse process is at the level of the dorsal surface of the centrum.
The neural canal, pedicles and metapophyses have the same morphology as in more anterior vertebrae (cf. above). Although the prezygapophyses are non-functional, they remain as small triangular surfaces on the medial margin of the metapophyses. Additionally, the neural arch and the postzygapophyses are respectively, anteroposteriorly longer and smaller than in T13. Only the basal portion of the neural spine is preserved and, although its original height cannot be estimated, it is 
probable that the spine was vertical. The anterior triangular depression and posterior triangular notch at the base of the neural spine are smaller than in T13.

Fifteenth thoracic (T15) (Fig. 54I-L). As mentioned above, T14-T20 are very similar in outline. The centrum, pedicles and neural arch of T15 are similar to those of T14 in having: 1) a cylindrical centrum fused with the posterior epiphysis; 2) two large foramina on the ventral surface of the centrum; 3 ) the neural canal being transversely rectangular with rounded angles; 4) transversely flattened pedicles; 5) reduced and non-functional zygapophyses; and 6) well developed metapophyses.

The centrum is more sub-circular in cross-section that in more anterior thoracics. Its anterior surface is not fused with the anterior epiphysis but firmly attached. Its lateral surface bears numerous nutrient foramina around the right transverse process. The large nutrient foramina on the ventral surface of the centrum are lateral to a low median ridge. In contrast with the more anterior vertebrae, there is only one large foramen on the dorsal surface of the centrum. The transverse processes are ventrolaterally oriented and more ventrally located than in T14. At their lateral end, the costal foveae for the R15 are deeper and smaller than those of T14. The costal foveae are rounded-to-squared in outline and slightly posterolaterally facing.

The neural arch of T15 is proportionally longer than in more anterior thoracics. Although only the base of the neural spine is preserved, it is likely that it was vertical and anteroposteriorly long, as in T14.

Sixteenth thoracic (T16) (Fig. 55A-D). The centra of T16 and T15 are subequal in size and share the same morphology. The anterior surface of the centrum is not fused to the anterior epiphysis. Although the posterior epiphysis is fused to the centrum, its suture is distinct in lateral view. Numerous nutrient foramina lie on the lateral and ventral surfaces of the centrum (larger on the ventral surface).

T16 differs essentially from $\mathrm{T} 15$ in the position and size of the transverse process. The transverse process of T16 is longer and more ventrally located than in T15. It extends ventrolaterally from the ventral margin of the lateral surface of the centrum. The transverse process is roughly tubular, being oval in cross-section and having a deep fovea for the head of the sixteenth rib at its lateral end. This fovea is missing on the left side, where the transverse process is incomplete.

Dorsally, the pedicles, neural canal, prezygapophyses, metapophyses and postzygapophyses show no differences when compared with more anterior vertebrae (T14-T15). At this level, the right metapophysis is damaged.

Similar to other vertebrae, the neural spine is incomplete and only a basal portion is preserved. In lateral view, the posterior surface of the neural spine is vertical. Finally, the anterior and posterior depressions at the base of the neural spine are significantly more reduced than in more anterior thoracics.

Seventeenth thoracic (T17) (Fig. 55E-H). The centrum of T17 is only slightly larger than that of T16; it is cylindrical and rounded in cross-section. The epiphyses are partially fused to the centrum but the fusion of the posterior epiphysis is more advanced than that of the anterior. The lateral and dorsal surfaces of the centrum present numerous nutrient foramina, which are larger on the dorsal surface of the centrum. Besides, a very large foramen lies on the right side of the ventral surface of the centrum, just lateral to midline. In more posterior vertebrae, the ventral nutrient foramina are larger and more numerous than in T17.

Similarly to T16, the most important feature distinguishing T17 from more anterior thoracics is the shape and size of the transverse process. The right transverse process is missing and the left one is partially damaged. As in T16, the transverse process is located at the ventrolateral corner of the centrum. It is dorsoventrally compressed with a more elongated costal fovea.

Dorsally, there is no difference between the neural arch of T17 and the arch in more anterior vertebrae. Part of the metapophyses and most of the neural spine are missing on T17. Just medial to the metapophyses, the prezygapophyses are still present as narrow triangular surfaces.

Eighteenth thoracic (T18) (Fig. 55I-L). The centrum of T18 is cylindrical and rounded in cross-section. Similarly to T17, the posterior epiphysis is more fused to the centrum than the anterior epiphysis. Two large foramina are observed in ventral view, near to the midline. The right foramen is considerably larger than the left one.

Two conspicuous features characterize T18 and distinguish it from more anterior vertebrae: 1 ) the transverse process (with the distal extremity and the costal foveae missing on both sides) is longer than in T16 and T17, extending ventrolaterally from the ventrolateral corner of the centrum and being dorsoventrally compressed; 2) the neural canal is transversely narrower than in more anterior thoracics, a feature accentuated in more posterior vertebrae (including the lumbar region).

Dorsal to the neural canal, the metapophyses, postzygapophyses and prezygapophyses have the same morphology as in more anterior thoracics. The neural spine is also incomplete and was probably vertical. The anterior and posterior depressions at the base of the spine are smaller and shallower than in T17.

Nineteenth thoracic (T19) (Fig. 56A-D). The centrum of T19 is cylindrical, circular in cross-section, and fused with its anterior and posterior epiphyses. It possesses two large foramina on its ventral surface. From the ventrolateral corner of the centrum, the transverse process extends ventrolaterally and was probably longer than in more anterior thoracics. In fact, most of the transverse process is missing on both sides and the size and form of the costal fovea cannot be evaluated.

Dorsally, the neural canal is narrower and lower than in T18 and is less dorsoventrally compressed than in T17. The pedicles are transversely flattened and the metapophyses are well-developed on the dorsal surface of the neural arch. The right metapophysis is incomplete and lacks its dorsal extremity. The zygapophyses are extremely reduced, not displaying any articular surface. 

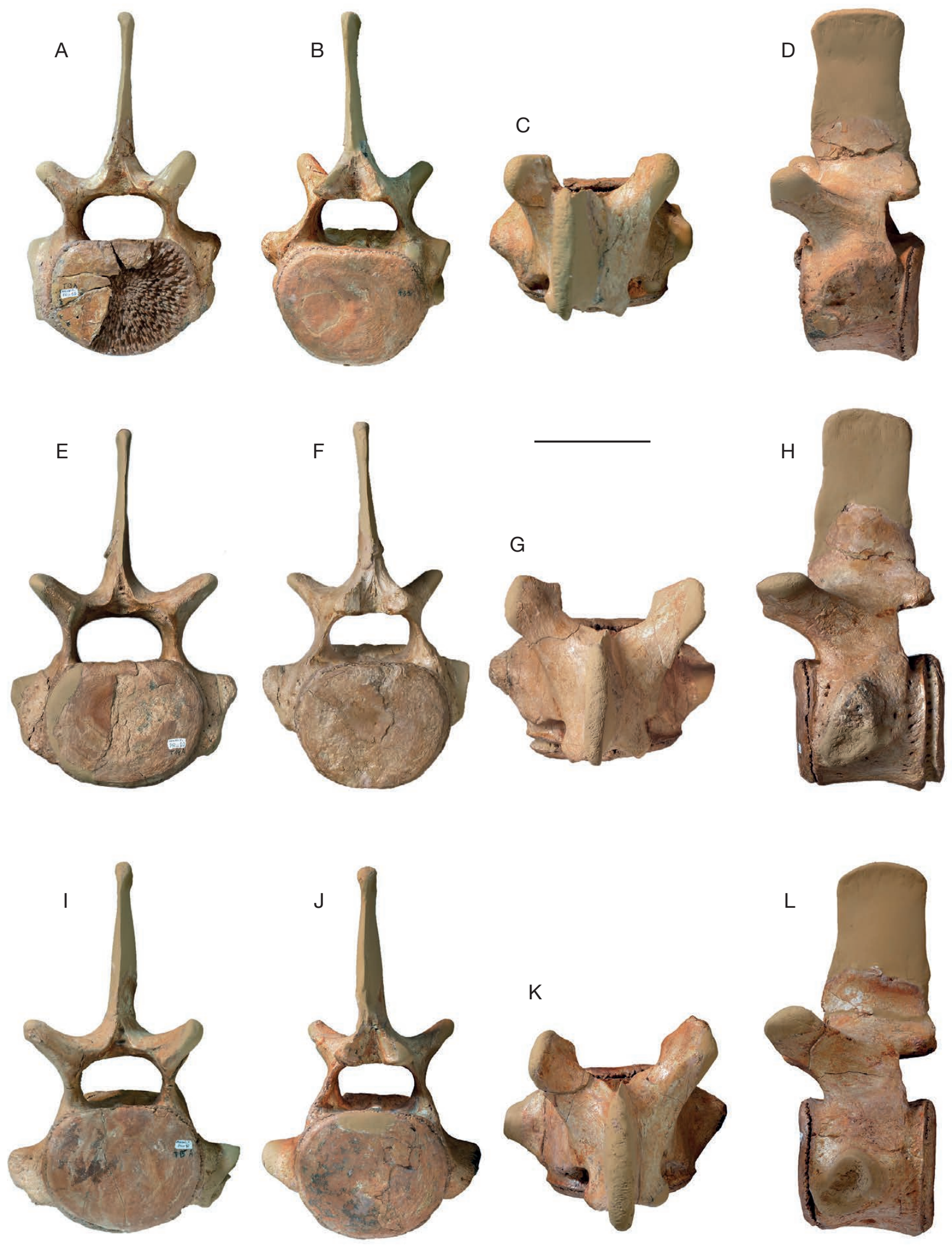

FIG. 54. - Thoracic vertebrae of MNHN.F.PRU10, holotype of Cynthiacetus peruvianus: A, thirteenth thoracic in anterior view; B, thirteenth thoracic in posterior view; $\mathbf{C}$, thirteenth thoracic in dorsal view; $\mathbf{D}$, thirteenth thoracic in left lateral view; $\mathbf{E}$, fourteenth thoracic in anterior view; $\mathbf{F}$, fourteenth thoracic in posterior view; $\mathbf{G}$, fourteenth thoracic in dorsal view; $\mathbf{H}$, fourteenth thoracic in left lateral view; I, fifteenth thoracic in anterior view; J, fifteenth thoracic in posterior view; K, fifteenth thoracic thoracic in dorsal view; L, fifteenth thoracic in left lateral view. Scale bar: $10 \mathrm{~cm}$. 
A large portion of the neural spine is preserved in T19. Its posterior surface is posterodorsally inclined in lateral view, rather than vertical as in more anterior thoracics. Finally, the anterior and posterior depressions at the base of the spine are very small.

Twentieth thoracic (T20) (Fig. 56E-H). The centrum of T20 is cylindrical and circular in cross-section. It is fused to the anterior and posterior epiphyses, which are circular and discshaped. The ventral and dorsal surfaces of the centrum have two large foramina, near the midline. The right foramen is smaller than the left, on both the ventral and dorsal surfaces. The transverse process is missing for almost its entire length. However, its base distinctly projects ventrolaterally from the ventrolateral corner of the centrum.

Similarly to T18 and T19, the transversely flattened pedicles are dorsoventrally higher than in more anterior vertebrae. Consequently, the neural canal is higher than wide. Dorsal to the neural canal, the neural arch is similar to that observed in more anterior thoracics and presents no articular surface. Part of right metapophysis, posterior postzygapophyses, and most of the neural spine are missing. There is no anterior or posterior depression at the base of the neural spine.

Ribs (R1 to R20) (Figs 57, 58, 59, 60). Among the twenty pairs of ribs, only the left twentieth rib (R20) is entirely missing in MNHN.F.PRU10. As in other basilosaurids (Uhen 2004; Buffrénil et al. 1990), the ribs are osteoclerotic and lack a medullary cavity. Moreover, their expanded apex may reflect some degree of pachyostosis (Dechaseaux 1961; Buffrénil et al. 1990; but see comments in Houssaye et al. 2015). Among fully aquatic Recent mammals, only the Sirenia present a pachyosteosclerotic rib cage (Domning 1977; Maas 2008).

All the ribs are laterally convex in anterior and posterior views. The curvature of the shaft increases from R1 to R8, and then decreases posteriorly. Only some ribs are fragmentary and partially preserved. The distal portions of the ribs are poorly preserved; when present, most of them display a rough, irregular surface, which indicates the presence of a cartilaginous end. In more anterior ribs, the cartilaginous end should continue into the costal cartilage, which extends ventrally and contacts the lateral margin of the sternum. Costal measurements are presented in Table 8 and follow those proposed for Dorudon atrox by Uhen (2004).

The first rib (R1) is the shortest one in the whole series (R1-R20). While the right $\mathrm{R} 1$ is entirely preserved, only the left $\mathrm{R} 1$ tuberculum is present. The shaft of R1 is strongly compressed anteroposteriorly and its angle (position where the curvature of the shaft is the most pronounced) is closer to the proximal extremity than to the distal end. Proximally, the $\mathrm{R} 1$ capitulum contacts the transverse process of the seventh cervical, while the tuberculum contacts the tubercular fovea in the transverse process of T1. Distally, the shaft is slightly more rounded in cross-section. No transverse inflation is observed in this region in $\mathrm{R} 1$.

Only the proximal half of the second rib (R2) is preserved on both sides. The curvature of R2 is more pronounced than in R1, and its shaft is also anteroposteriorly compressed. Moreover, the angle is proportionally closer to the articular surfaces than in R1. Proximally, the capitulum and tuberculum are separated by a distinct notch, which extends on the posterior surface of the rib, forming a shallow depression. The R2 tuberculum is transversely broader than the capitulum. The latter contacts both the posterior capitular fovea of T1 and the anterior capitular fovea of T2.

The third to ninth ribs (R3-R9) share the same morphology and differ from the most anterior ribs in being longer and proportionally more slender. Their length increase backwards, except for R9, which is shorter than R8 (Table 8). R3 to R9 are more curved than the first two ribs and their angle is more proximally located. The proximal portion of the costal shaft becomes more rounded in cross-section posteriorly, while the distal portion remains anteroposteriorly compressed. The distal end of R3-R9 presents a pronounced transverse inflation. It differs from the club-like extremity of the ribs in Basilosaurus, which has a circular cross-section. In Cynthiacetus peruvianus, the inflated apex is expanded in one plane, being thus anteroposteriorly flattened. The distal inflation is more pronounced in R3-R6 and decreases progressively in more posterior ribs; it is faint in R9 and absent in more posterior ribs.

Similarly to R1 and R2, the capitulum and the tuberculum of R3-R9 are separated from each other, although they become closer in more posterior ribs. The capitulum is more rounded in outline, while the tuberculum is oval and slightly larger than the capitulum.

The seventh (R7) and eighth (R8) ribs are the longest ribs in C. peruvianus and present the most pronounced curvature of the shaft. Posterior to R9, costal length and curvature decrease progressively posteriorly.

In R2-R8, the capitulum contacts the anterior capitular fovea of its corresponding vertebra $\left(T_{n}\right)$, as well as the posterior capitular fovea of the preceding thoracic vertebra $\left(\mathrm{T}_{\mathrm{n}-1}\right)$. Therefore, $\mathrm{R} 2$ to $\mathrm{R} 8$ have a triple articulation with the vertebral column (2 capitular and 1 tubercular articulations). The contact of the capitulum with its corresponding vertebra becomes progressively larger in more posterior ribs, at the expense of the contact with the preceding vertebra. In fact, $\mathrm{R} 8$ is the posteriormost rib that has a triple contact with the vertebral column.

Posterior to R8, in the R9-R13 series, the capitulum exclusively contacts the capitular fovea of its corresponding thoracic vertebra and the ribs have a double contact with the vertebral column (one capitular and one tubercular articulations). The capitulum and the tuberculum are separated by a notch in R9 and R10; they are adjacent but still distinguishable from each other in R11-R13; finally, they merge into a single articular head in R14-R20. The size of this proximal articular head decreases posteriorly.

Posterior to R16, the shortening of the costal shaft is more pronounced. The distal extremity of the corresponding ribs is anteroposteriorly compressed and it thus presents two sharp and well-distinguished medial and lateral edges. Finally, the posteriormost ribs are small and laterally convex sticks. 

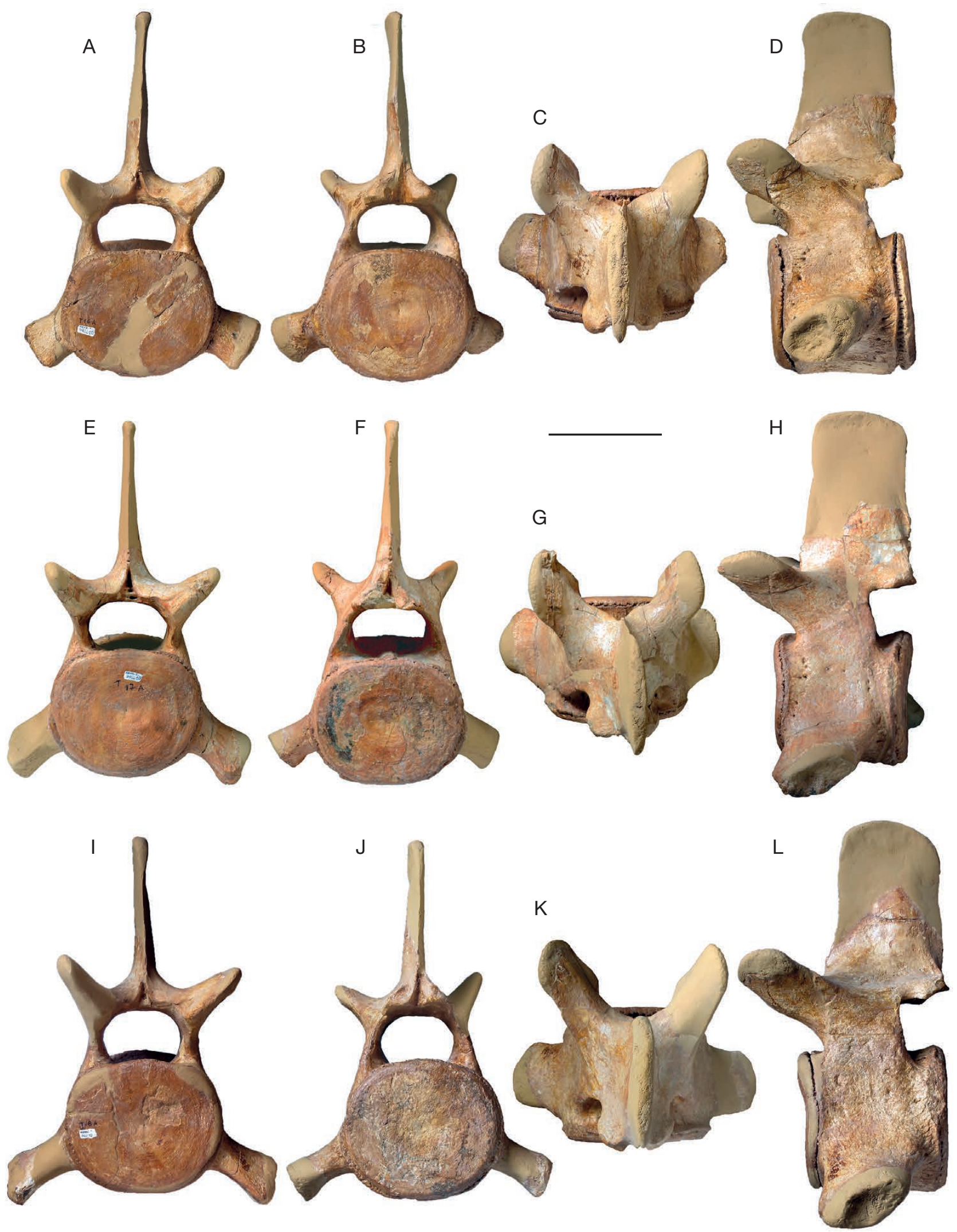

FIG. 55. - Thoracic vertebrae of MNHN.F.PRU10, holotype of Cynthiacetus peruvianus: A, sixteenth thoracic in anterior view; B, sixteenth thoracic in posterior view; C, sixteenth thoracic in dorsal view; D, sixteenth thoracic in left lateral view; E, seventeenth thoracic in anterior view; F, seventeenth thoracic in posterior view; G, seventeenth thoracic in dorsal view; H, seventeenth thoracic in left lateral view; I, eighteenth thoracic in anterior view; J, eighteenth thoracic in posterior view; K, eighteenth thoracic thoracic in dorsal view; L, eighteenth thoracic in left lateral view. Scale bar: $10 \mathrm{~cm}$. 
TABLE 8. - Measurements (in cm) of the ribs in MNHN.F.PRU10, holotype of Cynthiacetus peruvianus. Abbreviations: Length, actual length of the rib measured on its lateral margin and following the curvature of the rib, from the base of the tuberculum to the distal extremity of the rib; Proj. length, projected length of the rib, direct measurement from the capitulum to the distal extremity of the rib; AP breadth, anteroposterior breadth of the rib at the level of the angle; ML breadth, transverse width of the rib at the level of the angle; (e), estimated measurements.

\begin{tabular}{|c|c|c|c|c|c|c|}
\hline & Right R1 & Left R1 & Right R2 & Left R2 & Right R3 & Left R3 \\
\hline Length & 40 & - & - & $47(e)$ & $74(\mathrm{e})$ & 74 \\
\hline Proj. length & 27 & - & - & $35(e)$ & $45(\mathrm{e})$ & 48.5 \\
\hline AP breadth & 1.9 & - & 1.5 & 1.62 & 1.69 & 1.86 \\
\hline \multirow[t]{2}{*}{ ML breadth } & 5.5 & - & 5.4 & 4.63 & 3.78 & 4.03 \\
\hline & Right R4 & Left R4 & Right R5 & Left R5 & Right R6 & Left R6 \\
\hline Length & $83(\mathrm{e})$ & - & $85(\mathrm{e})$ & 85 & $96(\mathrm{e})$ & $92(\mathrm{e})$ \\
\hline Proj. length & $56(e)$ & - & $59(\mathrm{e})$ & $59(e)$ & $68(e)$ & $66(e)$ \\
\hline AP breadth & 2.00 & - & 2.21 & 2.07 & 23.98 & 2.68 \\
\hline \multirow[t]{2}{*}{ ML breadth } & 3.31 & - & - & 3.76 & 3.14 & 2.97 \\
\hline & Right R7 & Left R7 & Right R8 & Left R8 & Right R9 & Left R9 \\
\hline Length & 95 & $96(\mathrm{e})$ & 98 & 94 & 88.5 & 87 \\
\hline Proj. length & 68 & $66(e)$ & 66 & 67.5 & 68 & $66(e)$ \\
\hline AP breadth & 2.44 & 2.25 & $2.38(\mathrm{e})$ & 2.21 & 2.50 & 2.20 \\
\hline \multirow[t]{2}{*}{ ML breadth } & 3.52 & 3.39 & 3.08 & 3.74 & 3.93 & 3.63 \\
\hline & Right R10 & Left R10 & Right R11 & Left R11 & Right R12 & Left R12 \\
\hline Length & - & 84.5 & $80(\mathrm{e})$ & $77(\mathrm{e})$ & 73 & $71(\mathrm{e})$ \\
\hline Proj. length & - & 66 & 62 & $64(e)$ & $60(e)$ & $61(e)$ \\
\hline AP breadth & - & 2.23 & 3.4 & 2.67 & 2.42 & - \\
\hline \multirow[t]{2}{*}{ ML breadth } & - & 3.31 & 2.95 & 3.33 & $3.81(\mathrm{e})$ & - \\
\hline & Right R13 & Left R13 & Right R14 & Left R14 & Right R15 & Left R15 \\
\hline Length & 71.5 & $70(\mathrm{e})$ & 70 & - & $67(\mathrm{e})$ & $65(\mathrm{e})$ \\
\hline Proj. length & $57(\mathrm{e})$ & $59(\mathrm{e})$ & 58 & - & 56 & $55.5(\mathrm{e})$ \\
\hline AP breadth & 2.31 & 2.79 & 2.48 & - & 2.33 & 2.18 \\
\hline \multirow[t]{2}{*}{ ML breadth } & 3.24 & 3.82 & 3.81 & - & 3.19 & 3.21 \\
\hline & Right R16 & Left R16 & Right R17 & Left R17 & Right R18 & Left R18 \\
\hline Length & $66(\mathrm{e})$ & $66(\mathrm{e})$ & $57(\mathrm{e})$ & $55.5(\mathrm{e})$ & $54(\mathrm{e})$ & $50(\mathrm{e})$ \\
\hline Proj. length & $55(e)$ & $55.5(\mathrm{e})$ & $48(e)$ & $46(\mathrm{e})$ & $44(\mathrm{e})$ & $44(e)$ \\
\hline AP breadth & - & 2.66 & 1.87 & 1.97 & 1.78 & 1.79 \\
\hline \multirow[t]{2}{*}{ ML breadth } & - & - & 2.57 & 2.26 & 2.50 & 2.33 \\
\hline & Right R19 & Left R19 & Right R20 & Left R20 & & \\
\hline ML breadth & 2.50 & 2.41 & 2.20 & - & & \\
\hline
\end{tabular}

According to the reduced size of the last ribs and the position of the costal articulation, it is probable that the diaphragmatic rib is anteriorly located (R15 or R16); the last thoracic vertebrae were thus probably functionally analogous to the lumbo-caudal vertebrae, and participated in locomotion and the insertion of the epiaxial musculature (cf. Lumbar vertebrae).

Sternum (S1-S5). The sternum is made of five sternebrae. These elements are anteroposteriorly aligned and include the anterior manubrium (S1), three mesosternal elements (S2 to S4), and the anterior portion of the xiphisternum (S5). The overall size of the sternebrae decreases progressively from S1 to $S 4$. The intersternebrae contact was most likely assured by intersternebral and costal cartilages. A portion of cartilage is partially ossified in the posterior end of S4.

The manubrium (Fig. 61; length $[\mathrm{L}]=155 \mathrm{~mm}$, width at mid-length $[\mathrm{W}]=100 \mathrm{~mm}$, height at mid-length $[\mathrm{H}]=71 \mathrm{~mm}$ ) is the largest sternebra. In a transverse section, the ventral edge of $S 1$ is straight and horizontal, while the dorsal edge is dorsally convex. The ventral, dorsal and lateral surfaces of
S1 are smooth. The manubrium widens anteriorly, where its anterolateral corners are robust and dorsally inflated. Therefore, the lateral edges of $S 1$ are laterally concave in ventral or dorsal view. Finally, the body of the manubrium is slightly curved, being dorsally concave in lateral view. This curvature is less pronounced than in Dorudon atrox.

Posteriorly, the manubrium has two posterolaterally facing articular surfaces, which are straight in dorsal view and are at an angle of $c .90^{\circ}$ (Fig. 61A). As a consequence, the posterior end of the manubrium is strongly pointed in dorsal view. The articular surfaces are rough and originally contacted the intersternebral cartilage between $\mathrm{S} 1$ and $\mathrm{S} 2$.

The second (Fig. 62A-E, $\mathrm{L}=155 \mathrm{~mm}, \mathrm{~W}=100 \mathrm{~mm}, \mathrm{H}=$ $71 \mathrm{~mm}$ ) and third (Fig. 62F-J, L $=134 \mathrm{~mm}, \mathrm{~W}=114 \mathrm{~mm}$, $\mathrm{H}=61 \mathrm{~mm}]$ sternebrae are very similar in overall shape, being anteroposteriorly longer than transversely wide. Anteriorly and posteriorly, the intersternal articular surfaces are anterolaterally and posterolaterally facing, respectively. The orientation of these articular surfaces provides a hexagonal outline to S2 and $S 3$ in ventral view, both being anteriorly and posteriorly 

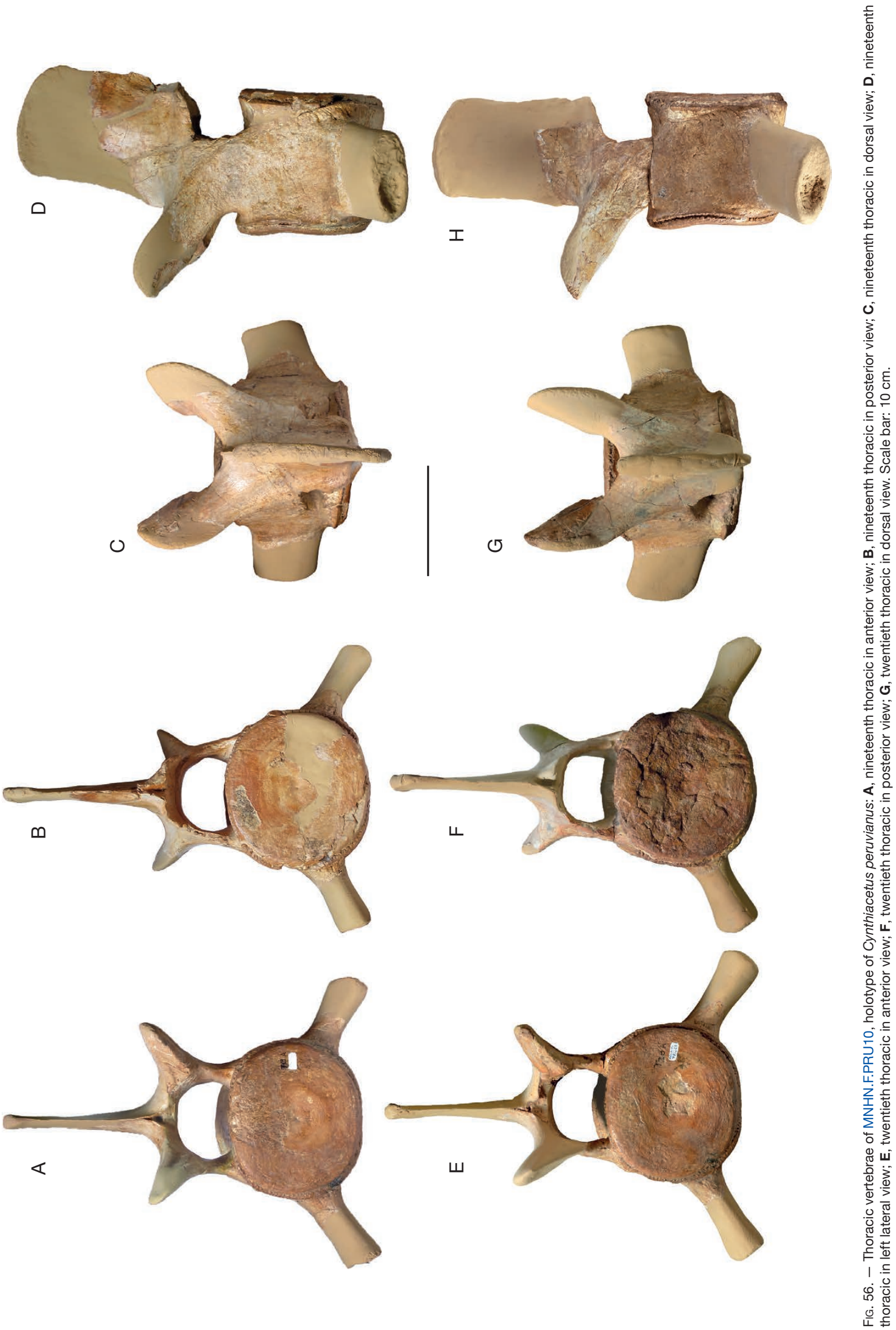


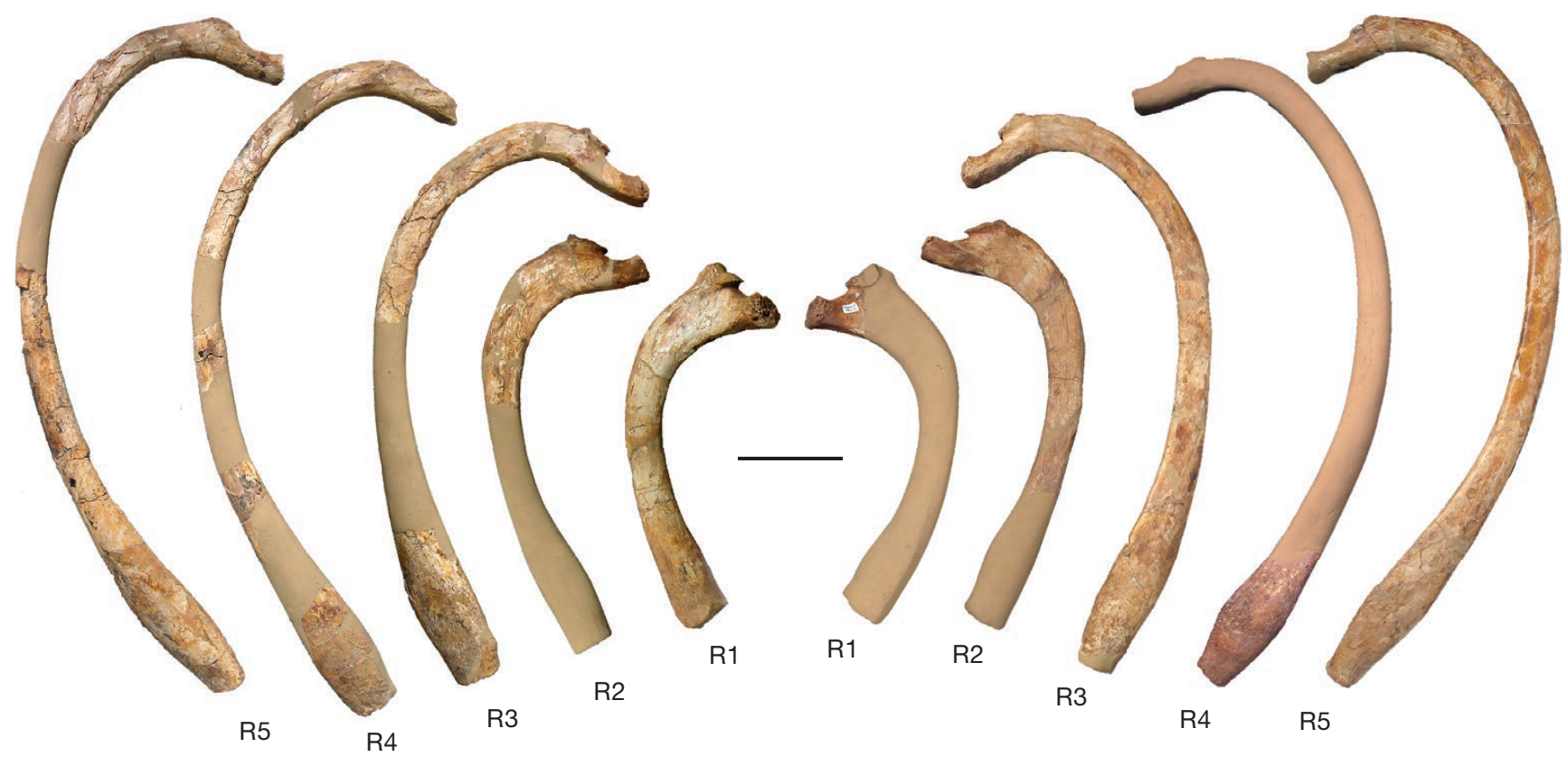

FIG. 57. - First to fifth ribs (R1-R5) of MNHN.F.PRU10, holotype of Cynthiacetus peruvianus in anterior view (right ribs on the left). Partially preserved ribs have been reconstructed. Scale bar: $10 \mathrm{~cm}$.

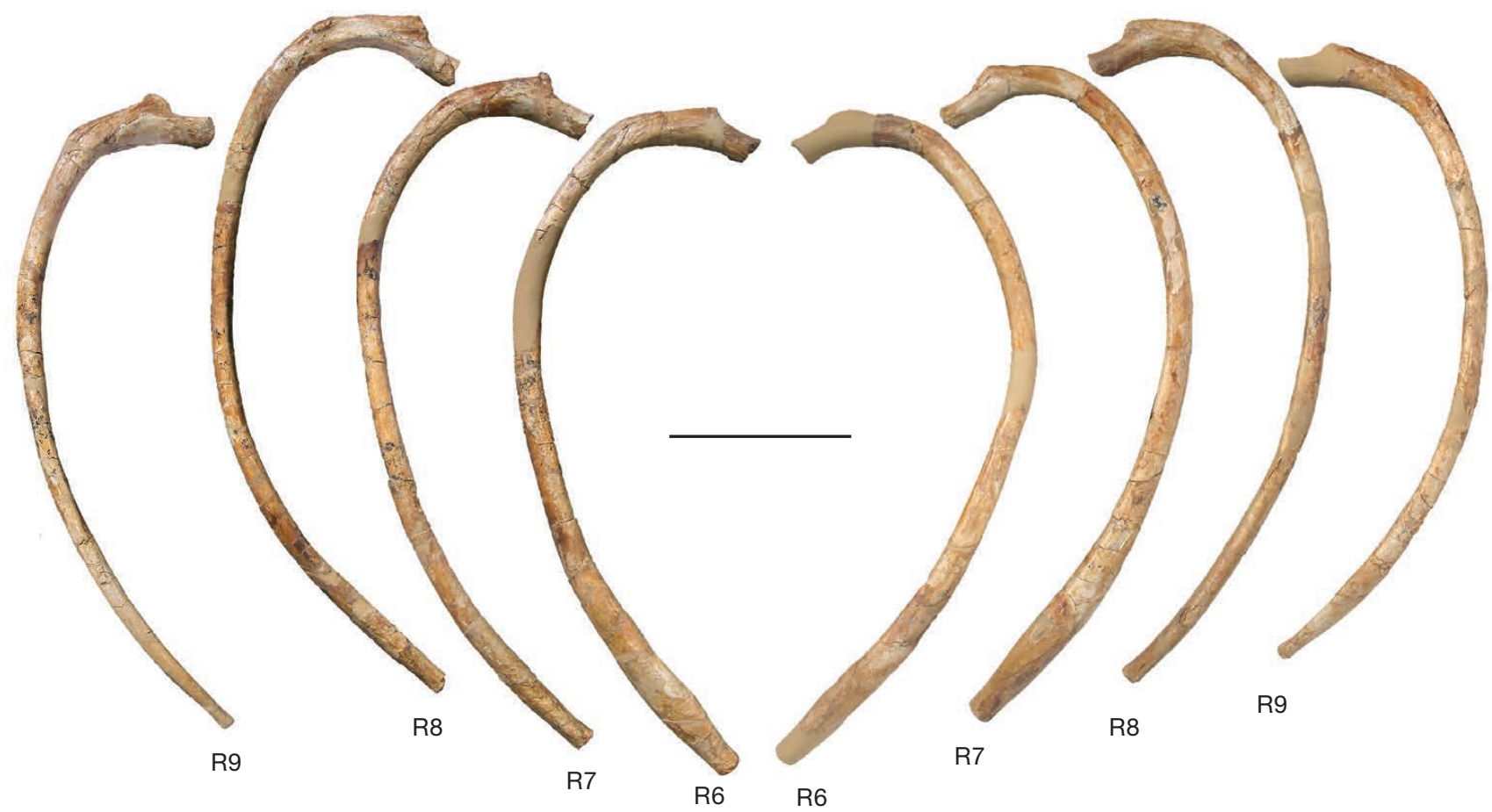

FIG. 58. - Sixth to ninth ribs (R6-R9) of MNHN.F.PRU10, holotype of Cynthiacetus peruvianus in anterior view (right ribs on the left). Partially preserved ribs have been reconstructed. Scale bar: $20 \mathrm{~cm}$.

pointed. The intersternal surfaces are rough and originally contacted the intersternebral cartilages.

The ventral surface in $\mathrm{S} 2$ and the ventral and dorsal surfaces of $S 3$ are smooth and flat, while the dorsal surface of S2 is smooth, but and convex dorsally. The lateral surfaces are extremely reduced; they are smooth in S2 and rough in S3, suggesting a contact with part of the costal cartilages.
In the fourth sternebra (Fig. $62 \mathrm{~K}-\mathrm{O}, \mathrm{L}=110 \mathrm{~mm}, \mathrm{~W}=$ $100 \mathrm{~mm}, \mathrm{H}=50 \mathrm{~mm}$ ), part of the intersternebral cartilage is ossified on its right posteroventral margin, providing a more pentagonal outline to the sternebra in ventral view. The anterior edge is rounded, not pointed as in S3 and S4. The ventral and dorsal surfaces are smooth and flat. $S 4$ is more dorsoventrally compressed than $S 2$ and $S 3$, and gets thinner 


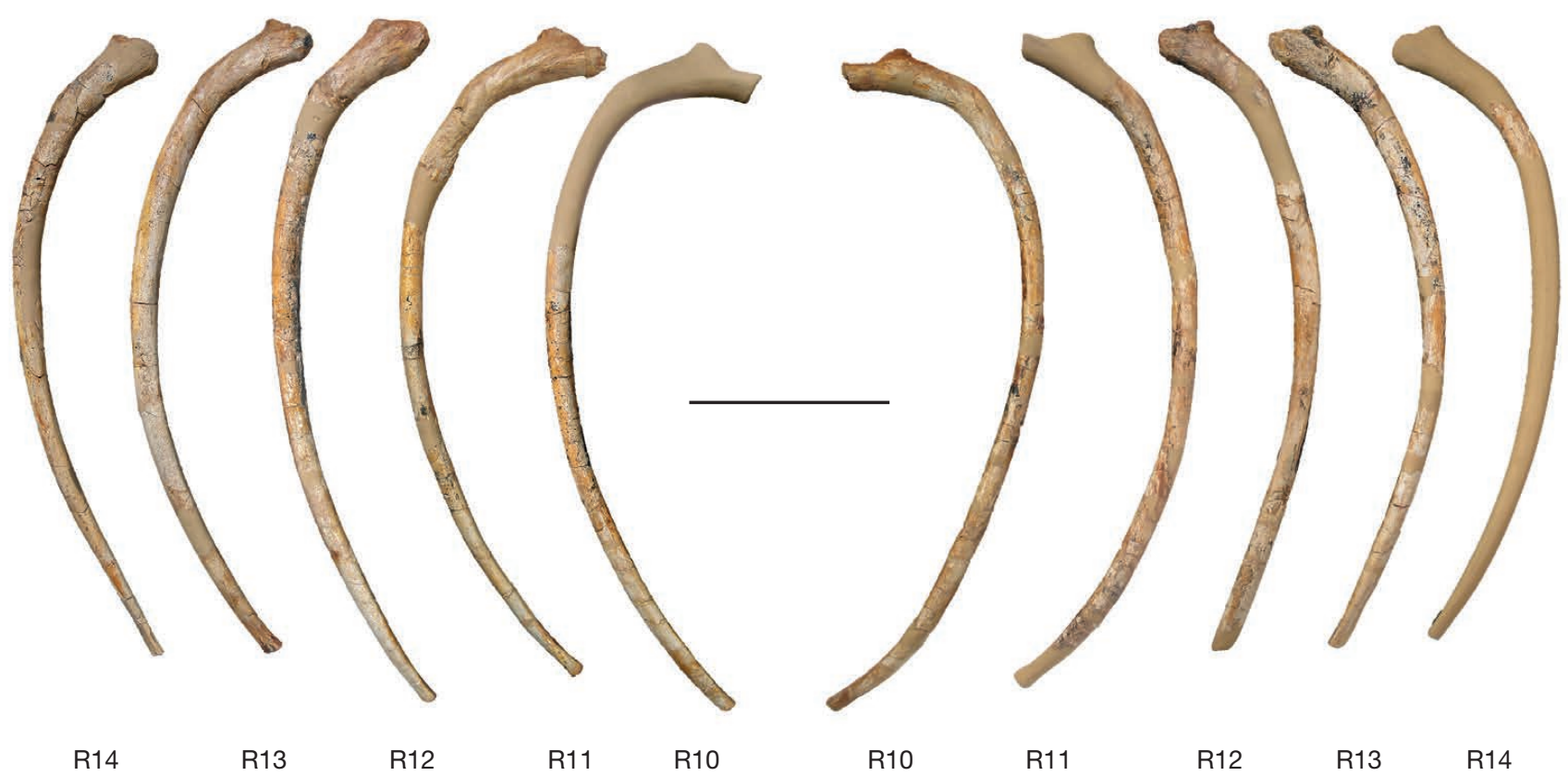

FIG. 59. - Tenth to fourteenth ribs (R10-R14) of MNHN.F.PRU10, holotype of Cynthiacetus peruvianus in anterior view (right ribs on the left). Partially preserved ribs have been reconstructed. Scale bar: $20 \mathrm{~cm}$.

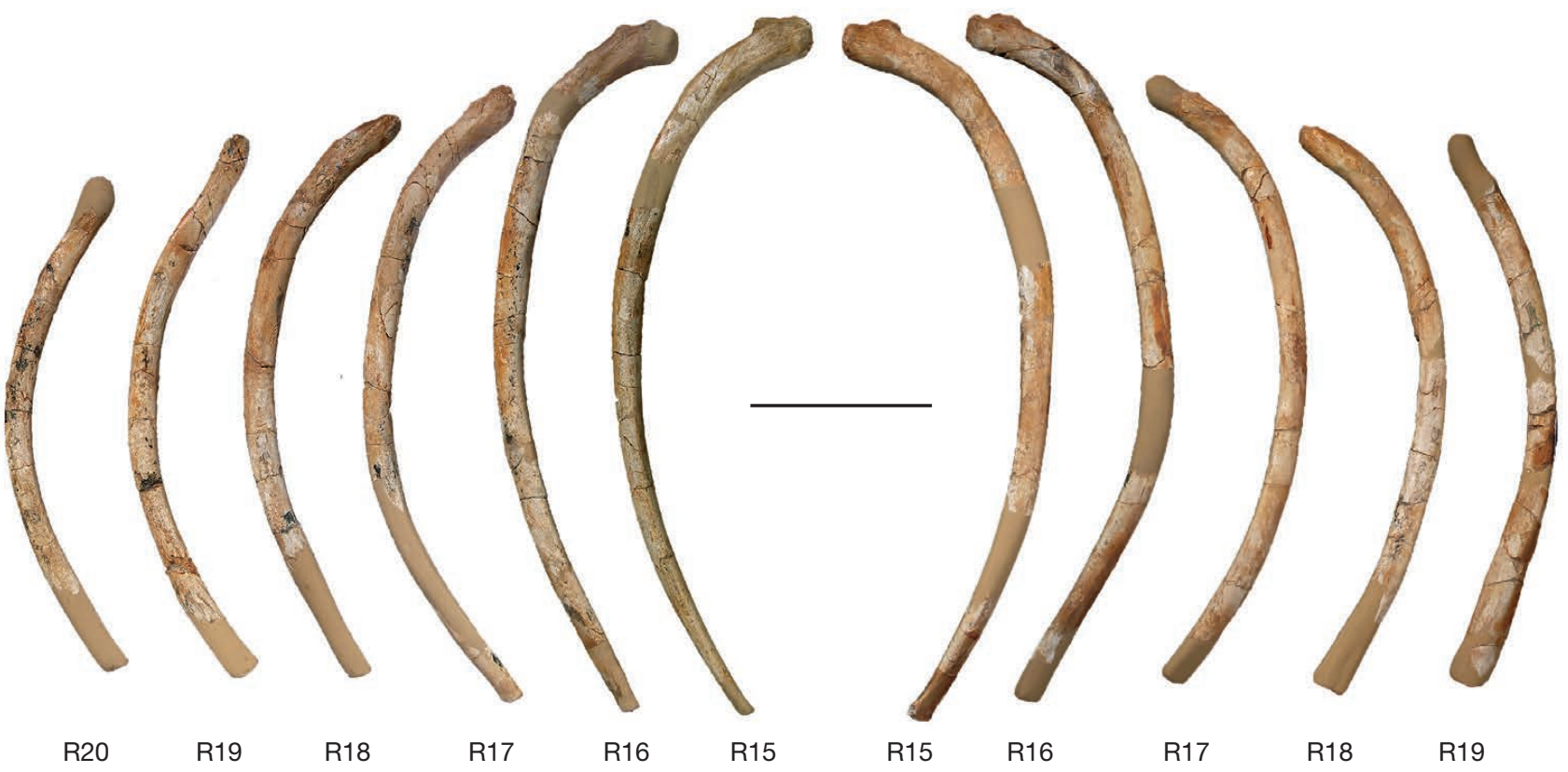

FIG. 60. - Fifteenth to twentieth ribs (R15-R20) of MNHN.F.PRU10, holotype of Cynthiacetus peruvianus in anterior view (right ribs on the left). Partially preserved ribs have been reconstructed and the left twentieth rib is missing. Scale bar: $15 \mathrm{~cm}$.

posteriorly. Similar to more anterior sternebrae, the anterior and posterior articular surfaces are rough and originally contacted intersternal and costal cartilages.

Only the anterior portion of the xiphisternum is preserved in MNHN.F.PRU10 (Fig. 63). It is strongly dorsoventrally compressed and oval in cross-section $(\mathrm{W}=67 \mathrm{~mm}, \mathrm{H}=$ $37 \mathrm{~mm}$ ). It bears a rough and concave articular surface with S4.
Lumbar region (Fig. 46B). The lumbar region of MNHN.F.PRU10 is complete and includes 17 vertebrae. Among the Basilosauridae, the highest number of lumbars is observed in Basilosaurus isis (Gingerich et al. 1990) and Dorudon atrox (Uhen 2004), with at least 20 lumbar vertebrae. In contrast, Saghacetus osiris (Kellogg 1936) and Stromerius nidensis Gingerich, 2007 present the lowest 
A
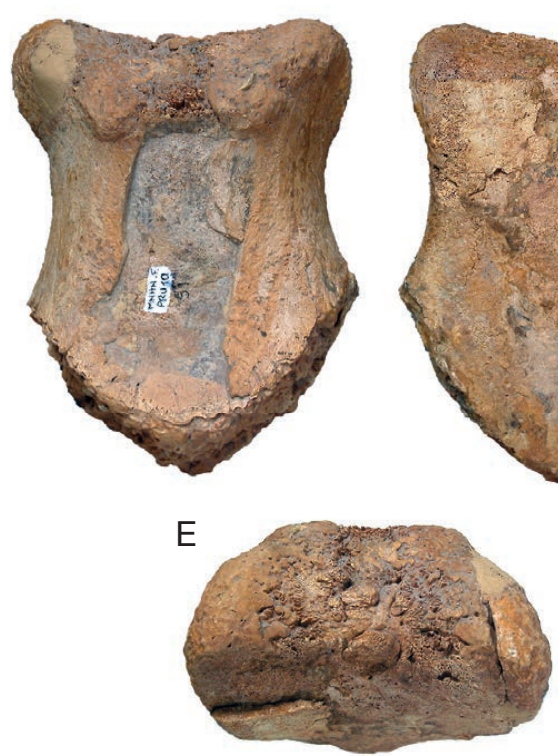

B
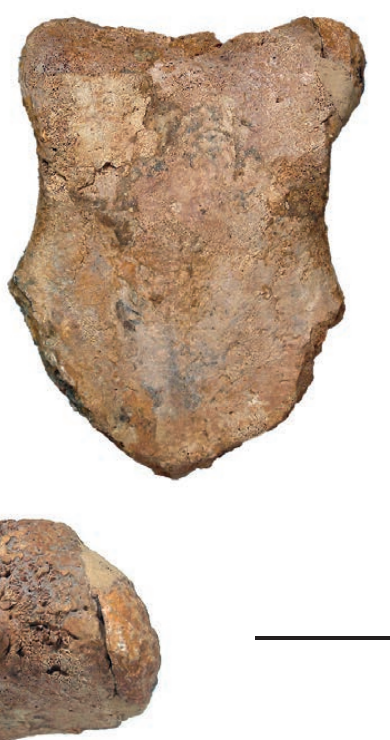

C

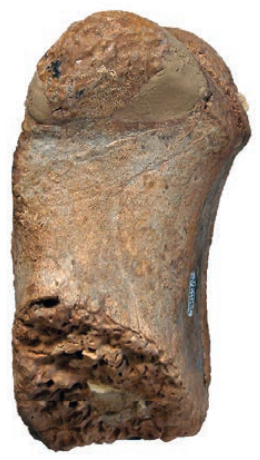

F

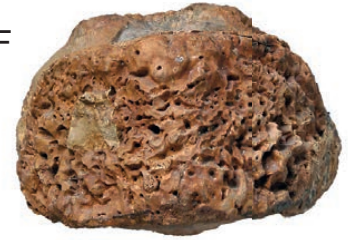

FIG. 61. - Manubrium of MNHN.F.PRU10, holotype of Cynthiacetus peruvianus: A, dorsal view; B; ventral view; C, left lateral view; D, right lateral view; E, anterior view; F, posterior view. Partially preserved portions have been reconstructed. Scale bar: $5 \mathrm{~cm}$.

A

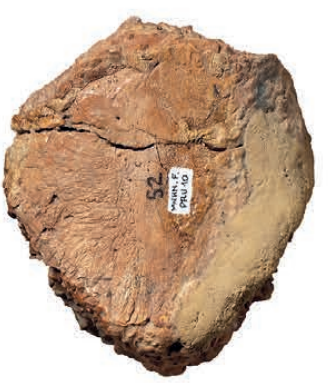

F

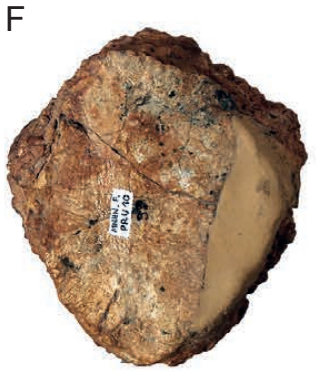

K

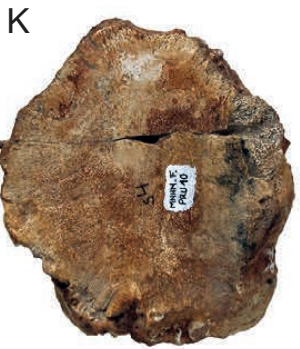

B

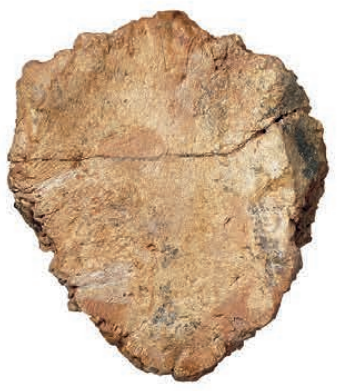

G

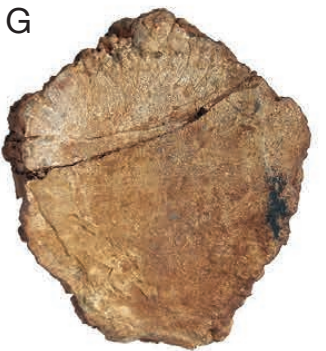

L

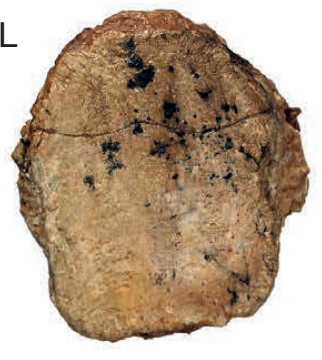

C
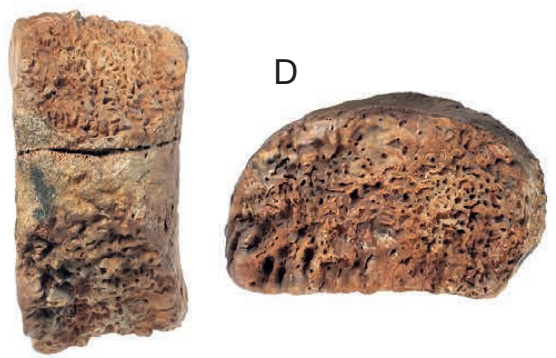

E

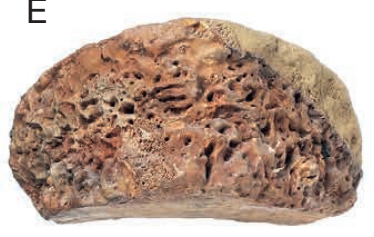

H
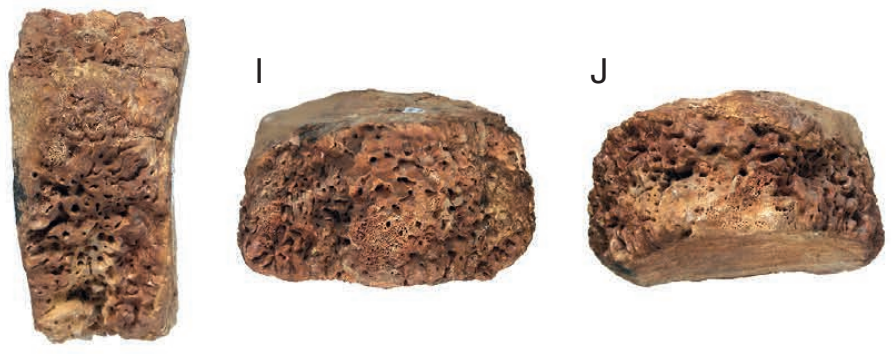

M

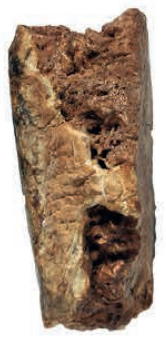

N

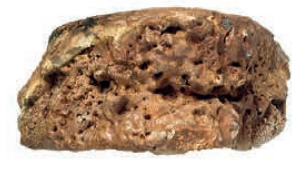

D

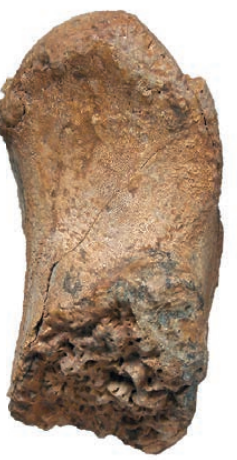

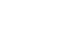 \\ .}



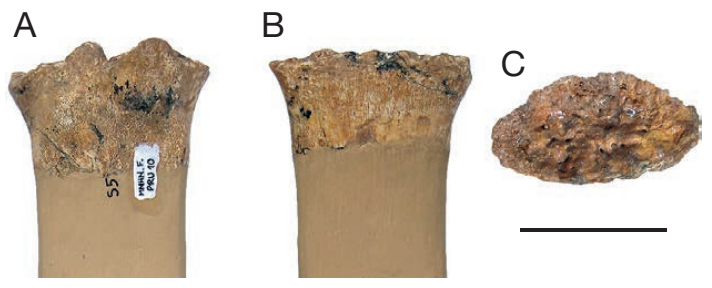

FIG. 63. - Xiphisternum of MNHN.F.PRU10, holotype of Cynthiacetus peruvianus in: A, ventral; $\mathbf{B}$, dorsal; C, anterior views. Only the anterior end of the bone is preserved. Scale bar: $5 \mathrm{~cm}$.
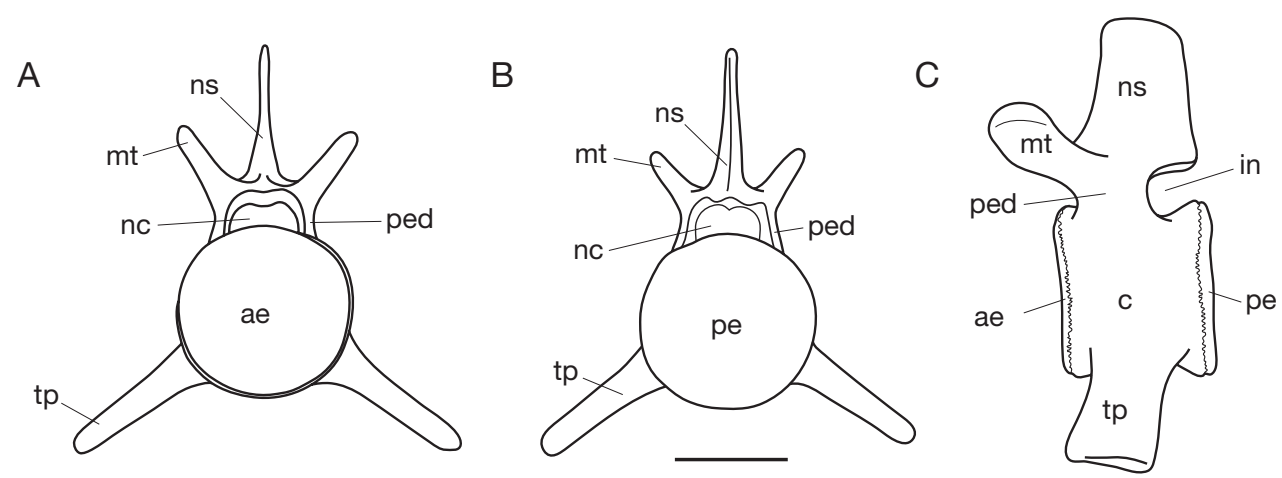

FIG. 64. - Morphology of the lumbar vertebrae in MNHN.F.PRU10, holotype of Cynthiacetus peruvianus. Reconstruction of the eleventh lumbar vertebra (L11): A, anterior; B, posterior; C, left lateral views. Abbreviations: ae, anterior epiphysis; c, centrum; in, intervertebral notch; mt, metapophysis; nc, neural canal; ns, neural spine; pe, posterior epiphysis; ped, pedicle; tp, transverse process. Scale bar: $10 \mathrm{~cm}$.

number of lumbar vertebrae (12) among Basilosauridae. The composite reconstructions of B. cetoides and Zygorhiza kochii (Kellogg 1936) include 15 lumbar vertebrae. In Recent cetaceans the total count of lumbar vertebrae varies within a same species and has a very wide interspecific range, from seven in the beluga Delphinapterus leucas (Pallas, 1776) to more than 30 in the right whale dolphin Lissodelphis borealis Peale, 1848 (Buchholtz \& Schur 2004).

Early protocetids have six lumbar and four sacral vertebrae (e.g. Maiacetus inuus Rodhocetus kasrani; see detailed review in Uhen 2014). The number of lumbars increases to eight in the protocetid Georgiacetus vogtlensis, while the number of sacrals remains unchanged (Hulbert 1998; Hulbert et al. 1998) in this species regarded as the sister taxon of the Pelagiceti (Uhen 2008a). As in Recent cetaceans, there is no sacral region in basilosaurids and the sum of both lumbar and sacral vertebrae in $G$. vogtlensis is equal to the actual lumbar count in Saghacetus osiris and Stromerius nidensis. Since these taxa possess the highest number of plesiomorphic features among the Basilosauridae (cf. Discussion; Gingerich 2007), we can hypothesize that the four posterior lumbars of Sa. osiris (L8 to L12) are homologous to the sacral vertebrae of $G$. vogtlensis. In fact, Uhen (2004) points out that the transverse processes in the four posterior lumbars of Dorudon atrox (L17-L20) are thicker than those of more anterior vertebrae and should be homologous of the sacral vertebrae of earlier protocetids (see more details in Uhen 2014).

In the evolutionary history of cetaceans, there is an evident trend to increase the lumbo-caudal vertebral count (Buchholtz \& Schur 2004; Buchholtz 2007). This increase is particularly pronounced in the Pelagiceti, were the hindlimb is atrophied and the propulsion is achieved by dorsoventral oscillations of the tail (Thewissen \& Fish 1997; Buchholtz 1998). In Recent cetaceans, these oscillations are performed by the strong axial musculature of lumbar and caudal regions (Howell 1930a, b; Getty 1975; Strickler 1980; Pabst 1990). In this context, the increase of lumbar vertebrae is likely related to the locomotor behavior. Indeed, the increase in the number of lumbo-caudal vertebrae augments the surface for the attachment of the axial musculature and the degree of deflection of the vertebral column (Buchholtz 1998). In modern cetaceans, the highest number of lumbo-caudal vertebrae corresponds to the fastest animals. In fact, the smallest count of lumbo-caudal vertebrae is observed in river dolphins (Inia geoffrensis (Blainville, 1817)), while the largest count (with proportionally shorter vertebrae) is in offshore dolphins (Lagenorhynchus spp.).

As proposed above, it is likely that the posterior thoracics of MNHN.F.PRU10 (from T16 to T20) did not participate in the rib cage but were functionally analogous to the postthoracic vertebrae. However, although the basilosaurids lumbar region is considerably longer than in earlier archaeocetes, it is difficult to evaluate the actual development of the axial musculature. Based on the axial skeleton, Uhen (2004) suggested that Dorudon atrox possessed an axial musculature intermediate between that of Recent terrestrial artiodactyls and that of Recent cetaceans. In fact, the body plan of Recent cetaceans is strongly derived and it is quite difficult to homologize the elements of the spinal muscles (Howell 1930a, Pabst 1990). The transverse processes, metapophyses and neural spine in the torso (posterior thoracic, lumbar and anterior caudal vertebrae) should provide the surfaces for the origin 
TABLE 9. - Main measurements (in mm) of the lumbar vertebral centra of MNHN.F.PRU10, holotype of Cynthiacetus peruvianus. (e), estimated measurements.

\begin{tabular}{|c|c|c|c|c|c|c|c|c|c|}
\hline & L1 & L2 & L3 & L4 & L5 & L6 & L7 & L8 & L9 \\
\hline Anterior width & 145.1 & 150.2 & $146(\mathrm{e})$ & 156.9 & 160.1 & 154.1 & 154.7 & 156.2 & 156.8 \\
\hline Posterior width & 151.9 & 149.9 & 154.1 & 162.7 & 159.6 & 156.5 & $165(\mathrm{e})$ & 162.5 & $160(\mathrm{e})$ \\
\hline Anterior height & 130.1 & 137 & 136 & 154.7 & 153.7 & 147.3 & 144.3 & 149.5 & 151.5 \\
\hline Posterior height & 141.4 & 136.7 & 146.8 & $155(\mathrm{e})$ & 154.6 & 147.9 & 155.5 & 155.7 & $152(\mathrm{e})$ \\
\hline Dorsal length & 134.1 & 129.2 & $134(\mathrm{e})$ & $136(\mathrm{e})$ & 137.3 & 140.2 & $138(e)$ & 135.2 & $132(\mathrm{e})$ \\
\hline \multirow[t]{2}{*}{ Ventral length } & 130.4 & 133.9 & 131.6 & 135.2 & 133.9 & 147.3 & $130(\mathrm{e})$ & 132.1 & 130.9 \\
\hline & L10 & L11 & L12 & L13 & L14 & L15 & L16 & L17 & \\
\hline Anterior width & 161.2 & 162.3 & 161 & 161.3 & 162.6 & 162.5 & 162 & 166.7 & \\
\hline Posterior width & 162.7 & 163.7 & 166 & 164.8 & 168 & 173.9 & 175 & 177.2 & \\
\hline Anterior height & 158.9 & 160.2 & 160.4 & 165.7 & 166.8 & 169 & 169.1 & 172.6 & \\
\hline Posterior height & 162.1 & 163.6 & 163.9 & 168.3 & 169.1 & 168.5 & 181.4 & 174.9 & \\
\hline Dorsal length & 143.1 & 141.5 & 141.7 & 144.9 & 143.3 & $145(\mathrm{e})$ & $150(\mathrm{e})$ & 158.5 & \\
\hline Ventral length & 137.6 & 141.5 & 143 & 138.7 & 143.3 & 141.2 & 151.5 & 142.5 & \\
\hline
\end{tabular}

and insertion of both epaxial and hypaxial muscles, including $M$. multifidus, $M$. longissimus, $M$. iliocostalis, $M$. extensor caudae and M. intratraversarius. However, these structures are incomplete in MNHN.F.PRU10, and the muscular attachments were probably aponeurotic or tendinous, as in Recent cetaceans. Therefore, it is difficult to evaluate the section and size of the epaxial and hypaxial muscles in C. peruvianus. Since the basilosaurid locomotion relies upon the size and force of the tail, they should have a more important lumbo-caudal musculature than protocetids and earlier archaeocetes.

The lumbar centra of MNHN.F.PRU10 are virtually complete, while the neural arch, neural spine and transverse processes are poorly preserved. Differing from the cervical and thoracic regions (where the shape and size of the vertebrae vary markedly along the vertebral column), the lumbar region of MNHN.F.PRU10 is relatively homogenous and the lumbar vertebrae strongly resemble each other. In fact, there is a single lumbar vertebral morphology. Morphological features and measurements of the lumbar vertebrae are presented in Table 9 and Figure 64.

The transverse processes of most lumbars of MNHN.F.PRU10 are broken at their base. Therefore, no indication is available on their length and overall morphology. Nevertheless, it is clear that the processes are ventrolaterally oriented (with a slight anterior component) and their anteroposterior length at base is greater than half the length of the centrum. All the lumbars have a neural spine, although the spine is broken at the base in all the vertebrae.

The overall size of the centrum gradually increases posteriorly (Fig. 65A). However, this increase is not as pronounced as in the middle thoracic region. Changes in centrum proportions and showed in Figure 65B. Although the centrum height increases more rapidly than the centrum width, the cross-section of the lumbar centra remains circular. As a matter of fact, in the Basilosauridae centrum width and height are isometrically correlated (Fig. 66, slope of the correlation = 0.92 , coefficient $R^{2}=0.98$ ) and the centrum cross-section is disc-shaped. Similarly to Dorudon and most non-basilosaurine basilosaurids, the lumbar centrum length of Cynthiacetus peruvianus is almost equal to the diameter of the centrum section, and thus both H/L and W/L ratios are close to 1 . This condition differs from that observed in Basilosaurus cetoides, Saghacetus osiris, and Stromerius nidensis, where the centra are proportionally longer than high. Indeed, in B. cetoides, Sa. osiris, and Str. nidensis, the mean H/L ratio is of $0.48,0.79$, and 0.81 , respectively. Although the proportional length of the lumbar centra decreases slightly posteriorly in most basilosaurids (except Sa. osiris and Str. nidensis, cf. below), the relative position of the vertebra and the $\mathrm{L} / \mathrm{H}$ centrum ratio are only correlated in B. cetoides (Fig. 67A, $\mathrm{R}^{2}=0.75$ ). Moreover, the allometric correlation in $B$. cetoides has a very low slope $(\mathrm{a}=0.06)$ and thus, we can consider that the proportional length of the centrum (represented by the $\mathrm{H} / \mathrm{L}$ ratio) evolves independently from the relative position of the vertebra in the lumbar region. In Sa. osiris and Str. nidensis, the proportional length of the centrum increases on more posterior vertebrae. As in other basilosaurids, the evolution of the $\mathrm{H} / \mathrm{L}$ ratio in both taxa is not correlated with the relative position of the vertebra in the lumbar region ( $\mathrm{R}^{2}$ inferior to 0.6$)$. A progressive lengthening of the centrum is also observed in Maiacetus inuus. In this protocetid, the lengthening is more pronounced than in Sa. osiris, and it strongly correlates with the relative position of the vertebra in the lumbar region (slope and coefficient of the correlation: $\mathrm{a}=-0.13, \mathrm{R}^{2}=0.81$ ). The variations of the centrum length in non-basilosaurine basilosaurids seem to be correlated to the centrum size rather than to the relative position of the vertebrae (Fig. 67B). Indeed, in the lumbars of $\mathrm{Sa}$. osiris, $\mathrm{H} / \mathrm{L}$ centrum ratio and centrum width are strongly correlated $\left(\mathrm{a}=-0.98, \mathrm{R}^{2}=0.68\right)$. This isometric scaling implies that the centrum lengthening and centrum cross-section evolve equally in Sa. osiris. Actually, the H/L centrum ratio is correlated to the centrum width in all other basilosaurids, except B. cetoides. However, each taxon possesses its own regression (in C. peruvianus, for example, the allometry parameters are: $\mathrm{a}=0.68, \mathrm{R}^{2}=0.68$ ). As a matter of fact, the shortening of the centrum (increase of the H/L ratio) is more pronounced in the largest vertebrae (not necessarily being more posteriorly located).

Since the transverse processes are poorly preserved, it is impossible to evaluate if they were thicker in most posterior lumbar vertebrae (presumably corresponding to the sacrum). However, the posterior three lumbars in MNHN.F.PRU10 are 

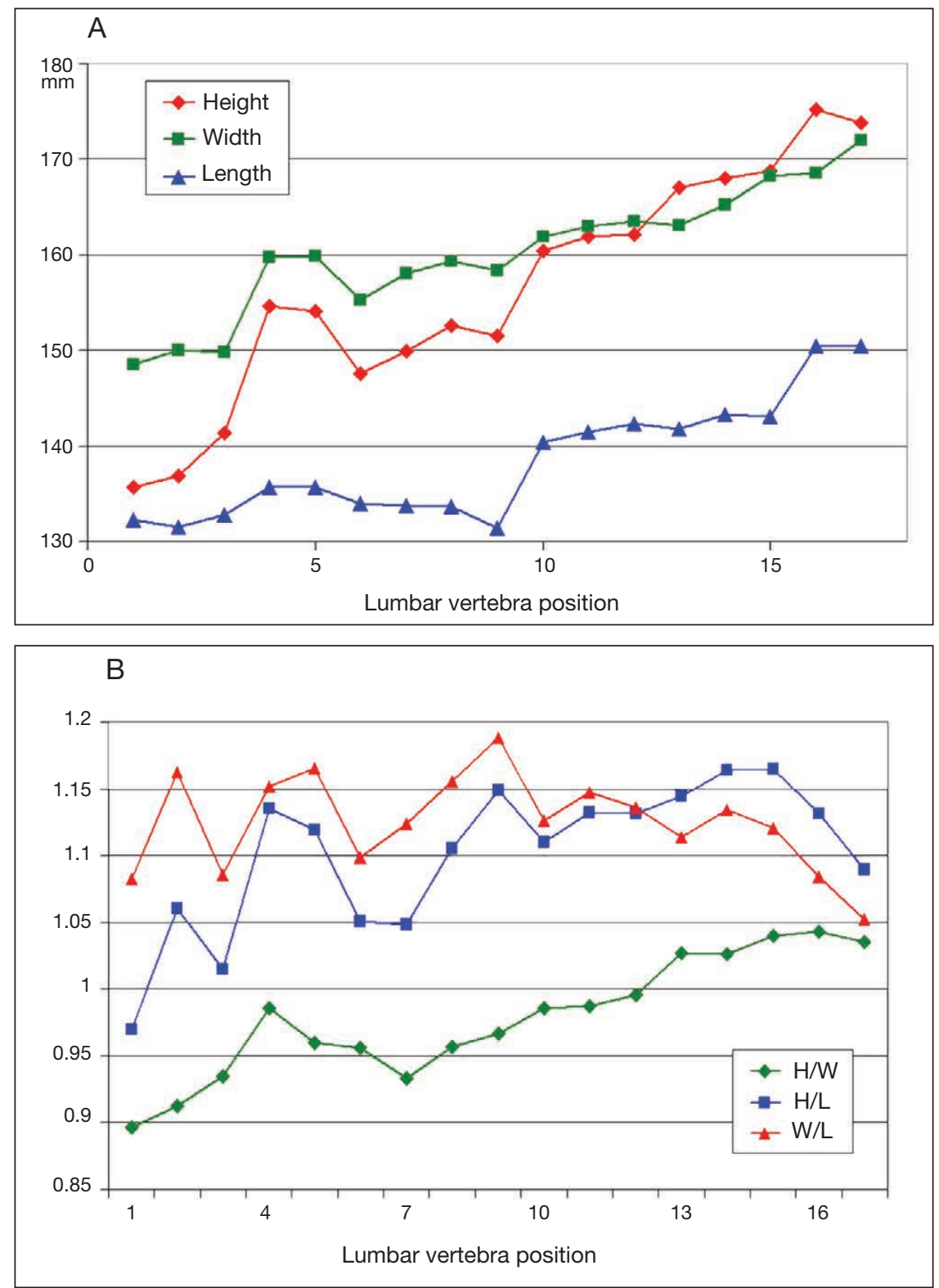

FIG. 65. - Evolution of the centrum dimensions of lumbar vertebrae of MNHN.F.PRU10, holotype of Cynthiacetus peruvianus: A, overall size; B, height-to-width, height-to-length, and width-to-length ratios.

proportionally longer than the rest of the lumbar vertebrae, and L17 is the longest vertebra along the vertebral column. The longest vertebra in most protocetids is generally regarded as sacral, while in most basilosaurids it belongs to the caudal region. Cynthiacetus peruvianus retains a more anterior position of the longest vertebra, which should indicate the location of the portion undergoing maximum deflection during the undulations of the column (Buchholtz 1998). The differences observed between the lumbar vertebrae are detailed in the following description.

First lumbar (L1) (Fig. 68A-D). The first lumbar is slightly larger than the last thoracic (T20). The centrum of L1 is cylindrical with an almost perfect circular cross-section, being slightly transversely wider than dorsoventrally high. Similar to the anterior vertebrae, the epiphyses are disc-shaped and slightly concave. They are firmly attached to the centrum. The fusion of the posterior epiphysis with the centrum is more advanced than that for the posterior epiphysis, but both epiphyses remain easily distinguishable from the centrum.

The ventral, dorsal and lateral surfaces of the centrum bear numerous small nutrient foramina, which are randomly located near the anterior and posterior margins of the centrum. A small ridge lies at midline, on the ventral surface of the centrum. On each side of this ridge is a large foramen. These foramina are asymmetrical, the left foramen being anterior to and larger than the right. Similarly, two large foramina on the dorsal surface of the centrum open into the neural canal. As in T20, the transverse processes extend from the ventrolateral margins of the centrum; they are dorsoventrally 


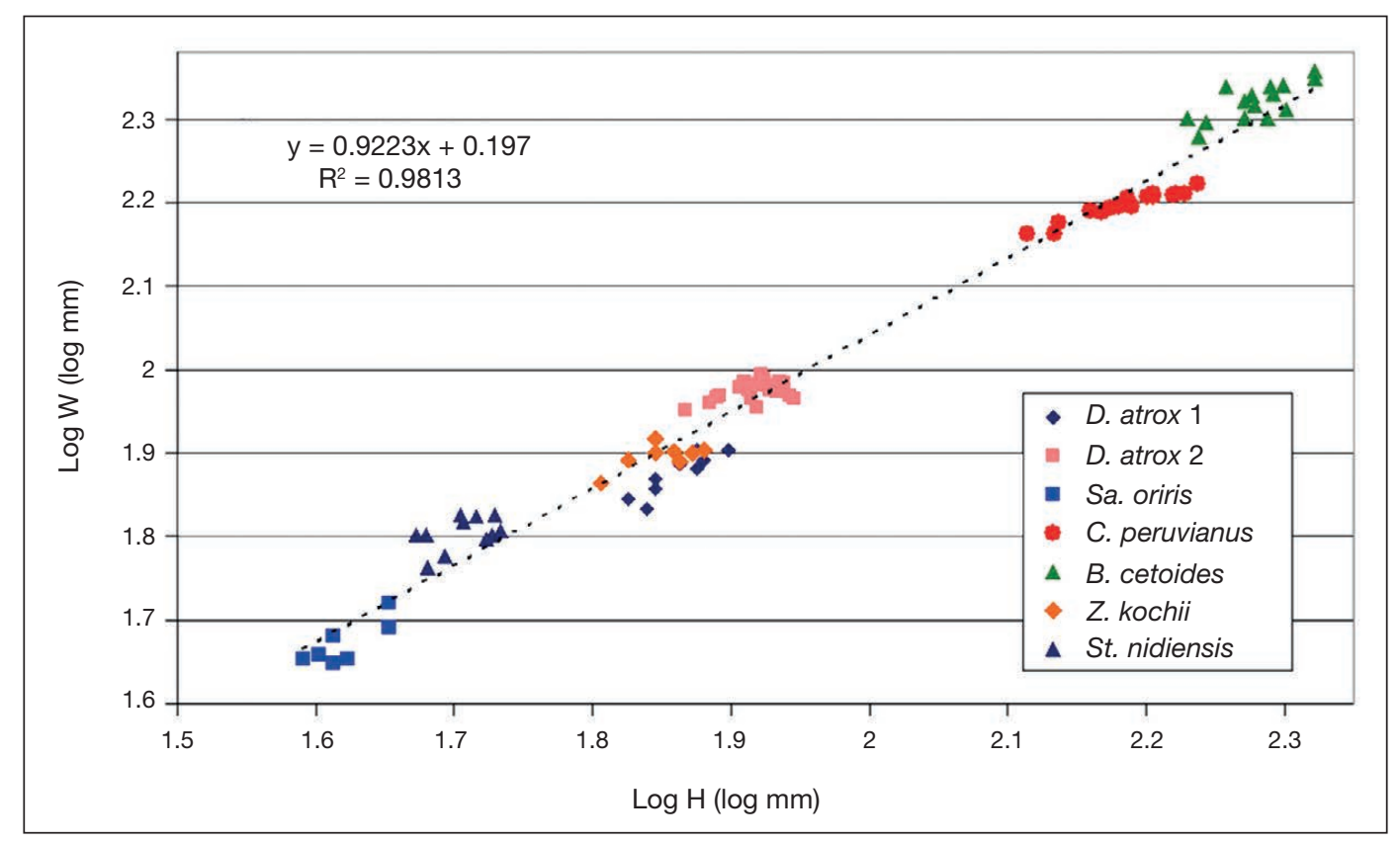

FIG. 66. - Evolution of the centrum width in function of the centrum height in the lumbar region of the Basilosauridae. Dorudon atrox 1 (UM 97512 ), D. atrox 2 (UM 101215); Saghacetus osiris (UM 97550), Cynthiacetus peruvianus (MNHN.F.PRU10), Basilosaurus cetoides (USNM 4675 and USNM 12261), Zygorhiza kochii (USNM 4678) and Str. nidensis (UM 100140).

compressed, ventrolaterally oriented and closer to the anterior edge of the centrum in lateral view; only their proximal portions are preserved.

Dorsal to the centrum, the neural arch is formed by the pedicles and laminae. The former extend dorsally from the dorsolateral margins of the centrum, where they form the lateral walls of the neural canal. They are strongly transversely flattened and closer to the anterior edge of the centrum than to the posterior edge. Consequently, the posterior intervertebral notch is more pronounced than the anterior notch. This feature is even more pronounced in more posterior vertebrae. Dorsally, the pedicles meet the laminae, the latter forming the roof of the neural canal. In contrast with most thoracic vertebrae, the neural canal of L1 is dorsoventrally higher than wide, and roughly hemispherical in cross-section. As in the posteriormost thoracics, the neural canal is significantly smaller than in anterior and middle thoracics. The laminae are much less developed than in the anterior thoracics and resemble more those in T20. Each lamina extends anterodorsally to form the metapophysis, and only the left metapophysis is partially preserved in L1. All the metapophyses in the lumbar region are elongated, linguiform, and dorsomedially facing. The prezygapophysis can be regarded as an inconspicuous crest on the medial margin of the metapophysis. Posterior to the level of the pedicles, the postzygapophyses are strongly reduced and do not present any articular surface. Contrary to most thoracic vertebrae, there is no anterior triangular depression or posterior triangular notch separating medially the right and left metapophyses and postzygapophyses. As a matter of fact, the postzygapophyses are continuous and form a unique surface that can be regarded as the posterior continuation of the roof of the neural canal. This pattern is maintained for all lumbar vertebrae. Metapophyses and postzygapophyses provide a Y-shaped outline to the neural arch in dorsal view, where the metapophyses form the arms of the $Y$ and are anterolaterally oriented. This Y-shaped outline is also observed in most posterior thoracics and anterior lumbars. Although they are poorly preserved and missing in most lumbar vertebrae, the postzygapohyses decrease progressively in length in more posterior vertebrae. As a consequence of this shortening, the neural arch is $\mathrm{V}$-shaped in dorsal view in more posterior vertebrae, as observed in L10-L14.

Finally, the neural spine is partially preserved in L2. It was probably rectangular and vertical in lateral view (although its anterior margin is entirely missing and only part of the posterior margin is preserved). The neural spine is transversely flattened. It narrows progressively anteriorly and dorsally and thus, it possesses a sharp anterior margin and a slightly wider posterior surface. The latter is proportionally narrower than in anterior thoracics and resembles those of posterior thoracics in lacking the median ridge and adjacent surfaces for muscular insertion.

Second lumbar (L2) (Fig. 68E-H). Except for its slightly larger dimensions, the second lumbar is similar to the first. Indeed, the centrum is cylindrical and partly fused with both epiphyses (the anterior epiphysis is more fused than in L1). Various small nutrient foramina lie on the lateral surfaces of the centrum, near the anterior and posterior edges. As for L1, two larger foramina separated by a low median ridge are observed on the dorsal and ventral surfaces of the centrum. The transverse processes extend from the ventrolateral margin of the centrum and are broken at their base; they were ventrolaterally oriented, dorsoventrally compressed, and slightly 

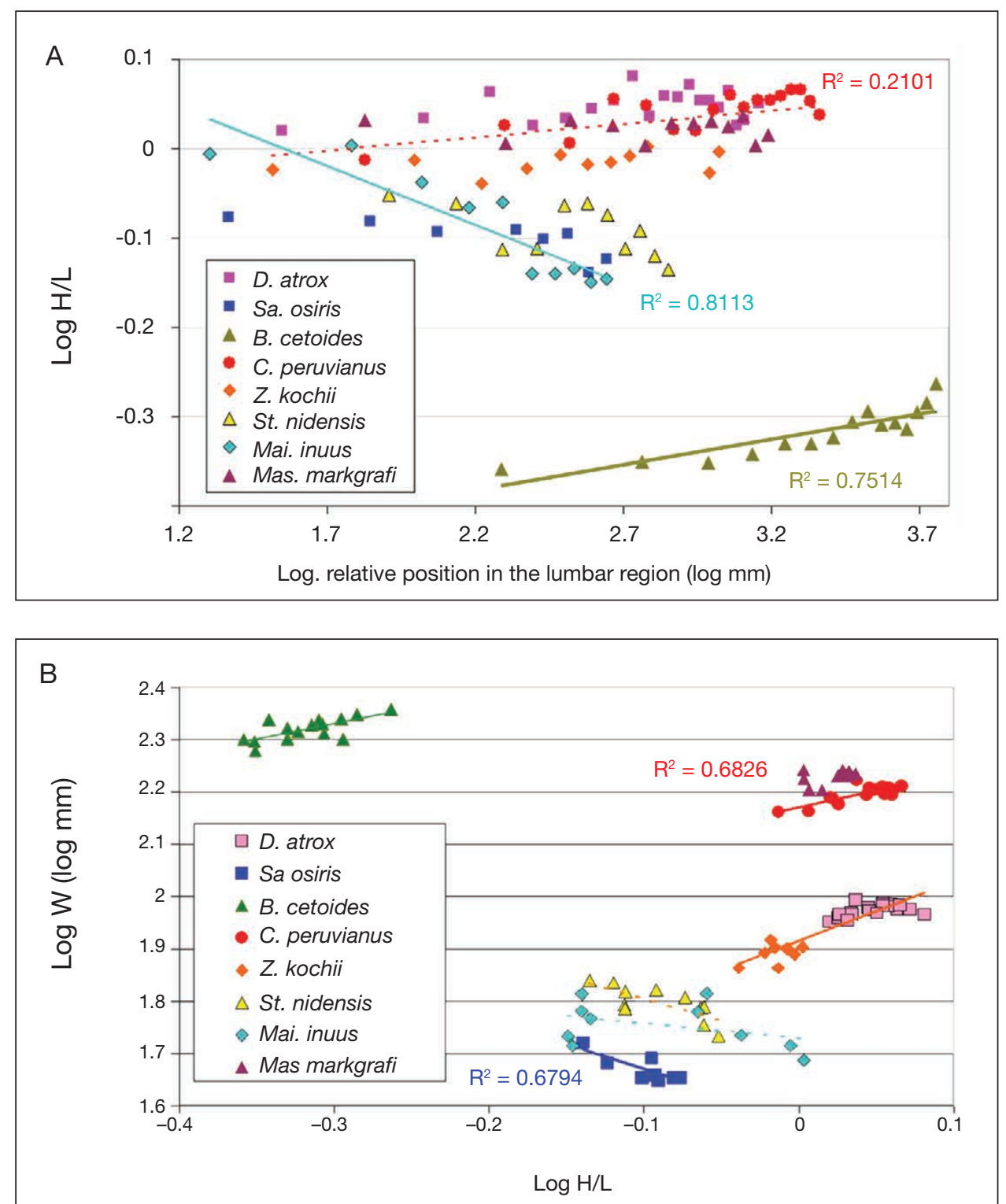

FIG. 67. - Evolution of the height/length $(\mathrm{H} / \mathrm{L})$ ratio in lumbar centra in function of: $\mathbf{A}$, the relative position in the lumbar region; $\mathbf{B}$, the centrum width. Dorudon atrox (UM 101215), Saghacetus osiris (UM 97550), Cynthiacetus peruvianus (MNHN.F.PRU10), Basilosaurus cetoides (USNM 4675 and USNM 12261), Zygorhiza kochii (USNM 4678), Stromerius nidensis (UM 100140), Maiacetus inuus (UM GSP 3551), and Masracetus markgrafi (SMNS 11414). Mai. inuus is the only protocetid used in the comparison, all the other taxa belonging to the Basilosauridae. The abscissa in (A) represents the distance from the anterior edge of $L 1$ to the mid-length level of the $n$ lumbar vertebra. It is calculated using the formula: $n-1 / X_{n}=\log \left[\Sigma L_{i}+\left(L_{n} / 2\right)\right] / i=1$ (where $L n$ is the dorsal length of the centrum in the $n$ lumbar vertebra). In $\mathrm{A}$ and $\mathrm{B}$, the $\mathrm{R}^{2}$ of the comparison taxa have been indicataed only when $>0.5$.

closer to the anterior edge of the centrum. The neural arch is partially preserved and somewhat twisted to the left. The pedicles are transversely flattened and closer to the anterior edge of the centrum. The neural canal is roughly semicircular in cross-section, and higher than wide. Dorsal to the neural canal, the neural spine is broken at its base and only its distal portion is preserved. The dorsal extremity of the neural spine is arched and dorsally convex. A large part of the metapophyses and postzygapohyses is missing.

Third lumbar (L3) (Fig. 68I-L). The centrum of L3 is similar to that of L2 in all dimensions. It is cylindrical, circular in cross-section, and fused with the anterior and posterior epiphyses, which are well defined. The right ventrolateral portion and part of the dorsal half are missing in the anterior and posterior epiphyses, respectively. Similarly to L1 and L2, two large foramina lie on the ventral and dorsal surfaces of the centrum. Most of the pedicles, transverse processes, and laminae are missing, with the transverse processes and pedicles broken at their base. The latter were slightly closer to the anterior edge of the centrum. While the transverse processes are dorsoventrally compressed, the pedicles are transversely flattened. The neural spine is incomplete but was probably roughly vertical.

Fourth lumbar (L4) (Fig. 69A-D). Morphologically, only a few differences are noted between L3 and L4, more particularly in the number of nutrient foramina lying on the centrum. 

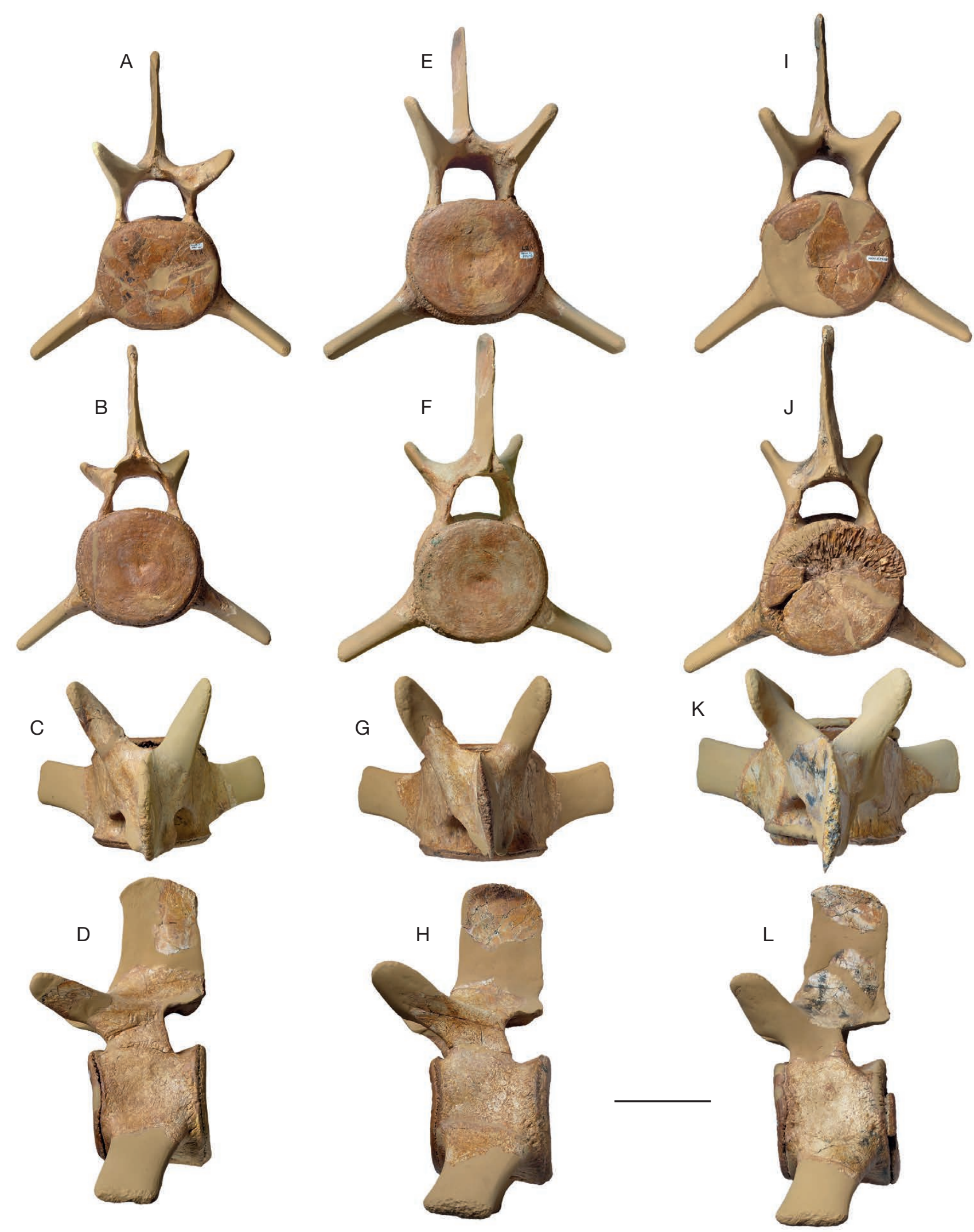

FIG. 68. - Lumbar vertebrae of MNHN.F.PRU10, holotype of Cynthiacetus peruvianus: A, first lumbar in anterior view; B, first lumbar in posterior view; C, first lumbar in dorsal view; D, first lumbar in left lateral view; E, second lumbar in anterior view; F, second lumbar in posterior view; G, second lumbar in dorsal view; $\mathbf{H}$, second lumbar in left lateral view; I, third lumbar in anterior view; J, third lumbar in posterior view; K, third lumbar in dorsal view; L, third lumbar in left lateral view. The missing portions of the bones (especially the transverse processes and neural spines) have been reconstructed. Scale bar: $10 \mathrm{~cm}$. 

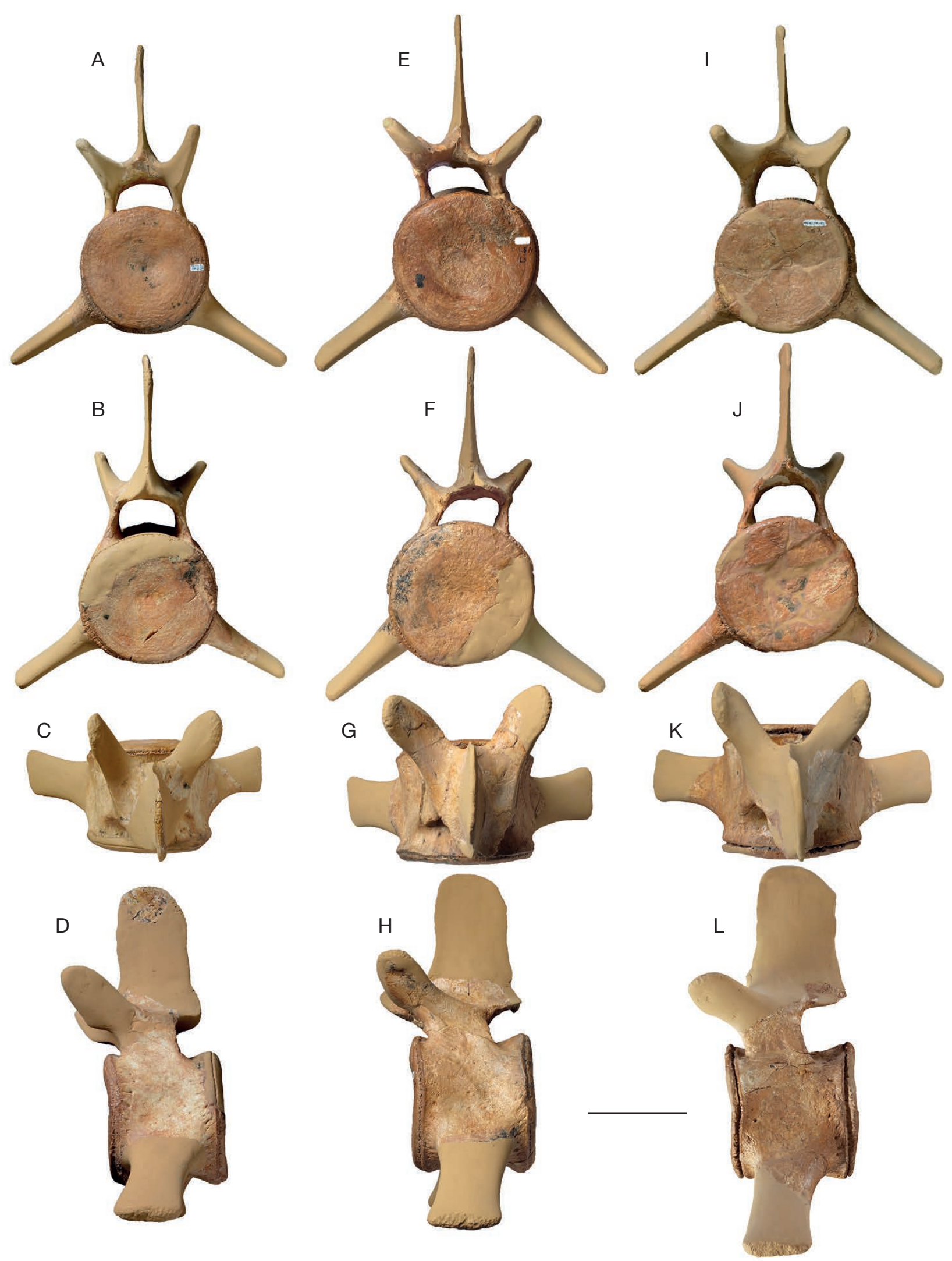

FIG. 69. - Lumbar vertebrae of MNHN.F.PRU10, holotype of Cynthiacetus peruvianus: A, fourth lumbar in anterior view; B, fourth lumbar in posterior view; C, fourth lumbar in dorsal view; D, fourth lumbar in left lateral view; E, fifth lumbar in anterior view; F, fifth lumbar in posterior view; G, fifth lumbar in dorsal view; H, fifth lumbar in left lateral view; I, sixth lumbar in anterior view; J, sixth lumbar in posterior view; K, sixth lumbar in dorsal view; L, sixth lumbar in left lateral view. The missing portions of the bones (especially the transverse processes and neural spines) have been reconstructed. Scale bar: $10 \mathrm{~cm}$. 
The centrum of L4 is larger than that of L3. It is cylindrical, circular in cross-section, and partly fused with both epiphyses (the dorsal portion of the posterior epiphysis is missing). On the lateral surfaces of the centrum, small nutrient foramina lie close to the anterior and posterior edges. Three larger nutrient foramina can be observed on the ventral surface of the centrum. These foramina are aligned transversely and located at midline, the central one being considerably smaller than the other two. The dorsal surface of the centrum is somewhat concave dorsally and possesses two large foramina, separated by a prominent ridge. The right transverse process is incomplete but better preserved than the left one. As in more anterior vertebrae, the transverse processes extend ventrolaterally from the ventrolateral margin of the centrum. They are dorsoventrally compressed and closer to the anterior edge of the centrum. Contrary to L3, the pedicles are well preserved. They are transversely flattened and, similarly to the pedicles, closer to the anterior edge of the centrum.

Most of the neural arch is missing in L4. However, we can estimate that the neural canal is transversely wider than dorsoventrally high. On the roof of the neural canal, an almost inconspicuous ridge runs anteroposteriorly along the midline. Such a ridge is more pronounced in more posterior lumbars. The metapophyses, postzygapophyses, and most of the neural spine are missing in L4.

Fifth lumbar (L5) (Fig. 69E-H). The centrum of L5 is slightly larger than that of L4 and very similar in morphology to those of more anterior lumbars, being cylindrical, circular in cross-section, and fused with both epiphyses. The latter are disc-shaped and somewhat concave. While the anterior epiphysis is entirely preserved, the right ventrolateral portion of the posterior epiphysis and the corresponding portion in the centrum are missing. The lateral surfaces bear various small nutrient foramina. The ventral surface bears a large fossa at midline; within this fossa are three large and subequally sized nutrient foramina. Similarly to more anterior vertebrae, two subequally sized foramina separated by a low median ridge lie on the concave dorsal surface of the centrum. The transverse processes are broken at their base and were similar to those in more anterior lumbars (cf. above). Although it is slightly crushed, the neural arch of L5 is one of the best preserved in the lumbar region. The pedicles were deformed during the fossilization and are shifted to the right. However, it is possible to reconstruct the neural canal as being roughly semicircular in cross-section and wider than high. The ridge observed on the roof of the neural canal is more pronounced in $\mathrm{L} 5$ than in L4, but remains less prominent than in more posterior lumbars. The laminae are well preserved and the metapophyses and postzygapophyses provide a V-shaped outline to the neural arch in dorsal view. Similarly to L1, the postzygapophyses are strongly reduced, while the metapophyses are well developed and dorsolaterally oriented in lateral view. The medial margin of each metapophysis is somewhat convex and forms an inconspicuous crest corresponding to the position of the prezygapophysis. Finally, L5 lacks its entire neural spine.
Sixth lumbar (L6) (Fig. 69I-L). As compared with L5, only a few differences are noted in L6. These differences include the number of large nutrient foramina on the ventral surface of the centrum and the less advanced degree of fusion for the anterior and posterior epiphyses. The cylindrical centrum is similar to more anterior vertebrae, being circular in cross-section, and bearing small nutrient foramina on the lateral surfaces and larger foramina on the dorsal and ventral surfaces. The broken transverse processes were ventrolaterally oriented, dorsoventrally compressed, and closer to the anterior edge of the centrum. Contrasting with L4 and L5 and more similar to L1-L3, the ventral surface of the centrum presents only two large foramina, close to midline and separated by a low median ridge. As for more anterior vertebrae, the pedicles are anteriorly located and the posterior intervertebral notch is more pronounced than the anterior notch. The metapophyses are broken. The postzygapophyses are reduced and only the base of the neural spine is preserved. The neural canal is transversely wider than high, and roughly semicircular in cross-section, as in more anterior vertebrae. Additionally, there is a low median ridge on its roof, similar to what is observed in L4 and L5.

Seventh lumbar (L7) (Fig. 70A-D). Only the vertebral body, pedicles, and base of the right transverse process are preserved in the seventh lumbar. The centrum is better preserved anteriorly, where it is fused with the anterior epiphysis (they remain, however, easily distinguishable from each other). In contrast, the fusion of the centrum with the posterior epiphysis is partial and the posterior surface of the centrum and the posterior epiphysis are only partly preserved. In overall view, L7 shares with L6: two large median nutrient foramina on the ventral and dorsal surfaces of the centrum; numerous small foramina on the lateral surfaces of the centrum; dorsoventrally compressed transverse processes, extending ventrolaterally from the ventrolateral margin of the centrum; and transversely flattened pedicles, being closer to the anterior edge of the centrum than to the posterior edge.

Eighth lumbar (L8) (Fig. 70E-H). The centrum of L8 is one of the best preserved in the lumbar region. It is almost subequal in size with that of L7. Similarly to more anterior lumbar vertebrae, the centrum is cylindrical, circular in cross-section, and fused with both epiphyses. The latter are disc-shaped and somewhat concave. The lateral surfaces of the centrum present numerous small nutrient foramina, closer to the anterior and posterior edges of the centrum. Only one large foramen is present on the left side of the ventral surface, near the midline.

The centrum decreases in height and width at its mid-length portion. This condition is more pronounced in more posterior vertebrae and provides an almost hourglass-shaped outline to the centrum (cf. below). The transverse processes are broken at their base. Although closer to the anterior edge of the centrum the transverse process is more posterior than on the anterior lumbars. In contrast, the transversely flattened pedicles remain anteriorly located, and the posterior intervertebral notch is more pronounced than the anterior one. Dorsally, the left metapophysis and the apex of the right metapophysis are missing. 

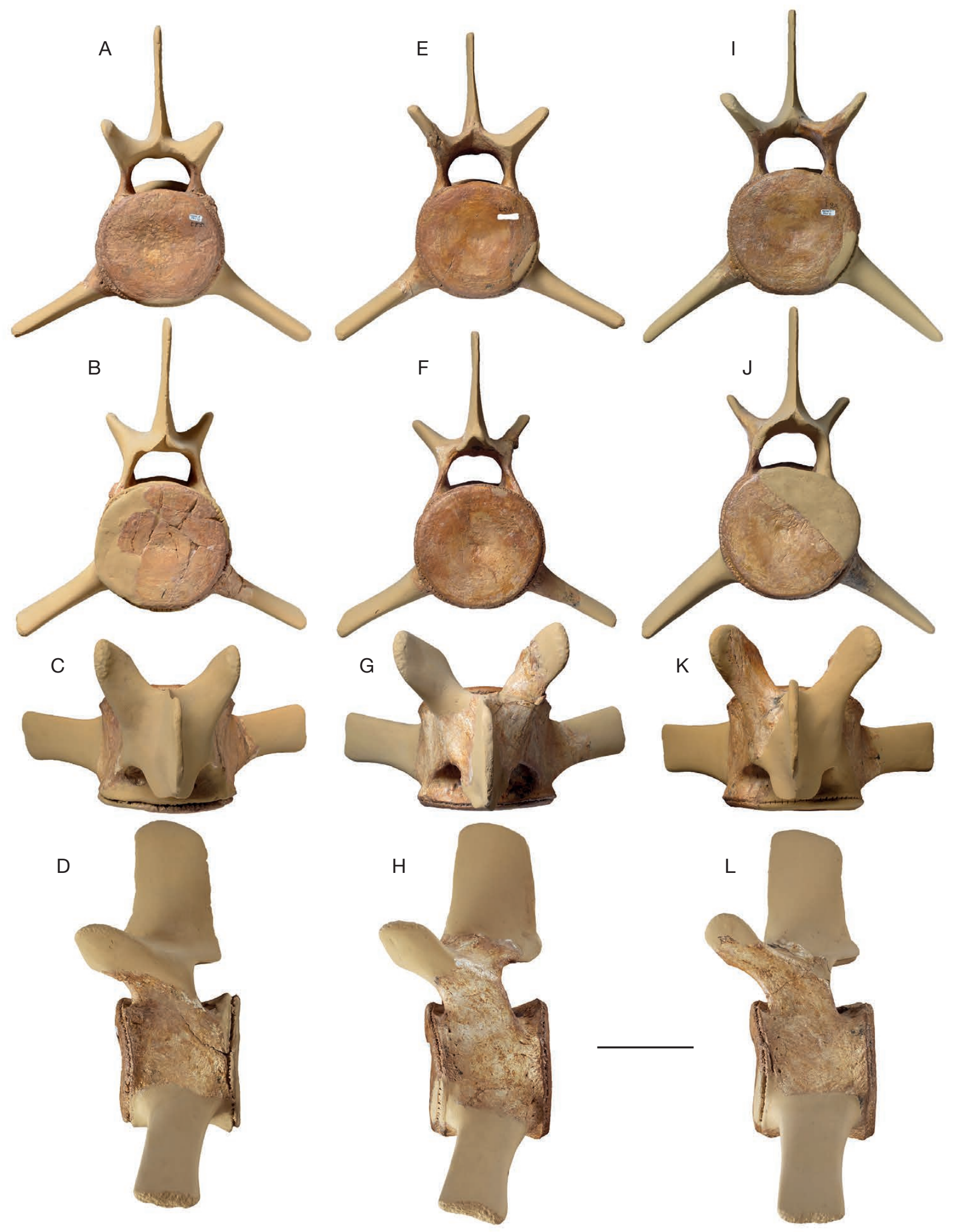

FIG. 70. - Lumbar vertebrae of MNHN.F.PRU10, holotype of Cynthiacetus peruvianus: A, seventh lumbar in anterior view; B, seventh lumbar in posterior view; $\mathbf{C}$, seventh lumbar in dorsal view; D, seventh lumbar in left lateral view; E, eighth lumbar in anterior view; $\mathbf{F}$, eighth lumbar in posterior view; G, eighth lumbar in dorsal view; H, eighth lumbar in left lateral view; I, ninth lumbar in anterior view; J, ninth lumbar in posterior view; K, ninth lumbar in dorsal view; L, ninth lumbar in left lateral view. The missing portions of the bones (especially the transverse processes and neural spines) have been reconstructed. Scale bar: $10 \mathrm{~cm}$. 
The latter is elongated and linguiform, similar to that in L5. The postzygapophyses and most of the neural spine are missing. The neural arch is $V$-shaped in dorsal view, with the apex of the $\mathrm{V}$ being posteriorly pointed. The neural canal is wider than high. The cross-section of the neural canal is larger at its mid-length than at its anterior or posterior end. This results from the decrease of the cross-section of the centrum at its mid-length. Additionally, the roof of the neural canal presents the low median ridge observed in more anterior lumbars.

Ninth lumbar (L9) (Fig. 70I-L). The centrum of L9 is subequal in size to that of L8. As in more anterior vertebrae, it is cylindrical, circular in cross-section, and fused with the anterior and posterior epiphyses. The reduction of the centrum cross-section at mid-length is as pronounced as in L8. Two large foramina lie on the ventral surface of the centrum, near the midline. These foramina are asymmetrical, the left foramen being larger than the right. In relation to the reduction of the centrum cross-section, the dorsal surface of the centrum is concave. It bears two large foramina, which open into the neural canal. The latter is not entirely preserved but was probably roughly oval, wider than high. Only the left pedicle and metapophysis are preserved in the neural arch of L9. As in other lumbars, the pedicle is transversely flattened. The elongated and linguiform metapophysis is dorsolaterally oriented in anterior view, and anterolaterally oriented in dorsal view. The size of the metapophysis probably increases posteriorly in the lumbar region. However, this can only be observed in the L9-L12 series, where the metapophyses are virtually complete. Although only the base of the right transverse process is preserved, it can be evaluated that the transverse processes were more posteriorly located than in the L1-L7 series, as is observed in L8.

Tenth lumbar (L10) (Fig. 71A-D). From L10 to L12, the centra of the lumbar vertebrae are more circular in cross-section that for the rest of the lumbar region. Although the neural spine and transverse processes are missing in vertebrae L10 to L14, these lumbars are the best preserved of the lumbar region. The centrum of L10 is larger than that of L9 in all dimensions. It is cylindrical and fused to both epiphyses, with the fusion of the anterior epiphysis being more pronounced. As in L9 and L8, the dorsal surface of the centrum is concave and presents two large nutrient foramina. In contrast with more anterior lumbars, the ventral surface of the centrum presents numerous large nutrient foramina. Among these foramina, three transversely aligned foramina are larger than the others. The base of the transverse processes is dorsoventrally compressed and extends ventrolaterally from the ventrolateral margin of the centrum.

Dorsally, the neural arch is better preserved than in most anterior lumbars. The pedicles are transversely flattened and closer to the anterior edge of the centrum. As compared with more anterior vertebrae, the pedicles are more medially located and do not extend from the dorsolateral margin of the centrum. Consequently, the neural canal of L11 is proportionally narrower than in anterior lumbars. This medial migration of the pedicles is even more pronounced in the
L11-L17 series. However, the pedicles shorten dorsoventrally more rapidly than they migrate medially on the dorsal surface of the centrum. As a consequence, the neural canal becomes more dorsoventrally compressed in posterior lumbars (from L10 to L17). The low ridge on the roof of the neural canal is more developed than in any anterior lumbar vertebra. This ridge is more accentuated in L11-L13, where it provides a roughly $\mathrm{M}$-shaped outline to the roof of the canal in anterior and posterior views. The subcomplete metapophyses are well developed and a crest on their medial margins (homologous of the prezygapophyses) is clearly visible. Posteriorly, the vestigial postzygapophysis is continuous with the roof of the neural canal and forms a posteriorly pointed process. Similarly to more anterior lumbars, the metapophyses and postzygapophyses provide a $\mathrm{V}$-shaped outline to the neural arch in dorsal view. The neural spine is broken at its base.

Eleventh lumbar (L11) (Fig. 71E-H). Like L10, the eleventh lumbar is one of the best-preserved. Its centrum is cylindrical, sub-equal in size to that of L10, and partially fused to the epiphyses. The cross-section of the centrum is smaller at midlength than at anterior and posterior extremities, providing a roughly hourglass-shaped outline to the centrum in dorsal view. The hourglass-shape outline is even more conspicuous in posterior lumbars. The ventral surface of the centrum bears five large nutrient foramina. These foramina are adjacent to each other and closer to the midline than to the lateral margins of the ventral surface. The dorsoventrally compressed transverse processes are somewhat more posteriorly located as compared with the more anterior lumbars. The neural canal is proportionally lower than in L10 and its roof possesses a more developed median ridge. These differences are even more pronounced in more posterior vertebrae. The neural spine is broken at its base.

Twelfth lumbar (L12) (Fig. 71I-L). The centrum of L12 resembles those of anterior lumbar vertebrae in being cylindrical and roughly circular in cross-section (the left posterodorsal corner of the centrum is broken). The centrum width is actually slightly lower than the centrum height; L12 is thus the anteriormost lumbar to have an $\mathrm{H} / \mathrm{W}$ ratio higher to 1 . This feature is also observed in more posterior lumbars (L14-L17). The number and size of the nutrient foramina on the ventral surface of the centrum are the same as in L11. Anterior and posterior epiphyses are fused to the centrum but remain well defined. The preserved parts of the transverse processes are similar in form and orientation to those of L11. The neural canal is more dorsoventrally compressed than in more anterior vertebrae, and the median ridge on its roof is as pronounced as in L11. Moreover, the metapophyses are large and slightly longer than in L11 and L10. The small crest-like surfaces corresponding to the prezygapophyses on the medial margins of the metapophyses remain easily distinguishable. As in more anterior vertebrae, the neural arch is $\mathrm{V}$-shaped in dorsal view and the vestigial postzygapophyses can barely be distinguished from the roof of the neural canal. The neural spine is entirely missing. 


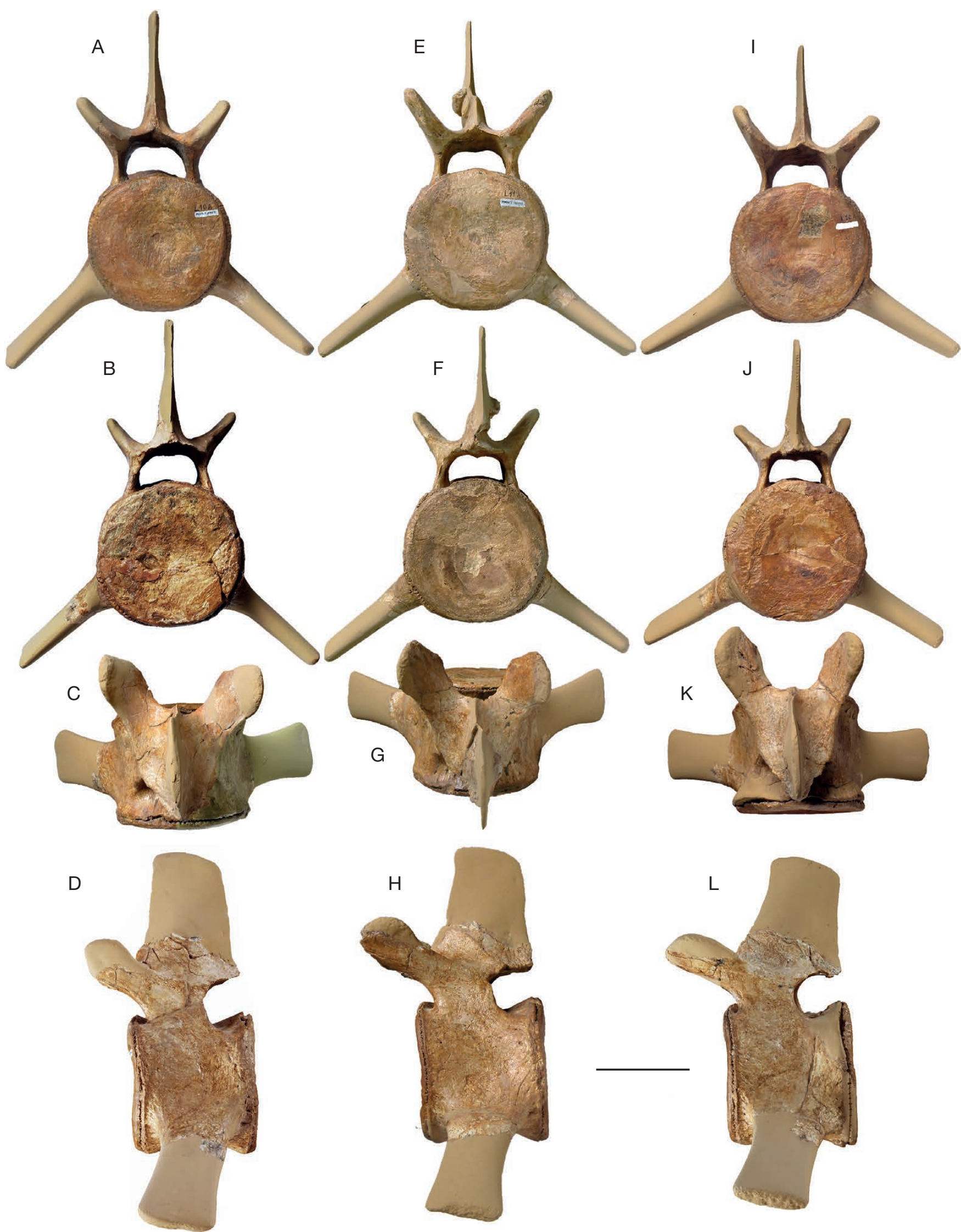

FIG. 71. - Lumbar vertebrae of MNHN.F.PRU10, holotype of Cynthiacetus peruvianus: A, tenth lumbar in anterior view; B, tenth lumbar in posterior view; C, tenth lumbar in dorsal view; D, tenth lumbar in left lateral view; E, eleventh lumbar in anterior view; $\mathbf{F}$, eleventh lumbar in posterior view; G, eleventh lumbar in dorsal view; H, eleventh lumbar in left lateral view; I, twelfth lumbar in anterior view; J, twelfth lumbar in posterior view; K, twelfth lumbar in dorsal view; L, twelfth lumbar in left lateral view. The missing portions of the bones (especially the transverse processes and neural spines) have been reconstructed. Scale bar: $10 \mathrm{~cm}$. 
Thirteenth lumbar (L13) (Fig. 72A-D). In overall view, the thirteenth lumbar is similar to the twelfth one: L12 and L13 are subequally sized and possess the same morphology. As in other lumbar vertebrae, the centrum is firmly attached to the epiphyses. Nevertheless, the fusion is not so advanced as in more anterior lumbars. In contrast with more anterior lumbars (except L8), the ventral surface of the centrum bears a single large depression at midline. This fossa is formed by the fusion of two large foramina. This pattern (two large foramina within a median fossa) is also observed in more posterior vertebrae, including the caudals. The transverse processes do not differ from those of the anterior lumbars, except for being relatively more posteriorly located. Only a portion of the right metapophysis and the base of the neural spine are preserved. The neural canal is well preserved, being lower than in L12 and with the ridge on its roof less marked than in more anterior lumbars (L10 to L12).

Fourteenth lumbar (L14) (Fig. 72E-H). L14 is among the best-preserved vertebrae of the lumbar region. Its centrum is cylindrical and partly fused with the epiphyses. As in other anterior lumbars, the cross-section of the centrum is larger at the anterior and posterior extremities, and smaller at midlength. Similarly to L13, a single large, rounded median foramen lies on the ventral surface of the centrum. The preserved portion of the transverse processes is similar to that of more anterior lumbars.

The neural arch is also well preserved. As mentioned above, the overall size and the proportional height of the neural canal decrease in lumbars posterior to L9. This reduction in size and proportional height is even more conspicuous in L14L17. The median ridge on the roof of the neural canal is less developed than in L13 and becomes inconspicuous in more posterior lumbars. The linguiform metapophyses are elongated and dorsolaterally oriented in anterior view. The vestigial prezygapohyses are still distinguishable on the medial margin of the metapophyses. The posteriorly pointed postzygapophyses are short and their posterior end is anterior to the level of the posterior end of the centrum. In more anterior vertebrae, the posterior edges of the centrum and postzygapophyses are located at about the same level. This anterior position of the postzygapophyses results from the shortening of the neural arch in L14, a condition that increases in posterior vertebrae. The neural spine is broken at its base.

Fifteenth lumbar (L15) (Fig. 72I-L). The cylindrical centrum of L15 shares with those of other lumbar vertebrae: a concave dorsal surface, with two large nutrient foramina opening into the neural canal; an almost circular transverse section, being larger at the anterior and posterior ends; smooth lateral surfaces with small nutrient foramina near the anterior and posterior edges; and two large foramina on its ventral surface, partly merged in L15. The epiphyses are disc-shaped and partly fused with the centrum; the fusion of the anterior epiphysis with the centrum is more pronounced. The transverse processes are dorsoventrally compressed at their base and slightly closer to the anterior edge of the centrum. The neural canal is even lower than in L14 and the median ridge on its roof is barely distinguishable. The pedicles are more medially located than in L14, and closer to the anterior margin of the centrum than to the posterior margin. Finally, both metapophysis and the neural spine are poorly preserved.

Sixteenth lumbar (L16) (Fig. 73A-D). The penultimate lumbar is slightly larger than L15. As in more anterior vertebrae, it possesses a cylindrical centrum, with an almost circular cross-section being much larger at its extremities than in its mid-length portion. Consequently, the centrum of L16 is hourglass-shaped in dorsal and ventral views. Its dorsal surface has two relative large nutrient foramina near the midline, while its ventral surface presents one large depression. This ventral fossa is divided into two large foramina by a wide bony septum. The incomplete transverse processes of L16 are yet better preserved than in more anterior vertebrae; they are ventrolaterally oriented and are slightly more dorsally located than in more anterior vertebrae. The neural arch is partly preserved. The pedicles are more medially located and shorter than in more anterior lumbars. Consequently, the neural canal is strongly reduced and dorsoventrally compressed. The ridge on the roof of the neural canal has almost disappeared. The metapophyses are missing and the postzygapohyses are shorter than in more anterior vertebrae. The shortening of the postzygapophyses is associated to a moderate lengthening of the posterior portion of the centrum, which is more pronounced in L17. The posterior end of the postzygapophyses is located posterior to the level of the transverse process and anterior to the level of the posterior edge of the centrum. The neural spine is not preserved.

Seventeenth lumbar (L17) (Fig. 73E-H). The last lumbar vertebra resembles more the penultimate. As in other posterior lumbars, the cross-section of the centrum is almost circular, being slightly dorsoventrally higher than transversely wide. Both anterior and posterior epiphyses are partially fused with the centrum, but remain easily distinguishable. The hourglass-shaped centrum is lower and narrower in its mid-length portion. As in L16, a large and rounded fossa lies on the ventral surface of the centrum. Within this fossa are two large foramina separated by a thin bony septum. The anteroposterior lengthening of the centrum is more pronounced in L17 than in L16. The transverse processes are more posteriorly located, being closer to the posterior edge of the centrum than to the anterior edge. The base of the transverse processes is ventrolaterally oriented, dorsoventrally compressed, and slightly more dorsally located than in more anterior vertebrae. Dorsal to the centrum, the reduction of the neural canal is even more pronounced, and L17 has the smallest neural canal of the whole lumbar series. The pedicles are dorsoventrally shorter and contact the metapophyses dorsally. The latter are incomplete on both sides. As a consequence of the anteroposterior lengthening of the centrum and the shortening of the postzygapophyses, the posterior edge of the postzygapophyses is at the same level as the posterior end of the transverse processes. As in all other lumbar vertebrae, the neural spine is not preserved. It is most 

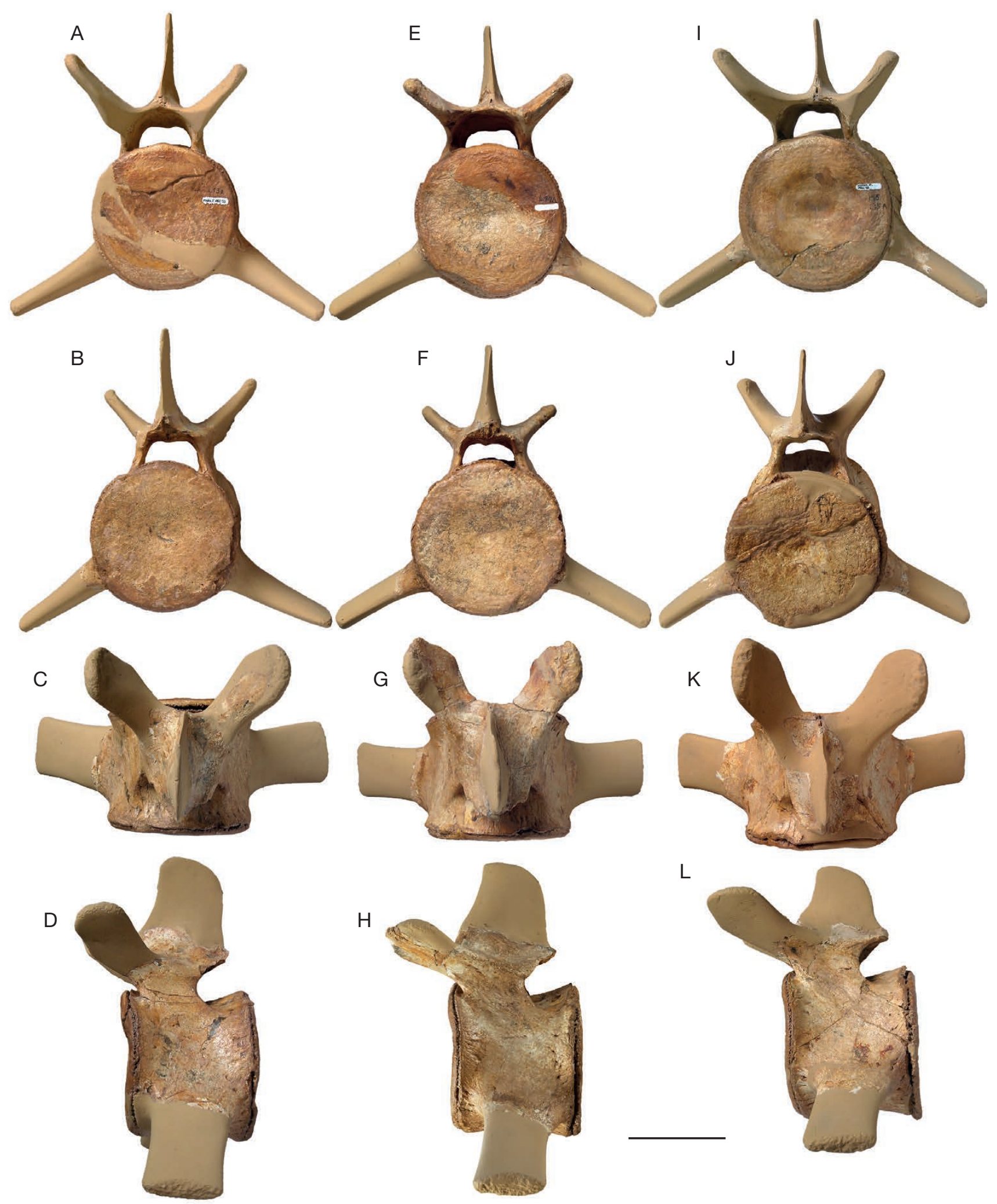

FIG. 72. - Lumbar vertebrae of MNHN.F.PRU10, holotype of Cynthiacetus peruvianus: A, thirteenth lumbar in anterior view; B, thirteenth lumbar in posterior view; C, thirteenth lumbar in dorsal view; D, thirteenth lumbar in left lateral view; E, fourteenth lumbar in anterior view; $\mathbf{F}$, fourteenth lumbar in posterior view; G, fourteenth lumbar in dorsal view; H, fourteenth lumbar in left lateral view; I, fifteenth lumbar in anterior view; J, fifteenth lumbar in posterior view; K, fifteenth lumbar in dorsal view; L, fifteenth lumbar in left lateral view. The missing portions of the bones (especially the transverse processes and neural spines) have been reconstructed. Scale bar: $10 \mathrm{~cm}$. 

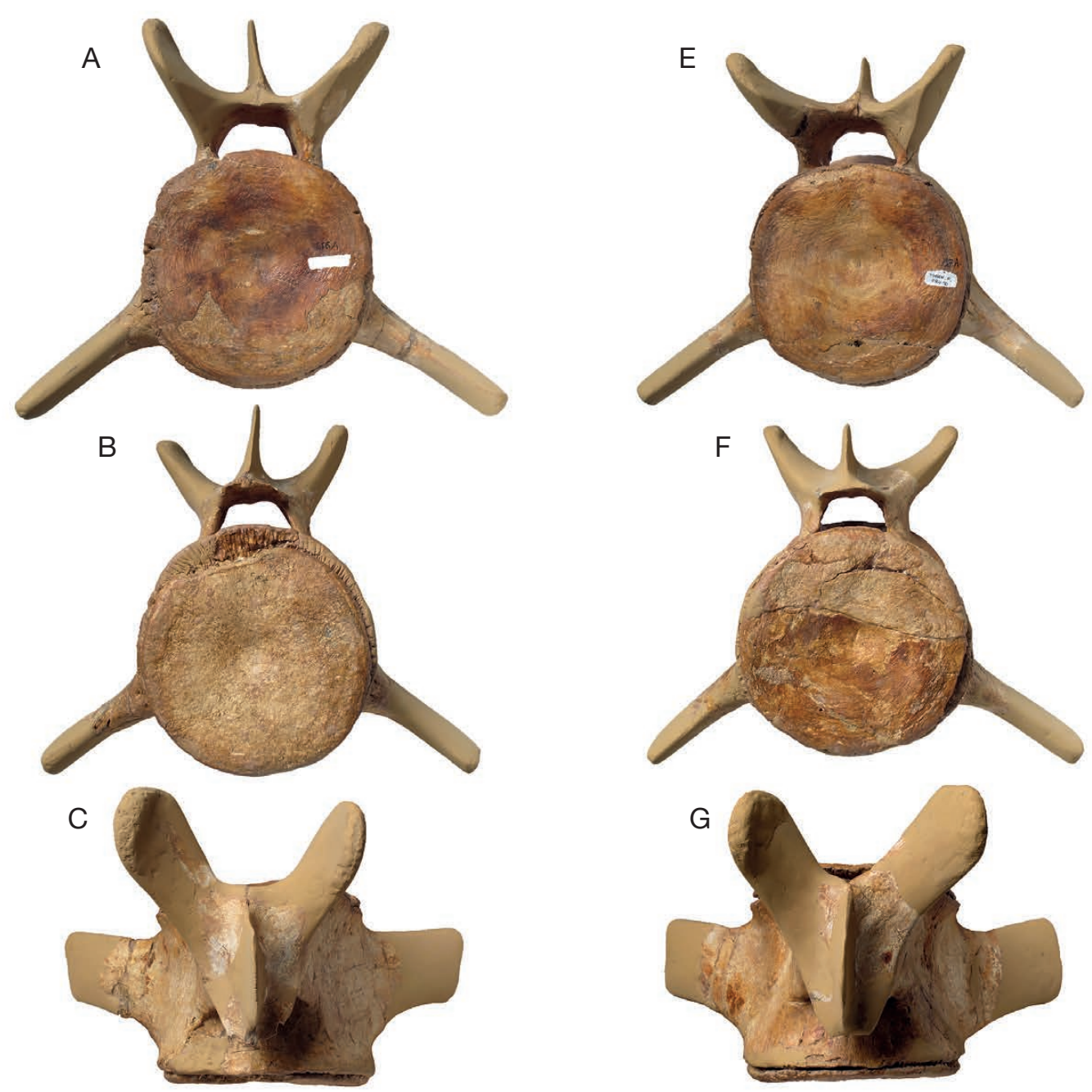

D

$\mathrm{H}$
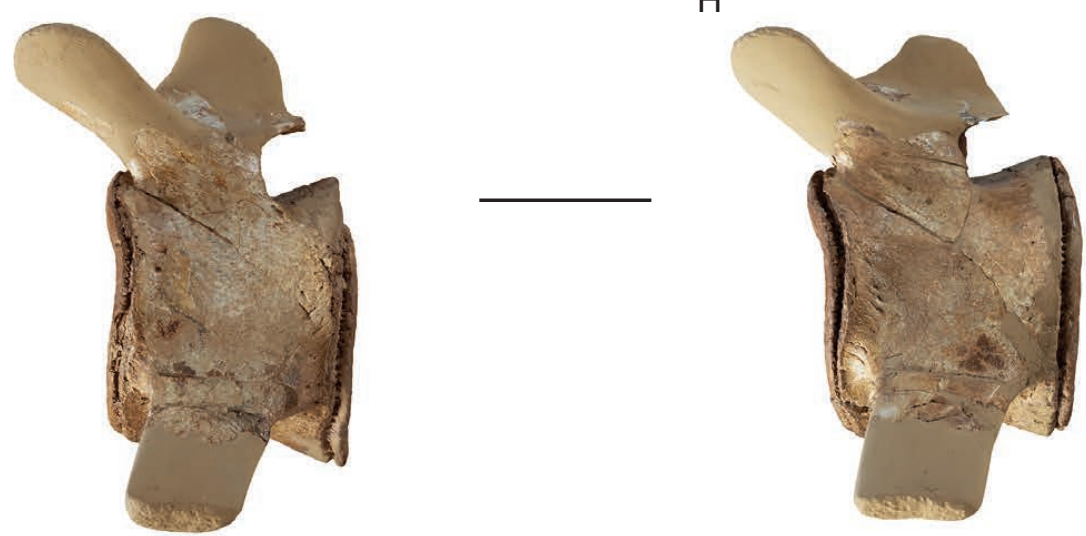

FIG. 73. - Lumbar vertebrae of MNHN.F.PRU10, holotype of Cynthiacetus peruvianus: A, sixteenth lumbar in anterior view; B, sixteenth lumbar in posterior view; C, sixteenth lumbar in dorsal view; $\mathbf{D}$, sixteenth lumbar in left lateral view; E, seventeenth lumbar in anterior view; $\mathbf{F}$, seventeenth lumbar in posterior view; $\mathbf{G}$, seventeenth lumbar in dorsal view; $\mathbf{H}$, seventeenth lumbar in left lateral view. The missing portions of the bones (especially the transverse processes and neural spines) have been reconstructed. Scale bar: $10 \mathrm{~cm}$.

likely that the neural spine decreases progressively in height posterior to L12, and L17 thus probably had the lowest and less developed neural spine of the lumbar region.

Caudal region (Fig. 46C). Since there is no sacral region in the Pelagiceti, the lumbar-to-caudal transition is indicated by the presence of hemal processes on the ventral surface of the centrum. These hemal processes are located closer to the posterior edge of the centrum and articulate with the chevrons. The caudal region of MNHN.F.PRU10 is incomplete and only the first ten caudal vertebrae and one chevron are preserved. The basilosaurid caudal region is almost completely 
A

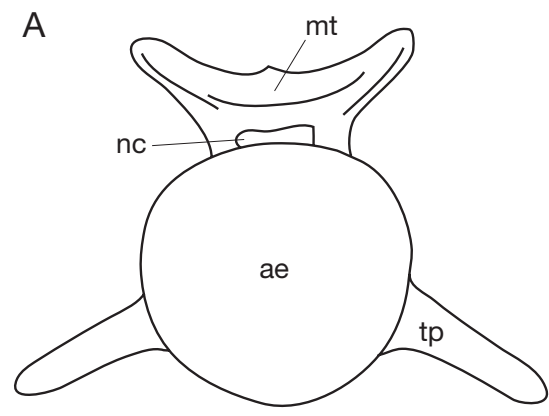

$\mathrm{D}$

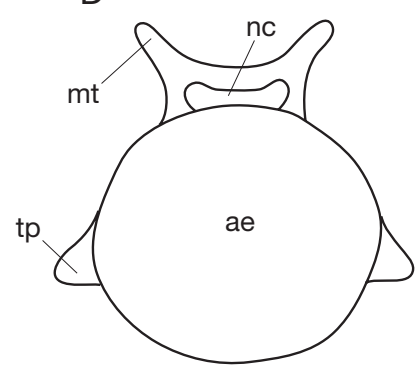

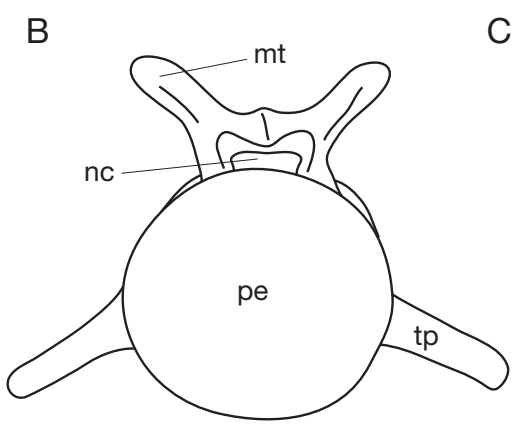

B

$\mathrm{E}$

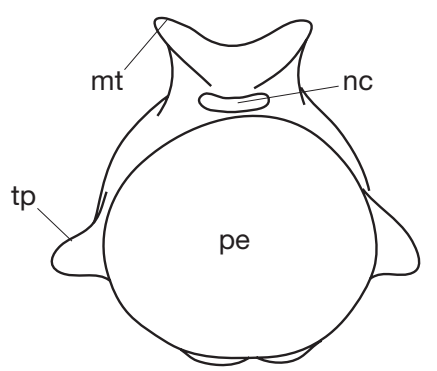

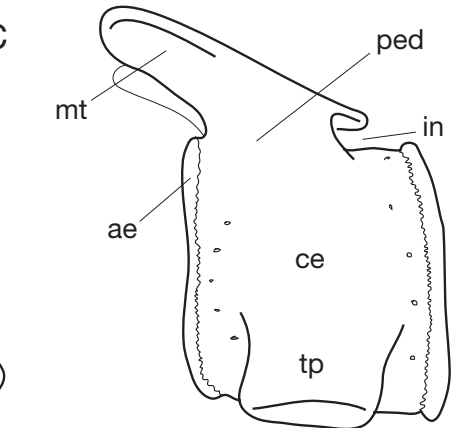

$\mathrm{F}$

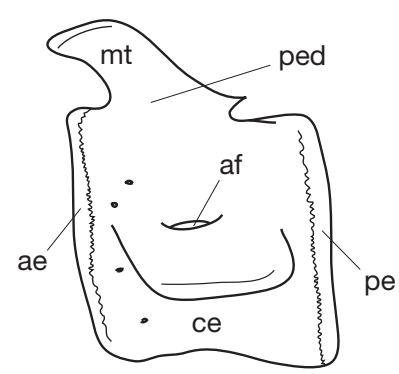

FIG. 74. - Main morphological characters observed in the caudal vertebrae in MNHN.F.PRU10, holotype of Cynthiacetus peruvianus: A, second caudal vertebra in anterior view; B, second caudal vertebra in posterior view; C, second caudal vertebra in left lateral view; $\mathbf{D}$, seventh caudal vertebra in anterior view; E, seventh caudal vertebra in posterior view; F, seventh caudal vertebra in left lateral view. Abbreviations: ae, anterior epiphysis; af, arterial foramen; ce, centrum; in, intervertebral notch; mt, metapophysis; nc, neural canal; pe, posterior epiphysis; ped, pedicle; tp, transverse process. Scale bar: $10 \mathrm{~cm}$.

TABLE 10. - Measurements (in mm) of the caudal vertebral centra of MNHN.F.PRU10, holotype of Cynthiacetus peruvianus. (e), estimated measurements.

\begin{tabular}{|c|c|c|c|c|c|c|c|c|c|}
\hline & Ca1 & Ca2 & Ca3 & Ca4 & Ca5 & Ca7 & Ca8 & Ca9 & Ca10 \\
\hline Anterior width & 168.27 & 168.87 & 168.68 & 167.89 & $173(\mathrm{e})$ & 161.17 & $159(\mathrm{e})$ & $152(\mathrm{e})$ & $145(e)$ \\
\hline Posterior width & 178.64 & 182 & 180.63 & 181.09 & 177.77 & $158(\mathrm{e})$ & 148.25 & $147(\mathrm{e})$ & $131(\mathrm{e})$ \\
\hline Anterior height & $175(\mathrm{e})$ & 172.27 & $159(\mathrm{e})$ & 163.31 & 162.15 & 149.93 & 145 & $146(\mathrm{e})$ & $145(\mathrm{e})$ \\
\hline Posterior height & 172.74 & $172(\mathrm{e})$ & 172.37 & 162.55 & 163.4 & $145(\mathrm{e})$ & $136(\mathrm{e})$ & 133.4 & $119(\mathrm{e})$ \\
\hline Dorsal length & 152.8 & $150(\mathrm{e})$ & 150.56 & 147.48 & 149.53 & 147.14 & 147.86 & 144 & $128(\mathrm{e})$ \\
\hline Ventral length & $143(\mathrm{e})$ & 152.6 & 145.73 & 143.3 & 149.51 & $136(\mathrm{e})$ & $132(\mathrm{e})$ & $134(\mathrm{e})$ & $126(\mathrm{e})$ \\
\hline
\end{tabular}

known in three species: Basilosaurus cetoides (Kellogg 1936), B. isis (Gingerich et al. 1990), and Dorudon atrox (Uhen 2004), where it includes twenty-one vertebrae. The same count of vertebrae is observed in the caudal region of the protocetid Maiacetus inuus (Gingerich et al. 2009), while the total number of caudal vertebrae remains unknown in other basilosaurids species.

The anterior caudals of Cynthiacetus peruvianus are morphologically similar to those of Dorudon atrox, and it is likely that $C$. peruvianus had a similar caudal count as Basilosaurus cetoides and $D$. atrox. In contrast, the caudal region of Recent cetaceans possesses a higher number of vertebrae, which can increase up to 50 in some delphinids (Buchholtz \& Schur 2004). The relatively low number of caudal vertebrae in basilosaurids indicates that they were slower and less agile than most modern cetaceans.

Usually, the caudal section of the basilosaurid vertebral column is divided into three well-differentiated regions: the anterior caudal region, the peduncular region, and the fluke (Kellogg 1936; Uhen 2004). Most caudal vertebrae preserved in MNHN.F.PRU10 belong to the anterior caudal region. These vertebrae can be regarded as functionally analogous to the lumbar vertebrae, and the locomotor musculature likely inserted on their neural arch. The last preserved caudal (Ca10) could be part of the peduncular region, since it is strongly shorter than the penultimate caudal (Ca9).

In overall view, the caudal vertebrae of Cynthiacetus peruvianus strongly resemble those of Dorudon atrox and Zygorhiza kochii in having anteroposteriorly shorter centra than in B. cetoides and Saghacetus osiris. However, the caudal vertebrae of Saghacetus osiris are not as elongated as in the basilosaurines. The vertebral morphology varies progressively in the caudal region of MNHN.F.PRU10. The morphological extremes are showed in Figure 74.

The caudal vertebrae of Cynthiacetus peruvianus are poorly preserved and most of the neural arches and transverse pro- 

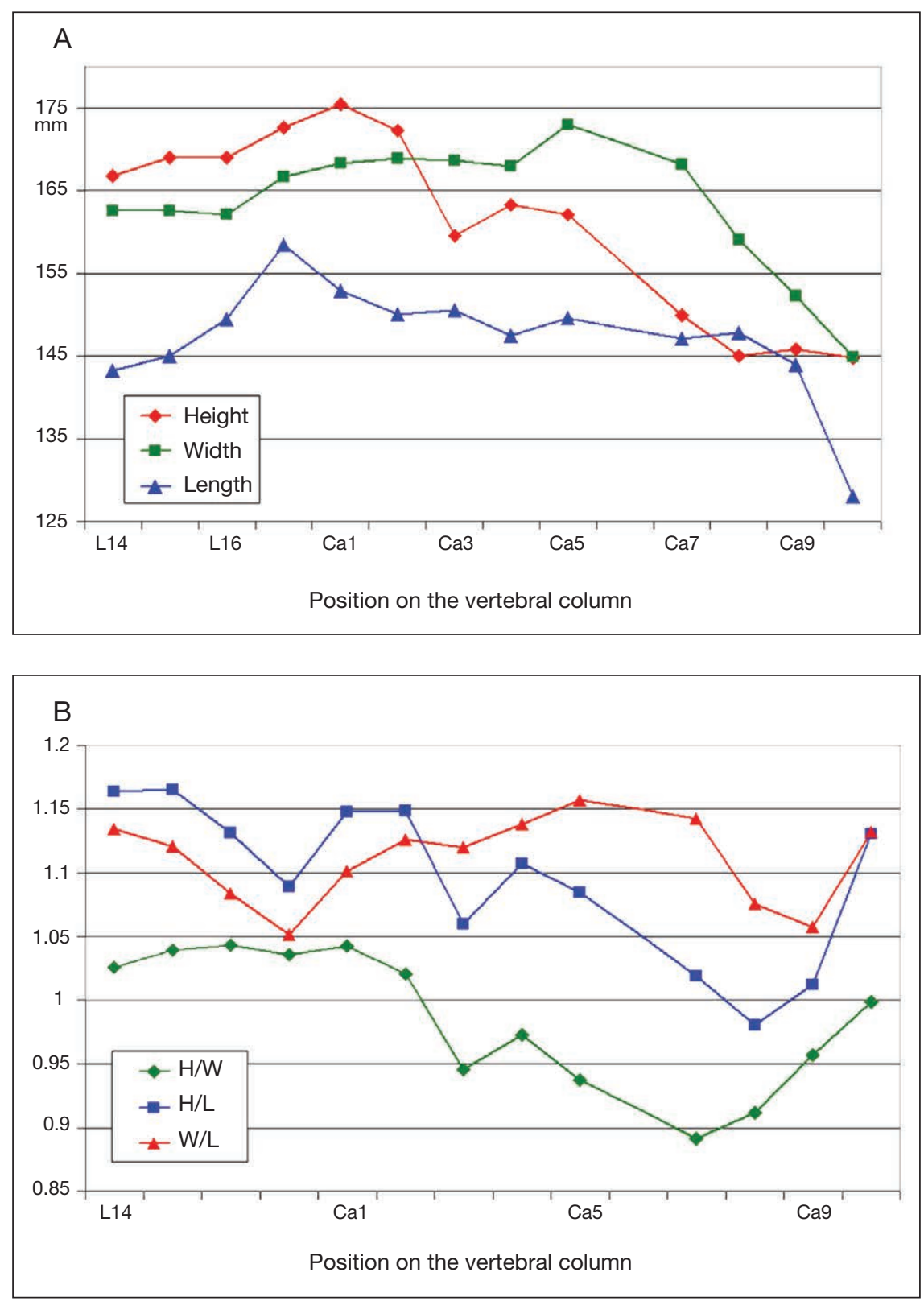

FIG. 75. - Evolution of the dimensions of centra in the caudal region of MNHN.F.PRU10, holotype of Cynthiacetus peruvianus: A, overall size; B, height-to-width, height-to-length, and width-to-length ratios.

cesses are broken. These structures have been reconstructed following the caudal vertebrae morphology in Basilosaurus cetoides and Dorudon atrox. The transverse processes decrease in size and are more posteriorly located in more posterior caudal vertebrae. Besides, the neural arch and neural spine decrease in size posteriorly, with the neural spine disappearing posterior to $\mathrm{Ca} 3$. Measurements of the caudal centra are given in Table 10.

The length and cross-section of the centra of the caudal vertebrae decrease posteriorly. As cited above, L17 is slightly longer than the other vertebrae, and the centrum length of $\mathrm{Ca} 1$ corresponds to that observed in L16 (Fig. 75A). The centrum length remains roughly stable in anterior caudal vertebrae and it decreases abruptly posterior to $\mathrm{Ca}$ 9. While the two anterior centra are dorsoventrally higher than transversely wide, the vertebrae posterior to $\mathrm{Ca} 2$ are wider than high and somewhat dorsoventrally compressed. This dorsoventral compression of the centra is certainly associated with the development of surfaces for the insertion of the epaxial musculature, including the $M$. flexor caudalis. The centrum width is greater than the centrum length in all the caudal vertebrae preserved in Cynthiacetus peruvianus and thus, the width/length ratio is greater than 1 in all of them (Fig. 75B).

First caudal (Ca1) (Fig. 76A-D). The centrum of Ca1 is subequal in width and height to that of L17, but it is anteroposteriorly shorter. As for the posterior lumbar vertebrae, the cross-section of the centrum increases towards its anterior and 

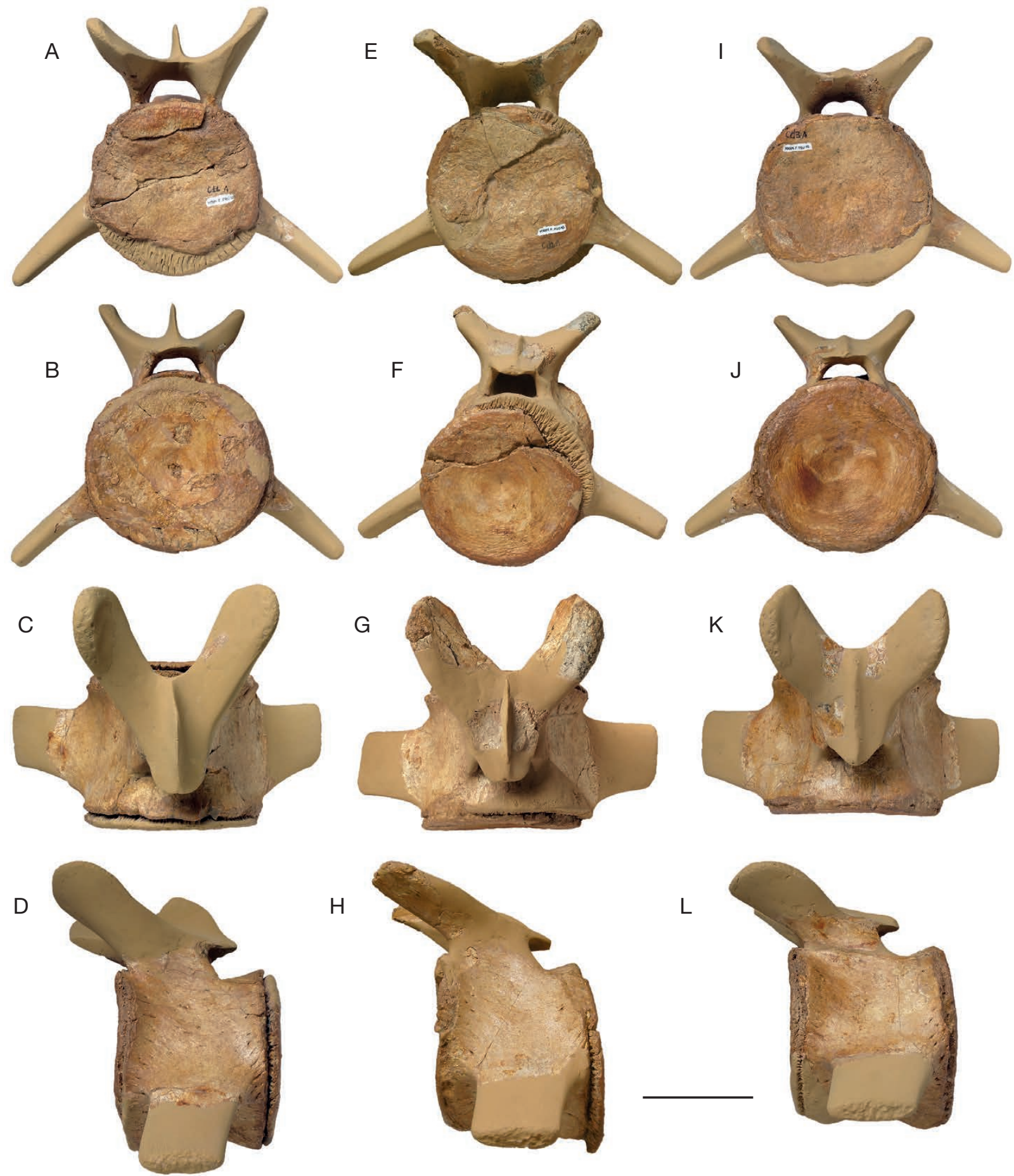

$\mathrm{H}$

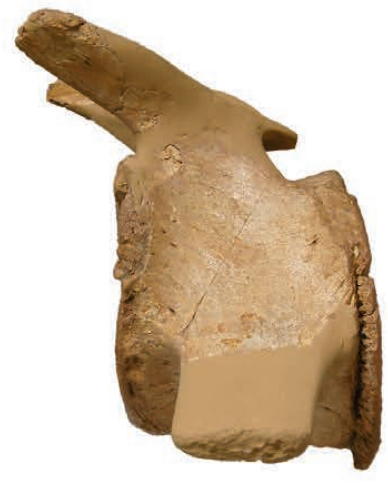

L

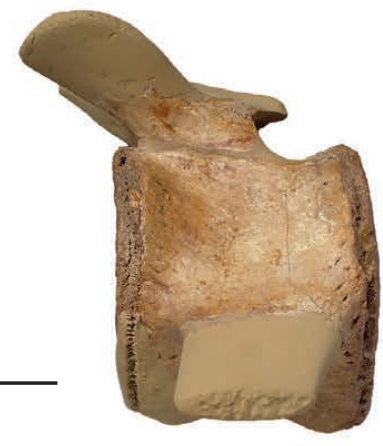

FIG. 76. - Caudal vertebrae of MNHN.F.PRU10, holotype of Cynthiacetus peruvianus: A, first caudal in anterior view; B, first caudal in posterior view; C, first caudal in dorsal view; D, first caudal in left lateral view; $\mathbf{E}$, second caudal in anterior view; F, second caudal in posterior view; G, second caudal in dorsal view; $\mathbf{H}$, second caudal in left lateral view; I, third caudal in anterior view; $\mathbf{J}$, third caudal in posterior view; $\mathbf{K}$, third caudal in dorsal view; L, third caudal in left lateral view. The missing portions of the bones (especially the transverse processes and neural spines) have been reconstructed. Scale bar: $10 \mathrm{~cm}$.

posterior margins, being shortest at its mid-length. Therefore, the centrum of $\mathrm{Ca} 1$ is vaguely hourglass-shaped. The anterior and posterior epiphyses are not fused with the centrum, and can easily be distinguished. While the anterior epiphysis is damaged and lacks part of its ventral portion, the posterior epiphysis is complete and better preserved. Similarly to the lumbar vertebrae, numerous small nutrient foramina lie on the lateral surfaces of the centrum. Additionally, the ventral surface of the centrum bears two large and anteroposteriorly elongated foramina. These foramina are located along the midline and are separated by a thin bony septum. Posterior to these foramina, two inconspicuous hemal processes lie near the posterior margin of the centrum. As for the thoracic and lumbar regions, the transverse processes of $\mathrm{Ca} 1$ are broken 
at their base. They extend ventrolaterally from a more dorsal level than in the lumbar region. The transverse processes are located at about the center of the lateral surface of the centrum, at equal distances from the anterior and posterior margins of the centrum. Dorsal to the centrum, the pedicles are transversely compressed and extend from a more medial position than in any lumbar vertebra. This condition reduces the transverse width of the neural canal, which is about half that of the centrum. Moreover, the pedicles are dorsoventrally lower than in anterior vertebrae. As a consequence, the neural canal is extremely compressed dorsoventrally. In lateral view, the pedicles of all the caudal vertebrae are closer to the anterior margin of the centrum than to the posterior margin. The pedicles continue dorsally into the laminae. Unfortunately, the latter are missing in Ca1. Since the metapophyses are well developed in L17 and Ca2, it is most likely that they were also prominent in Ca1. Although the posterior end of the neural arch is absent in all caudal vertebrae, we estimate that there is no postzygapophysis in this region and that the posterior end of the neural arch is posteriorly pointed.

Second caudal (Ca2) (Fig. 76E-H). Ca2 is similar to Ca1. Its centrum is only slightly smaller than that of $\mathrm{Ca} 1$, being roughly cylindrical and hourglass-shaped. The largest cross-section of the centrum is located at both anterior and posterior ends, where the centrum is unfused to both epiphyses. Two large adjacent foramina lie on the ventral surface of the centrum, at midline. These foramina are separated by a thin bony septum and located within a large depression. Posterior to this depression are the hemal processes, which are barely defined. The lateral surfaces of the centrum present small nutrient foramina, closer to its anterior and posterior margins. The transverse processes are broken at their base; they are dorsoventrally compressed and located at about the same level as in Ca1; they are slightly closer to the posterior margin of the centrum than to the anterior one. Dorsally, the neural arch of $\mathrm{Ca} 2$ is better preserved than in Ca1. As compared with more anterior vertebrae, the neural arch is strongly simplified and reduced. The pedicles are poorly preserved, closer to the anterior margin of the centrum. They delimit a small, dorsoventrally compressed neural canal. The metapophyses are well developed, linguiform and anterodorsally oriented in lateral view, an orientation similar to that in lumbar vertebrae. The metapophyses are broken in all the other caudal vertebrae, but it is likely that the size of the metapophyses decreased in more posterior vertebrae, since the neural arches in Ca7 and $\mathrm{Ca} 8$ are considerably smaller than in $\mathrm{Ca} 2$. However, we ignore if this reduction is progressive or more abrupt in more posterior vertebrae. In Dorudon atrox, the reduction of the metapophyses is more pronounced in vertebrae posterior to Ca5. The dorsal arch is posteriorly pointed and V-shaped in dorsal view, with the metapophyses forming the arms of the $\mathrm{V}$. The neural spine is not preserved but was probably extremely reduced.

Third caudal (Ca3) (Fig. 76I-L). Ca3 is similar to both Ca1 and $\mathrm{Ca} 2$. Its centrum is slightly smaller than that of $\mathrm{Ca} 2$ and its maximum cross-section is located at its anterior and posterior margins. Consequently, the centrum is also hourglass-shaped. Besides, the $\mathrm{Ca} 3$ centrum is the first to be transversely wider than dorsoventrally high. The dorsoventral compression is more pronounced than in $\mathrm{Ca} 2$ and $\mathrm{Ca} 4$. The anterior and posterior epiphyses are unfused to the centrum.

Ventrally, the hemal processes are more pronounced than in preceding vertebrae. There is one single large foramen on both the ventral and dorsal surfaces of the centrum. As in more anterior vertebrae, the lateral surfaces present small nutrient foramina.

The transverse processes and the neural arch of $\mathrm{Ca} 3$ are incomplete, with only their proximal portions preserved; they are proportionally thicker at their base than in $\mathrm{Ca} 2$ and they are located just ventral to the mid-height of the lateral surface of the centrum. In lateral view, these processes are located more posteriorly than in $\mathrm{Ca} 1$ and $\mathrm{Ca} 2$.

A large part of the neural arch is missing. The morphology of the neural canal and metapophyses is likely to have been similar to that observed in $\mathrm{Ca} 2$. As in other basilosaurids (Kellogg 1936; Uhen 2004), it is probable that Ca3 is the last vertebra displaying a vestigial neural spine.

Fourth caudal (Ca4) (Fig. 77A-D). Although the centrum of $\mathrm{Ca} 4$ is slightly smaller than that of $\mathrm{Ca} 3$, these two centra share a similar morphology: hourglass-shaped, with concave margins in lateral and dorsal views; partly preserved, unfused anterior and posterior epiphyses; a single, median and elongated nutrient foramen in both dorsal and ventral surfaces; numerous small nutrient foramina on the anterior and posterior margins of the lateral surface; and pronounced hemal processes for the articulation with the chevron. As a matter of fact, the centrum widens and lengthens progressively in more posterior vertebrae on the Ca4-Ca7 series. The transverse processes are broken at their base; they are more laterally oriented and thicker than in more anterior caudal vertebrae. Similarly to $\mathrm{Ca} 2$ and $\mathrm{Ca} 3$, the transverse process is closer to the posterior margin of the centrum than to the anterior. The posterior position of the transverse process is more pronounced in $\mathrm{C} 4$ than in more anterior vertebrae. The neural arch is damaged and only the base of the pedicles is preserved. The neural canal was probably similar to that of $\mathrm{Ca} 2$, being dorsoventrally compressed.

Fifth caudal (Ca5) (Fig. 77E-H). The dorsoventral compression (increase of the $\mathrm{W} / \mathrm{H}$ ratio) and relative lengthening (decrease of the $\mathrm{H} / \mathrm{L}$ ratio) of the centrum is more pronounced in $\mathrm{C} 5$ than in $\mathrm{Ca} 4$ and resembles more that observed in Ca3. Like in other caudal vertebrae, the centrum cross-section is larger at the anterior and posterior margins and the centrum is thus hourglass-shaped. The epiphyses are partially fused but can be easily differentiated from the centrum. Ventral and dorsal surfaces of the centrum present a single, elongated and large nutrient foramen. Similarly to other caudals, the lateral surfaces bear small nutrient foramina. Additionally, he hemal processes are well developed. As in $\mathrm{Ca} 4$, the neural arch is damaged and only the base of the pedicles is preserved in each side. 

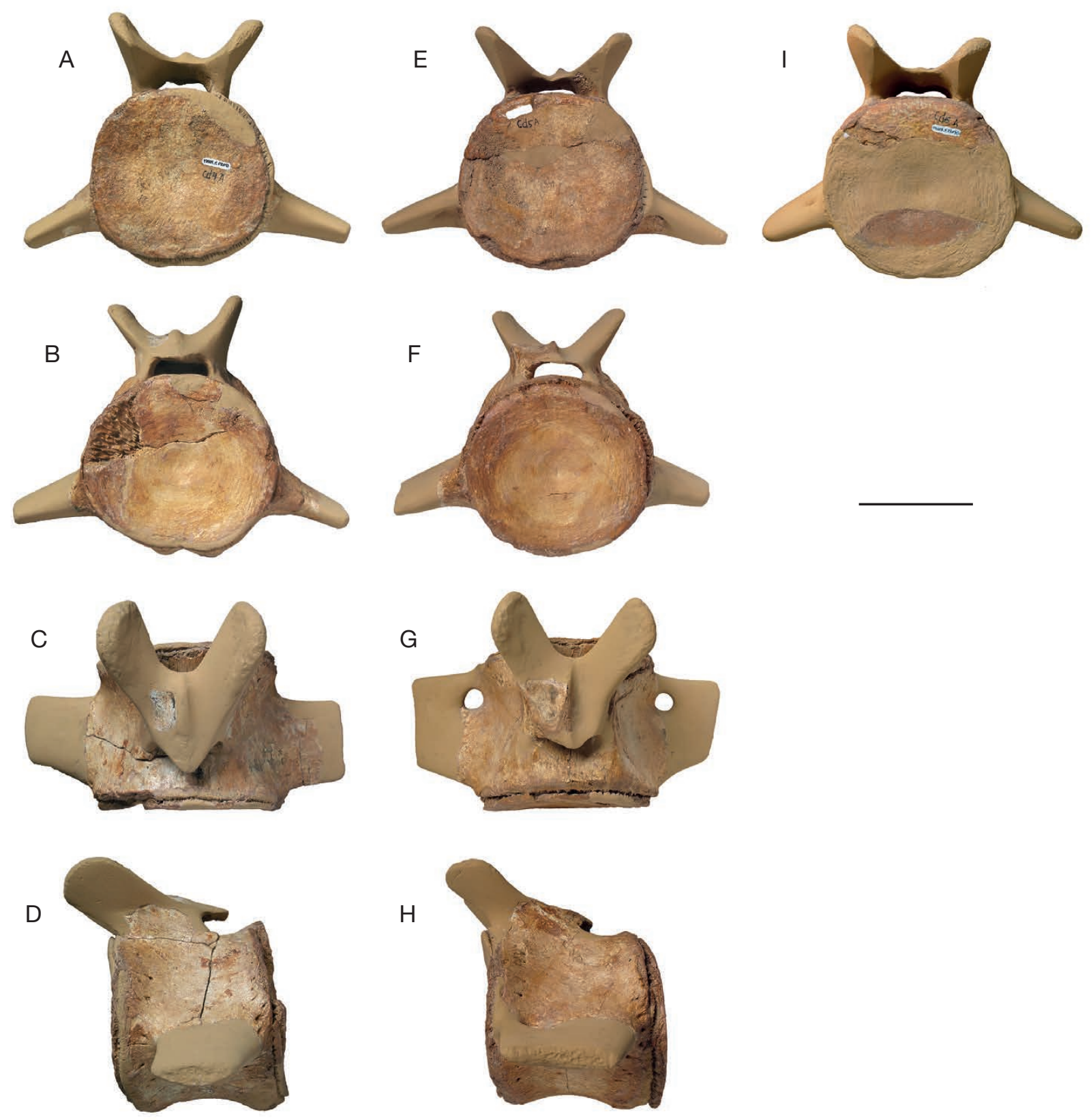

FIG. 77. - Caudal vertebrae of MNHN.F.PRU10, holotype of Cynthiacetus peruvianus: A, fourth caudal in anterior view; B, fourth caudal in posterior view; C, fourth caudal in dorsal view; D, fourth caudal in left lateral view; $\mathbf{E}$, fifth caudal in anterior view; $\mathbf{F}$, fifth caudal in posterior view; $\mathbf{G}$, fifth caudal in dorsal view; $\mathbf{H}$, fifth caudal in left lateral view; I, sixth caudal in anterior view. The missing portions of the bones (especially the transverse processes and neural spines) have been reconstructed. Scale bar: $10 \mathrm{~cm}$.

The distal portion of the transverse process is missing on both sides. However, the morphology of their base differs from the more anterior caudals in being anteroposteriorly longer, almost as long as the lateral surface of the centrum. A round and large foramen for the spinal artery lies close to the base of its anterior margin. The transverse process is almost laterally oriented and is supposed to have been proximodistally shorter than in more anterior vertebrae.

Sixth caudal (Ca6) (Fig. 77I). Only two fragments of $\mathrm{Ca} 6$ are preserved. These fragments have been identified as being part of the anterior epiphysis.
Seventh caudal (Ca7) (Fig. 78A-D). The centrum of Ca7 is incomplete and part of its right lateral half is missing. It is the most dorsoventrally compressed vertebra and its cross-section is considerably smaller than on Ca5. The height of the centrum decreases proportionally in the Ca7-Ca10 series. The size of the cross-section of the centrum increases towards its anterior and posterior margins, providing an hourglass-shaped outline to the centrum. However, this hourglass-shape is not as pronounced as in more anterior vertebrae and the ventral concavity of the centrum is less conspicuous than in $\mathrm{Ca} 5$. In lateral view, the anterior and posterior epiphyses are slightly inclined posterodorsally. 
Absent in more anterior vertebrae, this condition is present in $\mathrm{Ca}$ 7-Ca9. The anterior epiphysis is unfused to the centrum, while the fusion of the posterior epiphysis with the centrum is pronounced, particularly in the dorsal portion. A relatively large nutrient foramen lies on the ventral surface of the centrum, anterior to the well-developed hemal processes. The transverse processes are incomplete, but the left is better preserved. The arterial foramen is located closer to the anteroproximal corner of the transverse process and is smaller than in $\mathrm{Ca} 5$. As compared with anterior caudals, the transverse process of $\mathrm{Ca} 7$ is proportionally smaller. This reduction is more pronounced in posterior vertebrae. Dorsally, the neural arch is partly preserved. The pedicles are shorter and lower than in more anterior vertebrae. Moreover, the neural canal is extremely small and there is no neural spine. The metapophyses are broken at their base and are likely to have been much more reduced than in $\mathrm{Ca} 2$.

Eighth caudal (Ca8) (Fig. 78E-H). The centrum of Ca8 is less dorsoventrally compressed than that of $\mathrm{Ca} 7$, but it remains transversely wider than dorsoventrally high. The anterior epiphysis is better preserved and less fused to the centrum than the posterior epiphysis. The centrum is less hourglass-shaped than in more anterior vertebrae. As a matter of fact, the centrum is wider and higher at its anterior end than at its posterior end. It is also proportionally longer than in more anterior vertebrae and $\mathrm{H} / \mathrm{L}$ and $\mathrm{W} / \mathrm{L}$ ratios are thus smaller than in $\mathrm{Ca} 7$. A median nutrient foramen and two hemal processes lie on the ventral surface of the centrum, as in more anterior vertebrae. These structures are proportionally smaller than in $\mathrm{Ca} 7$ and $\mathrm{Ca} 5$. The neural arch of $\mathrm{Ca} 8$ is incomplete and only the pedicles and part of the roof of the neural canal are preserved. As compared with most lumbars and anterior caudals, the neural arch is strongly reduced. It is not $\mathrm{V}$-shaped, but triangular and posteriorly pointed. The distal extremity in both metapophyses is missing; nevertheless, they must have been quite reduced, similarly to what is observed in Dorudon atrox. The transverse processes of $\mathrm{Ca} 8$ are laterally oriented and occupy most of the anteroposterior breadth of the lateral surface of the centrum. A conspicuous arterial foramen lies at the base of the transverse process, visible on both sides.

Ninth caudal (Ca9) (Fig. 78I-L). Ca9 is the penultimate preserved caudal vertebra. Its centrum is slightly smaller than in $\mathrm{Ca} 8$, being transversely wider than high. The centrum of $\mathrm{Ca} 9$ is proportionally the longest caudal centrum in MNHN.F.PRU10. It resembles that of $\mathrm{Ca} 7$ and $\mathrm{Ca} 8$, being largest at its anterior extremity. The ventral and lateral surfaces are less concave than in anterior caudals. Although the epiphyses are incomplete, it is clear that they are slightly posterodorsally inclined in lateral view as is observed in $\mathrm{Ca} 7$ and $\mathrm{Ca} 8$. As in most other caudal vertebrae, the neural arch is almost completely missing, with only the base of the pedicles preserved. The transverse process is missing; it was probably present, but reduced, with a distinct arterial foramen at its base.
Tenth caudal (Ca10) (Fig. 78M-P). Ca10 is the smallest preserved caudal and is probably the first vertebra of the peduncular region. Its centrum is cylindrical, being anteroposteriorly shorter and dorsoventrally higher than the centrum of $\mathrm{Ca}$ 9. This trend probably continued posteriorly, in the peduncular region of the tail, where the centra are transversely compressed and proportionally shorter. Contrary to $\mathrm{Ca} 7-\mathrm{Ca}$ 9, the cross-sections are similar in size on the anterior and posterior extremities of the centrum. The posterior epiphysis and most of the anterior epiphysis and ventral portion of the centrum are missing in Ca10. No transverse process is preserved, but a pronounced notch is present on the lateral edge of the centrum. The neural arch is partly preserved; it bears an extremely reduced and roughly circular neural canal. As a consequence of the reduction of the centrum, the neural arch is proportionally larger than in $\mathrm{Ca} 7$.

Chevrons (hemal arches). Only one chevron (hemal arch) has been recovered and is referred to the ninth caudal vertebrae (Fig. 79). The chevrons are composed of two arms (nomenclature follows Kellogg 1936: fig. 69), which converge ventrally toward the body, the latter forming the ventral portion of the bone. In some cases, (always in neocetes) the body extends ventrally in a sharp, anteroposteriorly oriented crest named the hemal spine by Kellogg (1936: fig. 69). The ninth chevron of Cynthiacetus peruvianus is distinctly U-shaped in cross-section, a morphology that strongly differs from the markedly V-shaped morphology observed in the Neoceti. The arms have roughly the same (anteroposterior) width as the body. Each arm is slightly expanded at the apex, which contacts the articular facet on the posterior region of the centrum of the corresponding caudal vertebra. The arms are transversely flattened, being approximately twice longer (anteroposteriorly) than wide (transversely) at mid-length. The body is relatively flat dorsoventrally and forms a plane at an angle of approximately $45^{\circ}$ with the axes of the arms. The body is anteroposteriorly short, being twice shorter than transversely wide. Although this region is named hemal spine by Kellogg (1936), nothing in this chevron of Cynthiacetus resembles a spine. The dorsoventrally flat body of the chevron clearly differs from the condition observed in Neoceti, where the body extends ventrally in a large, transversely compressed spine forming an anteroposteriorly oriented sharp blade. The condition of the ninth haemal arch of $C$. peruvianus resembles in this respect those of Zygorhiza (Kellogg 1936: fig. 69) and Dorudon (Uhen 2004: 97A). However, in these genera the hemal spine strongly projects posteriorly, being elongated anteroposteriorly (in dorsal view) and roughly twice as long as the anteroposterior width of the arms. In C. peruvianus the hemal spine (if any) does not really project posteriorly since the body is approximately as long as the anteroposterior width of the arms. Kellogg (1936: fig. 70) also illustrates a distinctly V-shaped chevron of Zygorhiza kochii with a crest-like and transversely compressed hemal spine, which he referred to the posterior 

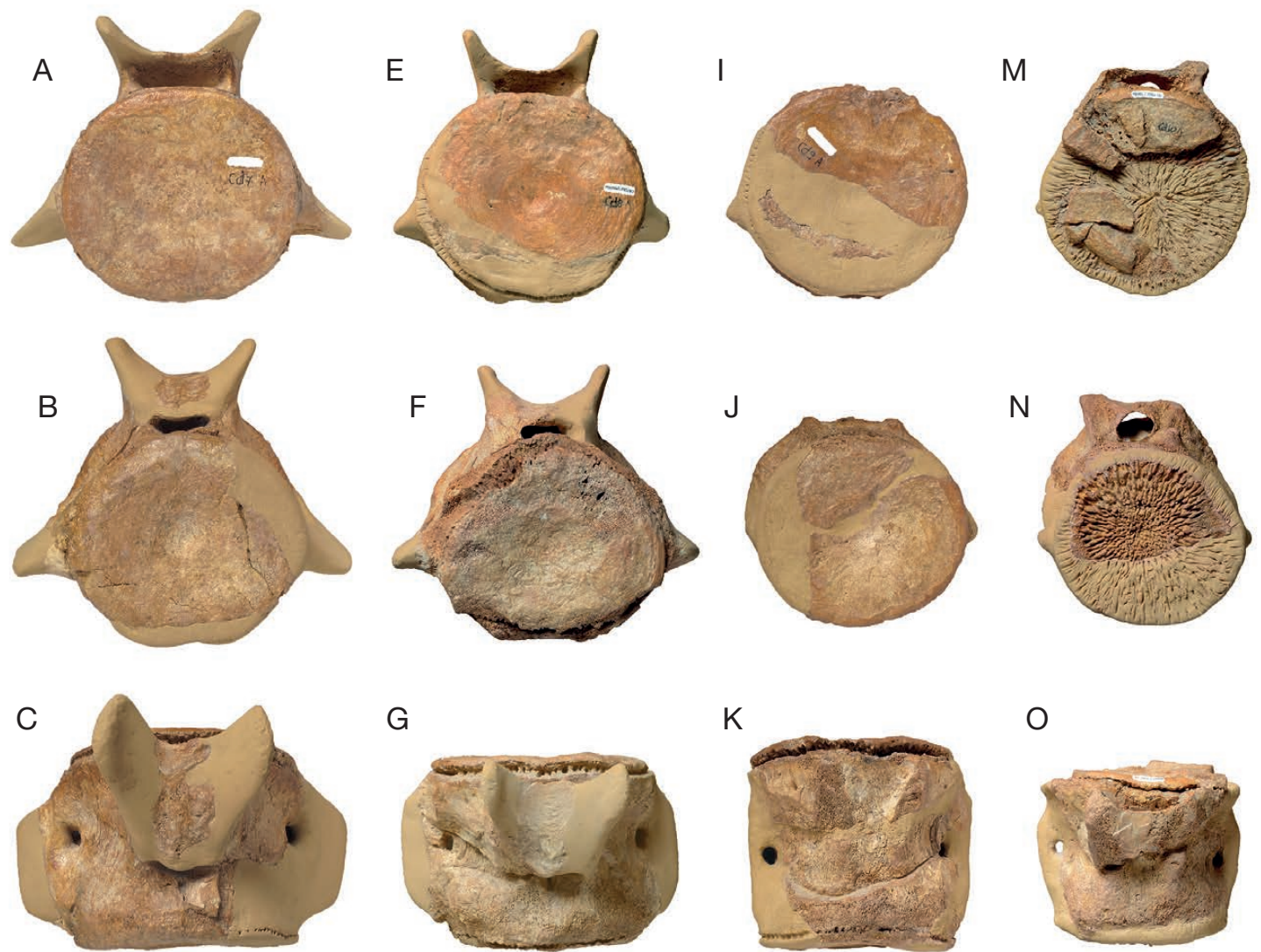

G

K

$\mathrm{O}$
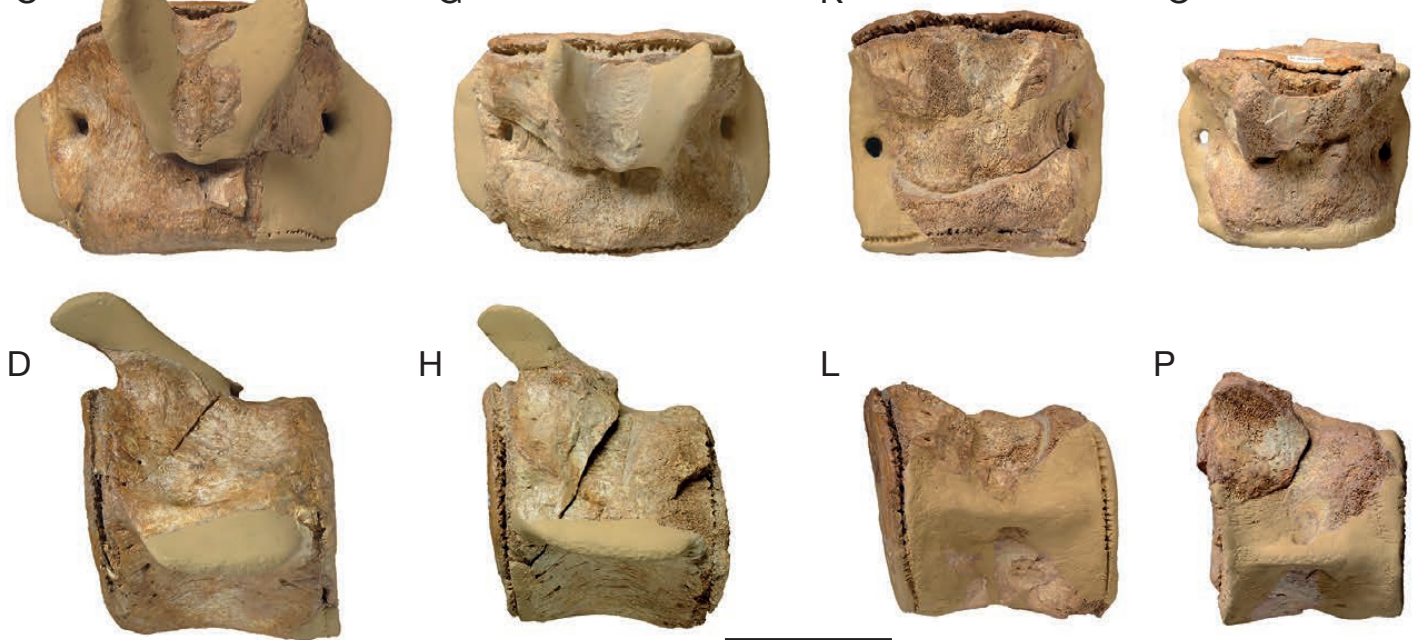

$\mathrm{H}$

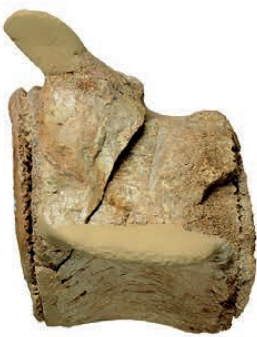

L

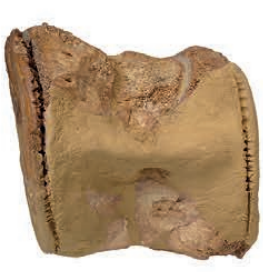

$\mathrm{P}$

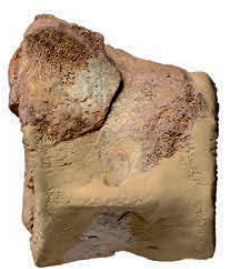

FIG. 78. - Caudal vertebrae of MNHN.F.PRU10, holotype of Cynthiacetus peruvianus: A, seventh caudal in anterior view; B, seventh caudal in posterior view; C, seventh caudal in dorsal view; D, seventh caudal in left lateral view; E, eighth caudal in anterior view; $\mathbf{F}$, eighth caudal in posterior view; G, eighth caudal in dorsal view; $\mathbf{H}$, eighth caudal in left lateral view; $\mathbf{I}$, ninth caudal in anterior view; $\mathbf{J}$, ninth caudal in posterior view; $\mathbf{K}$, ninth caudal in dorsal view; $\mathbf{L}$, ninth caudal in left lateral view; $\mathbf{M}$, tenth caudal in anterior view; $\mathbf{N}$, tenth caudal in posterior view; $\mathbf{O}$, tenth caudal in dorsal view; $\mathbf{P}$, tenth caudal in left lateral view. The missing portions of the bone (especially the transverse processes and neural spine) have been reconstructed. Scale bar: $10 \mathrm{~cm}$.
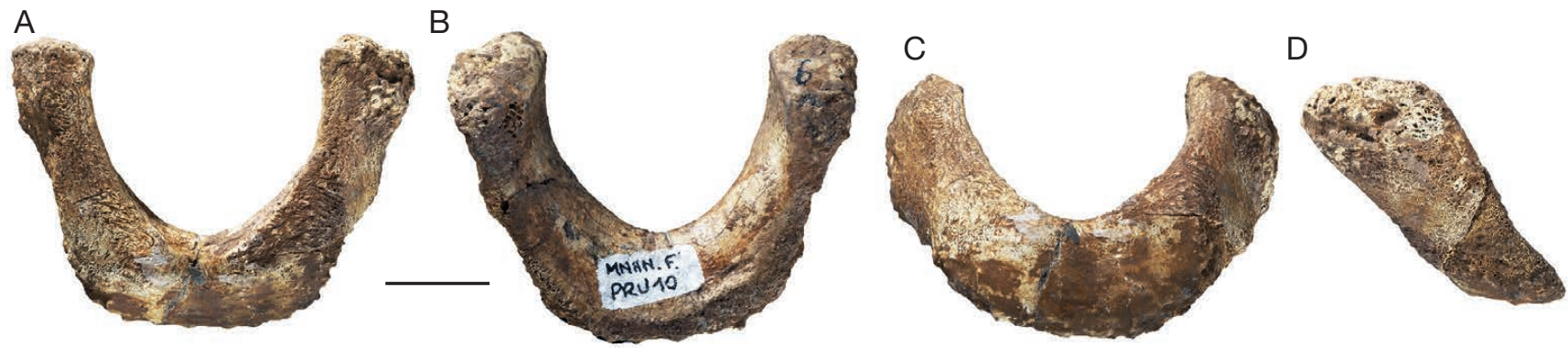

FIG. 79. - Haemal arch of the ninth caudal vertebra of MNHN.F.PRU10, holotype of Cynthiacetus peruvianus: A, anterior view; B, posterior view; C, ventral view; D, dorsal view; E, left lateral view. Scale bar: $3 \mathrm{~cm}$.

half of the caudal series. However, Uhen (2004) did not find that morphology in any of the haemal arches posterior to the fourth caudal vertebra of Dorudon atrox. Chevrons with a transversely narrow hemal spine are also found in protocetids (Maiacetus and an undescribed protocetid from the middle Eocene of Peru). 
TABLE 11. - Measurements (in mm) of the right scapula of MNHN.F.PRU10, holotype of Cynthiacetus peruvianus. (e), estimated measurements.

\begin{tabular}{lc}
\hline Measurements & $\mathbf{m m}$ \\
\hline $\begin{array}{l}\text { Maximum anteroposterior breadth of the scapular blade } \\
\text { Dorsoventral height of the scapula, from the lateral }\end{array}$ & $380(\mathrm{e})$ \\
$\quad$ margin of the glenoid cavity to the dorsalmost edge & $355(\mathrm{e})$ \\
$\quad$ of the scapular blade & 89.1 \\
$\begin{array}{l}\text { Maximum anteroposterior length of the glenoid cavity } \\
\text { Dorsoventral breadth of the coracoid process }\end{array}$ & 65.9 \\
$\quad \begin{array}{l}\text { at its distal extremity } \\
\quad \text { on its medial surface }\end{array}$ & 28.6 \\
$\begin{array}{l}\text { Dorsoventral breadth of the acromion at its mid-length } \\
\text { Anteroposterior breadth of the acromion }\end{array}$ & 45 \\
$\quad$ on its lateral surface & $52(\mathrm{e})$ \\
\hline
\end{tabular}

\section{Appendicular skeleton}

Only the right girdles and limbs of the holotype of Cynthiacetus peruvianus are partly preserved; the left were probably removed by scavengers or predators, since the rest of the skeleton was preserved in anatomical position.

Cynthiacetus peruvianus possesses typical basilosaurid girdles and appendicular skeleton. Its forelimb is dorsoventrally compressed into a flipper and most likely served as a stabilizer of the body rather than as a locomotor member. The hind limb is drastically reduced as is observed in all basilosaurids. Although less complete than the forelimb, it allows useful comparisons with the hind limb of other basilosaurids. A new interpretation of the orientation of the basilosaurid pelvic bone is proposed below.

Pectoral girdle and forelimb. The right pectoral girdle and forelimb of MNHN.F.PRU10 are reasonably complete and include the scapula, humerus, radius, ulna, five carpals, three metacarpals, and three phalanges (Fig. 80). In overall view, the forelimb of Cynthiacetus peruvianus strongly resembles that of other basilosaurids, especially Dorudon atrox (Uhen 1996, 2004). Contrary to most modern cetaceans, the humerus of $C$. peruvianus is longer than the radius and ulna, and the scapula bears a proportionally larger supraspinous fossa. Moreover, contrary to the condition of modern cetaceans the elbow joint is not ankylosed and its trochlea denotes flexion/ extension mobility, whereas the pronation/supination movements were not possible. A reconstruction of the forelimb of MNHN.F.PRU10 is shown in Figure 80. Proportionally, the forelimb of MNHN.F.PRU10 is considerably longer than that of Ancalecetus simonsi Gingerich \& Uhen, 1996 (which has the shortest forelimb among the Basilosauridae), but shorter (at the level of the humerus) than that of Basilosaurus cetoides, where the proximodistal lengths of the humerus and radius are, respectively, 45 and $20 \%$ of the condylobasal length. For comparison, the humeral and radial lengths in $C$. peruvianus are 30 and $20 \%$ of the condylobasal length, respectively. Besides, the forelimb of C. peruvianus is slightly longer than in D. atrox and Zygorbiza kochii, in which the humeral and radial lengths are 25 and $18 \%$ of the condylobasal length, respectively.
Scapula (pectoral girdle) (Fig. 81). The scapula is a transversely flattened lamina, anteroposteriorly broad and fan-shaped, with a convex dorsal margin in lateral view. At its base, the scapular blade is connected to the massive glenoid margin by the scapular neck. This right scapula is incompletely preserved, and the contact between the proximal part of the blade and the distal portion of the bone have been reconstructed (Fig. 80) on the basis of the scapula of Dorudon atrox (Uhen 2004). Measurements of the right scapula of MNHN.F.PRU10 are given in Table 11.

Both lateral and medial surfaces of the scapula are smooth and lack the striations observed in some Recent cetaceans. The anterior margin of the scapula of MNHN.F.PRU10 is poorly preserved but it is probable that it was anterodorsally oblique, with an anteriorly convex proximal half. This convexity is also present in Dorudon atrox (Uhen 2004), Ancalecetus simonsi (Gingerich \& Uhen 1996), and, to a lesser extent, in Basilosaurus cetoides (Kellogg 1936). It is absent in Zygorhiza kochii (Kellogg 1936). Although the proximal half of the posterior edge of the blade is missing, the morphology of the distal half indicates that it was probably posterodorsally oriented and concave posteroventrally, as in all other basilosaurids.

On the lateral surface of the scapula, the scapular spine runs proximodistally and is closer to the anterior margin of the scapula than to the posterior margin. Most of its distal portion is missing. The scapular spine reaches the dorsal edge of the scapula, where it is low and slightly anterolaterally inclined in dorsal view. At the level of the scapular neck, the ventral end of the spine turns anteriorly to form the dorsal border of the acromion. Bordered posteriorly by the scapular spine, the supraspinous fossa occupies the anterior portion of the lateral surface; it is somewhat anterolaterally facing, being medially shifted with respect to the general plane of the scapula. In lateral view, the supraspinous fossa is lanceolate with the apex distally oriented (Fig. 81). The M. supraspinatus originates on the supraspinous fossa and is an important abductor of the arm. Posterior to the spine is the large and triangular infraspinous fossa. It occupies most of the lateral surface of the scapula, being three times wider than the supraspinous fossa (Fig. 81). Ventrally, it extends on the lateral surface of the neck. Near the posterior edge of the scapula is a faint ridge that separates the infraspinous and teres fossae. The latter is the posteriormost and the smallest fossa in the lateral surface; it is very incomplete in MNHN.F.PRU10 and cannot be described. While both $M$. infraspinatus and $M$. deltoideus pars infraspinatus originate on the infraspinous fossa, the M. teres major pars lateralis has its origin in the teres fossa (Howell 1930a; Uhen 2004; Sanchez \& Berta 2010; Evans \& de Lahunta 2013). The former are extensor muscles of the humerus. The $M$. teres major is antagonist of the $M$. supraspinatus and adducts the arm.

The acromion is a large and thin process extending anterior to the scapular neck. Its anteriormost portion is missing in MNHN.F.PRU10, but it probably had proportions similar to those of most other basilosaurids. While in Basilosaurus cetoides and Zygorhiza kochii the acromion is anteriorly oriented, it is anteroventrally oriented in Dorudon atrox. The lateral and 


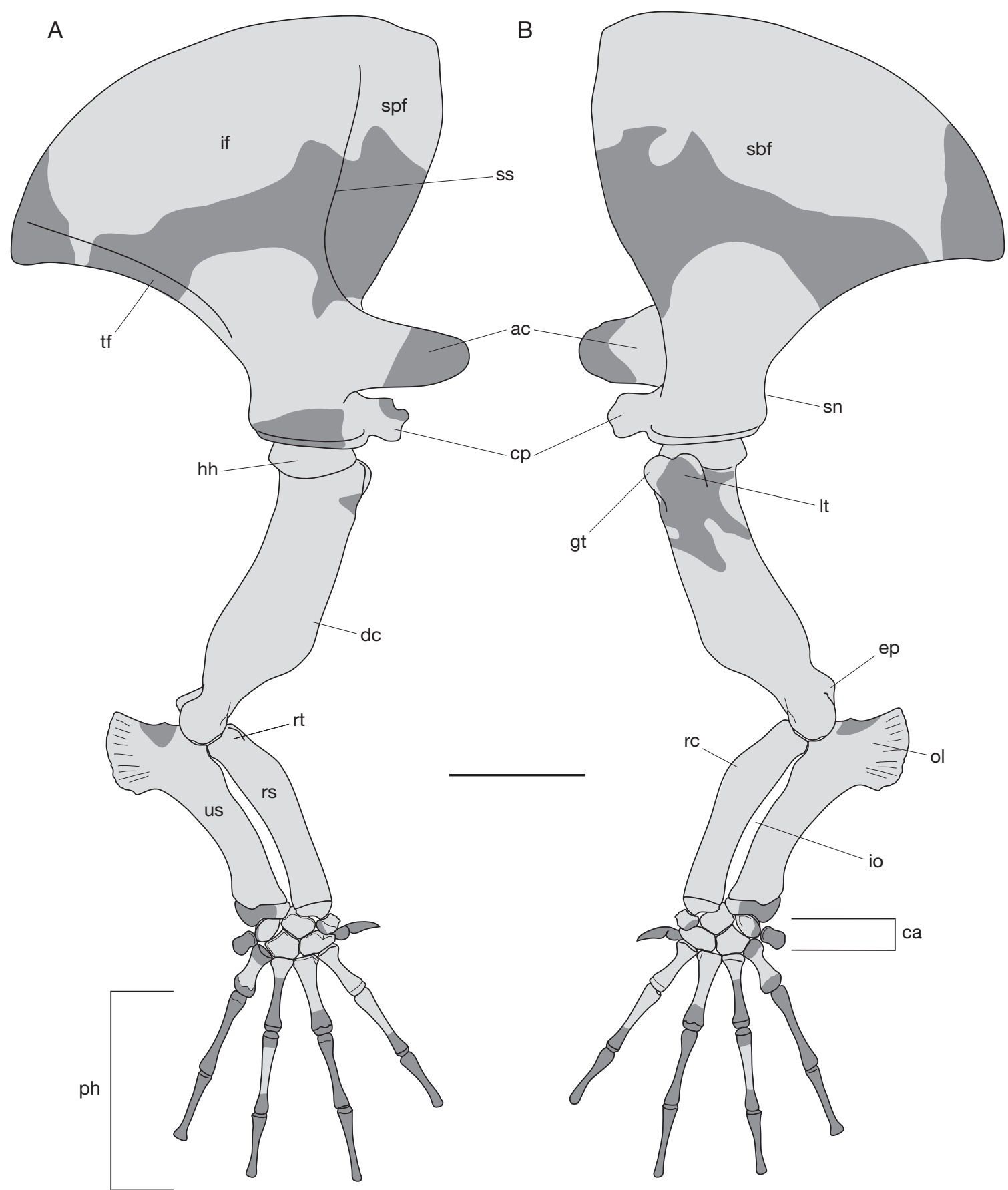

FIG. 80. - Reconstruction of the right forelimb of MNHN.F.PRU10, holotype of Cynthiacetus peruvianus: A, lateral view; B, medial view. Abbreviations: ac, acromion; ca, proximal and distal rows of the manus; $\mathbf{c p}$, coracoid process; dc, deltopectoral crest; ep, entepicondylar process; gt, greater tubercle of the humerus; hh, humeral head; if, infraspinous fossa; io, interosseous space for the interosseous membrane; is, interosseous space; It, lesser tubercle of the humerus; ol, olecranon; ph, phalanges; rc, radial crest; rs, radial shaft; rt, radial tuberosity; sbf, subscapular fossa; sn, scapular neck; spf, supraspinous fossa; ss, scapular spine; tf, teres fossa; us, ulnar shaft. Gray-shaded regions represent reconstructed part of bone. Reconstructions are based on Dorudon atrox, especially UM 101222 (Uhen 2004). Scale bar: $10 \mathrm{~cm}$.

medial surfaces of the acrominon bear part of the origin of the $M$. deltoideus and $M$. supraspinatus, which participate in the abduction of the forelimb.

The whole medial surface of the scapula constitutes the subscapular fossa. No crest, ridge, tuberosity or rough surface is observed in this fossa, which is slightly concave in its anteriormost portion. Ventrally, the subscapular fossa extends on the medial surface of the neck. The subscapular fossa receives the origin of the M. subscapularis, an antagonist of the $M$. infraspinatus and $M$. deltoideus pars infraspinatus, which essentially contributes to the adduction of the humerus.

The coracoid process extends from the anteroventral corner of the scapular neck. It is considerably shorter than the acromion and possesses three well-defined tuberosities at its 
TABLE 12. - Measurements (in $\mathrm{mm}$ ) of the right humerus of MNHN.F.PRU10, holotype of Cynthiacetus peruvianus.

\begin{tabular}{|c|c|}
\hline Measurements & $\mathbf{m m}$ \\
\hline $\begin{array}{l}\text { Maximum proximodistal breadth of the humerus, } \\
\text { from the humeral head to the distal end of the trochlea }\end{array}$ & 335 \\
\hline Maximum diameter of the humeral head & 86.2 \\
\hline $\begin{array}{l}\text { Anteroposterior breadth of the humeral diaphysis } \\
\text { at its proximal portion }\end{array}$ & 86.1 \\
\hline $\begin{array}{l}\text { Maximum anteroposterior breadth of the humeral diaphysis, } \\
\text { at the level of the distal extremity of the deltopetoral crest }\end{array}$ & 97.8 \\
\hline $\begin{array}{l}\text { Minimum transverse breadth of the humeral diaphysis, at } \\
\text { the level of the distal extremity of the deltopectoral crest }\end{array}$ & 46.1 \\
\hline $\begin{array}{l}\text { Length from the proximal end of the humeral diaphysis } \\
\text { to the distalmost end of the deltopectoral crest }\end{array}$ & 194.3 \\
\hline Anteroposterior breadth of the humeral trochlea & 47.9 \\
\hline Transverse breadth of the humeral trochlea & 43.5 \\
\hline
\end{tabular}

distal end. The $M$. coracobrachialis most likely originated on these tuberosities and contributed to the stabilization of the shoulder articulation. The coracoid process is medially curved and anteroventrally oriented. The dorsal and ventral surfaces of the coracoid process are distinctly concave and resemble a neck, emphasizing the inflated morphology of the apex. Since the elbow articulation is functional and the radial tuberosity is still present (on the radius, see below), it is likely that the M. biceps brachii is still present in Cynthiacetus peruvianus, contrary to Recent cetaceans (Howell 1930a; Sanchez \& Berta 2010). The proximal origin of the biceps is on the apex of the coracoid process. Since supination was most likely not possible in C. peruvianus, the $M$. biceps brachii was an important flexor of the elbow.

Ventral to the scapular neck is the glenoid cavity. A hardly differentiated supraglenoid tubercle is present on the anterior corner of the glenoid cavity, just ventral to the coracoid process, probably for the origin of the proximal tendon of the $M . b i$ ceps brachii (as observed in the dog and domestic artiodactyls: Barone 1968; Evans \& de Lahunta 2013). Part of the lateral border of the glenoid cavity is missing in MNHN.F.PRU10. Nonetheless, it is possible to evaluate that the glenoid cavity was originally oval, concave, and shallow. Small nutrient foramina lie on the medial and lateral borders of the glenoid cavity, particularly in its posterior half.

Humerus (Fig. 82). As mentioned above, only the right humerus is preserved in MNHN.F.PRU10. The humerus is significantly longer than the radius and ulna. Measurements are given in Table 12.

The proximal epiphysis of the humerus is massive and low. It includes the humeral head (articular surface for the glenoid cavity of the scapula), and the greater and lesser tubercles of the humerus. As in modern cetaceans and in contrast with terrestrial mammals, the humeral head is located posterolaterally with respect to the humeral diaphysis. It is hemispherical and separated from the diaphysis by a barely defined neck. The neck is more accentuated on the posterior surface of the epiphysis, where it forms a concave surface. The articular surface of the humeral head is posteroproximally oriented, being larger and more convex than the scapular glenoid cavity. Because of this morphology, the shoulder of MNHN.F.PRU10 probably had a wide range of motion. As a consequence of the orientation and position of the head, the lateral surface of the humeral diaphysis is proximolaterally oriented.

Anterior and medial to the humeral head are the greater and lesser tubercles, respectively. In MNHN.F.PRU10 most of the lesser tubercle of the humerus is missing. It is however likely that it was posteromedial to and less prominent than the greater tubercle. A shallow depression separates the lesser tubercle from the medial margin of the humeral head. The lesser tubercle receives the insertions of the M. subscapularis and $M$. teres major. The greater and lesser tubercles are separated by the bicipital groove, which conveys the proximal tendon of the $M$. biceps. The bicipital groove is shallow, narrow, and distomedially oriented. The greater tubercle bears a massive, rounded, and prominent crest, which extends parallel to the bicipital groove (anteromediodistally) and receives the insertion of the M. supraspinatus. The greater tubercle and the humeral head are separated by a shallow and narrow sulcus. Distal to this sulcus, the unfused contact of the anterior epiphysis and diaphysis can be observed in lateral view.

The humeral diaphysis is straight and transversely compressed, with two surfaces, lateral and medial, and two margins, anterior and posterior. In anterior view, the anterior margin and the medial surface are slightly concave medially, while the lateral surface is rather flat. The proximal quarter of the diaphysis is roughly oval in cross-section just below the head. The diaphysis narrows distally. Its anterior margin is strongly pinched transversely, bearing a long but narrow deltopectoral crest (about $75 \%$ of the proximodistal length of the diaphysis). The proximal extremity of the deltopectoral crest is oriented medially and converges toward the medial end of the crest of the greater tubercle. In anterior view, most of the deltopectoral crest is convex laterally. The $M$. deltoideus and $M$. pectoralis inserted on its lateral and medial surfaces, respectively. The posterior margin of the humerus is broader than the anterior and presents a small bulge (in lateral view) at the level of the distal extremity of the deltopectoral crest, just proximal to the olecranon fossa. The cross-section of the diaphysis distal to the deltopectoral crest is oval-shaped.

The distal epiphysis includes the humeral trochlea (articular surfaces for both radius and ulna), the olecranon fossa, and the entepicondylar process (ectepicondylar process damaged). In MNHN.F.PRU10, part of the lateral edge of the trochlea is missing. Nevertheless, it is possible to estimate the original cross-section of the epiphysis as being roughly square. Its posterior surface originally displayed the entepicondylar and ectepicondylar processes. The entepicondylar process is located on the medial margin of the posterior surface and forms a prominent and posteriorly oriented ridge. Although the lateral edge of the posterior surface is partially damaged, it is possible to evaluate that the ectepicondylar process was less developed than the entepicondylar process. Flexor muscles of the manus ( $M$. flexor carpi radialis, $M$. flexor carpi ulnaris) originated on the ridge of the entepicondylar process, while the extensor musculature of the manus (M. extensor carpi radialis and $M$. extensor carpi ulnaris) originated on the ectepicondylar 


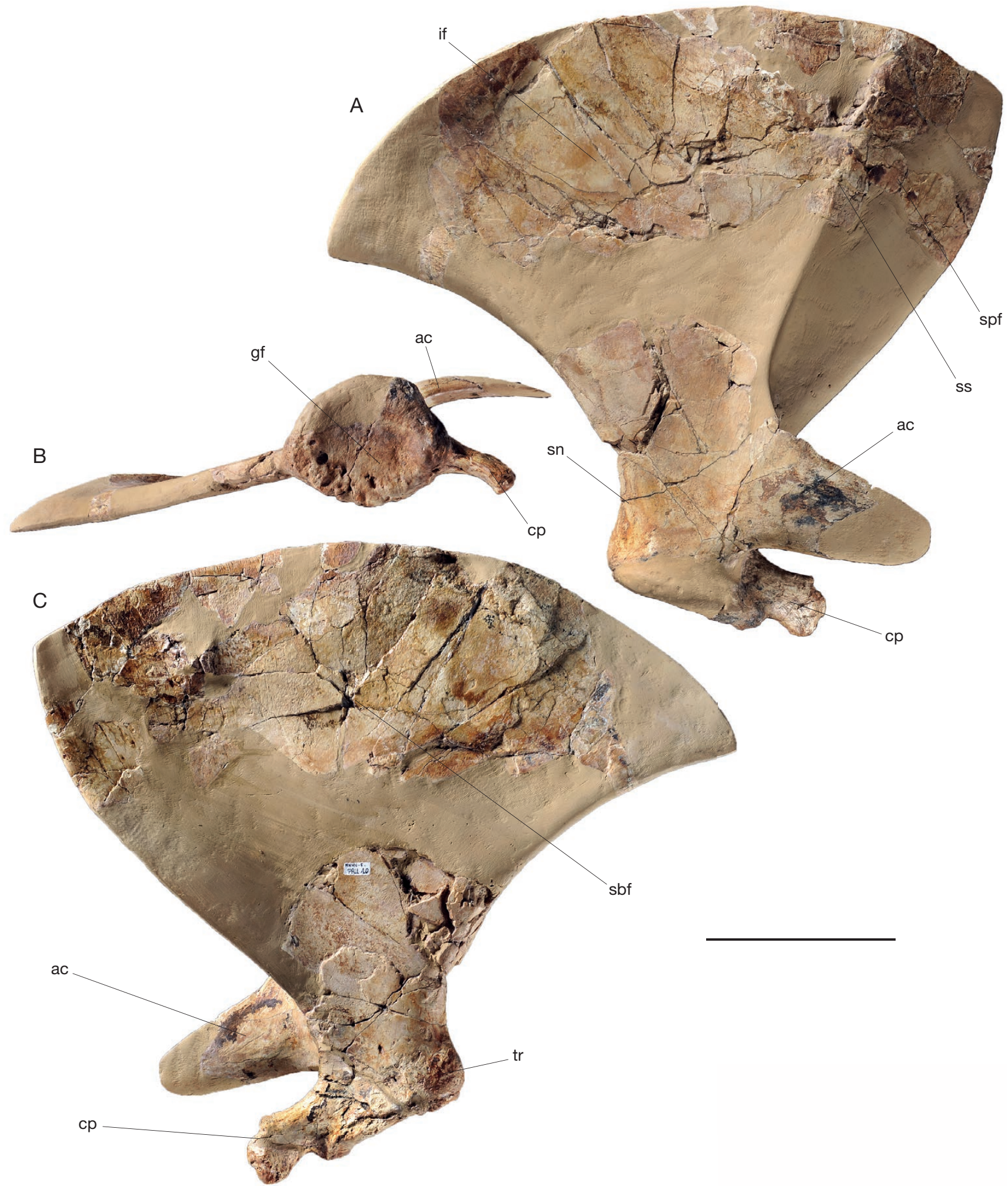

FIG. 81. - Right scapula of MNHN.F.PRU10, holotype of Cynthiacetus peruvianus: A, lateral view; B, ventral view; C, medial view. Abbreviations: ac, acromion; cp, coracoid process; gf, glenoid fossa; if, infraspinous fossa; sbf, subscapular fossa; sn, scapular neck; spf, supraspinous fossa; ss, scapular spine; tr, possible origin of the M. triceps brachii. Missing portions of the bone have been reconstructed. Scale bar: $10 \mathrm{~cm}$.

process. Consequently, the flexor musculature may have been more developed than the extensor musculature, as observed in Recent cetaceans, where both flexor and extensor muscles are reduced and, sometimes, originate more distally (Struthers
1888; Howell 1930a; Strickler 1978; Cooper et al. 2007). The entepicondylar and ectepicondylar processes delimit a shallow and small olecranon fossa. The humeral trochlea is the single articular surface for both radius and ulna. It is separated from 
TABLE 13. - Measurements (in $\mathrm{mm}$ ) of the right radius of MNHN.F.PRU10, holotype of Cynthiacetus peruvianus.

\begin{tabular}{lc}
\hline Measurements & mm \\
\hline Maximum proximodistal breadth of the radius & 221.11 \\
Maximum proximodistal breadth of the radial diaphysis & 175.74 \\
$\begin{array}{l}\text { Anteroposterior breadth of the radial diaphysis } \\
\quad \text { at the level of the anterior radial crest }\end{array}$ & 51.35 \\
$\begin{array}{l}\text { Anteroposterior breadth of the proximal epiphysis } \\
\quad \text { of the radius }\end{array}$ & 37.86 \\
$\begin{array}{l}\text { Transverse breadth of the proximal epiphysis } \\
\quad \text { of the radius }\end{array}$ & 46.30 \\
$\begin{array}{l}\text { Anteroposterior breadth of the distal epiphysis } \\
\quad \text { of the radius }\end{array}$ & 43.23 \\
$\begin{array}{l}\text { Transverse breadth of the distal epiphysis of the radius } \\
\quad\end{array}$ & 22.19 \\
\hline
\end{tabular}

the rest of the epiphysis by a narrow and shallow sulcus. Although the lateral edge of the trochlea is missing, it is likely that there was no vestigial capitulum in this region. The articular facet of the trochlea is saddle-shaped, slightly concave in its middle in anterior view, with elevated lateral and medial edges. These edges are markedly convex in lateral view and provide a rounded morphology to the distal epiphysis. The trochlea of MNHN.F.PRU10 is considerably shorter anteroposteriorly than the elongated distal epiphysis of the Recent cetaceans. The anterior portion of the trochlea contacts the proximal articular surface of the radius, while its posterior portion contacts the proximal articular surface of the ulna. The ulnar (posterior) portion of the trochlea is transversely narrower and anteroposteriorly longer than the radial (anterior) portion. As mentioned above, the elbow of Cynthiacetus peruvianus is not ankylosed and flexion-extension movements were possible. However, because the articular surface the trochlea is not significantly larger than the proximal articular surfaces of the radius and ulna, the elbow joint probably had a small range of flexion-extension.

Radius (Fig. 83). The radius of MNHN.F.PRU10 is well preserved and complete. The bone is slightly bent posteriorly especially in its proximal half. Its anterior edge is strongly convex proximally and its posterior edge slightly concave. The diaphysis is transversely flattened in its median portion and distal, but its proximal extremity is clearly wider than long. The proximal epiphysis is very robust and strongly widened transversely; it is approximately twice wider than long. In contrast the distal epiphysis is distinctly compressed transversely being twice longer than wide. The radius is anterior to the ulna and forms the anterior edge of the flipper as in modern cetaceans. The proximal epiphysis (radial head) articulates with the humeral trochlea and had a ligamentous contact with the proximal epiphysis of the ulna. The distal epiphysis articulates with the lunatum, scaphoid, and the distal epiphysis of the ulna. Measurements of the radius are shown in Table 13.

The proximal epiphysis of the radius is roughly rectangular in cross-section, being transversely almost twice wider than anteroposteriorly long. Its whole proximal surface forms the humeral articular surface, which contacts the anterior portion of the humeral trochlea. This surface is a roughly rectangular shallow and wide transverse groove, with lateral and medial edges distinctly concave, and anterior and posterior edge slightly convex and elevated. The articular surface is gently concave anteroposteriorly and slightly convex transversely. There is no true radial neck since, in anterior view, the width of the diaphysis regularly decreases distally from the epiphysis to mid-shaft of the bone. In terrestrial mammals with pronation-supination ability, the posteromedial edge of the radial head bears the articular surface for the ulna (the circumferencia articularis). In MNHN.F.PRU10 the posterior surface of the proximal epiphysis of the radius is a rough irregular surface with several pits and which bears no articular facet for the ulna. The posterior edge of the proximal epiphysis is roughly straight transversely while it is distinctly concave in mammals with pronation-supination ability. Therefore, it is clear that such movements were impossible in Cynthiacetus peruvianus and that the articulation was ankylosed, as observed in Dorudon atrox (Uhen 2004). As a matter of fact, just distal to the posterior edge of the proximal epiphysis on the posterior edge (ulnar side) of the diaphysis of the radius, is a rough triangular area $(c .3 \mathrm{~cm}$ wide proximally) with two small fossulae, which extends distally on the diaphysis on approximately $5 \mathrm{~cm}$. This structure corresponds to the contact area between the ulna and the radius and probably received robust interosseous ligaments of the forearm. The robustness of this ligamentous attachment is related to the fact that the ankylosis of the elbow was in course of achievement in basilosaurids. The distal extremity of this rough surface also received the proximal attachment for the interosseous membrane. A similar condition is apparently present in Basilosaurus, Dorudon, and Zygorhiza. It is noteworthy that in modern cetaceans (Neoceti) the proximal radio-ulnar contact bears distinct articular facets although no pronation-supination movements are possible.

Anteromedial to the humeral articular facet is a robust crest-like tuberosity, which extends on $20 \mathrm{~mm}$ distally on the diaphysis. This structure corresponds to the radial tuberosity, which extends on most of the anteroproximal region diaphysis in a rough and relatively flat large area. Posterior to the radial tuberosity and adjacent to it, on the medial side of the diaphysis, just distal to the epiphysis, is a rough surface, which is slightly elevated and approximatively circular (c. $15 \times 15 \mathrm{~mm}$ ). This structure (tuberosity + anterior flat surface + posterior circular elevation) received the insertion of the M. biceps brachii. The anterior extension of the radial tuberosity differs from the condition observed on terrestrial mammals with pronation-supination ability (e.g. the dog: Evans \& de Lahunta 2013) or in pinnipeds (Howell 1928), in which the tuberosity is only posteromedial. The radial tuberosity of Cynthiacetus peruvianus indicates a powerful insertion of the M. biceps brachii, which corroborates the good abilities of flexion of the elbow noted on the ulnohumeral articulation. A similar development of the radial tuberosity is also observed in Dorudon atrox and Basilosaurus cetoides. The $M$. biceps brachii and M. brachialis are considerably reduced or absent in Recent cetaceans (Howell 1930a; Cooper et al. 2007), and it is not clear if Cynthiacetus peruvianus had a 
A

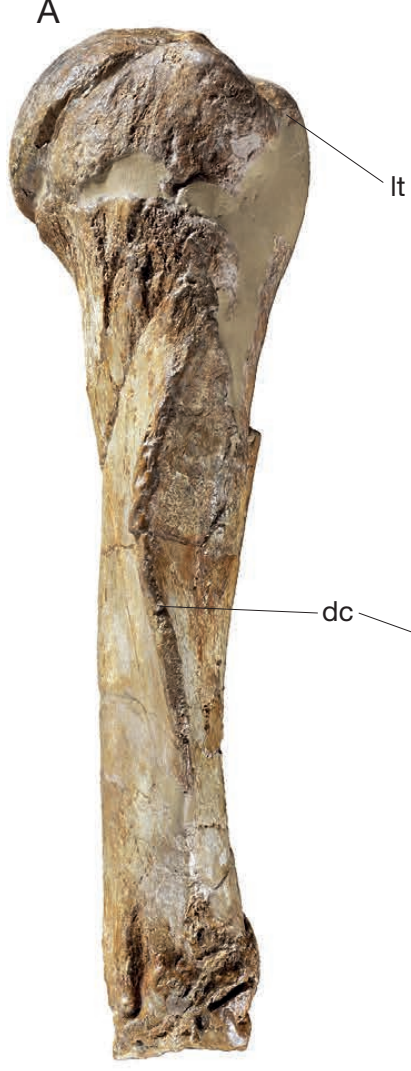

B

B

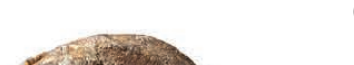

근

C

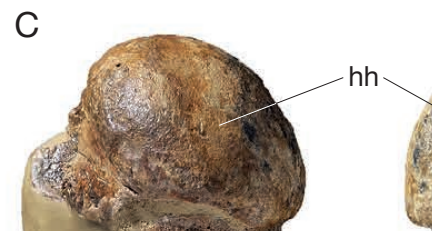

D
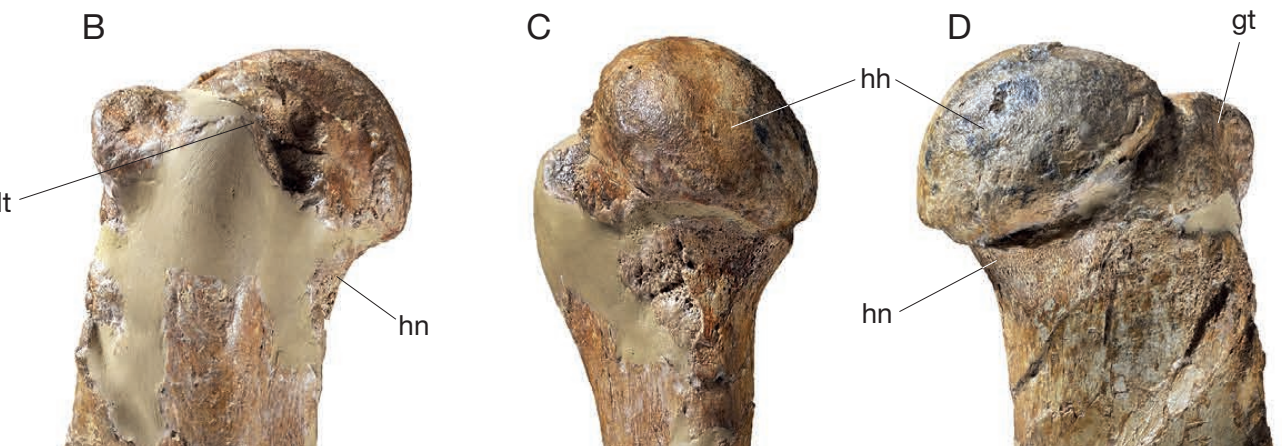
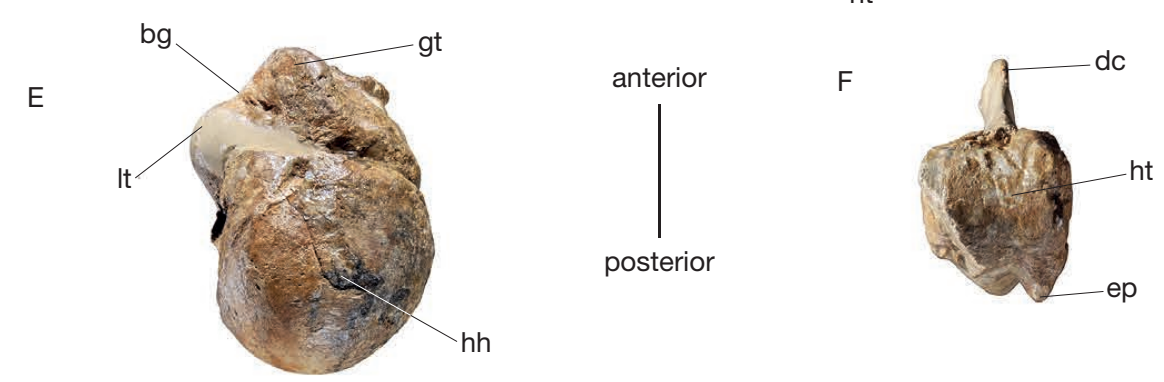

hh

FIG. 82. - Right humerus of MNHN.F.PRU10, holotype of Cynthiacetus peruvianus: A, anterior view; B, medial view; C, posterior view; D, lateral view; E, proximal view; F, distal view. Abbreviations: bg, bicipital groove; dc, deltopectoral crest; ep, entepicondylar process; gt, greater tubercle; hh, humeral head; hn, humeral neck; ht, humeral trochlea; It, lesser tubercle; olf, olecranon fossa. Missing portions of the bone have been reconstructed. Scale bar: $5 \mathrm{~cm}$.

well developed M. brachialis. Uhen (2004) reconstructed the insertion of the $M$. brachialis in Dorudon atrox on the lateral surface of the radial crest, distal to the insertion of the $M$. biceps brachii. A similar condition is observed in some hoofed terrestrial mammals (Barone 1968). However, if Cynthiacetus peruvianus had a well developed brachialis, it is likely that it would have inserted more proximo-posteriorly, on the anterior margin of the ulna (cf. below) and distal to the coronoid process of the ulna, as observed in some Recent Carnivora (dog: Evans \& de Lahunta 2013; pinnipeds: Howell 1928).

The diaphysis narrows distally and is strongly compressed transversely on most of its proximodistal length. This transverse compression is more pronounced than on the humerus and less than on the ulna (cf. below). In lateral view, the diaphysis is posteriorly bent and anteriorly convex as noted above.
The anterior margin of the diaphysis presents a thick and prominent elongated crest, which form a distinct angle on the proximal third of the anterior edge of the bone in lateral view. This crest extends on approximately $5 \mathrm{~cm}$ along the diaphysis. Following Kellogg (1936), we think that the pronator teres was probably inserted on it and on the medial side of the diaphysis adjacent to the crest, rather than the brachialis as hypothesized by Uhen (2004). This crest in Cynthiacetus peruvianus corresponds to the pronator ridge of mammals with pronation-supination ability. Because pronation-supination movements were not possible in $C$. peruvianus, the pronator teres, which has its origin on the medial epicondyle of the humerus, was probably acting as a flexor of the elbow rather than a pronator of the forearm. The M. supinator brevis (which turns the hand and the forearm upwards in mammals with 

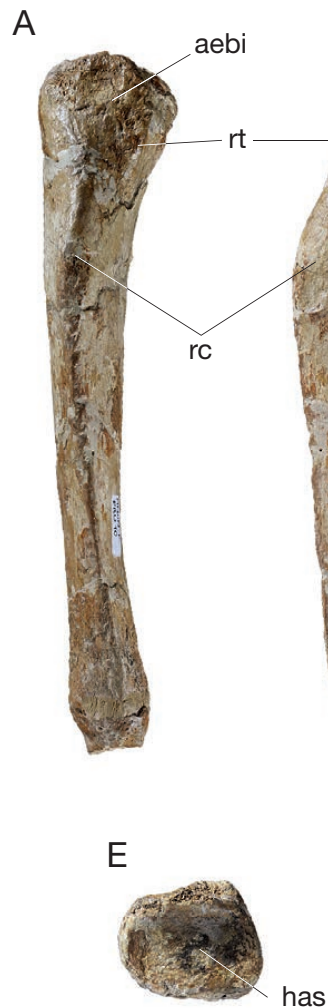

$\mathrm{B}$

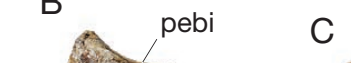
pebi $\quad \mathrm{C}$

D 0

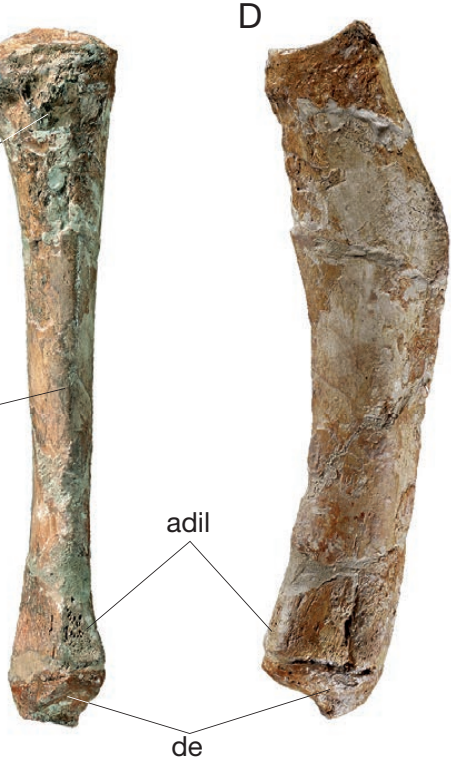

de

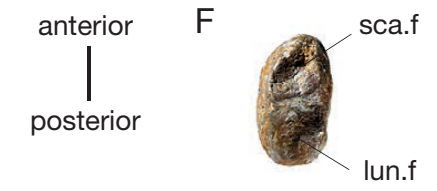

FIG. 83. - Right radius of MNHN.F.PRU10, holotype of Cynthiacetus peruvianus, in: A, anterior view; B, medial view; C, posterior view; D, lateral view; E, proximal view; F, distal view. Abbreviations: adil, attachment area for the distal interosseous ligament; aebi, anterior extension of the biceps brachii insertion; apil, attachment area for the proximal interosseous ligament; de, distal epiphysis; has, proximal articular facet for the humerus; lun.f, distal articular facet for the lunatum; pebi, posterior extension of the biceps brachii insertion; pmr, posterior margin of the radius for attachment for the interosseous membrane; rc, radial crest; rt, radial tuberosity; sca.f, distal articular facet for the scaphoid. Missing portions of the bone have been reconstructed. Scale bar: $5 \mathrm{~cm}$.

TABLE 14. - Main measurements (in mm) of the right ulna of MNHN.F.PRU10, holotype of Cynthiacetus peruvianus. (e), estimated measurements.

\begin{tabular}{lc}
\hline Measurements & $\mathrm{mm}$ \\
\hline $\begin{array}{l}\text { Maximum proximodistal breadth of the ulna, } \\
\text { from the proximalmost portion of the olecranon }\end{array}$ & 279.57 \\
$\quad$ to the distal articular surface of the ulna & \\
$\begin{array}{l}\text { Proximodistal breadth of the ulnar diaphysis } \\
\quad \text { at the anterior margin }\end{array}$ & 197.50 \\
$\begin{array}{l}\text { Maximum proximodistal breadth of the olecranon } \\
\quad \text { at its apex }\end{array}$ & 91.53 \\
$\begin{array}{l}\text { Maximum anteroposterior breadth of the ulna } \\
\quad \text { at the level of the proximal articular surface }\end{array}$ & 98.21 \\
$\begin{array}{l}\text { Anteroposterior breadth of the ulnar diaphysis } \\
\quad \text { at its mid-length level }\end{array}$ & $44.3(\mathrm{e})$ \\
$\begin{array}{l}\text { Anteroposterior breadth of the anterior portion } \\
\quad \text { of the humeral articular surface of the ulna }\end{array}$ & 50.96 \\
$\begin{array}{l}\text { Transverse breadth of the anterior portion } \\
\quad \text { of the humeral articular surface of the ulna }\end{array}$ & 32.43 \\
$\begin{array}{l}\text { Anteroposterior breadth of the distal epiphysis } \\
\quad \text { of the ulna }\end{array}$ & $50(\mathrm{e})$ \\
$\begin{array}{l}\text { Transverse breadth of the distal epiphysis of the ulna } \\
\quad\end{array}$ & $17(\mathrm{e})$ \\
\hline
\end{tabular}

pronation-supination ability) may have also inserted on the lateral surface of this crest and the adjacent area of the diaphysis. Given the lack of mobility of the forearm in C. peruvianus, what was left of the supinator brevis, which originates on the lateral epicondyle of the humerus, was most likely also acting as a flexor of the elbow.
Distal to the proximal ligamentous attachment with the ulna, the posterior margin of the radius bears the radial interosseous crest, which serves for the attachment of the interosseous membrane. At the distal portion of the radial diaphysis, the posterior margin of the radius slightly widens and forms the triangular distal ligamentous attachment for the ulna.

The distal epiphysis is highly compressed transversely, although slightly wider than the diaphysis. It is not completely fused with the diaphysis. Distally, this epiphysis presents two concave, anteroposteriorly aligned articular surfaces. The anterior surface is roughly triangular, with one apex of the triangle being anteriorly pointed; it articulates with the radial surface of the scaphoid and is anterodistally facing in lateral view. The posterior articular surface is smaller than the anterior articular surface. It is rather oval and posterodistally facing; this surface articulates with the radial surface of the lunatum. The two distal articular surfaces are separated by a prominent and sharp ridge, which is more salient on its lateral side.

Ulna (Fig. 84). The ulna is the posterior element of the forearm. In MNHN.F.PRU10, only the right ulna is preserved and the fusion of the distal epiphysis with the ulnar diaphysis is unachieved. Measurements of the ulna are given in Table 14. The ulna is more transversely compressed than the humerus and radius. The proximal epiphysis articulates with the posterior portion of the humeral trochlea and has a ligamentous attach- 


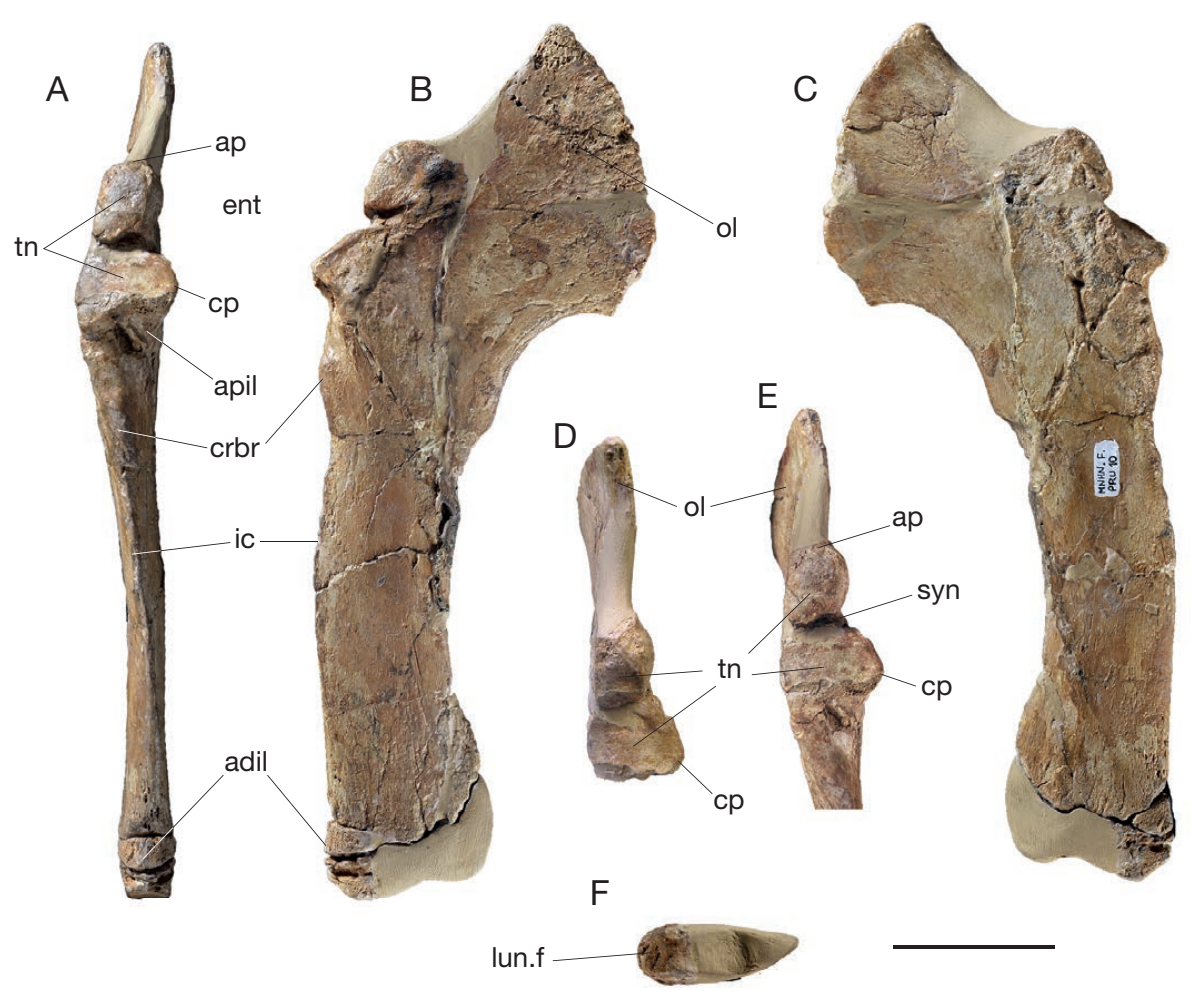

FIG. 84. - Right ulna of MNHN.F.PRU10, holotype of Cynthiacetus peruvianus, in: A, anterior view; B, medial view; C, lateral view; D, proximal epiphysis in proximal view; E, proximal epiphysis in anteroproximal view; F, distal epiphysis in distal view. Abbreviations: adil, attachment area for the distal interosseous ligament; apil, attachment area for the proximal interosseous ligament; bc, crest for the brachialis; cop, coronoid process; crbr, crista bor the insertion of the brachialis muscle; ent, facet for the contact with the enteepicondylar process; ic, crest for the interosseous ligament; lun.f, distal articular facet for the lunatum; ol, olecranon; syn, synovial fossa; tn, trochlear notch; uc, ulnar crest. Missing portions of the bone have been reconstructed. Scale bar: $5 \mathrm{~cm}$.

ment with the posterior surface of the radial head (see above). The distal epiphysis is partly preserved in MNHN.F.PRU10 and only the articular surface for the lunatum is preserved.

The proximal extremity includes the humeral articular surface and the olecranon. The humeral articular surface (or trochlear notch) is separated into two small anterior and large posterior surfaces by a deep transverse sulcus, which opens widely medially. The surface anterodistal to the sulcus is anteroproximally facing; it is large, roughly rectangular, and its transverse breadth is greater than its anteroposterior length. Part of its anterolateral angle is missing in MNHN.F.PRU10. In lateral view, this surface is straight and slopes anterodistally. The postero-proximal portion of the trochlear notch, posterior to the sulcus, is much smaller than the distal portion. It is anteriorly facing and vaguely oval-shaped. The anterior and posterior portions of the humeral articular surface (trochlear notch) are well exposed in anterior and proximal views. In lateral view, they form an angle of $c .145^{\circ}$. As a whole, the trochlear notch is not as saddle-shaped as in Dorudon atrox, which probably indicates a lesser mobility of the elbow. On the anteromedial angle of the trochlear notch, the coronoid process is well developed, salient and rounded. Because the anterior edge of the trochlear notch is damaged, the radial notch is not discernible on this specimen. However, given the rugose and irregular morphology observed on the contacting area on the radius, it is likely that a true articular radial notch was absent in Cynthiacetus peruvianus. On the proximal edge of the proximal portion of the trochlear notch is a rounded anconeal process that is part of the articular proximal epiphysis of the ulna and that was entering the olecranon fossa of the humerus when the elbow was extended.

Posterior to the trochlear notch is the olecranon. In lateral view, the olecranon is axe-shaped and posteroproximally oriented. It is proximodistally shorter at its base than at its apex. The olecranon is slightly expanded at the level of the epiphysis. The latter is missing and was not fused to the olecranon as usually observed in Dorudon atrox (Uhen 2004). The olecranon becomes thicker distally. The length of the olecranon is one third that of the diaphysis (between the trochlear notch and the distal epiphysis). It is apparently relatively shorter than in Dorudon atrox, in which it makes half the diaphysis. In posterior view, the apex of the olecranon is slightly convex laterally. It received the insertion of the $M$. triceps brachii. As in $D$. atrox (Uhen 2004), the M. triceps brachii has two origins, on the scapula and on the humerus. The scapular origin is probably in the posterior margin of the glenoid cavity, while the humeral origin is likely to have been distal to the lesser tubercle (this portion is missing in MNHN.F.PRU10). The $M$. triceps brachii is the main extensor of the elbow joint. Extensors and flexors of the digits originate respectively on the lateral and medial sides of the olecranon. Because these areas are smooth and flat surfaces, it is likely that these muscles were poorly developed in Cynthiacetus peruvianus, as observed in other basilosaurids and Recent cetaceans. 
A

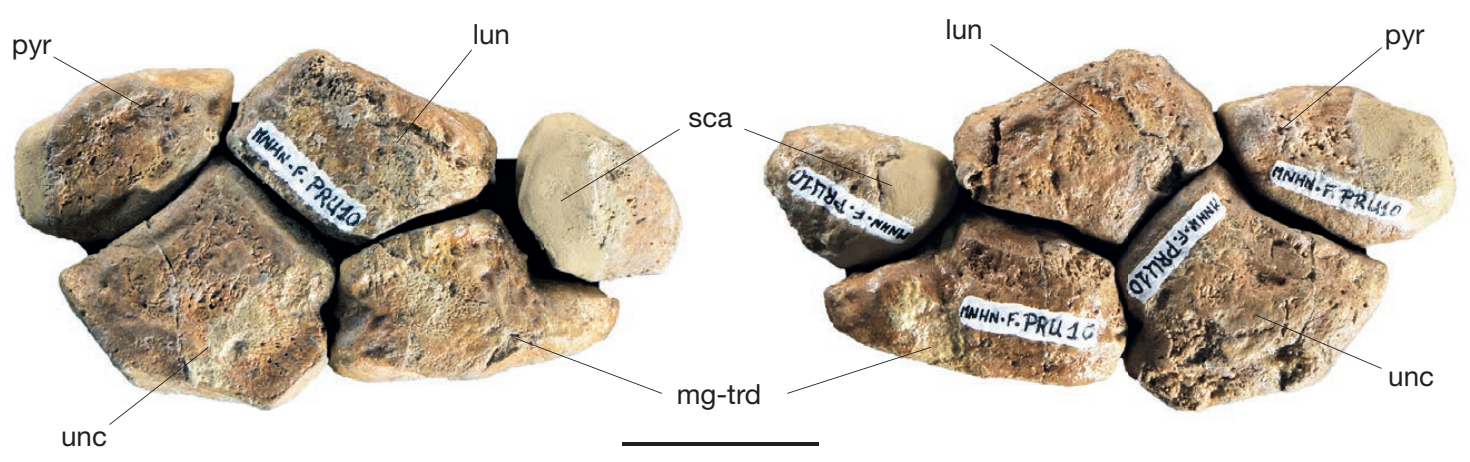

FIG. 85. - Articulated right carpals of MNHN.F.PRU10, holotype of Cynthiacetus peruvianus: A, palmar view; B, dorsal view. Abbreviations: lun, lunatum; mg-trd, magnum-trapezoid; unc, unciform; pyr, pyramidal; sca, scaphoid. Distal elements row is on top. Both pisiform and trapezium are missing in MNHN.F.PRU10. Missing portions of bone have been reconstructed. Scale bar: $2.5 \mathrm{~cm}$.

As mentioned above, the ulnar diaphysis is flattened in the plane of the flipper. It has two margins, anterior and posterior, and two smooth surfaces, lateral and medial. In lateral view, the ulnar diaphysis is slightly convex anteriorly. In contrast to the radius, the proximal portion of the ulna is also strongly compressed transversely.

Distal to the trochlear notch on the anterior margin of the diaphysis, is a rough and excavated area for ligament attachment. As noted above (radius section), there is no true articulation with the radius. Although this region is slightly damaged on the ulna, the condition observed on the radius indicates that a functional articular surface was absent. Just distal to the trochlear notch is a distinct pit, in which a robust interosseous ligament probably attached. As noted on the radius, robust ligamentous scars are observed just distal to the trochlear notch and correspond to a tight ligamentous attachment of the ulna and radius, a condition which prevented movements of the two bones.

Distomedial to the proximal radial ligamentous attachment on the anterior edge of the diaphysis, is a rounded and elongated tuberosity $(c .8 \times 40 \mathrm{~mm})$. This tuberosity is oblique in anterior view and its proximal end extends on the lateral side of the bone, just distolateral to the lateral angle of the trochlear notch. The distal end of the tuberosity is distinctly oriented toward the medial side of the bone. It matches the position of the insertion of the M. brachialis in other mammals The M. brachialis is a co-actor of the M. biceps brachii in the flexion of the elbow. In some Recent pinnipeds (Howell 1928) and mysticetes (Cooper et al. 2007), part of the orgin of the $M$. flexor digitorum communis is on the anterior edge of the ulna, distal to the insertion of the brachialis in pinnipeds. Therefore, the tuberosity of the ulna might also have been (in part) for the origin of this muscle. Because the M. biceps brachii (flexor of the elbow) was relatively powerful in C. peruvianus and because the muscles responsible for the movements of the fingers were probably not much developed, it is hypothesized that this robust crest more likely received the $M$. brachialis. If this interpretation is correct, it reinforces the hypothesis of a relatively powerful flexion of the elbow in Cynthiacetus peruvianus. Distal to the tuberosity for the M. brachialis is a sharp crest on the anterior margin of the diaphysis (Fig. 84), for the attachment of the interosseous ligament.

The distalmost portion of the anterior margin of the ulnar diaphysis presents a small, flat and grossly triangular surface for the distal ligamentous contact with the radius. Only the anterior extremity of the distal epiphysis is preserved in MNHN.F.PRU10. It presents one articular surface for the posteroproximal articular surface of the lunatum. This surface is vaguely triangular in shape and distoanteriorly oriented. The posterior articular surfaces (for both pyramidal and pisiform) are not preserved.

Carpus (Figs 85; 86). The carpus of Cynthiacetus peruvianus probably included seven independent elements (based on the condition in Dorudon atrox, Uhen 2004 and Ancalecetus simonsi, Gingerich \& Uhen 1996), but only five elements are preserved in MNHN.F.PRU10. Those are organized into two alternating rows. There are four elements in the most proximal row and three in the distal row. In the following description, the terms anterior and posterior are preferred to radial and ulnar.

The scaphoid (Fig. 86A-D) is the most anterior element in the proximal row of the carpus. It is the smallest element preserved on MNHN.F.PRU10, but, as in Dorudon atrox (Uhen 2004), it might have been larger than the trapezium, which is missing.

The scaphoid is not well preserved, especially in its posterior portion. Proximally, it has a slightly convex, roughly triangular surface, which articulates with the anterior articular surface of the radius. The scaphoid articulates posterodistally with the magnum-trapezoid, but this surface is missing in MNHN.F.PRU10. The small posterior surface for the contact with the lunatum is also missing (cf. below). Besides, there is no evidence for an articular surface between the trapezium and the scaphoid.

The lunatum (Fig. 86E-H) is the second anteriormost bone in the proximal row of the carpus. It is positioned at the level of the median axis of the manus. Anteriorly, it contacts the scaphoid; anteroproximally, the posterodistal articular surface 
A

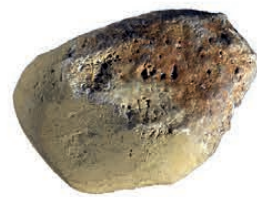

E

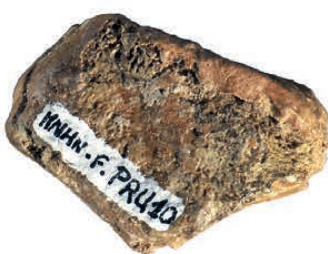

I

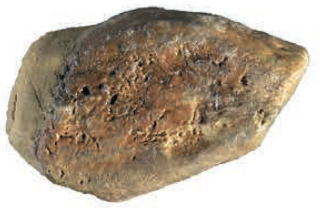

M

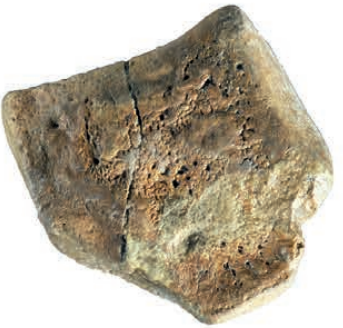

Q

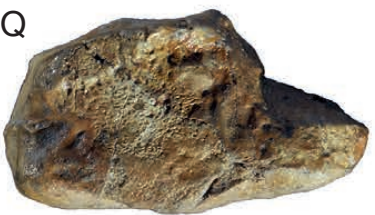

B

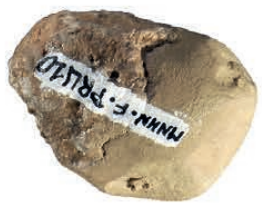

F

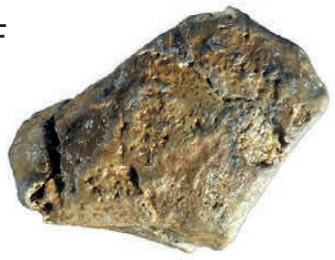

J
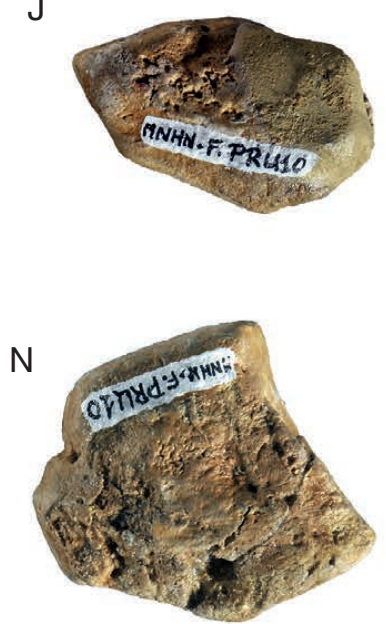

${ }^{R}$

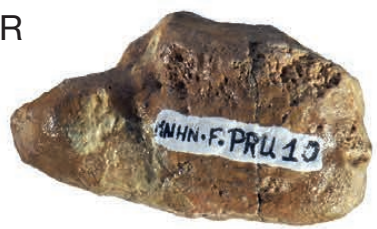

C

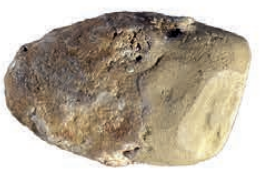

G

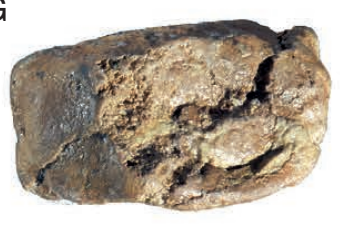

K

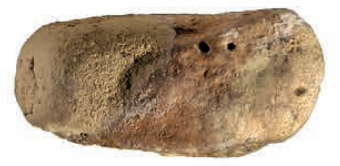

O

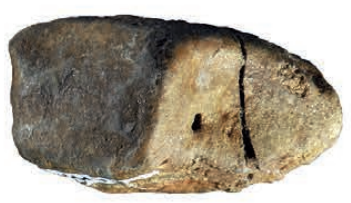

S

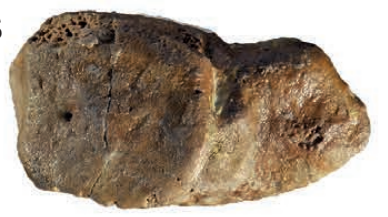

D

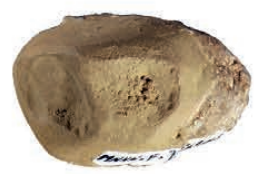

$\mathrm{H}$

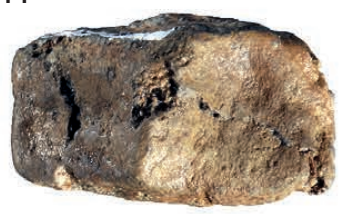

L

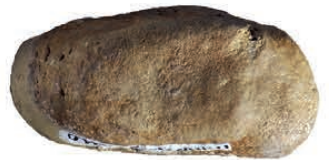

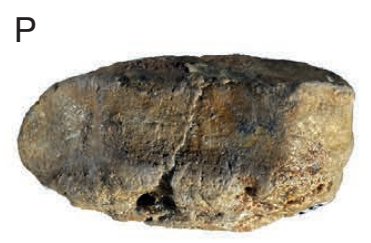

T

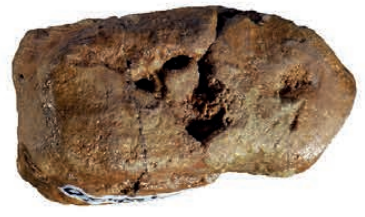

FIG. 86. - Right carpal elements of MNHN.F.PRU10, holotype of Cynthiacetus peruvianus: A, scaphoid in dorsal view; B, scaphoid in palmar view; C, scaphoid in proximal view; D, scaphoid in distal view; E, lunatum in dorsal view; $\mathbf{F}$, lunatum in palmar view; G, lunatum in proximal view; H, lunatum in distal view; I, pyramidal in dorsal view; $\mathbf{J}$, pyramidal in palmar view; $\mathbf{K}$, pyramidal in proximal view; L, pyramidal in distal view; $\mathbf{M}$, unciform in dorsal view; $\mathbf{N}$, unciform in palmar view; O, unciform in proximal view; $\mathbf{P}$, unciform in distal view; $\mathbf{Q}$, magnum-trapezoid in dorsal view; R, magnum-trapezoid in palmar view; $\mathbf{S}$, magnum-trapezoid in proximal view; T, magnum-trapezoid in distal view. Missing portions of bone have been reconstructed. Scale bar: $2 \mathrm{~cm}$.

of the radius; posteroproximally, the anterodistal articular surface of the ulna; anterodistally, the magnum-trapezoid; posterodistally, the unciform; and posteriorly, the pyramidal.

The articular surfaces for the pyramidal and ulna are adjacent, posteroproximally facing, and separated by a hardly distinguishable tuberosity. Consequently, the lunatum possesses a roughly pentagonal outline in dorsal (lateral) and palmar (medial) views. This pentagon is posteriorly pointed and its smallest side is anteriorly facing. This anterior surface does not present a well-individualized articular surface and the contact with the scaphoid is vague. In this respect, the lunatum of Cynthiacetus peruvianus differs from that of Dorudon atrox and resembles more that of Ancalecetus simonsi. All articular surfaces, except that for the scaphoid facet, are quadrilateral. The articular surfaces for the radius and magnum-trapezoid are slightly concave, while those for the unciform, ulna and pyramidal are rather flat.

The pyramidal (Fig. 86I-L) is the penultimate element in the proximal row of the carpus (in the anteroposterior axis). It is somewhat oval in dorsal view, being anteroposteriorly larger than proximodistally long. Moreover, the pyramidal is dorsopalmary compressed. The proximal surface of the pyramidal is proximally convex and contacts the ulna. This surface is roughly rounded and forms the largest articular surface of the pyramidal. The anterior edge of the pyramidal is strongly pointed and forms a sharp ridge, which separates the ulnar and semilunar facets. The semilunar articular facet 
TABLE 15. - Main measurements (in mm) of the right metacarpals of MNHN.F.PRU10, holotype of Cynthiacetus peruvianus.

\begin{tabular}{|c|c|c|c|c|}
\hline Measurement & Mc II & Mc III & Mc IV & Mc V \\
\hline Maximum proximodistal breadth of the diaphysis, excluding the epiphyses & 48.4 & - & - & 39.1 \\
\hline Anteroposterior breadth of the proximal epiphysis & 22.6 & 27.1 & 22.3 & 23.4 \\
\hline Dorsopalmar breadth of the proximal epiphysis & 11.9 & 16.8 & 13.9 & 17.2 \\
\hline Anteroposterior breadth at the mid-length of the diaphysis & 11.3 & 12 & - & 14.6 \\
\hline Dorsopalmar breadth at the mid-length of the diaphysis & 7.1 & 10.3 & - & 13.1 \\
\hline Anteroposterior breadth at of the distal epiphysis & 18.9 & - & - & - \\
\hline Dorsopalmar breadth of the distal epiphysis & 16.7 & - & - & - \\
\hline
\end{tabular}

(for the contact with the lunatum) is much smaller than the ulnar one, roughly flat and anterodistally facing. It continues posteriorly into a large, rectangular and distally convex surface. This is the unciform articular facet, which is somewhat parallel to the anterior surface of the pyramidal. It occupies most of the distal surface of the pyramidal. Posteriorly, the pyramidal probably contacted the pisiform. Unfortunately, the posterior end of the pyramidal is missing in MNHN.F.PRU10 and it is impossible to evaluate the actual shape and size of the articular surface for the pisiform.

The unciform (Fig. 86M-P) is the most posterior carpal in the distal row of the carpus. It is the most massive and largest carpal. As the carpals alternate, the unciform articulates proximally with both lunatum and pyramidal. Distally, it articulates with metacarpals III to V. Anteriorly, the unciform has a double articulation with the magnum-trapezoid.

The unciform is hexagonal in dorsal and palmar view. The largest articular surface contacts posteroproximally the pyramidal. It is proximally concave and roughly oval. Two ridges delimit anteriorly and posteriorly this facet. Anterior to the pyramidal facet is the articular surface for the lunatum, which is flat, rectangular, and anteroproximally facing. Distal to the lunatum facet, the unciform presents two anteriorly facing surfaces for the articulation with the magnum-trapezoid. The more proximal of these surfaces is roughly triangular and larger than the distal surface, which is oval. The magnum-trapezoid facets are separated by a narrow sulcus running from the dorsal to the palmar surface of the unciform. Distally, the unciform presents three articular surfaces for the metacarpals III to $\mathrm{V}$. The anterior articular facet is the smallest: it is squared, flat, anterodistally facing, and contacts the third metacarpal. The median articular facet is the largest. It is rectangular, concave, distally facing, and contacts the fourth metacarpal. Finally, the posterior facet is oval, flat, posterodistally facing, and probably contacted the fifth metacarpal.

The magnum-trapezoid (Fig. 86Q-T) is the central element in the distal row of the carpus. As indicated by its name, it results from the fusion of the magnum and trapezoid, the former being posteriorly located in respect to the latter. The magnum is roughly rectangular in dorsal view, while the trapezoid is more oval. Moreover, the trapezoid portion is much smaller than the magnum and could be regarded as a distal expansion on the anterior surface of the magnum. Therefore, the proximal and distal surfaces of the trapezoid are considerably smaller than those of the magnum. A sulcus on the palmar surface of the magnum-trapezoid corresponds to the position where the fusion of the carpals has occurred.

The magnum-trapezoid articulates proximally with the lunatum. The semilunar facet is rectangular, slightly convex proximally and lies on the proximal surface of the magnum portion. The contact of these carpals is anterodistally oriented in dorsal and palmar views. Posteriorly, the magnum portion presents two transversely elongated articular surfaces for the contact with the unciform. The two unciform facets are separated by a low and narrow keel, which corresponds to the sulcus observed in the anterior surface of the unciform.

Anteriorly, the proximal surface of the trapezoid portion and part of the anterior surface of the magnum portion form the articular surfaces for the scaphoid. These surfaces are almost perpendicular in both dorsal and palmar views. At this level, a hardly distinguishable notch indicates the position of the fusion of the trapezoid and magnum. Moreover, a small but deep fossa lies on the distal portion of the scaphoidal facet of the magnum, at the level where both magnum and trapezoid fused.

Distally, the magnum portion presents a large articular surface for the anteroproximal portion of the third metacarpal (Mc III). This surface is roughly rectangular, flat, and possesses two little foramina. Anterior to this surface is the articular surface for the second metacarpal (Mc II), which is on the distal surface of the trapezoid. The articular surface for Mc II is considerably smaller than that for Mc III. Finally, the anterior surface of the trapezoid portion presents a small rectangular and flat facet for the articulation with the trapezium. This facet is anterodistally facing.

The trapezium is the most anterior element of the distal row of the carpus and it articulates posteriorly with a small surface on the anteropalmar corner of the trapezoid portion of the magnum-trapezoid bone. The trapezium is missing in MNHN.F.PRU10. In Dorudon atrox (Uhen 2004), it is the smallest carpal and articulates distally with the first metacarpal.

Metacarpus (Fig. 87A-D, G-J). Four metacarpals are partly preserved in MNHN.F.PRU10. They correspond to the metacarpals II to V. As is observed in Dorudon atrox (Uhen 2004), Cynthiacetus peruvianus probably has a digit 1, resulting from the fusion of Mc I and the proximal phalanx. On the four metacarpals of MNHN.F.PRU10, the diaphyses are unfused to the epiphyses. The cross-section of the diaphysis increases in the proximal and distal ends. Mc II is the only entirely preserved metacarpal, while the distal portions are 
A

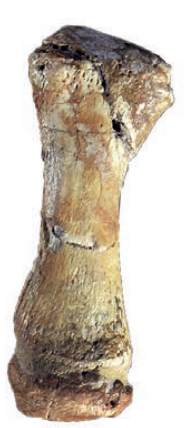

C

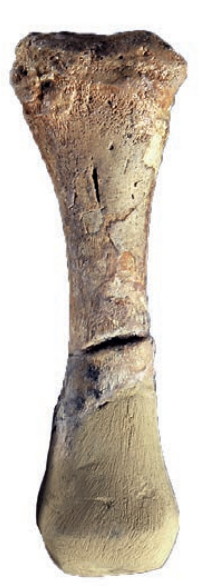

E

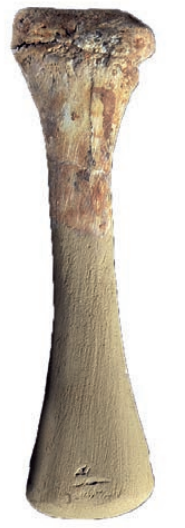

\section{G}

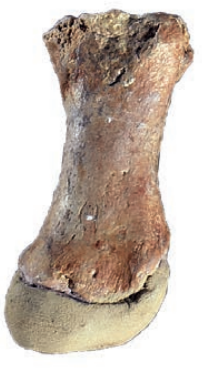

D

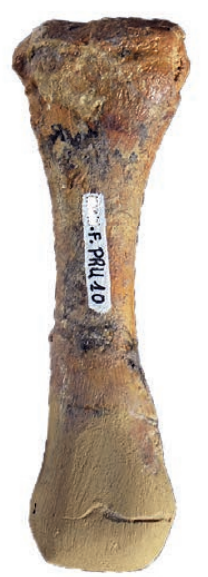

F

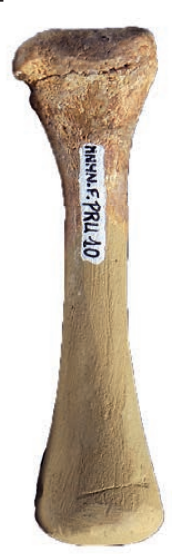

I

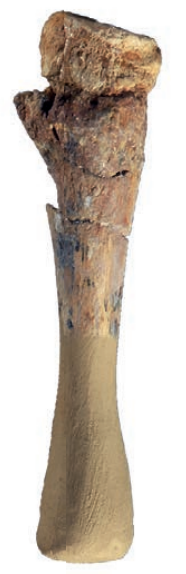

$\mathrm{H}$

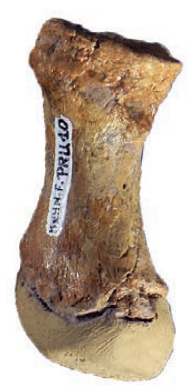

K

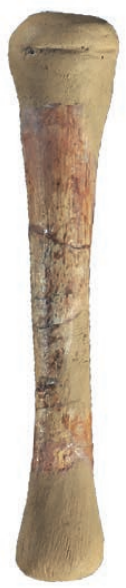

B

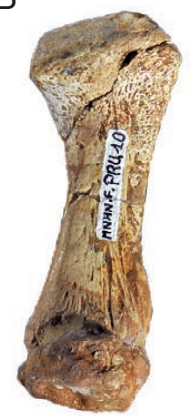
in palmar view; C, third metacarpal in dorsal view; D, third metacarpal in palmar view; E, fourth metacarpal in dorsal view; $\mathbf{F}$, fourth metacarpal in dorsal view; G, fifth metacarpal in dorsal view; H, fifth metacarpal in palmar view; I, probable proximal phalanges of digit 2 in dorsal view; J, probable proximal phalanges of digit 2 in palmar view; K, probable proximal phalanges of digit 4 in dorsal view; L, probable proximal phalanges of digit 4 in palmar view. Missing portions of bone have been reconstructed. Scale bar: $3 \mathrm{~cm}$.

missing in both Mc III and Mc IV, and only the diaphysis is preserved in Mc V. Measurements of the metacarpals of MNHN.F.PRU10 are given in Table 15.

The diaphysis of the second metacarpal (Mc II) is slightly inclined anteriorly with respect to the proximal epiphysis. It is strongly compressed dorsopalmarly, as in other metacarpals, and it is wider anteroposteriorly than thick dorsopalmarly. While the anterior epiphysis is dorsopalmarly compressed and has a convex articular surface for the trapezoid, the distal epiphysis is rounded and rather flat. The latter articulates with the proximal epiphysis of the phalanx of digit 2 . The diaphysis was probably shorter than Mc III and Mc IV.

The third metacarpal (Mc III) is the largest. It is dorsopalmarly flattened and was proximodistally longest that any metacarpal. Nevertheless, both the distal epiphysis and the distal end of the diaphysis are missing in MNHN.F.PRU10. The proximal epiphysis is somewhat convex-to-flat and presents two well-defined articular surfaces. The anterior surface is larger than the posterior surface, and articulates with the magnum-trapezoid. The posterior surface is posteroproxi- mally facing and articulates with the anterodistal surface on the unciform.

The anterior and posterior surfaces of the proximal epiphysis form rough and prominent surfaces. These surfaces should serve for the insertions of ligaments and/or tendons (tendinous insertions of the digital flexor and extensor musculature). The diaphysis of Mc III is dorsally convex in anterior view and its dorsopalmar breadth seems to be constant for its whole length.

Only the proximal portion of the fourth metacarpal (Mc IV) is preserved. As observed on Mc III, the proximal epiphysis and proximal portion of the diaphysis are dorsopalmarly compressed. The proximal epiphysis has a convex articular surface for the unciform and a relatively large tubercle on its posterior margin. This tubercle may be a site for muscular or ligament insertion. In contrast to Dorudon atrox, the diaphysis of Mc IV narrows abruptly towards its distal extremity. In this aspect, Mc IV resembles strongly the proximal phalanges of $D$. atrox. Actually, we consider this fragment of bone as a metacarpal because of the extreme dorsopalmar compression of the proximal epiphysis. Proximal phalanges 

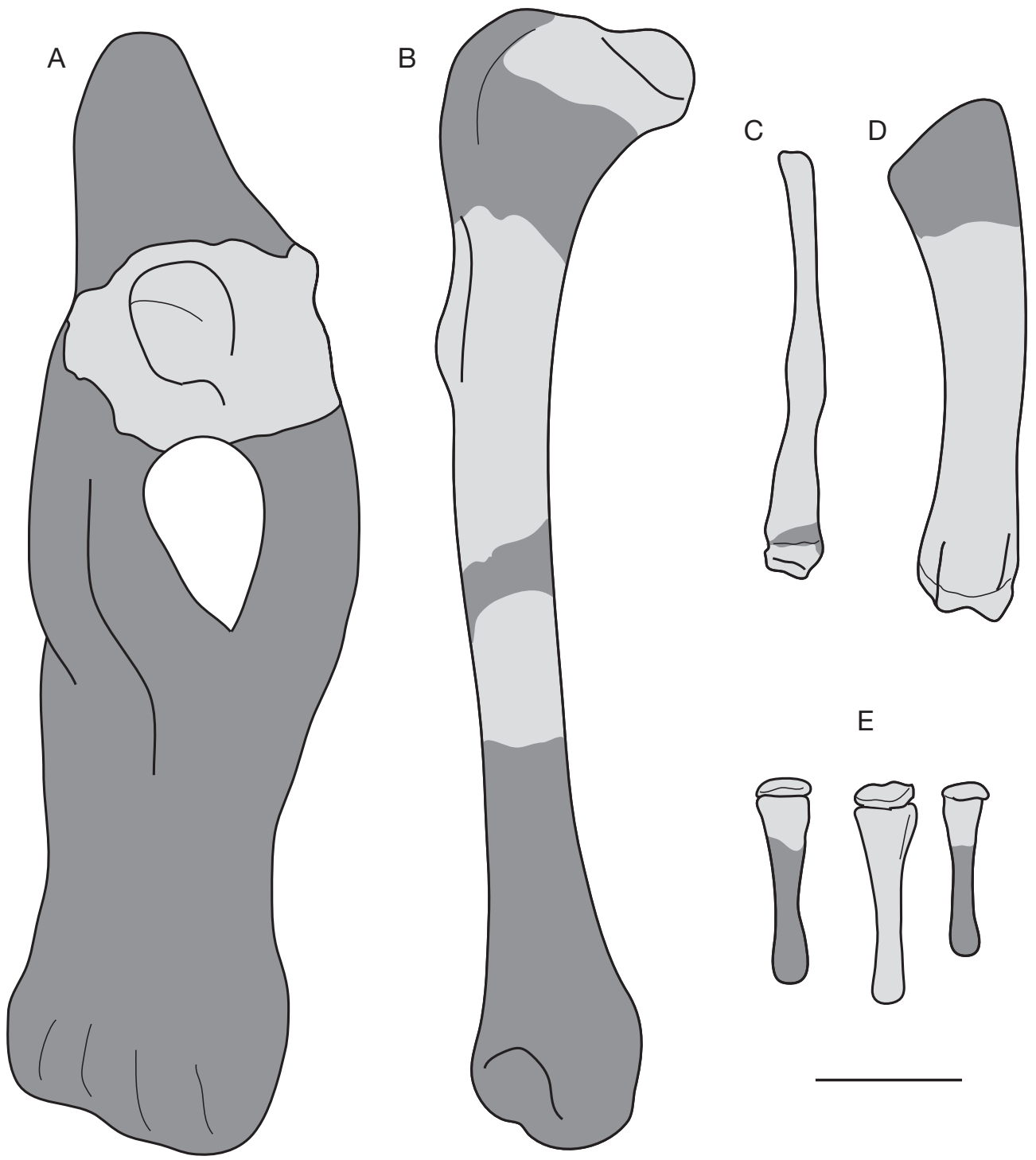

$\mathrm{E}$

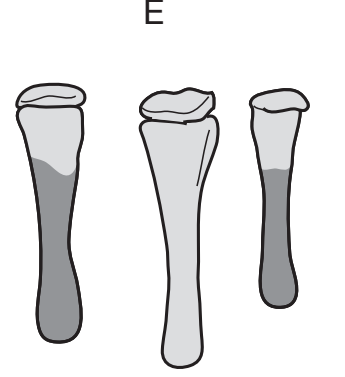

FIG. 88. - Preserved elements of the right hind limb of MNHN.F.PRU10, holotype of Cynthiacetus peruvianus: A, innominate in lateral view; B, femur; C, fibula; D, tibia; E, phalanges (1st $\mathrm{Ph}$ III-IV, from right to the left) in anterior view. Proportions are respected and the missing portions of bone have been reconstructed (gray-shaded regions). Scale bar: $3 \mathrm{~cm}$.

in D. atrox are distinctly circular in cross-section. It is unclear if the palmar surface is concave as in Mc II, or if the whole metacarpal is rather straight as in Mc III.

The fifth metacarpal (Mc V) is the shortest metacarpal preserved in MNHN.F.PRU10110. Its proximal diaphysis is somewhat rounded in cross-section and presents a proximally concave surface. It is the least dorsopalmarly compressed metacarpal. As for the other metacarpals, it bears strong tubercles on both the anterior and posterior surfaces for the insertion of ligaments and tendons. The diaphysis is massive and roughly rounded in cross-section. Its palmar surface is concave in anterior view and proportionally wider than in all other metacarpals (in respect to the proximodistal length).

Phalanges (Fig. 87E, F, K, L). Two fragments of phalanges are preserved in MNHN.F.PRU10. One of these fragments is a proximal portion, while the second is a median portion of a diaphysis. The proximal portion includes the proximal epiphysis and part of the diaphysis. It is probably the proximal phalanx of digit II. Its proximal epiphysis presents a rounded and somewhat concave articular surface for the contact with Mc II. The cross-section of the diaphysis is roughly triangular proximally; it decreases progressively towards the distal extremity, and at mid-length it is circular and smaller.

The diaphysial fragment is probably a part of the proximal phalanx of digit IV. As for the diaphysis of the proximal fragment, its cross-section is roughly circular and considerably smaller than in the metacarpals.

Pelvic girdle and hind limb. All basilosaurids have an extremely reduced pelvic girdle and hind limb, which have lost their locomotor function (Lucas 1900; Gingerich 


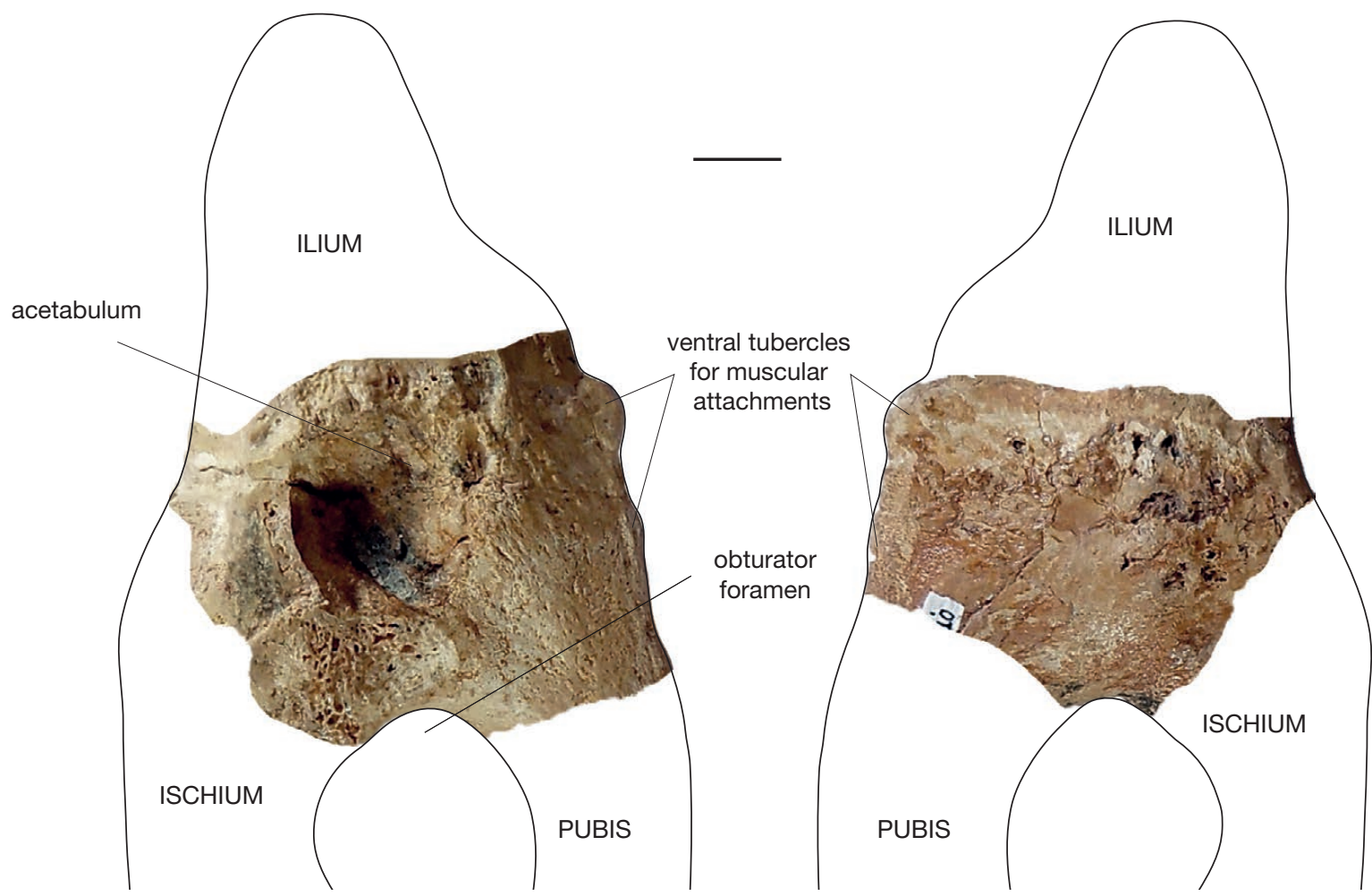

FIG. 89. - Right innominate of MNHN.F.PRU10, holotype of Cynthiacetus peruvianus: A, ventrolateral view; B, dorsomedial view. Black lines represent the hypothetical reconstruction for the innominate. Scale bar: $1 \mathrm{~cm}$.

et al. 1990; Uhen 1996, 2004; Uhen \& Gingerich 2001). Cynthiacetus peruvianus resembles the other basilosaurids in this respect, as it presents a hind limb proportionally smaller than in any other archaeocete family. Only the right girdle and hind limb are preserved in C. peruvianus, and include the acetabular region of the innominate, partial femur, partial tibia, fibula, and proximal phalanges of digits III to V. The patella, tarsals, and metatarsals are missing in MNHN.F.PRU10. Proportions and reconstructed parts of the hindlimb of MNHN.F.PRU10 are shown in Figure 88.

Innominate (Fig. 89). The innominate is the single bone of the pelvic girdle, formed by the fusion of the ilium, ischium, and pubis. These three elements meet at the acetabular region, where they form the acetabulum, which receives the femoral head. Most of the right innominate of MNHN.F.PRU10 is missing, and only a portion of the acetabular region is preserved. It includes the acetabulum and the anterior margin of the obturator foramen.

The basilosaurid innominate is known only for three other species (Basilosaurus cetoides [Lucas 1900]; B. isis [Gingerich et al. 1990]; Chrysocetus healyorum [Uhen \& Gingerich 2001]). It is difficult to establish the differences between the pelves of these species and that of Cynthiacetus peruvianus since in the latter it is extremely fragmented and since the right and left innominates are asymmetric in Basilosaurus (Lucas 1900; Gingerich et al. 1990). This slight asymmetry seems to be correlated with the reduction of the hindlimb and the loss of its locomotor function. Sub- sequent to the identification by Lucas (1900), Gingerich et al. (1990) and Uhen \& Gingerich (2001) proposed the rotation of the basilosaurid innominate in a parasaggital plane, with the ilium being posterodorsally oriented, the ischium being reduced, and the pubis forming most of the pelvic body. This orientation and rotation are discussed below (cf. Discussion). We follow the identification made by Gidley (1913) and Kellogg (1936), which reverses the original identification of right and left innominates of B. cetoides (Lucas 1900).

The acetabulum of Cynthiacetus peruvianus is better defined and more excavated than in Basilosaurus. It resembles more the condition observed in Chrysocetus healyorum. However, the acetabulum of Ch. healyorum is even more defined and proportionally larger than in MNHN.F.PRU10. In the latter, the medial (or dorsomedial) surface of the innominate is smooth, strongly convex, and presents no process, crest or tubercle. The three pelvic bones are well fused and it is difficult to determine the contribution of the ilium, ischium, or pubis. Posterior to the acetabulum is a portion of the anterior margin of the obturator foramen, which seems to be well developed and as large as in Basilosaurus and Chrysocetus.

On the ventral margin of the acetabular portion are two small tubercles, which probably serve for muscular attachment. It is difficult to determine which muscles attached on these tubercles. It has been suggested that the basilosaurid axial musculature was intermediate between the condition observed in Recent cetaceans and that observed in Recent 
A

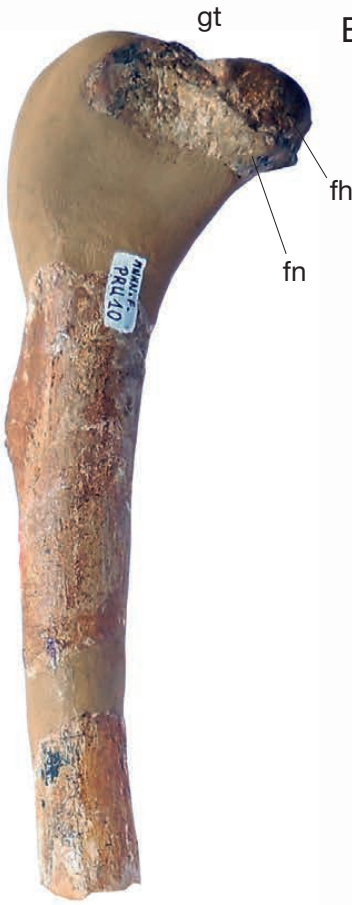

B

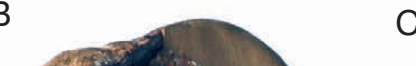

C

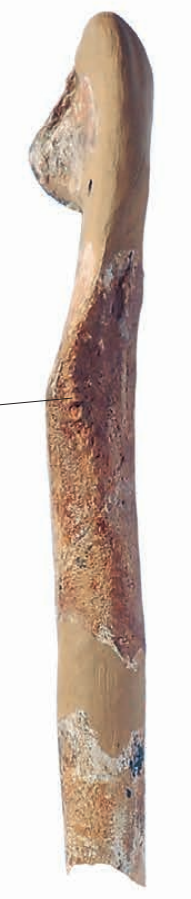

D

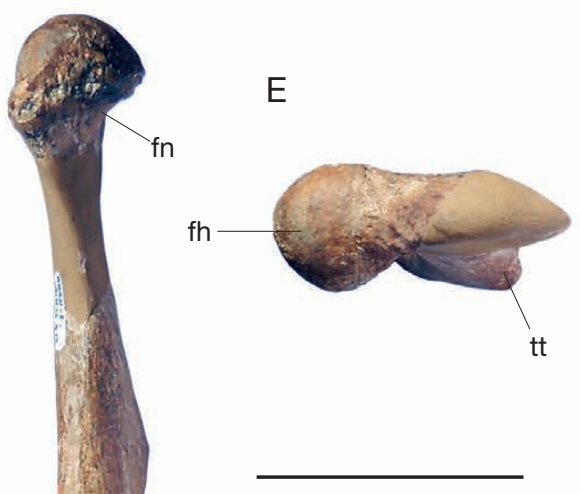

FIG. 90. - Right femur of MNHN.F.PRU10, holotype of Cynthiacetus peruvianus: A, anterior view; B, posterior view; C, lateral view; D, medial view; E, proximal view. Abbreviations: gt, great trochanter (reconstructed); fh, femoral head; fn, femoral neck; tt, third trochanter. The medial region of the diaphysis and a portion of the diaphysis distal to the proximal epiphysis have been reconstructed and are in a uniform beige colour. Scale bar: $5 \mathrm{~cm}$.

terrestrial ungulates (Uhen 1996, 2004). Following this assumption, it is most likely that the small processes on the ventral margin of the acetabular region served for the attachment of the $M$. quadratum lumborum, $M$. rectus abdominis, or M. obliqus abdominis (probably homologous of the M. ilioabdominis and M. iliobliqus in Howell 1930a). In Recent cetaceans, the pelvis serves for the attachment of reproductive organs (e.g. Struthers 1881; Howell 1930b; Tajima et al. 2004; Dines et al. 2014). In this context, one of the ventral processes described above could have served for the origin of $M$. levator ani.

Femur (Fig. 90). The femur articulates proximally with the acetabular fossa of the pelvis and distally with the tibia, fibula and patella (the latter being unknown in MNHN.F.PRU10).

The medial portion of the proximal epiphysis is formed by the femoral head, which is hemispherical and proximomedially oriented. There is no pronounced femoral neck and thus the femoral head is in continuity with the femoral diaphysis. Moreover, there is no lesser trochanter distal or medial to the femoral head. The lateral portion of the proximal epiphysis is missing in MNHN.F.PRU10 but was mostly formed by the greater trochanter of the femur. Present in both Basilosaurus cetoides (Lucas 1900) and B. isis (Gingerich et al. 1990), this greater trochanter is anteroposteriorly compressed and serves for the attachment of the M. gluteus medius (and M. gluteus minimus if present). In B. isis, the greater trochanter is strongly developed, blade-shaped, and fuses distally with the third trochanter.
Similar to the proximal epiphysis, the proximal portion of the diaphysis of MNHN.F.PRU10 is anteroposteriorly compressed. The diaphysis progressively becomes more rounded in cross-section towards its distal end, being rounded in cross-section at about its mid-length. Although part of the proximal end of the diaphysis is missing in MNHN.F.PRU10, a well-developed third trochanter is preserved on the lateral surface of the diaphysis. Contrary to Basilosaurus isis and similarly to B. cetoides, the third trochanter of the femur is separated from the greater trochanter. It is a prominent crest, anteroposteriorly oriented and slightly inclined posterolaterally. In lateral view, the third trochanter is closer to the posterior margin of the diaphysis than to the anterior margin. Distal to the third trochanter, the femoral diaphysis is straight and circular in cross-section. The distal portion of the diaphysis is missing in MNHN.F.PRU10 and it is difficult to evaluate if the distal portion of the femoral diaphysis was originally posterolaterally curved, as in B. isis.

The distal epiphysis of the femur is missing in MNHN.F.PRU10 and the architecture of the knee joint cannot be characterized. The distal extremity of the femur of Basilosaurus isis is quite modified, with two well-defined patellar surfaces and the medial condyle (tibial articular surface) being more anteriorly located than the lateral condyle (fibular articular surface). Moreover, the condyles are somewhat posteriorly facing and the knee of $B$. isis was always flexed to some degree (Gingerich et al. 1990). The conditions cited above are likely to have been present in Cynthiacetus peruvianus. 

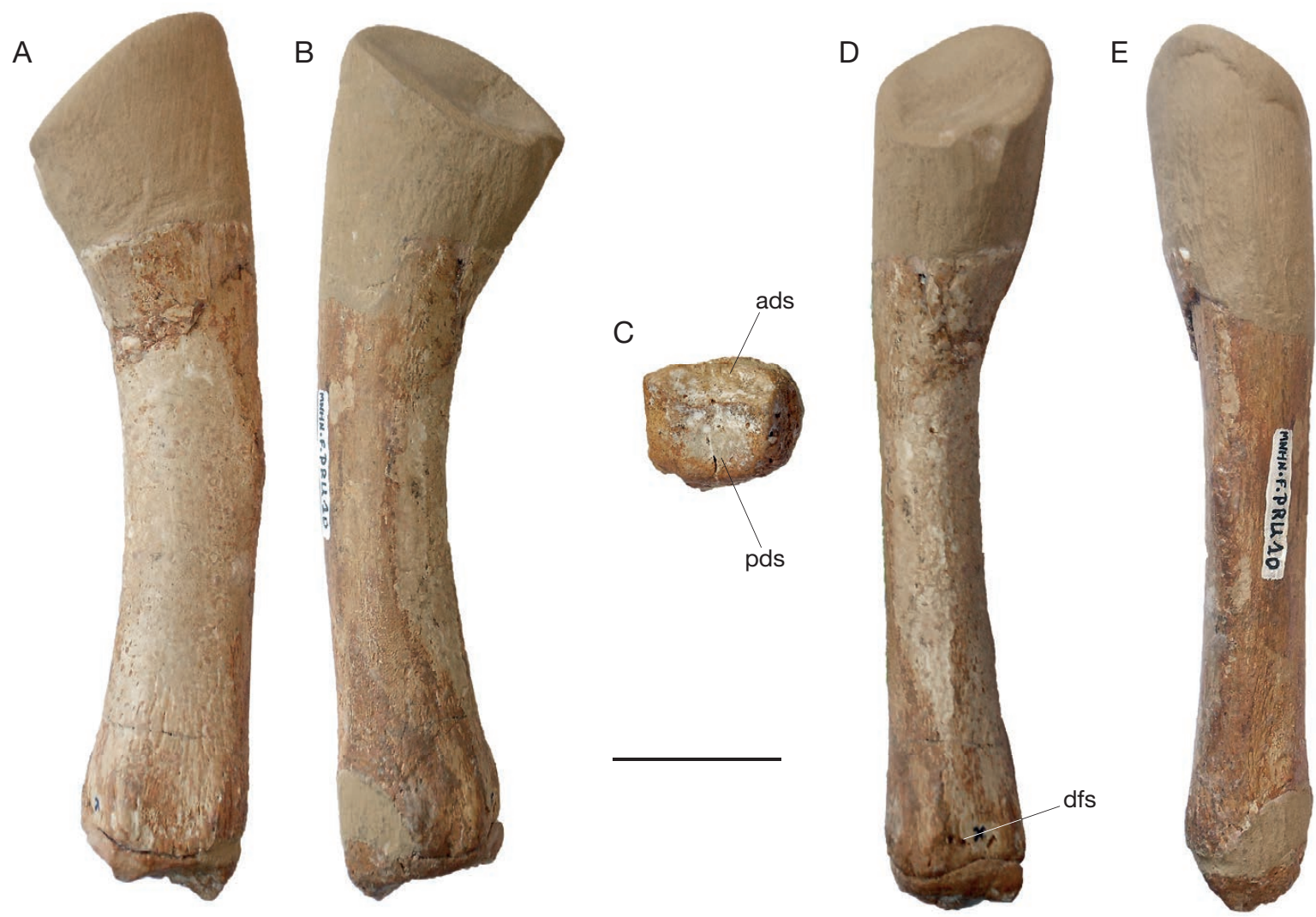

FIG. 91. - Right tibia of MNHN.F.PRU10, holotype of Cynthiacetus peruvianus: A, anterior view; B, posterior view; C, distal view; D, lateral view; E, medial view. Abbreviations: ads, anterior distal articular surface; dfs, distal fibular surface; pds, posterior distal articular surface. The proximal epiphysis and the proximal part of the diaphysis have been reconstructed. Scale bar: $2 \mathrm{~cm}$.

Tibia (Fig. 91). The proximal epiphysis and the proximal fourth of the diaphysis are missing in MNHN.F.PRU10. Until now, the only basilosaurid tibia known was that of Basilosaurus isis (Gingerich et al. 1990), in which the tibia is anteromedial to the fibula, due to the modified orientation of the distal extremity of the femur. It is probable that a similar relative position was present in Cynthiacetus peruvianus.

In Basilosaurus isis, the tibia the fibula fuse with each other at their proximal and distal extremities. This condition is not observed in MNHN.F.PRU10. However, since MNHN.F.PRU10 is a sub-adult specimen, it is possible that in ontogenetically older individuals the tibia fused with the fibula. In $B$. isis, the fusion of the tibia and fibula is achieved before the complete fusion of the diaphysis with the epiphyses.

The tibial diaphysis of MNHN.F.PRU10 is anteroposteriorly compressed (transverse breadth being greater than the anteroposterior diameter), medially convex, and presents two surfaces, anterior and posterior, and two margins, medial and lateral. As in B. isis, the diaphysis decreases in transverse width towards the distal extremity. The reduction in Cynthiacetus peruvianus is nevertheless less pronounced than in Basilosaurus isis. Moreover, the diaphysis has an elliptic cross-section that is larger proximally than distally. At its distal end, the diaphysis has an almost rectangular cross-section.
Although most of the proximal portion of the diaphysis is missing, it seems that it was anteriorly inflated. As in Basilosaurus isis, the anterior and posterior surfaces are smooth and present no particular crest or process. At about mid-length of the medial margin of the diaphysis is a rough surface that certainly serves for the attachment of the knee flexor musculature (probably $M$. popliteus or $M$. semitendinous). Laterally, the tibia articulates with the fibula but only the distal fibular articular surface is preserved in MNHN.F.PRU10. This articular surface is roughly triangular and is located on the distal extremity of the lateral margin. The fibular articular surface continues on the lateral surface of the distal epiphysis.

Although the distal epiphysis is entirely fused with the diaphysis, the suture with the diaphysis is still distinct. The lateral surface of the epiphysis can be regarded as the continuation of the distal fibular articular surface. Distally, the epiphysis presents two concave articular surfaces, which are anteroposteriorly aligned and separated by a prominent ridge. This transverse ridge is posteromedially oriented and closer to the anterior margin of the distal epiphysis. The posterior articular surface is roughly rectangular, less concave, and larger than the anterior articular surface, which is saddle-shaped. These surfaces probably contacted the astragalus or both the astragalus and navicular. No tarsal has been preserved in association with MNHN.F.PRU10, 

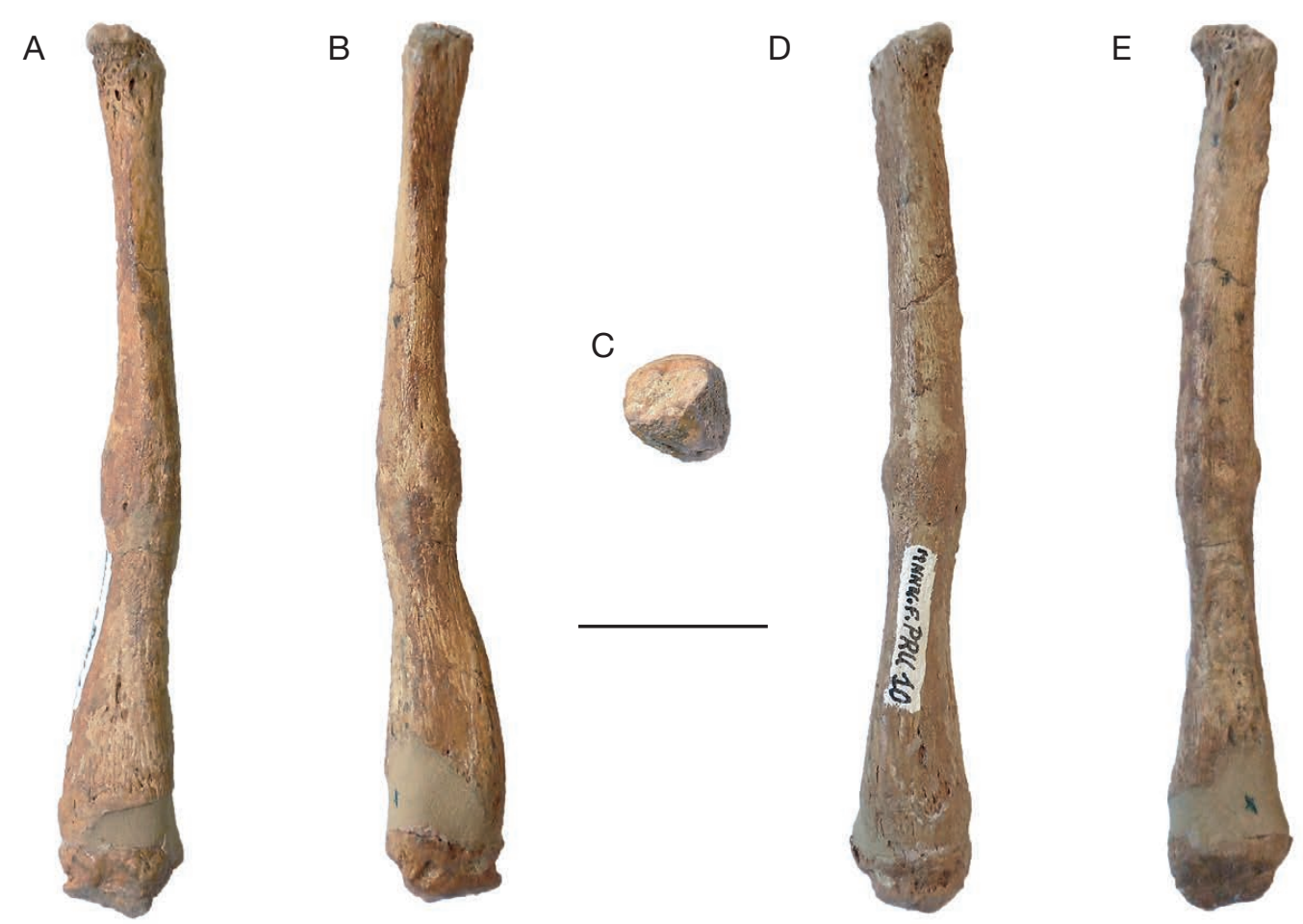

FIG. 92. - Right fibula of MNHN.F.PRU10, holotype of Cynthiacetus peruvianus: A, anterior view; B, posterior view; C, distal view; D, lateral view; E, medial view. Missing portions of the bone have been reconstructed (distal end of the diaphysis). Scale bar: $2 \mathrm{~cm}$.

and the architecture of the ankle cannot be characterized here. In contrast with Cynthiacetus peruvianus, the distal epiphysis of the tibia in Basilosaurus isis bears a single, deep articular surface (for the astragalus). The transverse ridge separating the two distal articular surfaces in $C$. peruvianus forms a strong and pointed process at the medial edge of the distal epiphysis. This process is also observed in B. isis, where it bears a small articular surface (probably analogous to the anterior articular surface on the distal epiphysis of MNHN.F.PRU10). Laterally, the transverse ridge meets the anterolateral corner of the distal epiphysis.

Fibula (Fig. 92). The fibula is transversely narrower and proximodistally shorter than the tibia. As compared with the fibula of Basilosaurus isis (Gingerich et al. 1990), the fibula of Cynthiacetus peruvianus is more slender and has a proportionally reduced cross-section in its proximal part.

The proximal epiphysis of the fibula is missing in MNHN.F.PRU10. It probably articulated medially with the proximal epiphysis of the tibia and proximally with the lateral condyle of the femur, as is observed in Basilosaurus isis. The fibular diaphysis is slightly compressed transversely at its proximal extremity and widens progressively towards its distal extremity, where it has a roughly rounded cross-section. At about mid-length, the fibular diaphysis is inflated and presents rough surfaces; this condition certainly results from bone deposition following a fracture of the slender diaphysis.

The distal epiphysis of the fibula is the broadest part of the fibula, being somewhat pyramidal and having two articular surfaces. The medial surface is quite irregular (roughly rectangular) and contacted the fibular facet of the astragalus. It is separated from the lateral articular surface by two strong anterior and posterior ridges. The lateral articular surface is considerably larger, strongly convex, roughly triangular in distal view, and it probably exclusively contacted the calcaneum. As for the tibia, the fibular-tarsal contact cannot be described in detail.

Phalanges (Fig. 93). Three phalanges are preserved in MNHN.F.PRU10. Following the differences in size observed in the metatarsals of Basilosaurus isis (Gingerich et al. 1990), we interpreted them as being the proximal phalanges corresponding to toes III to V (1stPh III-V).

The phalanx for digit IV is complete, while only the proximal portion of phalanges III and $\mathrm{V}$ is preserved. Following the size of the cross-section of the proximal extremities, we can estimate that the first phalanx of digit IV was the largest one, being followed by that of digit III. The proximal epiphyses are slightly concave proximally and roughly circular in cross-section. They are not fused with the corresponding diaphyses, and the cross-sections of the latter decrease abruptly distally. Indeed, the diaphysis of $1 \mathrm{st} \mathrm{Ph}$ IV is 1.7 times wider at its proximal end than at its distal end. 1 1 stPh IV bears numerous longitudinal ridges along its dorsal and palmar surfaces. This general morphology of 1 st $\mathrm{Ph}$ IV is likely to have been present in the two other, more fragmentarily preserved phalanges $(1 \mathrm{st} P h$ III and 1 stPh V). 

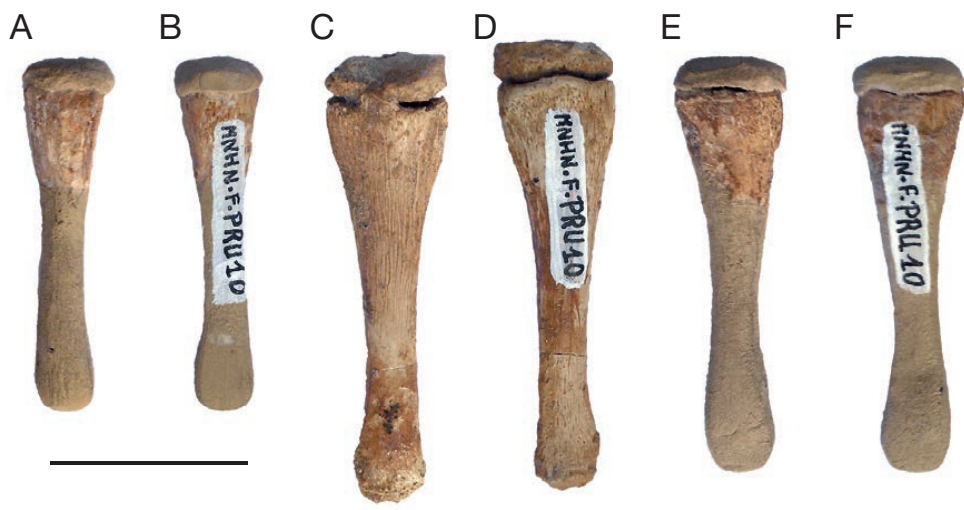

FIG. 93. - Phalanges of the hindlimb of MNHN.F.PRU10, holotype of Cynthiacetus peruvianus: A, proximal phalanx of digit III in dorsal view; B, proximal phalanx of digit III in plantar view; C, Proximal phalanx of digit IV in dorsal view; D, Proximal phalanx of digit IV in plantar view; E, Proximal phalanx of digit V in dorsal view; F, proximal phalanx of digit $\mathrm{V}$ in plantar view. Note the reconstruction of the distal portions in the diaphyses of the proximal phalanges of digits III and $\mathrm{V}$. Scale bar: $2 \mathrm{~cm}$.

\section{PHYLOGENY AND EVOLUTIONARY TRENDS}

\section{PHYLOGENETIC CONTEXT OF THE EARLY}

EVOLUTION OF CETACEANS

The skeleton of Cynthiacetus peruvianus described in this work is one of the most complete known for the family Basilosauridae. Its detailed anatomical study allowed for comparisons with several other basilosaurids and more distantly related archaeocetes. The large amount of anatomical data provided by this specimen is considered from a phylogenetic perspective, as compared to a selection of the best-preserved Paleogene cetaceans, archaeocetes as well as neocetes. The analysis presented in this section not only intends to establish the relationships of $C$. peruvianus among the Basilosauridae but also focuses on the relationships of the more derived archaeocetes in general and on the archaeocete-neocete transition.

Archaeocetes (or archaic whales) are usually included in five families: Pakicetidae (Gingerich \& Russell 1981; Thewissen et al. 1996), Ambulocetidae (Thewissen et al. 1996), Remingtonocetidae (Kumar \& Sahni 1986), Protocetidae (sensu Williams 1998), and Basilosauridae (sensu Uhen 1998). Due to the low number of described taxa and the fragmentary state of many specimens, the phylogenetic relationships within the earliest cetacean families Pakicetidae (three genera) and Ambulocetidae (two genera) are poorly constrained. Nevertheless, it is likely that they represent early specializations in the evolutionary history of cetaceans. On the oher hand, the recent description of new taxa and the subsequent phylogenetic analyses support the monophyly of the Remingtonocetidae (Geisler et al. 2005; Thewissen \& Bajpai 2009).

In contrast with earlier cetacean families, the phylogenetic relationships of protocetids and basilosaurids (the largest archaeocete families) have been more frequently tested (e.g. Abel 1908; Kellogg 1936; Uhen 1996; Uhen \& Gingerich 2001; Geisler et al. 2005). While the Protocetidae are most likely paraphyletic (Uhen \& Gingerich 2001; Geisler et al. 2005; Bianucci \& Gingerich 2011; Uhen et al. 2011), the monophyly of the Basilosauridae remains debated (e.g. Uhen 1998, 2005; Luo \& Gingerich 1999; Uhen \& Gingerich 2001;
Martínez-Cáceres \& Muizon 2011). Furthermore, because the diagnosis of the Basilosauridae was initially mostly based on plesiomorphic features, various early neocetes have been erroneously regarded as basilosaurids (e.g. Cope 1868; Pritchard 1939; Emlong 1966).

Among archaeocetes, basilosaurids are the closest relatives of modern cetaceans (Neoceti $=$ Odontoceti + Mysticeti $)$, and Basilosauridae + Neoceti form the clade Pelagiceti (Uhen 2008a). Moreover, the monophyly of the Neoceti, Odontoceti, and Mysticeti has been supported by several morphological, molecular, and combined datasets (e.g. Gatesy et al. 1999; Nikaido et al. 2001; Geisler \& Sanders 2003; May-Collado \& Agnarsson 2006; Agnarsson \& May-Collado 2008; McGowen et al. 2009; Fitzgerald 2010; Marx 2010; Geisler et al. 2011; Gatesy et al. 2013; Geisler et al. 2014; Marx \& Fordyce 2015; Sanders \& Geisler 2015). Nevertheless, the phylogenetic affinities between neocetes and basilosaurids remain unresolved, since most previous analyses included only one or two basilosaurids (Geisler \& Sanders 2003; Fitzgerald 2006; Steeman 2007; Marx 2010).

Uhen (1996, 1998, 2004, 2005) and Uhen \& Gingerich (2001) undertook stratocladistic analyses, which support the paraphyly of the Basilosauridae and the monophyly of the $\mathrm{Ne}$ oceti. They coded 17 to 18 cetacean taxa, including six to seven basilosaurid genera and both Odontoceti and Mysticeti at the sub-order level. The stratocladistic methodology enables the stratigraphic position to play an important part in determining the phylogenetic relationships. As a matter of fact, in Uhen's analyses, the affinities within the Pelagiceti depend more on the statigraphic position of the taxa than on the morphology. More recent phylogenetic analyses (Luo \& Gingerich 1999; Fitzgerald 2010; Martínez-Cáceres \& Muizon 2011) suggest a monophyletic Basilosauridae, as the sister taxon of the Neoceti. Nevertheless, the number of taxa included in these analyses is too small to be conclusive: on the one hand, Luo \& Gingerich (1999) and Fitzgerald (2010) only included three basilosaurids in their analyses, and on the other hand, Martínez-Cáceres \& Muizon (2011) included eight basilosaurids, but only two neocetes (one odontocete and one mysticete). 
A new parsimony analysis is presented here in order to obtain a better understanding of this important transition in cetacean evolution, with an emphasis on the emergence of the Neoceti within the Pelagiceti. The matrix used here is larger than that used in previous analyses focused on the Basilosauridae - Neoceti affinities (Uhen 1996, 2005; Uhen \& Gingerich 2001; Martínez-Cáceres \& Muizon 2011). This analysis includes the basilosaurid described here, Cynthiacetus peruvianus, a recently described early odontocete Echovenator sandersi, and an undescribed early mysticete (MUSM 1917) from the late Eocene of the Paracas Formation (Peru) and designated below as the "Media Luna Whale" (Martínez-Cáceres et al. 2011).

\section{SOME MAJOR TRENDS OF THE EVOLUTION}

\section{OF ARCHAEOCETES}

We present here some aspects of the evolutionary trends that are observed in the archaeocetes with special reference to the Basilosauridae. These trends focus on the rostrum morphology, the asymmetry of the rostrum, the supraorbital region, the neurocranium, the pelvic girdle, and the postcranial axial skeleton.

\section{Rostrum morphology}

Most archaeocetes, except for the highly specialized Remingtonocetidae, have a moderately narrow and elongated rostrum. In pakicetids, ambulocetids, protocetids, and basilosaurids the rostrum occupies $45-55 \%$ of the condylobasal length. In these taxa, the maximum transverse width of the rostrum (at the base of the rostrum) is about half the maximum length of the rostrum (e.g. Kellogg 1936; Gingerich et al. 1995; Thewissen et al. 1996; Hulbert 1998; Uhen 2004; Nummela et al. 2006). In contrast, remingtonocetids have a narrow and highly elongated rostrum (65-70\% of the condylobasal length), which is five times longer than wide (Kumar \& Sahni 1986; Thewissen \& Hussain 2000; Thewissen \& Bajpai 2009; Cooper et al. 2014).

Moreover, in contrast with the protocetids, in which some specializations have been pointed out (e.g. extreme narrowing of the palate in Takracetus simus; probable proboscis in Makaracetus bidens; clinorhynchy in Aegyptocetus), only a few minor differences can be mentioned within the Basilosauridae. Zygorhiza kochii possesses the proportionally longest and narrowest rostrum of the family, while Basilosaurus isis has the shortest and broadest rostrum. Moreover, the elongation of the basilosaurid rostrum is independent of the body size, and thus Cynthiacetus peruvianus (one of the largest known species) has a rostrum with similar proportions to that of both Dorudon atrox (a medium-sized species) and Saghacetus osiris (one of the smallest species). As a matter of fact, the general morphology and proportions of the rostrum remain quite stable across the basilosaurid family. On the other hand, among neocetes, the length and width of the rostrum vary greatly. For example, some archaic mysticetes (e.g. Fitzgerald 2006, 2010) have a considerably shortened and broad rostrum, while others (e.g. Sanders \& Barnes 2002; Deméré \& Berta 2008; Deméré et al. 2008; pers. obs.) present a longer rostrum, similar to that of basilosaurids except for the wider base. Besides, in toothless mysticetes, the lateral margin of the rostrum and mandible is no more laterally concave, but straight to laterally convex (e.g. Boessenecker \& Fordyce 2015). Some early odontocetes (Fordyce 2002; pers. obs.) also display a proportionally shorter and broader rostrum (as compared with the basilosaurid condition), whereas in other early odontocetes as some Xenorophidae (Kellogg 1923a; Geisler et al. 2014; pers. obs.) the rostrum is proportionally longer and narrower.

Two others significant characters at the base of the rostrum differentiate neocetes from archaeocetes. In all odontocetes the maxilla forms a pronounced antorbital notch just anterior to the level of the preorbital process of the frontal. This feature is absent in all the other cetaceans. On the other hand, early mysticetes possess a developed preorbital process of the maxilla, which extends posterolaterally from the posterolateral corner of the maxilla. Although in these archaic mysticetes the preorbital process is not as developed as in Recent mysticetes, it is proportionally more conspicuous than in any archaeocete or odontocete. This is the case in an undescribed toothed mysticete from the late Eocene of Peru, the "Media Luna Whale" (MUSM 1917), which has a preorbital process of the maxilla intermediate in size and morphology between the basilosaurid condition and the more derived mysticete condition (Martínez-Cáceres et al. 2011).

As stated above, the rostrum morphology is remarkably stable in all basilosaurids. Less than $30 \%$ of the rostrum is formed exclusively by the premaxilla, anteriorly. In dorsal view, the lateral margin of the rostrum is laterally concave. The Mx-PMx suture is strongly crenulated and does not form the distinctive sulcus observed in the earliest neocetes. Moreover, the external bony nares are located at the level of the diastema between P1 and P2, whereas they are more posteriorly located in most neocetes (except for MUSM 1917). By comparison, the position of the external bony nares varies slightly in protocetids, being always anterior to the level of P2 and posterior to the level of the upper canine.

Another feature that is worth mentioning here is the position and number of the infraorbital foramina. In most archaeocetes, they are located posterior to the level of the external bony nares (at about the level of P3 in basilosaurids). The maximum count of these foramina in archaeocetes is three, observed in a single specimen of Dorudon atrox (UM 93220). Most archaeocetes have a single infraorbital foramen on the lateral surface of the maxilla, except for some basilosaurid genera (Cynthiacetus, Zygorhiza, Dorudon) in which the number of foramina increases to two. In this context, the single infraorbital foramen of Saghacetus osiris can be interpreted as a plesiomorphic condition. Moreover, larger species (Basilosaurus isis and Cynthiacetus peruvianus) bear small accessory foramina for the maxillary canal at the posterolateral margin of the rostrum. It is unclear if these foramina are homologous to the numerous infraorbital foramina observed in neocetes. Except for one toothed mysticete (the "Media Luna Whale"), all neocete have numerous infraorbital foramina, which are located well posterior as compared with the archaeocetes (Mead \& Fordyce 2009). 


\section{Asymmetry of the rostrum}

Fahlke et al. (2011) pointed out that the rostrum in protocetids and basilosaurids is directionally asymmetrical. They also pointed out that this asymmetry is the plesiomorphic condition in archaeocetes, a statement that is uncertain because the rostra of pakicetids and ambulocetids is not sufficiently know to observe their respective condition. Additionally, they proposed that the asymmetry observed in the odontocete skull is a derived condition of the basilosaurid primitive asymmetry (which has been lost in mysticetes). Following Fahlke et al. (2011), the directional asymmetry of the rostrum could play a role in underwater hearing by enhancing the ability to decompose the sound (a strategy also observed in the Tengmalm's Owl, Aegolius funereus; Norberg 1978). This hypothesis explains satisfactorily the fact that the asymmetrical rostrum has always the same kind of torsion and direction (to the left) in basilosaurids and protocetids. However, the odontocete asymmetry can hardly correspond to the archaeocete asymmetry. In odontocetes, the asymmetry is strongly located in the facial region, on the supraorbital region of the skull, and not on the rostrum as in archaeocetes. Moreover, it has been proposed that the odontocete asymmetry is correlated with the development of soft organs (nasal air sacs and related structures) involved in the production of ultrasound for echolocation (Norris 1968; Mead 1975; Heyning 1989), whereas there is no evidence for the presence of such organs in any archaeocete (see further discussion on cetacean cranial asymmetry in Fahlke \& Hampe 2015).

\section{Supraorbital region in archaeocetes and early neocetes}

One of the most characteristic features in cetacean evolution is the clear tendency towards a lateral extension of the posteriormost portion of the facial region, dorsal to the orbits. This condition is directly correlated to the posterior migration of the external bony nares (telescoping of the skull; Miller 1923). In both Ambulocetidae and Pakicetidae the skull is narrow in the supraorbital region and has a Y-shaped cross-section. Moreover, the external bony nares remain anteriorly located on the rostrum and there is no evidence of telescoping. The small differences that can be pointed out within pakicetids include essentially the presence of a deep sulcus in the midline, between the supraorbital processes and the small, anteriorly directed supraorbital processes of the frontal (Nummela et al. 2006). In Ambulocetus natans, the supraorbital process is even less developed than in pakicetids, whereas the external bony nares are slightly more posteriorly located (Thewissen et al. 1996; Nummela et al. 2006).

The facial region changes drastically in more derived cetaceans: the longitudinal sulcus at midline between the orbits is absent and the supraorbital process of the frontal extends laterally. However, although the remingtonocetid supraorbital process of the frontal is more developed than in pakicetids and ambulocetids, it is proportionally smaller than in more derived cetaceans (protocetids, basilosaurids and neocetes). Since the rostrum is strongly elongated in remingtonocetids, the nasal is proportionally longer than in other cetaceans. The external bony nares are more posteriorly located than in Pakicetus and Ambulocetus.
By comparison with earlier archaeocetes, protocetids have a well-developed supraorbital process of the frontal, which is roughly triangular-to-pentagonal in dorsal view. The transverse breadth of the protocetid skull at the mid-length of the supraorbital shield is about $65 \%$ of the bizygomatic breadth. In some early protocetids (e.g. Artiocetus clavis), the zygomatic arch remains visible in dorsal view at the level of the orbit, while in more derived taxa (e.g. Georgiacetus vogtlensis) the supraorbital process of the frontal expands laterally and covers the orbital portion of the zygomatic arch (corresponding to the jugal) in dorsal view. This feature is also observed in basilosaurids and neocetes. Moreover, the posterior migration of the external bony nares is more accentuated in protocetids than in remingtonocetids.

The relative width of the supraorbital process and the telescoping of the external bony nares and facial region are even more conspicuous in basilosaurids, where the supraorbital shield occupies about $80 \%$ of the bizygomatic breadth. The inter-generic differences within basilosaurids will be discussed below.

The posterior migration of the nares is extreme in early neocetes, where the nasal is considerably reduced, and both maxilla and premaxilla extend far posteriorly. In most odontocetes, the supraorbital shield is proportionally wider than in basilosaurids and its lateral margin is convex laterally (whereas it is rather straight in basilosaurids) (but see Sanders \& Geisler 2015 for the unusual supraoccipital morphology of an early odontocete). Besides, the premaxilla and especially the maxilla are strongly modified in odontocetes and cover most of the supraorbital process of the frontal, forming the ascending process of the maxilla (Allen 1921; Kellogg 1923a; Fordyce 2002; Uhen 2008c). This seems to be one of the best synapomorphies of the clade (Muizon 1994; Geisler \& Sanders 2003; Geisler et al. 2011). Furthermore, in the extinct family Xenorophidae the lacrimal also participates extensively to the supraorbital region, covering the preorbital and part of the supraorbital process of the frontal.

Mysticetes also have a wide supraorbital process of the frontals. However, early toothed mysticetes differ from basilosaurids and odontocetes in having a supraorbital process with a strongly concave lateral margin in dorsal view, and a well-developed, posterolaterally projected postorbital process of the orbit. It is not clear whether this feature is a synapomorphy of the Mysticeti or a secondary specialization within a toothed mysticete clade, since it is lacking in some toothed mysticetes. Besides, it has been proposed that this feature could be unique to some toothed mysticetes, and related to the increase in size of the orbit as well as an unusually active feeding ecology (Marx 2010). This concave lateral margin of the supraorbital process is also present (but less pronounced than in toothed mysticetes) in the earliest family of toothless mysticetes (Eomysticetidae, Sanders \& Barnes 2002; Boessenecker \& Fordyce 2015).

\section{Supraorbital region within the Basilosauridae}

The supraorbital portion of the skull in Basilosauridae is mostly formed by the supraorbital process of the frontals, but also by 
the nasals, premaxillae, and maxillae, which form the median part of the facial region. Unfortunately, this portion of the facial region is well preserved only in eight of the 17 known basilosaurid species (Basilosaurus cetoides, B. isis, Cynthiacetus maxwelli, C. peruvianus, Dorudon atrox, Ocucajea picklingi, Saghacetus osiris, and Zygorhiza kochii).

The basilosaurid nasal is proportionally shorter than in earlier cetaceans, where the nasal is posteriorly pointed (e.g. Thewissen et al. 1996; Nummela et al. 2006). The nasal of Saghacetus osiris and Ocucajea picklingi roughly resembles that of protocetids in being rectangular and these two taxa lack the anterior process of the frontal that separates the nasals at midline. However, one specimen of Sa. osiris (Mn. 9 in Stromer 1908) may have possessed an extremely narrow and reduced anterior process of the frontal (not explicitly indicated in the reconstruction of Stromer 1908: table IV-I). Although the nasal of $\mathrm{Sa}$. osiris is usually rectangular in dorsal view, its posterior portion in one specimen of Sa. osiris (UM 97550) has a laterally convex lateral edge, a feature commonly observed in protocetids. As a matter of fact, the nasal of Sa. osiris and $O$. picklingi are very similar. In both species the maxilla is well expanded posteriorly and its posterior end is posterior to (in Sa. osiris) or at about the level of (in O. picklingi) the posterior end of the nasal. Since the supraorbital region of Sa. osiris and O. picklingi resembles more that of the protocetids than that of any other basilosaurid, the features observed in these taxa are regarded here as plesiomorphic within the Basilosauridae.

Except for Zygorhiza kochii, the nasal of all the other basilosaurid (Basilosaurus, Cynthiacetus, and Dorudon) is lanceolate, being pointed anteriorly and posteriorly, and having its maximum width approximately in the posterior third or half of its length (Fig. 94). Moreover, the posterior portions of the nasals are separated by a prominent anterior process of the frontal, which is slightly more developed in Dorudon atrox and Basilosaurus isis than in other species. Uhen (2005) mentions that there is no anterior process of the frontal in Cynthiacetus maxwelli, but a detailed comparison with the holotype of C. peruvianus allows us to reinterpret the sutures in the facial region and to identify a large anterior process of the frontal in C. maxwelli. Additionally, the nasal is anteriorly narrower in the two Cynthiacetus species than in any other basilosaurid.

The case of Zygorhiza kochii deserves a special attention. Although the supraorbital process is absent in the holotype (which is an incomplete cranium), one of the best-preserved skulls of $Z$. kochii (USNM 11962, adult specimen) presents an unusual morphology of the facial region, which is unique within the Basilosauridae (Fig. 94B). In contrast with other specimens of Z. kochii, USNM 11962 has a conspicuous anterior process of the frontal and its nasals are strongly reduced. Indeed, the maxilla of USNM 11962 extends far behind the posterior end of the nasal and the posterior extremity of the premaxilla is only slightly anterior to the end of the nasals. Since juvenile specimens of Dorudon atrox present the same pattern of the facial region as adults (Uhen 2004), it is probable that this region remains constant in other basilosaurids as well, independently of the ontogenetic age. In other adult specimens of $Z$. kochii, the supraorbital process is rectangular to oval and lacks the anterior process of the frontal (MMNS VP 130) or is narrower anteriorly and has only a small anterior process of the frontal (USNM 16638). These intraspecific differences observed in $Z$. kochii are also independent of the ontogenetic age of the specimens. In this context, USNM 11962 could represent either an aberrant condition or a different species. Noteworthily, USNM 11962 is the best-known specimen of $Z$. kochii and has been used in various phylogenetic analyses (Luo \& Gingerich 1999; Geisler \& Sanders 2003; Fitzgerald 2010; Geisler et al. 2011). Since the holotype of Z. kockii lacks this strongly diagnostic region, a systematic revision of the species is necessary in order to re-evaluate its diagnosis and referred specimens.

\section{Neurocranium}

The overall shape of the neurocranium does not vary considerably among the earliest cetaceans. In pakicetids, the length of the parietals on the sagittal plane, where they form a pronounced sagittal crest, approaches 30-35\% of the condylobasal length (CBL) (Nummela et al. 2006). A similar ratio is observed in protocetids (33\% of the CBL in Artiocetus clavis and 34\% of the CBL in Georgiacetus vogtlensis). As a consequence of the elongation of the rostrum, the parietals only occupy about $20 \%$ of the CBL at midline in Remingtonocetus harudiensis. Moreover, in all the taxa cited above the neurocranium does not expand laterally as it does in modern cetaceans, and the nuchal crest is strongly inclined posterodorsally in lateral view.

The basilosaurid neurocranium is morphologically intermediate between that of protocetids and that of modern cetaceans. In basilosaurids the sagittal crest is proportionally shorter than in protocetids and longer than in any neocete (occupying 17 to $23 \%$ of the CBL). Moreover, the braincase of some basilosaurids (especially Zygorhiza kochii) is more expanded laterally than in other archaeocetes, although it remains proportionally less expanded than in Recent neocetes (especially among odontocetes). Additionally, the nuchal crest of basilosaurids is roughly vertical in lateral view, contrasting with the strongly posterodorsally inclined crest of all protocetids. A vertical nuchal crest is also observed in early neocetes.

Following the geological time sequence and the differences between four basilosaurid crania, Andrews (1923) proposed a series of transformations leading to an increase in the length of the sagittal crest, a narrower temporal region, the elevation and the transverse constriction of the supraoccipital shield. According to Andrews (1923), Dorudon atrox would represent the primitive basilosaurid condition, while Saghacetus osiris would represent the derived condition. This interpretation has been supported by stratocladistic analyses (Uhen 1996, 2004, 2005). Nevertheless, the improved knowledge of the fossil record, with the description of the earliest cetacean families (Pakicetidae, Ambulocetidae, and Remingtonocetidae), leads to a reinterpretation of the observations made by Andrews (1923). Saghacetus osiris shares with protocetids a well-developed sagittal crest and a less inflated braincase. Moreover, it has the longest interparietal suture (23\% of the CBL at midline) among basilosaurids. Similarities with protocetids position the neurocranium of 

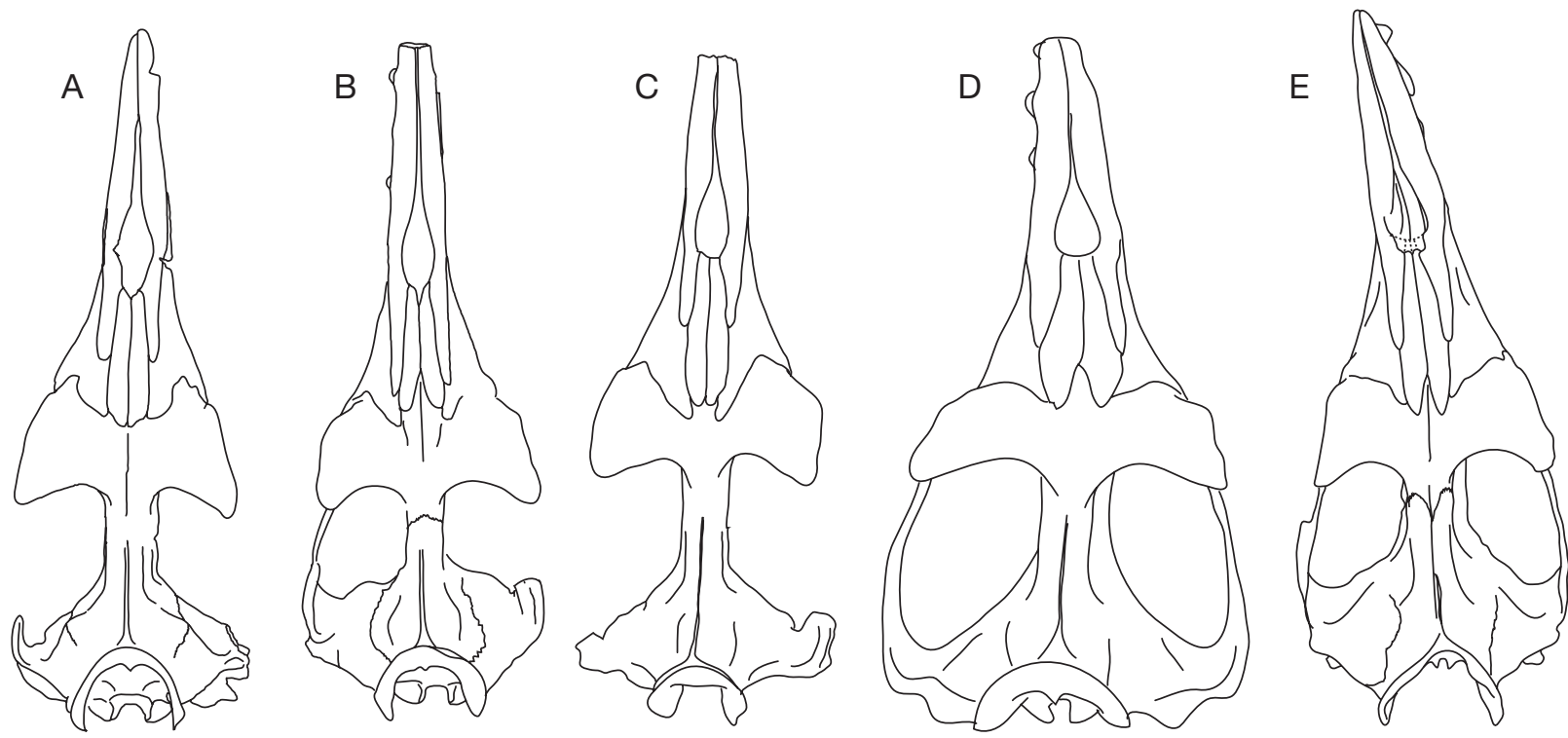

FIG. 94. - Comparison of the cranial morphologies of the Basilosauridae. Reconstruction of the dorsal view of: A, Zygorhiza kochii (USNM 16639); B, Z. kochii (USNM 11962); C, Saghacetus osiris (MNHN.F.LBE695); D, Basilosaurus isis (reconstructed from Fahlke et al. 2011); E, Cynthiacetus peruvianus (MNHN.F.PRU10). Not to scale.

Sa. osiris as a representative of the plesiomorphic condition within the basilosaurids. However, the cranium of Sa. osiris differs from that of other basilosaurids and protocetids in displaying a strong transverse compression of the supraoccipital shield, just dorsal to the level of the condyles, a feature diagnostic for the genus. Among basilosaurids, the shortest temporal region is observed in D. atrox and Zygorhiza kochii, where the interparietal suture occupies only $20-17 \%$ of the $\mathrm{CBL}$ at midline. Although it is quite difficult to estimate the increase in the braincase volume, the neurocrania referred to Zygorhiza seem to present the maximum lateral expansion. This condition is correlated with the reduction in height of the nuchal crests.

In neocetes, the reduction of the interparietal suture and the inflation of the braincase are more pronounced than in any archaeocete. Only a few neocetes present a well-developed sagittal crest (the eomysticetid Eomysticetus whitmorei, an unnamed toothed mysticete from South-Carolina, ChM PV 5720, and the archaic odontocete Mirocetus riabinini). It is likely that the presence of a sagittal crest in at least part of these taxa is a derived condition. In most neocetes, the orbitotemporal crest replaces functionally the sagittal crest (for the origin of the jaw musculature) and extends posteriorly from the posterior margin of the supraorbital process of the frontal towards the posterior end of the skull. The orbitotemporal crest is roughly absent in all archaeocetes (it can be slightly defined in the largest specimens). Moreover, in the tooth-bearing early mysticete Aetiocetus polydentatus and the early odontocete Simocetus rayi the interparietal suture occupies at midline only 5.5 and $5.4 \%$ of the condylobasal length, respectively. The interparietal suture remains visible in some early neocetes, but it disappears in more derived taxa. Finally, the parietals do not contact each other at midline in Recent cetaceans.
Other important differences in the neurocranium concern the shape and orientation of the occipital shield. The dorsal margin of the supraoccipital in all archaeocetes is anteriorly convex and has a semi-circular outline in dorsal view. While in non-basilosaurid archaeocetes the occipital shield is posteroventrally facing, the occipital shield of Pelagiceti is posteriorly (in basilosaurids) or posterodorsally facing. The supraoccipital is not exposed in dorsal view in any archaeocetes, while most early neocetes possess a dorsally exposed supraoccipital. Aetiocetidae, early Chaeomysticeti (e.g. Eomysticetus and Pelocetus), various undescribed Oligocene neocetes from the collection of the Charleston Museum (e.g. xenorophid ChM PV 4746, and toothed mysticete ChM PV 5720), and the archaic odontocetes Agorophius and Mirocetus (Sanders \& Geisler 2015; Godfrey et al. 2016) have a triangular supraoccipital shield, whereas most early odontocetes (e.g. Simocetus rayi) and mammalodontids have a more rounded and anteriorly convex supraoccipital shield, as in basilosaurids. The description of the specimens of the Charleston Museum and their inclusion in a phylogenetic analysis should allow a better understanding of the evolution of the supraocciptal shield within the Neoceti (see also Sanders \& Geisler 2015).

Finally, the dorsal exposure of the supraoccipital and the reduction of the sagittal crest are correlated with the position of the vertex, and thus with the telescoping of the cranium. Indeed, while in all archaeocetes the vertex is located posterior to the level of the anterior margin of the squamosal fossa, in various neocetes the vertex is located anterior to it. This latter condition is regarded here as apomorphic and has been proposed by other authors (Miller 1923; Barnes \& McLeod 1984; Fitzgerald 2010) as being diagnostic of the Mysticeti. However, the relative anterior position of the vertex is also present in some early odontocetes (e.g. Simocetus rayi and the partly undescribed agorophids of the Charleston Museum, 
see Godfrey et al. 2016), whereas the plesiomorphic condition (archaeocete-like) is also observed in both odontocetes and mysticetes (e.g. aetiocetids and mammalodontids). In order to determine if the anterior migration of the vertex is a synapomorphy of the Neoceti or a secondary convergence appearing in both Odontoceti and Mysticeti, a phylogenetic study needs to be undertaken (see below).

\section{Pelvic girdle and hind limb}

The hind limb of modern cetaceans has reached an extreme reduction and has lost any locomotor function. Indeed, in Recent taxa the hind limb skeleton remains within the body, being represented by an atrophied innominate that is sometimes associated with small, stick-like femur and tibia (Lönnberg 1910; Howell 1930b; Berzin 1972; Simôes-Lopes \& Gutstein 2004; Tajima et al. 2004; Dines et al. 2014; Gol'din 2014). In Recent cetaceans the hind limb receives the attachment of the reproductive apparatus and insertion of some hypaxial muscles in largest specimens (Struthers 1881; Dines et al. 2014). Moreover, the presence of an atavic, protruding hindlimb has been reported in the bottlenose dolphin (Ohsumi \& Kato 2008) and in some very large species, such as the humpback whale (Andrews 1921) and the sperm whale (Ogawa \& Kamiya 1957).

The progressive reduction of the cetacean hind limb is well attested by the fossil record and the evolution of the pelvis morphology can easily be reconstructed. In contrast, the more distal elements are unknown for most fossil species. As a matter of fact, the pelvis of the earliest cetaceans (e.g. Thewissen et al. 2001) resembles more that of terrestrial mammals than that of the living taxa. Indeed, pakicetids (Madar 2007), ambulocetids (Madar et al. 2002), remingtonocetids (Bebej et al. 2016), and protocetids (Gingerich et al. 1994, 2009; Hulbert 1998) share a pelvis with: 1) a well developed ilium, ischium, and pubis; 2) a large obturator foramen; 3) a functional hip joint; and 4) an auricular surface of the ilium attached to the sacral region (except for the protocetid Georgiacetus vogtlensis, for which there is no clear evidence for a sacro-pelvic contact). Moreover, Thewissen et al. (2006) proposed a developmental and genetic scenario for the reduction and lost of hind limb in cetaceans.

An important step of the cetacean pelvic reduction is visible in the Basilosauridae, where the ilium is strongly reduced and the body of the pelvis is proportionally elongated [posterior portion in Lucas (1900); pubic symphysis in Gingerich et al. (1990)]. These two features are also observed in extant neocetes (Lönnberg 1910; Howell 1930b; Tajima et al. 2004) and could be regarded as synapomorphies of the Pelagiceti. Besides, Uhen (1999) reported an incomplete protocetid pelvis (referred to Eocetus wardii) with a very unusual morphology, probably intermediate between the protocetid and basilosaurid conditions. The basilosaurid hind limb is known in four species (Basilosaurus cetoides, B. isis, Chrysocetus healyorum, and Cynthiacetus peruvianus). The first basilosaurid hindlimb was reported by Lucas (1900); and it belongs to, an incomplete adult specimen of B. cetoides (USNM 12261) from Alabama. USNM 12261 includes a fragmentary forelimb and mandible, the posterior portion of the axial skeleton, two pelves, and one femur. Because of its particular morphology and size, the pelves of USNM 12261 were erroneously reinterpreted as coracoids of a fossil bird (Alabamornis; Abel 1906). Later, Gidley (1913) and Kellogg (1936) reinterpreted these bones as the pelves of $B$. cetoides and suggested that Lucas (1900) reversed right and left sides. Gingerich et al. (1990) described the hindlimb of $B$. isis and proposed a reconstruction with a shift on the relative orientation of the basilosaurid pelvis (hypothesis 1, H1). According to this hypothesis, compared to earlier cetaceans and terrestrial mammals, the basilosaurid pelvis followed a rotation along a parasagittal plane of the body, which places the ilium in a posterodorsal position as compared to the acetabulum. According to this hypothesis, right and left innominates contact each other anteroventrally through a rough pubic symphysis (posterior end of the innominate in Lucas 1900). Following this interpretation (H1), the reduced ischium forms part of the ventral edge of the pelvis (Fig. 95). This reconstruction relies upon the original identification of the right and left sides for the innominates of Basilosaurus. The identification proposed by Lucas (1900) is indeed followed by Gingerich et al. (1990), differing from that proposed by Gidley (1913). These discrepancies indicate that the orientation of the basilosaurid innominates is difficult and not yet fully understood. As a matter of fact, Gingerich et al. (1990) have pointed out that there still exist some doubts concerning which pelvis is right or left in B. isis. More recently, Uhen \& Gingerich (2001) have followed H1 to describe the pelvis of $C h$. healyorum.

The pelvis of basilosaurids differs essentially from that of modern cetaceans in having well-defined obturator foramen and acetabular fossa. However, although reduced and completely separated from the axial skeleton, the pelvis of Recent cetaceans has the typical orientation of terrestrial mammals, with the ilium being anterior to the ischium (e.g. Struthers 1881; Lönnberg 1910; Kükenthal 1914; Howell 1930b) and the ischium being dorsal to the pubis (when both elements can be distinguished from each other; Struthers 1881; Andrews 1921). A similar orientation is also observed in protocetid archaeocetes. If the interpretation of the orientation of the innominates as proposed by Gidley (1913) and Kellogg (1936) is correct, then it is probable that no rotation is needed for the reconstruction of the basilosaurid pelvis (hypothesis 2, $\mathrm{H} 2$ ). If such a hypothesis is correct, the basilosaurid pelvis shares various characteristics with the modern cetaceans: ilium reduced and anteriorly located (anterodorsally oriented in the basilosaurid Chrysocetus healyorum and in the mysticete Balaena mysticetus); pubis reduced to absent; posterior lengthening of the ischium, with a pronounced rough surface. According to $\mathrm{H} 2$, the basilosaurid pubis is strongly reduced and thus, there is no true pelvic symphysis. This feature is also observed in Recent cetaceans, where the pelves are isolated and connected to each other through an inter-pelvic ligament, which inserts on the posterior end of the ischium (e.g. Struthers 1881, 1893). The presence of a rough surface on the posterior margin of the pelves of Basilosaurus could thus correspond to the attachment area for the inter-pelvic 

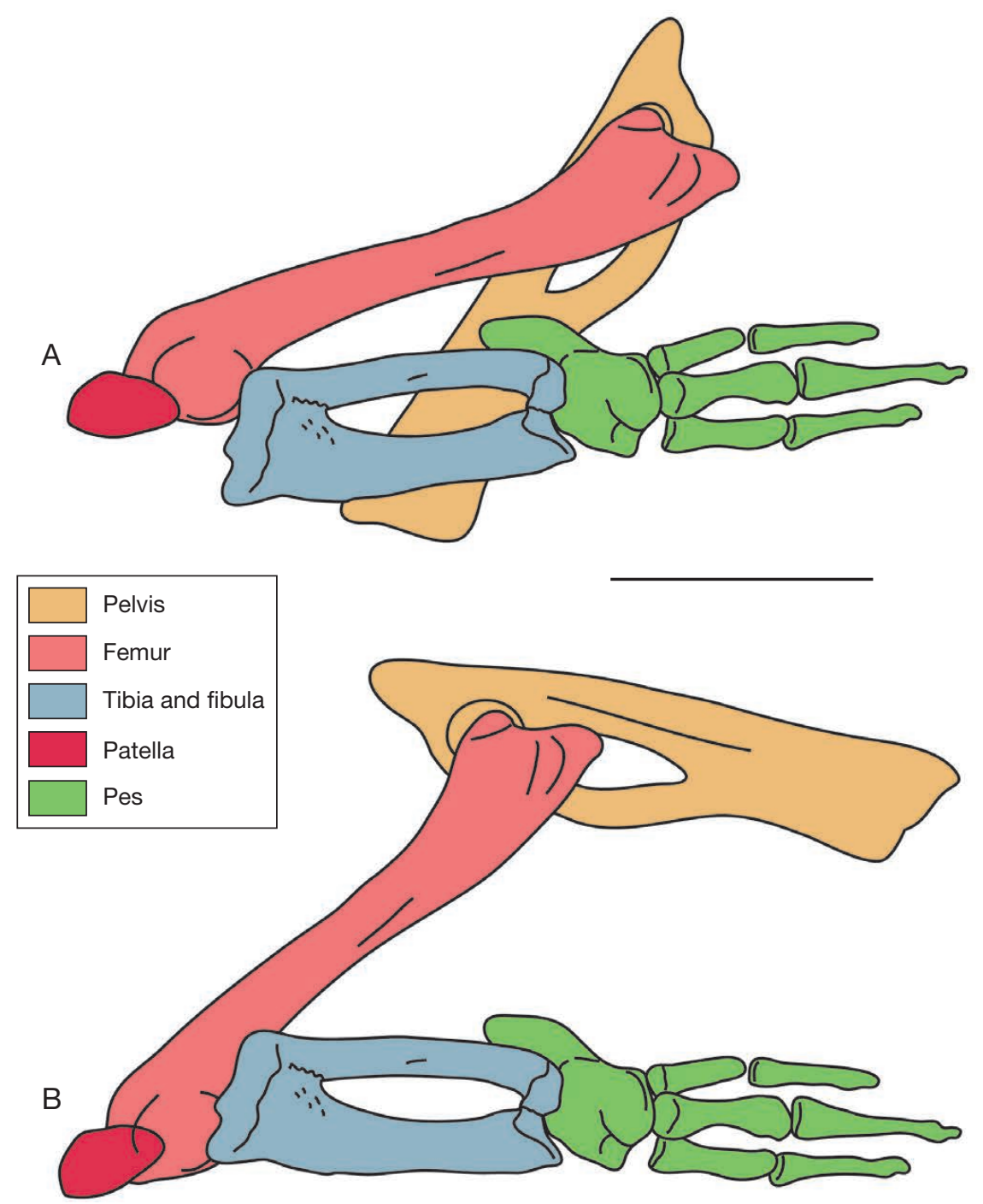

FIG. 95. - Orientation of the left pelvis and hindlimb in Basilosaurus isis: A, H1, hypothesis proposed by Gingerich et al. (1990); B, H2, hypothesis suggested in this work. Scale bar: $10 \mathrm{~cm}$.

ligament. Such a feature supports hypothesis H2. It is worth pointing out here that in Georgiacetus vogtlensis, the ischial ramus is more robust than the pubic ramus, supporting the identification of the ischium as the most important element of the pelvis in derived archaeocetes. After a comparison with earlier archaeocetes and more derived neocetes, hypothesis $\mathrm{H} 2$ is supported here rather than hypothesis $\mathrm{H} 1$ (see also Gol'din 2014). Therefore, the basilosaurid pelvis had probably an orientation similar to that observed in protocetids, with the ilium anteriorly oriented in Basilosaurus, and more anterodorsally oriented in Ch. healyorum. The pubis is reduced and slender, the ischium forms most of the posterodorsal part of the body, and the latter extends far posteriorly, especially in Basilosaurus isis.

\section{Chevrons}

Articulating with the corresponding caudal vertebrae, the chevrons (haemal arches) partly sustain the hypaxial musculature of the vertebral column, the latter being essential in aquatic vertebrates whose propulsory organ is the tail or the posterior part of the body. Chevrons of neocetes are generally large. They bear a transversely compressed haemal spine, which forms a sharp anteroposterior elongated carina on which part of the hypaxial musculature attaches (muscle hypaxialis lumborum, see Pabst 1990). Chevrons are unknown in early cetaceans (pakicetids, ambulocetids, and remingtonocetids), as well as in most "protocetids". The only exceptions are Maiacetus (Gingerich et al. 2009), with a well-preserved series, Rodhocetus, with the three first chevrons figured in lateral view by Gingerich et al. (1994), and Georgiacetus, with a single chevron mentioned by Hulbert (1998) and schematically figured by Hulbert et al. (1998: fig. 1). Among basilosaurids, chevrons are known in Basilosaurus (pers. observation), Cynthiacetus (this study), Dorudon (Uhen 2004), and Zygorhiza (Kellogg 1936).

The morphology of the chevrons varies significantly among cetaceans. In Recent neocetes and all extinct members of the clade for which these bones are known, the chevrons are markedly $\mathrm{V}$-shaped in anterior or posterior view, and their ventral aspect 
presents a generally large, ventrally projecting, and transversely compressed haemal process. In lateral view the chevrons of Neoceti are often anteroposteriorly longer at ventral apex as compared to the middle part of the bone, providing a characteristic axe shape. In Maiacetus the chevrons are distinctly V-shaped, with a large ventral blade-like haemal process strongly anteroposteriorly expanded at the apex; in this respect, they greatly resemble the condition observed in Recent cetaceans. According to the description of Hulbert (1998), the chevron of Georgiacetus was also probably V-shaped. Although nothing can be said about the chevrons of Rodhocetus, from the illustration of Gingerich et al. (1994: fig. 1a), which is a lateral view, a photo of the chevrons of the holotype kindly provided by P. Gingerich clearly shows that they are V-shaped. A V-shaped condition is also present in the protocetid Dhedacetus hayeni as can be observed on a photo of a chevron of the referred specimen IITR-SB 2625, kindly provided by $\mathrm{H}$ G Thewissen (Bajpai \& Thewissen 2015: fig. 8). Furthermore, chevrons of an undescribed "protocetid" from the Paracas Formation of Peru are also markedly V-shaped. The condition in basilosaurids differs significantly from that in other cetaceans: in the four taxa in which chevrons are known they are distinctly U-shaped; they bear no ventral crest-like haemal process and their ventral aspect is flat; in lateral view the posteroventral edge of the chevron is strongly expanded posteriorly; and the whole bone is markedly oblique and posteriorly projecting in lateral view. Such a contrasted morphology most likely corresponds to a specific function of the caudal region in basilosaurids. Although the morphofunctional study of the basilosaurid chevrons is beyond the scope of this study, we suspect that, this morphology, which is apparently unique among cetaceans, may represent an additional synapomorphy of the Basilosauridae. We did not include this character in the parsimony analysis below because we could not score it for any of the outgroup taxa (pakicetids, ambulocetids, and remingtonocetids) and for any of the extinct Neoceti included in our matrix. However, we think that this character deserves further functional and phylogenetic investigations, which may eventually reveal previously unknown functional implications for the caudal region of basilosaurids.

\section{RESULTS OF THE PARSIMONY ANALYSIS}

\section{Analysis with equally weighted characters}

First, an analysis with equally weighted characters was carried out, resulting in 60 most equi-parsimonious trees of 310 steps (consistency index, $\mathrm{CI}=0.529$; retention index, $\mathrm{RI}=0.802$ ) obtained using the TBR algorithm. The Bremer index of the nodes included in the Pelagiceti is given on the strict consensus tree presented in Figure 96.

\section{Topology of the strict consensus tree}

In line with previous studies (e.g. Uhen 1998; Uhen \& Gingerich 2001; Geisler et al. 2005; Thewissen \& Bajpai 2009), no protocetid synapomorphies were found and this group is regarded as paraphyletic. In our consensus tree, the five protocetid species form a pectinate pattern, in which the nodes represent intermediate evolutionary stages in the progressive acquisition of the Pelagiceti body plan. From the base, protocetids branch in the following order: Artiocetus clavis, Carolinacetus gingerichi, Rodhocetus kasrani, Protocetus atavus, and Georgiacetus vogtlensis. This study supports the basal position of $A$. clavis and the more crownward position of $G$. vogtlensis (Uhen 1998; Geisler et al. 2005). The main difference with previous results is the basal position of $C$. gingerichi, which is more crownward in Geisler et al. (2005), Thewissen \& Bajpai (2009), and Uhen et al. (2011). As stated above, G. vogtlensis is the most derived protocetid in our data set; it is thus regarded as the sister taxon of Pelagiceti, a result also obtained in previous analyses.

The Pelagiceti is divided into Basilosauridae (Fig. 96B) and Neoceti (Fig. 96N). This result is in agreement with Luo \& Gingerich (1999), Fitzgerald (2010), and Martínez-Cáceres \& Muizon (2011), while it departs from the results of Uhen (1998, 2004, 2005) and Uhen \& Gingerich (2001). Within the Basilosauridae, Saghacetus osiris is the sister taxon of all other basilosaurids. This study also supports the monophyly of the genus Basilosaurus, as well as the paraphyly of the dorudontines (Cynthiacetus and Dorudon). Another clade within the Basilosauridae groups together the genera Cynthiacetus, Dorudon, and Basilosaurus. This clade was also obtained by MartínezCáceres \& Muizon (2011). It is noteworthy that the relationships of three taxa, Zygorhiza, Ancalecetus and Chrysocetus are not resolved in the strict consensus. Furthermore, in 18 out of the 60 trees obtained, these three taxa have totally or partially unresolved relationships. This result may be the consequence of the incompleteness of the holotype and single specimen of Ancalecetus simonsi and Chrysocetus healyorum. Concerning $Z$ ygorhiza kochii, the significant polymorphism observed among the specimens referred to this species may in fact represent a taxonomic difference rather than individual variation.

The Neoceti are divided into two monophyletic Odontoceti (Fig. 960) and Mysticeti (Fig. 96M) clade. At its base, the Mysticeti are separated into two clades. The first one (referred here as the Clade M2) groups together the largest specimens (MUSM 1917, ChM PV5720, and Eomysticetus. whitmorei), with ChM PV5720 more closely related to E. whitmorei than to MUSM 1917, the "Media Luna Whale". The second clade at the base of the Mysticeti (referred here as the Clade M3) groups together the two mammalodontids (Janjucetus hunderi and Mammalodon colliveri) and the aetiocetids (Aetiocetus cotylalveus, $A$. weltoni, and Chonecetus goedertorum). This result agrees with Marx (2010) and Marx et al. (2015) and departs from previous analyses (Geisler \& Sanders 2003; Fitzgerald 2010; Deméré et al. 2008), where the Aetiocetidae are more closely related to the Chaeomysticeti (E. whitmorei) than to the Mammalodontidae. However, our analysis does not support the monophyly of the Mammalodontidae, which appear as paraphyletic since $M$. colliveri shares more characters with any aetiocetid than with J. hunderi. A paraphyletic Mammalodontidae was also obtained by Fitzgerald (2006) and Geisler et al. (2011), but departs from the results of Fitzgerald (2010) and Marx et al. (2015). Finally, the Aetiocetidae are monophyletic (Fig. 96A) and the genus Aetiocetus is paraphyletic, with $A$. cotylalveus more closely related to $C$. goedertorum than to A. weltoni; this last result differs from the monophyletic Aetiocetus in Marx et al. (2015). 


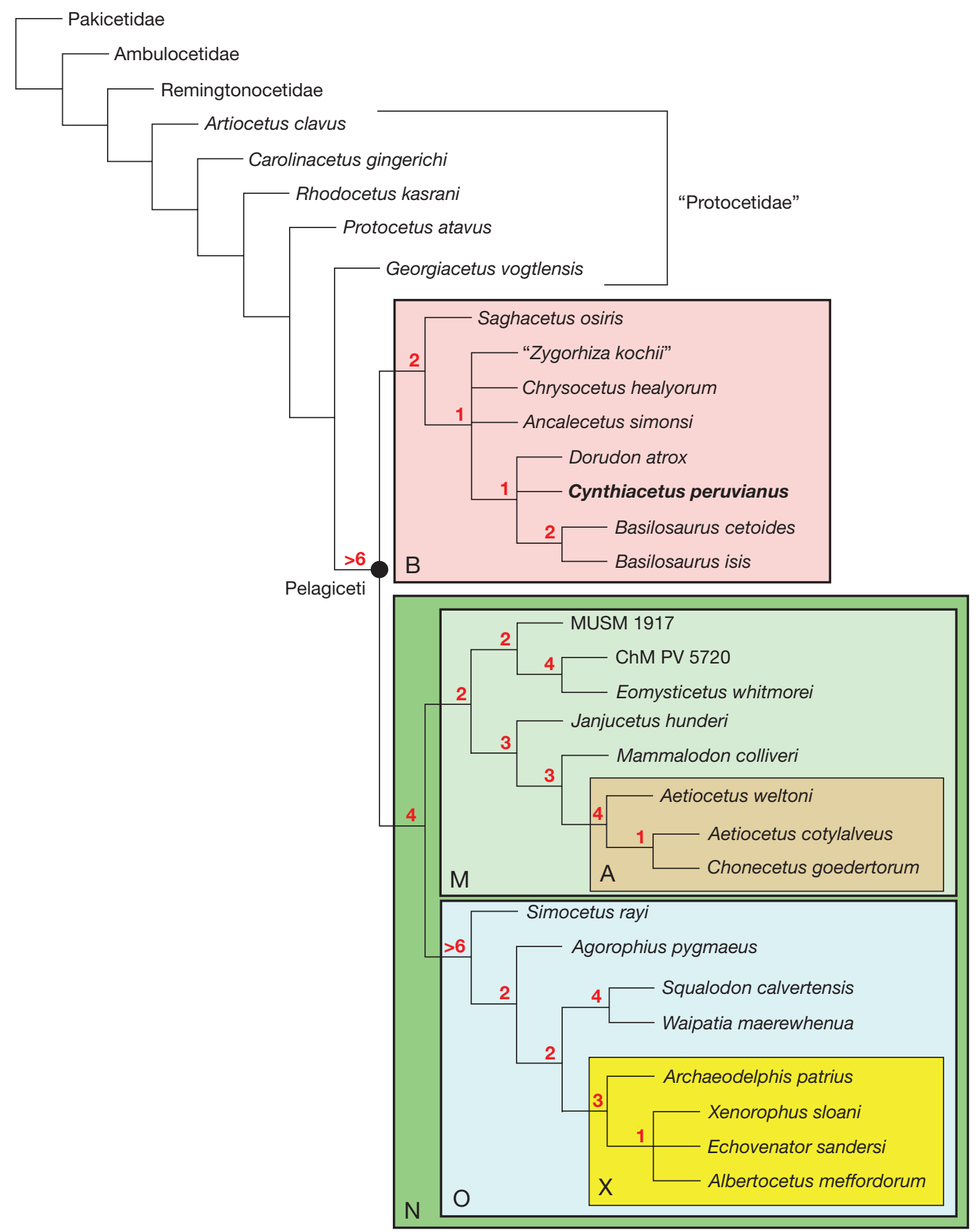

FIG. 96. - Strict consensus tree of the 60 equally most parsimonious trees obtained with equally weighted characters, using the TBR algorithm in Paup 4.0a150. Length of the tree $=310$ steps, $\mathrm{Cl}=0.517, \mathrm{RI}=0.796$. Coloured boxes designate previously named nodes. Bremer indices are provided for all Pelagiceti clades. The quotations marks for the taxon "Zygorhiza kochii" indicate the possibility that the specimens referred to this species may in fact represent different species. Abbreviations: A, Aetiocetidae; B, Basilosauridae; M, Mysticeti; N, Neoceti; O, Odontoceti; X, Xenorophidae.

Within the Odontoceti, Simocetus rayi is the sister taxon of the "Clade O2" which groups together all the other odontocetes. Within "Clade O2", Agorophius is the sister taxon of another unnamed clade (labeled here as "Clade O3"), which groups together the remaining odontocetes: Xenorophidae (Archaeodelphis patrius, Xenorophus sloani, Albertocetus meffordorum, and Echovenator sandersi), Squalodon calvertensis, and Waipatia maerewhenua. As a matter of fact, this study supports the monophyly of the Xenorophidae, agreeing with Geisler \& Sanders (2003), Uhen (2008b), Geisler et al. (2011), Geisler et al. (2014), and Churchill et al. (2016). Finally, S. calvertensis and W. maerewhenua are more closely related to each other than to any other odontocete coded in this analysis. 
Synapomorphies of the main clades

Georgiacetus vogtlensis + Pelagiceti. Our analysis points out two well-defined synapomorphies for this clade: 1) presence of small accessory denticles in mesial and/or distal margins in upper post-canine teeth (character 72, state 1); and 2) partial fusion of the three roots in upper molars (character 76, state 2).

Pelagiceti (Fig. 96). This clade is one of the strongest of this analysis with a Bremer index $>6$. It is supported by 19 unambiguous synapomorphies: 1) posterior edge of the external bony nares between the level of P1 and P2 (character 2, state 2$) ; 2$ ) posterior edge of the supraorbital process of the frontal posterolaterally oriented and forming an acute angle with the midline in the temporal region (character 36, state 2);3) pterygoid sinus fossa extends well anteriorly and forms a deep trough (character 39, state 3); 4) well-developed and transversely thin falcate process of the basioccipital (character 40 , state 1$)$;5) supraoccipital being nearly vertical and posteriorly facing (character 44 , state 1 ); 6) vertex almost dorsal to foramen magnum (character 48, state 1); 7) lateral extent of the exoccipital in ventral view, same as or less than mastoid process of the periotic (character 49, state 0 ); 8) moderate length of the anterior process of the periotic, between 59\% and $94 \%$ of the promontorial length (character 51 , state 1); 9) deep groove for the tensor tympani muscle clearly visible in ventral view (character 53, state 2); 10) external opening of the Eustachian tube at anterior end of the bulla (character 60 , state 0$)$; 11) median furrow of the tympanic bulla forming a broad embayment of the posterior edge of the bulla (character 61 , state 1 ); 12) posterior edge of the tympanic bulla does not contact the paroccipital process of the exoccipital (character 65 , state 0 ); 13) seven teeth on the maxilla (character 70 , state 1 ); 14) well developed accessory denticles in mesial and/or distal edge of the dental crown, in both upper and lower premolars and molars) (character 72, state 2); 15) loss of a protocone in upper dentition (character 75 , state 2$)$; 16) two anteroposteriorly aligned roots in upper molars (character 76, state 2); 17) greatly reduced size of the pelvis, being shorter than the first sacral vertebra (character 98 , state 1$) ; 18$ ) reduced obturator foramen, the diameter is smaller than that of the acetabulum (character 99, state 1); and 19) ventromedial expansion of the pubis well developed, ventromedial to the obturator foramen (character 100, state 2).

The clade is also defined by ten ambiguous synapomorphies. 1) two maxillary foramina (character 29 , state 1$)$; 2) presence of a low ridge on anterolateral side of pars cochlearis in ventral view (Character 56, state 1); 3) internal acoustic meatus forms an angle $<130^{\circ}$ with the long axis of the body of the periotic (Character 59, state 0); 4) elevated falciform process of the squamosal presenting an anteroposteriorly elongated surface for the contact with the outer lip of the tympanic bulla (character 63, state 1); 5) absence of lingual cingulum on post-canine (character 71, state 1 ); 6) singlerooted first upper premolar (character 73, state 0 ); 7) absence of the third upper molar (character 77, state 1);8) coronoid process of the dentary as wide as high (character 83 , state 0 ); 9) cervical vertebrae strongly compressed anteroposteriorly with length much shorter (>50\%) than height (character 87 , state 2); and 10) 14 thoracic vertebrae, (character 88 , state 1). Furthermore, a strongly reduced femur (character 101, state 2) may also be a synapomorphy of the Pelagiceti, but this character is only coded in three basilosaurids.

Basilosauridae (Fig. 96B). Four unambiguous synapomorphies can be listed for the family: 1) presence of well-defined embrasure pits between the upper incisors (character 5 , state $1)$;2) palate narrows at the level of or anterior to the last upper premolar (character 8, state 2);3) cleft on the mesial edge of the lower molars (character 78, state 1); and 4) Five first ribs with expanded distal end (character 93, state 1).

Moreover, two ambiguous synapomorphies of the clade are: 1) the highly elliptical and transverselly flattened anterior process of the periotic (character 55, state 0 ); and 2) the orientation of the posterior process of the periotic which forms an angle between 135 and $165^{\circ}$ with the long axis of the body (character 58 , state 1 ).

Clade B2 (all basilosaurids except Saghacetus osiris). Two unambiguous synapomorphies can be listed for this clade: 1) weak transverse constriction of the occipital shield at the level of the ventral edge of the supraoccipital: the occipital shield is almost as wide or wider than the intercondylar breadth (character 46, state 1); and 2) more than fifteen thoracic vertebrae (character 88 , state 2).

This clade is also supported by one ambiguous synapomorphy: spinous process of $\mathrm{T} 5$ to $\mathrm{T} 7$ is gently inclined to vertical, less than $15^{\circ}$ of inclination (character 89 , state 1 ).

Clade B3 (Basilosaurus + Cynthiacetus + Dorudon). Two unambiguous synapomorphies are given for this clade: 1) double-rooted first upper premolar (character 73, state 1); and 2) dorsally convex neural arch of the atlas (character 85 , state 1 ).

Two ambiguous synapomorphies of this clade are: 1 ) the posterior extension of the ventral exposition of the premaxilla, posterior to the level of P2 (character 3, state 2); and 2) nasal strongly tapers anteriorly, the lateral edge of the anterior half of the nasal is posterolaterally oriented (character 31 , state 2).

Neoceti (Fig. 96N). With the Pelagiceti, this very robust clade has one of the highest number of unambiguous synapomorphies. It has a Bremer index of 4 and 21 synapomorphies: 1) posterior edge of the external nares located between the level of P2 and M3 (character 2, state 3); 2) palate narrows posterior to the dental row (character 8 , state 0 ); 3 ) maxillo-premaxillary suture not crenulated (character 28 , state 1 ); 4) greatly exposed mesorostral groove in dorsal view, there is a gap between the premaxillae (character 30, state 2); 5) posterior end of the maxilla contacts the frontal medially (character 32 , state 1 ); 6) no sagittal crest (character 41 , state $0)$; 7) shorter interparietal suture, being anteroposteriorly shorter than the nasal at midline (character 42 , state 1); 8) nuchal crest are posterolaterally oriented in dorsal view (character 43, state 1); 9) supraoccipital anterodorsally inclined in lateral view and posterodorsally facing (character 
44 , sate 2$)$; 10) absence of a transverse constriction of the supraoccipital shield (character 46 , state 2 ); 11) short and thick dorsalmost portion of the nuchal crest, just lateral to the vertex (character 47, state 1); 12) vertex being well anterior to the foramen magnum (character 48 , state 2 ); 13 ) slender zygomatic process of the squamosal, which is missing its anterior expansion (character 50, state 1); 14) weak or no contact of the anterior process of the periotic with the falciform process of the squamosal (character 52, state 2); 15) absence or a clear fossa or groove for the tensor tympani muscle (character 53, state 3); 16) weak or no articulation of the medial edge of the tympanic bulla with the basioccipital crest (character 64, state 2); 17) mastoid portion of the posterior process of the periotic not exposed laterally (character 67, state 1); 18) P3 mesiodistally longer than P4 (character 74 , state 0$)$; 19) posterior edge of the mandibular symphysis is anterior to the level of the posterior edge of the lower first premolar (character 81 , state 0 ); 20) coronoid process being roughly triangular in lateral view (character 84 , state 2 ); and 21) distal humeral articular surface separated in two anteroposteriorly aligned surfaces that prevent the flexion/ extension of the forearm (character 94, state 1).

Ambiguous synapomorphies of the clade are: 1) absence of anterior process of the squamosal wedged between the posterior end of the nasals (character 9 , state 0 ); 2) transverse width of the skull across the orbit between $100 \%$ and $125 \%$ that of the base of the rostrum (character 10, state 1); 3) Alveoloar process of the maxilla wich does not extend posterior to the anterior edge of the orbit (character 17 , state 0$)$; 4) posterior extension of the maxillae, which separate the palatines on the midline of the palate (character 24 , state 1 ); 5) weak or no contact of the outer lip of the tympanic bulla with the falciform process of the squamosal (character 63, state 2); and 6) short mandibular symphysis, which forms less than $28 \%$ of the total length of the mandible (character 80 , state 0 ).

Mysticeti (Fig. 96M). It is suported by four unambiguous synapomorphies. These features are: 1) steep face on anterolateral edge of zygomatic (jugular) process of maxilla clearly separating it from rostral portion of maxilla (character 13, state 1$)$; 2) dorsoventral compression of the lateral margin of the maxilla at the base of the rostrum (character 15, state $1)$; 3) presence of the infraorbital plate (character 22, state 1); and 4) transversely thick and laterally expanded falcate process of the basioccipital (character 40, state 2).

Five ambiguous synapomorphies also support this clade: 1) Posterolateral process of the pars cochlearis, lateral to round window and medial to facial sulcus absent (character 57, state 0$)$; 2) internal acoustic meatus forms a tube that projects mediodorsally into the cranial cavity (character 59, state 1); 3) Distal end of the posterior process of the tympanic dorsoventrally thinner than or approximately as thick as the proximal end (character 66, state 0 ); 4) bullar facet on posterior process of periotic extends dorsally onto posteromedial face of posterior process (character 68, state 1 ); and 5) dorsally convex neural arch of the atlas (character 85 , state 1$)$.
Clade M2 [MUSM 1917 + Eomysticetus whitmorei + ChM PV5720]. This clade is diagnosed by three unambiguous synapomorphies: 1) well distinguished embrasure pit for upper incisors (character 5, state 1);2) dorsoventral compression of the median part of the rostrum, anterior to the external bony nares (character 16, state 1); and 3) triangular supraoccipital outline (character 45 , state 1 ).

Three ambiguous synapomorphies also support this clade: 1) narrow transverse width of the rostrum at base, less than $120 \%$ the intercondylar breadth (character 6 , state 1 ); 2) concave lateral margin of the rostral portion of the maxilla in dorsal view (character 24, state 0 ); and 3) more than eighteen thoracic vertebrae (character 88 , state 2 );

Clade M3 (Mammalodontidae + Aetiocetidae). Four unambiguous synapomorphies support this clade: 1) anteroposteriorly short skull (character 1, state 0); 2) large obit size (character 14 , state 2 ); 3) anteroposterior elongated anterior process of the periotic, being longer than the promontorium (character 51, state 2); and 4) straight mandibular ramus in dorsal view (character 82, state 1).

Two ambiguous synapomorphies also support this clade: 1) moderate to small vertebrarterial foramen of the axis (character 86 , state 1); and 2) less than fourteen thoracic vertebrae (character 88 , state 0$)$.

Clade M4 (Mammalodon colliveri + Aetiocetidae). Supported by three unambiguous synapomorphies: 1) dorsoventral compression of the anterior half of the maxilla (character 7 , state 1 ); 2) maxillo-premaxillary suture located within a deep groove (character 28, state 2); and 3) small accessory denticles in both mesial and/or distal margin of the postcanine teeth (character 72, state 1).

Two ambiguous synapomorphies also support this clade: 1) posterior process of periotic forms an angle between 135 and $165^{\circ}$ with the long axis of the body (character 58, state $1)$; and 2) distal end of the posterior process of the tympanic dorsoventrally thicker than proximal end (character 66, state 1).

Aetiocetidae (Fig. 96A). This family has the largest number of unambiguous synapomorphies (8) within the Mysticeti: 1) posterior end of the ascending process of the premaxilla over the supraorbital process of the frontal (character 4, state $3)$; 2) dorsoventral compression of the median portion of the rostrum, anterior to the external bony nares (character 16, state 1); 3) lacrimal extending medially and separating the lateral corner of the ascending process of the maxilla from the frontal (character 19, state 1); 4) posterior end of the maxilla meets the premaxilla medially (character 32 , state 2 ); 5) teeth posterior to $P 1$ have a small crown and are separated by large diastemata (character 69, state 1); 6) seven teeth in the maxilla (character 70 , state 1 ); 7) no third upper molar (character 77 , state 0 ); and 8) linguiform coronoid process, posterolaterally oriented and anteroposteriorly compressed (character 84 , state 0 ).

One ambiguous synapomorphy also supports this clade: mandibular symphysis fully separated with ligamentous connection (character 79, state 2). 
Odontoceti (Fig. 960). It is also one of the best-supported clades of this analysis (Bremer index $>6$ ). It is supported by 10 unambiguous synapomorphies, which are: 1 ) posterior end of the ascending process of premaxilla at the level of the orbit (character 4, state 3);2) ascending process of the maxilla extends over the supraorbital process of the frontal (character 11, state 1);3) presence of a distinct antorbital notch at the base of the rostrum (character 12, state 1); 4) absence of the lacrimal canal (character 18, state 1); 5) presence of premaxillary sac fossae (character 25 , state $1)$; 6) presence of the premaxillary foramina (character 27 , state 1 ); 7) more than two maxillary foramina on the dorsal surface of the maxilla (character 29, state 2); 8) frontal lower or at the same level than the nasal (character 35, state 1); 9) posterior edge of the well-developed supraorbital process of the frontal anterolaterally oriented (character 36, state 3 ); and 10) high ridge on the anterolateral side of pars cochlearis (character 56, state 2).

Four ambiguous synapomorphies also support this clade: 1) posterior end of the ventral exposure of premaxilla posterior to the level of P2 (character 3, state 2); 2) straight lateral margin of the rostral portion of the maxilla (character 21, state 1); 3) dorsal expansion of the alisphenoid in lateral view broadly overlapped by the parietal so that only a narrow stripe is visible on the ventral edge of the temporal fossa (character 37 , state 1); and 4) long posterolateral process of the pars cochlearis, lateral to the round window and medial to the facial sulcus (character 57 , state 2).

Clade O2 (Agorophius + Waipatia maerewhenua + Squalodon calvertensis + Xenorophidae). Three unambiguous synapomorphies support this clade: 1) shallow squamosal fossa (character 38 , state 1);2) small accessory denticles on both mesial and distal margins of the posterior upper and lower teeth (character 72 , state 1 ); and 3) presence of a third upper molar (character 77 , state 0$)$.

Five ambiguous synapomorphies also support this clade: 1) posterior end of the ascending process of the premaxilla posterior to the level of the orbit (character 4, state 4); 2) anterior process of periotic longer than promontorial length (character 51, state 2);3) nine to ten teeth on maxilla (character 70 , state 3 ); 4) lingual cingulum on postcanine teeth present (character 71, state 0 ); 5) long mandibular symphysis, between $33 \%$ and $40 \%$ the mandibular length (character 80 , state 1 ).

Clade O3 (Waipatia maerewhenua + Squalodon calvertensis + Xenorophidae). Only two unambiguous synapomorphies support this clade: 1) posterior margin of the external bony nares posterior to the dental row (character 2, state 4) and 2) wide supraorbital process of the frontal, width $>160 \%$ of the width of the base of the rostrum (character 10, state 3).

Two ambiguous synapomorphies can be also listed for this clade: 1) maxillae extend posteriorly and separate the palatines at midline (character 23, state 1);2) lateral margin of the maxilla laterally concave at the mid-length of the rostrum (character 24 , state 0$)$.
Clade O4 (Waipatia maerewhenua + Squalodon calvertensis). Although this remains debated, both species have been referred to the Platanistoidea; they are thought to be the closest relatives to Recent odontocetes, in our dataset. Nevertheless, the matrix was not created in order to test the validity of the Platanistoidea and/or Delphinida. Therefore, the synapomorphies of Clade O4 do not necessarily correspond to the platanistoid clade. The six unambiguous synapomorphies of Clade $\mathrm{O} 4$ are: 1) frontal higher than nasal (character 35 , state 0 ); 2 ) horseshoe shaped nuchal crest in dorsal view (character 43 , state 0 ); 3) no posterolateral process of the periotic (character 57 , state 0 ); 4) more than 10 teeth on the maxilla (character 70 , state 4); 5) posterior end of the mandibular symphysis between the anterior end of $\mathrm{p} 3$ and the posterior end of $\mathrm{p} 4$ (character 81, state 3); and 6) coronoid process of the dentary wider than high (character 83 , state 1 ).

Three ambiguous synapomorphies also support this clade: 1) cross-section of anterior process of periotic at mid-length elliptical and transversely flattened, transverse diameter is $<$ to $36 \%$ of dorsoventral diameter (character 55 , state 0 ); 2 ) medial furrow of tympanic bulla bisects bulla into a smaller posteromedial and a larger posterolateral portion (character 61, state 2);3) distal end of the posterior process of the tympanic bulla thinner or approximately as thick as proximal end (character 66 , state 0$)$.

Xenorophidae (Fig. 96X). The family is supported by three unambiguous synapomorphies: 1) enlarged lacrimal, forming a massive anterodorsal process (character 20, state 1);2) medial edge of the maxilla forms a crest-like process anterior to the orbit (character 26, state 1); and 3) elongate lateral tuberosity of the periotic (character 54 , state 2 ).

Six ambiguous synapomorphies also support this clade: 1) posterior end of ascending process of premaxilla over the supraorbital process (character 4, state 3); 2) dorsolateral edge of maxillary foramen (internal opening of the infraorbital canal) formed by lacrimal and/or jugal (character 21, state 2);3) mesorostral groove partially exposed on dorsal view, the premaxillae roof the the mesorostral groove but do not contact at midline (character 30 , state 1$)$; 4) posterior end of maxilla meets the premaxilla medially (character 32, state 2);5) premaxillae adjacent to nasal opening are pachyostotic in direction perpendicular to face, and pachyosteosclerotic but nasals and premaxillae equally project dorsall and anteriorly (character 34, state 1); and 6) mandibular symphysis very long and forms $48 \%$ of the mandible length (character 80 , state 2 ).

Clade X2 (Xenorophus sloani + Echovenator sandersi $+A l$ bertocetus meffordorum). Two unambiguous synapomorphies support this clade: 1) lacrimal extending over the supraorbital process of the frontal (character 20, state 2); and 2) lateral expansion of the premaxilla under the maxilla (character 33 , state 1).

One ambiguous synapomorphy also supports this clade: deep squamosal fossa, depth is equal to or more than the distance from the dorsal edge of the zygoma to the point above deepest part of squamosal fossa (character 38 , state 0 ). 


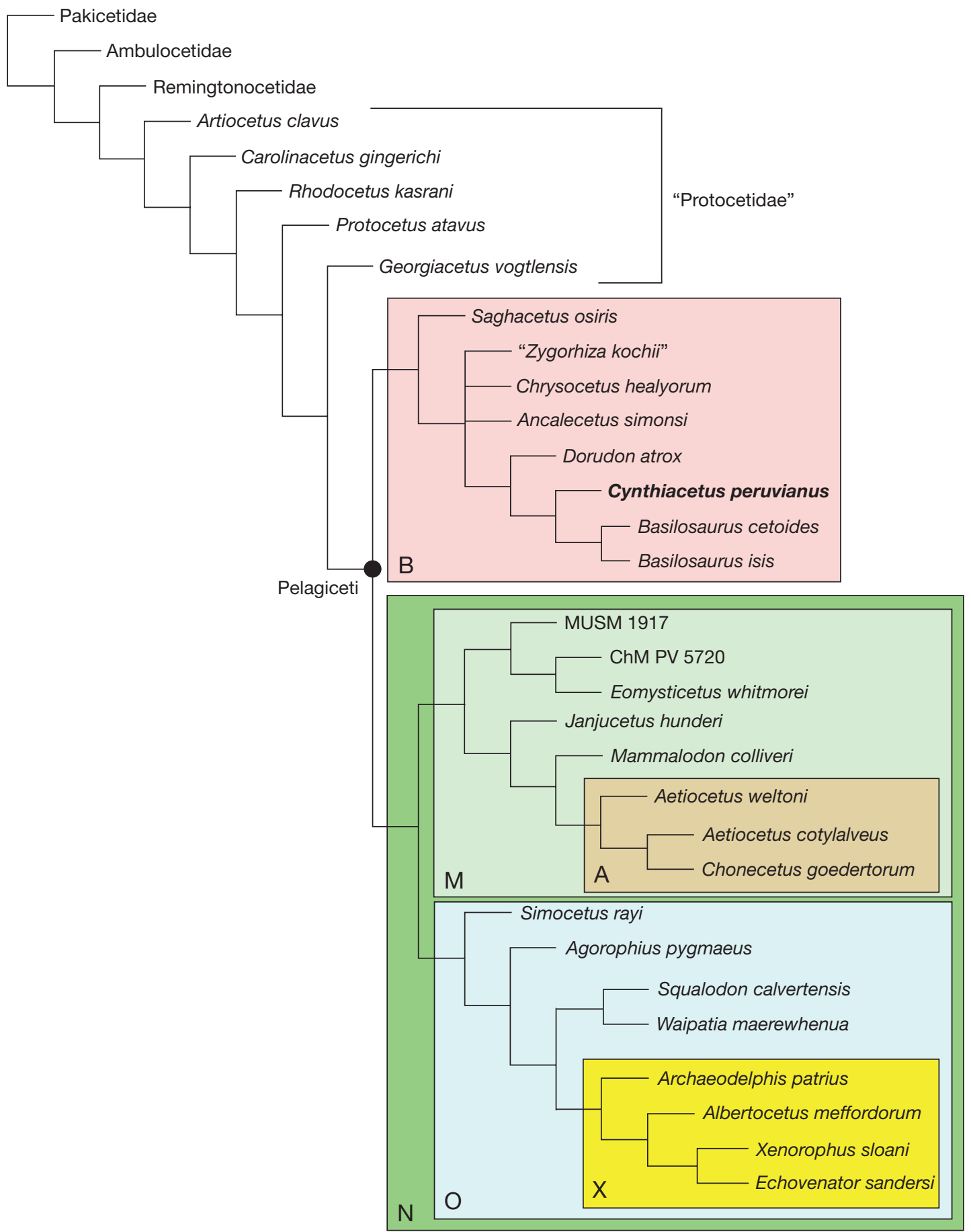

FIG. 97. - Strict consensus tree of the 5 equally most parsimonious trees obtained with homoplastic characters down-weighted following the method of Goloboff (1993), with $\mathrm{k}=3$. Note the better resolution for: 1) the clade including Dorudon atrox, Cynthiacetus peruvianus, and Basilosaurus spp.; and 2) the relationships within Xenorophidae. The quotations marks for the taxon "Zygorhiza kochii" indicate the possibility that the specimens referred to this species may in fact represent different species. A, Aetiocetidae; B, Basilosauridae; M, Mysticeti; N, Neoceti; O, Odontoceti; X, Xenorophidae.

\section{Analysis with down weighted homoplastic characters}

A second analysis was performed with down-weighted homoplastic characters following the method of Goloboff(1993), with the value of 3 for the constant $\mathrm{k}$. This analysis resulted in five most equiparsimonious trees. The consensus tree is shown in (Fig. 97). This tree is slightly better resolved than the tree with equally weighted characters. First, within the basilosaurid clade B3, including Basilo- saurus cetoides, B. isis, Cynthiacetus peruvianus, and Dorudon atrox, $D$. atrox is the first to branch off, followed by C. peruvianus, the latter being sister-group to Basilosaurus spp. Noteworthily, a sister-group relationship between the other species of Cynthiacetus, C. maxwelli, and Basilosaurus spp. was obtained in a previous analysis (Uhen 2004). Second, among xenorophids, Albertocetus meffordorum is sister-group to Echovenator sandersi + Xenorophus sloani. 
A

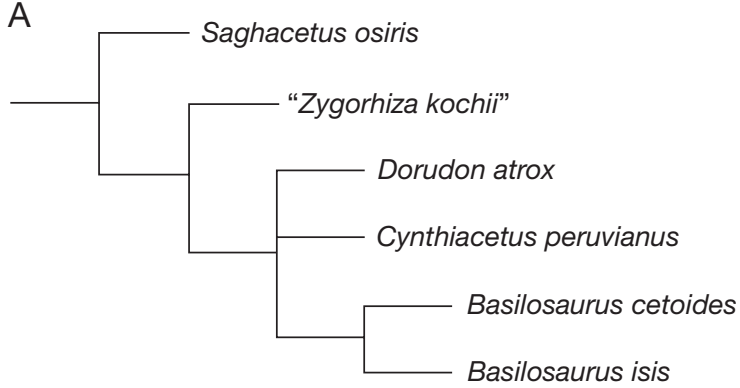

B

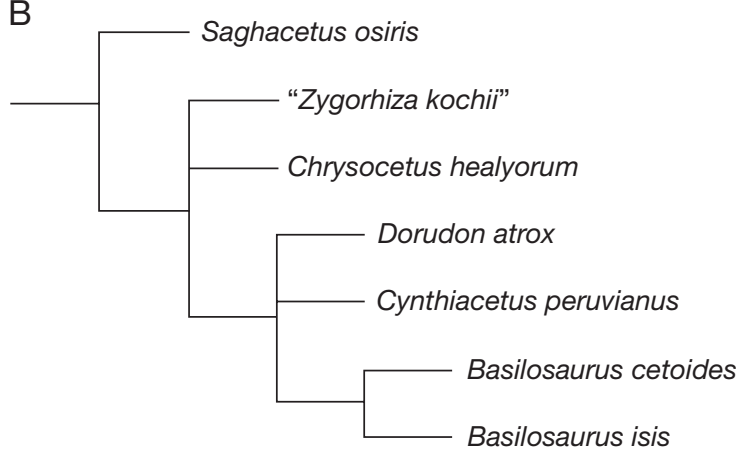

C

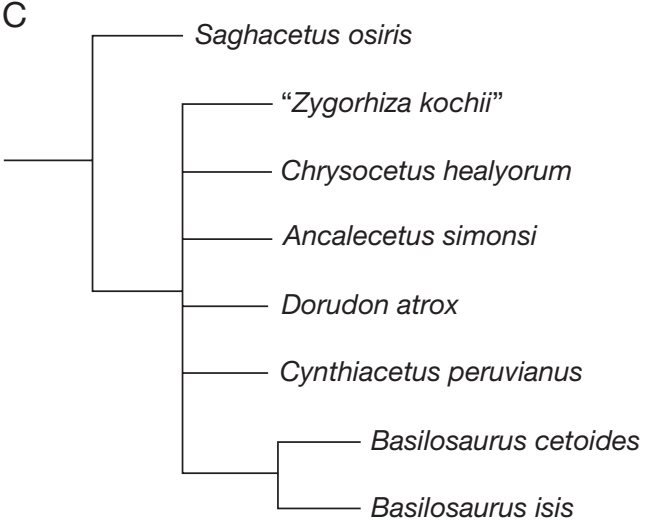

FIG. 98. - Strict consensus cladograms of the Basilosauridae obtained when A, both Chrysocetus healyorum and Ancalecetus simonsi are removed from the matrix; B, A. simonsi alone is removed from the matrix; $\mathbf{C}, \mathrm{Ch}$. healyorum alone is removed from the matrix. The quotations marks for the taxon "Zygorhiza kochii" indicate the possibility that the specimens referred to this species may in fact represent different species.

\section{DisCUSSION}

\section{Basilosauridae}

Two hypotheses concerning the status of the Basilosauridae as a clade were tested in this analysis. The first hypothesis suggests that the Basilosauridae are paraphyletic, as supported by the analysis of Uhen (1998). The matrix of the latter work was improved in Uhen \& Gingerich (2001) and Uhen (2005), and included seven basilosaurid taxa. In all these studies the basilosaurids form a paraphyletic group where either Saghacetus osiris (Uhen 1998) or Chrysocetus healyorum (Uhen \& Gingerich 2001; Uhen 2004, 2005) is the sister taxon of the Neoceti. However, these analyses were not strictly cladistic since the stratigraphical position of each taxon participated in the resolution of the affinities within the Pelagiceti clade. The second hypothesis champions the monophyly of the Basilosauridae and was supported by the cladistic analyses of Luo \& Gingerich (1999), Fitzgerald (2010), and Martínez-Cáceres \& Muizon (2011). Nevertheless, only one of these three analyses included more than three basilosaurid taxa (MartínezCáceres \& Muizon 2011).

Our dataset supports the monophyletic hypothesis. However, it is noteworthy that, if our analyses resulted in monophyletic Basilosauridae, they do not support the monophyly of the Dorudontinae.

As a matter of fact, some ambiguous synapomorphies of Clade B2 (all basilosaurids except Saghacetus) may actually be synapomorphies of all the Basilosauridae (clade B), since they were not coded in Saghacetus osiris (no direct observation of the periotic of Sa. osiris could be performed during this study). These characters are: deep tensor tympani exposed in ventral view (ch. 44), elliptical cross-section of the anterior process (ch.55), and absence of a mediodorsal tube for the internal acoustic meatus (ch. 59). Sa. osiris appears to be the earliest basilosaurid to branch off. Indeed, it shares various plesiomorphic features with the protocetids (transverse constriction of the supraoccipital, roughly rectangular nasal without posterior separation at midline and extreme narrowing anteriorly, single maxillary foramen, and neural spines in T5-T8 posteriorly inclined). This position of Sa. osiris differs strongly from that obtained by Uhen (1998), where it appears as the sister taxon of the Neoceti. The more crownward position of Sa. osiris in Uhen's stratocladistic analysis may be explained in part by the fact that $\mathrm{Sa}$. osiris is younger in age than Dorudon and Basilosaurus. Based on its stratigraphical position, Sa. osiris was thought to be more derived than other basilosaurids. Indeed, following, the descriptions of several basilosaurid skulls (Dart 1923), it was proposed that the extremely narrow supraoccipital, elongated snout, and less laterally expanded braincase observed in Sa . osiris were derived conditions relative to the wider occipital, shorter snout, and laterally expanded braincase of Dorudon atrox (Andrews 1923). In fact, when compared with the other taxa considered in this study, the differences in the rostrum length and braincase expansion are not significant enough to be coded differently in $D$. atrox and $S a$. osiris. Finally, the body size of Sa. osiris is somewhat similar to that of most protocetids (except the larger Georgiacetus vogtlenis) and smaller than that of all other basilosaurids (except Supayacetus muizoni and Ocucajea picklingi).

As stated above, the phylogenetic affinities between Ancalecetus, Chrysocetus, Zygorhiza, and Clade B3 (Basilosaurus, Cynthiacetus, Dorudon) are not resolved in our analyses. This result is likely related to the fact that both Chrysocetus healyorum and Ancalecetus simonsi are know from relatively incomplete skeletons and coded as [?] for several characters in our matrix. Ch. healyorum was proposed as the sister taxon of the Neoceti because it presents an accelerated eruption of permanent teeth (Uhen \& Gingerich 2001). The early dental eruption observed in Ch. healyorum was interpreted as a transitional condition between the ancestral 

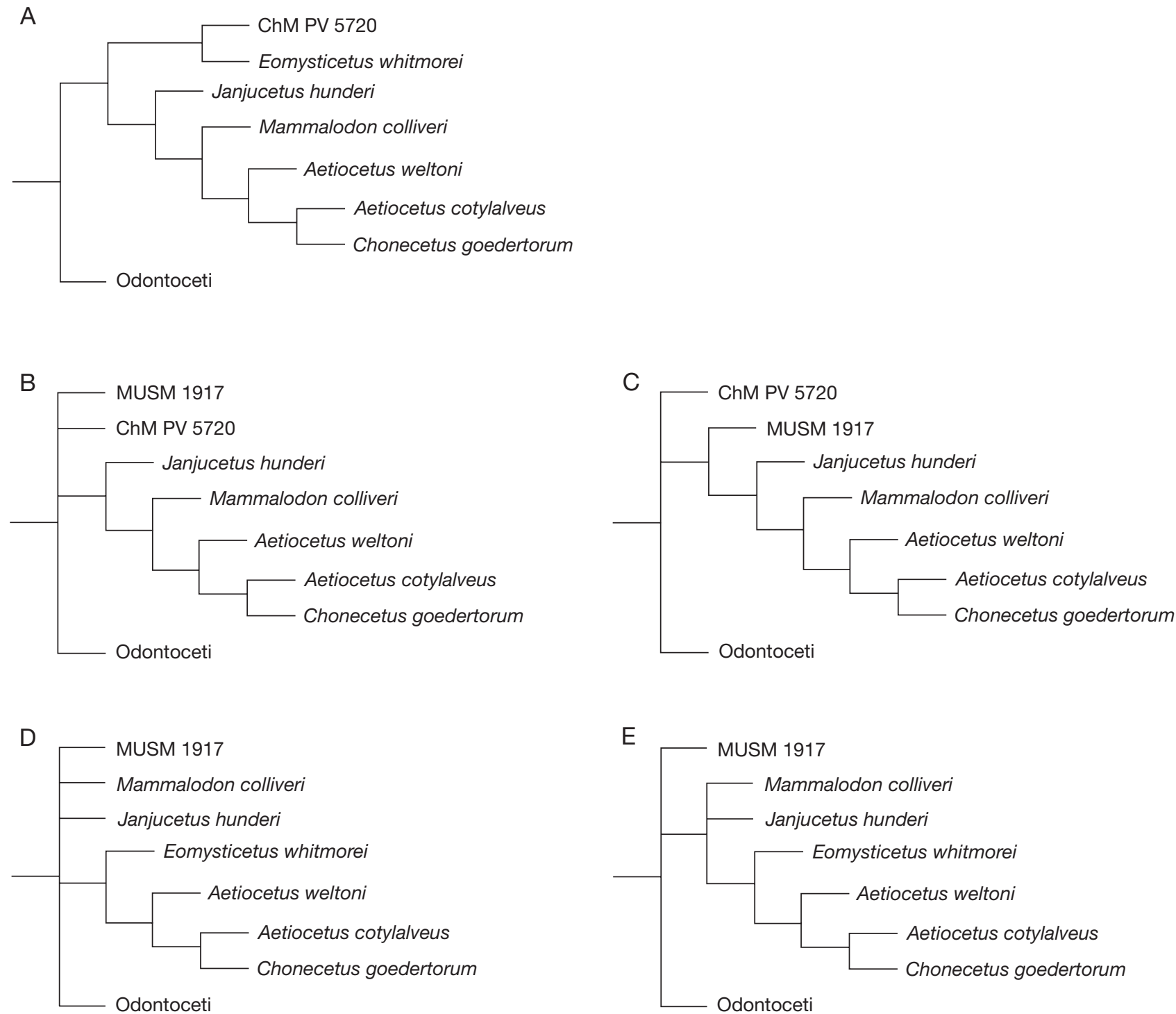

FIG. 99. - Concensus cladograms of the Neoceti obtained when: A, MUSM 1917 is removed from the matrix; B, Eomysticetus whitmorei is removed from the matrix (strict consensus); C, E. whitmorei is removed from the matrix (Adams consensus); $\mathbf{D}$, ChM PV 5720 is removed from the matrix (strict consensus); $\mathbf{E}$, ChM PV 5720 is removed from the matrix (Adams consensus).

basilosaurid diphyodont dentition and the derived neocete monophyodont dentition (Uhen \& Gingerich 2001). Since the dental eruption sequence is unknown for all the extinct neocetes from our taxonomic sampling, we decided not to include this character in our analysis.

Ancalecetus simonsi is only known from a single partly preserved skeleton. This taxon possesses a unique architecture of the forelimb, which is hypertrophied (autapomorphic condition within the Basilosauridae) and presents a fused elbow joint, being thus unable to realize flexion/extension movements of the forearm. A functionally analogous condition is observed in neocetes, where the elbow joint is ankylosed due to a transverse ridge marking the distal articular surface of the humerus. Although it is impossible to characterize the elbow articulation in $A$. simonsi, it is likely that the loss of movement in this taxon is convergent with the condition of neocetes. As for Chrysocetus healyo- rum, we decided to include $A$. simonsi in our analyses in order to test the presence of apomorphic features possibly shared by $A$. simonsi and Neoceti.

In order to test the impact of Ancalecetus simonsi and Chrysocetus healyorum on the topology of the consensus tree obtained in Fig 96 we successively removed them from the analysis with equally weighted characters. When both Ancalecetus simonsi and Chrysocetus healyorum are removed from the analysis, we obtain nine most parsimonious tree, where the Basilosauridae are still monophyletic (Fig. 98A). Similarly, when $A$. simonsi is removed alone the Basilosauridae remain monophyletic (Fig. 98B). However, if the Basilosauridae remain monophyletic when Chrysocetus is removed alone, the clade DorudonCynthiacetus-Basilosaurus (B3) is lost (Fig. 98C). Therefore, the monophyly of this later clade depends upon the inclusion of Ch. healyorum. It is therefore clear that, in spite of their relatively fragmentary states, the holotypes of $A$. simons $i$ and 
C. healyorum must be retained in the matrix. This clade B3 was also obtained by Martínez-Cáceres \& Muizon (2011) and in the context of the paraphyletic hypothesis of Basilosauridae, may be recognized as Basilosauridae sensu stricto. Furthermore, in the context of the monophyly of the family resulting form our first heuristic analysis and given the topology obtained in the analysis with downweighted homoplastic characters, it appears that the subfamiliy Dorudontinae is paraphyletic. In contrast, a subfamily Basilosaurinae could include the genera Cynthiacetus and Basilosaurus. However, because of the unique extreme elongation of the thoracic, lumbar, and caudal vertebrae in the latter, we suggest to restrict the subfamily Basilosaurinae to the single genus Basilosaurus.

\section{Mysticeti}

In our analysis, the clade Mysticeti, which is supported by a Bremer index of 2, appears to be moderately robust. Our analysis supports the mysticete affinities of the "Media Luna Whale" MUSM 1917. Besides, this taxon appears to be the sister group of the clade including ChM PV5720 and Eomysticetus whitmorei. The three taxa form the Clade M2 as defined above: MUSM 1917 + Eomysticetus whitmorei + ChM PV5720. As a matter of fact, ChM PV5720 and E. whitmorei possess several derived characters that are shared with the aetiocetids (massive and transversely expanded falcate process, triangular supraoccipital, massive and proportionally short zygomatic process, ascending process of the premaxilla extending well posterior on the supraorbital process, and wellexposed mesorostral groove). Moreover, ChM PV5720 and E. whitmorei share a high and well-developed sagittal crest, anteriorly pointed premaxilla (not coded in our analysis), and an elongated rostrum (not coded in our analysis).

Two of three synapomorphies of Clade M2 (MUSM 1917 + ChM PV 5720 + Eomysticetus whitmorei) are also observed in Aetiocetidae (characters 16 and 45) and were regarded as synapomorphies of a Chaeomysticeti + Aetiocetidae clade (Deméré et al. 2008; Geisler et al. 2011). The third synapomorphy of Clade M2 is present in the Basilosauridae and considered here as a reversal (ch. 5). Therefore, in order to test the strength of Clade M2, we compared the different phylogenetic relationships obtained when one of the three taxa included in the clade is removed.

We first removed MUSM 1917 from the matrix. The result did not differ from that of Figure 96.60 most equi-parsimonious trees were obtained and the strict consensus of these trees presents a clade formed by Eomysticetus whitmorei and ChM PV5720, which is the sister taxon of all the other mysticetes (Fig, 99 A Clade M3). The mysticeti are monophyletic and are still moderately supported by a Bremer index of 2 .

In contrast, the removal of Eomysticetus whitmorei strongly affects the phylogenetic relationships within the Mysticeti and, in the strict consensus of 120 most equi-parsimonious trees, not only the clade M2 is lost but also the monophyly of the Mysticeti falls (Fig. 99 B). This result is not surprising given the relatively low Bremer indices (2) obtained in the first analysis for this clade M2 as well as for the Mysticeti (Fig. 96). The monophyletic Neoceti are composed of four branches: 1) ChM PV 5720; 2) MUSM 1917;3) clade formed by $J$. hunderi $+M$. colliveri + Aetiocetidae; and 4) Odontoceti. The remaining parts of the tree are not affected. The Adams consensus of this analysis also resulted in the loss of the Mysticeti monophyly, but in this case the monophyletic Neoceti are composed of three branches: 1) ChM PV 5720; 2) clade formed by MUSM $1917+J$. hunderi $+M$. colliveri + Aetiocetidae; and 3) Odontoceti. Therefore, in the Adams consensus, only the inclusion of ChM PV 5720 within the Mysticeti is unresolved.

Similarly to the results obtained with the exclusion of Eomysticetus whitmorei, the exclusion of ChM PV5720 also affects significantly the topology of the consensus tree of the 300 most equi-parsimonious trees obtained (Fig. 99 C). The monophyly of the Mysticeti is similarly lost; the monophyletic Neoceti are composed of five branches whose relationships are unresolved: 1) MUSM1917; 2) Mammalodon colliveri; 3) Janjucetus hunderi; 4) a clade composed of E. whitmorei + Aetiocetidae; and 5) Odontoceti. Therefore, the exclusion of ChMPV 5720 resulted in an attraction of E. whitmorei by the Aetiocetidae This result is in agreement with Geisler et al. (2011) and Deméré et al. (2008). The Adams consensus resulted in the unresolved inclusion of MUSM 1917 among the Neoceti and in the monophyly of a clade composed of: 1) M. colliveri; 2) J. hunderi; and 3) E. whitmorei +Aetiocetidae.

Therefore, the two last analyses (exclusion of E. whitmorei and exclusion of ChM PV 5720) reveal that the monophyly of the Mysticeti and the position of MUSM 1917 within the Mysticeti depend upon the inclusion of both E. whitmorei and ChM PV5720.

Noteworthily, our analysis did not include Llanocetus denticrenatus Mitchell, 1989, another only partly described late Eocene species of toothed mysticete (Mitchell 1989). This taxon is considered either as one of the most basal mysticetes (Fitzgerald 2010), or as the closest relative to the toothless mysticetes (Steeman 2007). If $L$. denticrenatus is closely related to the Eomysticetidae (Steeman 2007), it is likely that both ChM PV5720 and MUSM 1917 could also be related to this family. In such a context, the inclusion of $L$. dentricrenatus in future analyses may potentially increase the number of mysticete synapomorphies observed in MUSM 1917. Unfortunately, most of the holotype of $L$. denticrenatus is undescribed and was not available during this study.

\section{Odontoceti and Xenorophidae}

In contrast with the Basilosauridae and the Mysticeti, the Odontoceti are supported by a high Bremer index (4). The phylogenetic relationships within the Odontoceti are independent of the inclusion/exclusion of any taxa considered in this study. As compared with some archaic, toothed mysticetes retaining a basilosaurid-like morphology, all the odontocetes in our taxonomic sampling are already derived and present all the synapomorphies of the clade. Our analyses differ essentially from those of Uhen (2008b), Geisler et al. (2011, 2014), and Churchill et al. (2016) in the more crownward position of the Xenorophidae, which are to be the sister taxon of the clade formed by Squalodon calvertensis and Waipatia maerewhenua (Clade O3). This position of xenorophids is most likely related to the narrowness of the rostrum 


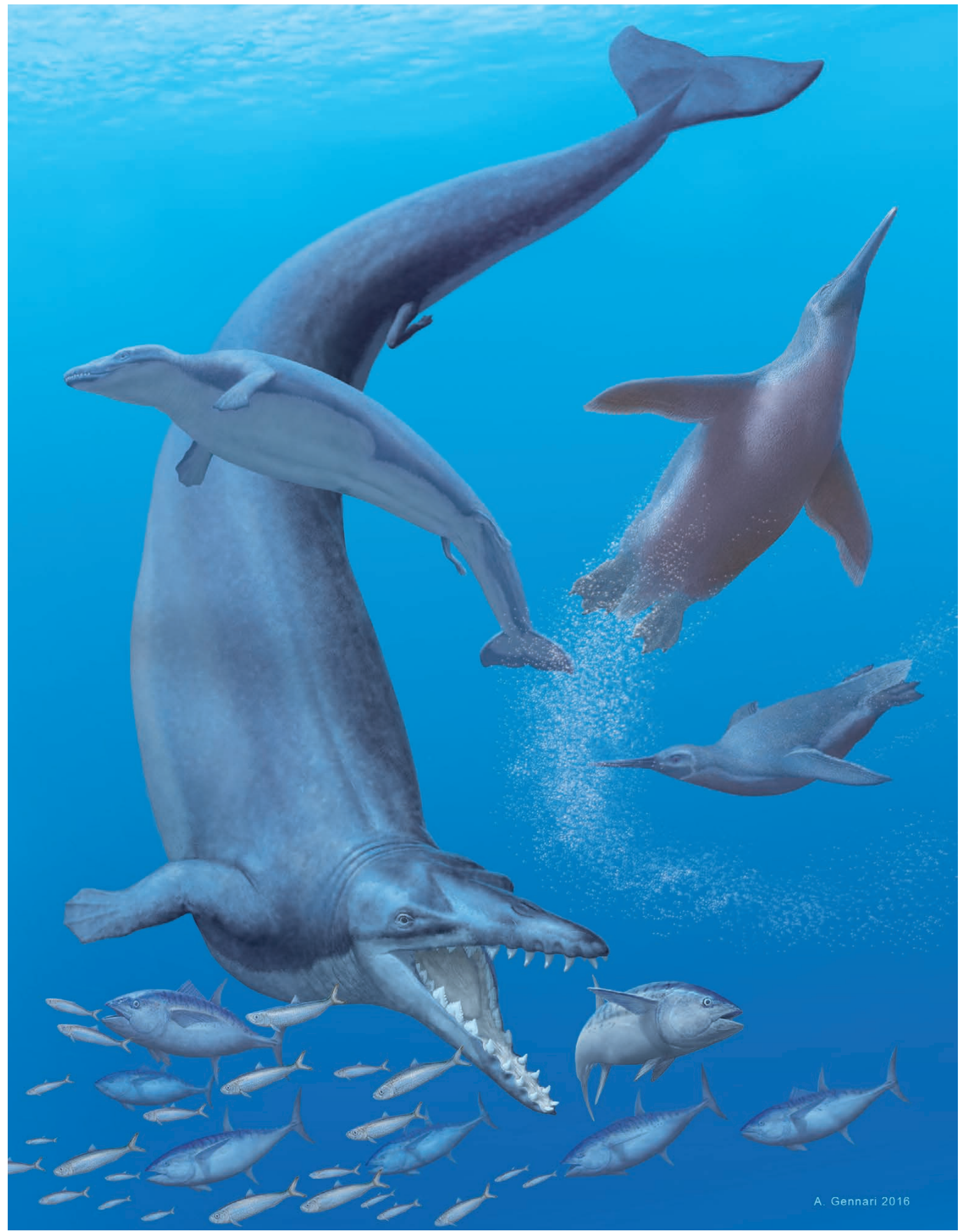

FIG. 100. - Artist reconstruction of Cynthiacetus peruvianus with some potential preys: large scombrid teleost fishes (aff. Scombramphodon), as found in the thoracic region of the holotype, and the contemporaneous giant penguin Inkayacu paracasensis. Length of the adult specimen of C. peruvianus, c. 9 m. Painting by Alberto Gennari. 
and the markedly posterior position of the external bony nares, shared with the two latter taxa. Moreover, taxa in Clade O3 differ from Agorophius and Simocetus in having a straighter lateral margin of the maxilla, which is regarded as a synapomorphic condition of the Neoceti. The addition of a higher number of crown odontocetes would most likely impact the relationships of stem members of the clade, as demonstrated in Geisler et al. (2014) and Churchill et al. (2016).

Among the monophyletic Xenorophidae, Archaeodelphis patrius appears as the earliest branching lineage in the tree. This result agrees with other cladistic analyses (Geisler \& Sanders 2003; Uhen 2008b; Geisler et al. 2011, 2014; Churchill et al. 2016). Furthermore, in the analysis with down-weighted homoplastic characters Albertocetus meffordorum is sister-group to Echovenator sandersi + Xenorophus sloani, a result in agreement with the topology obtained with a broader taxonomic sample by Churchill et al. (2016).

\section{CONCLUSIONS}

The study presented here of the remarkably complete holotype skeleton of Cynthiacetus peruvianus, from the late Eocene of Peru, represents the second thorough description of a basilosaurid taxon, following that of the smaller species Dorudon atrox by Uhen (2004), based on a large series of specimens. Because of the exceptional completeness and good preservation of the specimen described here, several muscles, vessels, and nerves could be reconstructed. These reconstruction of the soft anatomy suggest that the biology and ecology of $C$. peruvianus was probably similar to that previously inferred for $D$. atrox (Uhen 2004). Like all basilosaurids, C. peruvianus was a pelagic cetacean, which, considering the high reduction of its hind limbs, could not return to land any more. With its long rostrum bearing sharp incisors and canines it is likely to have been a single prey-feeding raptorial predator. During preparation of the holotype, the undigested head of a large scombrid teleost fish (c. $1.5 \mathrm{~m}$ long) was discovered in the anterior part of the thoracic region, suggesting that it may have been preyed upon by our basilosaurid. The fact that bones are perfectly preserved (not corroded) and that some of them are still articulated suggests that the head remained caught in the throat of the predator in the process of swallowing, which may have caused its death by suffocation. This fish specimen presents similarities with the genus Scombramphodon (N. Bonde, personal communication to $\mathrm{CM}$ ), a relatively large scombrid (c. 50 to $100 \mathrm{~cm}$ ) that could have represented part of the diet of $C$. peruvianus. Therefore, a reconstruction of $C$. peruvianus preying upon such fish is proposed in Figure 100. Additionally, the giant penguin Inkayacu paracasensis originates also from the Otuma Formation (Clarke et al. 2010); with a body size up to $1.5 \mathrm{~m}$, this large marine bird may have constituted another potential prey for C. peruvianus. Consequently, some individuals of $I$. paracasensis are also represented in Figure 100.

The cranial morphology of $C$. peruvianus indicates closer affinities with Dorudon and Basilosaurus than with the other basilosaurid genera. Our comparison has pointed out the fact that Saghacetus osiris may represent the basal morphotype of the Basilosauridae, since it shares the highest number of plesiomorphic features with earlier archaeocetes (the paraphyletic Protocetidae), whereas $C$. peruvianus presents a much more derived morphology, where the dental cingulum is reduced to absent, the frontal presents a large anterior process at the supraorbital shield, the occipital is proportionally wider, and the thoracic region is much more elongated than in Saghacetus.

Furthermore, with its subcomplete skeleton, the holotype of Cynthiacetus peruvianus constitutes a major asset for testing the phylogenetic relationships among basilosaurids and, because the latter are the most crownward archaeocetes, for investigating the archaeocete-neocete transition and thus the origin of all Recent cetaceans. Therefore, besides the thorough anatomical description of a large basilosaurid, a major goal of this study was to test hypotheses concerning the phylogenetic affinities of C. peruvianus and of several derived archaeocetes and early neocetes in the context of the archaeocete-neocete transition. A matrix of 101 characters and 32 taxa was built in order to perform a parsimony analysis. The taxonomic sampling included 3 outgroup taxa at the family level, five protocetid archaeocetes, eight basilosaurid archaeocetes, eight extinct odontocetes, and eight extinct mysticetes. Characters were mostly located in the cranial skeleton (84 of 101), since post-cranial elements are poorly preserved or unknown for most taxa (especially the Neoceti).

Our analysis supports the widely accepted paraphyly of the family Protocetidae and the subfamily Dorudontinae. Additionally, Pelagiceti, Basilosauridae, Neoceti, Odontoceti, Mysticeti, Aetiocetidae, and Xenorophidae are monophyletic. In all the analyses performed, Saghacetus osiris appears as the most basal basilosaurid. The clade formed by Basilosaurus isis, B. cetoides, Cynthiacetus peruvianus, and Dorudon atrox is also well supported and could represent a Basilosauridae sensu stricto taxon if the Basilosauridae sensu lato proved to be paraphyletic. In the context of a monophyletic Basilosauridae, as is suggested by our analysis we propose that Basilosaurinae only contains species of the genus Basilosaurus, due to their typical vertebral elongation.

This analysis also supports the mysticete affinities of the "Media Luna Whale" (MUSM 1917), proposed to be closely related to Eomysticetus wihtmorei and an undescribed toothed mysticete from South Carolina (ChM PV5720). The addition/ removal of ChM PV5720 also influences the relationships of toothed mysticetes with toothless mysticetes. Indeed, when ChM PV5720 is excluded from the analysis, the Aetiocetidae are more closely related to Chaeomysticeti than to other toothed mysticetes, as proposed by Deméré et al. (2008), Fitzgerald (2010), and Geisler et al. (2011). In contrast, when ChM PV5720 is included in the analysis, paraphyletic mammalodontids and monophyletic aetiocetids form a monophyletic group (in agreement with Marx 2010; Marx et al. 2015).

The inclusion in future analyses of other, undescribed archaic mysticetes, crown mysticetes, as well as a higher number of stem and crown odontocetes, will most likely contribute to an even better-constrained archaeocete-neocete transition, a point which is crucial to apprehend the processes having lead to the emergence of filter-feeding baleen whales and echolocating toothed whales. 


\section{Acknowledgements}

The holotype of Cynthiacetus peruvianus has been discovered in 1977 by one of us (CM) and collected with funds of the IFEA (Institut Français d'Études Andines) and of the CNRS (Centre national de la Recherche scientifique, France). The specimen was prepared at the MNHN (Muséum national d'Histoire naturelle) by Ronan Allain, Florent Goussard, Rodolfo Salas, Floréal Solé, Philippe Richir, Renaud Vacant, several members of the SAGA (Société amicale des Géologues amateurs), and one of us (CM). Special thanks are due to Dave Bohaska (Department of Paleobiology, United States National Museum of Natural History, Smithsonian Institution, Washington DC); Jonathan Geisler (in 2008, Georgia Southern University, Statesboro, Georgia); Philip Gingerich and Greg Gunnell (University of Michigan, Museum of paleontology, Ann Arbor, Michigan); Christine Lefèvre (Curator of Recent marine mammals collections, MNHN, Paris); George Phillips (Mississippi Museum of Natural Science, Jackson, Mississippi); Albert Sanders (Charleston Museum, Charleston, South Carolina) who generously provided full access to the specimens (published or unpublished) under their care. Furthermore, Philip Gingerich and Hans Thewissen kindly provided photos of unpublished chevrons of respectively Rodhocetus and Dhedacetus. This work benefited from fruitfull discussions with Erich Fitzgerald, Felix Marx, and Mark Uhen. Many thanks are due to Giovanni Bianucci and Jonathan Geisler for their detailed reviews of such a long manuscript. CT scan data were obtained at the Centre d'Imagerie Médicale de Bois-Bernard (Department of Pas-de-Calais, France) thanks to the generous collaboration of Fatiha Boumalk, Lyse Jokiel, Jean-Marc Lorphelin, and Philippe Somma. Photographs are by Christian Lemzaouda and Philippe Loubry (UMR 7207, CR2P) and by one of the authors (MM-C). Color correction of the photographs by Philippe Loubry. The artist reconstruction of Cynthiacetus peruvianus is by Alberto Gennari.

\section{REFERENCES}

ABEL O. 1906. - Ueber den als Beckengürtel von Zeuglodon beschriebenen Schultergürtel eines Vogels aus dem Eocän von Alabama. Centralblatt für Mineralogie, Geologie und Paläontologie 15: 450-458.

ABEL O. 1908. - The genealogical history of the marine mammals. Annual Report of the Smithsonian Institution 1907: 473-496.

ABEL O. 1913. - Die vorfahren der bartenwale. Denkschriften der Kaiserlichen Akademie der Wissenschaften Mathematisch-Naturwissenschaftliche Klasse 90: 155-224.

Agnarsson I. \& May-Collado L. J. 2008. - The phylogeny of Cetartiodactyla: The importance of dense taxon sampling, missing data, and the remarkable promise of cytochrome b to provide reliable species-level phylogenies. Molecular Phylogenetics and Evolution 48 (3): 964-985. https://doi.org/10.1016/j. ympev.2008.05.046

Allen G. M. 1921. - A new fossil cetacean. Bulletin of the Museum of Comparative Zoology 65 (1): 1-14. http://www.biodiversitylibrary.org/part/39690

ANDREWs C. W. 1906. - A Descriptive Catalogue of the Tertiary Vertebrata of the Fayum, Egypt. British Museum of Natural History, London, 398 p. https://doi.org/10.5962/bhl.title.55134

ANDREWS R. C. 1921. - A remarkable case of external hind-limbs in a humpback whale. American Museum Novitates 9: 1-6. http:// hdl.handle.net/2246/4849
ANDREWs C. W. 1923. - Note on the skulls from which the endocranial casts described by Dr. Dart were taken. Proceedings of the Zoological Society of London 42: 648-654.

Bajpai S. \& Thewissen H. G. 2014. - Protocetid cetaceans (Mammalia) from the Eocene of India. Palaeontologia Electronica 17 (3): 1-19.

BARNES L. G. 1990. - The fossil record and evolutionary relationships of the genus Tursiops, in LEATHERWOOD S. \& REEVES R. R. (eds), The Bottlenose Dolphin. Academic Press, New York: 3-26. https://doi.org/10.1016/B978-0-12-440280-5.50005-6

Barnes L. G. \& Mitchell E. D. 1978. - Cetacea, in Maglio V. J. \& COOKe H. B. S. (eds), Evolution of African mammals. Harvard University Press, Cambridge: 582-602.

BARNES L. G. \& MCLEOD S. A. 1984. — The fossil record and phyletic relationships of gray whales, in JONES M. L., SWARTZ S. L. \& LEATHERWOOD S. (eds), The Gray Whale. Academic Press, Orlando: 3-32.

Barnes L. G., Kimura M., Furusawa H. \& Sawamura H. 1994. - Classification and distribution of Oligocene Aetiocetidae (Mammalia; Cetacea; Mysticeti) from western North America and Japan. The Island Arc 3(4): 392-431. https://doi. org/10.1111/j.1440-1738.1994.tb00122.x

Barnes L. G., Goedert J. L. \& Furusawa H. 2001. — The earliest known echolocating toothed whales (Mammalia; Odontoceti): preliminary observations of fossils from Washington State. Mesa Southwest Museum Bulletin 8: 91-100.

BARONE R. 1968. - Anatomie comparée des mammiferes domestiques: Tome 1, Ostéologie. Troisième édition. Frères Vigot Publisher, Paris, $761 \mathrm{p}$.

Bebej R. M., Zalmout I. S., El-aziz A. A. A., Antar M. S. M. \& GingERICH P. D. 2016. - First remingtonocetid archaeocete (Mammalia, Cetacea) from the middle Eocene of Egypt with implications for biogeography and locomotion in early cetacean evolution. Journal of Paleontology 89: 882-893. https://doi. org/10.1017/jpa.2015.57

BerzIN A. A. 1972. - The Sperm Whale. Pacific Scientific Research Institute of Fisheries and Oceanography. Israel Program for Scientific Translations, Jerusalem. U. S. Dept. of Commerce, National Technical Information Service, Springfield, 394 p. https://doi. org/10.1002/iroh.19730580618

BiANUCCI G. \& GingeriCH P. D. 2011. - Aegyptocetus tarfa, n. gen. et sp. (Mammalia, Cetacea), from the middle Eocene of Egypt: clinorhynchy, olfaction, and hearing in a protocetid whale. Journal of Vertebrate Paleontology 31 (6): 1173-1188. https://doi.org /10.1080/02724634.2011.607985

Boessenecker R. W. \& Fordyce R. E. 2015. — Anatomy, feeding ecology, and ontogeny of a transitional baleen whale: a new genus and species of Eomysticetidae (Mammalia: Cetacea) from the Oligocene of New Zealand. PeerJ 3: e1129. https://doi. org/10.7717/peerj.1129

BONAPARTE C. L. 1849. - Classification af Havapatedyrene i Pinnipedia, Cete og Sirenia. Forhandlinger ved de skandinaviske Naturforskeres femte Møde Kjøbenhaven 1847: 1-618.

BORSUK-BIALYNICKA M. 1988. - New remains of Archaeoceti from the Paleogene of Antarctica. Polish Polar Research 9 (4): 437-445.

Bouetel V. \& MuizOn C. DE 2006 - The anatomy and relationships of Piscobalaena nana (Cetacea, Mysticeti), a Cetotheriidae s.s. from the early Pliocene of Peru. Geodiversitas 28 (2): 319-395.

BuCHHOLTZ E. A. 1998. - Implications of vertebral morphology for locomotor evolution in early Cetacea, in THEWISSEN J. G. M. (ed.), The Emergence of Whales: Evolutionary Patterns in the Origin of Cetacea. Plenum press, New York and London: 325351. https://doi.org/10.1007/978-1-4899-0159-0_11

BuchHoltz E. A. 2007. - Modular evolution of the Cetacean vertebral column. Evolution \& Development 9 (3): 278-289. https://doi.org/10.1111/j.1525-142X.2007.00160.x

BuchHoltz E. A. \& SCHuR S. A. 2004. - Vertebral osteology in Delphinidae (Cetacea). Zoological Journal of the Linnean Society 140:383-401. https://doi.org/10.1111/j.1096-3642.2003.00105.x 
Buffrénil V. De, Ricqlès A. De, Ray C. E. \& Domning D. P. 1990. - Bone histology of the ribs of the archaeocetes (Mammalia: Cetacea). Journal of Vertebrate Paleontology 10 (4): 455-466. https://doi.org/10.1080/02724634.1990.10011828

Buono M., Fernández M., Tambussi C., Mors T. \& Reguero M. 2011. - Un arqueoceto (Cetacea: Archaeoceti) del Eoceno medio de Isla Marambio (Formación La Meseta), Antártida. IV Congreso latinoamericano de paleontología de vertebrados, San Juan. Ameghiniana 48 (4) Suplemento 2011: R149-R150.

Buono M. R., Fernandez M. S., Reguero M. A., Marenssi S. A., SANTILlana S. N. \& MÖRS T. 2016. — Eocene basilosaurid whales from the La Meseta Formation, Marambio (Seymour) Island, Antarctica. Ameghiniana 53: 296-315.

CAppetTa H. \& Traverse M. 1988. — Une riche faune de sélaciens dans le bassin à phosphate de Kpogamé-Hahotoé (Éocène moyen du Togo). Note préliminaire et précisions sur la structure et l'âge du gisement. Geobios 21 (3): 359-365. https://10.1016/ S0016-6995(88)80058-5

Churchill M., Martínez-Cáceres M., Muizon C. De, MnieCKOWSKI J. \& GeISLER J. H. 2016. - A new toothed whale from the Oligocene of South Carolina and the origin of high frequency hearing in whales. Current Biology 26: 1-6. https:// doi.org/10.1016/j.cub.2016.06.004

Clarke J. A., Ksepka D. T., Salas-Gismondi R., Altamirano A. J., Shawkey M. D., D’Alba L., Vinther J., DeVries T. J., BABY P. 2010. - Fossil evidence for evolution of the shape and color of penguin feathers. Science 330: 954-957. https://doi. org/10.1126/science. 1193604

Clementz M. T., Fordyce R. E., Peek S. L. \& Fox D. L. 2012. Ancient marine isoscapes and isotopic evidence of bulk-feeding by Oligocene cetaceans. Palaeogeography, Palaeoclimatology, Palaeoecology 400: 28-40. https://doi.org/10.1016/j.palaeo.2012.09.009

Cooper L. N., Dawson S. D., Reidenberg J. S. \& Berta A. 2007. - Neuromuscular anatomy and evolution of the cetacean forelimb. The Anatomical Record: Advances in Integrative Anatomy and Evolutionary Biology 290 (9): 1121-1137. https://dx.doi. org/10.1002/ar.20571

Cooper L. N., Hieronymus T. L., Vinyard C. J., Bajpai S. \& THEWISSEN J. M. G. 2014. — New applications for constrained ordination: Reconstructing feeding behaviors in fossil Remingtonocetinae (Cetacea: Mammalia), in Hembree D. I., Platt B. F. \& SMITH J. J. (eds), Experimental Approaches to Understanding Fossil Organisms. Springer, The Netherlands: 89-107. https://doi. org/10.1007/978-94-017-8721-5_5

Cope E. D. 1868. - Second contribution to the history of the Vertebrata of the Miocene period of the United States. Proceedings of the Academy of Natural Sciences of Philadelphia 20: 184-194. http://www.jstor.org/stable/4059884

Cope E. D. 1890. - The Cetacea. The American Naturalist 24 (283): 599-616. https://doi.org/10.1086/275154

Currey J. D. 1984. - The Mechanical Adaptations of Bones. Princeton University Press, Princeton, 294 p.

DAMES W. 1894. - Über Zeuglodonten aus Aegypten und die Beziehungen der Archaeoceten zu den übrigen Cetaceen. Paläontologische Abhandlungen, Jena 1: 189-222.

DART R. A. 1923. — The brain of the Zeuglodontidae (Cetacea). Proceedings of the Zoological Society of London 42: 615-654.

DeCHASEAUX C. 1961. - Moulages endocrâniens de bovidés fossiles. Annales de Paléontologie 47: 51-73.

DELFORTRIE M. 1873. - Un Zeuglodon dans les faluns du sud-ouest de la France. Journal de Zoologie 1874: 25-30.

Deméré T. A. \& BerTA A. 2008. - Skull anatomy of the Oligocene toothed mysticete Aetiocetus weltoni (Mammalia, Cetacea): implications for the mysticete evolution and functional anatomy. Zoological Journal of the Linnean Society 154: 308-352. https:// doi.org/10.1111/j.1096-3642.2008.00414.x

Deméré T. A., McGowen M., Berta A. \& Gatesy J. 2008. Morphological and molecular evidence for a stepwise evolutionary transition from teeth to baleen in mysticete whales. Systematic Biology 57 (1): 15-37. https://doi.org/10.1080/10635150701884632

DeVries T. J. 1998. — Oligocene deposition and Cenozoic sequence boundaries in the Pisco Basin (Peru). Journal of South American Earth Sciences 11 (3): 217-231. https://doi.org/10.1016/ S0895-9811(98)00014-5

DeVries T. J. 2004. - Eocene mollusks from the Pisco Basin (Southern Peru): Evidence for re-evaluating the age of the Otuma Formation. XII Congreso Peruano de Geologia. Resúmenes Extendidos: 615-618.

DeVries T. J. 2007. — Cenozoic Turritellidae (Gastropoda) from southern Peru. Journal of Paleontology 81 (2): 331-351. https:// doi.org/10.1666/0022-3360(2007)81[331:CTGFSP]2.0.CO;2

DeVries T. J., Narváez Y., Sanfilippo A., Malumian N. \& Tapia P. 2006. - New Microfossil evidence for a Late Eocene age of the Otuma Formation (Southern Peru). XIII Congreso Peruano de Geologia. Resúmenes Extendidos: 615-618.

Dines J. P., Otárola-Castillo E., Ralph P., Alas J., Daley T., SMith A. D. \& DeAn M. D. 2014. - Sexual selection targets cetacean pelvic bones. Evolution 68 (11): 3296-3306. https:// doi.org/10.1111/evo.12516

DomniNG D. P. 1977. - Observations on the myology of Dugong dugon (Müller). Smithsonian Contributions to Zoology 226: 1-57. https://doi.org/10.5479/si.00810282.226

Dunbar R. B., Marty R. C. \& BaKer P. A. 1990. - Cenozoic marine sedimentation in the Sechura and Pisco basins, Peru. Palaeogeography, Palaeoclimatology, Palaeoecology 77 (3-4): 235261. https://doi.org/10.1016/0031-0182(90)90179-B

EALEs N. B. 1950. - The skull of the foetal narwhal, Monodon monoceros L. Philosophical Transactions of the Royal Society of London 235 (621): 1-33. https://doi.org/10.1098/rstb.1950.0013

EARGLE D. H. 1959 - Stratigraphy of Jackson Group (Eocene), South-Central Texas. AAPG Bulletin 43: 2623-2635. https:// doi.org/10.1306/0bda5f36-16bd-11d7-8645000102c1865d

EMLONG D. 1966. - A new archaic cetacean from the Oligocene of Northwest Oregon. Bulletin of the Museum of Natural History, University of Oregon 3: 1-5. http://hdl.handle.net/1794/19998

Evans H. E. \& DE LAHUnTA A. 2013. - Miller's Anatomy of the Dog. Saunders, St Louis, 850 p.

FahlKe J. M., Gingerich P. D., Welsh R. C. \& Wood A. R. 2011. - Cranial asymmetry in Eocene archaeocete whales and the evolution of directional hearing in water. Proceedings of the National Academy of Sciences 108 (35): 14545-14548. https:// doi.org/10.1073/pnas.1108927108

FAHLKE J. M. \& HAMPE O. 2015. - Cranial symmetry in baleen whales (Cetacea, Mysticeti) and the occurrence of cranial asymmetry throughout cetacean evolution. The Science of Nature 102 (9-10): 1-16. https://doi.org/10.1007/s00114-015-1309-0

Fitzgerald E. M. G. 2004. — A review of the Tertiary fossil Cetacea (Mammalia) localities in Australia. Memoirs of Museum Victoria 61: 183-208.

FitzGerald E. M. G. 2006. - A bizarre new toothed mysticete (Cetacea) from Australia and the early evolution of baleen whales. Proceedings of the Royal Society B: Biological Sciences 273 (1604): 2955-2963. https://doi.org/10.1098/rspb.2006.3664

FitzGerald E. M. G. 2010. - The morphology and systematics of Mammalodon colliveri (Cetacea: Mysticeti), a toothed mysticete from the Oligocene of Australia. Zoological Journal of the Linnean Society 158: 367-476. https://doi.org/10.1111/j.1096-3642.2009.00572.x

FORDYCE R. E. 1981. - Systematics of the odontocete Agorophius pygmaeus and the family Agorophiidae (Mammalia: Cetacea). Journal of Paleontology 55 (5): 1028-1045. http://www.jstor. org/stable/1304528

FordyCE R. E. 1994. - Waipatia maerewhenua, new genus and new species (Waipatiidae, new family), an archaic late Oligocene dolphin (Cetacea: Odontoceti: Platanistoidea) from New Zealand. Proceedings of the San Diego Society of Natural History 29: 147-176. https://doi.org/10.5962/bhl.part.10662 
FordyCE R. E. 2002. - Simocetus rayi (Odontoceti, Simocetidae, new family); a bizarre new archaic Oligocene dolphin from the eastern North Pacific in EMrY R. J. (ed.), Cenozoic Mammals of Land and Sea: Tributes to the Career of Clayton E. Ray. Smithsonian Contributions to Paleobiology 93: 185-222. https://dx.doi. org/10.5479/si.00810266.93

ForDYCE R. E. 2004. - The transition from Archaeoceti to Neoceti: Oligocene archaeocetes in the southwest Pacific. Journal of Vertebrate Paleontology 24 (supplement 3): 258-259.

FordYCE R. E. \& MUIZON C. DE 2001. - Evolutionary history of Cetaceans: a review, in MAZIN J. M \& BuffrénIL V. DE (eds), Secondary Adaptation of Tetrapods to Life in the Water. Pfeil Verlag, Munich: 169-233.

FrAAS E. 1904. - Neue Zeuglodonten aus dem unteren Mittelecocan vom Mokattam bei Cairo. Geologische und paleontologische Abhandlungen 6: 1-24.

Fraser F. C. \& Purves P. E. 1960. - Anatomy and function of the cetacean ear. Proceedings of the Royal Society of London. Series B, Biological Sciences 152 (946): 62-77. https://doi.org/10.1098/ rspb.1960.0024

Gatesy J., Milinkovitch M. C., Waddell V. \& Stanhope M. 1999 - Stability of cladistic relationships between Cetacea and higher level artiodactyl taxa. Systematic Biology 48: 6-20. https:// doi.org/10.1080/106351599260409

Gatesy J., Geisler J. H., Chang J., Buell C., Berta A., MereDiTH R. W., Springer M. S. \& MCGowen M. R. 2013 - A phylogenetic blueprint for a modern whale. Molecular Phylogenetics and Evolution 66: 479-506. https://doi.org/10.1016/j. ympev.2012.10.012

GeISLER J. H. \& LuO Z.-X. 1996. - The petrosal and inner ear of Herpetocetus sp. (Mammalia: Cetacea) and their implications for the phylogeny and hearing of archaic mysticetes. Journal of Paleontology 70 (6): 1045-1066. https://doi.org/10.1017/ S0022336000038749

Geisler J. H. \& Luo Z.-X. 1998. - Relationship of Cetacea to terrestrial ungulates and the evolution of cranial vasculature in Cete, in THeWISSEN J. G. M. (ed.), The Emergence of Whales: Evolutionary Patterns in the Origin of Cetacea. Plenum press, New York and London: 163-212. https://doi.org/10.1007/9781-4899-0159-0_6

Geisler J. H. \& SAnders A. E. 2003. - Morphological evidence for the phylogeny of Cetacea. Journal of Mammalian Evolution 10 (1/2): 23-129. https://doi.org/10.1023/A:1025552007291

GeISLER J. H. \& UHEN M. D. 2005. - Phylogenetic relationships of extinct cetartiodactyles: results of simultaneous analyses of molecular, morphological and stratigraphical data. Journal of Mammalian Evolution 12: 145-160. https://doi.org/10.1007/ s10914-005-4963-8

Geisler J. H., McGowen M. R., Yang G. \& Gatesy J. 2011. A supermatrix analysis of genomic, morphological, and paleontological data for crown Cetacea. BMC Evolutionary Biology 11: 1-33.

Geisler J. H., Colbert M. W. \& Carew J. L. 2014. — A new fossil species supports an early origin for toothed whale echolocation. Nature 508: 383-386. https://doi.org/10.1038/nature13086

Geisler J. H., SAnders A. E. \& Luo Z.-X. 2005. - A new protocetid whale (Cetacea: Archaeoceti) from the late Middle Eocene of South Carolina. American Museum Novitates 3480: 1-65. https://doi.org/10.1206/0003-0082(2005)480[0001:ANPW CA]2.0.CO;2

GERVAIS P. 1876. - Remarques au sujet du genre Phocodon d'Agassiz. Journal de Zoologie 5: 64-70.

GETTY R. 1975. - Sisson and Grossman's The Anatomy of the Domestic Animals. W. B. Saunders Company, Philadelphia, 2095 p.

Gibbes R. W. 1845. - Description of the teeth of a new fossil animal found in the Green Sand of South Carolina. Proceedings of the Academy of Natural Sciences of Philadelphia 2 (9): 254-256. http://www.jstor.org/stable/4058734
Gibbes R. W. 1847. - On the fossil genus Basilosaurus, Harlan, (Zeuglodon, Owen,) with a notice of specimens from the Eocene Green Sand of South Carolina. Journal of the Academy of Natural Sciences of Philadelphia, Second Series 1 (1): 2-15. https://doi.org/10.5962/bhl.title.16324

GIDLEY J. W. 1913. - A recently mounted Zeuglodon skeleton in the United States National Museum. Proceedings of the United States National Museum 44: 649-654. https://doi.org/10.5479/ si.00963801.44-1975.649

Gingerich P. D. 1992. - Marine mammals (Cetacea and Sirenia) from the Eocene of Gebel Mokattam and Fayum, Egypt: stratigraphy, age, and paleoenvironments. University of Michigan Papers on Paleontology 30: 1-84. http://hdl.handle. net/2027.42/48630

GINGERICH P. D. 2007. - Stromerius nidensis, new archaeocete (Mammalia, Cetacea) from the upper Eocene Qasr El-Sagha Formation, Fayum, Egypt. Contributions from the Museum of Paleontology, University of Michigan 31 (13): 363-378. http:// hdl.handle.net/2027.42/57499

Gingerich P. D. 2010. — Cetacea, in Werdelin L. \& SANDERS W. (eds), Cenozoic Mammals of Africa. University of California Press, Berkeley: 873-899.

GiNGERICH P. D. 2015. - New partial skeleton and relative brain size in the Late Eocene archaeocete Zygorhiza kochii (Mammalia, Cetacea) from the Pachuta Marl of Alabama, with a note on contemporaneous Pontogeneus brachyspondylus. Contributions from the Museum of Paleontology, University of Michigan 32: 161-188. http://hdl.handle.net/2027.42/113064

Gingerich P. D. \& Russell D. E. 1981. - Pakicetus inachus, a new archaeocete (Mammalia, Cetacea) from the early-middle Eocene Kuldana Formation of Kohat (Pakistan). Contributions from the Museum of Paleontology, University of Michigan 25 (11): 235-246. http://hdl.handle.net/2027.42/48501

Gingerich P. D. \& Russell D. E. 1990. — Dentition of early Eocene Pakicetus (Mammalia, Cetacea). Contributions from the Museum of Paleontology, University of Michigan 28 (1): 1-20. http://hdl.handle.net/2027.42/48537

GingERICH P. D. \& UHEN M. D. 1996. - Ancalecetus simonsi, a new dorudontine archaeocete (Mammalia, Cetacea) from the early late Eocene of Wadi Hitan, Egypt. Contributions from the Museum of Paleontology, University of Michigan 29 (13): 359-401. http://hdl.handle.net/2027.42/48634

Gingerich P. D., Smith B. H. \& Simons E. L. 1990 - Hindlimbs of Eocene Basilosaurus: evidence of feet in whales. Science 249: 154-157. https://doi.org/10.1126/science.249.4965.154 Gingerich P. D., Raza M. S., Arif M., Anwar M. \& Zhou X. 1994. - New whale from the Eocene of Pakistan and the origin of cetacean swimming. Nature 368: 844-847. https:// doi.org/10.1038/368844a0

Gingerich P. D., Arif M., Bhatti M. A., Raza H. A. \& Raza, S. M. 1995. - Protosiren and Babiacetus (Mammalia, Sirenia and Cetacea) from the middle Eocene Drazinda Formation, Sulaiman Range, Punjab (Pakistan). Contributions from the Museum of Paleontology, University of Michigan 29 (12): 331357. http://hdl.handle.net/2027.42/48651

Gingerich P. D., Arif M., Bhatti M. A., ANWAR M. \& SANDERS W. J. 1997. - Basilosaurus drazindai and Basiloterus hussaini, new Archaeoceti (Mammalia, Cetacea) from the Middle Eocene Drazinda Formation, with a revised interpretation of ages of whale-bearing strata in the Kirthar Group of the Sulaiman Range, Punjab (Pakistan). Contributions from the Museum of Paleontology, University of Michigan 30 (2): 55-81. http://hdl. handle.net/2027.42/48652

Gingerich P. D., Ul-Haq M., Zalmout I., Khan I. H. \& MALKANi M. S. 2001a. - Origin of whales from early artiodactyls: hands and feet of Eocene Protocetidae from Pakistan. Science 293 (5538): 2239-2242. https://doi.org/10.1126/ science. 1063902 
Gingerich P. D., Ul-HaQ M., Khan I. H. \& Zalmout I. S. 2001b. - Eocene stratigraphy and archaeocete whales (Mammalia, Cetacea) of Drug Lahar in the eastern Sulaiman Range, Balochistan (Pakistan). Contributions from the Museum of Paleontology, University of Michigan 30 (11): 269-319. http://hdl.handle.net/2027.42/48661

Gingerich P. D., Zalmout I. S., UL-HaQ M. \& BHATTi M. A. 2005. - Makaracetus bidens, a new protocetid archaeocete (Mammalia, Cetacea) from the early middle Eocene of Balochistan (Pakistan). Contributions from the Museum of Paleontology, University of Michigan 31 (9): 197-210. http://hdl.handle.net/2027.42/41260

Gingerich P. D., Ul-Haq M., Koenigswald W., SANDers W. J., Smith B. H. \& ZalmuT I. S. 2009 - New protocetid whale from the Middle Eocene of Pakistan: Birth on land, precocial development, and sexual dimorphism. PLoS ONE 4 (2): 1-20. https://doi.org/10.1371/journal.pone.0004366

Godfrey S. J., Uhen M. D., Osborne J. E. \& Edwards L. E. 2016. - A new specimen of Agorophius pygmaeus (Agorophiidae, Odontoceti, Cetacea) from the early Oligocene Ashley Formation of South Carolina, USA. Journal of Paleontology 90: 154-169. https://doi.org/10.1017/jpa.2016.4

GOL'DIN P. 2014. - Naming an innominate: pelvis and hindlimbs of Miocene whales give an insight into evolution and homology of cetacean pelvic girdle. Evolutionary Biology 41: 473-479. https:// doi.org/10.1007/s11692-014-9281-8

Gol'din P. \& ZvONOK E. 2013. - Basilotritus uheni, a new Cetacean (Cetacea, Basilosauridae) from the Late Middle Eocene of Eastern Europe. Journal of Paleontology 87 (2): 254-268. https:// doi.org/10.1666/12-080R.1

GoLOBOFF P. A. 1993. - Estimating character weights during tree search. Cladistics 9: 83-91. https://doi.org/10.1111/j.1096-0031.1993. tb00209.x

Grateloup J. P. S. 1840. — Description d'un fragment de mâchoire fossile, d'un genre nouveau de reptile (saurien). Actes de l'Académie nationale des Sciences Belles-Lettres et Arts de Bordeaux 2: 201-210. https://doi.org/10.5962/bhl.title.5039

HARLAN R. 1834. - Notice of fossil bones found in the Tertiary formation of the State of Louisiana. Transactions of the American Philosophical Society 4: 397-403. https://doi.org/10.2307/1004838

HARLAN R. 1835. - Description of the remains of the "Basilosaurus", a large fossil marine animal, recently discovered in the horizontal limestone of Alabama. Transactions of the Geological Society Pennsylvania 1: 348-357.

HeCTOR J. 1881. - Notes on New Zealand Cetacea, recent and fossil. Transactions and Proceedings of the New Zealand Institute 13: 434-437.

HEYNING J. E. 1989. - Comparative facial anatomy of beaked whales (Ziphiidae) and a systematic revision among the families of extant Odontoceti. Contributions in Science of the Natural History Museum of Los Angeles 405: 1-64.

Houssaye A., Tafforeau P., Muizon C. De \& Gingerich P. D. 2015. - Transition of Eocene whales from land to sea: evidence from bone microstructure. PLoS ONE 10: e0118409. https://doi. org/10.1371/journal.pone.0118409

HowELL A. B. 1928. - Contribution to the comparative anatomy of the eared and earless seals (genera Zalophus and Phoca). Proceedings of the United States National Museum 73 (15):1-42. https://doi. org/10.5479/si.00963801.73-2736.1

Howell A. B. 1930a. - Myology of the narwhal (Monodon monoceros). American Journal of Anatomy 46 (2): 187-215. https://doi. org/10.1002/aja.1000460202

Howell A. B. 1930b. - Aquatic Mammals: their Adaptations to Life in the Water. C. C. Thomas Publisher, Springfield, 338 p. https:// doi.org/10.5962/bhl.title.20077

HulberT R. C. JR. 1998. - Postcranial osteology of the North American middle Eocene protocetid Georgiacetus, in THEWISSEN J. G. M. (ed.), The Emergence of Whales: Evolutionary Patterns in the Origin of Cetacea. Plenum press, New York and London: $235-$ 267. https://doi.org/10.1007/978-1-4899-0159-0_8
Hulbert R. C. Jr., Petkewich R. M., Bishop G. A., Burky D. \& Aleshire D. P. 1998. - A new middle Eocene protocetid whale (Mammalia: Cetacea: Archaeoceti) and associated biota from Georgia. Journal of Paleontology 72: 907-927. http://www.jstor. $\mathrm{org} / \mathrm{stable} / 1306667$

INTERNATIONAL COMMISSION ON ZOOLOGICAL NOMENCLATURE 1999. - International Code of Zoological Nomenclature, 4th edition. International Trust for Zoological Nomenclature, London, $306 \mathrm{p}$.

KASUYA T. 1973. - Systematic consideration of recent toothed whales based on the morphology of the tympano-periotic bone. Scientific Reports of the Whales Research Institute 25: 1-103.

KellogG R. 1923a. - Description of an apparently new toothed cetacean from South Carolina (with two plates). Smithsonian Miscellaneous Collections 76 (7): 1-7. http://hdl.handle.net/10088/23638

KeLlOGG R. 1923b. - Description of two squalodonts recently discovered in the Calvert Cliffs, Maryland, and notes on the sharktoothed cetaceans. Proceedings of the United States National Museum 62 (16): 1-69. https://doi.org/10.5479/si.00963801.62-2462.1

KellogG R. 1936. - A review of the Archaeoceti. Carnegie Institution of Washington Publications 482: 1-366.

KeLLOGG R. 1965. - A new whalebone whale from the Miocene Calvert Formation. Bulletin of the United States National Museum 247 (1): $1-45$.

KLAAUW C. J. VAN DER 1931. — The auditory bulla in some fossil mammals. Bulletin of the American Museum of Natural History 62: 1-352. http://hdl.handle.net/2246/353

KocH A. C. 1846. - Kurze Beschreibung des Hydrarchos harlani (Koch) eines riesenmässigen Meerungeheuers und dessen Entdeckung in Alabama in Nordamerika im Frühjahr 1845. Königl. Hofbuchdruckerei C. C. Meinhold and Söhnen, Dresden, 20 p.

KÖHLER R. \& FORdYCE R. E. 1997. - An archaeocete whale (Cetacea: Archaeoceti) from the Eocene Waihao Greensand, New Zealand. Journal of Vertebrate Paleontology 17 (3): 574-583. http://dx.doi.org/10.1080/02724634.1997.10011004

KÜKENTHAL W. G. 1914. — Untersuchungen an Walen (Zweiter Teil). Jenaische Zeitschrift für Naturwissenschaft 51: 1-122.

Kumar K. \& SAHNi A. 1986. - Remingtonocetus harudiensis, new combination, a middle Eocene archaeocete (Mammalia, Cetacea) from western Kutch, India. Journal of Vertebrate Paleontology 6 (4): 326-349. https://doi.org/10.1080/02724634.1986.10011629

LAmbert O., Bianucci G. \& Post K. 2009. - A new beaked whale (Odontoceti, Ziphiidae) from the middle Miocene of Peru. Journal of Vertebrate Paleontology 29 (3): 910-922. http:// www.jstor.org/stable/20627100

Lambert O., Collareta A, Landini W., Post K., Ramassamy B., Di Celma C., Urbina M. \& Bianucci G. 2015. - No deep diving: evidence of predation on epipelagic fish for a stem beaked whale from the Late Miocene of Peru. Proceedings of the Royal Society B 282: 20151530. https://doi.org/10.1098/rspb.2015.1530

LANCASTER W. C. 1990. - The middle ear of the Archaeoceti. Journal of Vertebrate Paleontology 10 (1): 117-127. https://doi. org/10.1080/02724634.1990.10011795

LEIDY J. 1852. - Description of Pontogeneus priscus. Proceedings of the Academy of Natural Sciences of Philadelphia 6: 52.

LÖNNBERG E. 1910. - The pelvic bones of some Cetacea. Arkiv for Zoology 7 (10): 1-15.

LUCAS F. A. 1900. - The pelvic girdle of Zeuglodon, Basilosaurus cetoides (Owen), with notes on other portions of the skeleton. Proceedings of the United States National Museum 23: 327-331.

LuO Z.-X. 1998. - Homology and transformation of cetacean ectotympanic structures, in THEWISSEN J. G. M. (ed.), The Emergence of Whales: Evolutionary Patterns in the Origin of Cetacea. Plenum press, New York and London: 269-301. https://doi. org/10.1007/978-1-4899-0159-0_9

Luo Z.-X. \& Gingerich P. D. 1999. - Terrestrial Mesonychia to aquatic Cetacea: Transformation of the basicranium and evolution of hearing in whales. University of Michigan Papers on Paleontology 31: 1-98. http://hdl.handle.net/2027.42/48633 
LuO Z.-X. \& MARSH K. 1996. — Petrosal (periotic) and inner ear of a Pliocene kogiine whale (Kogiinae, Odontoceti): implications on relationships and hearing evolution of toothed whales. Journal of Vertebrate Paleontology 16 (2): 328-348. https://doi.org/10.10 80/02724634.1996.10011320

MAAS M. C. 2008. - Histology of bones and teeth, in PERrIN W. F., Wursig B. \& ThEWISSEN J. G. M. (eds), Encyclopedia of Marine Mammals, 2nd edition. Academic Press, San Diego: 124-129.

MADAR S. I. 2007. — The postcranial skeleton of early Eocene pakicetid cetaceans. Journal of Paleontology 81 (1): 176-200. https://doi.org/10.1666/0022-3360(2007)81\%5B176:TPSOEE\%5D2.0.CO;2

Madar S. I., Thewissen J. G. M. \& Hussain S. T. 2002. Additional holotype remains of Ambulocetus natans (Cetacea, Ambulocetidae), and their implications for locomotion in early whales. Journal of Vertebrate Paleontology 22: 405-422. https://doi. org/10.1671/0272-4634(2002)022[0405:AHROAN]2.0.CO;2

MADDISON W. P. \& MADDISON D. R. 2010 - Mesquite: a modular system for evolutionary analysis. Version 2.74. Available at: http:// mesquiteproject.org.

MAROCCO R. \& Muizon C. DE 1988. - Los vertebrados del Neogeno de La Costa Sur del Perú: Ambiente sedimentario y condiciones de fosilización. Bulletin de l'Institut français d'Études andines 17 (2): 105-117. http://www.documentation.ird.fr/hor/fdi:30044

Martínez-CÁCeres M. \& Muizon C. DE 2011. - A new basilosaurid (Cetacea, Pelagiceti) from the Late Eocene to Early Oligocene Otuma Formation of Peru. Comptes Rendus Palevol 10 (7): 517-526. https://doi.org/10.1016/j.crpv.2011.03.006

Martínez-Cáceres M., Muizon C. De, Lambert O., Bianucci G. SALAS-Gismondi R. \& URBINA-SCHMidT M. 2011. - A toothed mysticete from the Middle Eocene to Lower Oligocene of the Pisco Basin, Peru: new data on the origin and feeding evolution of Mysticeti. Sixth Triennial Conference on Secondary Adaptation of Tetrapods to Life in Water, San Diego: 56, 57.

MARX F. 2010. - The more the merrier? A large cladistic analysis of mysticetes, and comments on the transition from teeth to baleen. Journal of Mammalian Evolution 18 (2): 77-100. https:// doi.org/10.1007/s10914-010-9148-4

MarX F. G. \& FordyCe R. E. 2015. - Baleen boom and bust: a synthesis of mysticete phylogeny, diversity and disparity. Royal Society Open Science 2: 140434. https://doi.org/10.1098/ rsos. 140434

MarX F. G., Tsai C.-H. \& Fordyce R. E. 2015. — A new Early Oligocene toothed 'baleen'whale (Mysticeti: Aetiocetidae) from western North America: one of the oldest and the smallest. Royal Society Open Science 2: 150476. https://10.1098/rsos.150476

Marx F. G., Lambert O. \& Uhen M. D. 2016. - Cetacean Paleobiology. John Wiley \& Sons, Chichester, 319 p.

May-Collado L. \& Agnarsson I. 2006. - Cytochrome b and bayesian inference of whale phylogeny. Molecular Phylogenetics and Evolution 38 (2): 344-354. https://doi.org/10.1016/j. ympev.2005.09.019

McGowen M. R., Spaulding M. \& GATESY J. 2009. — Divergence date estimation and a comprehensive molecular tree of extant cetaceans. Molecular Phylogenetics and Evolution 53: 891-906. https://doi.org/10.1016/j.ympev.2009.08.018

MEAD J. G. 1975. - Anatomy of the external nasal passages and facial complex in the Delphinidae (Mammalia: Cetacea). Smithsonian Contributions to Zoology 207: 1-67. https://doi.org/10.5479/ si.00810282.207

MEAD J. G. \& FORDYCE R. E. 2009. - The therian skull: a lexicon with emphasis on the odontocetes. Smithsonian Contributions to Zoology 627: 1-216. https://doi.org/10.5479/si.00810282.627

Miller G. S. 1923. - The telescoping of the cetacean skull (with eight plates). Smithsonian Miscellaneous Collections 76 (5): 1-70. http://hdl.handle.net/10088/23639

MitCHell E. D. 1989. - A new cetacean from the late Eocene La Meseta formation, Seymour Island, Antarctic Peninsula. Cana- dian Journal of Fisheries and Aquatic Sciences 46 (12): 2219-2235. https://doi.org/10.1139/f89-273

MOUSTAFA Y. S. 1954. - Additional information on the skull of Prozeuglodon isis and the morphological history of the Archaeoceti. Proceedings of the Egyptian Academy of Sciences 9: 80-88.

MuizOn C. DE 1988. — Les relations phylogénétiques des Delphinida (Cetacea, Mammalia). Annales de Paléontologie 74 (4): 159-227.

Muizon C. DE 1991. - A new Ziphiidae (Cetacea) from the early Miocene of Washington State (USA) and phylogenetic analysis of the major groups of odontocetes. Bulletin du Muséum national d'Histoire naturelle, Section C, 4ème série, 12 (3-4): 279-326.

MuizOn C. DE 1994. — Are the squalodonts related to platanistoids? Proceedings of the San Diego Museum of Natural History 29: 135-146.

Muizon C. DE \& DeVries T. J. 1985. — Geology and paleontology of late Cenozoic marine deposits in the Sacaco area (Peru) Geologische Rundschau 74 (3): 547-563.

MÜLlER J. 1849. - Über die fossilen Reste der Zeuglodonten von Nordamerica, mit Rücksicht auf die europäischen Reste aus dieser Familie. G. Reimer, Berlin, 38 p.

Nikaido M., Matsuno F., Hamilton H., Brownell Jr. L. R., CaO Y., Ding W., Zuoyan Z., Shedlock A. M., Fordyce R. E., HASEgaWA M. \& OKADA N. 2001. - Retroposon analysis of major cetacean lineages: the monophyly of toothed whales and the paraphyly of river dolphins. Proceedings of the National Academy of Sciences 98 (13): 7384-7389. https://doi.org/10.1073\%2Fpnas. 121139198

NORBERG R. A. 1978. - Skull asymmetry, ear structure and function, and auditory localization in Tengmalm's owl, Aegolius funereus (Linnaeus). Philosophical Transactions of the Royal Society of London. Series B, Biological Sciences 282: 325-410. https://doi. org/10.1098/rstb.1978.0014

NORRIS K. S. 1968. - The evolution of acoustic mechanisms in odontocete cetaceans, in DraKe E. T. (ed.), Evolution and Environment. Yale University Press, New Haven: 297-324.

Nummela S., Hussain S. T. \& Thewissen J. G.M. 2006. Cranial anatomy in the Pakicetidae (Cetacea, Mammalia). Journal of Vertebrate Paleontology 26 (3): 746-759. https://doi org/10.1671/0272-4634(2006)26[746:CAOPCM]2.0.CO;2

OELSCHLÄGER H. A. 1986a. - Tympanohyal bone in toothed whales and the formation of the tympano-periotic complex (Mammalia: Cetacea). Journal of Morphology 188: 157-165. https://doi.org/ 10.1002/jmor.1051880203

OelsChläger H. A. 1986b. - Comparative morphology and evolution of the otic region in toothed whales (Cetacea, Mammalia). The American Journal of Anatomy 177: 353-368. https:// doi.org/10.1002/aja.1001770306

OgaWA T. \& KamiYa T. 1957. - A case of the cachalot with protruded rudimentary hind-limbs. Scientific reports of the Whales Research Institute 12: 197-208.

OHSUMI S. \& KATO H. 2008. - A bottlenose dolphin (Tursiops truncatus) with fin-shaped hind appendages. Marine Mammal Science 24 (3): 743-745. https://doi.org/10.1111/j.1748-7692.2008.00202.x

OWEN R. 1839. - Observations on the Basilosaurus of Dr. Harlan (Zeuglodon cetoides). Transactions of the Geological Society of London, series 2, 6: 69-79. https://doi.org/10.1144/transgslb.6.1.69

PABST D. A. 1990. - Axial muscles and connective tissues of the bottlenose dolphin, in LEATHERWOOD S. \& REEVES R. R. (eds), The Bottlenose Dolphin. Academic Press, San Diego: 51-67. https:// doi.org/10.1016/B978-0-12-440280-5.50007-X

POMPECKJ J. F. 1922. - Das Ohrskelett von Zeuglodon. Senckenbergiana 4: 43-100.

PRITCHARD B. G. 1939. - On the discovery of a fossil whale in the older Tertiaries of Torquay, Victoria. The Victorian Naturalist 55 (9): 151-159.

RIDEWOOD W. G. 1923. - Observations on the skull in foetal specimens of whales of the genera Megaptera and Balanoptera. Philosophical Transactions of the Royal Society of London. Series B 211: 209-272. https://doi.org/10.1098/rstb.1923.0005 
SAHNi A. \& Mishra V. P. 1975. - Lower Tertiary vertebrates from western India. Monograph of the Palaeontological Society of India 3: 1-48.

SANCHEZ J. A. \& BERTA A. 2010. - Comparative anatomy and evolution of the odontocete forelimb. Marine Mammal Science 26 (1): 140-160. https://doi.org/10.1111/j.1748-7692.2009.00311.x

SANDERS A. E. \& BARNES L. G. 2002. - Paleontology of the late Oligocene Ashley and Chandler Bridge formations of South Carolina, 3: Eomysticetidae, a new family of primitive mysticetes (Mammalia: Cetacea), in EMrY R. J. (ed.), Cenozoic Mammals of Land and Sea: Tributes to the Career of Clayton E. Ray. Smithsonian Contributions to Paleobiology 93: 313-356. https://dx.doi. org/10.5479/si.00810266.93

SANDERS A. E. \& Geisler J. H. 2015. - A new basal odontocete from the upper Rupelian of South Carolina, USA, with contributions to the systematics of Xenorophus and Mirocetus (Mammalia, Cetacea). Journal of Vertebrate Paleontology 35: e890107. https://doi.org/10.1080/02724634.2014.890107

SCHALler O. 2007. - Illustrated Veterinary Anatomical Nomenclature, 2nd edition. Enke Verlag, Stuttgart, 614 p.

SEELEY H. G. 1876. - Notice of the occurrence of remains of a British fossil Zeuglodon (Z. wanklyni, Seeley) in the Barton Clay of the Hampshire coast. Quarterly Journal of the Geological Society 32: 428-432. https://doi.org/10.1144/GSL. JGS.1876.032.01-04.47

Simôes-Lopes P. C. \& Gutstein C. S. 2004. - Notes on the anatomy, positioning and homology of the pelvic bones in small cetaceans (Cetacea, Delphinidae, Pontoporiidae). Latin American Journal of Aquatic Mammals 3 (2): 1-6. https://doi. org/10.5597/lajam00060

Sujper E. J. 1936. - Die Cetaceen. Capita Zoologica 7: 1-590.

STEEMAN M. E. 2007. - Cladistic analysis and a revised classification of fossil and recent mysticetes. Zoological Journal of the Linnean Society 150 (4): 875-894. https://doi.org/10.1111/ j.1096-3642.2007.00313.x

STRICKLER T. L. 1978. - Myology of the shoulder of Pontoporia blainvillei, including a review of the literature on shoulder morphology in the Cetacea. American Journal of Anatomy 152 (3): 429-431. https://doi.org/10.1002/aja.1001520310

STRICKLER T. L. 1980. - The axial musculature of Pontoporia blainvillei, with comments on the organization of this system and its effect on fluke-stroke dynamics in the Cetacea. American Journal of Anatomy 157 (1): 49-59. https://doi.org/10.1002/ aja.1001570106

STROMER E. 1903. - Zeuglodon-reste aus dem Oberen Mitteleocän des Fajum. Beiträge zur Paläontolgie und Geologie ÖstrerreichUngarns und des Orients 25: 65-100.

STromer E. 1908. - Die Archaeoceti des ägyptischen Eozäns. Beiträge zur Paläontolgie und Geologie Östrerreich-Ungarns und des Orients 21: 106-178.

STRUTHERS J. 1881. - The bones, articulations, and muscles of the rudimentary hind-limb of the Greenland right whale (Balaena mysticetus). Journal of Anatomy and Physiology 15: 141-321.

STRUTHERS J. 1888. - On some points in the anatomy of a Megaptera longimana. Part II. The Limbs. Journal of Anatomy and Physiology 22: 240-282.

STRUTHERS J. 1893. - On the rudimentary hind-limb of a great fin-whale (Baloenoptera musculus) in comparison with those of the humpback whale and the Greenland right-whale. Journal of Anatomy and Physiology 27 (3): 291-335.

SwOFFORD D. L. 1993. - Phylogenetic Analysis Using Parsimony (PAUP), Version 3.1.1. University of Illinois, Champaign.

SWOFFORD D. L. 2002. — PAUP*: Phylogenetic analysis using parsimony (and other methods), version 4.0b1.0. Sunderland, Massachusetts: Sinauer.

Tajima Y., Hayashi Y. \& Yamada, T. K. 2004. — Comparative anatomical study on the relationships between the vestigial pelvic bones and the surrounding structures of finless porpoises
(Neophocaena phocaenoides). Journal of Veterinary Medical Science 66 (7): 761-766.

Thewissen J. G. M. 1994. - Phylogenetic aspects of cetacean origins: a morphological perspective. Journal of Mammalian Evolution 2 (3): 157-184. https://doi.org/10.1007/BF01473527

THEWISSEN J. G. M. \& BAJPAI S. 2001. - Dental morphology of Remingtonocetidae (Cetacea, Mammalia). Journal of Paleontology 75 (2): 463-465. https://doi.org/10.1666/0022-3360(2001)075<0463:DMORCM> 2.0.CO;2

Thewissen J. G. M. \& BAJPAI S. 2009. - New skeletal material for Andrewsiphius and Kutchicetus, two Eocene cetaceans from India. Journal of Paleontology 83 (5): 635-663. http://www.jstor. org/stable/20627654

THEWISSEN J. G. M. \& FISH F. E. 1997. — Locomotor evolution in the earliest cetaceans: functional model, modern analogues, and paleontological evidence. Paleobiology 23 (4): 482-490. http:// www.jstor.org/stable/2401132

Thewissen J. G. M. \& Hussain S. T. 1998. - Systematic review of the Pakicetidae, early and middle Eocene Cetacea (Mammalia) from Pakistan and India. Bulletin of Carnegie Museum of Natural History 34: 220-238.

Thewissen J. G. M. \& Hussain S. T. 2000. — Attockicetus praecursor, a new remingtonocetid cetacean from marine Eocene sediments of Pakistan. Journal of Mammalian Evolution 7 (3): 133-146. https://doi.org/10.1023/A:1009458618729

THEWISSEn J. G. M., MaDAR, S. I. \& Hussain S. T. 1996. - Ambulocetus natans, an Eocene cetacean (Mammalia) from Pakistan. Courier Forschungsinstitut Senckenberg 191: 1-79.

Thewissen J. G. M., Williams E. M. \& Hussain S. M. 2001. Eocene mammal faunas from northern Indo-Pakistan. Journal of Vertebrate Paleontology 21 (2):347-366. https://doi.org/10.1671 /0272-4634(2001)021[0347:EMFFNI]2.0.CO;2

Thewissen J. G. M., Cohn M. J., Stevens L. S., Bajpai L. S., HeYning J. \& Horton JR. W. E. 2006. - Developmental basis for hind-limb loss in dolphins and origin of the cetacean bodyplan. Proceedings of the National Academy of Science 103 (22): 8414-8418. https://doi.org/10.1073\%2Fpnas.0602920103

True F. W. 1908. - The fossil cetacean, Dorudon serratus Gibbes. Bulletin of the Museum of Comparative Zoology 52 (4): 5-78.

UhEN M. D. 1996. — Dorudon atrox (Mammalia, Cetacea): Form, function, and phylogenetic relationships of an archaeocete from the late middle Eocene of Egypt. Ph.D. dissertation, University of Michigan, Ann Arbor, 608 p. http://hdl.handle.net/2027.42/129905

UhEN M. D. 1998. - Middle to Late Eocene Basilosaurines and Dorudontines, in THEWISSEN J. G. M. (ed.), The Emergence of Whales: Evolutionary Patterns in the Origin of Cetacea. Plenum press, New York: 29-61. https://doi.org/10.1007/978-1-48990159-0 2

UHEN M. D. 1999. - New species of protocetid archaeocete whale, Eocetus wardii (Mammalia: Cetacea) from the Middle Eocene of North Carolina. Journal of Paleontology 73 (3): 512-528.

UhEN M. D. 2004. - Form, function, and anatomy of Dorudon atrox (Mammalia, Cetacea): an archaeocete from the middle to late Eocene of Egypt. University of Michigan Papers on Paleontology 34: 1-222. http://hdl.handle.net/2027.42/48670

UHEN M. D. 2005. - A new genus and species of archaeocete whale from Mississippi. Southeastern Geology 43 (3): 157-172.

Uhen M. D. 2008a. - New protocetid whale from Alabama and Mississippi, and a new cetacean clade, Pelagiceti. Journal of Vertebrate Paleontology 28 (3): 589-593. https://doi. org/10.1671/0272-4634(2008)28[589:NPWFAA]2.0.CO;2

UHEN M. D. 2008b. - A new Xenorophus-like odontocete cetacean form the Oligocene of North Carolina and a discussion of the basal odontocete radiation. Journal of Systematic Paleontology 6 (4): 433-452. https://doi.org/10.1017/S1477201908002472

Uhen M. D. 2008c. - Archaeoceti, in Janis C. M., ScotT K. M. \& JACOBS L. L. (eds), Evolution of Tertiary Mammals of North America 2: 557-565. 
UHEN M. D. 2014. - New material of Natchitochia jonesi and a comparison of the innominata and locomotor capabilities of Protocetidae. Marine Mammal Science 30 (3): 1029-1066. https://doi.org/10.1111/mms.12100

Uhen M. D. \& Gingerich P. D. 2001. — New genus of dorudontine archaeocete (Cetacea) from the Middle-to-Late Eocene of South Carolina. Marine Mammal Science 17(1): 1-34.

Uhen M. D., Pyenson N., DeVries T. \& Urbina M. 2008. - The oldest cetaceans from the Southern Hemisphere: new archaeocetes from the Pisco Basin of Southern Peru. Journal of Vertebrate Paleontology 28 (3): 154A.

Uhen M. D., Pyenson N. D., DeVries T. J., Urbina M. \& Renne P. R. 2011. - New middle Eocene whales from the Pisco Basin of Peru. Journal of Paleontology 85 (5): 955-969. https://doi.org/10.1666/10-162.1

Van Beneden P.-J. \& Gervais P. 1880. - Ostéographie des cétacés vivants et fossiles. A. Bertrand, Paris, 634 p. https://doi. org/10.5962/bhl.title.50302

VAN VALEN L. 1968. - Monophyly or diphyly in the origin of whales. Evolution 22: 37-41. https://doi.org/10.2307/2406647

WEST R. M. 1980. - Middle Eocene large mammal assemblage with Tethyan affinities, Ganda Kas Region, Pakistan. Journal of Paleontology 54 (3): 508-533. http://www.jstor.org/stable/1304193

Wible J. R. 2003. - On the cranial osteology of the short-tailed opossum Monodelphis brevicaudata (Didelphidae, Marsupialia). Annals of Carnegie Museum 72 (3): 137-202.

Wible J. R. 2008. - On the cranial osteology of the Hispaniolan solenodon, Solenodon paradoxus Brandt, 1833 (Mammalia, Lipotyphla, Solenodontidae). Annals of Carnegie Museum 77 (3): 321-402. https://doi.org/10.2992/0097-4463-77.3.321

WiBLE J. R. 2010. — Petrosal anatomy of the nine-banded armadillo Dasypus novemcinctus Linnaeus, 1758 (Mammalia, Xenarthra, Dasypodidae). Annals of the Carnegie Museum 79 (1): 1-28. https://doi.org/10.2992/007.079.0101

Wible J. R., Novacek M. J. \& Rougier G. W. 2004. — New data on the skull and dentition in the mongolian late Cretaceous eutherian mammal Zalambdalestes. Bulletin of the American Museum of Natural History 281: 1-144. http://hdl.handle.net/2246/449

Wible J. R., Rougier G. W., NovaceK M. J. \& Asher R. J. 2009. - The eutherian mammal Maelestes gobiensis from the Late Cretaceous of Mongolia and the phylogeny of Cretaceous Eutheria. Bulletin of the American Museum of Natural History 327: 1-123. https://doi.org/10.1206/623.1

Williams E. M. 1998. — Synopsis of the earliest cetaceans: Pakicetidae, Ambulocetidae, Remingtonocetidae, and Protocetidae, in THEWISSEN J. G. M. (ed.), The Emergence of Whales: Evolutionary Patterns in the Origin of Cetacea. Plenum press, New York: 1-28. https://doi.org/10.1007/978-1-4899-0159-0_1 


\section{APPENDICES}

ApPendix 1. - Taxon list, specimens, and references.

The taxa selected in this study are considered at the species or genus level (with exception of the outgroup, see discussion below). Several of these taxa are based on a single specimen (cf. below). Moreover, all the operational taxonomic units (OTU) are considered as monophyletic (including the basilosaurid Zygorhiza, see comments above). Most of the ingroup taxa (protocetids, basilosaurids, mysticetes, and odontocetes) were coded from personal observations made directly on original specimens and/or casts. In contrast, the outgroup taxa (especially Ambulocetidae and Remingtonocetidae) have been coded essentially from bibliographic data.

\section{Outgroup}

The outgroup includes the three most basal cetacean families, Pakicetidae, Ambulocetidae, and Remingtonocetidae.

\section{Pakicetidae}

They constitute the geologically oldest family of cetaceans recognized so far. They include three to possibly four genera (Pakicetus, Ichthyolestes Dehm \& Oettingen-Spielberg, 1958, Nalacetus Thewissen \& Hussain, 1998, and possibly Himalayacetus Bajpai \& Gingerich, 1998). Pakicetus, the best-known genus of the family, includes four species. The first described species of the family, P. attocki West, 1980, was initially diagnosed as a protocetid ("Protocetus" attocki) and subsequently placed in a new genus Pakicetus (Gingerich \& Russell 1981). Specimens used in this work include casts of GSP-UM 084 (cranium of Pakicetus inachus Gingerich \& Russell, 1981) and GSP-UM 081 (mandibular fragment of $P$. inachus). Bibliographic data are: Gingerich \& Russell (1981), Gingerich \& Russell (1990), Thewissen \& Hussain (1998), and Madar (2007).

\section{Ambulocetidae}

This family includes two species, Ambulocetus natans, known from a partial skeleton (H-GSP 18507), and the poorly known Gandakasia potens Dehm \& Oettingen-Spielberg, 1958. The coding for this taxon follows the descriptions of the holotype (Thewissen et al. 1996; Madar et al. 2002) and comparisons in Madar (2007).

\section{Remingtonocetidae}

This family includes six genera (Bebej et al. 2016). First named Protocetus harudiensis Sahni \& Mishra, 1975, Remingtonocetus harudiensis is the type species of the type genus of the family (established by Kumar \& Sahni 1986). The taxon was coded following Kumar \& Sahni (1986), Thewissen \& Bajpai (2001, 2009), and Geisler et al. 2005).

\section{INGROUP}

The ingroup includes 29 taxa belonging to Protocetidae, Basilosauridae, and Neoceti.

\section{Protocetidae}

The middle Eocene family Protocetidae includes 20 species referred to 19 genera. It is the largest family of archaeocetes. Protocetids are known from the Tethys Ocean (e.g. Fraas 1904; Kellogg 1936; Gingerich et al. 1995, 2001a, b; Bianucci \& Gingerich 2011), as well as from the Atlantic (Cappetta \& Traverse 1988; Hulbert 1998; Uhen 1999; Geisler et al. 2005) and possibly the South-Pacific (Uhen et al. 2011, but see Gol'din \& Zvonok 2013) oceans. Therefore, it is likely that protocetids were the first cetaceans to spread over all the oceans (but see a recent remingtonocetid record from Egypt, Bebej et al. 2016). As a matter of fact, the protocetid family results from an artificial grouping based on several plesiomorphic characters. Up to now, there is no cladistic analysis supporting the validity of the Protocetidae as a clade. Five genera and species are included in this study.

Artiocetus clavis Gingerich, ul-Haq, Zalmout, Khan \& Malkani, 2001. Known from a single partial skeleton from the Eocene Domanda Formation of Pakistan. It is the only known species of the genus. The coding of this taxon is based on direct observations on the holotype (GSP-UM 3458) and Gingerich et al. (2001a).

Carolinacetus gingerichi Geisler, Sanders \& Luo, 2005. North American protocetid from the middle Eocene Tupelo Bay Formation from South Carolina, this taxon is only known from a partial skeleton (ChM PV5401). The coding of this taxon is based on direct observation of the holotype and Geisler et al. (2005).

Rodhocetus kasrani Gingerich, Raza, Arif, Anwar \& Zhou, 1994. Protocetid from the middle Eocene Domanda Formation of Pakistan. Two species have been referred to the genus and Rodhocetus kasrani is the type species. This taxon was coded from GSP-UM 3012 (holotype), Gingerich et al. (1994), and Geisler et al. (2005).

Protocetus atavus Fraas, 1904. First described as a protocetid. It comes from the middle Eocene Mokattam Formation of Egypt. It is the only species of the genus. It was coded following bibliographic data (Kellogg 1936; Geisler \& Uhen 2005; Geisler et al. 2005).

Georgiacetus vogtlensis Hulbert, 1998. Protocetid from the middle Eocene of Georgia, Mississippi, and South Carolina. The holotype (GSM 350) comes from the Blue Bluff Unit of Georgia. The only species of the genus was coded essentially from an incomplete specimen (GSM 350) and bibliographic data (Hulbert 1998; Hulbert et al. 1998).

\section{Basilosauridae}

The Basilosauridae is the second largest family of archaeocetes. It includes at least 17 species and 13 genera. As for the protocetids, they have been reported from almost all the seas of the 
world (Harlan 1834; Owen 1839; Dames 1894; Stromer 1903; True 1908; Andrews 1906; Kellogg 1936; Gingerich et al. 1990; Gingerich 1992, 2007; Gingerich \& Uhen 1996; Köhler \& Fordyce 1997; Uhen 1998, 2004, 2005; Uhen \& Gingerich 2001; Martínez-Cáceres \& Muizon 2011; Uhen et al. 2011; Gol'din \& Zvonok 2013). Because many basilosaurid taxa are only known from very incomplete axial skeletons (Basilosaurus drazindai, Basiloterus hussaini, Basilotritus uheni Gol'din \& Zvonok, 2013, Masracetus markgrafi, and Stromerius nidensis), eight taxa only have been selected for this analysis. Two of these (Basilosaurus cetoides and Basilosaurus isis) belong to the subfamily Basilosaurinae.

Basilosaurus cetoides Owen, 1839. It is the first described archaeocete and Basilosaurus is thus the type genus of Basilosauridae and Basilosaurinae. Basilosaurus cetoides is known from the Bartonian - early Priabonian of the United States. It was described in detail by Kellogg (1936) and included in most important phylogenetic studies. The type of $B$. cetoides is currently reported as missing and the coding of this taxon is thus based on referred specimens (UNM 4674, USNM 4675, USNM 13690) and bibliographic data (Kellogg 1936; Lucas 1900).

Basilosaurus isis (Andrews, 1904). Very large basilosaurid from the Eocene of Egypt. The holotype is a partial right dentary (CGM 10208). The coding of this taxon is based on referred specimens housed at the University of Michigan (WH-74, UM 93231) and bibliographic references (Andrews 1906; Kellogg 1936; Gingerich et al. 1990; Fahlke et al. 2011).

Dorudon atrox Andrews, 1906. Dorudon atrox is one of the best known basilosaurid (Uhen 2004) and is from the early Priabonian of Egypt. It has been used in several previous phylogenetic analyses (e.g. Luo \& Gingerich 1999; Uhen \& Gingerich 2001; Uhen 2004; 2005; Fitzgerald 2010). Specimens studied in this analysis are: UM 93220, UM 101222, UM 100146, UM 94811, and UM 94814. Bibliographic data are from: Andrews (1906), Dart (1923), Kellogg (1936), and Uhen (2004).

Saghacetus osiris Dames, 1894. With Basilosaurus cetoides and Dorudon atrox, Saghacetus osiris is also one of the best known basilosaurids from the late Eocene of Egypt. Initially described as a species of the genus Dorudon, the species "Dorudon" (Zeuglodon) osiris was referred to its own genus, Saghacetus, by Gingerich (1992). It is the only recognized species of the genus. Specimens used in the analysis are: MNHN.F.LBE695 (partial skull and dentary), UM 997550 (skull and partial skeleton), and UM uncatalogued specimen ("pink whale", postcranial skeleton). Bibliographic data are from: Dames (1894), Stromer (1903, 1908), Andrews (1906), and Kellogg (1936).

Zygorhiza True, 1908. Is a basilosaurid from the late Eocene of the United States. Zygorhiza kochii is the only species described of this genus. However, Köhler \& Fordyce (1997) referred a
New Zealand specimen (UO 221000) to the genus Zygorhi$z a$, but did not specify to which extent this specimen differs from $Z$. kochii. Since the holotype (MfNB MB.Ma.43248) is a partially preserved cranium with no diagnostic features, most phylogenetic studies are based on the specimens housed at USNM (especially USNM 11962, which possesses a unique architecture of the facial region, see above). As a matter of fact, $Z$. kochii is the most polymorphic basilosaurid species. Indeed, two cranial morphotypes are observed in the collections of the USNM. The differences concern both the rostrum and the cranium. Additionally, a specimen referred to that species (MMNS VP 130) lacks the denticulations on the cingula observed in the other specimens of Zygorhiza. For the feasibility of this work, all the studied specimens previously referred to the genus are considered as Zygorhiza sp. However, a careful reassessment of the genus is needed in order to clarify the taxonomic validity of $Z$. kochii. Specimens used in the coding are: USNM 11962; USNM 16638; USNM 16639; MMNS VP 130; and OU 221000 (cast). Bibliographic data come from Kellogg (1936), Köhler \& Fordyce (1997), and Uhen (1999).

Cynthiacetus peruvianus Martínez-Cáceres \& Muizon, 2011. Basilosaurid from the late Eocene-early Oligocene Otuma Formation of Peru. Coded from the holotype (MNHN.F.PRU10).

Ancalecetus simonsi Gingerich \& Uhen, 1996. Basilosaurid from the early Priabonian of Egypt. The holotype (CGM 42290, currently, the only specimen referred to the species) includes a partial skull, forelimb and vertebrae. It was coded from Gingerich \& Uhen (1996).

Chrysocetus healyorum Uhen \& Gingerich, 2001. Basilosaurid from the Priabonian of North Carolina, USA. The holotype (SCSM 87.195) is the only specimen referred to the species. Coded from a cast of the holotype (housed at the University of Michigan) and from Uhen \& Gingerich (2001).

Neoceti

The Neoceti include the two suborders of Recent cetaceans, the Mysticeti and the Odontoceti, which are respectively known since the late Eocene and the early Oligocene. The earliest mysticetes have been reported from the late Eocene of Antartica (Mitchell 1989) and Peru (Martínez-Cáceres et al. 2011) and the earliest odontocetes are from the early Oligocene of the East and West coasts of the United States (South Carolina and Oregon (e.g. Barnes et al. 2001; Fordyce 2002; Uhen 2008b; Sanders \& Geisler 2015). However, part of the early recognized taxa come from the late Oligocene. Sixteen taxa have been coded in our matrix, which includes eight odontocetes and eight mysticetes.

Simocetus rayi Fordyce, 2002. One of the earliest known odontocetes. It is known from a single specimen (USNM 256517), which includes a partial skull and mandible as well as a few post-cranial elements. The holotype comes from the 
Rupelian Alsea Formation of Oregon, USA. Coded from the holotype and Fordyce (2002). Two other undescribed specimens reported by Barnes et al. (2001) from Oregon could also be referred to this taxon, or at least to the Simocetidae.

Archaeodelphis patrius Allen, 1921. Early odontocete from the Chattian Tiger Leap Formation of South Carolina, USA. It is only known from a single specimen (MCZ 15749), a partially preserved skull. The taxon is coded from a cast of the holotype housed at the MNHN and from the original description (Allen 1921).

Xenorophus sloani Kellogg, 1923. Early odontocete from the Rupelian Ashley Formation of South-Carolina, USA. Only one specimen has been referred to X. sloani (USNM 11049), but several specimens from the same horizon (more complete than the holotype of $X$. sloani) have been referred to this taxon. Xenorophus Kellogg, 1923 was first referred to the Agorophiidae, then regarded as incertae sedis, and recently grouped together with other odontocetes in the Xenorophidae. This taxon has been coded from the holotype and Kellogg (1923a).

Echovenator sandersi Churchill, Martínez-Cáceres, Muizon, Mnieckowski \& Geisler, 2016. Xenorophid from the Rupelian Chandler Bridge Formation of South Carolina, USA. Coded from the holotype (GSM 1098).

Albertocetus meffordorum Uhen, 2008. Xenorophid from the Chattian Belgrade Formation of North Carolina, USA. Coded from the holotype (USNM 525001, a partially preserved skull) and from Uhen (2008b).

Agorophius Cope, 1895. With Squalodon Grateloup, 1840, Agorophius is one of the first described early odontocetes. Up to now, only one species has been referred to the genus, $A$. pygmaeus (Müller, 1849) (Fordyce 1981). Moreover, Agorophius is the type genus of the family Agorophiidae. Unfortunately, the holotype of the species was destroyed and is only known from the original description (Müller 1849). The taxon is coded here from two specimens referred to this genus, from the Rupelian Ashley Formation of South Carollina. One of these specimens (ChM PV4256) has been recently referred to $A$. pygmaeus (Godfrey et al. 2016), while the second one (ChM PV5258) is likely a new species of the genus Agorophius. Both specimens were first coded by Geisler \& Sanders (2003).

Squalodon calvertensis Kellogg, 1923. Squalodon is the first described early odontocete. It was first regarded as a reptile (Grateloup 1840), then recognized as an archaic cetacean (Cope 1868). Squalodon calvertensis is one of the best-known squalodontids, from the Miocene of the United States. The holotype (USNM 10484) comes from the Burdigalian of the Calvert Formation, Maryland. We coded the taxon from the holotype, from referred specimens (USNM 10949, USNM
22902, USNM 23537, USNM 310600, USNM 328643), and from bibliographic data (Kellogg 1923b; Geisler \& Sanders 2003).

Waipatia maerewhenua Fordyce, 1994. Odontocete from the Duntroonian (late Oligocene) Otekaikae Limestone Formation of New Zealand. Waipatia Fordyce, 1994 is the type genus of the family Waipatiidae, which includes two genera (Waipatia and Otekaikea Tanaka \& Fordyce, 2014). Waipatia maerewhenua is coded from a cast of the holotype (OU 22095, skull and post-cranial elements) and from the original description (Fordyce 1994).

ChM PV5720. Undescribed toothed mysticete from the Chandler Bridge Formation of South Carolina (Rupelian). The taxon was coded directly from the specimen. This specimen was first coded in Geisler \& Sanders (2003).

Mammalodon colliveri Pritchard, 1939. Initially described as an archaeocete, $M$. colliveri is a toothed mysticete from the Chattian Jan Juc Marl Formation, Australia. Mammalodon Pritchard, 1939 is the type genus of the family Mammalodontidae. This taxon was coded based on a cast of the holotype (NMV P216929) in the MNHN collection and from Fitzgerald (2010) and Marx (2010).

Janjucetus hunderi Fitzgerald, 2006. Toothed mysticete from the Chattian Jan Juc Marl Formation, Australia. Janjucetus hunderi belongs to the Mammalodontidae (Fitzgerald 2010; Marx 2010) and there is only one specimen referred to the species. It was coded from a cast of the holotype (NMV P216929) in the MNHN collection and from Fitzgerald (2006, 2010) and Marx (2010).

Aetiocetus cotylalveus Emlong, 1966. First toothed cetacean to be referred to the Mysticeti (Van Valen 1968). Aetiocetus Emlong, 1966 is the type genus of the family Aetiocetidae, which includes at least four genera (Marx et al. 2015). Aetiocetus cotylalveus comes from the Chattian Yaquina Formation of Oregon, USA. It is coded from bibliographic data (Emlong 1966; Barnes et al. 1994; Marx 2010).

Aetiocetus weltoni Barnes Kimura, Furusawa \& Sawamura, 1994. Toothed mysticete from the Chattian Yaquina Formation of Oregon, USA. It is coded from bibliographic data (Barnes et al. 1994; Deméré \& Berta 2008).

Chonecetus goedertorum Barnes, Kimura, Furusawa \& Sawamura, 1994. Toothed mysticetes from the Chattian Pysht Formation of Washington, USA. Chonecetus Russell, 1968 belong to the Aetiocetidae (Barnes et al. 1994). It was coded from a cast of the holotype (LACM 131146) in the MNHN collection and bibliographic data (Barnes et al. 1994; Fitzgerald 2010). 
Eomysticetus whitmorei Sanders \& Barnes, 2002. Toothless odontocete from the Chattian Chandler Bridge Formation of South Carolina. Eomysticetus is the type genus of the Eomysticetidae, the earliest family of Chaeomysticeti. The taxon is coded from direct observation of the holotype (ChM PV4253) and from bibliographic data (Sanders \& Barnes 2002; Geisler \& Sanders 2003; Geisler et al. 2011).
The "Media Luna Whale" (MUSM 1917). It is an undescribed new genus and species of basal toothed mysticete referred to as the "Media Luna Whale" (Martínez-Cáceres et al. (2011). It comes from the late Eocene of the Paracas Formation at Media Luna on the southern coast of Peru. It was coded from direct observation of the specimen in the MUSM. 
SKULL

1 Skull length (ordered) (modified from Uhen 1998; Uhen \& Gingerich 2001; Geisler et al. 2005; Martínez-Cáceres \& Muizon 2011): [0] short, condylobasal length less than seven times the inter-condylar breadth; [1] moderate, condylobasal length between seven and eight times the inter-condylar breadth; [2] elongated, condylobasal length more than eight times the inter-condylar breadth.

2 Posterior margin of external bony nares, anterior edge of the nasal (ordered) (modified from Geisler \& Sanders 2003; Geisler et al. 2005; Geisler \& Luo 1998; Uhen \& Gingerich 2001; Fitzgerald 2010; Geisler et al. 2011): [0] anterior to the level of $\mathrm{C} 1$; [1] between the posterior edge of $\mathrm{C} 1$ and the anterior edge of $\mathrm{P} 1$; [2] between the posterior edge of $\mathrm{P} 1$ and the posterior edge of $\mathrm{P} 2$; [3] between $\mathrm{P} 3$ and the posterior edge of the posteriormost tooth; [4] posterior to the dental row.

3 Posterior end of the ventral (palatal) exposure of the premaxilla (ordered) (modified from Geisler et al. 2005; Fitzgerald 2010): [0] anterior to or at the posterior edge of P1; [1] between the level of P1 and P2; [2] posterior to the level of P2.

4 Posterior end of the ascending process of premaxilla (ordered) (modified from Geisler \& Sanders 2003; Geisler et al. 200; Fitzgerald 2010): [0] anterior to the level of P2; [1] over diastema between P2 and P3; [2] between the level of $\mathrm{P} 3$ and the anterior edge of the orbit; [3] over the supraorbital process; [4] posterior to the orbit.

5 Embrasure pits between upper incisors (modified from Uhen \& Gingerich 2001; Geisler et al. 2005): [0] absent; [1] present.

6 Transverse width of the base of the rostrum (modified from Uhen \& Gingerich 2001; Geisler et al. 2005; Fitzgerald 2010): [0] wide, width at least $140 \%$ the inter-condylar breadth; [1] narrow, width of the rostrum is less than $120 \%$ the inter-condylar breadth.

7 Angle of the lateral edge of maxilla with the palate on the rostrum in cross-section (Geisler et al. 2011): [0] 60 to $45^{\circ}$; [1] highly acute angle and the maxilla is dorsoventrally flattened.

8 Palate narrows (ordered) (Uhen \& Gingerich 2001; Geisler et al. 2005; Martínez-Cáceres \& Muizon 2011): [0] posterior to the dental row; [1] at the level of the upper molars; [2] at the level of or anterior to the last upper premolar.

9 Anterior process of the frontal, wedged between the posterior ends of the nasals: [0] absent; [1] triangular and small, its base is transversely narrower than the nasal; [2] large, its base is transversely wider than the nasal.

10 Transverse width of the skull across the orbit (ordered): [0] narrow, less than $80 \%$ the width at the base of the rostrum; [1] width is between $100 \%$ and $125 \%$ that of the base of the rostrum, and the orbital portion of the jugal may be exposed in dorsal view (a small supraorbital process of the frontal is present); [2] width is between $130 \%$ and $150 \%$ that of the base of the rostrum, and the orbital portion of the jugal is not exposed in dorsal view (a large supraorbital process of the frontal is present); [3] wide, more than $160 \%$ that of the base of the rostrum, and the orbital portion of the jugal is not exposed in dorsal view (a wide supraorbital process of the frontal is present).

11 Ascending process of the maxilla extends over the supraorbital process of the frontal (modified from Geisler \& Sanders 2003): [0] absent; [1] present.

12 Lateral margin of the maxilla forming a $V$-shaped notch at the base of the rostrum, just anterior to the orbit (modified from Geisler \& Sanders 2003): [0] absent; [1] present.

13 Steep face on anterolateral edge of zygomatic (jugular) process of maxilla clearly separating it from rostral portion of maxilla (Geisler \& Sanders 2003): [0] absent; [1] present.

14 Orbit size, as measured between the distalmost points on orbital rims of pre- and postorbital processes of the frontal (ordered) (modified from Marx 2010): [0] small, orbital diameter less than $15 \%$ of the bizygomatic breadth; [1] moderate, orbital diameter between 15 and $25 \%$ of the bizygomatic breadth; [2] large, orbital diameter between more than $25 \%$ of the bizygomatic breadth.

15 Dorsoventral compression of the lateral margin of the maxilla at the base of the rostrum lateral to the posteriormost teeth, when present: [0] absent; [1] present.

16 Dorsoventral compression of the median portion of the skull, anterior to the external bony nares, as observed in lateral view: [0] absent; [1] present.

17 Posterior end of the alveolar process of the maxilla respect to the orbit (modified from Geisler et al. 2005; Martínez-Cáceres \& Muizon 2011): [0] the alveolar process does not extend posterior to the anterior edge of the orbit; [1] the alveolar portion slightly extends posteriorly and the anterior edge of the orbit is at the level of the upper molars.

18 Lacrimal foramen or canal (Geisler et al. 2011): [0] present; [1] absent.

19 Lacrimal extending medially separating the lateral corner of the ascending process of the maxilla from the more anterior portion of the maxilla: [0] absent; [1] present.

20 Lacrimal: [0] small, sandwiched by both maxilla and preorbital process of the frontal; [1] enlarged, forms a massive anterodorsal process; [2] very enlarged, it extends posteriorly over the supraorbital process of the frontal, forming an actual ascending process of the lacrimal.

21 Dorsolateral edge of the maxillary foramen (internal opening of infraorbital canal) (Geisler et al. 2011): [0] formed by maxilla; [1] maxilla participates with the lacrimal and/or jugal; [2] formed by lacrimal and/or jugal. 
22 Maxilla ventral to the maxillary foramen, in the anterior wall of the orbit: [0] thick; [1] thin and forms an actual infraorbital plate, which can have an almost straight or concave posterior edge.

23 Medial edges of the palatine (modified from MartínezCáceres \& Muizon 2011): [0] contact each other at midline forming an actual inter-palatine suture; [1] the maxillae extend posteriorly and separate the palatines at midline.

24 Lateral margin of the rostral portion of the maxilla in dorsal view (ordered): [0] concave; [1] straight; [2] convex.

25 Premaxillae anterior to nasal openings (modified from Muizon 1988; Barnes 1990; Geisler et al. 2011): [0] convex transversely; [1] flat or concave surface, which forms the premaxillary sac fossa.

26 Premaxilla forms a marked process anterior to the bony nares and medial to the premaxillary sac fossa: the medial crest of the premaxillary (Geisler et al. 2011): [0] absent; [1] present.

27 Premaxillary foramina (modified from Geisler et al. 2011): [0] absent; [1] present.

28 Maxillo-premaxillary suture in dorsal view (modified from Geisler et al. 2011): [0] crenulated; [1] not crenulated; [2] not crenulated and within a deep groove.

29 Number of maxillary foramina (ordered) (modified from Geisler et al. 2011): [0] one; [1] two; [2] three or more.

30 Mesorostral groove (ordered) (modified from Geisler et al. 2011): [0] not exposed in dorsal view, the roof of the mesorostral canal is formed by the premaxilla; [1] partially exposed in dorsal view, the premaxillae roof the mesorostral groove but do not contact at midline; [2] greatly exposed in dorsal view.

31 Anterior half of the nasal (ordered): [0] wider at its anterior end, the lateral edge is posteromedially oriented; [1] almost the same width along the entire length, the lateral edge is roughly parallel to the midline; [2] the nasal tappers anteriorly, the lateral edge is posterolaterally oriented.

32 Posterior end of the maxilla meets medially: [0] nasal; [1] frontal; [2] premaxilla.

33 Lateral expansion of the premaxilla overlying the supraorbital process of the frontal and underlying the ascending process of the maxilla: [0] absent; [1] present.

34 Premaxillae adjacent to nasal opening (modified from Geisler et al. 2011): [0] thin dorsoventrally and porous internally; [1] pachyostotic, in direction perpendicular to face, and pachyosteosclerotic but nasals and premaxillae equally project dorsally and anteriorly.

35 Frontals higher than nasals in lateral view (modified from Geisler et al. 2011): [0] present; [1] absent.

36 Orientation of the posterior edge of the supraorbital portion of the frontal in dorsal view: [0] anterolaterally oriented, there is no actual supraorbital process of the frontal; [1] straight and laterally oriented, the posterior edge of the supraorbital process is almost perpendicular to the midline; [2] posterolaterally oriented and forming an acute angle with the midline in the temporal region, the posterior edge of the supraorbital process can be posteriorly concave; [3] the supraorbital process is well expanded but its posterior edge is slightly anterolaterally oriented, forms an obtuse angle with the midline in the temporal region, the posterior edge of the supraorbital process can be posteriorly convex.

37 Dorsal expansion of the alisphenoid in lateral view (Geisler et al. 2011): [0] exposed laterally in the ventral wall of the braincase; [1] broadly overlapped by the parietal so that only a narrow strip on the ventral edge of temporal fossa is visible.

38 Squamosal fossa (modified from Geisler et al. 2011) [0] deep, depth is the same or more than the distance from the dorsal edge of the zygoma to the point above deepest part of squamosal fossa; [1] shallower than this distance.

39 Pterygoid sinus (ordered) (modified from Luo \& Gingerich 1999; Uhen \& Gingerich 2001; Geisler et al. 2005; Martínez-Cáceres \& Muizon 2011): [0] absent; [1] present but obscured in ventral view by the bulla, occupies region between anterior end of involucrum and alisphenoid portion of pterygoid ridge; [2] breaches posterior wall of tube for foramen ovale and extends slightly anterior to the tympanic bulla; [3] enlarged, forms a deep anteroposterior trough which approaches the internal nares.

40 Falcate process of the basioccipital (modified from, Barnes \& McLeod 1984; Thewissen 1994; Geisler \& Luo 1998; Luo \& Gingerich 1999; Uhen \& Gingerich 2001; Geisler et al. 2005; Geisler et al. 2011): [0] absent or poorly developed; [1] well developed and transversely thin; [2] transversely thick and laterally expanded.

41 Sagittal crest: [0] present [1] absent.

42 Interparietal suture at midline (Martínez-Cáceres \& Muizon 2011): [0] as long as or longer than the nasal at midline; [1] shorter than the nasal or absent.

43 Nuchal crest in dorsal view (Geisler et al. 2011): [0] horseshoe shaped or U-shaped; [1] V-shaped; [2] transverse.

44 Orientation of supraoccipital shield (modified from Uhen \& Gingerich 2001; Geisler et al. 2005): [0] posteroventrally facing, not exposed in dorsal view; [1] almost vertical above the foramen magnum, partially or poorly exposed in dorsal view; [2] posterodorsally facing, well exposed in dorsal view.

45 Shape of the supraoccipital in dorsal view (Geisler \& Sanders 2003; Geisler et al. 2011): [0] rounded; [1] triangular, well pointed anteriorly.

46 Transverse constriction in the occipital shield, at the level of the ventral edge of the supraoccipital (MartínezCáceres \& Muizon 2011): [0] pronounced, the occipital shield is narrower than the intercondylar breadth; [1] weak, the occipital shield is almost as wide as or wider than the intercondylar breadth; [2] absent. 
47 Dorsalmost portion of the nuchal crest (MartínezCáceres \& Muizon 2011): [0] elevated and thin, the nuchal crest is well expanded; [1] short and thick, the nuchal crest is rather smooth or massive.

48 Position of the vertex in dorsal view (Martínez-Cáceres \& Muizon 2011): [0] well posterior to the level of the foramen magnum, the condyles are not exposed in dorsal view; [1] almost dorsal to the foramen magnum, the condyles may be partially exposed in dorsal view; [2] well anterior to the level of the foramen magnum and posterior to the level of the anterior margin of the floor of the squamosal fossa; [3] anterior to the level of the anterior margin of the floor of the squamosal fossa.

49 Lateral extent of exoccipital in ventral view (Geisler et al. 2005): [0] same as or less than the mastoid process of periotic; [1] greater than mastoid process of periotic.

50 Zygomatic process of the squamosal: [0] transversely slender and presenting a long and low anterior expansion; [1] transversely slender without any anterior expansion; [2] transversely wider, short and massive.

\section{Petrotympanic complex}

51 Length of anterior process of the periotic (ordered) (modified from Geisler et al. 2011 ch203): [0] short, length $<36 \%$ of the length of pars cochlearis; [1] moderate, length between 59 and $94 \%$ of the promontorial length; [2] longer than the promontorial length.

52 Contact of the anterior process of the periotic with the skull (ordered) (modified from Luo \& Gingerich 1999; Geisler et al. 2005): [0] the process strongly articulates with the falcifom process of the squamosal and is overlapped by the entoglenoid process in ventral view; [1] partially articulated with the falciform process, well exposed in ventral view; [2] absent or extremely reduced.

53 Fossa or groove for tensor tympani muscle (ordered) (Luo \& Gingerich 1999; Geisler et al. 2005; modified from Luo \& Marsh 1996): [0] shallow, bowl-shaped pit; [1] deep groove that is partially hidden in ventral view by a medial shelf of the tegmen tympani; [2] deep groove that is clearly visible; [3] reduced or absent, the groove is almost inconspicuous.

54 Lateral tuberosity (ordered) (Muizon 1991; Geisler \& Luo 1996; Luo \& Marsh 1996; Geisler et al. 2011): [0] Absent; [1] present, forms a bulbous prominence lateral to fossa for malleus; [2] present and elongate, forms a lateral process that articulates dorsally with squamosal.

55 Shape of the cross-section through anterior process at mid-length (modified from Fitzgerald 2010): [0] highly elliptical and transversely flattened, transverse diameter is $<36 \%$ of the dorsoventral diameter; [1] ovoid, transverse diameter is between 51 and $78 \%$ of the dorsoventral diameter; [2] approximately circular, transverse diameter between 85 and $134 \%$ of the dorsoventral diameter.
56 Ridge on anterolateral side of pars cochlearis, in ventral view (ordered) (Geisler et al. 2011; Luo \& Marsh 1996): [0] absent; [1] present and low; [2] present and high, forms an anteroposterior ridge that also forms the medial edge of a trough for tensor tympani muscle.

57 Posterolateral process of the pars cochlearis, lateral to the round window and medial to the facial sulcus (ordered): [0] absent; [1] present and short; [2] present and long.

58 Orientation of posterior process of periotic (Fitzgerald 2010): [0] forms an angle $<130^{\circ}$ with the long axis of the body; [1] forms an angle between 135 and $165^{\circ}$.

59 Internal acoustic meatus (Geisler et al. 2005): [0] flush or nearly flush with the surrounding dorsal surface of the periotic; [1] forms a tube that projects mediodorsally into the endocranial cavity.

60 Position of external opening of the Eustachian tube (Luo \& Gingerich 1999; Geisler et al. 2005): [0] at anterior end of bulla; [1] on medial side of bulla.

61 Median furrow of tympanic bulla (Geisler et al. 2005; modified from Geisler \& Luo 1998; Luo \& Gingerich 1999): [0] absent or very narrow notch on posterior edge of bulla; [1] present, forms broad embayment of the posterior edge of bulla; [2] bisects bulla into a smaller posteromedial and a larger posterolateral portions.

62 Base of posterior process of tympanic (Kasuya 1973; Luo \& Gingerich 1999; Geisler et al. 2005): [0] forms a single columnar pedicle; [1] perforated and forms medial and lateral pedicles.

63 Contact between the falciform process of the squamosal with the tympanic bulla (modified from Luo \& Gingerich 1999; Geisler et al. 2005): [0] low with circular facet for articulation with tympanic; [1] high, it forms a long ridge with an elongate facet which contacts the tympanic; [2] weak or absence of contact between a well developed falciform process and the tympanic bone.

64 Articulation of medial edge of the tympanic bulla with basioccipital (ordered) (Luo \& Gingerich 1999; Geisler et al. 2005): [0] present along entire medial edge of bulla; [1] present but small; [2] absent, wide gap separates both bones.

65 Posterior edge of tympanic (Geisler \& Luo 1998; Luo \& Gingerich 1999; Geisler et al. 2005): [0] does not contact exoccipital; [1] contacts paroccipital process of the exoccipital.

66 Dorsoventral breadth of the distal end of the posterior process of the tympanic bulla (modified from Geisler et al. 2005): [0] thinner than or approximately the same thickness as the proximal end; [1] thicker than the proximal end.

67 Mastoid exposure of posterior process of the periotic on the outside of skull (Geisler \& Luo 1996; Luo \& Marsh 1996; Geisler et al. 2011): [0] exposed externally; [1] not exposed, enclosed by the exoccipital and squamosal. 
68 Bullar facet on posterior process of periotic (Fordyce 1994; Geisler et al. 2011): [0] restricted to ventral surface [1]; extends dorsally onto posteromedial face of posterior process.

\section{Dentition}

69 Teeth posterior to P1 (ordered): [0] well developed teeth with high crown and separated by short diastemata; [1] very small teeth separated but very large diastemata; [2] absent.

70 Number of teeth on maxilla (ordered) (Geisler et al. 2011): [0] none; [1] seven; [2] eight; [3] nine to ten; [4] more than 10 .

71 Lingual cingulum on post-canine teeth (Geisler et al. 2011): [0] present; [1] absent.

72 Accessory cusps on posterior premolars and molars (lowers and uppers) (ordered) (Geisler et al. 2005; modified from Uhen 1998; Uhen \& Gingerich 2001): [0] absent; [1] present but small; [2] present and large.

73 Roots of P1 (Uhen 1999; Uhen \& Gingerich 2001; Geisler et al. 2005): [0] one root; [1] two roots.

74 P3 mesiodistally longer than P4 (modified from Geisler et al. 2005): [0] absent [1] present.

$75 \mathrm{M} 1$ and M2 protocone (ordered) (Thewissen \& Hussain 2000; Geisler et al. 2005): [0] present and large; [1] present but reduced to a minute cusp; [2] absent.

76 Roots of the upper molars (ordered) (Uhen \& Gingerich 2001; Geisler et al. 2005; modified from Uhen 1998): [0] three completely separated; [1] three partially separated; [2] two.

77 M3 (modified from Geisler et al. 2005; Geisler \& Luo 1998): [0] present; [1] absent.

78 Cleft on the mesial edge of the lower molars: [0] absent; [1] present.

\section{Mandible}

79 Mandibular symphysis (Uhen 1998; Uhen \& Gingerich 2001; Geisler et al. 2005): [0] fused; [1] unfused but sutured; [2] not sutured: fully separated with ligamentous connection.

80 Length of mandibular symphysis (ordered) (Geisler et al. 2011): [0] Short, mandibular symphysis forms less than $28 \%$ of the total mandibular length; [1] long, symphysis length between $33 \%$ and $40 \%$ of the mandibular length; [2] very long, symphysis forms more than $48 \%$ of the length of the mandibles.

81 Posterior end of the mandibular symphysis (ordered) (Uhen 1998; Uhen \& Gingerich 2001; Geisler et al. 2005): [0] anterior to the level of the posterior edge of $\mathrm{p} 1$; [1] between the posterior end of $\mathrm{p} 1$ and the anterior end of p3; [2] between the anterior end of p3 and posterior end of $\mathrm{p} 4$; [3] posterior to the level of fourth post-canine teeth.

82 Mandibular ramus in dorsal view: [0] laterally concave; [1] straight; [2] laterally convex.
83 Coronoid process of the dentary: [0] pronounced, at least as high as wide; [1] wider than high; [2] very reduced the coronoid process can be regarded as a crest on the dorsal edge of the dentary.

84 Shape of the coronoid process: [0] linguiform, posterodorsally oriented, higher than wide and anteroposteriorly compressed; [1] linguiform, posterodorsally oriented, but almost as wide as high, with an almost straight anterior border and a concave posterior margin; [2] roughly triangular.

\section{Axial postcranial skeleton}

85 Neural arch of the atlas (not taking into account the neural spine): [0] flat; [1] dorsally convex

86 Vertebrarterial foramen of the axis (modified from Geisler \& Sanders 2003): [0] oval and wide; [1] rounded, moderateto-small; [2] very small or absent.

87 Cervical vertebra anteroposterior compression, length of the centrum with respect to the height (ordered) (Martínez-Cáceres \& Muizon 2011): [0] absent: length equal or greater than height; [1] slight compression: length smaller (60\%-90\%) than height; [2] pronounced compression, length much smaller $(>50 \%)$ than height.

88 Number of thoracic vertebrae (ordered) (Martínez-Cáceres \& Muizon 2011; modified from Uhen 1998; Uhen \& Gingerich 2001; Geisler et al. 2005): [0] less than fourteen, (1] fourteen; [2] fifteen to eighteen; [3] more than eighteen.

89 Spinous processes of T5 to T7 (modified from Geisler et al. 2005): [0] steeply inclined: angle with plane of the anterior face of the centrum $>25^{\circ}$; [1] gently inclined to vertical, angle with plane of the anterior face of the centrum $<15^{\circ}$.

90 Length of posterior lumbar or anterior sacral vertebrae, whichever is longer (ordered) (Geisler et al. 2005; modified from Uhen \& Gingerich 2001): [0] short, centrum length $\leq 150 \%$ the length of $\mathrm{T} 1$; [1] slightly elongate, $150 \% \leq$ centrum length $\leq 200 \%$ the length of T1; [2] elongate, $200 \% \leq$ centrum length $\leq 250 \%$ the length of T1; [3] greatly elongate, centrum length $\geq 250 \%$ the length of $\mathrm{T} 1$.

91 Articulation between sacral vertebrae and ilium of pelvis (ordered) (Uhen 1998; Uhen \& Gingerich 2001; Geisler et al. 2005): [0] broad area of articulation between pelvis and one or two sacral vertebrae; [1] no articulation between vertebrae and pelvis.

92 Presence of a sacrum with fused vertebrae (Geisler $\mathrm{et}$ al. 2005; modified from Uhen 1998; Uhen \& Gingerich 2001): [0] present; [1] absent.

93 First five ribs (Geisler et al. 2005): [0] distal ends similar in diameter to proximal portions; [1] distal ends expanded and bulbous.

\section{Appendicular postcranial skeleton}

94 Distal articulation of the humerus: [0] convex and hemispheric, it enables flexion and extension of the forearm; [1] two surfaces in the anteroposterior axis, separated by a ridge which prevents flexion and extension of the forearm. 
95 Radius shaft (Uhen 1998; Uhen \& Gingerich 2001; Geisler et al. 2005): [0] circular to slightly ovoid in crosssection; [1] flattened mediolaterally, highly elliptical in cross-section.

96 Trapezoid and magnum (Uhen 1998; Uhen \& Gingerich 2001; Geisler et al. 2005): [0] separate; [1] fused.

97 Distal carpal articular surfaces (e.g. unciform, magnum) (Uhen 1998; Uhen \& Gingerich 2001; Geisler et al. 2005): [0] curved to allow for substantial movement; [1] flat.

98 Pelvis size (Uhen \& Gingerich 2001; Geisler et al. 2005): [0] large, has well-developed ilium with total length >
$300 \%$ the length of the first sacral vertebra; [1] greatly reduced with a small ilium, total length $\leq$ the length of the first sacral vertebra.

99 Obturator foramen (Geisler et al. 2005; modified from Hulbert 1998): [0] larger than acetabulum; [1] smaller than acetabulum.

100 Ventromedial expansion of pubis ventromedial to obturator foramen (ordered) (Hulbert 1998; Geisler et al. 2005): [0] absent; [1] present but small expansion; [2] present and extreme expansion.

101 Femur (ordered) (Uhen 1998; Uhen \& Gingerich 2001; Geisler et al. 2005): [0] large; [1] moderate; [2] small. 


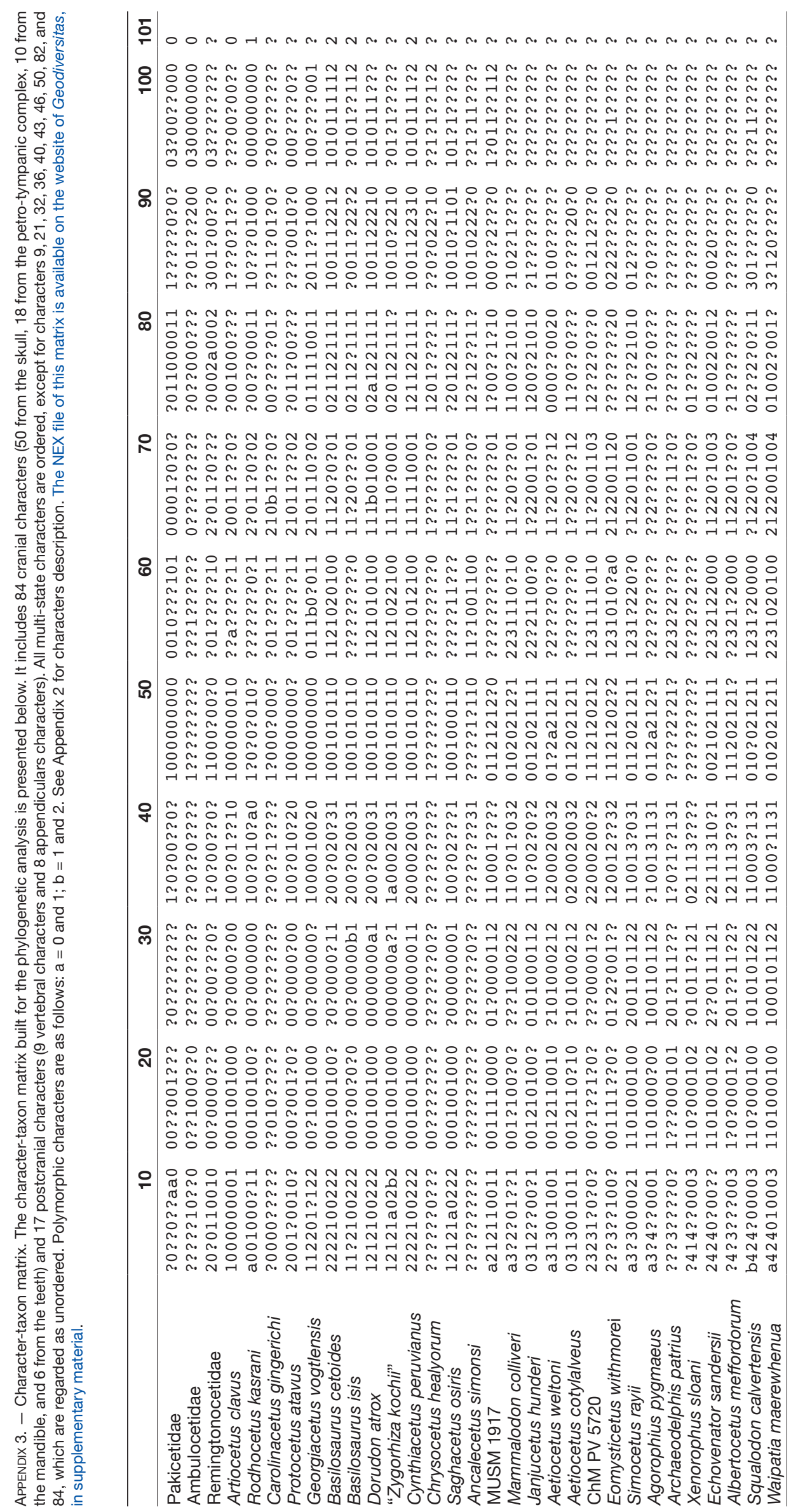


Aegolius funereus (Linnaeus, 1758)

Aegyptocetus Bianucci \& Gingerich, 2011

Aetiocetus Emlong, 1966

Aetiocetus cotylalveus Emlong, 1966

Aetiocetus polydentatus Barnes Kimura, Furusawa \& Sawamura, 1994

Aetiocetus weltoni Barnes, Kimura, Furusawa \& Sawamura, 1994

Agorophius Cope, 1895

Alabamornis Abel, 1906

Albertocetus Uhen, 2008

Albertocetus meffordorum Uhen, 2008

Ambulocetus Thewissen, Madar \& Hussain, 1996.

Ambulocetus natans Thewissen, Madar \& Hussain, 1996

Ancalecetus Gingerich \& Uhen, 1996

Ancalecetus simonsi Gingerich \& Uhen, 1996

Archaeodelphis Allen, 1921

Archaeodelphis patrius Allen, 1921

Artiocetus Gingerich, ul-Haq, Zalmout, Khan \& Malkani, 2001

Artiocetus clavis Gingerich, ul-Haq, Zalmout, Khan \& Malkani, 2001

Balaena Linnaeus, 1758

Balaena mysticetus, Linnaeus, 1758

Basilosaurus Gibbes, 1847

Basilosaurus cetoides (Owen, 1839)

Basilosaurus drazindai Gingerich, Arif, Bhatti, Anwar \& Sanders, 1997

Basilosaurus isis (Andrews, 1904)

Basiloterus Gingerich Arif, Bhatti, Anwar \& Sanders, 1997

Basiloterus hussaini, Gingerich, Arif, Bhatti, Anwar \& Sanders, 1997

Basilotritus Gol'din \& Zvonok, 2013

Cardita Bruguière, 1792

Carolinacetus Geisler, Sanders \& Luo, 2005

Carolinacetus gingerichi Geisler, Sanders \& Luo, 2005

Chonecetus Russell, 1968

Chonecetus goedertorum Barnes, Kimura, Furusawa \& Sawamura, 1994

Chrysocetus Uhen \& Gingerich, 2001

Chrysocetus healyorum Uhen \& Gingerich, 2001

Cynthiacetus Uhen, 2005

Cynthiacetus maxwelli Uhen, 2005

Cynthiacetus peruvianus Martínez-Cáceres \& Muizon, 2011

Delphinapterus Lacépède, 1804

Delphinapterus leucas (Pallas, 1776)

Dhedacetus Bajpai \& Thewissen, 2014

Dhedacetus hyaeni Bajpai \& Thewissen, 2014

Dorudon Gibbes, 1845

Dorudon atrox Andrews, 1906

Echovenator Churchill, Martínez-Cáceres, Muizon, Mnieckowski \& Geisler, 2016

Echovenator sandersi Churchill, Martínez-Cáceres, Muizon, Mnieckowski \& Geisler, 2016

Eocetus Uhen, 1999

Eocetus wardii Uhen, 1999

Eomysticetus Sanders \& Barnes, 2002

Eomysticetus whitmorei Sanders \& Barnes, 2002

Georgiacetus Hulbert, 1998

Georgiacetus votglensis Hulbert, 1998

Himalayacetus Bajpai \& Gingerich, 1998

Ichthyolestes Dehm \& Oettingen-Spielberg, 1958

Inia Orbigny, 1834 
Inia geoffrensis (Blainville, 1817)

Inkayacu, Clarke, Ksepka, Salas-Gismondi, Altamirano, Shawkey, D’Alba, Vinther, DeVries, Baby, 2010

Inkayacu paracasensis, Clarke, Ksepka, Salas-Gismondi, Altamirano, Shawkey, D’Alba, Vinther, DeVries, Baby, 2010

Janjucetus Fitzgerald, 2006

Janjucetus hunderi Fitzgerald, 2006

Kekenodon Hector, 1881

Kekenodon onomata Hector, 1881

Lagenorhynchus Gray, 1846

Lissodelphis Gloger, 1841

Lissodelphis borealis Peale, 1848

Maiacetus Gingerich, ul-Haq, Koenigswald, Sanders, Smith \& Zalmout, 2009

Maiacetus innus Gingerich, ul-Haq, Koenigswald, Sanders, Smith \& Zalmout, 2009

Makaracetus Gingerich, Zalmout, ul-Haq \& Bhatti, 2005

Makaracetus bidens Gingerich, Zalmout, ul-Haq \& Bhatti, 2005

Mammalodon Pritchard, 1939

Mammalodon colliveri Pritchard, 1939

Masracetus Gingerich, 2007

Masracetus markgrafi Gingerich, 2007

Mirocetus Mchedlidze, 1970

Mirocetus riabinini Mchedlidze, 1970

Nalacetus Thewissen \& Hussain, 1998

Ocucajea Uhen, Pyenson, DeVries, Urbina \& Renne, 2011

Ocucajea picklingi Uhen, Pyenson, DeVries, Urbina \& Renne, 2011

Pakicetus Gingerich \& Russell, 1981

Pelocetus Kellogg, 1965

Phococetus Gervais, 1876

Phococetus vasconum Delfortrie, 1873

Pontogeneus Leidy, 1852

Pontogeneus brachyspondylus (Müller, 1849)

Pontogeneus priscus Leidy, 1852

Remingtonocetus Kumar \& Sahni, 1986

Remingtonocetus harudiensis Kumar \& Sahni, 1986

Rodhocetus Gingerich, Raza, Arif, Anwar, \& Zhou, 1994

Rodhocetus kasrani Gingerich, Raza, Arif, Anwar, \& Zhou, 1994

Saghacetus Gingerich, 1992

Saghacetus osiris (Dames, 1894)

Simocetus Fordyce, 2002

Simocetus rayi Fordyce, 2002

Squalodon Grateloup, 1840

Squalodon calvertensis Kellogg, 1923

Stromerius Gingerich, 2007

Stromerius nidensis Gingerich, 2007

Supayacetus Uhen Pyenson, DeVries, Urbina \& Renne, 2011

Supayacetus muizoni Uhen Pyenson, DeVries, Urbina \& Renne, 2011

Takracetus Gingerich, Arif \& Clyde, 1995

Takracetus simus Gingerich, Arif \& Clyde, 1995

Turritella Lamarck, 1799

Turritella lagunillasensis Rivera, 1957

Turritella woodsi Lisson, 1925

Waipatia Fordyce, 1994

Waipatia maerewhenua Fordyce, 1994

Xenorophus Kellogg, 1923

Xenorophus sloani Kellogg, 1923

Zygorhiza True, 1908

Zygorhiza kochii (Reichenbach, 1847). 
TABLE OF CONTENTS

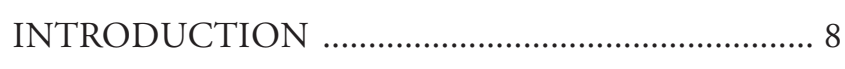

MATERIAL AND METHODS _......................... 9

GEOLOGICAL SETTING …………………….... 10

SYSTEMATIC PALAEONTOLOGY …........................ 11

DESCRIPTION OF THE HOLOTYPE

OF CYNTHIACETUS PERUVIANUS ....................... 16

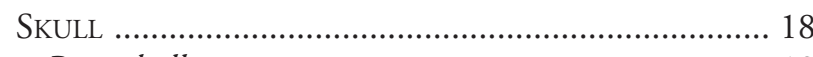

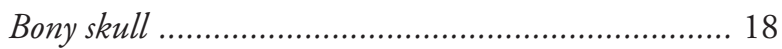

General morphology . ......................................... 18

Premaxilla (PMx) ............................................. 18

Maxilla $(\mathrm{Mx})$.................................................. 24

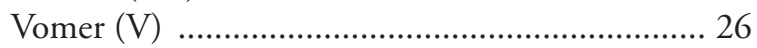

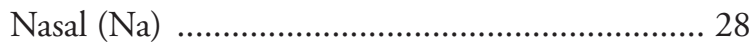

Jugal (J) ............................................................ 28

Lacrimal (La) ................................................... 28

Frontal (Fr) ...................................................... 30

Palatine (Pal) ....................................................... 31

Pterygoid $(\mathrm{Pt})$......................................................... 32

Orbitosphenoid (OS) …………………………... 33

Basisphenoid (BS) ……………………………... 34

Alisphenoid (Al) ……………………………..... 34

Parietal (Pa) ………………………………… 34

Squamosal (Sq) ………………………………... 36

Exoccipital (EO) .................................................. 41

Supraoccipital (SO) ............................................ 42

Basioccipital (BO) ……………………………... 43

Periotic (Pe) ........................................................ 44

Tympanic Bulla (TB) ………………………..... 48

Malleus (Ma) ..................................................... 49

Mandible ……………..................................... 50

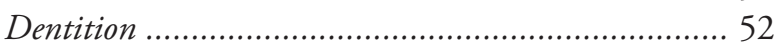

Upper dentition . ................................................. 52

Lower dentition . ................................................... 54

POSTCRANIAL SKELETON ........................................... 56

Hyoid apparatus ....................................................... 56

Stylohyal ............................................................ 56

Basihyal ......................................................... 56

Thyrohyal ......................................................... 56

Axial postcranial skeleton ......................................... 57

Cervical region ……........................................... 59

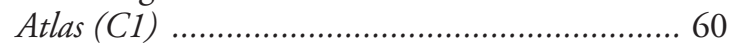

Axis (C2) ...................................................... 60

Third cervical (C3) ........................................... 62

Fourth cervical (C4) ........................................ 63

Fifth cervical (C5) ………………………........ 64

Sixth cervical (C6) …………………................. 64
Seventh cervical (C7) ......................................... 65

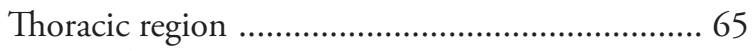

First thoracic (T1) ........................................... 67

Second thoracic (T2) .......................................... 70

Third thoracic (T3) .......................................... 72

Fourth thoracic (T4) ....................................... 72

Fifth thoracic (T5) ……………….................. 72

Sixth thoracic (TG) .......................................... 72

Seventh thoracic (T7) ...................................... 74

Eighth thoracic (T8) ......................................... 74

Ninth thoracic (T9) .......................................... 74

Tenth thoracic (T10) ........................................... 74

Eleventh thoracic (T11) .................................... 76

Twelfth thoracic (T12) ...................................... 76

Thirteenth thoracic (T13) ................................... 76

Fourteenth thoracic (T14) ................................ 76

Fifteenth thoracic (T15) ................................... 78

Sixteenth thoracic (T16) .................................. 78

Seventeenth thoracic (T17) ................................. 78

Eighteenth thoracic (T18) ................................. 78

Nineteenth thoracic (T19) .................................. 78

Twentieth thoracic (T20) ................................. 80

Ribs (R1 to R20) ………………….................. 80

Sternum (S1-S5) ............................................. 82

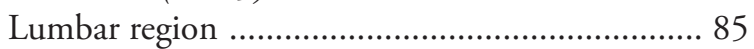

First lumbar (L1) ........................................... 89

Second lumbar (L2) .......................................... 90

Third lumbar (L3) ............................................ 91

Fourth lumbar (L4) ........................................ 91

Fifth lumbar (L5) ............................................ 94

Sixth lumbar (LG) ........................................... 94

Seventh lumbar (L7) ....................................... 94

Eighth lumbar (L8) ....................................... 94

Ninth lumbar (L9) ........................................... 96

Tenth lumbar (L10) ......................................... 96

Eleventh lumbar (L11) ....................................... 96

Twelfth lumbar (L12) ..................................... 96

Thirteenth lumbar (L13) .................................. 98

Fourteenth lumbar (L14) ................................. 98

Fifteenth lumbar (L15) ..................................... 98

Sixteenth lumbar (L16) .................................... 98

Seventeenth lumbar (L17) ................................. 98

Caudal region ................................................. 100

First caudal (Ca1) ......................................... 102

Second caudal (Ca2) ........................................ 104

Third caudal (Ca3) .......................................... 104

Fourth caudal (Ca4) ...................................... 104

Fifth caudal (Ca5) ........................................ 104

Sixth caudal (Ca6) ........................................ 105

Seventh caudal (Ca7) .................................... 105

Eighth caudal (Ca8) ....................................... 106

Ninth caudal (Ca9) ....................................... 106

Tenth caudal (Ca10) ...................................... 106

Chevrons (hemal arches) ..................................... 106

Appendicular skeleton …...................................... 108 
Pectoral girdle and forelimb 108

Scapula (pectoral girdle)

Humerus

110

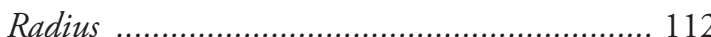

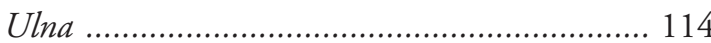

Carpus ………………………………........ 116

Metacarpus ………………………………..... 118

Phalanges .................................................... 120

Pelvic girdle and hind limb .............................. 121

Innominate ..................................................... 121

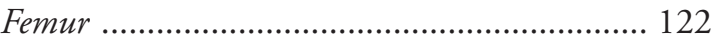

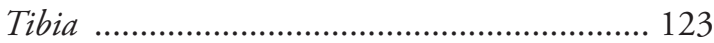

Fibula …………………………………..... 124

Phalanges ………………………………........ 124

PHYLOGENY AND EVOLUTIONARY TRENDS . 125

PHYLOGENETIC CONTEXT OF THE EARLY EVOLUTION OF CETACEANS …………………………………... 125

SOME MAJOR TRENDS OF THE EVOLUTION

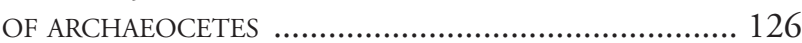

Rostrum morphology .......................................... 126

Asymmetry of the rostrum ..................................... 127

Supraorbital region in archaeocetes and early neocetes .127

Supraorbital region within the Basilosauridae ......... 127

Neurocranium .................................................. 128

Pelvic girdle and hind limb ................................ 130

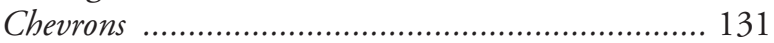

RESULTS OF THE PARSIMONY ANALYSIS ....................... 132

Analysis with equally weighted characters ................ 132

Topology of the strict consensus tree ......................... 132

Synapomorphies of the main clades ......................... 134

Georgiacetus vogtlensis + Pelagiceti ....................... 134

Pelagiceti ........................................................... 134

Basilosauridae ................................................... 134

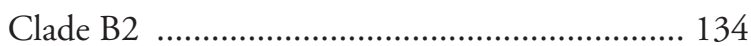

Clade B3 …................................................. 134

Neoceti ............................................................ 134

Mysticeti ………................................................ 135

Clade M2 …………........................................ 135

Clade M3 …................................................. 135

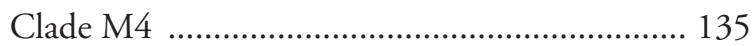

Aetiocetidae ......................................................... 135

Odontoceti ......................................................... 136

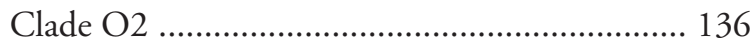

Clade O3 ………….................................... 136

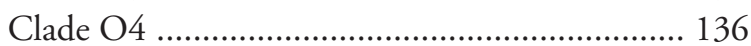

Xenorophidae .................................................. 136

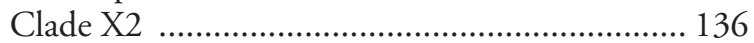

Analysis with down weighted homoplastic characters ... 137

DISCUSSION ......................................................... 138

Basilosauridae .................................................... 138

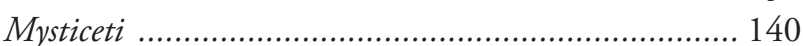

Odontoceti and Xenorophidae ................................. 140
CONCLUSIONS ………………………………..... 142

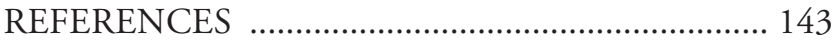

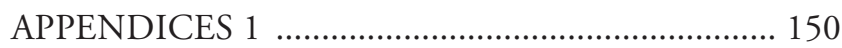

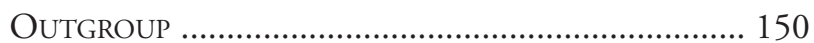

Pakicetidae ……........................................... 150

Ambulocetidae ................................................. 150

Remingtonocetidae ............................................ 150

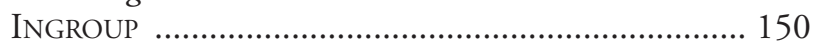

Protocetidae .................................................................. 150

Artiocetus clavis ............................................... 150

Carolinacetus gingerichi .................................... 150

Rodhocetus kasrani ........................................... 150

Protocetus atavus ............................................. 150

Georgiacetus vogtlensis ........................................ 150

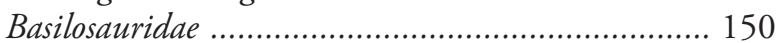

Basilosaurus cetoides ......................................... 151

Basilosaurus isis .............................................. 151

Dorudon atrox ................................................... 151

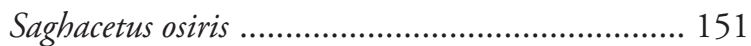

Zygorbiza ...................................................... 151

Cynthiacetus peruvianus ...................................... 151

Ancalecetus simonsi ............................................ 151

Chrysocetus healyorum ………………………..... 151

Neoceti .......................................................... 151

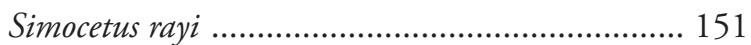

Archaeodelphis patrius ......................................... 152

Xenorophus sloani ............................................ 152

Echovenator sandersi ........................................ 152

Albertocetus meffordorum ................................... 152

Agorophius ....................................................... 152

Squalodon calvertensis ........................................ 152

Waipatia maerewhenua ...................................... 152

ChM PV5720. ................................................ 152

Mammalodon colliveri ..................................... 152

Janjucetus hunderi ............................................ 152

Aetiocetus cotylalveus .......................................... 152

Aetiocetus weltoni ............................................. 152

Chonecetus goedertorum ..................................... 152

Eomysticetus whitmorei ...................................... 153

The "Media Luna Whale" (MUSM 1917) ........ 153

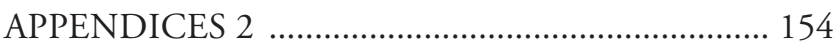

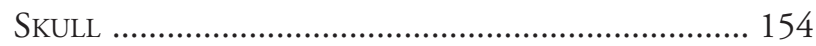

Petrotympanic complex ....................................... 156

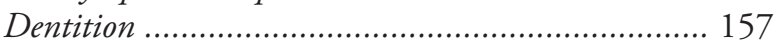

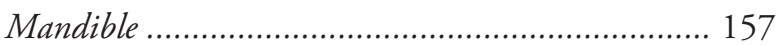

Axial postcranial skeleton ...................................... 157

Appendicular postcranial skeleton ........................... 157

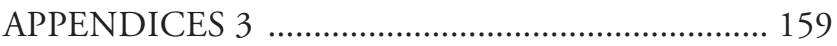

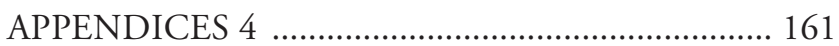

